\title{
EXPERIMENTAL STUDY ON SLIP RESISTANCE PERFORMANCE OF ASTM A1010 STAINLESS STEEL BOLTED CONNECTIONS
}

by

\author{
Omar Cameron \\ Bachelor of Engineering \\ University of Technology, Jamaica (UTECH), 2007
}

\author{
A Thesis \\ Presented to Ryerson University \\ In partial fulfillment of the \\ Requirement for the degree of \\ Master of Applied Science \\ In the Program of \\ Civil Engineering
}

Toronto, Ontario, Canada, 2017

(C) Omar Cameron 2017 


\section{AUTHOR'S DECLARATION}

I hereby declare that I am the sole author of this thesis. This is a true copy of the thesis, including any required final revisions, as accepted by my examiners.

I authorize Ryerson University to lend this thesis to other institutions or individuals for the purpose of scholarly research.

I further authorize Ryerson University to reproduce this thesis by photocopying or by other means, in total or in part, at the request of other institutions or individuals for the purpose of scholarly research.

I understand that my thesis may be made electronically available to the public. 


\title{
EXPERIMENTAL STUDY ON SLIP RESISTANCE PERFORMANCE OF ASTM A1010 STAINLESS STEEL BOLTED CONNECTIONS
}

\author{
Omar Cameron \\ Master of Applied Science, Civil Engineering \\ RYERSON UNIVERSITY, Toronto, Canada, 2017
}

\begin{abstract}
The primary aim of this experimental research was to provide information on the slip coefficient performance of ASTM A1010 stainless steel material and to ascertain if its behaviour is comparable to that of $350 \mathrm{~W}$ Structural Steel. In accomplishing this task, it was important to examine other parameters associated with slip resistance testing, such as (i) bolt relaxation and (ii) the effect of temperature variation and re-usability of high strength bolts. In the 2014 edition of the Canadian Highway Bridge Design Code, the slip coefficient for clean mill scale and hot dip galvanized surface condition for the $350 \mathrm{~W}$ structural steel is specified as 0.35 , whereas for blastedclean surface condition is specified as 0.5 . Although test results in this research showed lower values for tested structural steel plates, the slip coefficient of A1010 stainless steel material performed better than the $350 \mathrm{~W}$ structural steel for each surface condition and at the same temperature range. Recommendations regarding the slip resistance test method and the methodology for achieving the required surface conditions in slip resistance connection were drawn.
\end{abstract}




\section{ACKNOWLEDGEMENTS}

Firstly, the author would like to thank the Lord God Almighty for giving him the strength knowledge needed in completing this research. Next, I would like to express my sincere gratitude and appreciation to my supervisor Dr. Khaled Sennah and my co-supervisor Dr. Sameh Salib for giving me this incredible research opportunity. Without their continuous support (financially and otherwise), suggestions and guidance throughout this journey, completion of this thesis would not be possible. I would also like to thank the Ministry of Transportation, Ontario (MTO) for their advice and financial contributions in the form of a research grant.

I would also like to acknowledge a list of companies who have made significant contribution to this research, namely: Arcelor Mittal of Chicago, USA (Mr. Martin Francis); McCann Equipment of Ontario, Canada (Mr. Jim McCann); Central Welding Ltd of North Bay, Ontario, Canada (Ms. Stefanie Bailey); and Tresman Steel Industries Ltd of Ontario, Canada (Mr. Roberto Trentin). Last but by no means the least, I would like to express my deepest gratitude to Nidal Jaalouk, Domenic Valle, Alan Machin and Min Yao, the technical staff at Ryerson University, for their dedication and assistance to me throughout this journey of completing the experimental tests. 


\section{DEDICATION}

While everything I do in my life is owed all to the grace and mercies of my Lord and Saviour Jesus Christ, I want to take this opportunity to dedicate this particular achievement to my wife Ann Marie Cameron and children Kiar-Ra and K'zar-ryo Cameron (whom I love and adore so much), for their continued love, support, sacrifice and understanding during my time of study.

I would also like to dedicate this research to my mother Leonie Cameron, who is my rock and support. Finally, my deepest thanks and appreciation goes to my siblings Sonji, Sharnette and Sheldon Cameron, for their continued love and support. 


\section{Contents}

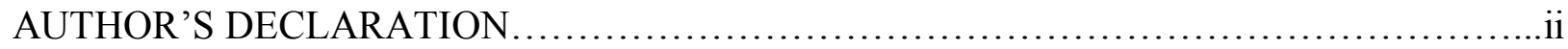

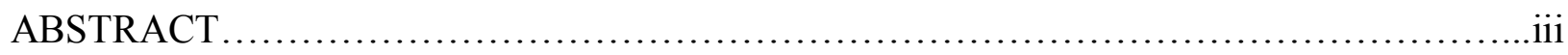

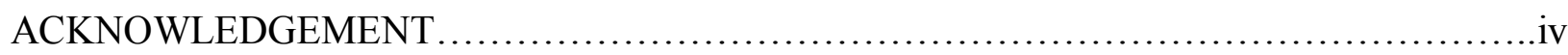

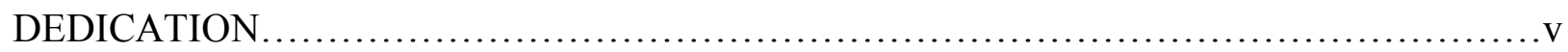

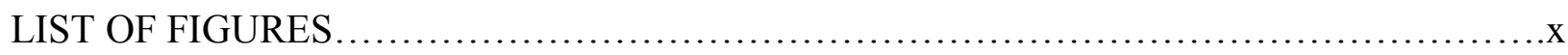

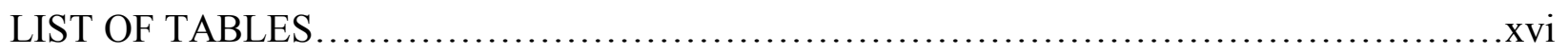

1 Chapter 1: INTRODUCTION ................................................... 1

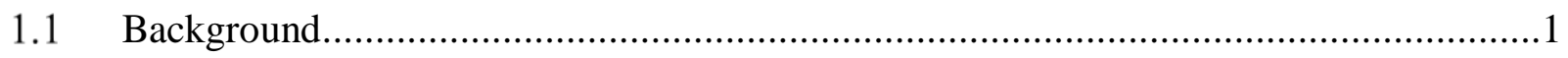

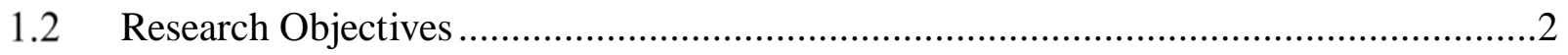

1.3 Research Overview ...............................................................................

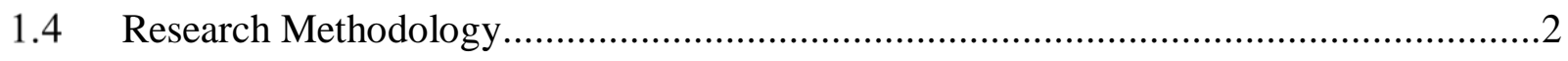

2 Chapter 2: ASTM A1010 AS A STRUCTURAL MATERIAL .................... 4

3 Chapter 3 LITERATURE REVIEW ................................................. 8

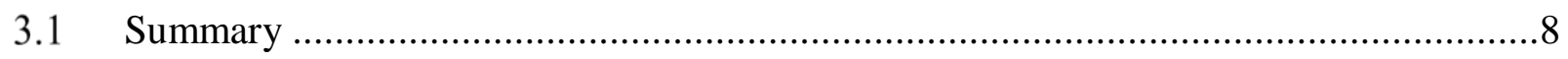

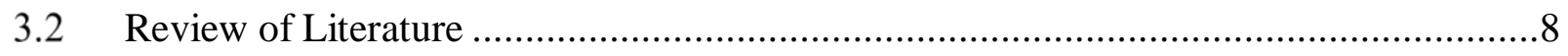

3.2.1 Previous Slip Resistance and Bolt Relaxation studies .....................................8

3.2.2 Current Design Standards and Specifications ............................................. 17

3.2.3 Bolts Pretension .................................................................................. 18

3.2.4 Snug Tightening of High Strength Bolts.................................................. 18

3.2.5 Turn-of-the-Nut Pre-tensioning Method ............................................... 18

4 Chapter 4 EXPERIMENTAL PROGRAM …........................................20

4.1 Rationale of the Experimental Research Program ............................................20

4.2 Experimental Program 1: Bolt reusability ......................................................20

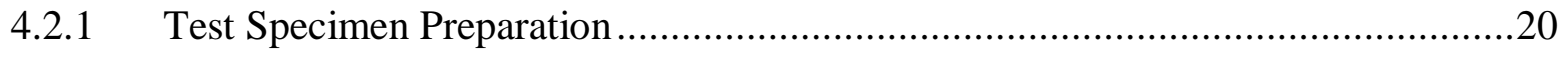

4.2.2 Verification of High Strength Bolt and Stainless Steel Bolt Reusability .............21 
4.3 Experimental Program 3: Bolt Pre Load Subjected to Temperature Variation Testing .25

4.4 Experimental Program 2: Slip Critical Testing at Room Temperature.......................29

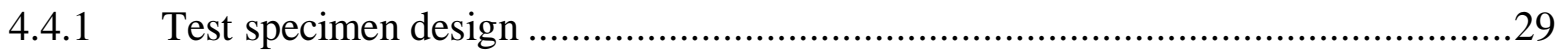

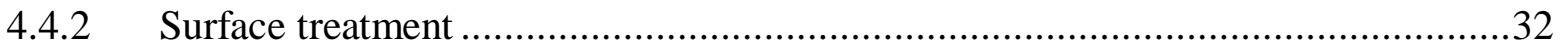

4.4.3 Snug-tightening condition determination.................................................34

4.4.4 Verification testing of snug -tightening condition ........................................ 34

4.4.5 Verification testing of clamping force .....................................................35

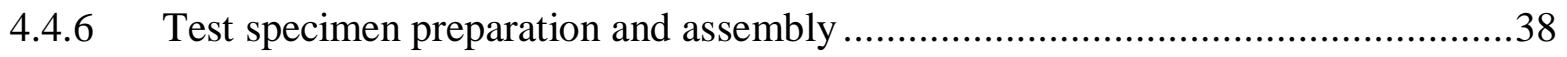

4.4.7 Test specimen surface preparation.............................................................39

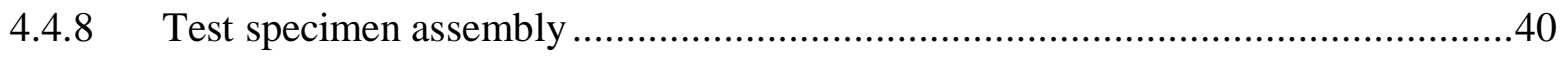

4.4.9 Specimen testing .......................................................................... 44

4.5 Experimental Program 3: Bolt Relaxation Testing ..........................................46

4.6 Experimental Program 5: Slip Coefficient for Specimens Subjected to Temperature

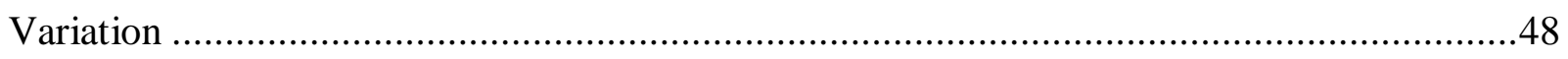

5 EXPERIMENTAL RESULTS AND DISCUSSION ON HIGH-STRENGTH

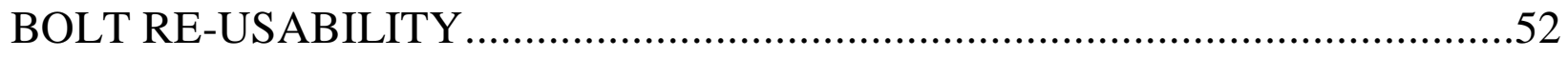

5.1 High Strength Bolt Reusability with Unlubricated Threading Results ......................52

5.1.1 A325 High strength bolt with unlubricated threading ..................................52

5.1.2 Galvanized A325 high-strength bolt with unlubricated threading ......................53

5.1.3 B8 Class 1 Stainless steel bolt with unlubricated threading .............................54

5.2 High Strength Bolt Reusability with Lubricated Threading Results .........................55

5.2.1 Galvanized A325 high strength bolt lubricated threading ................................55

5.2.2 B8 Class 1 Stainless steel bolt with lubricated threading ...............................56

6 Chapter 6: EXPERIMENTAL RESULTS AND DISCUSSION ON BOLT PRELOAD SUBJECT TO TEMPERATURE VARIATION ...................................57 


\section{Chapter 7: EXPERIMENTAL RESULTS AND DISCUSSION FOR SLIP}

COEFFICIENT AT AMBIENT TEMPERARURE ...........................................61

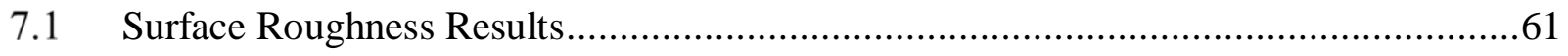

7.2 Determination of Clamping Force Results for A325 Bolts .........................................61

7.3 Slip Resistance Coefficient at 173 kN Clamping Force.................................................64

7.4 Slip Resistance Coefficient at $203 \mathrm{kN}$ clamping force ...............................................73

7.5 Observations of slip test result and comparison with similar research .........................79

8 Chapter 8: EXPERIMENTAL RESULTS AND DISCUSSION FOR BOLT

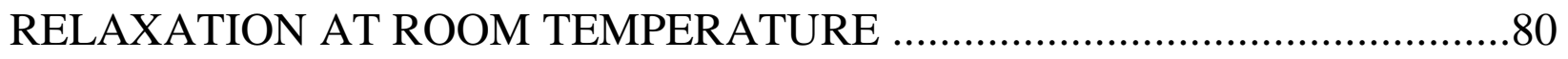

8.1 Bolt Relaxation at $173 \mathrm{kN}$ and $203 \mathrm{kN}$ Clamping Force ......................................... 80

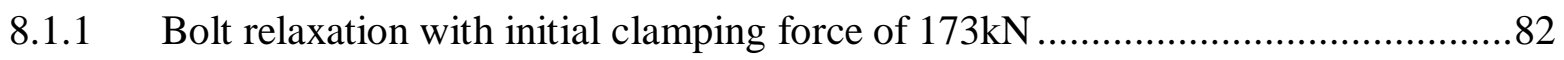

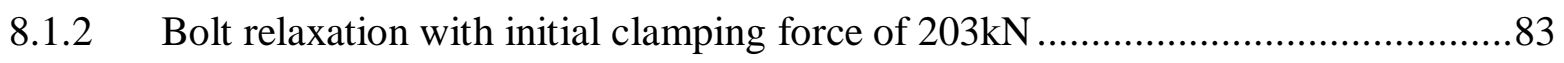

9 Chapter 9: EXPERIMENTAL RESULTS AND DISCUSSION ON THE TEMPERATURE EFFECTS ON SLIP COEFFICIENT ...................................84

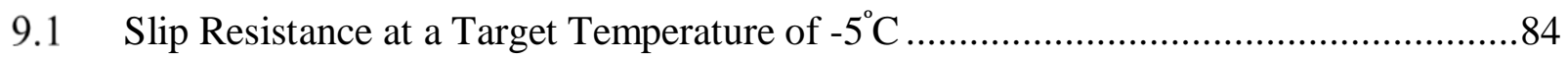

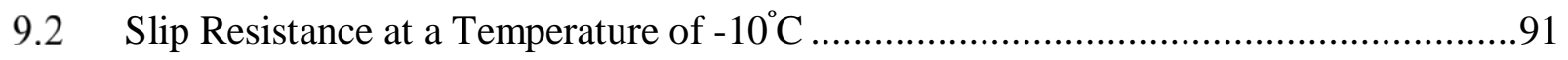

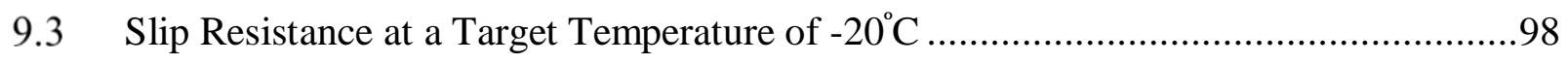

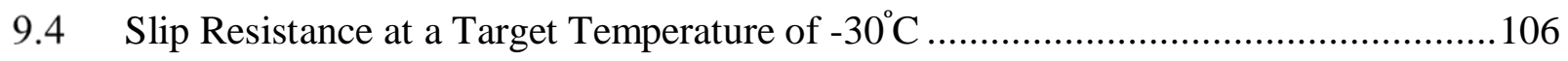

9.5 Analysis of Temperature Effect on Slip Coefficient for Different Surface Condition.111

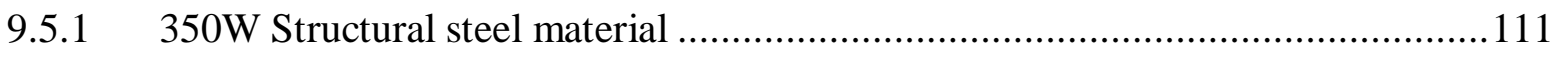

9.5.2 ASTM A1010 Stainless steel material ............................................................112

10 Chapter 10: CONCLUSIONS AND RECOMMENDATIONS FOR FUTURE

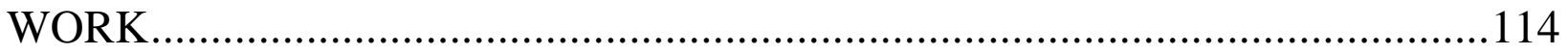

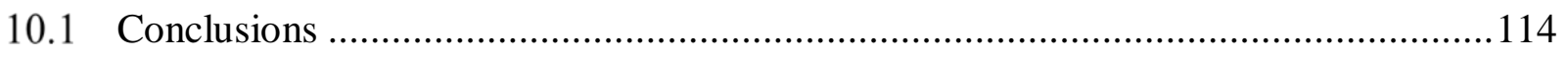

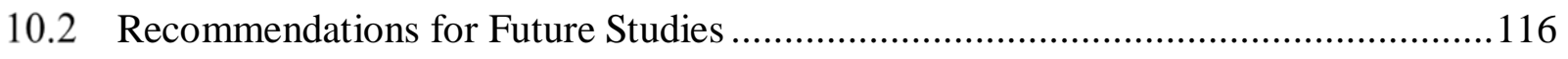


Appendix A: Bolt Reusability Testing (unlubricated and lubricated threading)...117

Appendix B: Temperature Effect on Bolt Pre-load testing ...............................127

Appendix C: Slip Coefficient Testing at $173 \mathrm{kN}$ Clamping Force at Ambient

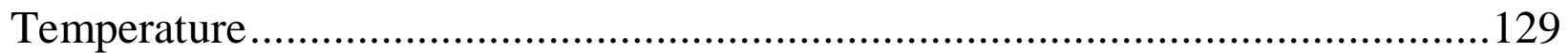

Appendix D: Slip Coefficient Testing at $203 \mathrm{kN}$ Clamping Force at Ambient

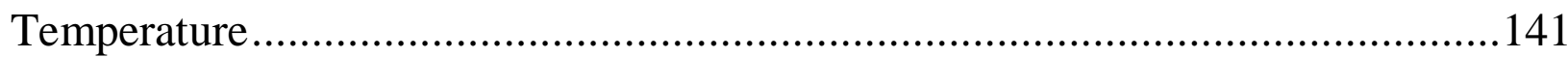

Appendix E: Slip Coefficient Testing at Varying Temperature ........................152 Appendix F: Comparison of Slip Coefficient at Ambient Temperature and Low

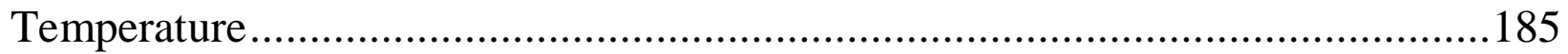

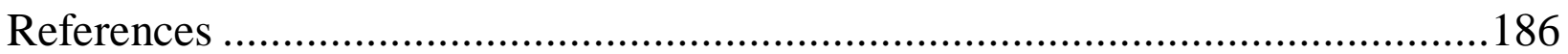

\section{LIST OF FIGURES}


Figure 1-1: Bolted steel bridge connection made of structure steel (photo courtesy of KTA-Tator, Inc.) 1

Figure 1-2: Steel main girder made from structure steel (photo courtesy of KTA-Tator, Inc.) ......1

Figure 2-1: Corrosion Performance of different steel types (Fletcher et al. 2005)......................5

Figure 2-2: V-Notch impact curves for $6.4 \mathrm{~mm}$ (1/4”) thick plate (Fletcher et al., 2005)............6

Figure 2-3: Ultimate tensile strength capacity of ASTM A1010 (Fletcher et al., 2005) .............6

Figure 2-4: Elongation capacity of ASTM A1010 (Fletcher et al. 2005) ..................................7

Figure 3-1: Stress versus time graph, (Dewolf and Yang, 2000) .......................................... 14

Figure 4-1: Sample specimens of high-strength bolts with raised embossment on head of used in this research (a) galvanized A325 bolt, (b) regular A325 bolt and (c) B8 class 1 stainless steel bolt .21

Figure 4-2: Sample of high-strength bolt with raised embossment on the bolt head removed used in the verification stage (a) galvanized A325 bolt, (b) regular A325 bolt and (c) B8 class 1 stainless steel bolt .21

Figure 4-3: (a) View of Wilhelm Skidmore Bolt Tensioning machine and (b) view of degrees turn calibrated on front brushing of Skidmore Wilhelm Machine.

Figure 4-4: Incremental torqueing of structural bolt using Skidmore Wilhelm machine and electric torque wrench .23

Figure 4-5: Attachment on the Mini-Max ultrasonic bolt elongation measuring device to torqued bolt head inside of Skidmore Wilhelm machine. .23

Figure 4-6: Castrol Pyroplex red multi-purpose grease lubricant. .24

Figure 4-7: Application of multi-purpose grease lubricant to the threads of galvanized bolt.......24

Figure 4-8: Application of multi-purpose grease lubricant to the threads of stainless steel bolt ..24 Figure 4-9: Burnsco Environmental Chamber used for conditioning High-Strength bolt ...........25

Figure 4-10: Alcoholic-based acetone used to clean bolt head surface after grinding ...............26

Figure 4-11: (a) Conditioner used to clean away trace of residual acetone left on bolt head and (b)

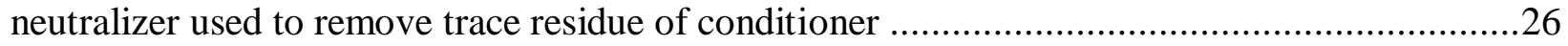

Figure 4-12: Attachment of Type K-thermocouple wires to the head of bolts.........................27

Figure 4-13: (a) M Bond 200 Adhesive Kit and (b) M Bond 200 adhesive and catalyst ............27

Figure 4-14: View of bolts, washers and nuts placed inside environmental chamber................28 
Figure 4-15: (a) Attachment of Mini-Max ultrasonic bolt tensioning transducer to the head of bolt and (b) tensioning of bolt assembly using electric torque wrench ....................................28

Figure 4-16: Front and side views of the short-duration compression slip test specimen ...........30

Figure 4-17: Side view of short-duration compression slip resistance test specimen with bolt,

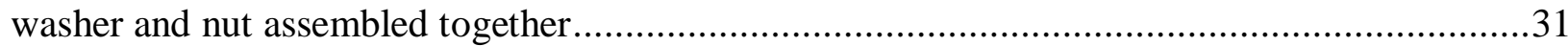

Figure 4-18: Water jet cutting machine (source: Antech Technologies Inc.) ...........................31

Figure 4-19: Water jet-cutting process (source: Ant Applied New Technologies - AG)............31

Figure 4-20: Equipment and method use for the determination of surface roughness ...............33 Figure 4-21: Galvanized plate with label number stamped in the side before hot dip galvanization

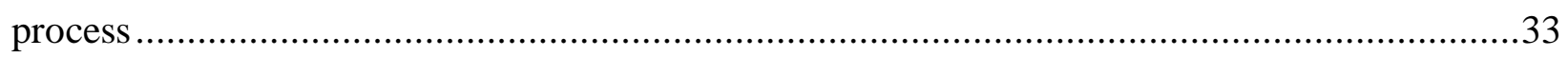

Figure 4-22: Wilhelm Skidmore bolt tensioning device prepared for clamping force verification test

Figure 4-23: Wilhelm Skidmore bolt tensioning device prepared for clamping force verification test at $120^{\circ}$ of a turn. 37 Figure 4-24: Clamping force stencil made from plastic sheeting (a) stencil for $170^{\circ}$ turn, (b) $152^{\circ}$ turn for A325 bolt (from the hand tightened position). .38 Figure 4-25: Clamping force stencil made from plastic sheeting (a) stencil for $160^{\circ}$ turn for galvanized bolt (from the hand tightened position, (b) all three stencil side by side .38 Figure 4-26: Specimen plates arranged to be final surface treated (a) galvanized plates to be wire brushed and (b) blasted clean surface to be cleaned with a regular brush to remove dust .39 Figure 4-27: Specimen plates arranged to be final surface treated (a) A1010 clean mill scale surface to be cleaned with acetone and (b) $350 \mathrm{~W}$ Steel clean mill scale to be cleaned with acetone ........40 Figure 4-28: (a) Galvanized plates with galvanized bolts been scribe with $160^{\circ}$ stencil and (b) Galvanized plates with A325 bolts been scribe with $152^{0}$ stencil. .......................................40 Figure 4-29: Typical initial assembly of three plate of a specimen with 7/8" diameter bolt .......41 Figure 4-30: Rotation of centre plate of specimen assembly (a) $350 \mathrm{~W}$ clean mill scale plates with A325 bolts and (b) hot -dip galvanized plates with A325 bolt. .41

Figure 4-31: Rotation of centre plate of specimen assembly hot-dip galvanized plates with galvanized bolts

Figure 4-32: Galvanized plates with the two degree turn applied to the plate based on the type bolt to use (a) $160^{\circ}$ for galvanized bolt and (b) $152^{\circ}$ for A325 bolt 
Figure 4-33: (a) Fabrication of clamping gig and (b) clamping gig to be used to hold specimen assembly during clamping..... .44

Figure 4-34: Alignment of the electric torque wrench with zero mark on front plate of specimen

Figure 4-35: (a) MTS Hydraulic Universal Testing machine and (b) $500 \mathrm{kN}$ capacity portable load cell.

Figure 4-36: Compressive loading of centre plate of specimen assembly during slip testing ......46

Figure 4-37: Digital screen of X-Y plotter for the MTS hydraulic universal testing machine .....46 Figure 4-38: (a) Raised indentation/marking on the head of structural bolts and (b) bolt head after removal of raised indentation/marking through the process of grinding ..............................48

Figure 4-39: Placement of dry fitted sample inside of environmental chamber......

Figure 4-40: Placement of insulating foam to back of K-thermocouple wire, then replacement of specimen into environmental chamber.

Figure 4-41: (a) Thermally insulted transportation bag with frozen gel pack, (b) transportation of specimen ready for testing .50

Figure 5-1: A325 High strength bolt re usability cycle for loading and unloading of the bolt .....52 Figure 5-2: Galvanized A325 high strength bolt re usability cycle for loading and unloading of the bolt with unlubricated threading. .53

Figure 5-3: B8 Class 1 stainless steel bolt re usability cycle for loading and unloading of the bolt with unlubricated threading. .54

Figure 5-4: Galvanized A325 high strength bolt re usability cycle for loading and unloading of the bolt with lubricated threading.

Figure 5-5: B8 Class 1 Stainless steel bolt re usability cycle for loading and unloading of the bolt with lubricated threading. .56 Figure 6-1: Variation in bolt pre-load as measured by the wilhelm skidmore bolt tensioning device for A325 high strength bolt. .58 Figure 6-2: Variation in bolt pre-load as calculated by using equation 3 - 2 for A325 bolt.........59 Figure 6-3: Variation in bolt pre-load as measured by the wilhelm skidmore bolt tensioning device for galvanized A325 high strength bolt..... Figure 6-4: Variation in bolt pre load as calculated by using equation 3 - 2 for A325 high strength bolt. 
Figure 7-1: Slip load definition curves, Yura et al, (1981)

Figure 7-2: Force-displacement relationship for $350 \mathrm{~W}$ structural steel clean mill scale surface condition for test specimen 2 with A325 bolt.

Figure 7-3: Force-displacement relationship for 350W structural steel blast-clean surface condition for test specimen 1 with A325 bolt . .68

Figure 7-4: Force-displacement relationship for 350W structural steel with hot dip galvanized surface condition for test specimen 1 with galvanized bolt

Figure 7-5: Force-displacement relationship for 350W structural steel with hot dip galvanized surface condition for test specimen 1 with A325 bolt .70

Figure 7-6: Force-displacement relationship for A1010 stainless steel with clean mill scale surface condition for test specimen 2 with galvanized bolt .71

Figure 7-7: Force-displacement relationship for A1010 stainless steel with blast-clean surface condition for test specimen 2 with galvanized bolt

Figure 7-8: Force-displacement relationship for $350 \mathrm{~W}$ structural steel with clean mill scale surface condition for test specimen 2 with A325 bolt. .73 Figure 7-9: Force-displacement relationship for 350W structural steel with blast-clean surface condition for test specimen 3 with A325 bolt .74 Figure 7-10: Force-displacement relationship for 350W structural steel with hot hip galvanized surface condition for test specimen 1 with A325 bolt .75 Figure 7-11: Force-displacement relationship for 350W structural steel with hot dip galvanized surface condition for test specimen 3 with galvanized bolt .76 Figure 7-12: Force-displacement relationship for A1010 stainless steel with clean mill scale surface condition for test specimen 2 with galvanized bolt .77 Figure 7-13: Force-displacement relationship for A1010 stainless steel with blast-clean surface condition for test specimen 3 with galvanized bolt .78 Figure 9-1: Force-displacement relationship for 350W structural steel with blasted clean surface condition with $\mathrm{A} 325$ bolt for test specimen 1 at $-5^{0} \mathrm{C}$ temperature .85 Figure 9-2: Force-displacement relationship for 350W structural steel with clean mill scale surface condition with $\mathrm{A} 325$ bolt for test specimen 1 at $-5^{\circ} \mathrm{C}$ temperature .86 Figure 9-3: Force-displacement relationship for 350W structural steel with hot dip galvanized surface condition with galvanized bolt for test specimen 1 at $-5^{0} \mathrm{C}$ temperature .87 
Figure 9-4: Force-displacement relationship for A1010 stainless steel with blast-clean surface condition with galvanized bolt for test specimen 1 at $-5^{0} \mathrm{C}$ temperature .88

Figure 9-5: Force-displacement relationship for A1010 stainless steel with blast-clean surface condition with galvanized bolt for test specimen 2 at $-5^{0} \mathrm{C}$ temperature .89 Figure 9-6: Mean Temperature vs time progression throughout testing for various surface condition at $-5^{0} \mathrm{C}$ .91

Figure 9-7: Force-displacement relationship for structural steel with blasted clean surface condition with $\mathrm{A} 325$ bolt for test specimen 1 at $-10^{\circ} \mathrm{C}$ temperature. .92 Figure 9-8: Force-displacement relationship for structural steel with clean mill scale surface condition with $\mathrm{A} 325$ bolt for test specimen 1 at $-10^{\circ} \mathrm{C}$ temperature. .93 Figure 9-9: Force-displacement relationship for structural steel with hot dip galvanized surface condition with galvanized bolt for test specimen 1 at $-10^{\circ} \mathrm{C}$ temperature. .94 Figure 9-10: Force-displacement relationship for stainless steel with clean mill scale surface condition with galvanized bolt for test specimen 1 at $-10^{0} \mathrm{C}$ temperature. .95 Figure 9-11: Force-displacement relationship for stainless steel with blasted clean surface condition with galvanized bolt for test specimen 1 at $-10^{0} \mathrm{C}$ temperature. .96 Figure 9-12: Mean temperature vs time progression throughout testing for various surface condition at $-10^{\circ} \mathrm{C}$ .98 Figure 9-13: Force-displacement relationship for structural steel with blast-clean surface condition with $\mathrm{A} 325$ bolt for test specimen 1 at $-20^{\circ} \mathrm{C}$ temperature .99 Figure 9-14: Force-displacement relationship for structural steel with clean mill scale surface condition with A325 bolt for test specimen 1 at $-20^{\circ} \mathrm{C}$ temperature. 100 Figure 9-15: Force-displacement relationship for structural steel with hot dip galvanized surface condition with galvanized bolt for test specimen 1 at $-20^{\circ} \mathrm{C}$ temperature. 101 Figure 9-16: Force-displacement relationship for A1010 stainless steel with clean mill scale surface condition with galvanized bolt for test specimen 1 at $-20^{\circ} \mathrm{C}$ temperature 102 Figure 9-17: Force-displacement relationship for A1010 stainless steel with blasted clean surface condition with galvanized bolt for test specimen 1 at $-20^{\circ} \mathrm{C}$ temperature. 103 Figure 9-18: Mean temperature vs time progression throughout testing for various surface condition at $-20^{\circ} \mathrm{C}$ 105 
Figure 9-19: Force-displacement relationship for structural steel with blast-clean surface condition with $\mathrm{A} 325$ bolt for test specimen 1 at $-30^{\circ} \mathrm{C}$ temperature 106 Figure 9-20: Force-displacement relationship for structural steel with clean mill scale surface condition with $\mathrm{A} 325$ bolt for test specimen 1 at $-30^{\circ} \mathrm{C}$ temperature. 107 Figure 9-21: Force-displacement relationship for structural steel with clean mill scale surface condition with galvanized bolt for test specimen 1 at $-30^{\circ} \mathrm{C}$ temperature. 108 Figure 9-22: Force-displacement relationship for stainless steel with blast-clean surface condition with galvanized bolt for test specimen 1 at $-30^{\circ} \mathrm{C}$ temperature .109 Figure 9-23: Mean temperature vs time progression throughout testing for various surface condition at $-20^{\circ} \mathrm{C}$ 111 Figure 9-24: Effect of varying temperature on 350W Structural steel with clean mill scale surface condition 112

Figure 9-25: Effect of varying temperature on 350W structural steel with blasted clean surface condition. 112 Figure 9-26: Effect of varying temperature on ASTM A1010 stainless steel with clean mill scale surface condition. Figure 9-27: Effect of varying temperature on ASTM stainless steel with blasted clean surface condition .113 


\section{LIST OF TABLES}

Table 2-1: Chemical composition of ASTM A1010 material (Fletcher et al., 2005)..................5

Table 2-2: Specified Mechanical Properties of ASTM A1010 (Fletcher et al, 2005) ..................5

Table 2-3: Corrosion testing temperature $=77^{0}\left(25^{\circ} \mathrm{C}\right)$ and $\mathrm{pH}=7.0$ chloride concentration

(Fletcher et al., 2005) .......................................................................................6

Table 3-1: Bolt relaxation results, (Yang and Dewolf 2000) .................................................14

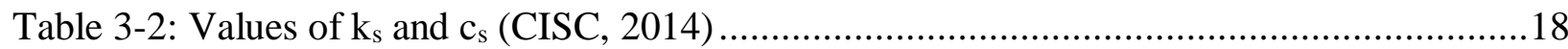

Table 3-3: Nut rotation for snug-tight condition for turn-of-the-nut pretensioning (RCSC, 2000)

Table 4-1: Text matrix to study the effect of temperature variation on bolt pre-tension.............26

Table 4-2: Summary of the various clamping forces, the total number of tested specimens, .......30

Table 4-3: Surface Preparation Standard (adopted from Society for Protective Coating) (2014).32

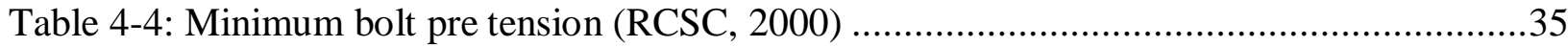

Table 4-5: A325 high strength bolt clamping force verification at $173 \mathrm{kN}$.............................36

Table 4-6: A325 high-strength bolt clamping force verification table at $120^{\circ}$ or $1 / 3$ of a turn .....37

Table 4-7: Breakdown of specimen plates surface treatment before complete assembly with bolt.

Table 4-8: Breakdown of testing procedure with clamping force at $173 \mathrm{kN}$..........................42

Table 4-9: Breakdown of testing procedure with clamping force at $203 \mathrm{kN}$.........................43

Table 4-10: Breakdown of testing periods for bolt relaxation testing ................................47

Table 4-11: Breakdown of the test parameters used within this section of the research. ...........49

Table 4-12: Showing temperature monitoring during slip testing .....................................51

Table 6-1: Analysis of hexagonal A325 high strength bolt at one third of a turn .....................58

Table 6-2: Simple regression analysis of measured wilhelm skidmore experimental data for A325

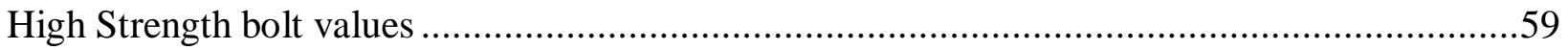

Table 6-3: Analysis of hexagonal galvanized A325 high strength bolt at one third of a turn.......59

Table 6-4: Simple regression analysis of measured Wilhelm Skidmore experimental data for

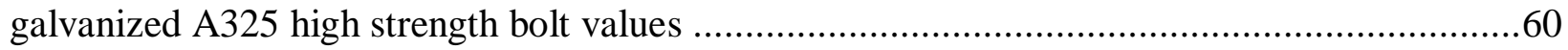

Table 7-1: Results of mean surface roughness measurement for selected specimens ...............61

Table 7-2:Determination of degrees turn to obtain a clamping force of $173 \mathrm{kN}$ from hand tightened position using skidmore device for regular A325 high strength bolt. 
Table 7-3: Determination of degrees turn to obtain a clamping force of $173 \mathrm{kN}$ from hand tightened position using skidmore device.

Table 7-4: Determination of clamping force for a degrees turn of $120^{\circ}$ from snug tightened position using skidmore device for regular A325 high strength bolt.

Table 7-5: Determination of degrees turn to obtain a clamping force of $173 \mathrm{kN}$ from hand tightened position using skidmore device for A325 galvanized bolt

Table 7-6: Determination of clamping force for a degrees turn of $120^{\circ}$ from snug tightened position using skidmore device for galvanized A325 bolt

Table 7-7: Results of values of slip load and slip coefficient for the three specimen tested along with mean value .68

Table 7-8: Results of values of slip load slip coefficient for the three specimen tested along with mean values .68

Table 7-9: Results of values of slip load and slip coefficient for the three specimen tested along with mean values.

Table 7-10: Results of values of slip load and slip coefficient for the three specimen tested along with mean values

Table 7-11: Results of values of slip load and slip coefficient for the three specimen tested along with mean values .71

Table 7-12: Results of values of slip load and slip coefficient for the three specimen tested along with mean values. .72

Table 7-13: Results of values of slip load and slip coefficient for the three specimen tested along with mean values.

Table 7-14: Results of values of slip load and slip coefficient for the three specimen tested along with mean values.

Table 7-15: Results of values of slip load and slip coefficient for the three specimen tested along with mean values. .75

Table 7-16: Results of values of slip load and slip coefficient for the three specimen tested along with mean values.

Table 7-17: Results of values of slip load slip coefficient for the three specimen tested along with mean values .77 
Table 7-18: Results of values of slip load and slip coefficient for the three specimen tested along with mean values

Table 8-1: Bolt relaxation mean change in length and standard deviation after $72 \mathrm{hrs}$ for a clamping force of $173 \mathrm{kN}$ .82

Table 8-2: Bolt relaxation mean change in length and standard deviation after $72 \mathrm{hrs}$ for a clamping force of $203 \mathrm{kN}$

Table 9-1: Results of values of slip load and slip coefficient for the three specimen tested along with mean values

Table 9-2: Results of values of slip load and slip coefficient for the three specimen tested along with mean values.

Table 9-3: Results of values of slip load and slip coefficient for the three specimen tested along with mean values.

Table 9-4: Results of values of slip load and slip coefficient for the three specimen tested along with mean value .88

Table 9-5: Results of values of slip load and slip coefficient for the three specimen tested along with mean value

Table 9-6: Mean temperature progression throughout testing of specimen for various surface treatment at $-5^{0} \mathrm{C}$

Table 9-7: Results of values of slip load and slip coefficient for the three specimen tested along with mean values.

Table 9-8: Results of values of slip load and slip coefficient for the three specimen tested along with mean values.

Table 9-9: Results of values of slip load and slip coefficient for the three specimen tested along with mean values.

Table 9-10: Results of values of slip load and slip coefficient for the three specimen tested along with mean values. . .95

Table 9-11: Results of values of slip load and slip coefficient for the three specimen tested along with mean values.

Table 9-12: Mean temperature progression throughout testing of specimen for various surface treatment at $-10^{\circ} \mathrm{C}$ .97 
Table 9-13: Results of values of slip load and slip coefficient for the three specimen tested along with mean values

Table 9-14: Results of values of slip load and slip coefficient for the three specimen tested along with mean values. 100

Table 9-15: Results of values of slip load and slip coefficient for the three specimen tested along with mean values. 101

Table 9-16: Results of values of slip load and slip coefficient for the three specimen tested along with mean values 102

Table 9-17: Results of values of slip load and slip coefficient for the three specimen tested along with mean values. 103

Table 9-18: Mean temperature progression throughout testing of specimen for various surface treatment at $-20^{\circ} \mathrm{C}$ .104

Table 9-19: Results of values of slip load and slip coefficient for the three specimen tested along with mean values. .106 Table 9-20: Results of values of slip load and slip coefficient for the three specimen tested along with mean values 107

Table 9-21: Results of values of slip load and slip coefficient for the three specimen tested along with mean values. .108

Table 9-22: Results of values of slip load and slip coefficient for the three specimen tested along with mean values. 109 Table 9-23: Mean temperature progression throughout testing of specimen for various surface treatment at $-30^{\circ} \mathrm{C}$ 


\section{Chapter 1: INTRODUCTION}

\subsection{Background}

Since the late 1960s, unpainted weathered steel has been used extensively in Ontario to construct bridges (whether as the entire superstructure or as support members such as beams). This was primarily done to reduce the maintenance requirement associated with the coating of structural steel members of bridges. However, weathering steel has not performed well in bridges where chloride from de-icing salt sprays onto the steel and prevent the development of a proper protective patina on the surface of weathering steel.

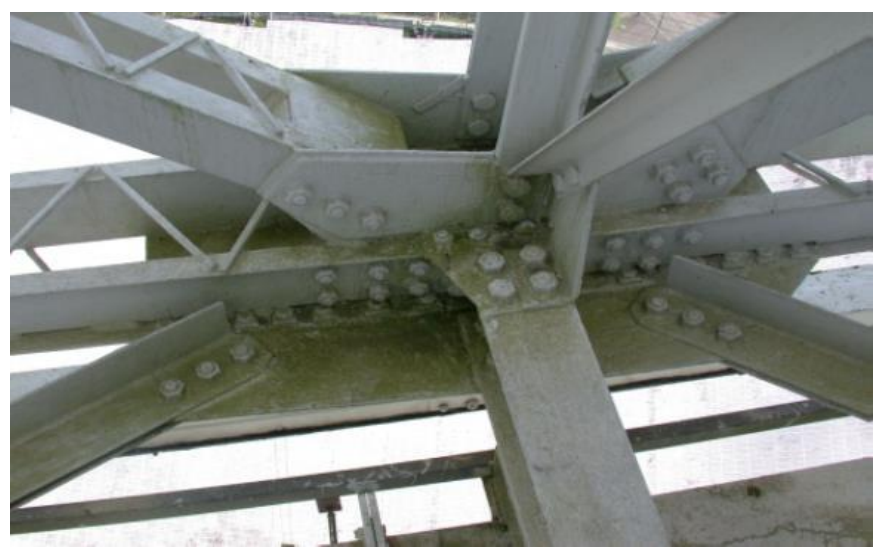

Figure 1-1: Bolted steel bridge connection made of structure steel (photo courtesy of KTATator, Inc.)

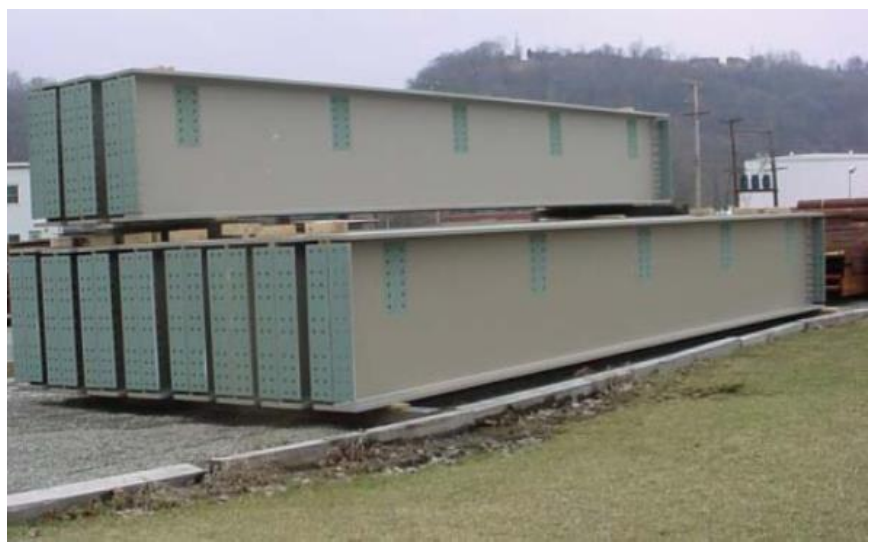

Figure 1-2: Steel main girder made from structure steel (photo courtesy of KTA-Tator, Inc.) 


\subsection{Research Objectives}

The objective of this thesis is to provide a database of information that would assist in qualifying ASTM A1010 stainless steel as well as stainless steel bolts to be used in bridges for sustainable construction and retrofitting works. To achieve this objective, laboratory testing on actual-size specimens was conducted to:

1. Investigate the re-usability of high-strength bolt, high-strength galvanized bolts and stainless steel bolts;

2. Investigate the effect of temperature variation on bolt pretension;

3. Investigate the coefficients of slip resistance for bolted connections made of ASTM A1010 stainless steel plates at room temperature;

4. Investigate the stress relaxation of the most suitable grade of high-strength bolts and its effect on the slip resistance of connections; and

5. Investigate the effect of temperature variation on the coefficients of slip resistance for bolted connections made of ASTM A1010 stainless steel plates.

\subsection{Research Overview}

This thesis is broken down into 10 Chapters (with most Chapters being further divided into different subdivisions). The first Chapter includes the introduction, research objectives, thesis overview and research methodology. The second Chapter presents relevant information on ASTM A1010 stainless steel, its properties and structural suitability. The third Chapter reviews previous research done in the field of slip resistance, bolt relaxation, re-usability of high-strength bolts and temperature effect on bolt pre-load. Chapter 4 presents the experimental program done in this research. The results, analysis and discussions are presented in Chapters 5 through 9, while Chapter 10 presents the conclusion and recommendations for future research.

\subsection{Research Methodology}

This research is intended to provide information on qualifying ASTM A1010 stainless steel as a material that can be used in bridge construction and retrofitting. However, there presently exist very limited information on the short- and long-term structural performance of ASTM A1010 stainless steel. In addition, there is virtual silence in various codes on the use of ASTM A1010 steel. 
In light of the above-mentioned facts, this research employed the following methodologies in order to accomplish the research objectives:

i. Because limited information exists on tests similar to those to be done in this research, a comprehensive literature review was conducted on each of the five experiments required to be conducted in this research. However, this information would be obtained from tests conducted on carbon steel to correlate results with existing data and consider them as basis of confidence to conduct tests on A1010 steel plates and bolts. As such, a sensitivity study was first conducted to:

a) provide similar and standardized testing procedure for A1010 steel research; and

b) provide correlation with existing research data for carbon steel to gain confidence on the developed test setup in the structures laboratory.

ii. Five different experimental programs were carried out to provide information on (1) highstrength bolt re-usability, (2) effect of temperature on bolt pre-load, (3) slip resistance testing at room temperature, (4) bolt stress relaxation, and (5) temperature effect on slip resistance testing.

iii. The results from tests let to draw conclusions and recommendations for further research.

For the purpose of this research, the clamping force was induced into the bolted connection through the use of $22 \mathrm{~mm}$ diameter (7/8") A325 high-strength bolt and galvanized A325 high-strength bolt. The specific clamping force value was determined by using a Wilhelm Skidmore bolt tensioning device and applied to the plates through the use of a constructed template of the degrees turn that corresponds to this clamping force. Two different clamping force were used in this research namely: (i) the minimum clamping of $173 \mathrm{kN}$ corresponding to $70 \%$ of the tensile capacity of the bolt according to Table 7 in the Canadian Standard for Limit State Design for Buildings, CSAS16-14 (CISC, 2014) and (ii) the clamping force corresponding to one-third of a turn according to the Specification for Structural Joints using ASTM A325 or A490 Bolts (RCSC, 2000). 


\section{Chapter 2: ASTM A1010 AS A STRUCTURAL MATERIAL}

Stainless steel is a family of iron-based alloys that must contain at least $10.5 \%$ chromium amongst other alloy. The presence of chromium creates an invisible surface film that resists oxidation and makes the material "passive" or corrosion resistant. Other elements, such as nickel or molybdenum are added to increase corrosion resistance, strength or heat resistance. According to Armao and Kotecki (2003) there are 5 categories of stainless steel, namely:

1. Austenitic Stainless steel: This material contains between 16 to $20 \%$ chromium and 8 to $24 \%$ nickel plus manganese.

2. Ferritic Stainless Steel: This material contains approximately 10.5 to $30 \%$ chromium and up to $20 \%$ carbon.

3. Martensitic Stainless Steel: This material contains between 11to18\% chromium and up to $1.2 \%$ carbon, with manganese and nickel in small quantities.

4. Duplex Stainless Steel: This material solidifies as $100 \%$ Ferritic, however approximately one half of the Ferritic is transformed to austenitic stainless steel during the cooling phase.

5. Precipitation Hardening Stainless Steel: This material has 3 classes of precipitation hardened stainless, namely: (i) exist austenitic, (ii) martensitic and (iii) semi-austenitic stainless steel.

According to Fletcher et al. (2005), a new class of stainless steel for bridge construction was developed by Arcelor Mittal of Chicago, USA in the 1990s. This steel, designated and codified as ASTM A1010 stainless steel (also known in the industry as Duracorr), contains approximately $12 \%$ chromium steel and is highly resistant to atmospheric corrosion as shown in Figure 2-1. When examined, ASTM A1010 stainless steel contains a micro-structure, that is fine-grained in nature, of tempered martensitic and ferrite which allows this material to possess it desirable fabrication characteristics. The complete chemical composition of ASTM A1010 stainless steel is shown in Table 2-1(Fletcher et al. 2005). Also codified by ASTM A240 as UN S41003, this steel meets the same AASHTO properties of strength and impact as do regular 350W and HPS 50W steels, up to $100 \mathrm{~mm}$ (4") thick (see Tables 2-2 and 2-3 as well as Figures 2-2 through 2-4). 


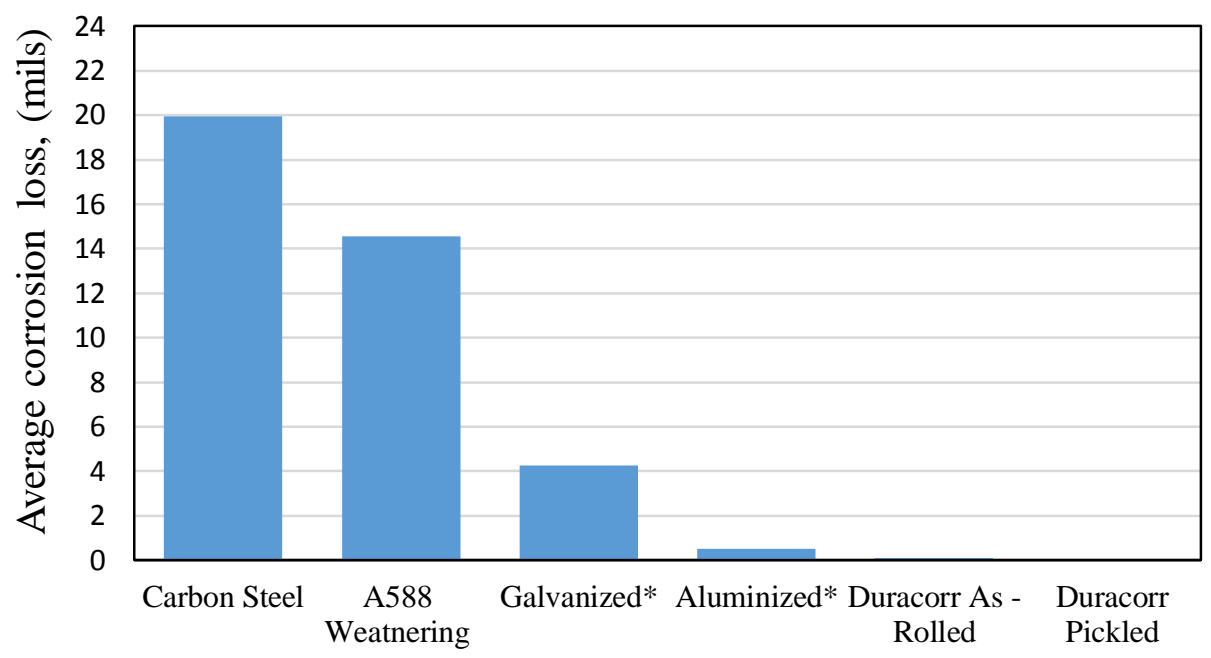

Material

Figure 2-1: Corrosion Performance of different steel types (Fletcher et al. 2005)

Table 2-1: Chemical composition of ASTM A1010 material (Fletcher et al., 2005)

\begin{tabular}{|l|c|c|c|c|c|c|c|}
\hline \multicolumn{7}{|c|}{ Composition of Duracorr (ASTM A1010) } \\
\hline Element & $\mathrm{C}$ & $\mathrm{Mn}$ & $\mathrm{P}$ & $\mathrm{S}$ & $\mathrm{Si}$ & $\mathrm{Ni}$ & $\mathrm{Cr}$ \\
\hline Min. & - & - & - & - & - & - & 10.5 \\
\hline Max. & 0.03 & 1.5 & 0.04 & $0.03^{*}$ & 1 & 1.5 & 12.5 \\
\hline \multicolumn{7}{|c|}{$* 0.005$ max. for bridge applications } \\
\hline
\end{tabular}

C-carbon, Mn- manganese, P-phosphorus, S-sulphur, Si-silicon, Ni-nickel and Crchromium

Table 2-2: Specified Mechanical Properties of ASTM A1010 (Fletcher et al, 2005)

\begin{tabular}{|l|c|c|c|}
\hline \multirow{2}{*}{} & \multicolumn{3}{|c|}{ ASTM A1010 } \\
\cline { 2 - 4 } & $\begin{array}{c}\text { ASTM A240 } \\
\text { (UNS41003) }\end{array}$ & $\begin{array}{c}\text { Grade 40 } \\
\text { (Optional) }\end{array}$ & $\begin{array}{c}\text { Grade 50 } \\
\text { (Standard) }\end{array}$ \\
\hline $\begin{array}{l}\text { Ultimate tensile strength } \\
\text { Min, ksi (MPa) }\end{array}$ & $445 \mathrm{MPa}(66 \mathrm{ksi})$ & $445 \mathrm{MPa}(66 \mathrm{ksi})$ & $485 \mathrm{MPa}(70 \mathrm{ksi})$ \\
\hline Yield strength, ksi (MPa) & $275 \mathrm{MPa}(40 \mathrm{ksi})$ & $275 \mathrm{MPa}(40 \mathrm{ksi})$ & $345 \mathrm{MPa}(50 \mathrm{ksi})$ \\
\hline $\begin{array}{l}\text { Elongation in } 50 \mathrm{~mm}(2 ") \\
\text { min. }\end{array}$ & $18 \%$ & $18 \%$ & $18 \%$ \\
\hline Brinell Hardness, max. & $223 \mathrm{HB}$ & - & - \\
\hline
\end{tabular}




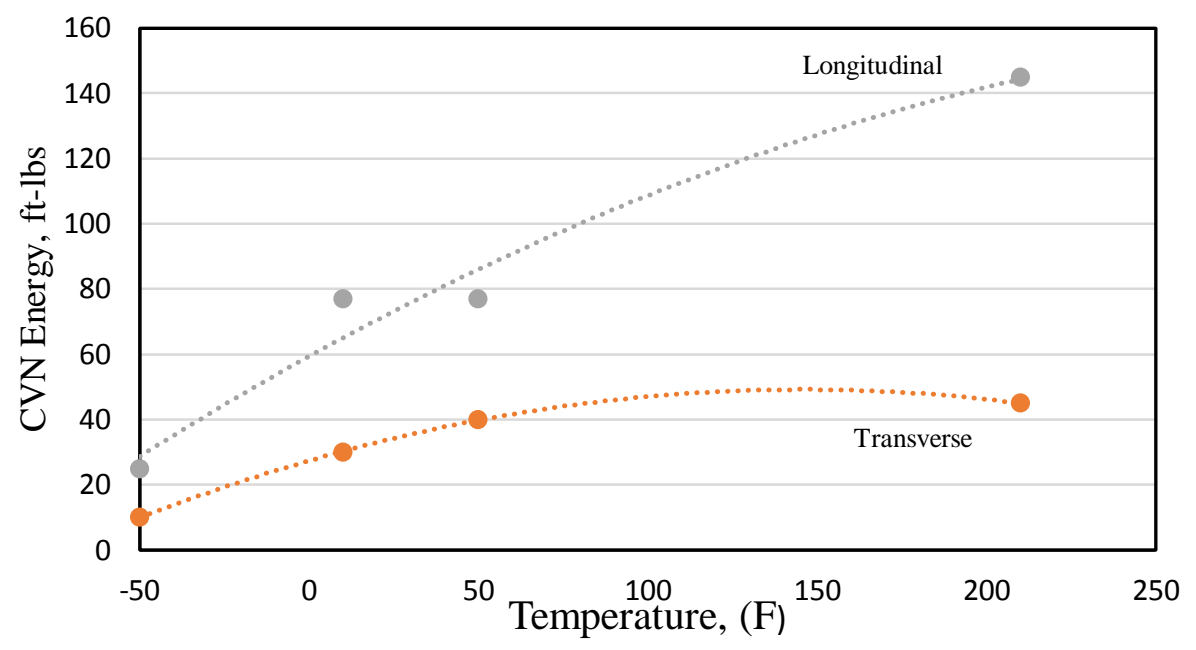

Figure 2-2: V-Notch impact curves for $6.4 \mathrm{~mm}$ (1/4") thick plate (Fletcher et al., 2005)

Table 2-3: Corrosion testing temperature $=77^{\circ}\left(25^{\circ} \mathrm{C}\right)$ and $\mathrm{pH}=7.0$ chloride concentration (Fletcher et al., 2005)

\begin{tabular}{|l|c|c|c|c|c|c|}
\hline Alloy & $\mathbf{5 0}$ & $\mathbf{1 5 0}$ & $\mathbf{2 5 0}$ & $\mathbf{1 0 0 0}$ & $\mathbf{5 0 0 0}$ & $\mathbf{2 0 0 0 0}$ \\
\hline Type 304 & 0.1 & 0.1 & 0.1 & 0.2 & 0.2 & 0.2 \\
\hline Duracorr & 0.3 & 0.5 & 0.4 & 2.1 & 1.2 & 2.6 \\
\hline Weathering Steel & 3.7 & 3.5 & 4.1 & 4.3 & 3.5 & 3.1 \\
\hline Galvanized Steel & 7.4 & 16 & 11 & 7.6 & 6.3 & 5.9 \\
\hline Aluminium 5083 & 0.6 & 3.9 & 0.9 & 4.8 & 4.8 & 2.3 \\
\hline
\end{tabular}

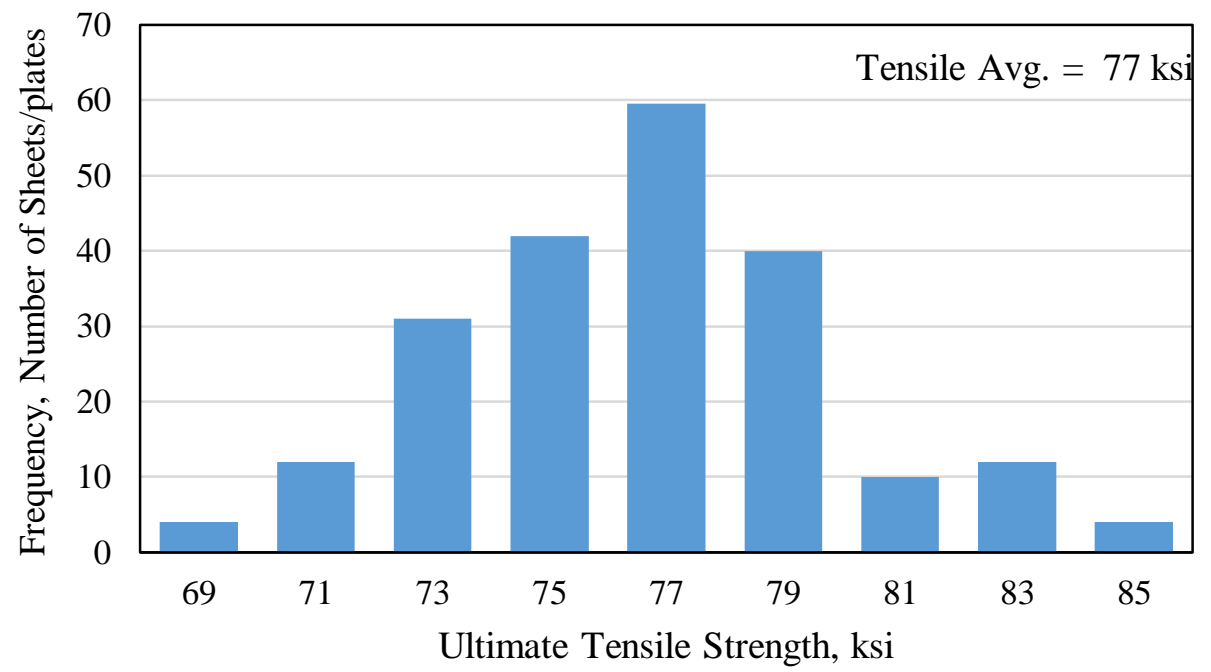

Figure 2-3: Ultimate tensile strength capacity of ASTM A1010 (Fletcher et al., 2005) 


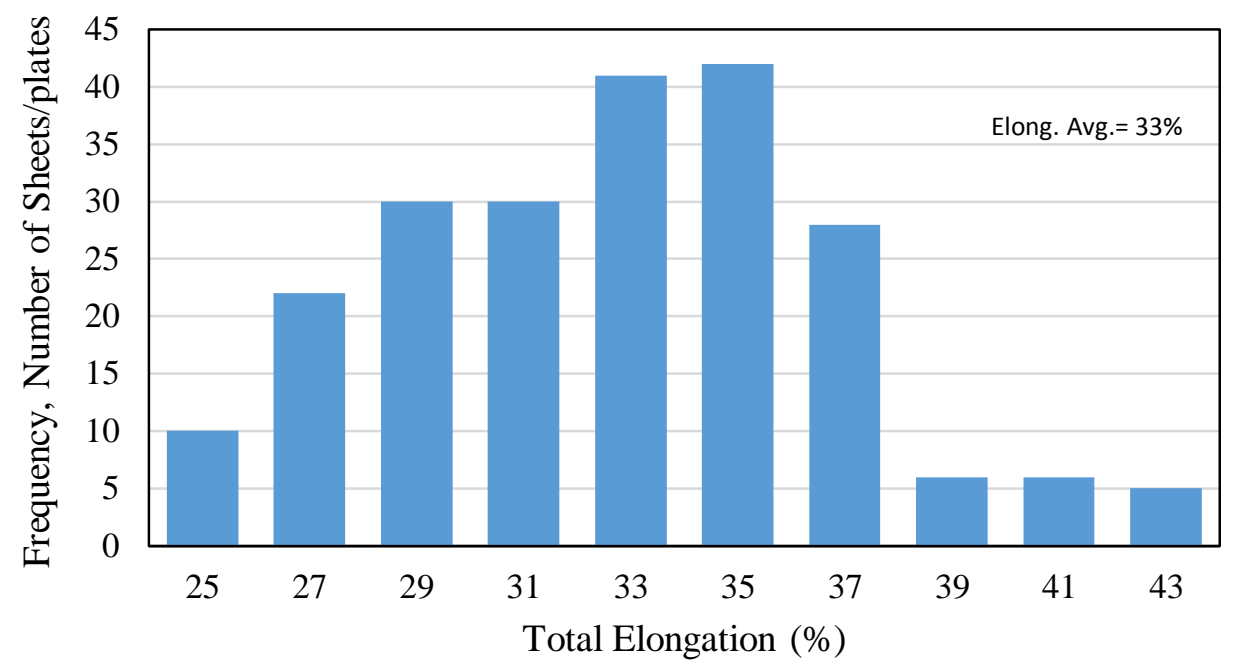

Figure 2-4: Elongation capacity of ASTM A1010 (Fletcher et al. 2005)

It is important to note that though classified as a member of the stainless steel family, ASTM A1010 stainless steel does not possess the same bright shiny appearance as other stainless steel materials of a higher chromium content. In fact, ASTM A1010 material, as milled scale surface condition, possesses a dull grey colour similar to that of 350W or 350AT steel and can be machined and bent in the same way (Fletcher et al., 2005). However, the primary difference between ASTM A1010 stainless steel and other traditional bridge construction steel is the manner/way in which it is cut. Whereas, traditional bridge steel can be cut using any conventional cutting process including oxy-fuel cutting, ASTM A1010 is more difficult to cut using oxy-fuel cutting or laser cutting. The primary/preferred means of cutting is (i) saw cutting, (ii) water-jet cutting or (iii) plasma cutting (Fletcher et al., 2005). In light of finding, ASTM A1010 stainless steel is more limited to on site fabrication or modification. Any fabrication or modification would require the services of a machine shop or plant. 


\section{Chapter 3 LITERATURE REVIEW}

\subsection{Summary}

The primary focus of this Chapter is to provide an overview of relevant research publications published on slip-critical joints, and present their findings that relate directly to this research. Although there are limited research publications on the behaviour of slip-resistance of stainless steel bolted joints or on its testing procedure, relevant information was found in related research that gives repeatable procedure on slip-resistance testing of other material that can be applied to our research. Based on literature review, a slip-critical joint is a joint that under tension, shear or moment produced by specified load (under service load condition), slip of the assembly does not occur over the life of the structure. The Research Council on Structural Connection guide (RCSC, 2009) states that slip-critical joint that transmits shear loads or shear loads in combination with tensile loads, in which the bolts have been pre-tensioned in the installed assembly (applying a prespecified clamping force on the faying surfaces) and with faying surfaces that have been prepared to provide a calculable resistance against slip.

\subsection{Review of Literature}

\subsubsection{Previous Slip Resistance and Bolt Relaxation studies}

There have being many test programs that have been conducted to investigate the slip resistance of bolts connections. In order for these test results to be of any useful benefit, there are two important test parameter that need to, or must, be observed or maintained, namely: (i) the accurate representation of the plates faying surfaces and (ii) the method of measurement of the bolt pretension force (clamping force) used in the test setup. One of the latest studies on the slip resistance of slip critical joints was conducted by Annan and Chiza (2014). They performed experimental and analytical studies of the slip resistance of metalized and galvanized faying surfaces in steel bridge construction. Annan and Chiza (2014) concluded that metalized and galvanized faying surfaces are two of the most effective surface protection methods. Metalizing method refers to the thermal spraying on of molten zinc or aluminium alloy onto the metal surface, whereas hot dip galvanizing method refers to the complete immersion of the steel part, first in a solution of pickling acid flux and then in a bath of molten zinc. Annan and Chiza suggested that the faying surface condition of the steel part plays an integral role in the slip resistance coefficient for the slip-critical joint. As such, they recommend that the faying surface be cleaned with a solvent 
to remove any oil or lubricant left over on the metal from the fabrication process. Annan and Chiza tested 25 short-duration slip critical specimens in both compression and tension. They also analysed the effect of the phenomenon of relaxation of the faying surfaces that are in the slip critical joint. From the results, they found that there was a loss of clamping force form the bolt, which indicated that there was a relaxation of the faying surfaces. This relaxation however varied for different surface conditions when compared to the pre-tensioned clamping force. The slip testing program conducted by Annan and Chiza (2014) included testing at two different clamping force, namely: (i) a clamping force that was equal to $70 \%$ of the bolt preload for a $7 / 8$ " diameter ASTM A325 bolt (that is approximately $174 \mathrm{kN}$ ) and (ii) a clamping force that was equal to $90 \%$ of the bolt preload for a 7/8" diameter ASTM A325 bolt (that is approximately $224 \mathrm{kN}$ ). From the results of these tests, they found that the average slip coefficient for faying surfaces, that were blast-cleaned with a surface profile of 2.6 and 4.5 mils and used a clamping force of $174 \mathrm{kN}$ in the compression test, was 0.38 and 0.53 , respectively. Whereas in the tension test under the same angular surface profile of 2.6 mils, the average slip coefficient was 0.36 for both clamp forces of $174 \mathrm{kN}$ and $224 \mathrm{kN}$. They also found that tests conducted with the faying surface being metalized galvanized (that is two of mating surfaces were metalized and the other was hot dip galvanized) produced much larger slip resistance coefficient when compared to those found elsewhere (RCSC, 2009).

Hechtman et al. (1955) conducted a research study on the slip resistance of joints under static loading. They tested joints that were double-lapped in nature and was subjected to compression, tension and torsional loads. They also seek to determine if (i) the difference in faying surface condition, (ii) the number of faying surface, (iii) the number of bolts in a joint and (iv) the tensioning of the bolts (bolt tension) had a direct impact on the slip behaviour of the joint. From their research, it was noticed that the primary test specimen used was of Class A surface condition (unpainted clean mill scale steel) as currently stated in the Canadian Highway Bridge Design code (CSA, 2014). In order to calculate the slip coefficient, they choose to use the slip load as that load at which major slip was first observed. They concluded that (i) the faying surface area, (ii) the plate-lap thickness and (iii) the bolt pattern had no direct impact on the slip behaviour of the joint.

Despite the limited number of previous experimental work and studies done on the slip resistance of slip critical joints, Nah and Kim (2011) conducted slip resistance testing on 5 different kinds of 
faying surface treatment. The 5 kinds of faying surface conditions used were (i) clean mill, (ii) red lead painted surface, (iii) rusted surface, (iv) zinc rich painted surface, and (v) shot blast surface finish. They conducted their testing considering two main parameters, namely: (i) the faying surface treatment and its effect and (ii) the number of lap plates. As for the various surface treatments, Nah and Kim considered (i) clean mill surface condition left the same way it was delivered, (ii) exposing the steel elements outdoor for one month after the shot blast process was done to the metal to achieve a rusted condition and (iii) applying to the metal red lead paint with thickness of the application controlled at $65 \mu \mathrm{m}$ as well as $125 \mu \mathrm{m}$, (iv) galvanizing plate surface in the form of painting. The metal surface was sprayed with a zinc primer and the thickness was controlled to $128 \mu \mathrm{m}$ as well as $226 \mu \mathrm{m}$ respectively, and (v) shot blasting with angular profile in the range of $0.5 \mathrm{~mm}$ to $1.4 \mathrm{~mm}$. The clamping force used in this study was $178 \mathrm{kN}$. Research findings revealed that the slip coefficient for the specimen with clean mill scale faying surface condition was between the ranges of 0.23 to 0.29 . For specimens with red lead painted surface condition, the average slip coefficient was 0.21 for the thickness of $65 \mu \mathrm{m}$. However, for the thickness of $125 \mu \mathrm{m}$ the slip coefficient fell to 0.09. For zinc primer specimen, the average slip coefficient was in the order of 0.42. Nah and Kim also indicated that for the shot-blasted surface finish, the average surface finish was $0.5 \mathrm{~mm}$ with a standard deviation of 0.08 .

Corbett and McGee (2014) conducted extensive experimentation and analysis to determine the slip efficiency and tension creep of different faying surface coating. They tested 5 replicated slip assembly and 9 tension creep assembly (a total of 15 plates and 9 plates, respectively). The clamping force for their procedure was obtained by a load cell, installed horizontally to the test plates. Corbett and McGee calculated the slip coefficients, and determined that the mean slip coefficient was very close to the value stated in the Canadian Highway Bridge Design Code.

Nah et al. (2009) conducted experimental research to determine the clamping force of high strength bolts when subjected to different temperature range. Their objective of research was to develop from laboratory data and regression analysis an equation to estimate the clamping force of a specimen subjected to temperature variation between $-10{ }^{0} \mathrm{C}$ to $50{ }^{0} \mathrm{C}$ using a hexagonal bolt. In addition, they tested two different method of clamping force application using hexagonal bolts subjected to (i) torque and (ii) tension. The bolt pre-load was considered to be satisfactory when a 
standard force of $178 \mathrm{kN}$ was achieved. To apply this clamping force to the specimen Nah et al. proposed using the turn-of-the-nut method, with the angle that corresponds to $178 \mathrm{kN}$ varying from $155^{\circ}$ to $171^{0}$. This was higher than the standard turn-of-the-nut of $120^{\circ} \pm 30^{\circ}$. They recommended that the turn-of-the-nut angle be revised to $120^{\circ} \pm 30^{\circ}$ which should meet a more accurate clamping force for bolts with high strength bolt of a diameter of $20 \mathrm{~mm}$. Two types of bolts were used during testing, namely: (i) hexagonal bolt KS B1010 and (ii) torque shear bolt KS B2819. They were subjected to temperature variation of $-10,0,10,20,30,40$ and $50{ }^{\circ} \mathrm{C}$. A total of 120 bolts were tested, half of which were KS B1010 bolt and the remaining half were KS B2819. Results showed that for high strength bolts subjected to temperature variation, the clamping force was vulnerable to temperature fluctuation.

Vasarhelyi and Chiang (1967) examined the coefficient of friction in joints of various steel. They investigated whether the number of faying surface has an effect on the jointed assembly. In their study, they made a deliberate attempt to differentiate between the true coefficient of friction (which was determined by testing the friction directly, through the application of a compression force to the test specimens) and nominal friction coefficient (which was determined by using a tension test joint). The difference existed between the interpretation/calculation of the two terms (i.e. coefficient of friction and coefficient of slip) was defined as the coefficient of friction was calculated as the load at which any one of the elements in the joint assembly moved (which is most often at the end of the joint assembly) while the coefficient of slip was calculated as the load at which large slip between the elements of the joint assembly occurs. From the results and discussion of this study, it was concluded that the friction coefficient was not affected by the number of faying surface. It was also concluded that even though with some joints the coefficient of slip was significantly higher than the coefficient of friction, there were many joint assemblies where the two coefficients were basically identical.

Grondin et al. (2007) conducted experimentations to measure the slip coefficient for Grade ASTM A588 steel. A total of 99 tension double-lap splice joint specimen were tested. The main test parameters that was examined were (i) the faying surface condition and its effect, (ii) the bolt pretension level, (iii) bolt hole diameter, (iv) the effect of the heating of the steel and (v) the fabrication of the bolt hole. The turn-of-the-nut method of pre-tensioning was used to clamp the 
specimen by means of high strength bolt. They indicated that according to Kulak et al. (1987), a higher than average pre-tension force is achieved when using the turn-of-the-nut method and the pre-tension of the bolts reaches almost the tensile strength of the bolt. The Drilling holes in the specimens was done using two different processes, namely: drilled and punched, with the bolt size being 3/4" diameter A325 bolt. Similarly, the plate thicknesses were of two sizes, namely: 1/2" and 5/8" thick. They concluded that almost the entire test specimen showed a significant change (or increase) in the average slip coefficient when comparing the degreased plates and the as received plates. With the degreased plate specimens showing a much higher average slip coefficient. Surface preparation also had a very strong effect on the slip resistance value. Grondin et al. stated that when a comparison of the fabrication process used to drill the bolt hole, the result showed no significant difference in the average slip coefficient value when using the drilling or punching process.

Reuther et al. (2014) set out to evaluate the load loss behaviour of bolted steel assemblies using ASTM A325 high strength bolts under the influence of multiple variables as that experience under field condition. This experimental program looked at measuring the tension loads over a period of 42 days in bolted steel joint assemblies, made from $22 \mathrm{~mm}$ thick plates and $20 \mathrm{~mm}$ diameter ASTM A325 high strength bolts of lengths between 76 to $89 \mathrm{~mm}$. In addition, two different bolted steel joint assemblies were considered in this study in order to determine the degree or level of relaxation within the bolt of the joint assemblies. Those are (i) assemblies employing direct tension indicators and (ii) assemblies that did not have any kind of load-indicating device. In order to determine the change in bolt length within the bolted assemblies, ultrasonic techniques were used. This ultrasonic measurement was then converted to load or stress through the manipulation of Hooke's law which states:

$\delta=\frac{P L}{E A}$

And after manipulation, it becomes

$\mathrm{P}_{\mathrm{A}}=\frac{\delta E A_{s}}{L_{e}}$

where: $\mathrm{P}_{\mathrm{A}}=$ applied load; $\mathrm{E}=$ modulus of elasticity; $\mathrm{A}_{\mathrm{s}}=$ stressed area; and $\mathrm{L}_{\mathrm{e}}=$ effective length. Further to this equation they stated that the effective length includes the grip length of the bolt, $\mathrm{T}_{\mathrm{g}}$, plus a section of the bolt head and nut as follows. 
$L_{e}=T_{p}+n T_{w}+T d+1 / 3 D_{n}+1 / 2 D_{t}=T_{g}+1 / 3 D_{n}+1 / 2 D_{t}$

where $T_{p}=$ plate thickness; $n=$ number of washers; $T_{w}=$ washer thickness; $T_{d}=$ direct tension indicator (DTI) thickness; $\mathrm{D}_{\mathrm{n}}=$ nominal bolt diameter; and $\mathrm{D}_{\mathrm{t}}=$ threaded bolt diameter.

Reuther et al. also indicated that stressed area can be calculated as follows.

$\mathbf{A}_{\mathrm{s}}=\frac{\left(\boldsymbol{L}_{t} A_{t}\right)+\left(\boldsymbol{L}_{\boldsymbol{u}} A_{n}\right)}{\boldsymbol{L}_{e}}$

Where $\mathrm{L}_{\mathrm{t}}=$ length of the threaded section in the effective length plus the provisional length for the nut; $A_{t}=$ area of the threaded section; $L_{u}=$ length of the unthreaded section in the effective length plus the provisional length for the bolt head; $A_{n}=$ nominal area.

Fifty-four sample assemblies were tested using varying tensioning methods, bolt length and bolt diameter. From these testing it was observed that the loss or reduction in the bolt pretension occurred mainly within the first $72 \mathrm{hrs}$ after tensioning and that stabilization was achieved thereafter.

Dewolf and Yang (2000) conducted research to investigate the relaxation of high-strength bolted connected using galvanized steel. Their testing program was developed to examine $3 \mathrm{key}$ parameters, namely (i) the shear capacity of the bolt subjected to short-term duration testing, (ii) the level of bolt relaxation as a function of time as well as how this relaxation impact the shear capacity of the bolt and (iii) the slip resistance subjected to long-term loading. The variables for this research were as follows: (i) the plates faying surface condition (galvanized or un-galvanized), (ii) the nominal galvanized coating thickness $(0,5,10,15,20$ mils), (iii) bolt size (7/8"), (iv) bolt hole type and size (standard hole 15/16" diameter and over size hole of $11 / 8$ " diameter), (v) clamping force (173.5 kN or $39 \mathrm{kips})$ and (vi) plate Thickness (25.4 mm thick). For each galvanized faying surface coating thickness and un-galvanized surface for the slip resistance testing, 3 samples were tested. Also, for the relaxation testing for each coating thickness, 3 samples were tested. Overall a total of 30 tests were conducted, of which half was of the standard bolt hole type and the reminder was of the oversize bolt hole type. Based on experimental findings, Dewolf and Yang concluded that for galvanized coatings with a maximum thickness of 5 mils both the 
allowable stresses and the slip coefficient were within the acceptable range as stated in the AASHTO bridge specification. Also the size of the bolt hole showed no significant impact on the slip coefficient. However, they discovered that there was a loss in the clamping force over time, and this loss was due in part to the creep phenomenon in the faying surface with a thicker coating. As a result, this creep phenomenon created a significant reduction in the slip resistance of the bolted joint. As for the relaxation testing, a graph of clamping stress versus time was plotted as shown in Figure 3-1. In addition, Table 3-1 shows the relationship between the three tested specimens and the amount of relaxations.

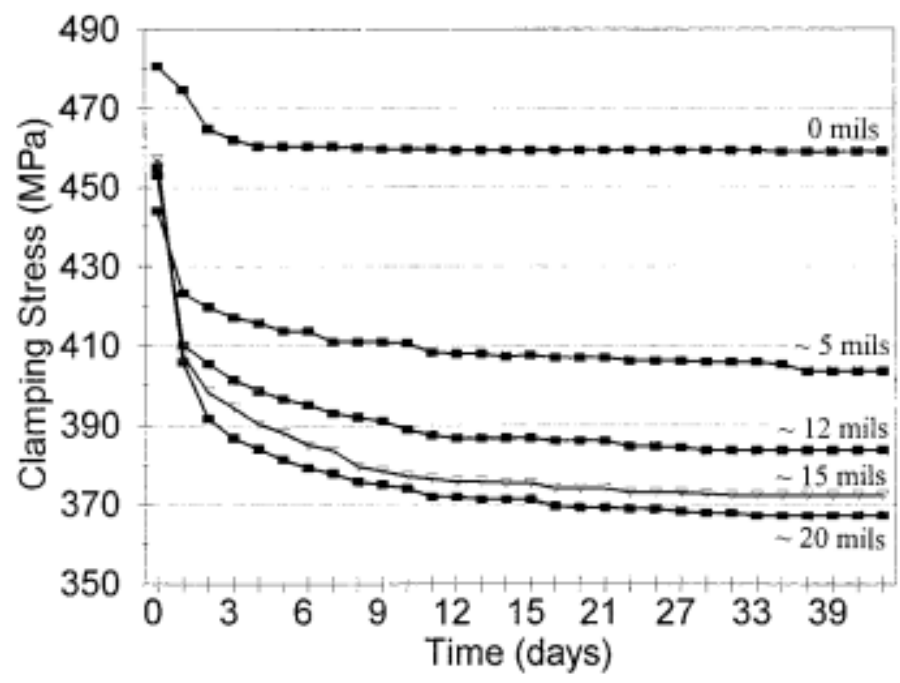

Figure 3-1: Stress versus time graph, (Dewolf and Yang, 2000)

Table 3-1: Bolt relaxation results, (Yang and Dewolf 2000)

\begin{tabular}{c|c|c|c|c}
\hline \hline \multirow{2}{*}{$\begin{array}{c}\text { Nominal } \\
\text { galvanized } \\
\text { coating } \\
\begin{array}{c}\text { thickness } \\
\text { (mils) }\end{array}\end{array}$} & \multicolumn{2}{|c|}{$\begin{array}{c}\text { Loss of Clamping Force (\%) } \\
\text { after 42 Days }\end{array}$} \\
\cline { 2 - 4 }$(1)$ & & & & $\begin{array}{c}\text { Average } \\
\text { loss } \\
(\%)\end{array}$ \\
\hline 0 & $(2)$ & $(3)$ & $(4)$ & $(5)$ \\
\hline 5 & 14.4 & 6.3 & 5.9 & 5.6 \\
10 & 14.6 & 11.0 & 14.3 & 12.4 \\
15 & 16.2 & 19.1 & 17.3 & 15.3 \\
20 & 18.4 & 20.6 & 16.3 & 19.6 \\
\hline \hline
\end{tabular}


Li and Yamada (1972) conducted stress relaxation experimentation on two types of austenitic stainless steel materials at room temperature, namely: Type 304 stainless steel and Type 316 stainless steel. Both stainless steel materials were subjected to heat treatment, with Type 304 stainless steel undergoing heat treatment at a temperature of $1100{ }^{\circ} \mathrm{C}$ as well as $850{ }^{\circ} \mathrm{C}$ for 30 minutes and then left to air cool. Type 316 stainless steel underwent heat treatment at a temperature of $1100{ }^{\circ} \mathrm{C}$ for 30 minutes and then left in air to cool. The shape of the specimens used in this research was rod shape with a gage length of $50.8 \mathrm{~mm}$ and a section diameter of $2.54 \mathrm{~mm}$. The research included the determination of the strain effect within these stainless steel materials. Therefore, both types of stainless steel were tested at 4 different strain levels. Li and Yamada found that the typical shape of the log stress vs log strain rate curve for type 304 stainless steel, that was heat treated to $1100{ }^{\circ} \mathrm{C}$, concaved upwards and was similar to metals that had a body centred cubic (bcc) crystalline structure. They also reported that this was quite a contrast to similar natured materials such as TD nickel that is basically a straight line. And those for a material with a face centred cubic (fcc) crystalline structure had a downward shaping log stress vs log strain rate curve. They further discovered that the shape of the log stress vs log strain rate curve for type 304 stainless steel that was heat treated to $850^{\circ} \mathrm{C}$ and type 316 stainless steel show similar results as that of type 304 that was heat treated to $1100{ }^{\circ} \mathrm{C}$.

Borello et al. (2010) performed research to examine the performance of bolted steel slip critical connections with filler plates. In structural steel design, filler plates are typically used with longspan truss connection systems, splicing of girders or columns. In orders for filler plates to be considered as fully-developed components, adequate amount of bolts or equivalent welds must be present to enable a uniform distribution of stress between the filler plate and the member being connected. Borello et al. tested 16 filler plated specimens consisting of a top wide flange column and a bottom wide flange column. ASTM F2280 "Twist-off" structural bolts were used to assembly two of the bolted specimens, with the rest of the bolted specimens being bolted with ASTM A490 High Strength Bolt, utilizing the turn-of-nut method to pretension them. In order to achieve maximum slip of the joint assembly (between the splice plate, filler plates and the columns), the condition of negative bearing was applied to the top column. A total of 24 bolts, 229 $\mathrm{mm}$ long, were used to connect the top column to the splice plate and a total of 64 bolts were used 
to connect the bottom column. Test results showed that the slip resistance of the filler plate bolted connection was not affected by the oversize nature of the bolt hole.

Jhang et al. (2006) conducted experimentation where they investigated the effect of non-linear elasticity and the induced stress within a high strength bolt analysed using ultrasonic velocity. They stated that there are 4 methods of applying the initial clamping force and thus determining the bolt preload. Each of which has its own advantages and disadvantages as follows.

Method 1 - Torque Wrench Method: It seeks to determine the clamping force by estimating torque applied to high-strength bolt. This method however contains significant errors, due mainly in part to the loss of friction during the conversion of torque energy to pre-load process.

Method 2 - Angle Control Method: It considers the analysis of the linear relationship between the nut rotation and axial force. This region may be very difficult to determine during an experiment or on-site.

Method 3 - Strain Gauges Method: This method examines induced stress within the bolt by measuring change in shear. However, the primary difficult with this method is that the attachment of strain gauges in on-site to the bolt head may be impractical.

Method 4 - Ultrasonic Velocity Method: It is a more reliable method of directly determining the clamping force within the bolt through the use of ultrasonic velocity.

Jhang et al. (2006) conducted two different experiments to verify the accuracy of the clamping force by using the ultrasonic velocity method. The primary difference between the two experiments were the method of applying the bolt clamping force and the effect it had on the ultrasonic velocity passing through the bolt. The first experiment one used two M16/10.9T samples and using a tension tester to apply the clamping force. Whereas the second experiment used three M16/10.9T samples with a torque wrench being used to apply the clamping force. Results showed that for the stress-strain relationship in the first experiment, there was a very stable linear relation. As for the second experiment, results showed a decrease in the ultrasonic velocity with an increase in the torque value, up to an approximately value of 220 N.m. Jhang et al. further concluded that both sets of results were expected based on the theoretical tendencies and equations used in analysis, which seems to validate the effectiveness of using this technique. 
Yura et al. (1981) performed both compression slip and tension slip tests in two parts. One part was done by the University of Texas where they tested two different surface conditions utilizing two different methods of clamping force application, namely: (i) clamping with 7/8" A325 high strength bolts and (ii) clamping with a hydraulic bolts and rod. Part two was done by the Federal Highway Administration where they used only hydraulic bolt and rod, with two surface conditions. Part one of their research testing contained both tension and compressive slip testing, whereas part two only contained compressive slip testing. They concluded that for the clean mill scale specimens that were clamped with 7/8" A325 high strength bolt, the slip coefficient ranged in values between 0.18 and 0.19 . Whereas for the sand-blasted specimens of clamped with the 7/8" A325 high strength bolt, the slip coefficient ranged between 0.70 and 0.77 .

\subsubsection{Current Design Standards and Specifications}

The design and evaluation of slip-critical connections is governed by various codes and clauses. However, the CSA-S16-14 (CISC, 2014) and CSA-S6-14 (CSA, 2014) state that the design criteria of the slip-resistant joint should be such that under the forces and moments produced by specified loads, slip of the assembly shall not occur. In addition, the effect of factored loads shall not exceed the resistance of a bearing-type connection.

The slip resistance, $\mathbf{V}_{\mathbf{s}}$, of bolts in a bolted joint is calculated as follows with constants shown in Table 3-2.:

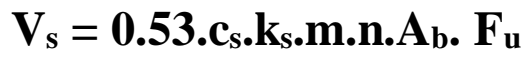

where: $\mathrm{c}_{\mathrm{s}}=$ value relates to the assigned specified initial tension $\left(70 \%\right.$ of $\left.\mathrm{Fu}_{\mathrm{u}}\right) ; \mathrm{ks}_{\mathrm{s}}=$ slip resistance coefficient (as obtained from experimental testing done in compliance with the Research Council on Structural Connection's testing method for the determination of Slip Coefficient for Coating used in Bolted Joints); $\mathrm{m}=$ number of shear planes ( 1 for single shear or 2 for double-shear); $\mathrm{n}=$ number of bolts; $A_{b}=$ cross-sectional area of a bolt; and $F_{u}=$ ultimate strength of the bolt material.

CSA-S16-13 also specifies that in case when long slotted holes are used in slip-critical connections, the value of $\mathrm{V}_{\mathrm{s}}$ shall be taken as 0.75 of the values obtained from equation 3-5. 
Table 3-2: Values of $\mathrm{k}_{\mathrm{s}}$ and $\mathrm{c}_{\mathrm{s}}$ (CISC, 2014)

\begin{tabular}{|c|c|c|c|c|}
\hline \multicolumn{2}{|c|}{ Contact surface of bolted parts } & \multirow[b]{2}{*}{$\mathbf{k}_{\mathbf{s}}$} & \multicolumn{2}{|c|}{$\frac{c_{1}}{\text { Turn-of-nut }}$} \\
\hline Class & Description & & $\begin{array}{l}\text { A325M and } \\
\text { A325 bolts }\end{array}$ & $\begin{array}{l}\text { A490M and } \\
\text { A490 bolts }\end{array}$ \\
\hline A & $\begin{array}{l}\text { clean mill scale, or blasted- } \\
\text { cleaned with Class A coatings }\end{array}$ & 0.33 & 0.82 & 0.78 \\
\hline B & $\begin{array}{l}\text { Blasted-cleaned or blasted- } \\
\text { cleaned with Class B coating }\end{array}$ & 0.50 & 0.90 & 0.85 \\
\hline $\mathbf{C}$ & $\begin{array}{l}\text { Hot-dip galvanized with wire } \\
\text { brushed surfaces }\end{array}$ & 0.40 & 0.90 & 0.85 \\
\hline
\end{tabular}

\subsubsection{Bolts Pretension}

According to Specification for Structural Joint using ASTM A325 or A490 Bolts (RCSC, 2000), there are 4 different methods of determining the pretension of bolted connections using the bolt calibration method, namely: (I) Turn-of-the-nut pre-tensioning method; (ii) Calibrated wrench pretensioning method; (iii) Twist off type tension control bolt pre-tensioning method; and (iv) Direct tension indicator pre-tensioning method. This section presents a review of the turn-of-nut pretensioning method which was used in this research experimental program.

\subsubsection{Snug Tightening of High Strength Bolts}

CISC (2014) states that the snug-tightening of high-strength bolted connection involves the alignment of the joint holes, followed by inserting of the high-strength bolt into the joint holes and tightening the assembly until all of the joint connection mating surfaces are in full contact with each other. In other words, the snug-tightened condition is the tightness that is attained with a few impacts of an impact wrench or the full effort of an ironworker using an ordinary spud wrench to bring the connected plies into firm contact. Once this has been done, the pre-tensioning procedural method can be applied.

\subsubsection{Turn-of-the-Nut Pre-tensioning Method}

The Specification for Structural Joint using ASTM A325 or A490 Bolts indicates that the turn-ofthe-nut pre-tensioning method is a method that is both reliable and simple to conduct. It establishes 
the relationship between the turn-of-the-nut relative to the bolt from the snug-tightened position to the amount of pre-tension in the bolt. The amount of turn-of-the-nut relative to the bolt is given in Table 3-3, which represents a relationship between the bolt length and the diameter of the bolt.

Table 3-3: Nut rotation for snug-tight condition for turn-of-the-nut pretensioning (RCSC, 2000)

\begin{tabular}{|c|c|c|c|}
\hline \multirow[b]{2}{*}{ Bolt L ength } & \multicolumn{3}{|c|}{ Disp osition of outer face of bolted parts } \\
\hline & $\begin{array}{l}\text { Both faces } \\
\text { normal to } \\
\text { bolt axis }\end{array}$ & $\begin{array}{l}\text { One face normal to } \\
\text { bolt axis, other } \\
\text { sloped not more than } \\
1: 20_{d}\end{array}$ & $\begin{array}{l}\text { Both faces sloped not more than } \\
1: 20 \text { from normal to bolt axis }\end{array}$ \\
\hline $\begin{array}{l}\text { Not more than } \\
4 \mathrm{db}\end{array}$ & $1 / 3$ turn & $1 / 2$ turn & $2 / 3$ turn \\
\hline $\begin{array}{l}\text { More than } 4 \mathrm{db} \\
\text { but not more } \\
\text { than } 8 \mathrm{db}\end{array}$ & $1 / 2$ turn & $2 / 3$ turn & $5 / 6$ turn \\
\hline $\begin{array}{l}\text { More than } 8 \mathrm{db} \\
\text { but not more } \\
\text { than } 12 \mathrm{db}\end{array}$ & $2 / 3$ turn & $5 / 6$ turn & 1 turn \\
\hline $\begin{array}{l}\text { a Nut rotation } \\
\text { for required } \\
\text { degrees; for } \mathrm{r} \\
45 \text { degrees } \\
\text { b Applicable or } \\
\text { c When the bol } \\
\text { by testing in } \\
\text { fitting steel. } \\
\text { d Beveled wash }\end{array}$ & $\begin{array}{l}\text { relative to b } \\
\text { thotations of } \\
\text { uired nut rot } \\
\text { to joints in } \\
\text { ength exceed } \\
\text { suitable tensi } \\
\text { not used }\end{array}$ & $\begin{array}{l}\text { egardless of the element } \\
\text { turn and less, the tolera } \\
\text { of } 2 / 3 \text { turn and more, } t \\
h \text { all material within the } \\
d b \text {, the required nut rota } \\
\text { alibrator that simulates } t\end{array}$ & $\begin{array}{l}\text { nut or bolt) being turned. } \\
\text { ce is plus or minus } 30 \\
\text { lerance is plus or minus } \\
\text { grip is steel } \\
\text { on shall be determined } \\
\text { conditions of solidly }\end{array}$ \\
\hline
\end{tabular}




\section{Chapter 4 EXPERIMENTAL PROGRAM}

\subsection{Rationale of the Experimental Research Program}

Based on the fact that there currently exist no literature or experimental data on the use of ASTM A1010 stainless steel, it was prudent to begin experimental investigation at the low end of testing specification. As such, all the testing parameters considered in this research were of the minimum specification, when compared to similar research such (Yang et al., 2000). In particular, these test parameters are (i) method of clamping force determination, (ii) level of surface roughness, (iii) method of surface treatment and (vi) method of application of clamping and the minimization of clamping force variation. Comparatively, based on review of similar research done in the literature, all conducted testing used parameters that were significantly higher than those used in this research. This approach was not adopted by this research, as it sought to determine the minimum benchmark specification that would produce acceptable design results of slip coefficient, utilizing common constructional practices in the steel industry today. In addition, another rationale behind the selected approach used in this research is that upon careful review of associated literature, many critical information or parameters were not reported on, which makes it difficult to ascertain (i) the true nature of their test results for fair comparison or evaluation, and (ii) completely duplicating their testing methods. Finally, the test results presented in this research are by no means the standards by which to assess or design ASTM A1010 stainless steel, instead it provides benchmark for future researchers to start further testing and experimentation on this material.

\subsection{Experimental Program 1: Bolt reusability}

Based on the research parameters used within this phase of experimental testing, it was divided into two major categories, namely: (i) bolt reusability testing with unlubricated bolt threading; and (ii) bolt reusability testing with lubricated bolt threading. In this research, an ultrasonic bolt elongation monitoring device, called Mini-Max, was used in this research to measure bolt tension through measuring change in bolt length before and after applying the pre-load.

\subsubsection{Test Specimen Preparation}

In order to accommodate the attachment of the magnetic transducer of the Mini-Max ultrasonic bolt elongation monitoring device, all raised embossment on the head of the bolt, shown in Figure 
4-1, had to be removed by grinding and the head of the bolt made flat and true as shown in Figure 4-2.

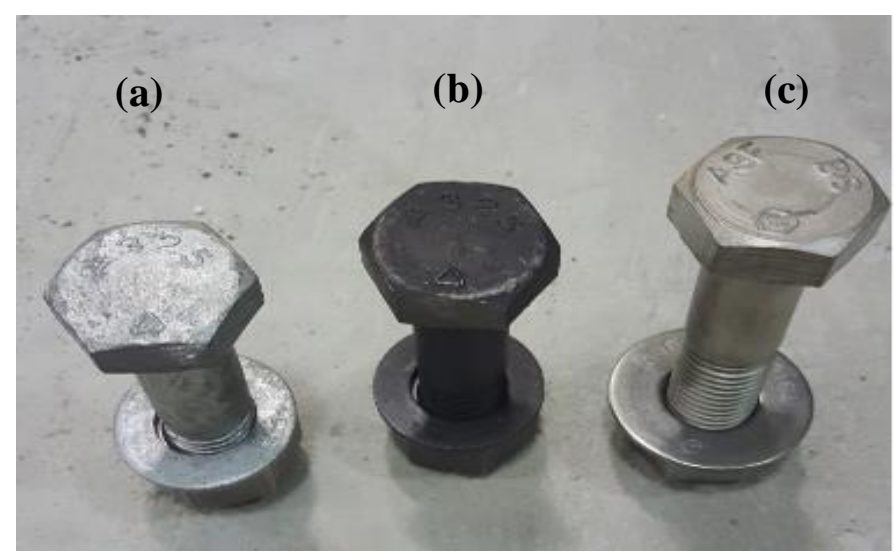

Figure 4-1: Sample specimens of high-strength bolts with raised embossment on head of used in this research (a) galvanized A325 bolt, (b) regular A325 bolt and (c) B8 class 1 stainless steel bolt

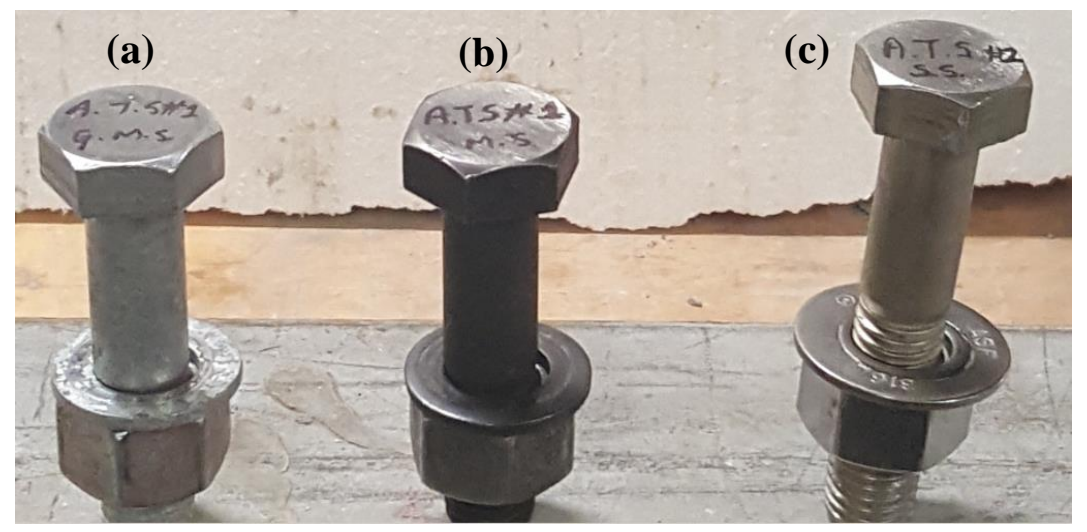

Figure 4-2: Sample of high-strength bolt with raised embossment on the bolt head removed used in the verification stage (a) galvanized A325 bolt, (b) regular A325 bolt and (c) B8 class 1 stainless steel bolt

\subsubsection{Verification of High Strength Bolt and Stainless Steel Bolt Reusability}

According to Kulak et al. (2001), the turn-of-the-nut method of pre-tensioning a bolt produces excess tension within the threaded portion of the bolt, causing the stress in this region to exceed its elastic limit. As such an examination of how many times a high-strength bolt can be subjected to repeated tightening and loosening before it becomes unusable needs to be conducted. In this 
phase of the research program, tests were conducted to examine the behaviour of B8 class 1 stainless steel bolts, A325 high strength bolt and A325 high strength galvanized bolts. One bolt from each bolt group was used to determine the reusability characteristic of each bolt. Each bolt was placed in the Wilhelm Skidmore bolt tensioning machine as shown in Figure 4-3a and torqued to one-third of a turn, loosened and then re-torqued as shown in Figure 4-3b.
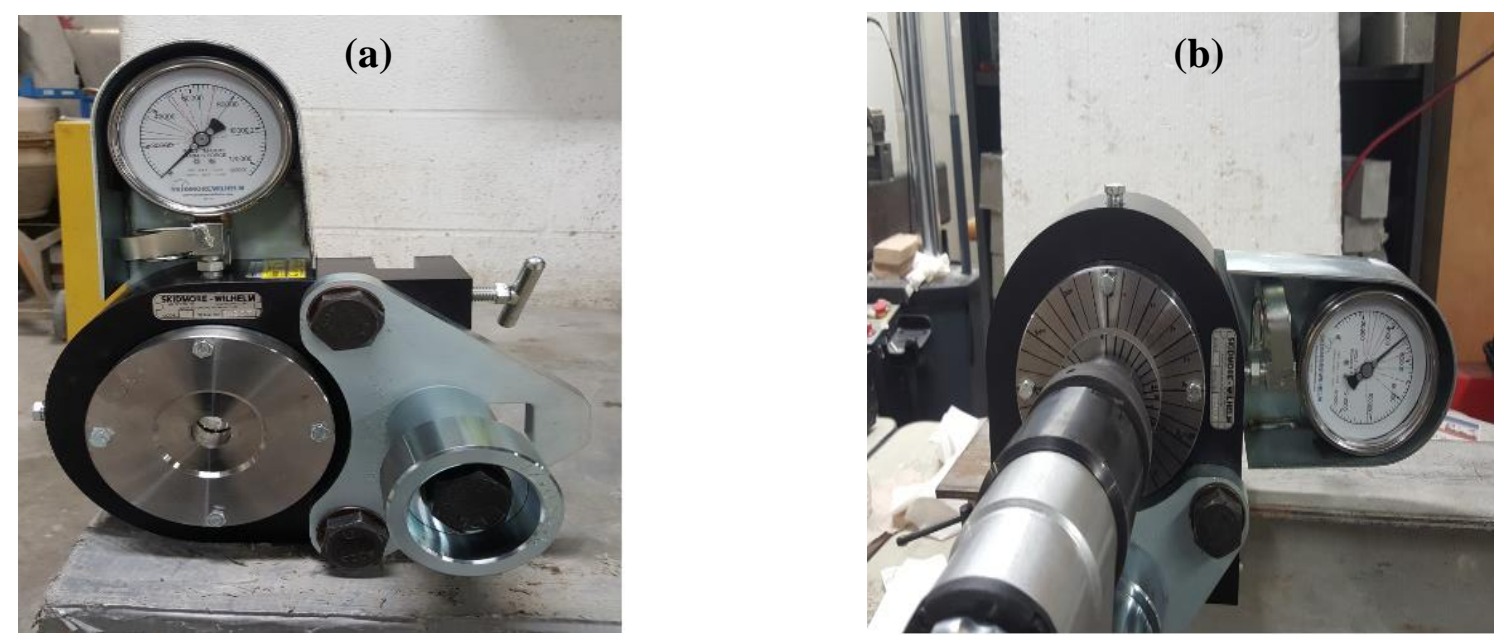

Figure 4-3: (a) View of Wilhelm Skidmore Bolt Tensioning machine and (b) view of degrees turn calibrated on front brushing of Skidmore Wilhelm Machine

The torqueing was done at $10^{\circ}$ increments up to $120^{\circ}$ or one-third of a turn. They were then loosened at $40^{\circ}$ increments back to $0^{\circ}$. The corresponding load and bolt elongation was record for each bolt type and analysed, Figure 4-4 show incremental torqueing and loosening data collection. The bolt incremental elongation was obtained by attaching a Mini-Max bolt elongation monitoring devise to the head of the bolt and the reading taken at each increment, as shown in Figure 4-5. Kulak et al. (2001) stated that galvanized high-strength bolts may differ in behaviour from A325 highstrength bolts. This behavioural difference is owed to the phenomenon of "galling". This phenomenon occurs when the zinc layer that surround the threads of the bolt becomes loose upon repeated torqueing and loosening action and causes the nut to seize. They recommended that lubrication could be applied to the threading of the galvanized bolts to reduce the effect of galling. Because the batch of A325 galvanized bolt test and the B8 class 1 bolt test used in this research did not contain any lubrication from the manufacturer, multi-purpose grease, as shown in Figure 4-6, was applied to the thread of these test bolt samples (see also Figure 4-7 and 4.8). The process 
of incremental torqueing and loosening was then repeated on the bolts to compare the behaviour with that of bolt before lubrication.

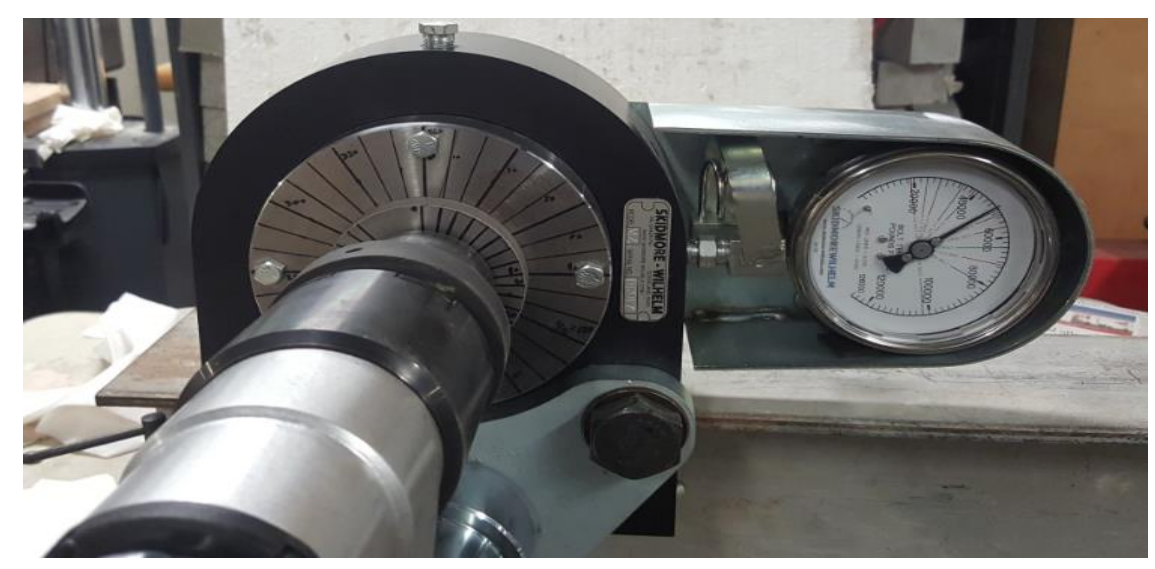

Figure 4-4: Incremental torqueing of structural bolt using Skidmore Wilhelm machine and electric torque wrench

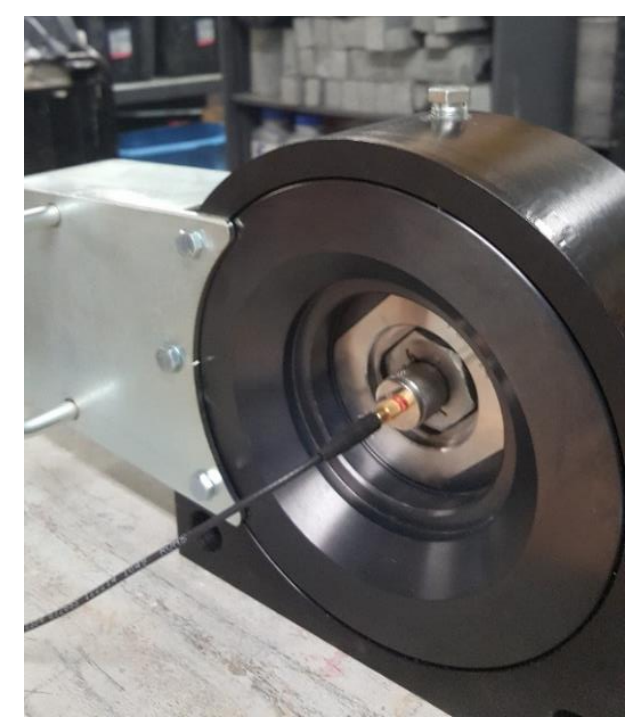

Figure 4-5: Attachment on the Mini-Max ultrasonic bolt elongation measuring device to torqued bolt head inside of Skidmore Wilhelm machine 


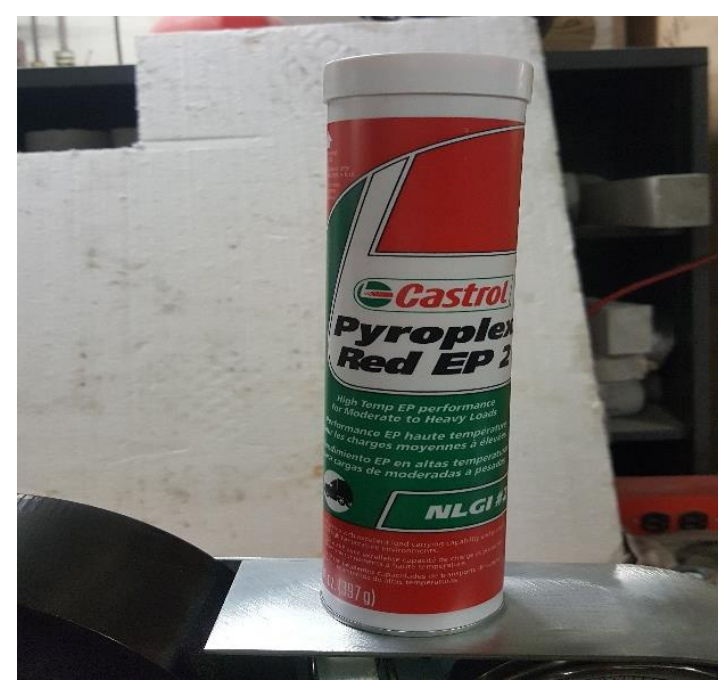

Figure 4-6: Castrol Pyroplex red multi-purpose grease lubricant

Figure 4-7: Application of multi-purpose grease lubricant to the threads of galvanized bolt

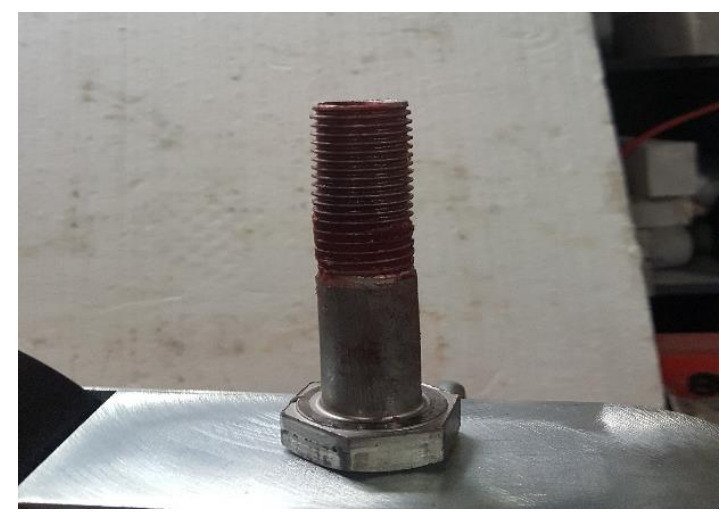

Figure 4-8: Application of multi-purpose grease lubricant to the threads of stainless steel bolt 


\subsection{Experimental Program 3: Bolt Pre Load Subjected to Temperature Variation Testing}

The effect of temperature variation on the performance of high-strength bolt pre-load was investigated to examine whether there is an impact on the bolt pre-load for slip-critical joint. The research program in this phase included the testing of bolt, washer and nut assembly for the primary type of bolts being used in the research, namely: regular A325 high-strength bolt and galvanized A325 high strength bolts. Each bolt, washer and nut assembly was subjected to temperature level varying as follows: $20^{\circ} \mathrm{C},-5^{\circ} \mathrm{C},-10^{\circ} \mathrm{C},-20^{\circ} \mathrm{C}$ and $-30^{\circ} \mathrm{C}$, with each temperature range having five bolts tested. The varying temperature was achieved through the use of a Burnsco Environmental Chamber shown in Figure 4-9. The test procedure was executed as laid out in Table 4-1. Firstly, any raised indentation or markings on the head of the bolts were removed by grinding. After the indentation removal process, each bolt head was cleaned using acetone as shown in Figure 4-10 to assist in removing any residual metal filings left over from the grinding process. Next, a conditioner was used to clean any residual acetone from the surface of the bolt heads (see Figure 4-11a). Finally, before the attachment of the thermocouples to measure bolt actual temperature, a neutralizer was used to remove any traces of the conditioner from the bolt head (see Figure 4-11b). Type K-thermocouple wire was then attached to the head of each bolt as shown in Figure 4-12 using M-Bond glue, shown in Figure 4-13, before they were placed inside of the environmental chamber.

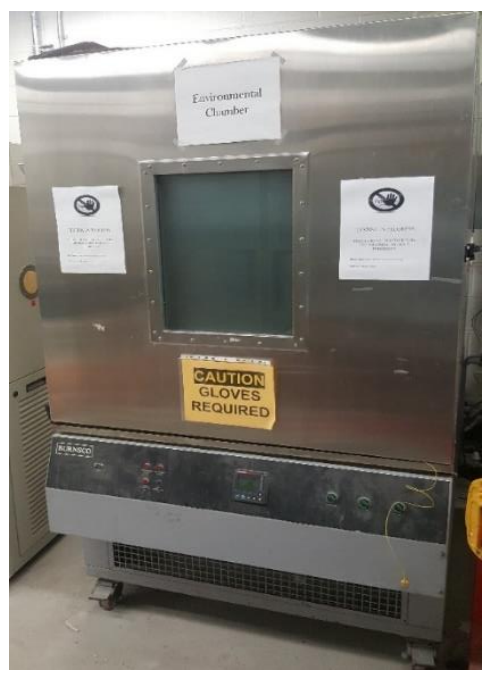

Figure 4-9: Burnsco Environmental Chamber used for conditioning High-Strength bolt 
Table 4-1: Text matrix to study the effect of temperature variation on bolt pre-tension

\begin{tabular}{|c|c|c|c|}
\hline & & & Turn Angle \\
\hline Set group \# & Bolt type & Sample identity & (degrees) \\
\hline \multirow[t]{5}{*}{1} & \multirow{5}{*}{$\begin{array}{l}\text { A325 High } \\
\text { tensile bolt }\end{array}$} & $1-\mathrm{A}-(20)$ & 170 \\
\hline & & $1-A-(-5)$ & 170 \\
\hline & & 1-A-(-10) & 170 \\
\hline & & $1-\mathrm{A}-(-20)$ & 170 \\
\hline & & $1-\mathrm{A}-(-30)$ & 170 \\
\hline \multirow[t]{5}{*}{2} & \multirow{5}{*}{$\begin{array}{c}\text { A325 High } \\
\text { tensile } \\
\text { galvanized } \\
\text { bolt }\end{array}$} & $1-\mathrm{B}-(20)$ & 170 \\
\hline & & $2-B-(-5)$ & 170 \\
\hline & & $2-B-(-10)$ & 170 \\
\hline & & $2-B-(-20)$ & 170 \\
\hline & & $2-B-(-30)$ & 170 \\
\hline
\end{tabular}

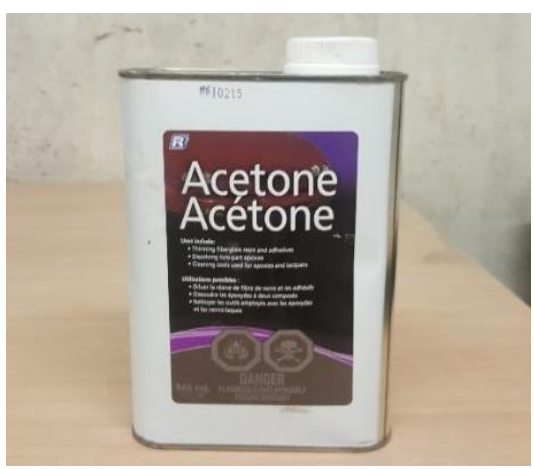

Figure 4-10: Alcoholic-based acetone used to clean bolt head surface after grinding
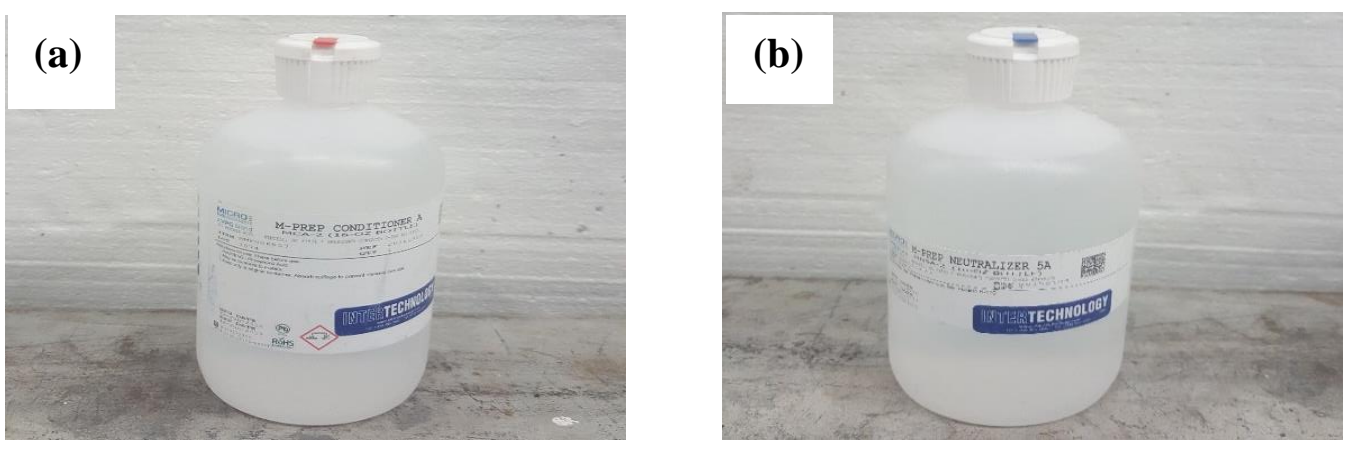

Figure 4-11: (a) Conditioner used to clean away trace of residual acetone left on bolt head and (b) neutralizer used to remove trace residue of conditioner 


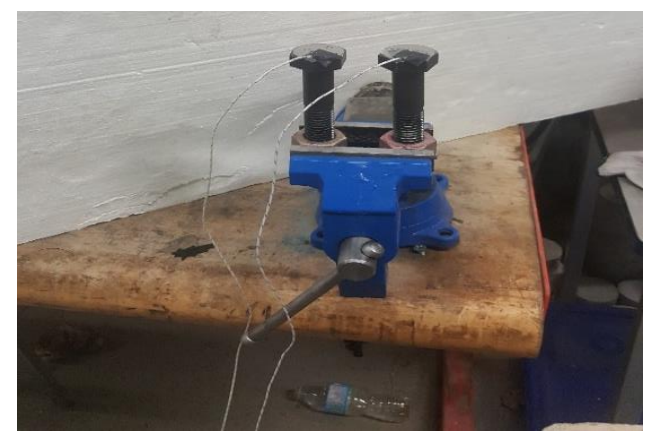

Figure 4-12: Attachment of Type K-thermocouple wires to the head of bolts
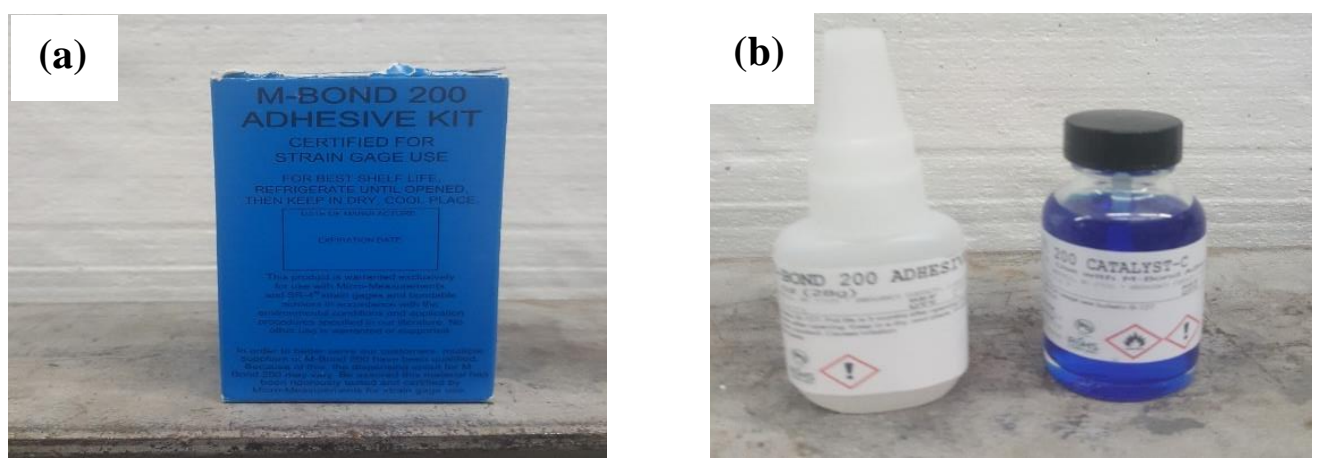

Figure 4-13: (a) M Bond 200 Adhesive Kit and (b) M Bond 200 adhesive and catalyst

All 5 high-strength bolt, washer and nut assemblies from the A325 and galvanized A325 bolts were placed inside of the environmental chamber (a total of 10 assemblies were placed inside of the environmental chamber at the same time, as shown in Figure 4-14. The B8 class 1 stainless steel bolt was discontinued from use within this research from this point onward due to the failure of this bolt type during bolt reusability testing (i.e. not been able to develop the required minimum bolt tension using turn-of-the-nut method). The temperature in the environmental chamber was then set $3^{\circ} \mathrm{C}$ below the prescribed temperature (with the exception of the $20^{\circ} \mathrm{C}$ temperature range), so as to ensure that once a bolt assembly was taken out of the chamber, enough time was available to conduct the testing before the assembly's temperature raised above the designated temperature. All the bolt assembly for each bolt type was left inside the environmental chamber for a period of $24 \mathrm{hrs}$ so as to acclimatize the assembly properly to the required temperature. Before the bolt, washer and nut assemblies were removed from the environmental chamber, their temperature were read using Extech TM300 Dual Type K/J Input Thermometer device. The bolt, washer and nut assembly was then removed one set at a time from the chamber and placed inside of the Skidmore 
tensioning device, the transducer of the Mini-Max ultrasonic bolt elongation monitoring device was then attached to the head of the bolt as shown in Figure 4-15a. Next, the free end of the thermocouple wire was connected to a digital thermometer device to monitor the temperature. The initial bolt length was taken and recorded for future reference. The nut was then used to tension the bolt to $203 \mathrm{kN}$ using an electric torque wrench as shown in Figure 4-15b. The elongation after tensioning was then recorded and analysed. This was done for all the bolts within each bolt group, at each varying temperature. The average result for each 5 bolt assemblies within each bolt type at each temperature range was determined and recorded.

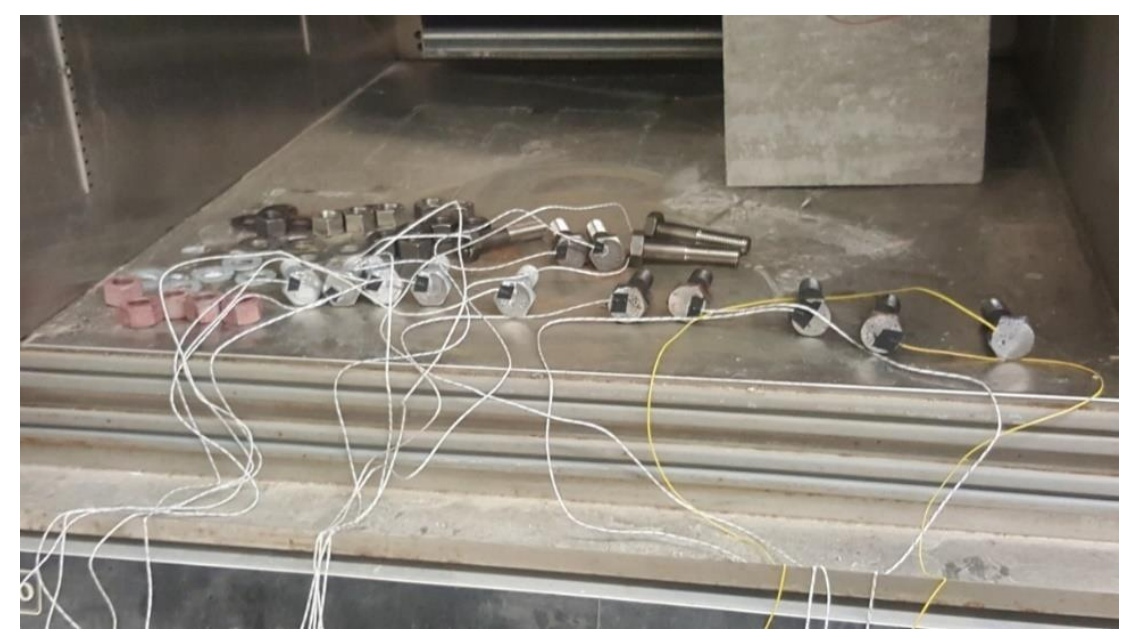

Figure 4-14: View of bolts, washers and nuts placed inside environmental chamber
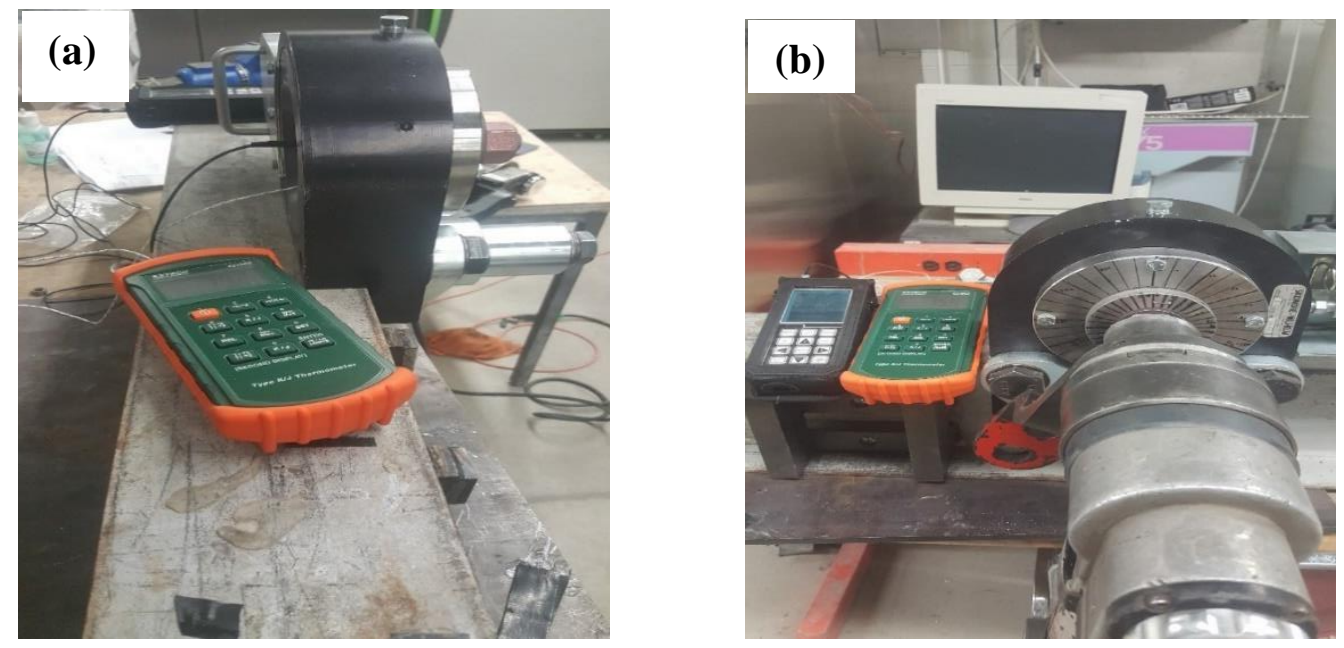

Figure 4-15: (a) Attachment of Mini-Max ultrasonic bolt tensioning transducer to the head of bolt and (b) tensioning of bolt assembly using electric torque wrench 


\subsection{Experimental Program 2: Slip Critical Testing at Room Temperature}

Based on the objectives of this research, short-duration compression slip resistance tests were developed to analyse the slip coefficient of ASTM A1010 stainless steel and 350W structural steel. The faying surface condition of ASTM A1010 stainless steel was prepared in accordance to the Specification for Structural Joints for Class A (unpainted clean mill scale steel surface) and Class B (unpainted blasted clean steel surface) surface conditions. Whereas the faying surface condition for the $350 \mathrm{~W}$ structural steel was prepared to Classes A and B as above in addition to Class C (hotdip galvanized and roughened surface). A total of 4 specimens were assembled for each set of surface condition for A1010 stainless steel, shown in Table 4-2, were tested for each surface treatment condition within the ASTM A1010 stainless steel group. They were tested at two different clamping force as shown in Table 4-2, namely (i) $173 \mathrm{kN}$, representing the $70 \%$ tensile capacity of the bold, and (ii) $203 \mathrm{kN}$ representing the force resulting from the application of the Turn-of-the-Nut method. Similarly, for 350W structural steel, a total of 30 sets of assembled test specimens were tested, again using two different clamping forces shown in Table 4-2. The procedure laid out by the Specifications for Structural Joints using ASTM A325 and A490 bolts, similar slip-critical testing procedure found in literature, was adopted in this phase of research. However, some modification and additional operational techniques/procedures had to be developed and implemented to address the application of the clamping force, using the turn-ofthe-nut procedure for the pre-tensioning of the bolts.

\subsubsection{Test specimen design}

The short duration compressive test of ASTM A1010 stainless steel specimen consisted of 3 identical plates of size 101.6 x 101.6 x $15.875 \mathrm{~mm}$ as shown in Figure 4-16. A $25.4 \mathrm{~mm}$ diameter hole was cut $38 \mathrm{~mm}$ from the top of the plate and $50.8 \mathrm{~mm}$ from the edge of the plate. Figure 4-17 shows the assembled slip coefficient test specimen. Based on the experimental restriction on the type of plate fabrication method (i.e. A1010 stainless steel plates cannot be flame- or heat-cut) and the difficulty with saw-cutting of this metal, the process of water jet cutting was used to fabricate the ASTM A1010 stainless steel parts as shown in Figure 4-18 and 4.19. 
Table 4-2: Summary of the various clamping forces, the total number of tested specimens, surface treatment of each specimen and the degree turn relating to the clamping force

\begin{tabular}{|c|c|c|c|c|c|c|c|c|}
\hline \multirow{2}{*}{ Specimen type } & \multirow{2}{*}{$\begin{array}{l}\text { Class of surface } \\
\text { condition }\end{array}$} & \multirow{2}{*}{ Surface condition } & \multicolumn{2}{|c|}{ Clamping force } & \multicolumn{3}{|c|}{$\begin{array}{l}\text { Degree turn (from hand tightened } \\
\text { position) (degrees) }\end{array}$} & \multirow{2}{*}{$\begin{array}{c}\text { Number of } \\
\text { specimens in each } \\
\text { set }\end{array}$} \\
\hline & & & $173 \mathrm{kN}$ & $203 \mathrm{kN}$ & 152 & 160 & 170 & \\
\hline 350W Structural Steel & A & $\begin{array}{l}\text { Clean mill scale (Solvent } \\
\text { clean) }\end{array}$ & $v$ & -- & $v$ & -- & -- & 4 \\
\hline 350W Structural Steel & $\mathrm{A}$ & $\begin{array}{l}\text { Clean mill scale (solvent } \\
\text { clean) }\end{array}$ & -- & v & -- & -- & $v$ & 4 \\
\hline 350W Structural Steel & B & White Metal Blast Clean & $v$ & -- & $v$ & -- & -- & 3 \\
\hline 350W Structural Steel & $\mathrm{B}$ & White metal blast clean & -- & v & -- & -- & $v$ & 4 \\
\hline 350W Structural Steel & $\mathrm{C}$ & Hot dip galvanized & $v$ & -- & $v$ & $\checkmark$ & -- & 3 \\
\hline 350W Structural Steel & $\mathrm{C}$ & Hot dip galvanized & -- & v & -- & -- & $v$ & 4 \\
\hline A1010 Stainless Steel & A & $\begin{array}{c}\text { Clean mill scale (solvent } \\
\text { clean) }\end{array}$ & $\checkmark$ & -- & -- & $\checkmark$ & -- & 4 \\
\hline A1010 Stainless Steel & A & $\begin{array}{c}\text { Clean mill scale (solvent } \\
\text { clean) }\end{array}$ & -- & $v$ & -- & & $\checkmark$ & 4 \\
\hline A1010 Stainless Steel & B & White metal blast clean & $v$ & -- & -- & $\checkmark$ & -- & 4 \\
\hline A1010 Stainless Steel & $\mathrm{B}$ & White metal blast clean & -- & v & -- & & $\checkmark$ & 4 \\
\hline
\end{tabular}

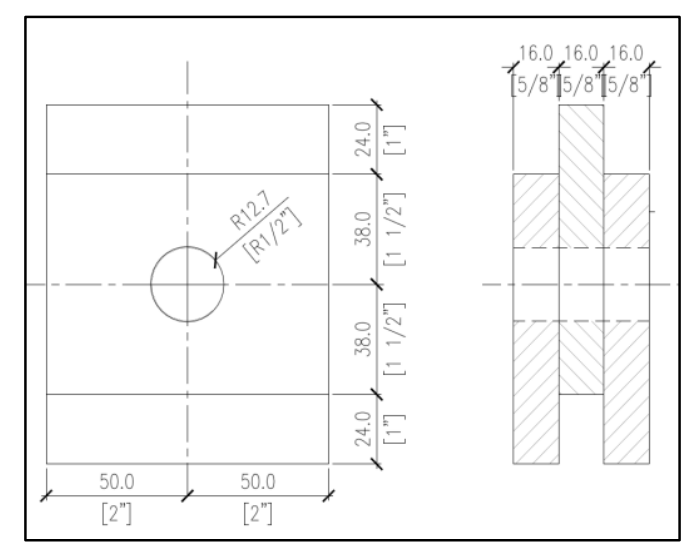

Figure 4-16: Front and side views of the short-duration compression slip test specimen 


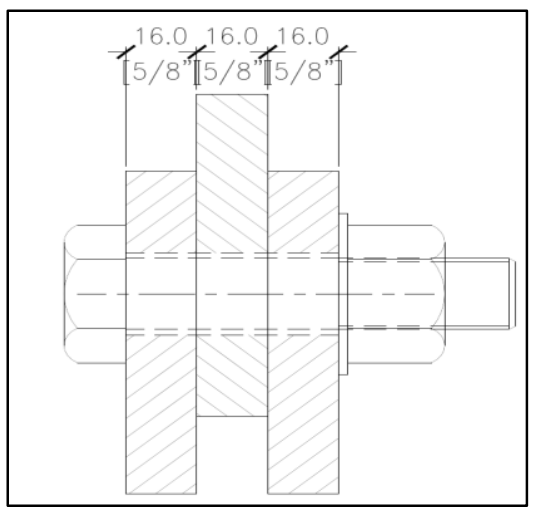

Figure 4-17: Side view of short-duration compression slip resistance test specimen with bolt, washer and nut assembled together

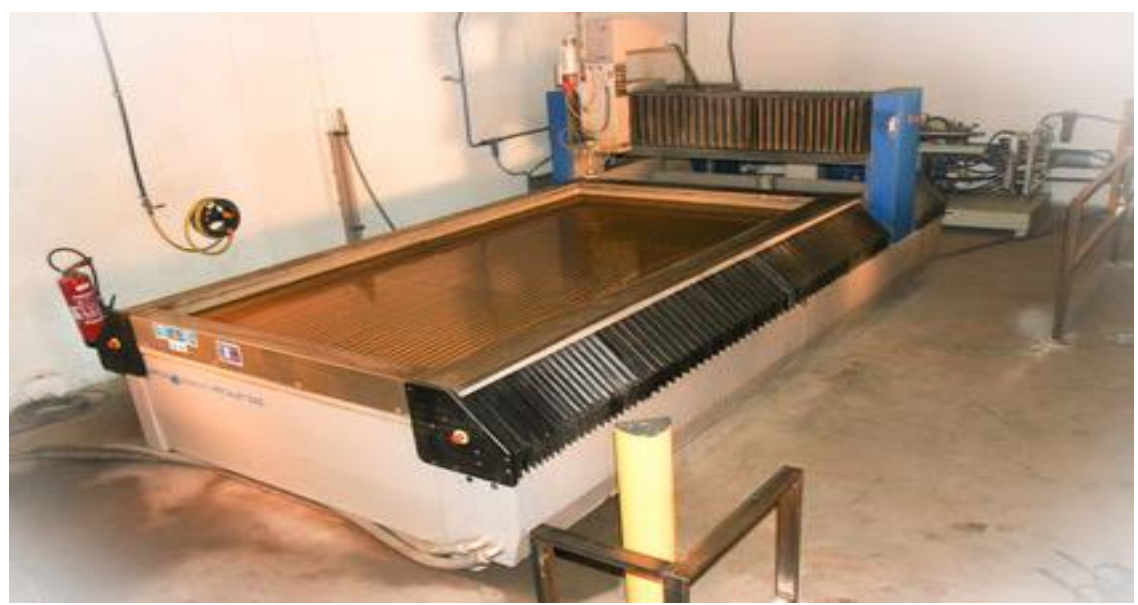

Figure 4-18: Water jet cutting machine (source: Antech Technologies Inc.)

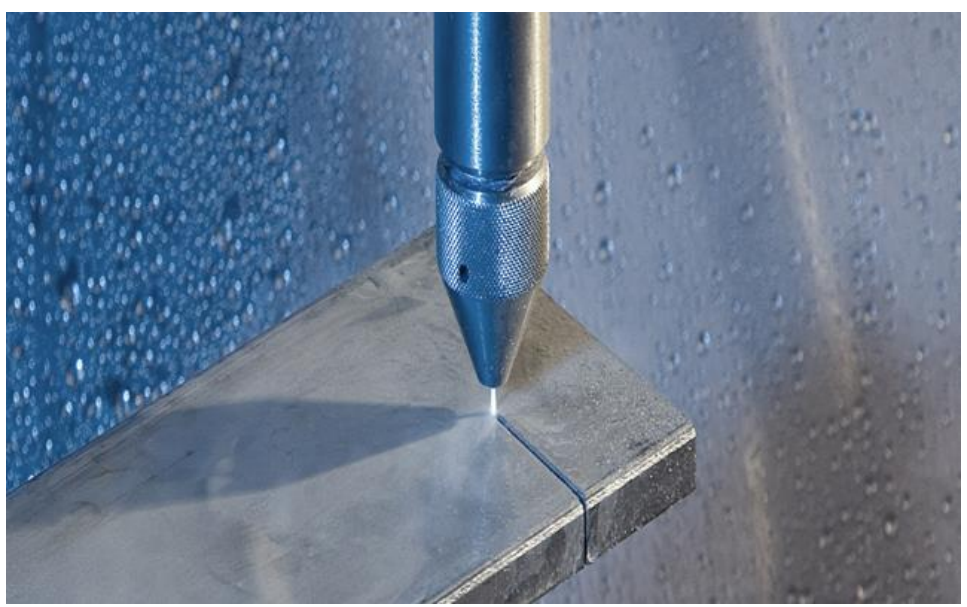

Figure 4-19: Water jet-cutting process (source: Ant Applied New Technologies - AG) 
As for the $350 \mathrm{~W}$ structural steel short-duration compressive slip-resistance test specimen, they were developed using the same geometry outlined in Figure 4-16. However, individual plates were saw-cut and the bolt hole was mechanically drilled. Specific attention was paid to the condition of the top and bottom surfaces of the plates (ensuring that they were flat, square and levelled) to reduce the effect of eccentric loading during the test phase. All burrs that was probably left and the plates from the fabrication process was removed by filing before surface treatment was done to them.

\subsubsection{Surface treatment}

Once fabrication of test specimens was completed, the specimens were grouped and prepared for surface treatment. Class A surface condition for both ASTM A1010 stainless steel and 350W structural steel specimens were cleaned with a cleaning solvent (acetone). However, this was done immediately before application of the clamping force. The Specification from the Society for Protective Coating for White Metal Finish, SSPC SP5, (2014) was used to prepare the Class B surface finish shown in Table 4-3. The surface cleaning method utilized in this research was sandblasting process. This sandblasting procedure was done by Kings Mill Sandblasting Company. Once completed, all the blast-cleaned plates were cleaned with a solvent (acetone) before testing operation was conducted. The Brown and Sharpe Surfcom 112 stylus machine was used to determine the mean angular surface profile of the specimens, see Figure 4-20. As there was no set standard to which specimen surface roughness is required, this research used the maximum allowable surface roughness that could be obtained using the process of sand-blasting. This maximum value was also verified through sensitivity study conducted at two sand-blasting companies (namely: Vibra Ltd and King Mills Sandblasting company).

Table 4-3: Surface Preparation Standard (adopted from Society for Protective Coating) (2014)

\begin{tabular}{lccccc}
\hline System & SSPC Code & NACE & $\begin{array}{c}\text { CDN Govt. } \\
\text { (CGSB) }\end{array}$ & $\begin{array}{c}\text { Swedish } \\
\text { standard }\end{array}$ & $\begin{array}{c}\text { British } \\
\text { standard }\end{array}$ \\
\hline White metal blast & SSPC - SP5 & NACE \#1 & $\begin{array}{c}31 \text { GP } 404 \\
\text { Type 1 }\end{array}$ & Sa.3 & $\begin{array}{c}\text { B4232 } \\
\text { First } \\
\text { quality }\end{array}$ \\
\hline
\end{tabular}




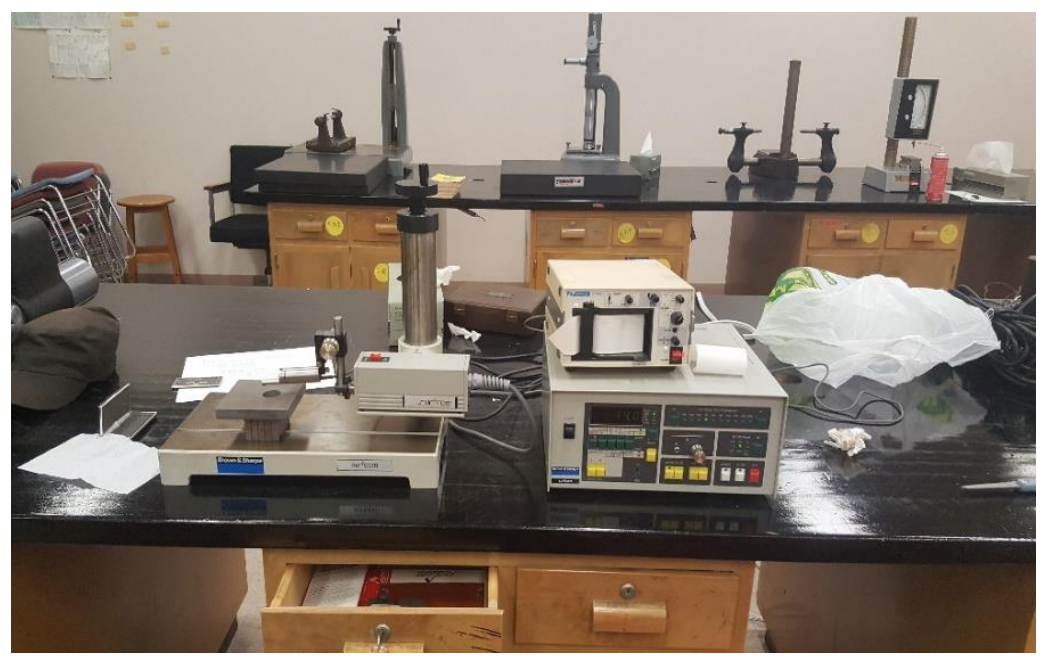

Figure 4-20: Equipment and method use for the determination of surface roughness

Before hot dip galvanization of the plates in Class $\mathrm{C}$ surface finish was done, the plates were grouped in set of threes and numbers were then stamped on the edges, as shown in Figure 4-21, for the purpose of identification and uniformity. The steel plates for Class $\mathrm{C}$ surface finish that was to be hot-dip galvanized was first submersed in a caustic cleaning solution (this is an alkaline solution used to remove dirt and other contaminants). They were then placed in a bath of pickling acid and then fluxed. They were then submersed into a hot dip kettle of molten zinc and allow to heat up to the temperature of the molten zinc to ensure that adequate chemical bonding occurs between the parts and the molten zinc. Once the plates have cooled, no further roughening of the metal surface was done. Quality assurance checks was done to ensure that the angular profile for each plate met the standard specification. The galvanized angular profile was found to be approximately 1.0 mils.

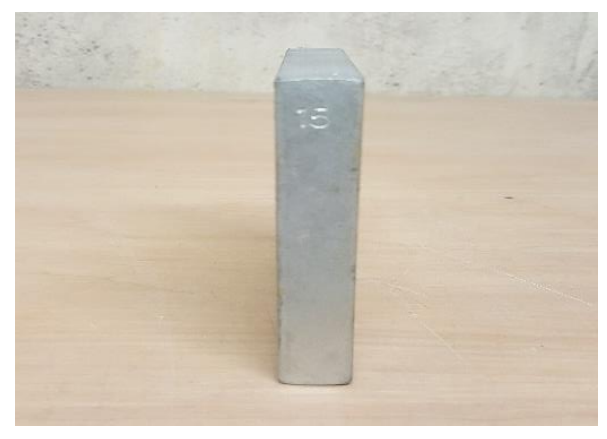

Figure 4-21: Galvanized plate with label number stamped in the side before hot dip galvanization process 


\subsubsection{Snug-tightening condition determination}

Based on the nature of this research, with the modification in the testing method (relating specifically to how the initial clamping force is applied to the specimen), it is of vital importance to ensure that an efficient, accurate and repeatable method of verifying the clamping force applied to the plates by turn-of-the-nut method is developed and used. And that these turn-of-the-nut angles meet current specification. In order to determine the clamping force to be used, the snug-tightened position must be developed first. Based on the definition of snug-tightened condition stated in previous chapter, it is a condition that is achieved by making sure that all the faying surfaces are in full contact with each other, using a hand wrench to tighten the bolt and nut assembly to the point where it cannot be unwound by hand. Through careful review of literature and past work done, this point or position is very vague and there exist very little information (if any at all) as to the specific value (whether as degree turn or $\mathrm{kN}$ ) of snug-tight condition. In addition, deciphering through literature it was discovered that using the hand wrench to tighten the bolt and nut assembly to the point where all the faying surface are in full contact with each other and the nut cannot be unwound, is dependent on two critical factors, namely: (i) the strength of the person applying the tightening force (which is very subjective), and (ii) the hardness of the material been clamped (which varies from material to material). In light of this finding and application in this research, in order to correlate the two clamping methods, the point of snug-tightened condition (in terms of degree turn) was established and verified for use as a datum point for these two clamping forces.

\subsubsection{Verification testing of snug -tightening condition}

The determination of the snug-tightened position was done firstly through the use of the Wilhelm Skidmore bolt tensioning device. Five A325 high-strength bolts were tested using a hand wrench to tighten each bolt and nut assembly to the point where the nut cannot be unwound and taking the corresponding degree turn that correlates to that point. Also the Mini-Max ultrasonic bolt elongation monitoring device was used to measure the original bolt length before tightening and the elongation after tightening. Once this step was completed, the average degree turn value was determined and used as the snug-tightening position value for the purpose of this research. 


\subsubsection{Verification testing of clamping force}

According to the Canadian Highway Bridge Design Code, the initial clamping force within the bolted slip critical joint should be $70 \%$ of the specified minimum tensile strength of the bolt. This value is $173 \mathrm{kN}$ for A325 high strength bolt of 7/8" diameter. The Research Council on Structural Connections provides a detailed description of various minimum initial clamping force for ASTM A325 and ASTM 490 high strength bolts and the corresponding bolt diameters as shown in Table 4-4.

Table 4-4: Minimum bolt pretension (RCSC, 2000)

\begin{tabular}{|c|c|c|}
\hline \multirow{2}{*}{$\begin{array}{l}\text { Nominal Bolt } \\
\text { Diameter, } d_{b o} \text { in. }\end{array}$} & \multicolumn{2}{|c|}{$\begin{array}{l}\text { Specified Minimum Bolt } \\
\text { Pretension, } T_{m} \text { kips }\end{array}$} \\
\hline & $\begin{array}{l}\text { ASTM A325 } \\
\text { and F1852 }\end{array}$ & $\begin{array}{l}\text { ASTM A490 } \\
\text { and F2280 }\end{array}$ \\
\hline $\boldsymbol{k}$ & 12 & 15 \\
\hline$\%$ & 19 & 24 \\
\hline $\mathbf{*}$ & 28 & 35 \\
\hline 承 & 39 & 49 \\
\hline 1 & 51 & 64 \\
\hline $1 \%$ & 56 & 80 \\
\hline 114 & 71 & 102 \\
\hline $1 \%$ & 85 & 121 \\
\hline $1 \%$ & 103 & 148 \\
\hline \multicolumn{3}{|c|}{$\begin{array}{l}\text { Equal to } 70 \text { percent of the specified minimum tensile strength } \\
\text { of bolts as specified in ASTM Specifications for tests of full-size } \\
\text { ASTM A325 and A490 bolts with UNC threads loaded in axial } \\
\text { tension, rounded to the nearest kip. }\end{array}$} \\
\hline
\end{tabular}

In this research, two clamping forces were used namely: (i) $173 \mathrm{kN}$ (39 kips) and (ii) 1/3 of a turn $\left(120^{\circ}\right)$. However, in order to correlate this clamping force to degrees turn to correspond with the turn-of-the-nut method, 5 bolt and nut assemblies of each bolt type were tested using the Wilhelm Skidmore bolt tensioning device as shown in Table 4-5. For the clamping force at $173 \mathrm{kN}$, five A325 high-strength bolt and nut specimens were inserted into the Wilhelm Skidmore bolt tensioning device and brought to the snug-tight position (based on the snug-tightened degree turn developed above), an electric torque wrench was then connected to the nut section of the assembly 
and a mark placed on the socket of the wrench to coincide with the zero mark of the front plate of the Skidmore device as shown in Figure 4-22.

Table 4-5: A325 high-strength bolt clamping force verification at $173 \mathrm{kN}$

\begin{tabular}{|l|c|c|}
\hline Test description & $\begin{array}{c}\text { Bolt } \\
\text { number }\end{array}$ & $\begin{array}{c}\text { Bolt } \\
\text { tension } \\
\text { (using } \\
\text { Skidmore) } \\
\text { (lbf) }\end{array}$ \\
\hline $\begin{array}{l}\text { Determining the degree } \\
\text { turn corresponding to the }\end{array}$ & 1 & 39000 \\
$\begin{array}{l}\text { application of 173 kN } \\
\text { pretension force from the } \\
\begin{array}{l}\text { snug-tightened position } \\
\text { of 50 }\end{array}\end{array}$ & 3 & 39000 \\
\hline
\end{tabular}

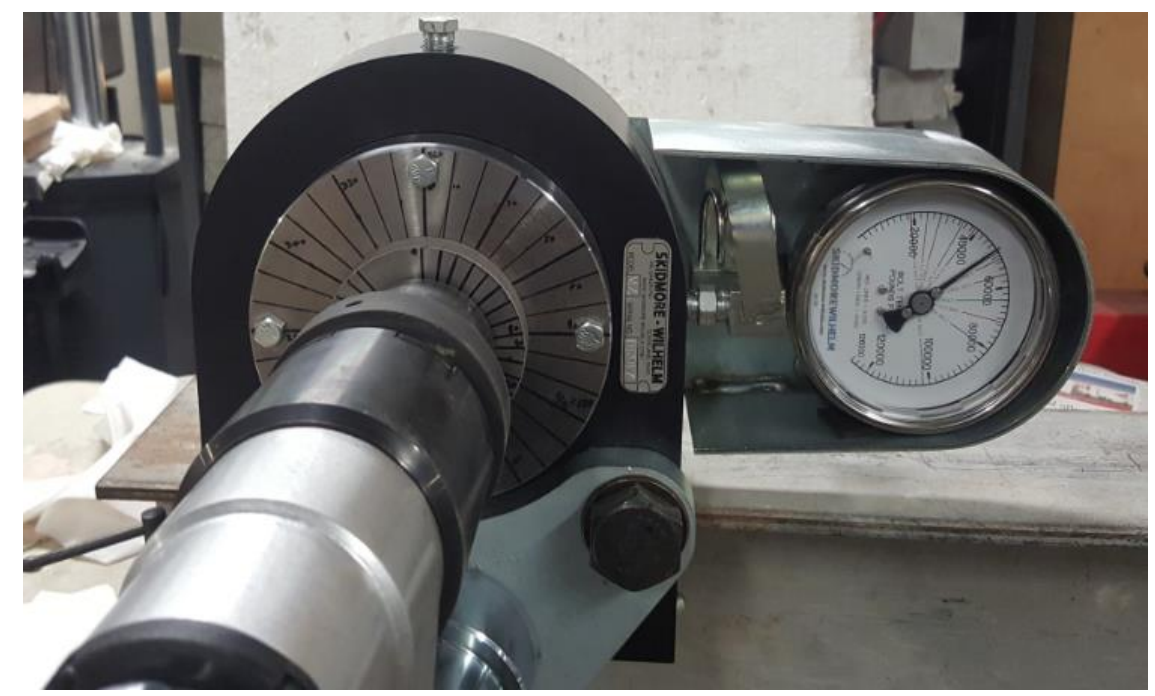

Figure 4-22: Wilhelm Skidmore bolt tensioning device prepared for clamping force verification test

The assembly was then tensioned using the electric wrench until the Skidmore dial read the prescribed value of $173 \mathrm{kN}$ (39 kips). The degree turns at which this was achieved was then recorded and reflected in within the results chapter of this research. The average of all 5 bolt and nut assemblies tested was then determined and the value used was the degree turn that correlates to the clamping force of $173 \mathrm{kN}$ (39 kips). In order to determine the second of the two clamping 
values which was used in this research, 5 A325 high-strength bolt and nut assemblies were tested with the Skidmore device as laid out in Table 4-6 below. However, with the turn-of-the-nut method (applying one third of a turn or $120^{\circ}$ ), the clamping force value that coincide with this degree turn was determined. The bolt and nut assembly was first brought to the pre-determined snug-tight position or degree turn inside of the Skidmore using a hand wrench. Once achieved, the electric torque wrench was connected to the nut portion of the bolted assembly and a mark made on the socket of the wrench to coincide with the zero mark on the front plate of the Skidmore (see Figure 4-23). The nut was then turned until $1 / 3$ of a turn or $120^{\circ}$ was achieved. The tension reading from the Skidmore for all 5 bolt and nut assemblies tested was then averaged and used as the corresponding clamping force for the one third of a turn.

Table 4-6: A325 high-strength bolt clamping force verification table at $120^{\circ}$ or $1 / 3$ of a turn

\begin{tabular}{|c|c|c|}
\hline Test description & $\begin{array}{c}\text { Bolt } \\
\text { number }\end{array}$ & $\begin{array}{c}\text { Degree } \\
\text { turns }\end{array}$ \\
\hline Determining the & 1 & 120 \\
Skidmore value for & 2 & 120 \\
1/3 of a turn from the & 3 & 120 \\
snug-tightened & 4 & 120 \\
position of $50^{\circ}$ & 5 & 120 \\
\hline
\end{tabular}

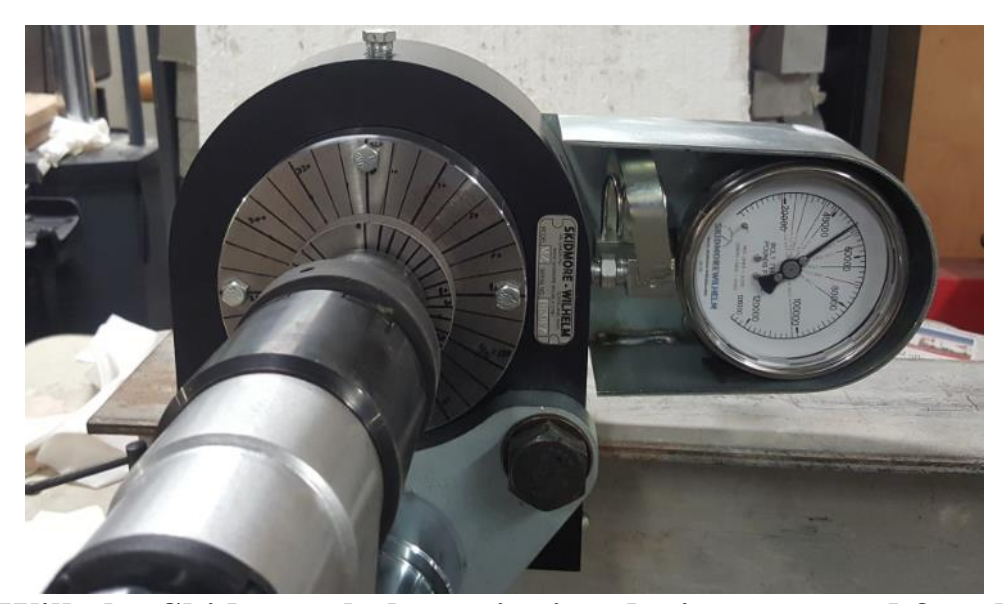

Figure 4-23: Wilhelm Skidmore bolt tensioning device prepared for clamping force verification test at $120^{\circ}$ of a turn. 
The above two clamping methods described were then repeated for galvanized high-strength bolts to determine the degree turn for the galvanized bolt that correlates to $173 \mathrm{kN}$ as well as the clamping force for the galvanized bolt that correlates to one third of a turn or $120^{\circ}$ after snugtightening. Five galvanized A325 high-strength bolt was used for each clamping force determination. Once completed, these two clamping force values were used throughout this research and were applied to the various plate assemblies for slip-resistance testing.

\subsubsection{Test specimen preparation and assembly}

From the clamping force verification process outlined above, 3 specially-fabricated turn angle templates were designed and cut out from hard plastic sheeting as shown in Figure 4-24 and Figure 4-25 and used to scribe the required pre-tensioned turn-of-the-nut angle onto the test specimen's outer plate.

(a)

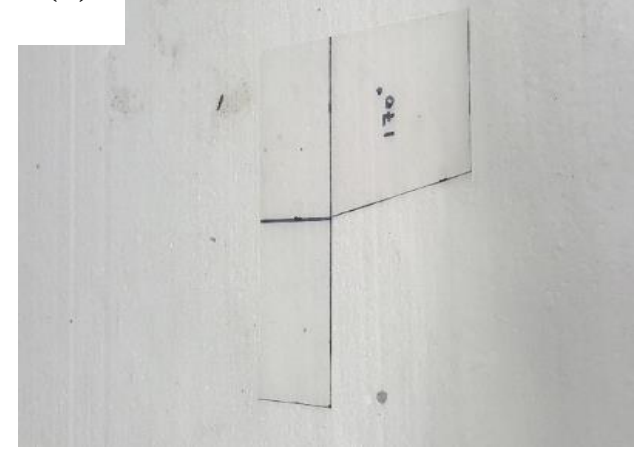

(b)

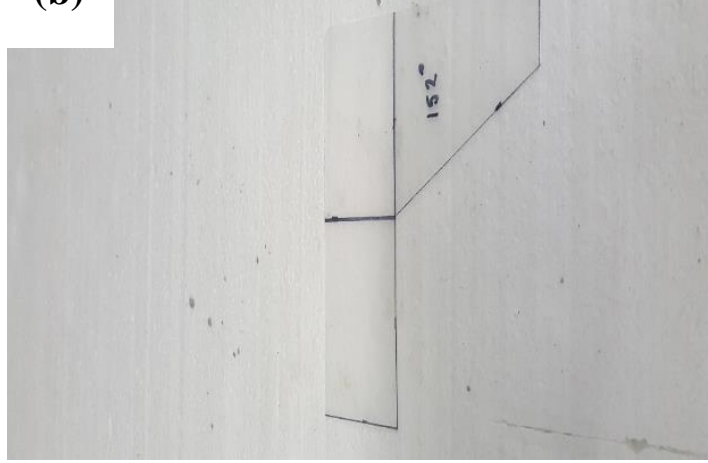

Figure 4-24: Clamping force stencil made from plastic sheeting (a) stencil for $170^{\circ}$ turn, (b) $152^{\circ}$ turn for $\mathrm{A325}$ bolt (from the hand tightened position)

(a)

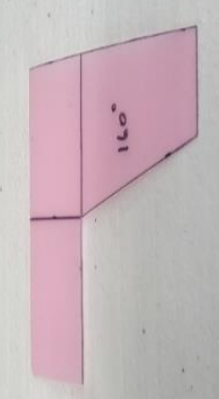

(b)

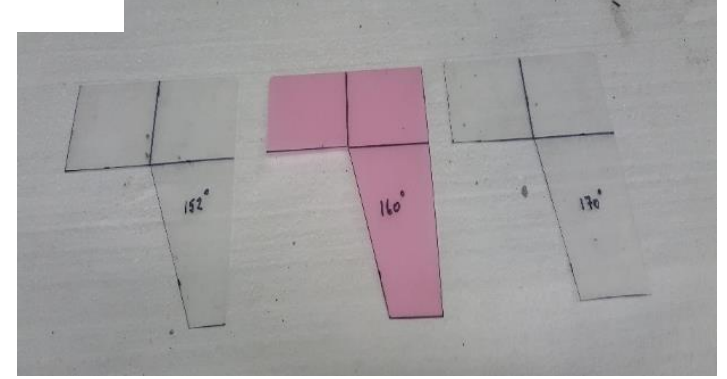

Figure 4-25: Clamping force stencil made from plastic sheeting (a) stencil for $160^{\circ}$ turn for galvanized bolt (from the hand tightened position, (b) all three stencil side by side 


\subsubsection{Test specimen surface preparation}

The surface condition of various test plate assemblies per Table 4-7 was verified and completed before assembling of the specimens. Plates were arranged in groups based on the surface condition, then the final stage before testing surface treatment was applied to the relevant plates. Figure 4-26 Figure 4-27 depict the plates arranged for final surface treatment.

Table 4-7: Breakdown of plates for surface treatment before complete assembly

\begin{tabular}{|c|c|c|c|c|}
\hline & $\begin{array}{c}\text { Set } \\
\text { number }\end{array}$ & Test material & $\begin{array}{l}\text { Surface type } \\
\text { (class) }\end{array}$ & Surface preparation description \\
\hline \multirow{5}{*}{$\begin{array}{l}\text { Slip test plate } \\
\text { thickness }=5 / 8^{\prime \prime}\end{array}$} & 1 & $\begin{array}{l}\text { Structural Steel } \\
\quad(350 \mathrm{~W})\end{array}$ & $\begin{array}{l}\text { A (Clean mill } \\
\text { scale) }\end{array}$ & $\begin{array}{l}\text { An alcohol based acetone chemical was used to remove all grease, } \\
\text { dust and other contaminants from the surface of the clean mill scale } \\
\text { structural steel plate as shown in figure. }\end{array}$ \\
\hline & 2 & $\begin{array}{l}\text { Structural Steel } \\
(350 \mathrm{~W})\end{array}$ & $\begin{array}{l}\text { B (Blast- } \\
\text { cleaned) }\end{array}$ & $\begin{array}{l}\text { A brush was used to remove all dust and left over particles from the } \\
\text { sandblasting process as shown in figure. }\end{array}$ \\
\hline & 3 & $\begin{array}{l}\text { Structural Steel } \\
\quad(350 \mathrm{~W})\end{array}$ & $\begin{array}{l}\text { C }(\text { Hot dip } \\
\text { galvanized })\end{array}$ & $\begin{array}{l}\text { A steel brissel wire brush was used to brush the surface of the hot } \\
\text { dip galvanized plates has shown in figure. }\end{array}$ \\
\hline & 4 & Stainless Steel & $\begin{array}{l}\text { A (Clean mill } \\
\text { scale) }\end{array}$ & $\begin{array}{l}\text { An alcohol based acetone chemical was used to removed all } \\
\text { grease, dust and other contaminants from the surface of the A1010 } \\
\text { stainless steel plate as shown in figure. }\end{array}$ \\
\hline & 5 & Stainless Steel & $\begin{array}{l}\text { B (Blast- } \\
\text { cleaned) }\end{array}$ & $\begin{array}{l}\text { A brush was used to remove all dust and left over particles from the } \\
\text { sandblasting process as shown in figure. }\end{array}$ \\
\hline
\end{tabular}

(a)

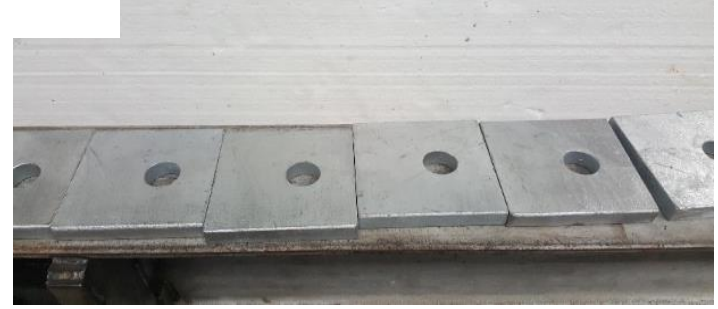

(b)

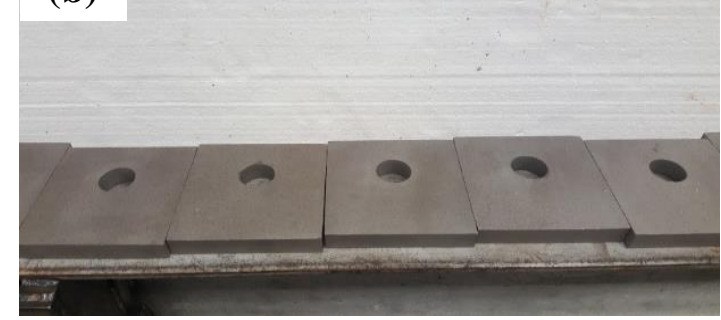

Figure 4-26: Specimen plates arranged to be final surface treated (a) galvanized plates to be wire brushed and (b) blasted clean surface to be cleaned with a regular brush to remove dust 
(a)

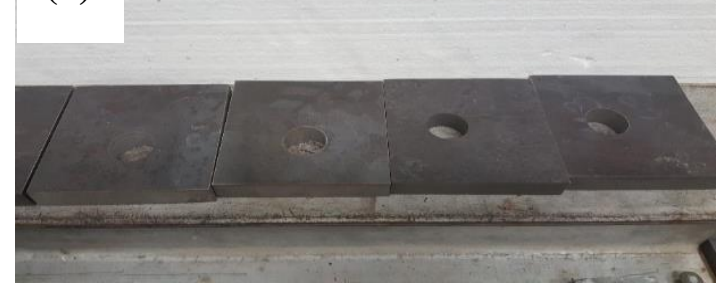

(b)

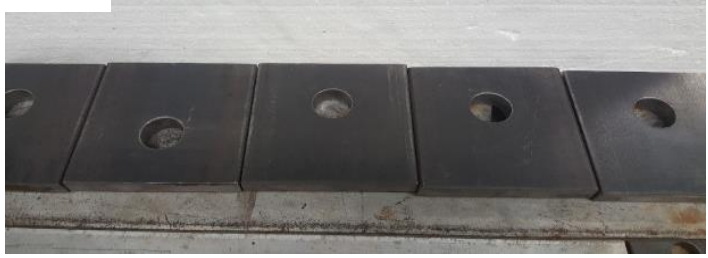

Figure 4-27: Specimen plates arranged to be final surface treated (a) A1010 clean mill scale surface to be cleaned with acetone and (b) $350 \mathrm{~W}$ Steel clean mill scale to be cleaned with acetone

\subsubsection{Test specimen assembly}

The degree turn stencil was used to scribe the degree turn on the respective front plate of the selected specimen assembly as shown in Figure 4-28. During the process of assembling, the three plates to form a specimen assembly, a $22 \mathrm{~mm}$ diameter A325 high strength bolt was inserted into the bolt hole of three plates as shown Figure 4-29. The centre plate was then rotated $180^{\circ}$ and all the side check for alignment and the two outer plates checked to ensure that they were levelled as shown in Figure 4-30 and Figure 4-31. It is important to note that for the application of the $173 \mathrm{kN}$ clamping force, two different degree turns was used to apply this force, depending on the bolt being used (see Figure 4-32 and Table 4-8 for more details). For the 1/3 turn or $120^{\circ}$ clamping force, only one value of the degree turns (which was $170^{\circ}$ ) was used as shown in Table 4-9, (i.e. both types of high-strength bolts were tested at this degree turn).
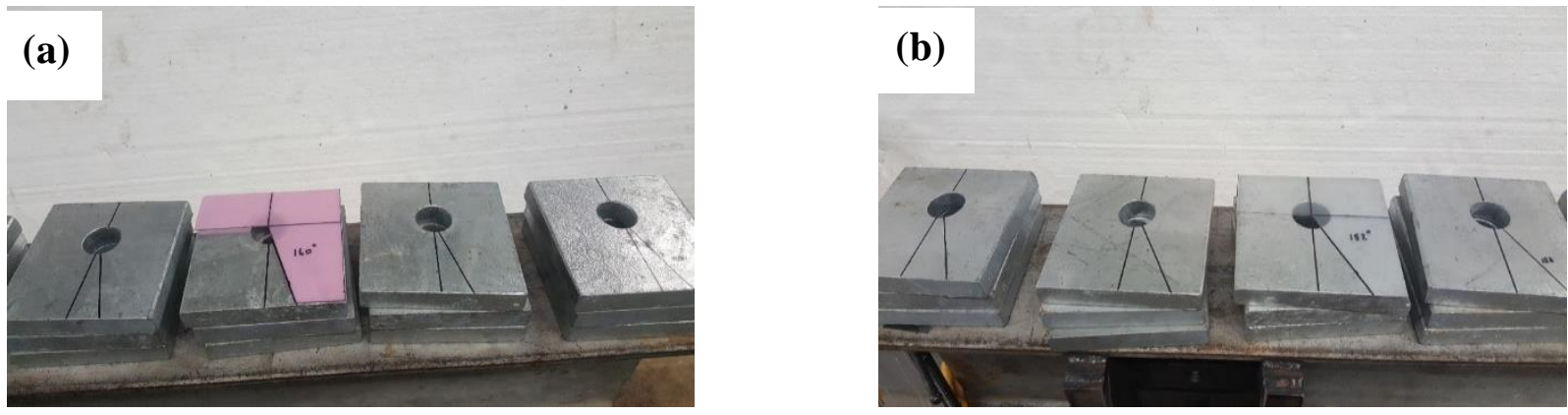

Figure 4-28: (a) Galvanized plates with galvanized bolts been scribe with $160^{\circ}$ stencil and (b) Galvanized plates with A325 bolts been scribe with $152^{0}$ stencil. 


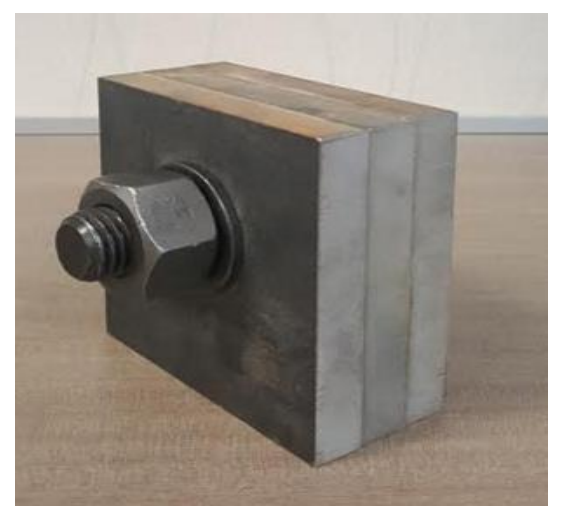

Figure 4-29: Typical initial assembly of three plate of a specimen with 7/8" diameter bolt
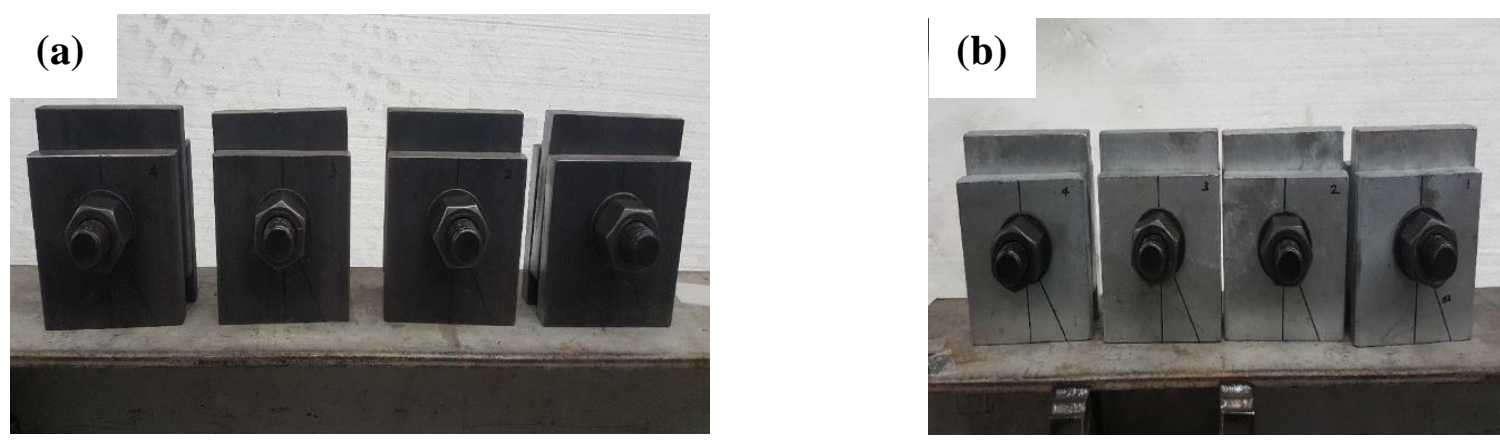

Figure 4-30: Rotation of centre plate of specimen assembly (a) $350 \mathrm{~W}$ clean mill scale plates with A325 bolts and (b) hot dip galvanized plates with A325 bolt

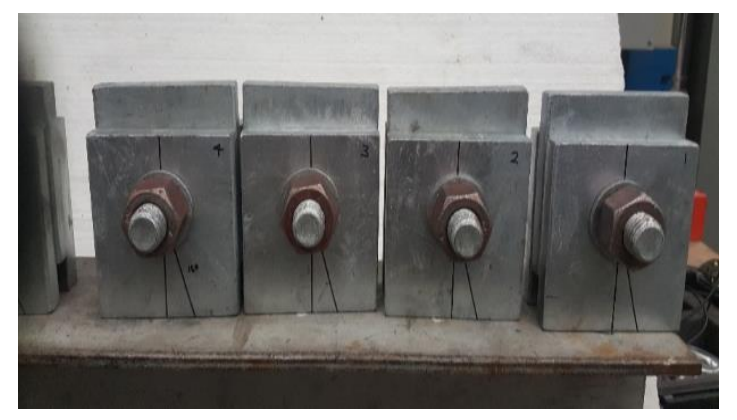

Figure 4-31: Rotation of centre plate of specimen assembly hot-dip galvanized plates with galvanized bolts 
(a)

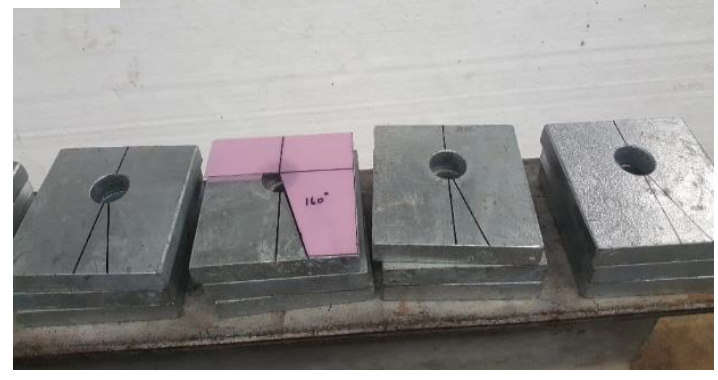

(b)

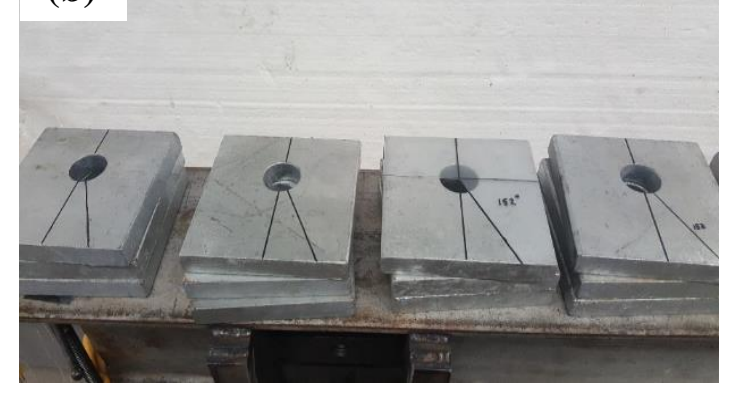

Figure 4-32: Galvanized plates with the two degree turn applied to the plate based on the type bolt to use (a) $160^{\circ}$ for galvanized bolt and (b) $152^{\circ}$ for A325 bolt

Table 4-8: Breakdown of testing procedure with clamping force at $173 \mathrm{kN}$

\begin{tabular}{|c|c|c|c|c|c|c|}
\hline $\begin{array}{l}\text { Slip test } \\
\text { plate } \\
\text { thickness = } \\
5 / 8^{\prime \prime} \text {, bolt } \\
\text { dia. = } 7 / 8^{\prime \prime}\end{array}$ & $\begin{array}{c}\text { Set } \\
\text { number }\end{array}$ & $\begin{array}{c}\text { Test } \\
\text { material }\end{array}$ & $\begin{array}{c}\text { Surface } \\
\text { type (class) }\end{array}$ & $\begin{array}{c}\text { Sample } \\
\#\end{array}$ & Type bolt & $\begin{array}{c}\text { Degrees } \\
\text { turn } \\
\text { (from the } \\
\text { hand } \\
\text { tightened } \\
\text { position) }\end{array}$ \\
\hline \multirow{24}{*}{$\begin{array}{l}\text { Using turn- } \\
\text { of-the-nut } \\
\text { method } \\
\text { with } \\
\text { Skidmore } \\
\text { equipment }\end{array}$} & \multirow{4}{*}{1} & \multirow{4}{*}{$\begin{array}{l}\text { Structural } \\
\text { Steel } \\
(350 \mathrm{~W})\end{array}$} & \multirow{4}{*}{$\begin{array}{l}\text { A (clean } \\
\text { mill scale) }\end{array}$} & 1 & \multirow{4}{*}{$\begin{array}{c}\text { Regular } \\
\text { A325 bolt }\end{array}$} & \multirow{4}{*}{$152^{\circ}$} \\
\hline & & & & 2 & & \\
\hline & & & & 3 & & \\
\hline & & & & 4 & & \\
\hline & \multirow{4}{*}{2} & \multirow{4}{*}{$\begin{array}{l}\text { Structural } \\
\text { Steel } \\
(350 \mathrm{~W})\end{array}$} & \multirow{4}{*}{$\begin{array}{l}\text { B (Blast- } \\
\text { clean) }\end{array}$} & 1 & \multirow{4}{*}{$\begin{array}{c}\text { Regular } \\
\text { A325 bolt }\end{array}$} & \multirow{4}{*}{$152^{\circ}$} \\
\hline & & & & 2 & & \\
\hline & & & & 3 & & \\
\hline & & & & 4 & & \\
\hline & \multirow{4}{*}{3} & \multirow{4}{*}{$\begin{array}{l}\text { Structural } \\
\text { Steel } \\
(350 \mathrm{~W})\end{array}$} & \multirow{4}{*}{$\begin{array}{c}\text { C }(\text { Hot } \\
\text { dip } \\
\text { galvanized })\end{array}$} & 1 & \multirow{4}{*}{$\begin{array}{c}\text { Galvanized } \\
\text { A325 High } \\
\text { strength } \\
\text { bolt }\end{array}$} & \multirow{4}{*}{$160^{\circ}$} \\
\hline & & & & 2 & & \\
\hline & & & & 3 & & \\
\hline & & & & 4 & & \\
\hline & \multirow{4}{*}{4} & \multirow{4}{*}{$\begin{array}{l}\text { Structural } \\
\text { Steel } \\
(350 \mathrm{~W})\end{array}$} & \multirow{4}{*}{ 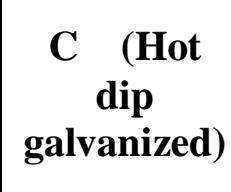 } & 1 & \multirow{4}{*}{$\begin{array}{c}\text { Regular } \\
\text { A325 bolt }\end{array}$} & \multirow{4}{*}{$152^{\circ}$} \\
\hline & & & & 2 & & \\
\hline & & & & 3 & & \\
\hline & & & & 4 & & \\
\hline & \multirow{4}{*}{5} & \multirow{4}{*}{$\begin{array}{l}\text { Stainless } \\
\text { Steel }\end{array}$} & \multirow{4}{*}{$\begin{array}{l}\text { A (clean } \\
\text { mill scale) }\end{array}$} & 1 & \multirow{4}{*}{$\begin{array}{c}\text { Galvanized } \\
\text { A325 High } \\
\text { strength } \\
\text { bolt }\end{array}$} & \multirow{4}{*}{$160^{\circ}$} \\
\hline & & & & 2 & & \\
\hline & & & & 3 & & \\
\hline & & & & 4 & & \\
\hline & \multirow{4}{*}{6} & \multirow{4}{*}{$\begin{array}{c}\text { Stainless } \\
\text { Steel }\end{array}$} & \multirow{4}{*}{$\begin{array}{l}\text { B (Blast- } \\
\text { clean) }\end{array}$} & 1 & \multirow{4}{*}{$\begin{array}{c}\text { Galvanized } \\
\text { A325 High } \\
\text { strength } \\
\text { bolt }\end{array}$} & \multirow{4}{*}{$160^{\circ}$} \\
\hline & & & & 2 & & \\
\hline & & & & 3 & & \\
\hline & & & & 4 & & \\
\hline
\end{tabular}


Table 4-9: Breakdown of testing procedure with clamping force at $203 \mathrm{kN}$

\begin{tabular}{|c|c|c|c|c|c|c|}
\hline $\begin{array}{l}\text { Slip test } \\
\text { plate } \\
\text { thickness = } \\
5 / 8^{\prime \prime} \text {, bolt } \\
\text { dia. = 7/8" }\end{array}$ & $\begin{array}{c}\text { Set } \\
\text { number }\end{array}$ & $\begin{array}{c}\text { Test } \\
\text { material }\end{array}$ & $\begin{array}{c}\text { Surface } \\
\text { type (class) }\end{array}$ & $\begin{array}{c}\text { Sample } \\
\#\end{array}$ & Type bolt & $\begin{array}{l}\text { Degrees } \\
\text { turn } \\
\text { (from the } \\
\text { hand } \\
\text { tightened } \\
\text { position) }\end{array}$ \\
\hline \multirow{23}{*}{$\begin{array}{c}\text { Using } \\
\text { turn-of-nut } \\
\text { method } \\
\text { with } \\
\text { Skidmore } \\
\text { equipment }\end{array}$} & \multirow{4}{*}{1} & \multirow{4}{*}{$\begin{array}{c}\text { Structural } \\
\text { Steel } \\
(350 \mathrm{~W})\end{array}$} & \multirow{4}{*}{$\begin{array}{c}\text { A (clean } \\
\text { mill scale) }\end{array}$} & 1 & \multirow{4}{*}{$\begin{array}{l}\text { Regular } \\
\text { A325 bolt }\end{array}$} & \multirow{4}{*}{$170^{\circ}$} \\
\hline & & & & 2 & & \\
\hline & & & & 3 & & \\
\hline & & & & 4 & & \\
\hline & \multirow{4}{*}{2} & \multirow{4}{*}{$\begin{array}{c}\text { Structural } \\
\text { Steel } \\
(350 \mathrm{~W})\end{array}$} & \multirow{4}{*}{$\begin{array}{c}\text { B } \\
\text { (Blast- } \\
\text { cleaned) }\end{array}$} & 1 & \multirow{4}{*}{$\begin{array}{l}\text { Regular } \\
\text { A325 bolt }\end{array}$} & \multirow{4}{*}{$170^{\circ}$} \\
\hline & & & & 2 & & \\
\hline & & & & 3 & & \\
\hline & & & & 4 & & \\
\hline & \multirow{3}{*}{3} & \multirow{3}{*}{$\begin{array}{c}\text { Structural } \\
\text { Steel } \\
(350 \mathrm{~W})\end{array}$} & \multirow{3}{*}{$\begin{array}{c}\mathrm{C} \quad \text { (Hot } \\
\text { dip } \\
\text { galvanized) }\end{array}$} & 1 & \multirow{4}{*}{$\begin{array}{l}\text { Galvanized } \\
\text { A325 High } \\
\text { strength } \\
\text { bolt }\end{array}$} & \multirow{3}{*}{$170^{\circ}$} \\
\hline & & & & 2 & & \\
\hline & & & & 3 & & \\
\hline & \multirow{4}{*}{4} & \multirow{4}{*}{$\begin{array}{c}\text { Structural } \\
\text { Steel } \\
(350 \mathrm{~W})\end{array}$} & \multirow{4}{*}{$\begin{array}{c}\mathrm{C} \text { (Hot } \\
\text { dip } \\
\text { galvanized) }\end{array}$} & $\begin{array}{l}4 \\
1\end{array}$ & & \multirow{4}{*}{$170^{\circ}$} \\
\hline & & & & 2 & \multirow{3}{*}{$\begin{array}{l}\text { Regular } \\
\text { A325 bolt }\end{array}$} & \\
\hline & & & & 3 & & \\
\hline & & & & 4 & & \\
\hline & \multirow{4}{*}{5} & \multirow{4}{*}{$\begin{array}{c}\text { Stainless } \\
\text { Steel }\end{array}$} & \multirow{4}{*}{$\begin{array}{l}\text { A (clean } \\
\text { mill scale) }\end{array}$} & 1 & \multirow{4}{*}{$\begin{array}{c}\text { Galvanized } \\
\text { A325 High } \\
\text { strength } \\
\text { bolt }\end{array}$} & \multirow{4}{*}{$170^{\circ}$} \\
\hline & & & & 2 & & \\
\hline & & & & 3 & & \\
\hline & & & & 4 & & \\
\hline & \multirow{4}{*}{6} & \multirow{4}{*}{$\begin{array}{c}\text { Stainless } \\
\text { Steel }\end{array}$} & \multirow{4}{*}{$\begin{array}{c}\text { B } \\
\text { (Blast- } \\
\text { clean) }\end{array}$} & 1 & \multirow{4}{*}{$\begin{array}{c}\text { Galvanized } \\
\text { A325 High } \\
\text { strength } \\
\text { bolt }\end{array}$} & \multirow{4}{*}{$170^{\circ}$} \\
\hline & & & & 2 & & \\
\hline & & & & 3 & & \\
\hline & & & & 4 & & \\
\hline
\end{tabular}

Once the respective degree turn was scribed onto the various outer plate of each test specimen assembly for the $173 \mathrm{kN}$ clamping force for the slip resistance testing, the completed assembly was then placed into a specially designed and fabricated gig as shown in Figure 4-33. The middle plate was then properly adjusted to ensure that the bottom of the centre hole was bearing or touching the bottom of the bolt within the assembly before hand-tightening was completed. Upon completing the hand-tightening process and electric toque wrench was placed over the nut of the bolt assembly and a mark scribed on the socket of the wrench to coincide with the zero position on the front plate, see Figure 4-34. The nut has then turned until the scribed mark on the wrench 
socket matched up with the required degree turn on the front of the plate. Once completed, the tensioned assembly was then moved to the bolt relaxation process phase (see bolt relaxation testing phase) before conducting the slip test on the universal MTS machine.
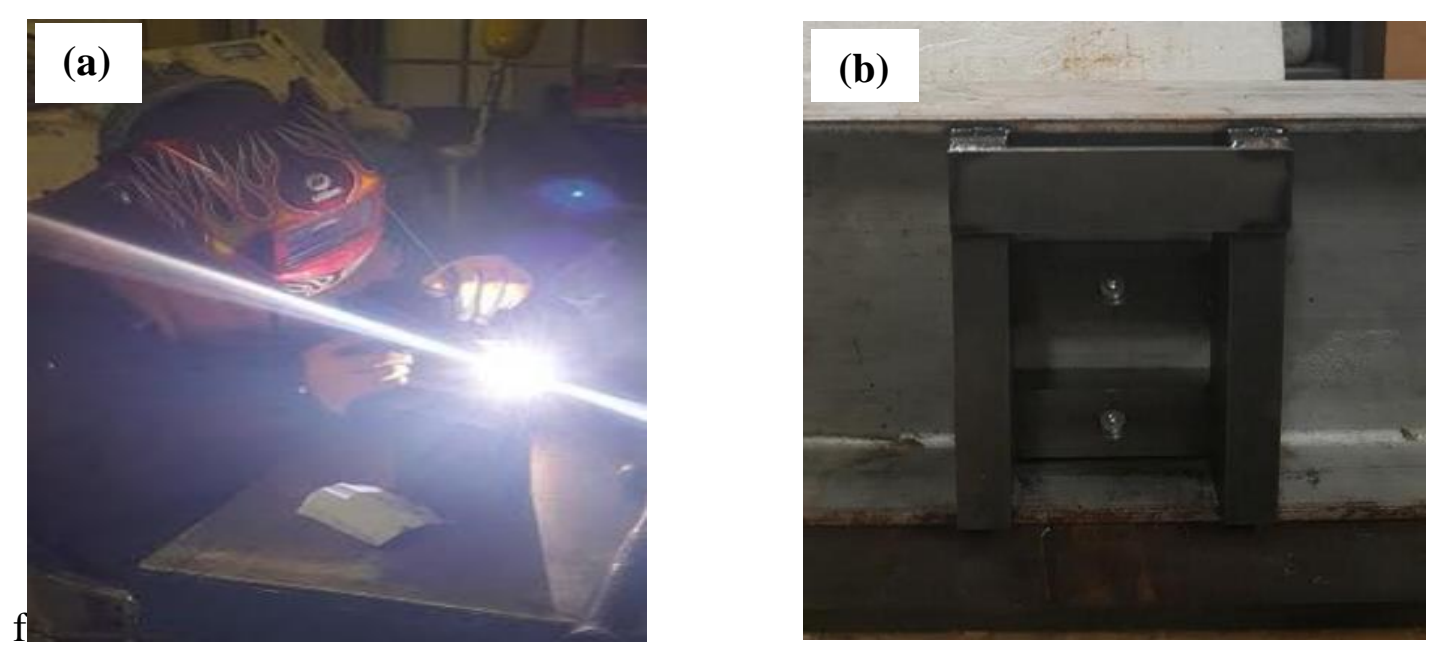

Figure 4-33: (a) Fabrication of clamping gig and (b) clamping gig to be used to hold specimen assembly during clamping

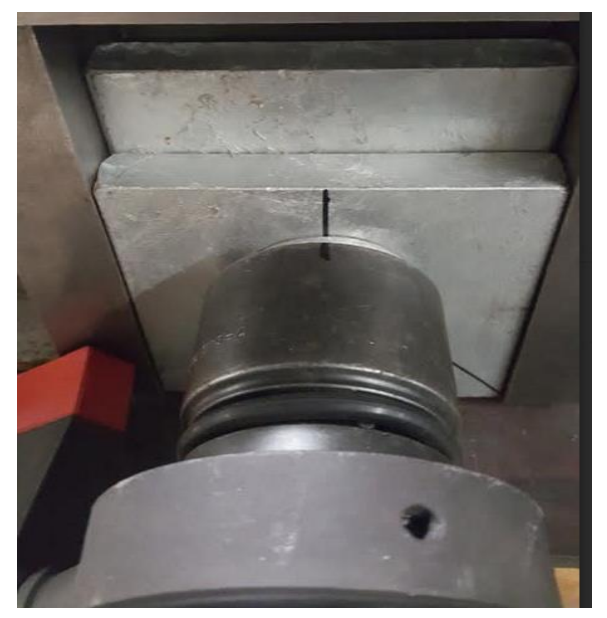

Figure 4-34: Alignment of the electric torque wrench with zero mark on front plate of specimen

\subsubsection{Specimen testing}

Table 4-8 shows the breakdown of the test parameters used in this research. The short-duration compressive slip-resistance testing was conducted on a $500 \mathrm{kN}$ MTS hydraulic Universal testing 
machine shown in Figure 4-35(a) with the use of a portable load cell of $500 \mathrm{kN}$ capacity shown in Figure 4-35(b). This was done in order to apply the initial settling load of $4.45 \mathrm{kN}$ as stated by Yura and Frank (1985) to the specimen assembly. Special care and attention was paid to the mounting of the specimen assembly onto the MTS machine load plates so as to mitigate against eccentric loading of the plates. The general testing procedure used in this research was adopted from the Research Council on Structural Connections Specifications for Structural Joints using ASTM A325 and A490 bolts as well as from Yura and Frank (1985) for specimen clamping force detail. The compressive force was applied to the centre plate of the specimen assembly as shown in Figure 4-36, at a loading rate of $0.07 \mathrm{~mm}$ per minute until slip occurred. The force-displacement history for each test was monitored on an X-Y plotter as shown in Figure 4-37. Once a slip of 1.35 mm was achieved, the test was terminated and a new specimen assembly was placed in the MTS machine for testing.
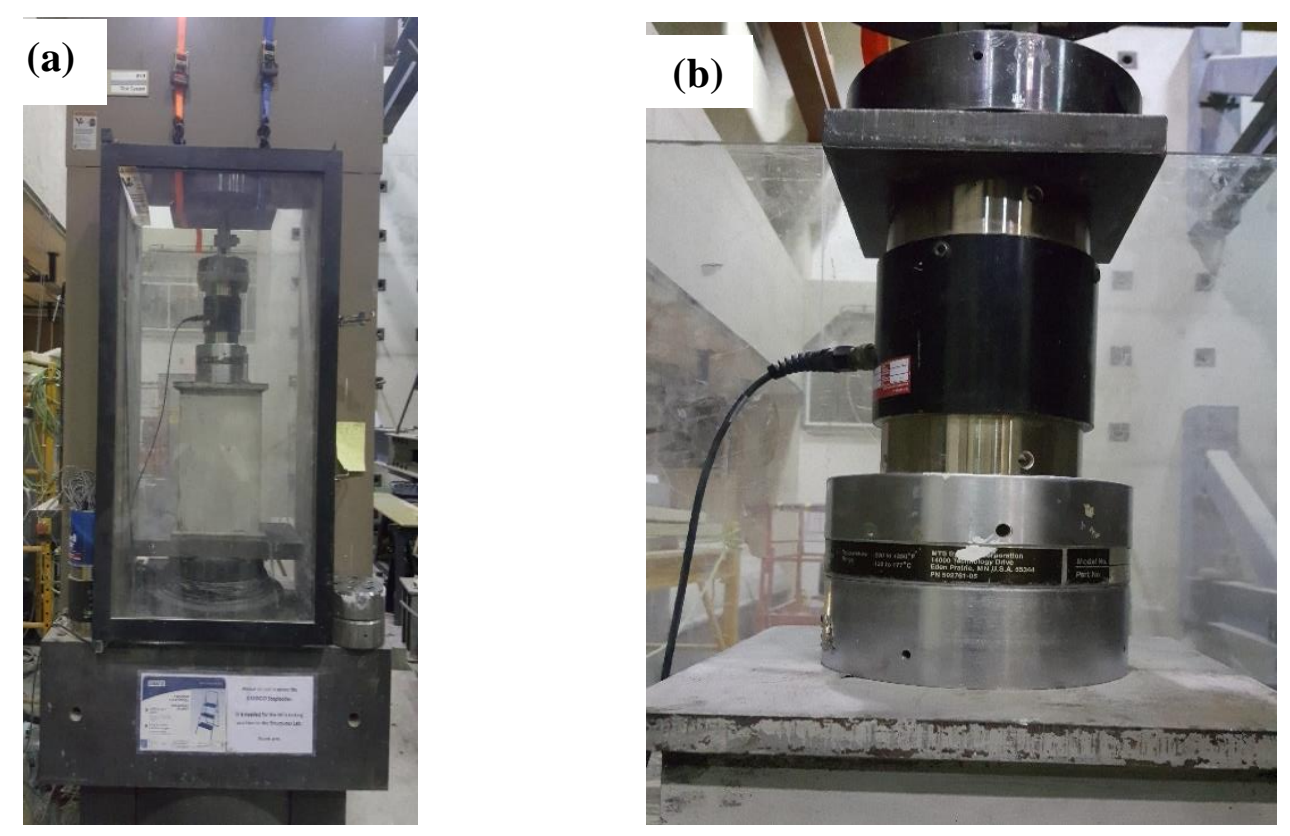

Figure 4-35: (a) MTS Hydraulic Universal Testing machine and (b) $500 \mathrm{kN}$ capacity portable load cell 


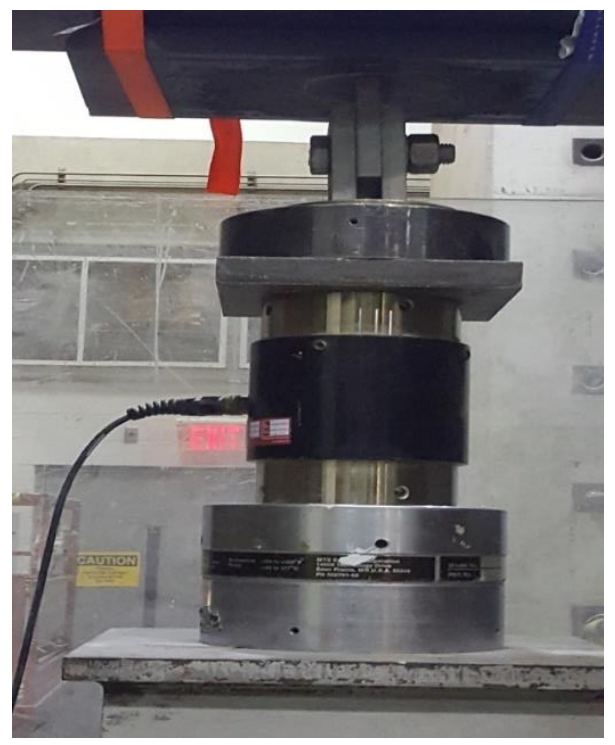

Figure 4-36: Compressive loading of centre plate of specimen assembly during slip testing

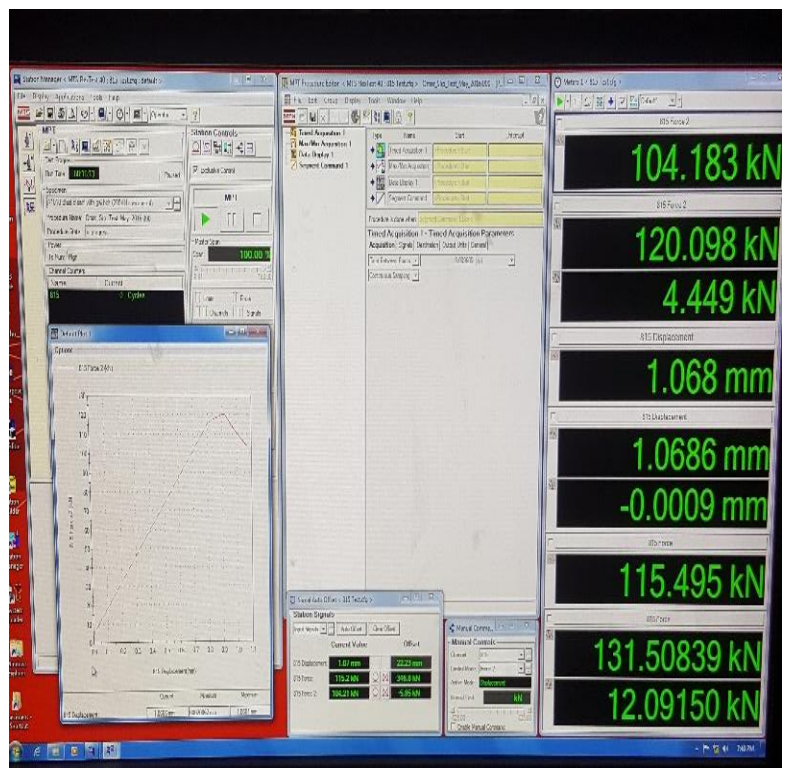

Figure 4-37: Digital screen of X-Y plotter for the MTS hydraulic universal testing machine

\subsection{Experimental Program 3: Bolt Relaxation Testing}

The testing for bolt relaxation began by removing all the raised indentations/marking on the head of the bolts by grinding. Figure 4-38 shows views of the bolt head before and after grinding. A total of 24 high-strength bolts were tested in this research. These bolts were used in conjunction with the slip-critical testing plates used in experimental procedure in section 4.2. After the removal of the indentation from the head of the bolt, they were placed into the specimen assembly as 
highlighted in experimental procedure 4.2. The pretension length of each bolt was then taken and recorded through the use on the Mini-Max ultrasonic bolt tension monitoring device. The completed assembly was then tensioned to the required degree turn. The immediate post-tensioned length of the bolt assembly was then taken and recorded again by using the Min-Max device. The tensioned specimen assembly was then put aside for a total period of $72 \mathrm{hrs}$. However, the lengths of the bolted assembly were checked and re-measured after $36 \mathrm{hrs}$ and then after $72 \mathrm{hrs}$ before slip-resistance testing was performed on the specimen assembly. The complete procedure outlined in this section was performed twice for this research, one time at a clamping force of $173 \mathrm{kN}$ and a second time at a clamping force of $203 \mathrm{kN}$ (see

Table 4-10 for more details).

Table 4-10: Breakdown of testing periods for bolt relaxation testing

\begin{tabular}{|c|c|c|c|c|}
\hline $\begin{array}{c}\text { Slip test plate } \\
\text { thickness }=5 / 8 " \\
\text { bolt dia. = 7/8" }\end{array}$ & $\begin{array}{c}\text { Set } \\
\text { number }\end{array}$ & Test mate rial & $\begin{array}{c}\text { Surface type } \\
\text { (class) }\end{array}$ & Sample \# \\
\hline \multirow{26}{*}{$\begin{array}{l}\text { (Using turn-of-the } \\
\text { nut method with } \\
\text { Skidmore } \\
\text { equipment) }\end{array}$} & \multirow{4}{*}{1} & \multirow{4}{*}{$\begin{array}{c}\text { Structural steel } \\
(350 \mathrm{~W})\end{array}$} & \multirow{4}{*}{$\begin{array}{c}\text { A (Clean mill } \\
\text { scale) }\end{array}$} & 1 \\
\hline & & & & 2 \\
\hline & & & & 3 \\
\hline & & & & 4 \\
\hline & \multirow{4}{*}{2} & \multirow{4}{*}{$\begin{array}{c}\text { Structural steel } \\
(350 \mathrm{~W})\end{array}$} & \multirow{4}{*}{$\begin{array}{l}\text { B (Blast- } \\
\text { cleaned) }\end{array}$} & 1 \\
\hline & & & & 2 \\
\hline & & & & 3 \\
\hline & & & & 4 \\
\hline & \multirow{4}{*}{3} & \multirow{4}{*}{$\begin{array}{c}\text { Structural steel } \\
(350 \mathrm{~W})\end{array}$} & \multirow{4}{*}{$\begin{array}{l}\text { C (Hot dip } \\
\text { galvanized with } \\
\text { gal. bolt) }\end{array}$} & 1 \\
\hline & & & & 2 \\
\hline & & & & 3 \\
\hline & & & & 4 \\
\hline & \multirow{4}{*}{4} & \multirow{4}{*}{$\begin{array}{l}\text { Structural Steel } \\
\quad(350 \mathrm{~W})\end{array}$} & \multirow{4}{*}{$\begin{array}{l}\text { C (Hot-Dip } \\
\text { galvanized with } \\
\text { A325 Bolt) }\end{array}$} & 1 \\
\hline & & & & 2 \\
\hline & & & & 3 \\
\hline & & & & 4 \\
\hline & \multirow{5}{*}{5} & \multirow{5}{*}{ Stainless steel } & \multirow{5}{*}{$\begin{array}{c}\text { A (Clean mill } \\
\text { scale) }\end{array}$} & 1 \\
\hline & & & & 2 \\
\hline & & & & 3 \\
\hline & & & & 4 \\
\hline & & & & 5 \\
\hline & \multirow{5}{*}{6} & \multirow{5}{*}{ Stainless steel } & \multirow{5}{*}{$\begin{array}{l}\text { B Blast- } \\
\text { clean) }\end{array}$} & 1 \\
\hline & & & & 2 \\
\hline & & & & 3 \\
\hline & & & & 4 \\
\hline & & & & 5 \\
\hline
\end{tabular}



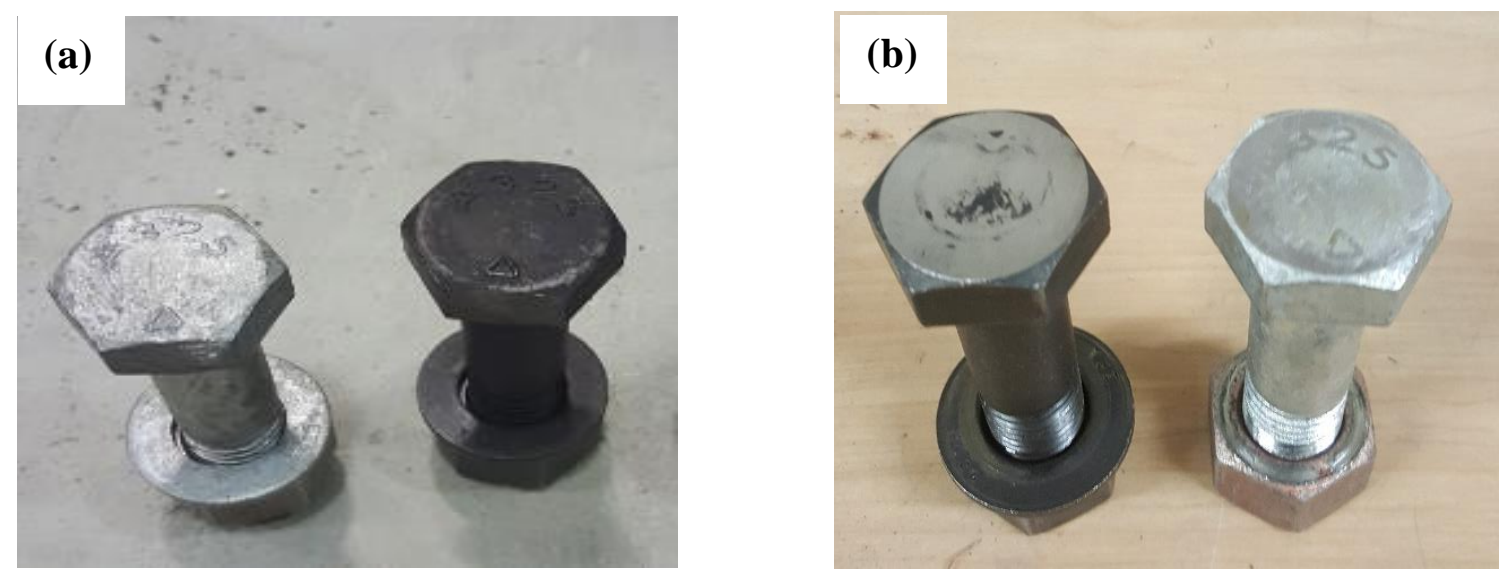

Figure 4-38: (a) Raised indentation/marking on the head of structural bolts and (b) bolt head after removal of raised indentation/marking through the process of grinding

\subsection{Experimental Program 5: Slip Coefficient for Specimens Subjected to Temperature Variation}

Testing procedure used in this phase of research was based on the adopted from the RCSC Specifications for Structural Joints using ASTM A325 and A490 bolts for short-duration compressive slip-critical testing. However, some modifications and additions were considered to accommodate the effect of temperature variations as laid out in Table 4-11. Firstly, for the test temperature of each surface condition, the plates were prepared as mentioned in Section 4.2.6. The plates, bolts, washers and nuts for all 3 specimens were dry-fitted and placed inside of the Burnsco environmental chamber as shown in Figure 4-39 and the temperature gauge on the environmental chamber was set to $2^{\circ} \mathrm{C}$ below the designated temperature. This was done so as to ensure that once each dry-fitted assembly was taken out of the chamber, enough time was available to perform bolt pre-tensioning to $203 \mathrm{kN}$ the electric torque wrench before the specimen temperature increased to the extent it passes the designated temperature. The dry-fitted specimen assembly for each temperature range and for each surface condition was left inside the environmental chamber for a minimum period of 36 hours so as to allow the specimens to properly acclimatize to the required temperature. Once acclimatization was achieved, the pre-tensioning of the specimens was done. K-thermocouple wires along with an insulating foam pad covering the outer portion of the exposed thermocouple wire were then clamped to the side of the middle plate as shown in Figure 4-40. 
Table 4-11: Breakdown of the test parameters used within this section of the research

\begin{tabular}{|c|c|c|c|c|c|c|}
\hline $\begin{array}{l}\text { Slip test Plate } \\
\text { thickness = 5/8", } \\
\text { bolt dia. }=7 / 8^{\prime \prime}\end{array}$ & $\begin{array}{c}\text { Set } \\
\text { group \# }\end{array}$ & $\begin{array}{l}\text { Surface type } \\
\text { (class) }\end{array}$ & Test material & Sample identity & $\begin{array}{c}\text { Number of } \\
\text { samples }\end{array}$ & $\begin{array}{c}\text { Total number } \\
\text { of plates }\end{array}$ \\
\hline \multirow{20}{*}{$\begin{array}{l}\text { Using turn of the } \\
\text { nut method: effect } \\
\text { of temperature on } \\
\text { slip resistance } \\
\text { determination }\end{array}$} & \multirow{4}{*}{1} & \multirow{4}{*}{ A } & \multirow{4}{*}{$\begin{array}{l}\text { A (Clean mill } \\
\text { scale) }\end{array}$} & $1-\mathrm{A}-(-5)$ & 3 & 9 \\
\hline & & & & 1-A-(-10) & 3 & 9 \\
\hline & & & & $1-\mathrm{A}-(-20)$ & 3 & 9 \\
\hline & & & & $1-\mathrm{A}-(-30)$ & 3 & 9 \\
\hline & \multirow{4}{*}{2} & \multirow{4}{*}{$\mathrm{B}$} & \multirow{4}{*}{$\begin{array}{l}\text { B (Blasted } \\
\text { clean) }\end{array}$} & $2-B-(-5)$ & 3 & 9 \\
\hline & & & & $2-B-(-10)$ & 3 & 9 \\
\hline & & & & 2-B-(-20) & 3 & 9 \\
\hline & & & & 2-B-(-30) & 3 & 9 \\
\hline & \multirow{4}{*}{3} & \multirow{4}{*}{$\mathrm{C}$} & \multirow{4}{*}{$\begin{array}{c}\mathrm{C} \text { (Hot dip } \\
\text { galvanized } \\
\text { with gal. bolt) }\end{array}$} & $3-C-(-5)$ & 3 & 9 \\
\hline & & & & $3-C-(-10)$ & 3 & 9 \\
\hline & & & & $3-C-(-20)$ & 3 & 9 \\
\hline & & & & $3-C-(-30)$ & 3 & 9 \\
\hline & \multirow{4}{*}{4} & \multirow{4}{*}{$\begin{array}{l}\text { Stainless Steel } \\
\text { (A) }\end{array}$} & \multirow{4}{*}{$\begin{array}{l}\text { A (Clean mill } \\
\text { scale) }\end{array}$} & 4-SSA-(-5) & 3 & 9 \\
\hline & & & & 4-SSA-(-10) & 3 & 9 \\
\hline & & & & 4-SSA-(-20) & 3 & 9 \\
\hline & & & & 4-SSA-(-30) & 3 & 9 \\
\hline & \multirow{4}{*}{5} & \multirow{4}{*}{$\begin{array}{l}\text { Stainless Steel } \\
\text { (B) }\end{array}$} & \multirow{4}{*}{$\begin{array}{l}\text { B (Blasted } \\
\text { clean) }\end{array}$} & 5-SSB-(-5) & 3 & 9 \\
\hline & & & & 5-SSB-(-10) & 3 & 9 \\
\hline & & & & 5-SSB-(-20) & 3 & 9 \\
\hline & & & & 5-SSB-(-30) & 3 & 9 \\
\hline
\end{tabular}

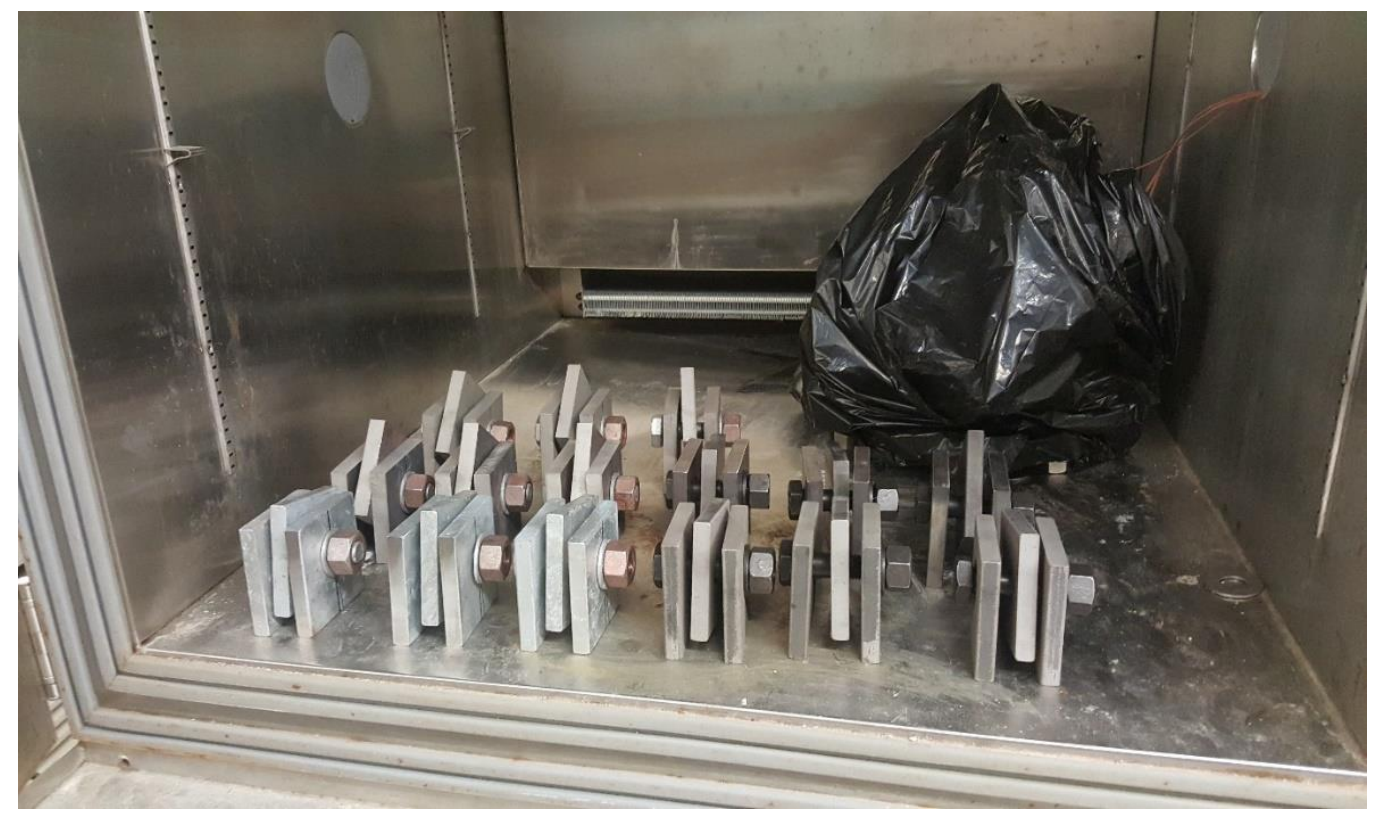

Figure 4-39: Placement of dry-fitted sample inside of environmental chamber 
The specimen was then placed back inside the environmental chamber to re-acclimatize the specimen back to the required temperature. They were left in environmental chamber for an additional 36 hours before testing. Upon re-acclimatization of the specimens, they were then taken out of the environmental chamber, one at a time, placed inside of an insulated cooler bag (containing frozen gel packs) and transported to the MTS Universal Testing machine, see Figure 4-41. This was done so as to mitigate against any significant loss/gain in temperature prior to commencement of slip testing. The specimen temperature was taken and recorded at the start slipresistance testing and every 2-minute interval throughout the duration of the test. Table 4-12 shows the test matrix for this phase of testing.

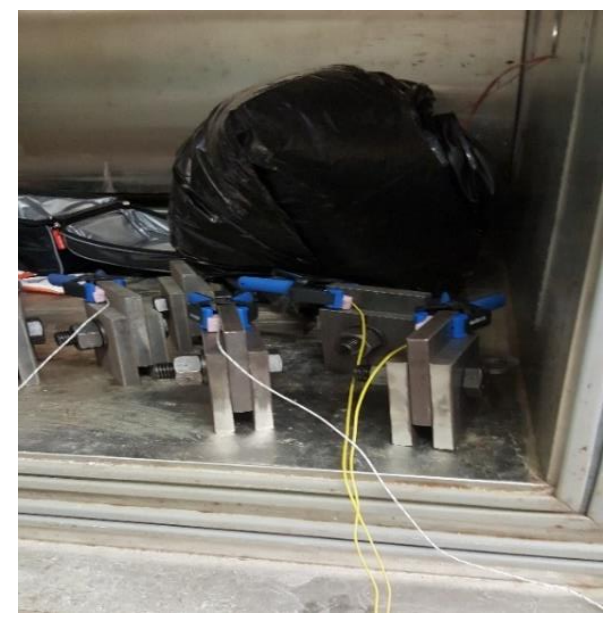

Figure 4-40: Placement of insulating foam to back of K-thermocouple wire, then replacement of specimen into environmental chamber
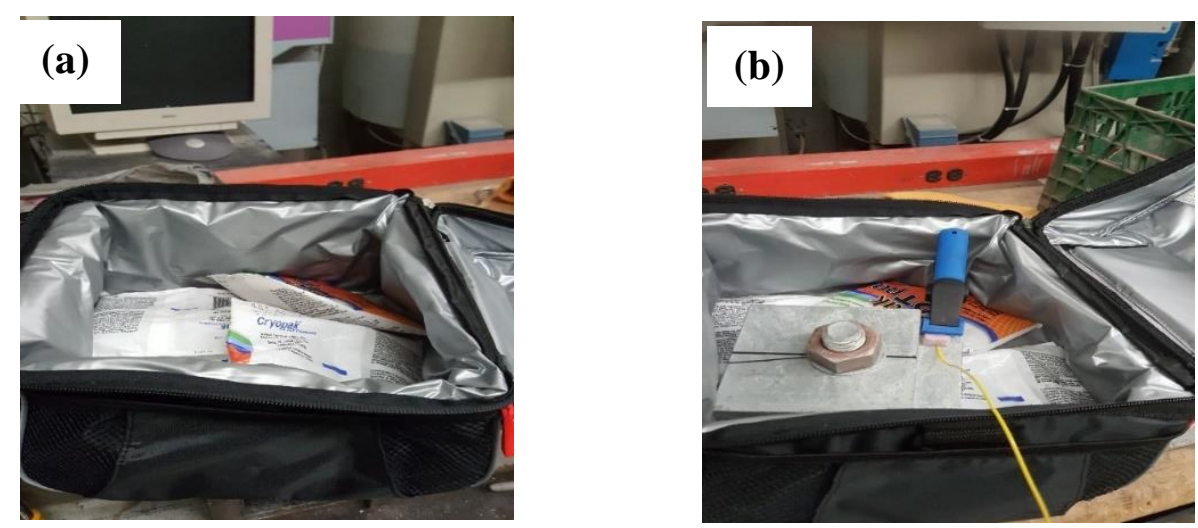

Figure 4-41: (a) Thermally insulted transportation bag with frozen gel pack, (b) transportation of specimen ready for testing 
Table 4-12: Text matrix for slip-resistance tests considering temperature monitoring

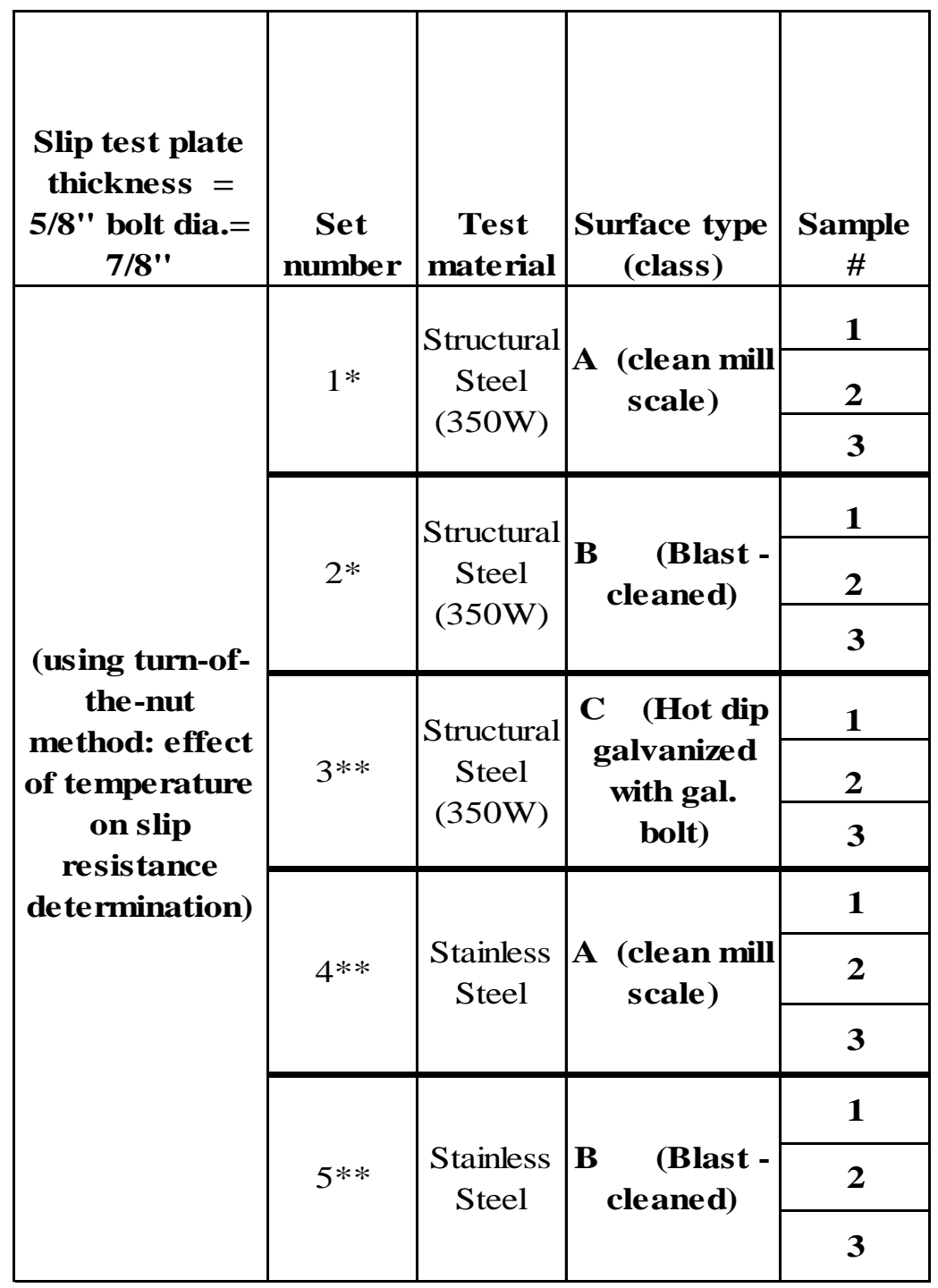




\section{EXPERIMENTAL RESULTS AND DISCUSSION ON HIGH-STRENGTH BOLT RE-USABILITY}

\subsection{High Strength Bolt Reusability with Unlubricated Threading Results}

Loading and unloading of the bolt samples to simulate the reuse of a bolt (i.e. tightening the nut and untightening the nut repeatedly) was done to ascertain the total number of times that the bolts could be reused before its strength or structural capacity is affected. According to previous studies done by Kulak et al. (2001), the turn-of-nut method of bolt tensioning will likely induce within the bolt a tension that will tend to exceeds the elastic limit of the bolt (threaded portion). Hence for high-strength bolts, repeated tightening of the nut is not recommended. In other words, the highstrength bolt should preferably be used only once. The following subsections examined this finding for the 3 bolt types considered in this research.

\subsubsection{A325 High strength bolt with unlubricated threading}

Figure 5-1 depicts the change in bolt elongation with increase of bolt tension when the test is repeated more than 5 times for unlubricated A325 high strength bolt. It was observed that the bolt could be reused for a total of 4 times before the bolt strength is affected or the bolt-to-nut interaction becomes a problem for the bolted connection see.

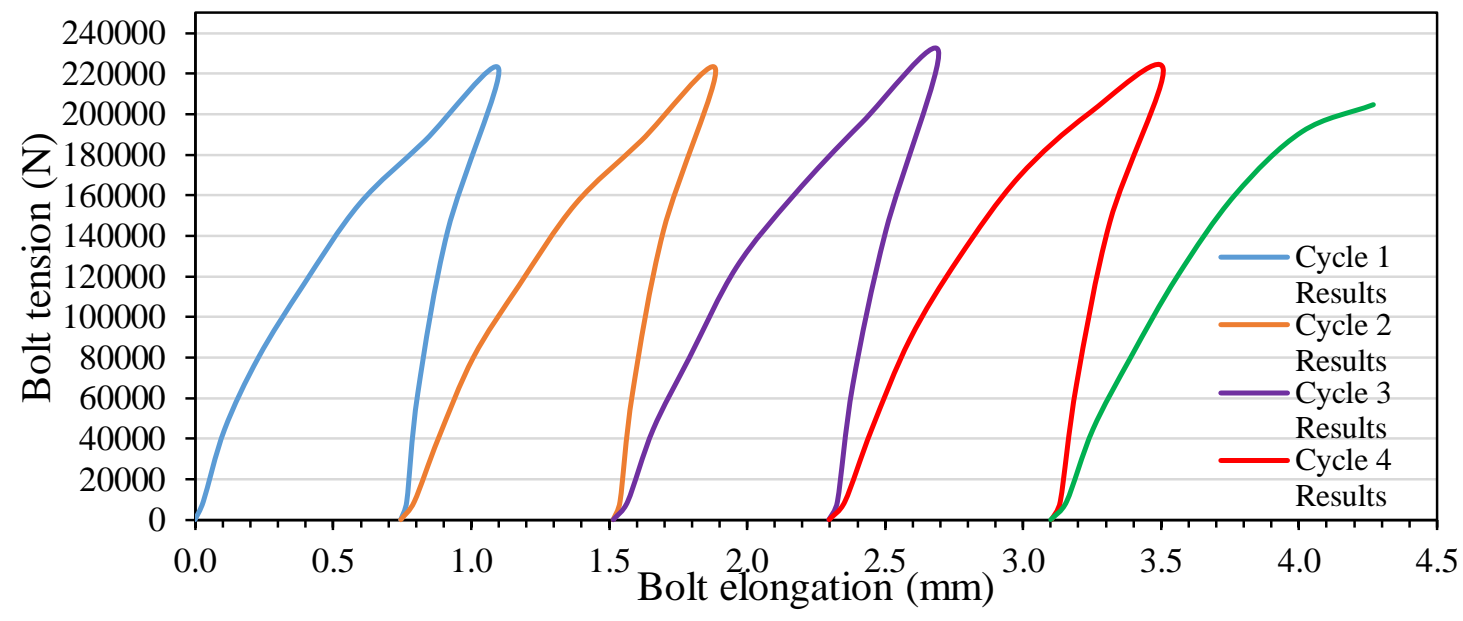

Figure 5-1: A325 High strength bolt re usability cycle for loading and unloading of the bolt with unlubricated threading 


\subsubsection{Galvanized A325 high-strength bolt with unlubricated threading}

Figure 5-2 depicts the change in bolt elongation with increase of bolt tension when the test is repeated for the galvanized A325 high-strength bolt. It can be observed that when the threads are unlubricated, it can only be reused one time. This may be attributed to the galling effect of the galvanized material between the threads of the bolts and the nut. As a result, it causes the nut to jam or seize up on the threaded portion of the bolt upon reuse of the same bolt and nut configuration. Hence, it is recommended that the unlubricated galvanized bolts be used once in bolted joint connection.

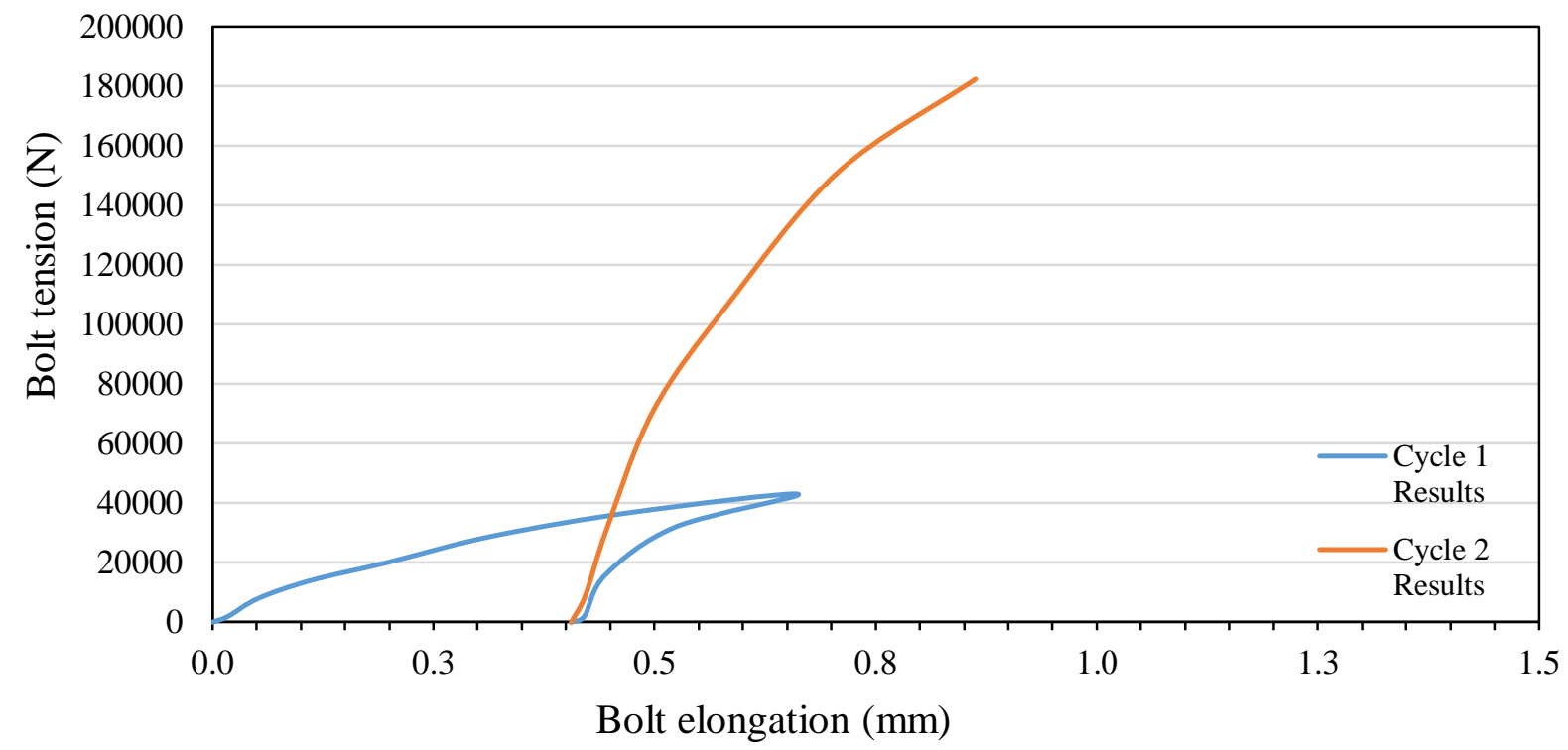

Figure 5-2: Galvanized A325 high strength bolt re usability cycle for loading and unloading of the bolt with unlubricated threading. 


\subsubsection{B8 Class 1 Stainless steel bolt with unlubricated threading}

Figure 5-3 depicts the change in bolt elongation with increase of bolt tension when the test is repeated more than 5 times for the A193 B8 class 1 stainless steel bolt. Results show that the bolt can be re-used up to 4 times. However, it was noticeable that when using the turn-of-nut method of tensioning the bolt to one-third of a turn (i.e. $120^{\circ}$ beyond the snug-tight condition), the load remained fairly constant while the elongation of the bolt continued. Galling action as reported by Kulak et al. (2001) was noticed after the fourth set of loading and unloading of the bolt and nut. Hence, further investigation was needed to ascertain if lubricating the threads of the galvanized A325 and A193 B8 class 1 stainless steel bolt would eliminate this problem and whether this lubrication would affect the strength of the bolt. In any case, results showed that the bolt could not continue carrying tensile load to $70 \%$ of its capacity. Rather, the maximum load carried by the bolt in each loading stage was in the range of 50 to $60 \mathrm{kN}$ which gives an indication that this type of bolting can be used only for sung-tight conditions.

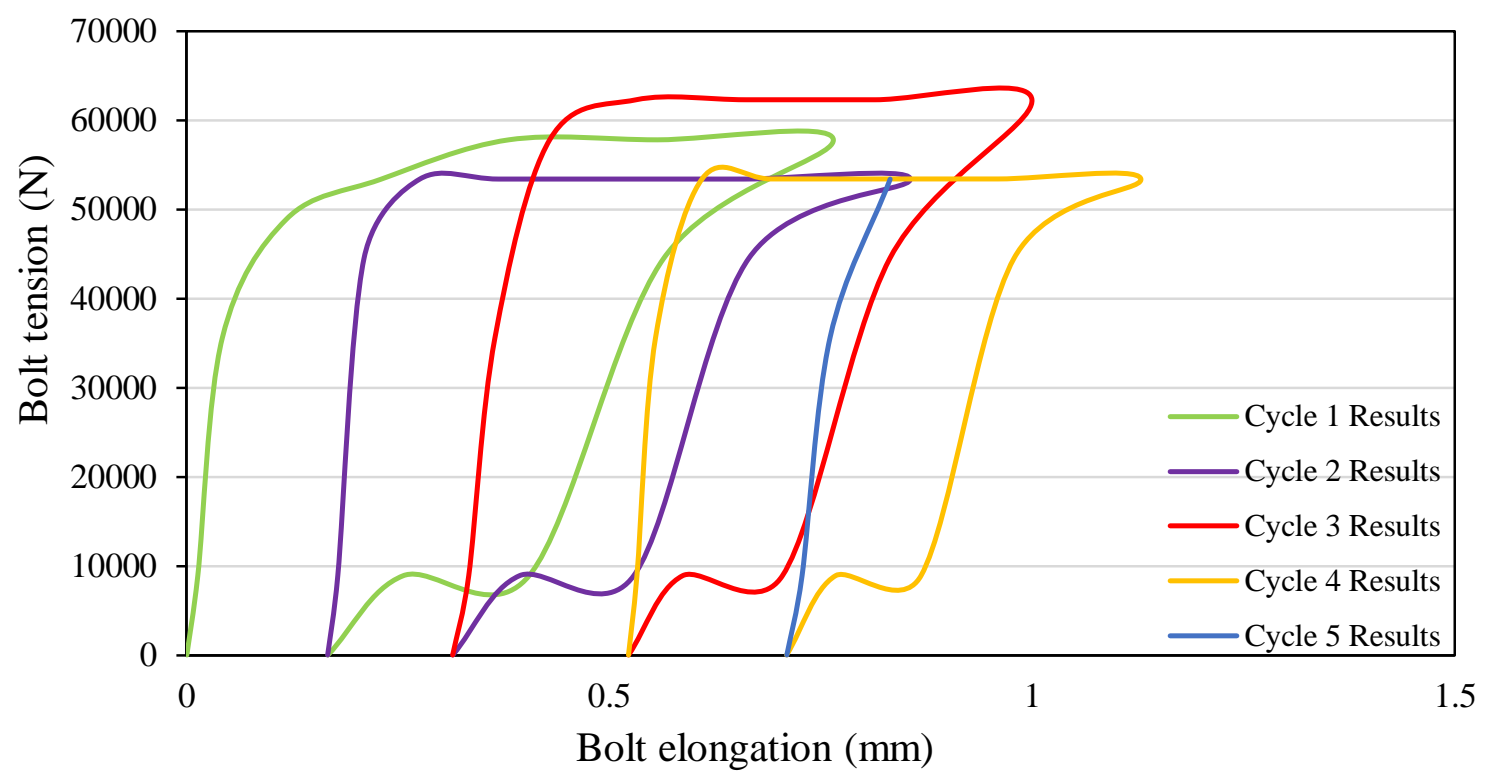

Figure 5-3: B8 Class 1 stainless steel bolt re usability cycle for loading and unloading of the bolt with unlubricated threading. 


\subsection{High Strength Bolt Reusability with Lubricated Threading Results}

\subsubsection{Galvanized A325 high strength bolt lubricated threading}

Figure 5-4 depicts the change in bolt elongation with increase of bolt tension when the test is repeated more than 5 times for lubricated A325 high-strength galvanized bolt. Upon application of lubricant to the bolt threads, one may notice an increase in the number of reusability cycles as well as an increase in the level of bolt tension value. The reusability capacity of the galvanized high strength bolt moved from $1 \frac{1}{2} 2$ cycles shown in Figure 5-2 to 5 cycles shown in Figure 5-4. However, though galvanized A325 high-strength bolts are usually delivered with some amount of lubrication on the threading (placed by manufacturer), it is recommended to conduct rotational capacity test (as per ASTM F3125/F3125M Standard) before installation of galvanized high strength bolt in slip-critical jointed connection.

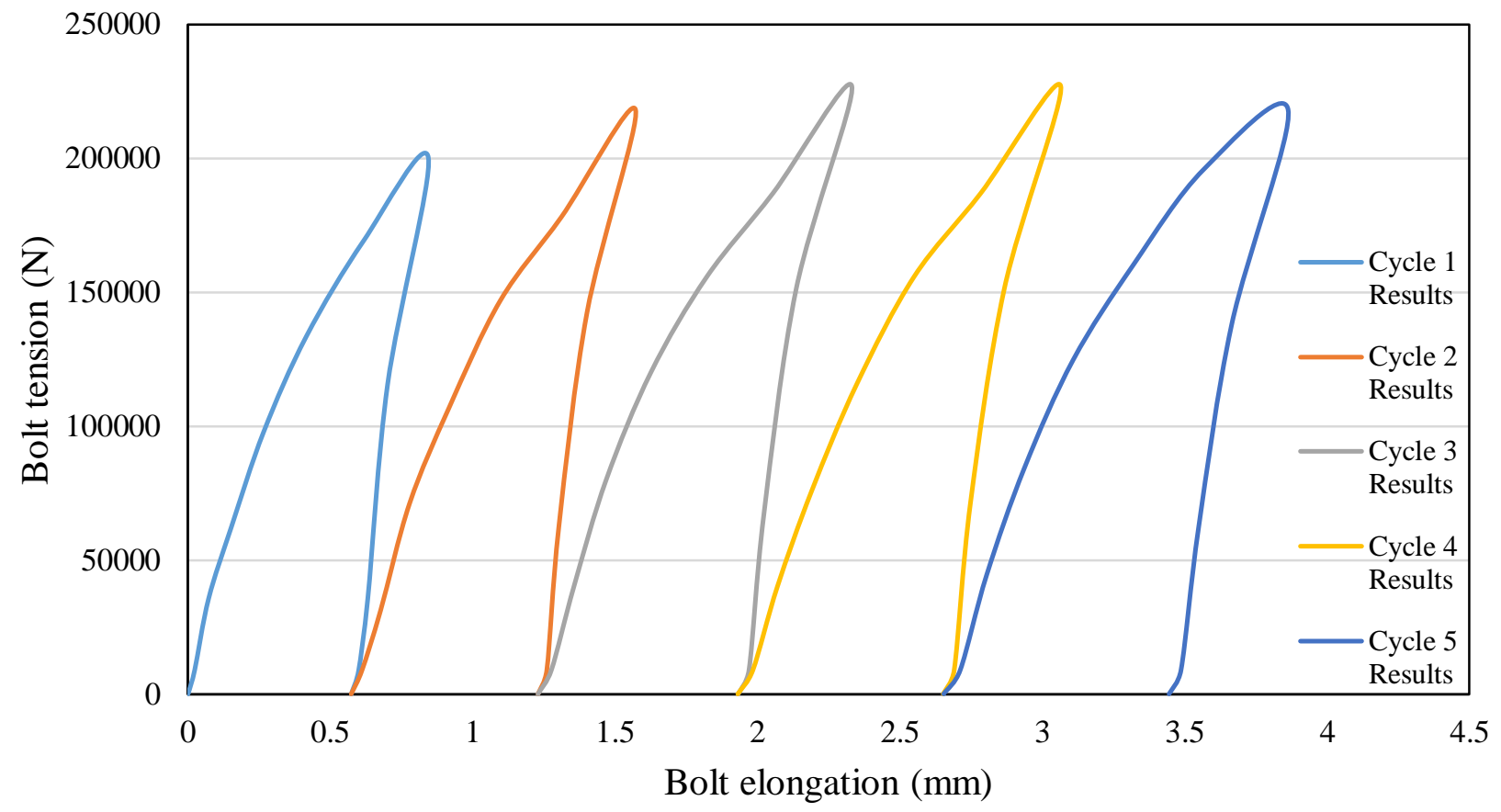

Figure 5-4: Galvanized A325 high strength bolt re usability cycle for loading and unloading of the bolt with lubricated threading. 


\subsubsection{B8 Class 1 Stainless steel bolt with lubricated threading}

Figure 5-5 depicts the change in bolt elongation with increase of bolt tension when the test is repeated more than 5 times for the lubricated B8 class 1 stainless steel bolt. Similar results were observed for lubricated bolt and those for the unlubricated bolt shown in Figure 5-3 (i.e. the total number of reuse increased from four times to five times without any galling effect occurring). Also there was a noticeably increase in the bolt tension value compared to the unlubricated bolt but not to the same magnitude as that for galvanized A325 high-strength bolt. It is important to note that the tensile force developed in the B8 class 1 stainless steel bolt (for both unlubricated and lubricate thread condition) was significantly smaller than that developed one in either the regular A325 or galvanized A325 high strength bolt. It is interesting to observe that the manufacturer's tensile specification is developed from pulling tests, not from torqueing test.

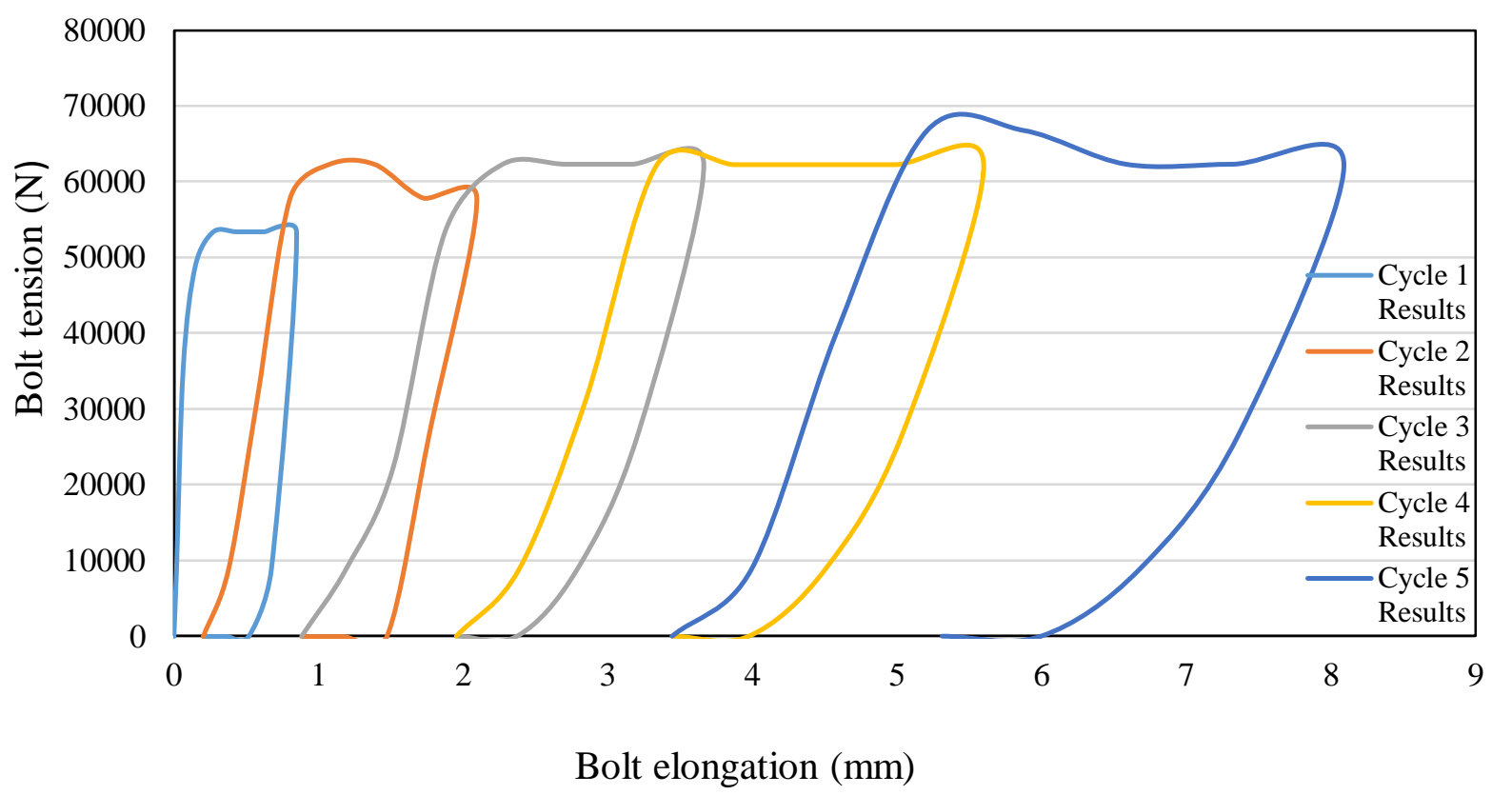

Figure 5-5: B8 Class 1 Stainless steel bolt re usability cycle for loading and unloading of the bolt with lubricated threading. 


\section{Chapter 6: EXPERIMENTAL RESULTS AND DISCUSSION ON BOLT PRE-LOAD SUBJECT TO TEMPERATURE VARIATION}

A total of 5 bolt specimens were tested for each temperature range. Experimental data were recorded as the mean Wilhelm Skidmore reading, mean change in length and the mean initial length as shown in Table 6-1 and Figure 6-3 and 6-2 for A325 bolts. The mean calculated bolt preload was calculated using the bolt initial length and the change in length using equation 3-2. From the performance of simple linear regression analysis in Microsoft Excel, the link between the temperature and the bolt pre-load was established. It can be seen that for the A325 bolts, the change in Wilhelm Skidmore measured pre-load is very small (i.e. -0.015 as shown in Table 6-2), with a high p-value of 0.954 , showing that the effect of pretension temperature is highly insignificant. This shows a negligible effect of adverse low temperatures on the measured bolt pre-load from the Wilhelm Skidmore bolt tensioning device. This can also be seen visually from Figure 6-1, where the trend-line between the data points does not seem to show a positive or a negative change, rather it stays pretty much straight throughout. On the other hand, using the calculated bolt pre-load based on the elongation of the bolts under adversely low temperature conditions alone, it can be seen from Figure 6-2 that there is a clear link between the temperature and the calculated bolt preload values. However, since the calculated bolt pre-load is based solely on the elongation of the bolt and it may not truly represent the bolt strength which also depends on other bolt characteristics such as bolt manufacturing defect, rate of cooling between bolt of the same production batch, etc.

As for galvanized A325 bolts, a total of 5 bolt specimens were tested for each temperature range. From performing the simple excel regression analysis in Microsoft Excel, the link between the temperature and the bolts pre-load was established. Tables 6-3 and 6-4 as well as Figures 6-3 and 6-3. It can be observed that for the galvanized A325 bolts, the change in bolt tension measured using Wilhelm Skidmore device with change in pre-load temperature is adversely linear, (i.e.1.01745 with a p-value of 0.13969 as shown in Table 6-4). This can be visually observed in Figure 6-3, where the trend line between the data points seems to show a negative change with the decrease in temperature. Using the calculated bolt preload based on the elongation of the bolts under adversely low temperature, it also can be observed from Figure 6-4 that there is a clear and more pronounced link between the adverse temperature and the calculated bolt pre-load values. 
Table 6-1: Analysis of hexagonal A325 high strength bolt at one third of a turn

\begin{tabular}{|c|c|c|c|c|c|}
\hline \multirow{2}{*}{ Temperature } & \multicolumn{5}{|c|}{ Clamping force determination at one third of a turn } \\
\cline { 2 - 6 } & $\begin{array}{c}\text { Mean initial } \\
\text { length (mm) }\end{array}$ & $\begin{array}{c}\text { Mean } \\
\text { change } \\
\text { in length } \\
(\mathrm{mm})\end{array}$ & $\begin{array}{c}\text { Mean } \\
\text { Skidmore } \\
\text { tension }(\mathrm{kN})\end{array}$ & $\begin{array}{c}\text { Mean } \\
\text { calculated } \\
\text { tension }(\mathrm{kN})\end{array}$ & $\begin{array}{c}\text { Standard } \\
\text { deviation } \\
(\mathrm{kN})\end{array}$ \\
\hline 20 & 101.321 & 0.206 & 207.29 & 154.84 & 41.65 \\
\hline-5 & 100.630 & 0.241 & 211.74 & 181.86 & 66.45 \\
\hline-10 & 100.678 & 0.324 & 225.97 & 245.00 & 19.05 \\
\hline-20 & 101.050 & 0.244 & 210.85 & 183.93 & 71.64 \\
\hline-30 & 100.364 & 0.314 & 206.40 & 237.82 & 62.03 \\
\hline
\end{tabular}

- Hexagonal A325 High Strength Bolt

Linear (Hexagonal A325 High Strength Bolt)

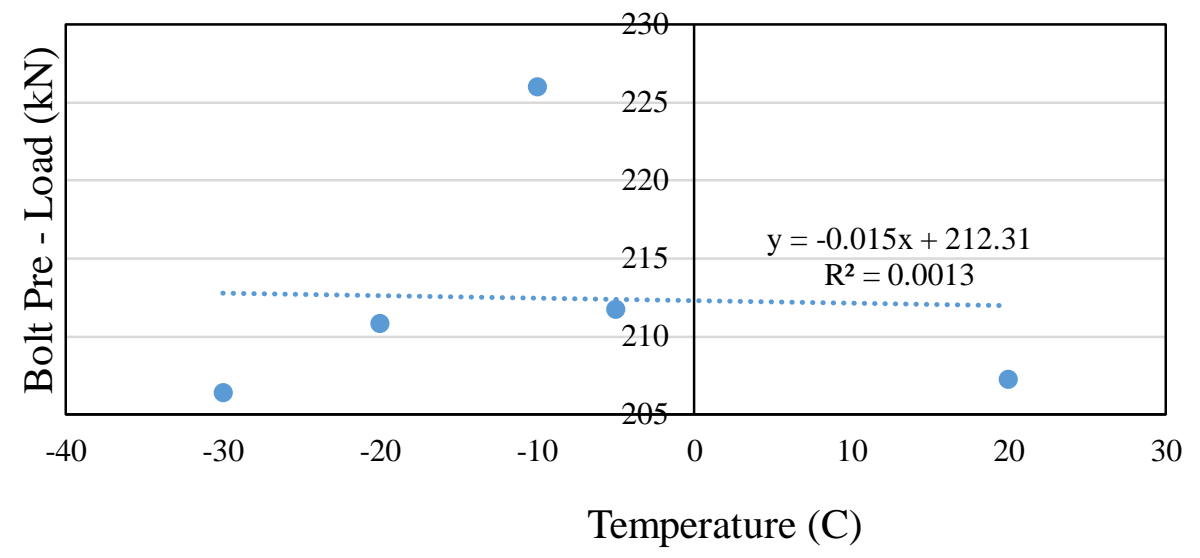

Figure 6-1: Variation in bolt pre-load as measured by the Wilhelm Skidmore bolt tensioning device for A325 high strength bolt 


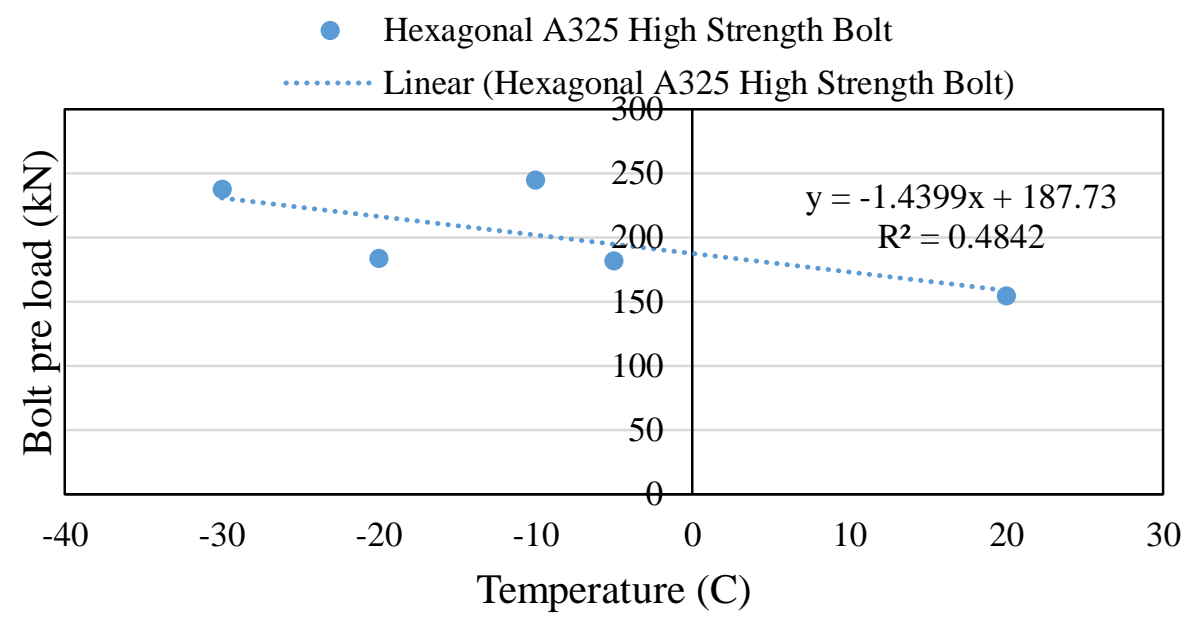

Figure 6-2: Variation in bolt pre-load as calculated by using equation 3-2 for A325 bolt

Table 6-2: Simple regression analysis of measured Wilhelm Skidmore experimental data for A325 High Strength bolt values

\begin{tabular}{lcc}
\hline & Coefficients & P-value \\
\hline Intercept & 212.311661 & $2.26 \mathrm{E}-05$ \\
Temperature & 0.01503624 & 0.954305 \\
\hline
\end{tabular}

Table 6-3: Analysis of hexagonal galvanized A325 high strength bolt at one third of a turn

\begin{tabular}{|c|c|c|c|c|c|}
\hline \multirow{2}{*}{ Temperature } & \multicolumn{5}{|c|}{ Clamping force determination at one third of a turn } \\
\cline { 2 - 6 } & $\begin{array}{c}\text { Mean initial } \\
\text { length }(\mathrm{mm})\end{array}$ & $\begin{array}{c}\text { Mean } \\
\text { change in } \\
\text { length } \\
(\mathrm{mm})\end{array}$ & $\begin{array}{c}\text { Mean } \\
\text { Skidmore } \\
\text { tension }(\mathrm{kN})\end{array}$ & $\begin{array}{c}\text { Mean } \\
\text { calculated } \\
\text { tension }(\mathrm{kN})\end{array}$ & $\begin{array}{c}\text { Standard } \\
\text { deviation } \\
(\mathrm{kN})\end{array}$ \\
\hline 20 & 102.065 & 0.187 & 180.60 & 139.31 & 12.08 \\
\hline-5 & 101.330 & 0.254 & 184.16 & 190.41 & 16.86 \\
\hline-10 & 100.954 & 0.333 & 232.20 & 251.02 & 30.27 \\
\hline-20 & 101.236 & 0.339 & 230.42 & 254.48 & 38.55 \\
\hline-30 & 100.965 & 0.328 & 221.52 & 246.79 & 69.72 \\
\hline
\end{tabular}


- Hexagonal Galvanized A325 High Strength Bolt

Linear (Hexagonal Galvanized A325 High Strength Bolt)

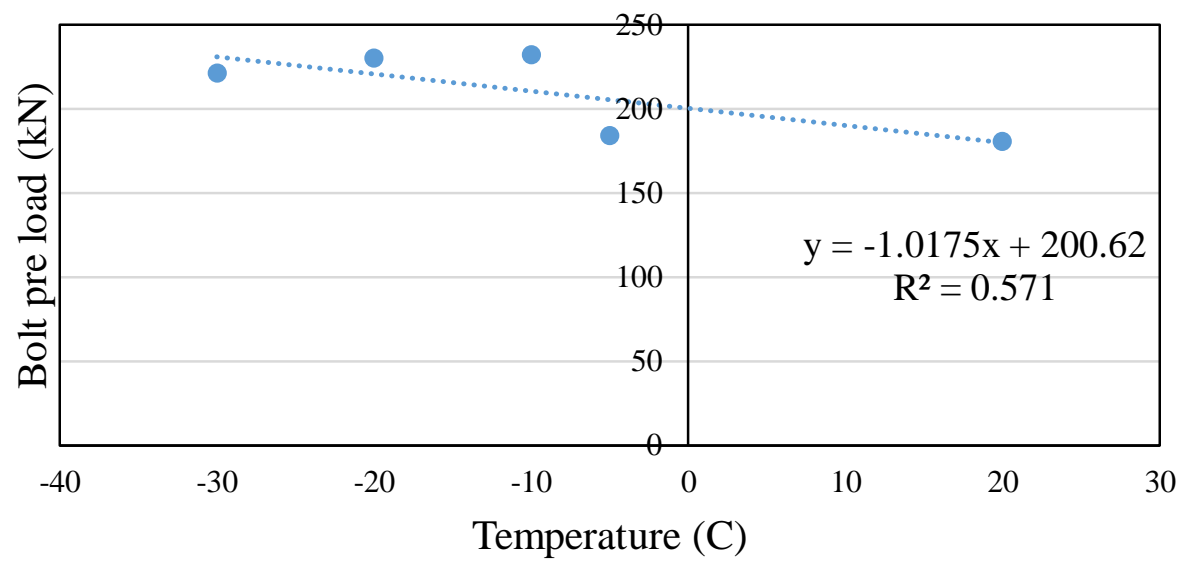

Figure 6-3: Variation in bolt pre-load as measured by the Wilhelm Skidmore bolt tensioning device for galvanized A325 high strength bolt

- Hexagonal Galvanized A325 High Strength Bolt

Linear (Hexagonal Galvanized A325 High Strength Bolt)

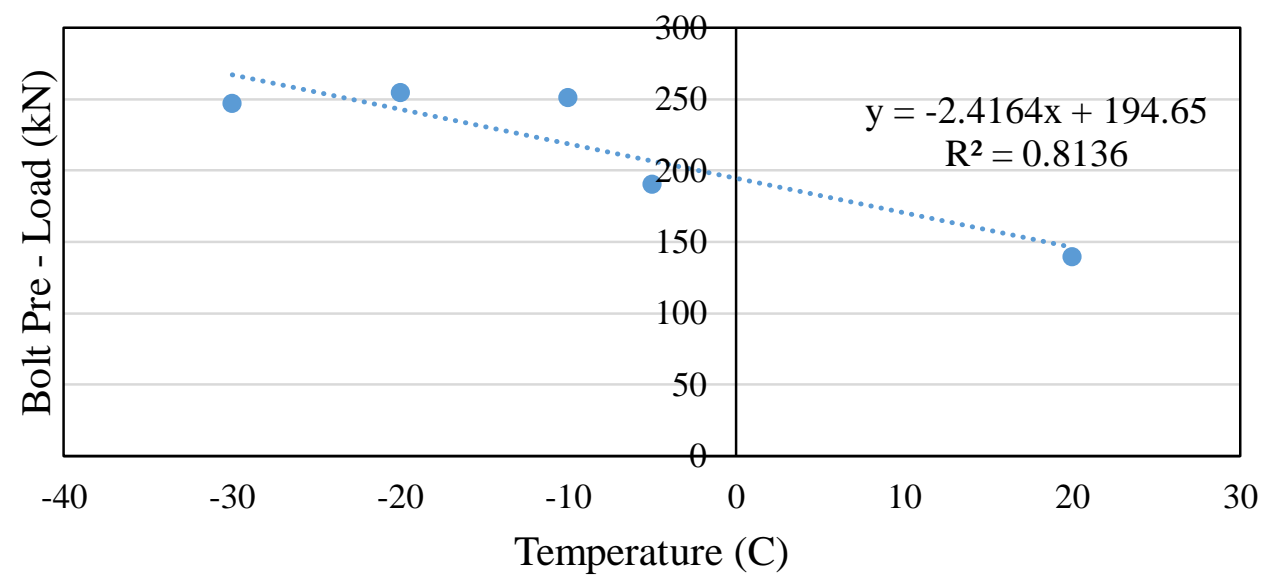

Figure 6-4: Variation in bolt pre load as calculated by using equation 3-2 for galvanized A325 high strength bolt

Table 6-4: Simple regression analysis of measured Wilhelm Skidmore experimental data for galvanized A325 high strength bolt values

\begin{tabular}{lrc}
\hline & Coefficients & P-value \\
\hline Intercept & 200.620987 & 0.0002493 \\
Temperature & -1.017452 & 0.1395694 \\
\hline
\end{tabular}




\section{Chapter 7: EXPERIMENTAL RESULTS AND DISCUSSION FOR SLIP COEFFICIENT AT AMBIENT TEMPERARURE}

The experimental results of slip-resistance testing at room temperature are presented, analysed and discussed in this section. One sample of each set of slip-resistance test results is presented herein. However, complete set of data in graphical and tabulated forms are presented in Appendices A through D for each bolt group and surface condition.

\subsection{Surface Roughness Results}

For a surface, the roughness is most often measured by using a form/type of Brown and Sharpe Surfcom 112B stylus instrument, with the measured results generally quoted as the mathematical average value, in other words the average roughness value (Ra), which is generally stated/expressed in micrometres $(\mu \mathrm{m})$. In this research, the process of sand-blasting was employed to obtain the desired surface condition of blasted clean. The maximum sand grit size that was used to produce this surface roughness was black shot 12 (grit size 12). Table 7-1 shows a breakdown of the mean values of roughness obtained from the sandblasting process.

Table 7-1: Results of mean surface roughness measurement for selected specimens

\begin{tabular}{|c|c|c|c|c|c|c|}
\hline \multirow[b]{2}{*}{ Material } & \multirow[b]{2}{*}{ Process } & \multirow[b]{2}{*}{$\begin{array}{l}\text { Specimen } \\
\text { number }\end{array}$} & \multicolumn{2}{|c|}{ Mean $R_{a}$ value } & \multicolumn{2}{|c|}{ Mean $R_{\max }$ value } \\
\hline & & & $\begin{array}{c}\text { side A } \\
(\mu \mathrm{m})\end{array}$ & $\begin{array}{c}\text { side } B \\
(\mu \mathrm{m})\end{array}$ & $\begin{array}{c}\text { side } A \\
(\mu \mathrm{m})\end{array}$ & $\begin{array}{c}\text { side } B \\
(\mu \mathrm{m})\end{array}$ \\
\hline \multirow{5}{*}{$350 \mathrm{~W}$ structural steel } & \multirow{5}{*}{ Sand-blasting } & 1 & 13.78 & 13.28 & 102.6 & 109 \\
\hline & & 2 & 13.45 & 12.98 & 139 & 114 \\
\hline & & 3 & 14.1 & 13.6 & 132 & 111 \\
\hline & & 4 & 12.6 & 12.1 & 102.5 & 108.4 \\
\hline & & 5 & 13.2 & 12.75 & 113 & 107 \\
\hline \multirow{5}{*}{ Stainless steel } & \multirow{5}{*}{ Sand-blasting } & 1 & 17.1 & 19.9 & 157.9 & 191.5 \\
\hline & & 2 & 12.6 & 17.2 & 121.4 & 216 \\
\hline & & 3 & 16.1 & 16.8 & 166.0 & 158.7 \\
\hline & & 4 & 16.0 & 15.75 & 144.9 & 125.9 \\
\hline & & 5 & 18.2 & 18.5 & 230.4 & 201.9 \\
\hline
\end{tabular}

\subsection{Determination of Clamping Force Results for A325 Bolts}

Based on the nature of this research and the changes made in the testing procedure when compared to those found in similar research such as Fisher et al. (1974), the degree turn corresponding to the minimum clamping force of $173 \mathrm{kN}$ had to be determined as presented in in Table 7-2 Table 7-3. 
A total of ten A325 high-strength bolts were tension inside the Wilhelm Skidmore bolt tensioning device from two different positions, namely: (i) hand-tightened position and (ii) snug-tightened position. From the hand-tightened position, the degree turns required to obtain a clamping force/bolt tension of $173 \mathrm{kN}$ ranged from $130^{\circ}$ to $170^{\circ}$ with an average value of $152^{\circ}$ turns as depicted in Table 7-2. From the snug-tightened position of $50^{\circ}$ turns, the degree turns required to acquire a bolt tension of $173 \mathrm{kN}$ ranged from $90^{\circ}$ to $110^{\circ}$ with an average value of $101^{\circ}$. Thus, for the A325 high-strength bolt, a degree turn of $152^{\circ}$ from the hand-tightened position was used to apply pretension to the plates in each specimen. Five A325 bolts were used to determine the clamping force that correlates to the third of a turn or $120^{\circ}$ turn from the snug-tightened position. A breakdown of the 5 tests is provided in Table 7-4, as it shows the clamping force for $120^{\circ}$ turn ranging in value from $197 \mathrm{kN}$ to $206 \mathrm{kN}$ with an average clamping force of $203 \mathrm{kN}$.

Table 7-2:Determination of degrees turn to obtain a clamping force of $173 \mathrm{kN}$ from hand tightened position using Skidmore device for regular A325 high strength bolt

\begin{tabular}{|c|c|c|c|c|}
\hline \multirow{2}{*}{ Test description } & Bolt number & $\begin{array}{c}\text { Bolt tension (using } \\
\text { Skidmore, lbf }\end{array}$ & $\begin{array}{c}\text { Degree } \\
\text { turns }\end{array}$ & $\begin{array}{c}\text { Average } \\
\text { degree } \\
\text { turn }\end{array}$ \\
\hline \multirow{2}{*}{$\begin{array}{c}\text { Determining the degree turn } \\
\text { resulting from the application } \\
\text { of } 173 \mathrm{kN} \text { from the hand } \\
\text { tightened position }\end{array}$} & 2 & 39,000 & $160^{\circ}$ & \\
\cline { 2 - 4 } & 3 & 39,000 & $130^{\circ}$ & \multirow{2}{*}{$152^{\circ}$} \\
\cline { 2 - 4 } & 5 & 39,000 & $160^{\circ}$ & \\
\cline { 2 - 4 } & & 39,000 & $170^{\circ}$ & \\
\hline
\end{tabular}

Table 7-3: Determination of degrees turn to obtain a clamping force of $173 \mathrm{kN}$ from hand tightened position using Skidmore device

\begin{tabular}{|c|c|c|c|c|}
\hline \multirow{2}{*}{ Test description } & Bolt number & $\begin{array}{c}\text { Bolt tension } \\
\text { (using } \\
\text { Skidmore), lbf }\end{array}$ & $\begin{array}{c}\text { Degree } \\
\text { turns }\end{array}$ & $\begin{array}{c}\text { Average } \\
\text { degree } \\
\text { turn }\end{array}$ \\
\hline $\begin{array}{c}\text { Determining the degree turn } \\
\text { resulting from the }\end{array}$ & 1 & 39,000 & $100^{\circ}$ & \\
\cline { 2 - 4 } $\begin{array}{c}\text { application of } 173 \mathrm{kN} \text { from } \\
\text { the snug tightened position } \\
\text { of 500 }\end{array}$ & 3 & 39,000 & $90^{\circ}$ & \multirow{2}{*}{$101^{\circ}$} \\
\cline { 2 - 4 } & 4 & 39,000 & $110^{\mathbf{o}}$ & \\
\cline { 2 - 4 } & 5 & 39,000 & $100^{\circ}$ & \\
\hline
\end{tabular}


Table 7-4: Determination of clamping force for a degrees turn of $120^{\circ}$ from snug tightened position using Skidmore device for regular A325 high strength bolt

\begin{tabular}{|c|c|c|c|c|c|}
\hline \multirow{2}{*}{ Test description } & $\begin{array}{c}\text { Bolt } \\
\text { number }\end{array}$ & $\begin{array}{c}\text { Bolt tension (using } \\
\text { Skidmore), lbf }\end{array}$ & $\begin{array}{c}\text { Degree } \\
\text { turns }\end{array}$ & $\begin{array}{c}\text { Average } \\
\text { Skidmore } \\
\text { value (lbf) }\end{array}$ & $\begin{array}{c}\text { Average } \\
\text { Skidmore } \\
\text { value (kN) }\end{array}$ \\
\hline \multirow{2}{*}{\begin{tabular}{c} 
Determining the Skidmore \\
value for 1/3 of a turn from \\
the snug tightened position \\
\cline { 2 - 4 } of $50^{\circ}$
\end{tabular}} & 1 & 45,500 & $120^{\circ}$ & & \\
\cline { 2 - 4 } & 4 & 46,500 & $120^{\circ}$ & \multirow{2}{*}{403,284} \\
\cline { 2 - 4 } & 5 & 46,000 & $120^{\circ}$ & \\
\cline { 2 - 4 } & & 44,500 & $120^{\circ}$ & \\
\hline
\end{tabular}

For the A325 Galvanized high-strength bolt, another degrees turn was determined due to the fact that this bolt had a galvanized coating on the threading which tends to offer resistance to the application of a clamping force. Table 7-5 presents the results of the 5 bolt samples tested to determine the degrees turn for A325 galvanized bolt. An average degrees turn of $110^{\circ}$ from the snug-tightened position was observed. Results from 5 galvanized bolt samples tested at $120^{\circ}$ turn were presented in Table 7-6and show an average clamping force of $187 \mathrm{kN}$ when using this galvanized bolt. This showed that when using regular A325 high-strength bolt and galvanized A325 high-strength bolt, two different clamping forces have to be used to determine the slipcoefficient, both at the minimum clamping force of $173 \mathrm{kN}$ and at one third of a turn $\left(120^{\circ}\right)$.

Table 7-5: Determination of degrees turn to obtain a clamping force of $173 \mathrm{kN}$ from handtightened position using Skidmore device for A325 galvanized bolt

\begin{tabular}{|c|c|c|c|c|}
\hline \multirow{2}{*}{ Test description } & Bolt number & $\begin{array}{c}\text { Bolt tension } \\
\text { (using } \\
\text { Skidmore), lbf }\end{array}$ & $\begin{array}{c}\text { Degree } \\
\text { turns }\end{array}$ & $\begin{array}{c}\text { Average } \\
\text { degree } \\
\text { turn }\end{array}$ \\
\hline \multirow{3}{*}{$\begin{array}{c}\text { Determining how much degree turn is } \\
173 \mathrm{kN} \text { from the snug tightened } \\
\text { position of 50 }\end{array}$} & 1 & 39,000 & $110^{\circ}$ & \\
\cline { 2 - 4 } & 3 & 39,000 & $100^{\circ}$ & \multirow{2}{*}{$110^{\circ}$} \\
\cline { 2 - 4 } & 4 & 39,000 & $110^{\circ}$ & $110^{\circ}$ \\
\cline { 2 - 4 } & 5 & 39,000 & $120^{\circ}$ & \\
\hline
\end{tabular}


Table 7-6: Determination of clamping force for a degrees turn of $120^{0}$ from snug tightened position using Skidmore device for galvanized A325 bolt

\begin{tabular}{|c|c|c|c|c|c|}
\hline \multirow{2}{*}{ Test description } & $\begin{array}{c}\text { Bolt } \\
\text { number }\end{array}$ & $\begin{array}{c}\text { Bolt tension } \\
\text { (using } \\
\text { Skidmore), } \\
\text { lbf }\end{array}$ & $\begin{array}{c}\text { Degree } \\
\text { turns }\end{array}$ & $\begin{array}{c}\text { Average } \\
\text { Skidmore } \\
\text { value } \\
\text { (lbf) }\end{array}$ & $\begin{array}{c}\text { Average } \\
\text { Skidmore } \\
\text { value (N) }\end{array}$ \\
\hline \multirow{3}{*}{$\begin{array}{c}\text { Determining the Skidmore value } \\
\text { for } 1 / 3 \text { of a turn from the snug } \\
\text { tightened position of } 50^{\circ}\end{array}$} & 1 & 40,000 & 120 & & \\
\cline { 2 - 4 } & 2 & 42,000 & 120 & \multirow{2}{*}{42,200} & 187,715 \\
\cline { 2 - 5 } & 4 & 43,000 & 120 & & \\
\cline { 2 - 5 } & 5 & 42,000 & 120 & 120 & \\
\hline
\end{tabular}

\subsection{Slip Resistance Coefficient at 173 kN Clamping Force}

For this phase of the testing program, 3 identical specimens were tested for each surface condition, and in some cases, 4 identical specimens were used, bringing the total number of specimens tested to 26 for each of the two clamping forces used. Each tested specimen was allowed to relax after the application of the clamping force for a period of 72 hours. During this time, bolt relaxation was monitored through recording the change in length over time (discussed further in Chapter 6). According to Yang et al. (2000), the design of slip-critical high-strength bolted connections to transfer service shear loads through the process of friction is developed between the contact surfaces of the joint plate material through the action of the clamping bolts. In similar research conducted by Yura et al. (1981), the slip resistance coefficient for an individual test specimen is calculated from the equation below:

Slip Resistance Coefficient $(\mathrm{Ks})=\frac{\operatorname{slip} \text { load }(k N)}{2 x \text { clamping force }(k N)}$

Yura et al. (1981) used 3 different types of curves as shown in

Figure 7-1 to evaluate the slip load behaviour of a high strength friction-type bolted connection subjected to slip. Three types of curves are usually observed and the slip load associated with each type is defined as follows:

Curve (a): slip load is the maximum load, provided it occurs before a slip of $0.5 \mathrm{~mm}(0.02 \mathrm{inch})$ is recorded;

Curve (b): slip load is the load at which the slip rate increases suddenly; and

Curve (c): slip load is the load corresponding to a deformation of $0.5 \mathrm{~mm}(0.02 \mathrm{inch})$. 


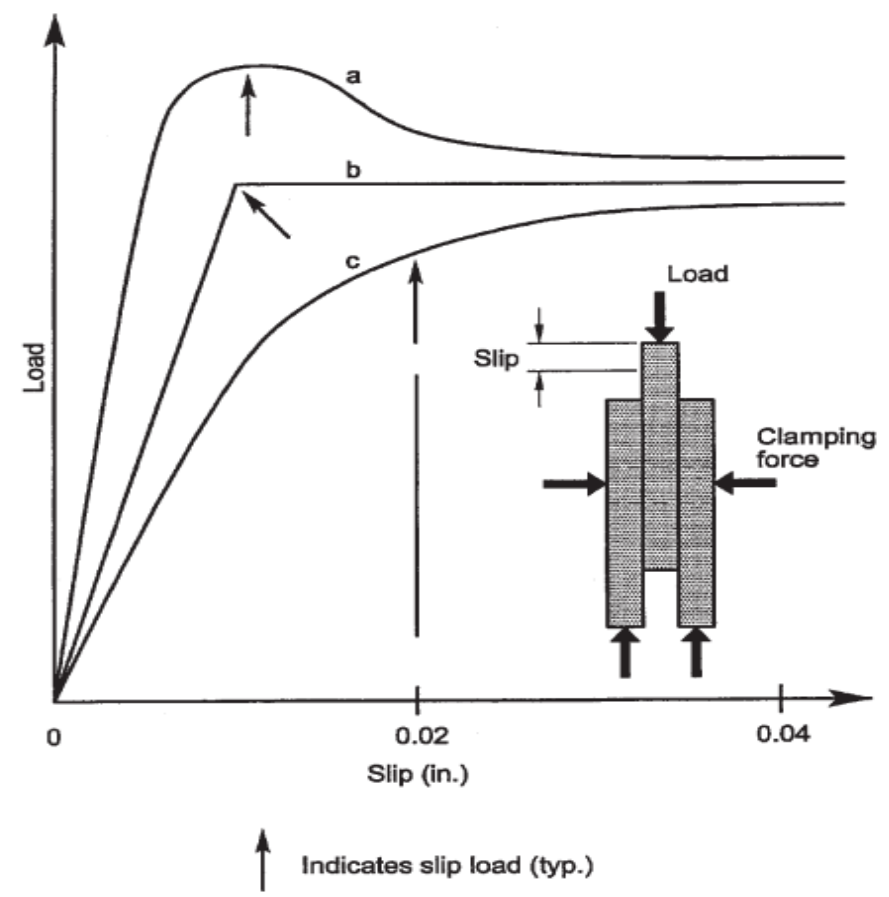

Figure 7-1: Slip-load definition curves (Yura et al. 1981)

By referencing these curves throughout this research, the slip load was determined at a displacement of $0.5 \mathrm{~mm}(0.02 \mathrm{inch})$ irrespective of the graph shape. The primary objective of this research was to assess the behaviour of A1010 stainless steel under slip-critical testing and to determine the slip coefficient for the material at room temperature, with different surface treatments and then compare the results with similar testing done on $350 \mathrm{~W}$ structural steel material of similar surface treatment. The primary technique of applying the clamping force to the test specimens was the turn-of-the-nut method. As such two different clamping forces were used throughout this research $(173 \mathrm{kN}$ and $203 \mathrm{kN})$. With the $173 \mathrm{kN}$ being the minimum clamping force as recommended elsewhere (RCSC, 2000; Yura et al., 1981). The clamping force of $203 \mathrm{kN}$ related to the derived clamping force was determined by this research using the turn-of-the-nut method for A325 high-strength bolt and the Wilhelm Skidmore bolt tensioning device.

A sample graph of the results for the various material and surface treatment for the two clamping forces are shown below in Figure 7-2 through Figure 7-7 (with the rest of the test result graphs shown in appendix C) for the $173 \mathrm{kN}$ clamping force and Figure 7-8 through Figure 7-13 (with 
rest of the test result graphs shown in appendix D) for $203 \mathrm{kN}$ clamping force. A summary of the mean slip load and slip coefficient (as calculated from equation 7-1) is presented in the accompanying tables, Table 7-7 through Table 7-12 for the $173 \mathrm{kN}$ clamping force and Table 7-13 through Table 7-18 for the $203 \mathrm{kN}$, for the various material surface treatment. From analysis of the slip critical testing at $173 \mathrm{kN}$ clamping force, the mean slip load and slip coefficient for the 350W structural steel with (a) clean mill scale, (b) blasted clean, and (c) hot-dip galvanized show a mean slip load ranging from $53.44 \mathrm{kN}$ for clean mill scale surface condition to $79.8 \mathrm{kN}$ for blasted-clean surface condition and mean slip coefficient ranging between 0.152 for clean mill scale surface condition to 0.196 for blast-cleaned surface condition. For A1010 stainless steel slip critical testing, results show that A1010 steel has a similar slip resistance performance at the clamping force of $173 \mathrm{kN}$ when compared to the $350 \mathrm{~W}$ structural steel material, with mean slip loads ranging from $58.8 \mathrm{kN}$ for clean mill scale surface condition to $78.2 \mathrm{kN}$ for blasted clean surface condition.

In the present research, these results are close in value to similar research findings found in the literature (Fisher et al. 2000; Yura et al., 1981 and Yang et al., 2000). Yang et al. reported mean slip coefficient for standard size hole ranging from 0.34 to 0.53 at a clamping from of $173.5 \mathrm{kN}$. By mere surface examination, the results of slip coefficient reached in the current research would seem to be low, however, it was not clear whether Yang et al. tested the specimens immediately after the application of the clamping force or after relaxation of the specimens occurred. Also they utilize the most accurate method of obtaining and minimizing variation in the clamping force, which is strain gauge bolts. Other research conducted by Yura et al. (1981) reported mean slip coefficient (for similar specimen set up and test method), ranging from 0.18 to 0.19 for clean mill scale surface condition and from $0.75 \mathrm{~mm}$ to $0.77 \mathrm{~mm}$ for blast-clean surface condition. In light of their results, the result obtained in the current research for $350 \mathrm{~W}$ structural steel and A1010 stainless steel clean mill scale surface condition in on par with their study. However, for the blastcleaned surface condition for both $350 \mathrm{~W}$ structural steel and A1010 stainless steel, the slip coefficient was lower than those obtained in their study. This research concludes that the low values for slip coefficient could be due in part to the slight variation in the testing approaches utilized between the two researches. In that, the research conducted by Yura et al. in 1981 did not report measurement values for their surface roughness condition as well as the fact that their specimens where left exposed to the environment. However the specimens in the current research 
were tested shortly after blast-cleaning was done. This could be a contributing factor for the difference in mean slip coefficient. Also, Yura et al. did not indicate the time period between application of the clamping force and start of testing of the specimen. According to research by others (Fisher et al., 2000; Yang et al. 2000), this will have a direct impact on the level of slip load recorded and in turn the slip coefficient calculated.

When the turn-of-nut bolt pre-tensioning method was used to apply the clamping force in this research, it showed that the mean slip load for different surface conditions ranged from $63.276 \mathrm{kN}$ for a clean mill scale surface to $82.1 \mathrm{kN}$ for blast-cleaned surface condition. Once again these results were on the lower side of slip coefficient when compared to those in similar research. However, this research conclude that the various factors outlined above also had an impact on the values received. Similarly, when A1010 stainless steel results were compared to 350W structural steel results, they showed slightly improved slip resistance performance, with values for mean slip load ranging from $77.5 \mathrm{kN}$ for blast-cleaned surface to $60.5 \mathrm{kN}$ for clean mill scale. It was noticed that in this research for the A1010 stainless steel material for both clamping force used, the mean slip load and slip coefficient for the clean mill scale surface condition was lower than those of blast-clean surface condition, which is a similar result pattern obtained for the $350 \mathrm{~W}$ structural steel (for both clamping force).

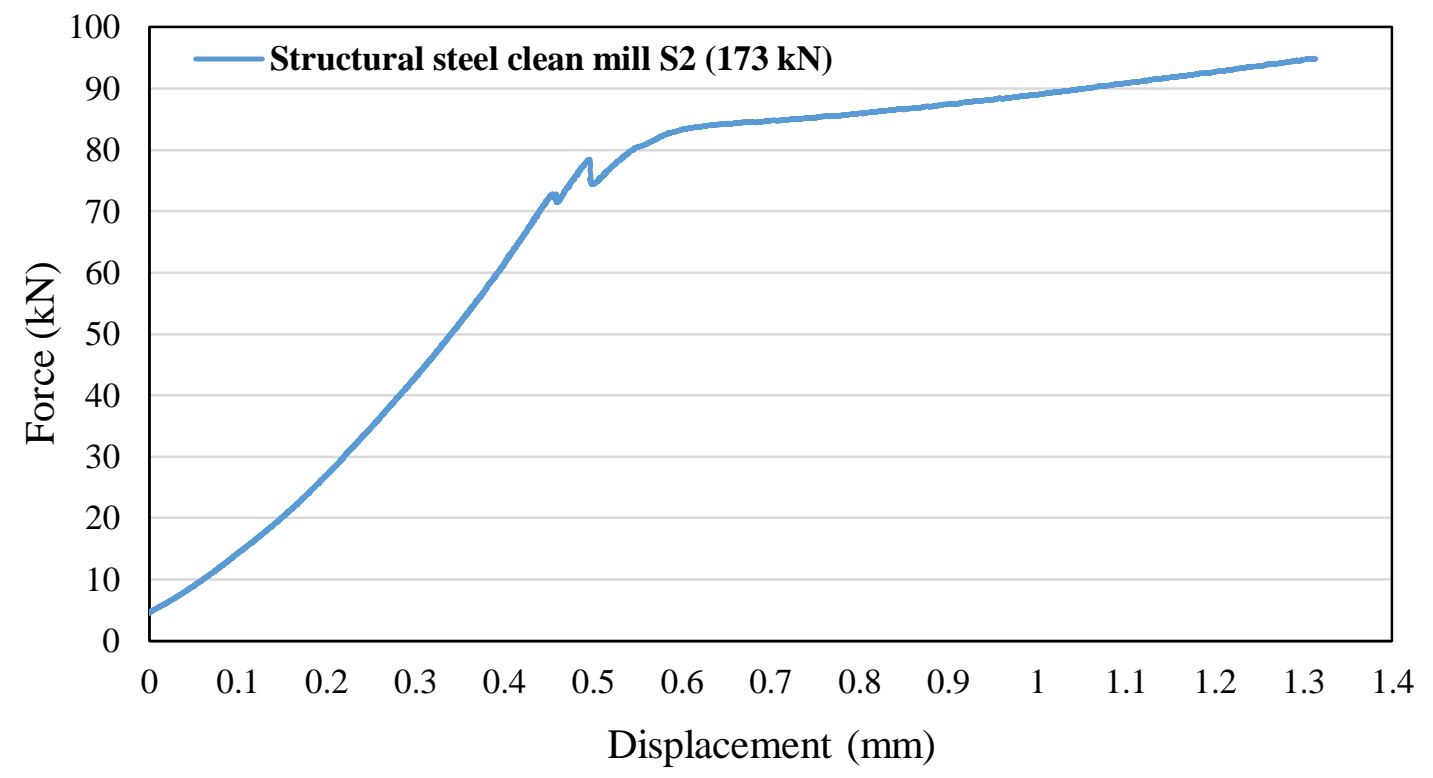

Figure 7-2: Force-displacement relationship for $350 \mathrm{~W}$ structural steel clean mill scale surface condition for test specimen 2 with A325 bolt 
Table 7-7: Results of values of slip load and slip coefficient for the three specimen tested along with mean value

\begin{tabular}{|c|c|c|c|c|}
\cline { 2 - 5 } \multicolumn{1}{c|}{} & $\begin{array}{c}\text { Specimen 1 } \\
\text { result }\end{array}$ & $\begin{array}{c}\text { Specimen 2 } \\
\text { result }\end{array}$ & $\begin{array}{c}\text { Specimen 3 } \\
\text { result }\end{array}$ & Mean \\
\hline Slip load $(\mathrm{N})$ & 45,470 & 75,000 & 39,858 & $\mathbf{5 3 , 4 4 2 . 6 7}$ \\
\hline $\begin{array}{c}\text { Slip coefficient } \\
\left(\mathrm{k}_{\mathrm{s}}\right)\end{array}$ & 0.131 & 0.216 & 0.115 & $\mathbf{0 . 1 5 4}$ \\
\hline
\end{tabular}

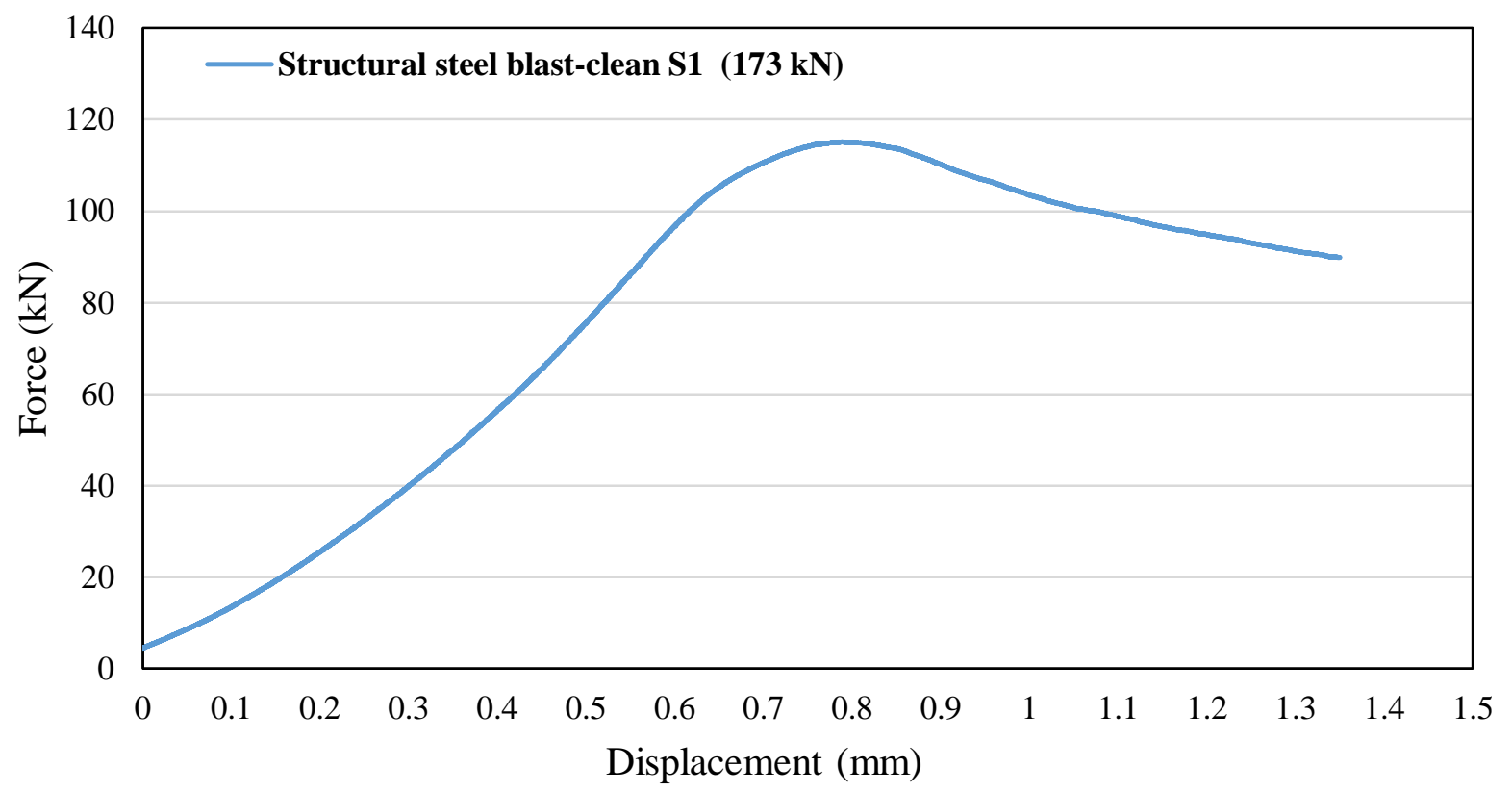

Figure 7-3: Force-displacement relationship for $350 \mathrm{~W}$ structural steel blast-clean surface condition for test specimen 1 with A325 bolt

Table 7-8: Results of values of slip load slip coefficient for the three specimen tested along with mean values

\begin{tabular}{|c|c|c|c|c|c|}
\cline { 2 - 6 } \multicolumn{1}{c|}{} & $\begin{array}{c}\text { Specimen 1 } \\
\text { result }\end{array}$ & $\begin{array}{c}\text { Specimen 2 } \\
\text { result }\end{array}$ & $\begin{array}{c}\text { Specimen 3 } \\
\text { result }\end{array}$ & $\begin{array}{c}\text { Specimen 4 } \\
\text { result }\end{array}$ & Mean \\
\hline Slip load $(\mathrm{N})$ & $75,424.03$ & $79,219.18$ & $83,785.77$ & $79,800.48$ & $\mathbf{7 9 , 5 5 7 . 3 7}$ \\
\hline $\begin{array}{c}\text { Slip coefficient } \\
\left(\mathrm{k}_{\mathrm{s}}\right)\end{array}$ & $0 . .217$ & 0.230 & 0.241 & 0.230 & $\mathbf{0 . 2 3 0}$ \\
\hline
\end{tabular}




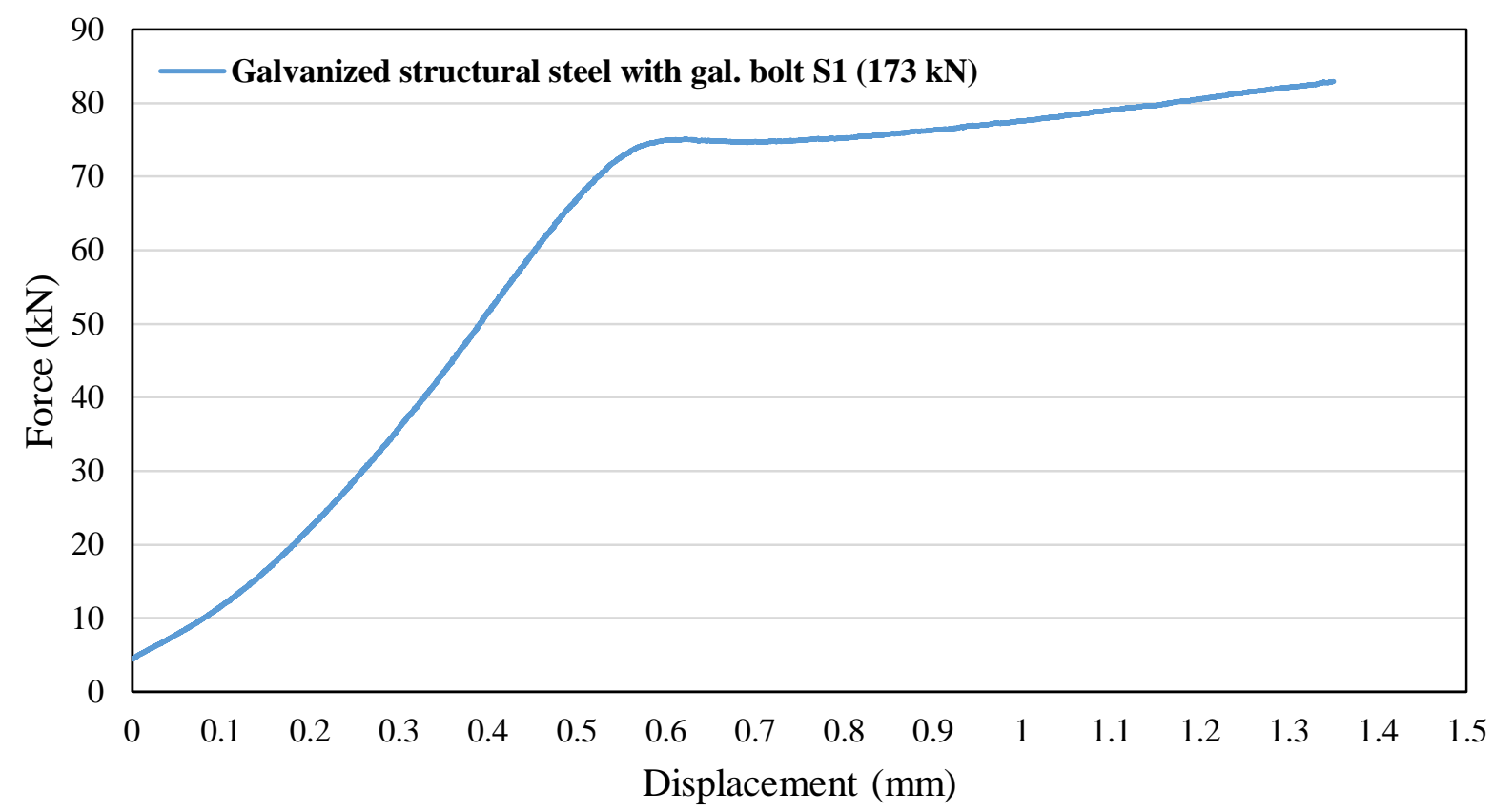

Figure 7-4: Force-displacement relationship for 350W structural steel with hot dip galvanized surface condition for test specimen 1 with galvanized bolt

Table 7-9: Results of values of slip load and slip coefficient for the three specimen tested along with mean values

\begin{tabular}{|c|c|c|c|c|c|}
\cline { 2 - 6 } \multicolumn{1}{c|}{} & $\begin{array}{c}\text { Specimen } \\
\text { 1 result }\end{array}$ & $\begin{array}{c}\text { Specimen 2 } \\
\text { result }\end{array}$ & $\begin{array}{c}\text { Specimen 3 } \\
\text { result }\end{array}$ & $\begin{array}{c}\text { Specimen 4 } \\
\text { result }\end{array}$ & Mean \\
\hline Slip load (N) & $67,008.0$ & $53,776.2$ & $69,733.6$ & $62,148.0$ & $\mathbf{6 3 1 6 6 . 4}$ \\
\hline $\begin{array}{c}\text { Slip coefficient } \\
\text { (ks) }\end{array}$ & 0.193 & 0.155 & 0.200 & 0.179 & $\mathbf{0 . 1 8 2}$ \\
\hline
\end{tabular}




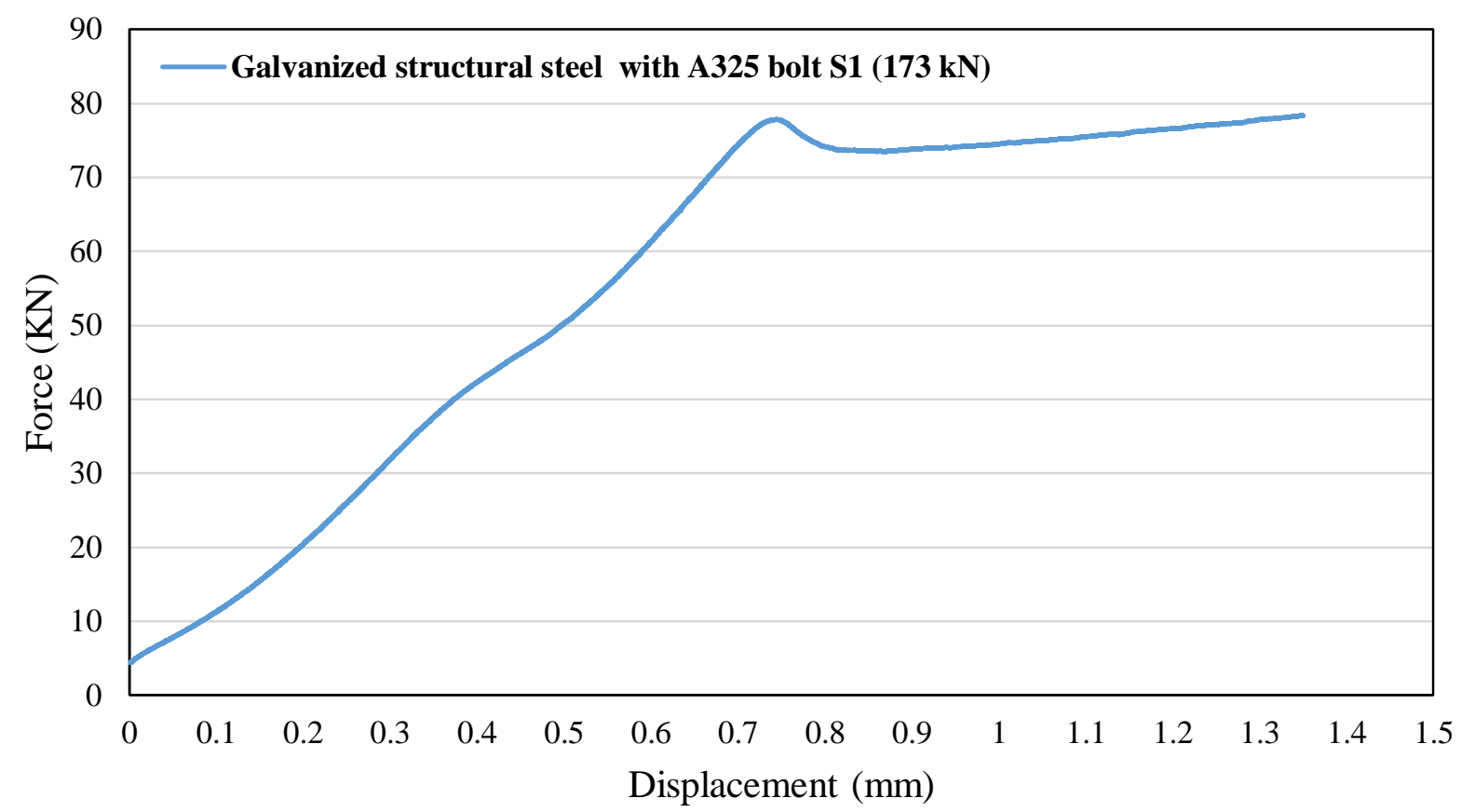

Figure 7-5: Force-displacement relationship for $350 \mathrm{~W}$ structural steel with hot dip galvanized surface condition for test specimen 1 with A325 bolt

Table 7-10: Results of values of slip load and slip coefficient for the three specimen tested along with mean values

\begin{tabular}{|c|c|c|c|c|c|}
\cline { 2 - 6 } \multicolumn{1}{c|}{} & $\begin{array}{c}\text { Specimen 1 } \\
\text { result }\end{array}$ & $\begin{array}{c}\text { Specimen 2 } \\
\text { result }\end{array}$ & $\begin{array}{c}\text { Specimen 3 } \\
\text { result }\end{array}$ & $\begin{array}{c}\text { Specimen 4 } \\
\text { result }\end{array}$ & Mean \\
\hline Slip load (N) & $50,321.8$ & $68,074.5$ & $70,841.5$ & 68,062 & $\mathbf{6 4 , 3 2 4 . 9 3}$ \\
\hline $\begin{array}{c}\text { Slip coefficient } \\
\left(\mathrm{k}_{\mathrm{s}}\right)\end{array}$ & 0.145 & 0.196 & 0.204 & 0.196 & $\mathbf{0 . 1 8 5}$ \\
\hline
\end{tabular}




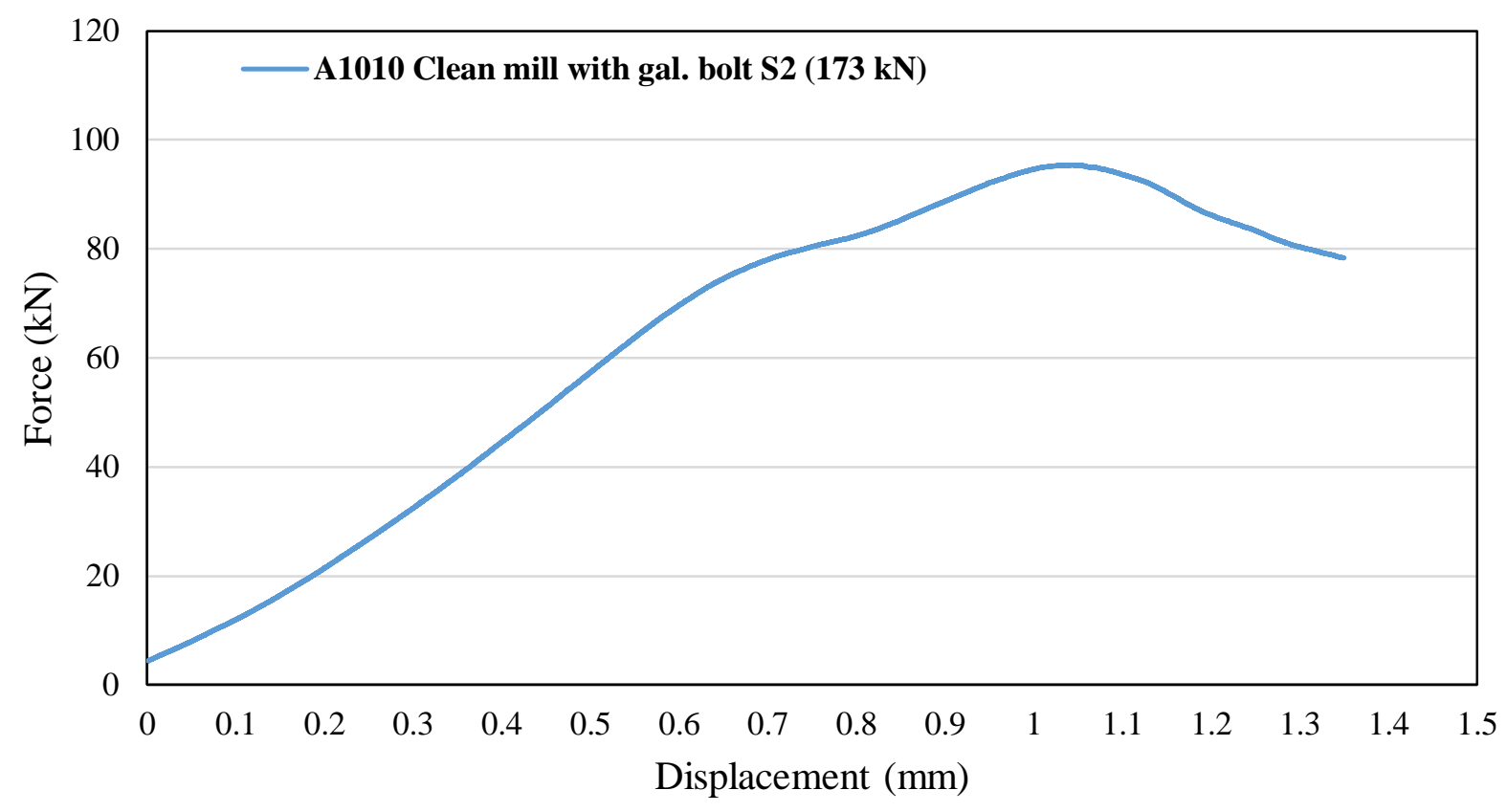

Figure 7-6: Force-displacement relationship for A1010 stainless steel with clean mill scale surface condition for test specimen 2 with galvanized bolt

Table 7-11: Results of values of slip load and slip coefficient for the three specimen tested along with mean values

\begin{tabular}{|c|c|c|c|c|c|}
\cline { 2 - 6 } \multicolumn{1}{c|}{} & $\begin{array}{c}\text { Specimen 1 } \\
\text { result }\end{array}$ & $\begin{array}{c}\text { Specimen 2 } \\
\text { result }\end{array}$ & $\begin{array}{c}\text { Specimen 3 } \\
\text { result }\end{array}$ & $\begin{array}{c}\text { Specimen 4 } \\
\text { result }\end{array}$ & Mean \\
\hline Slip load $(\mathrm{N})$ & $57,636.75$ & $57,315.79$ & $57,308.33$ & $62,831.44$ & $\mathbf{5 8 , 7 7 3 . 0 8}$ \\
\hline Slip coefficient $\left(\mathrm{k}_{\mathrm{s}}\right)$ & 0.166 & 0.165 & 0.165 & 0.181 & $\mathbf{0 . 1 6 9}$ \\
\hline
\end{tabular}




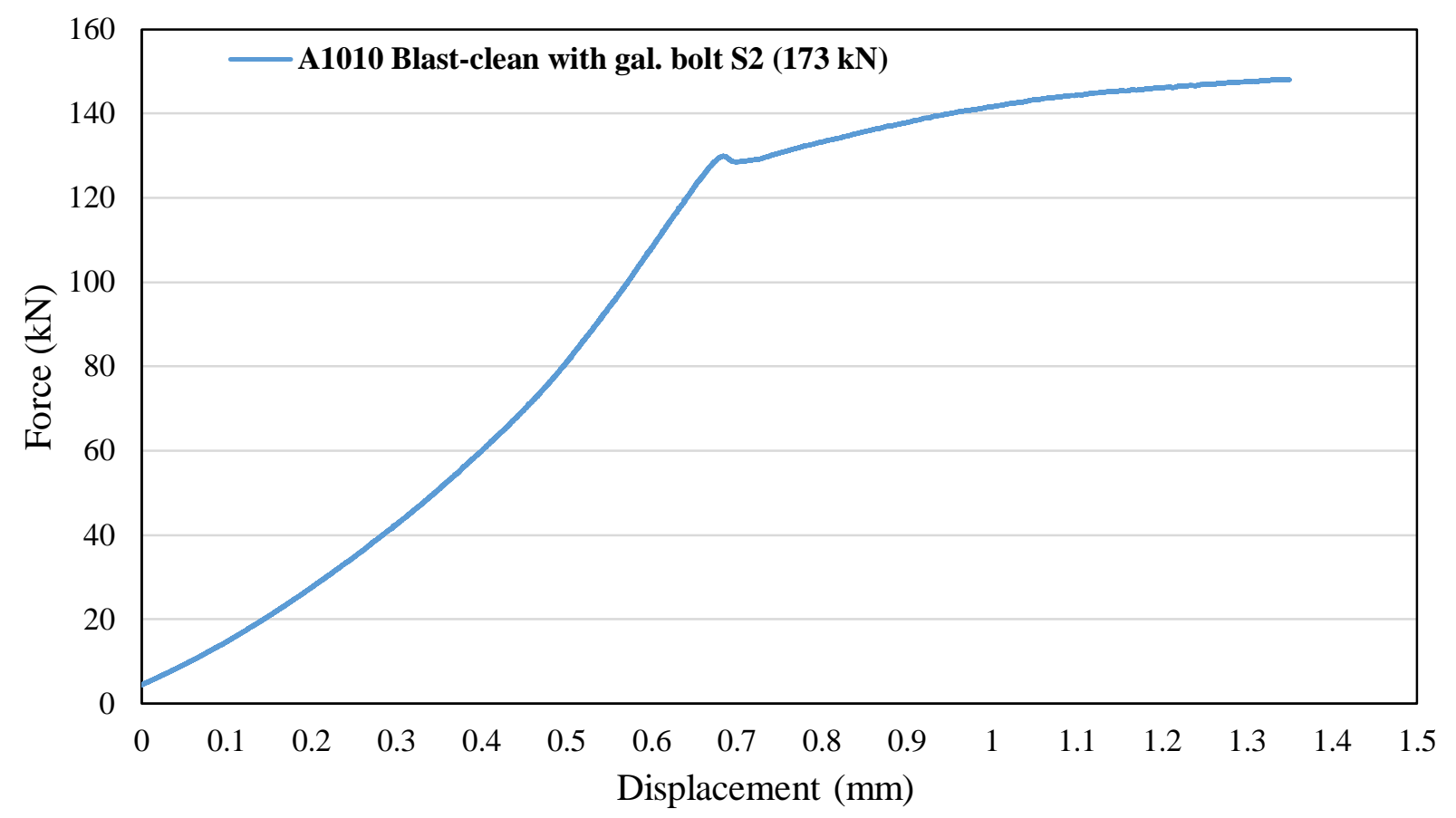

Figure 7-7: Force-displacement relationship for A1010 stainless steel with blast-clean surface condition for test specimen 2 with galvanized bolt

Table 7-12: Results of values of slip load and slip coefficient for the three specimen tested along with mean values

\begin{tabular}{|c|c|c|c|c|c|}
\cline { 2 - 6 } \multicolumn{1}{c|}{} & $\begin{array}{c}\text { Specimen 1 } \\
\text { result }\end{array}$ & $\begin{array}{c}\text { Specimen 2 } \\
\text { result }\end{array}$ & $\begin{array}{c}\text { Specimen 3 } \\
\text { result }\end{array}$ & $\begin{array}{c}\text { Specimen 4 } \\
\text { result }\end{array}$ & Mean \\
\hline Slip load $(\mathrm{N})$ & $75,518.58$ & $80,870.58$ & $77,177.39$ & $79,127.65$ & $\mathbf{7 8 , 1 7 3 . 5 5}$ \\
\hline Slip coefficient $\left(\mathrm{k}_{\mathrm{s}}\right)$ & 0.218 & 0.233 & 0.222 & 0.228 & $\mathbf{0 . 2 2 5}$ \\
\hline
\end{tabular}




\subsection{Slip Resistance Coefficient at $203 \mathrm{kN}$ clamping force}

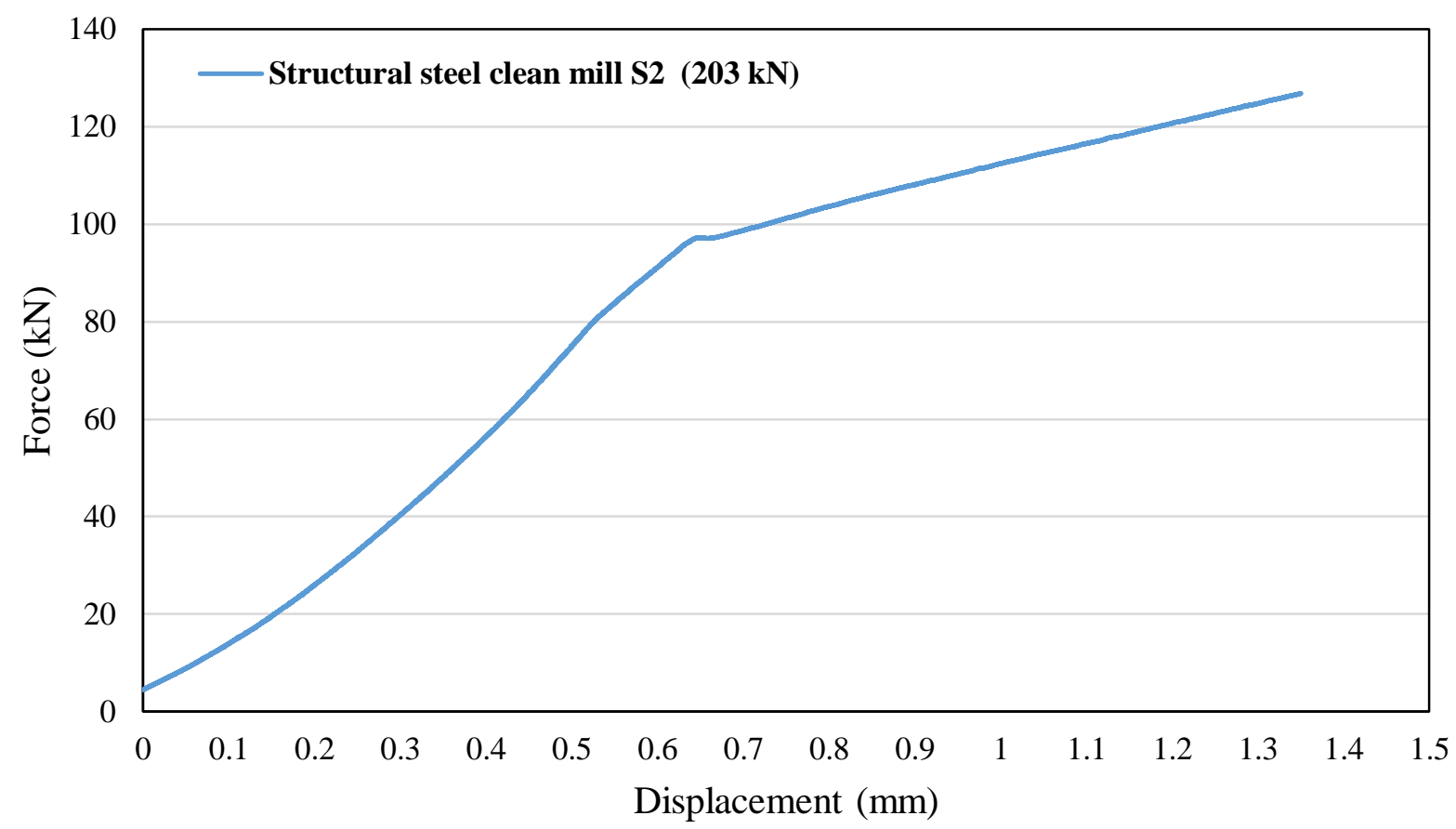

Figure 7-8: Force-displacement relationship for $350 \mathrm{~W}$ structural steel with clean mill scale surface condition for test specimen 2 with A325 bolt

Table 7-13: Results of values of slip load and slip coefficient for the three specimen tested along with mean values

\begin{tabular}{|c|c|c|c|c|c|}
\cline { 2 - 6 } \multicolumn{1}{c|}{} & $\begin{array}{c}\text { Specimen 1 } \\
\text { result }\end{array}$ & $\begin{array}{c}\text { Specimen 2 } \\
\text { result }\end{array}$ & $\begin{array}{c}\text { Specimen 3 } \\
\text { result }\end{array}$ & $\begin{array}{c}\text { Specimen 4 } \\
\text { result }\end{array}$ & Mean \\
\hline Slip load (N) & $56,080.46$ & $74,957.85$ & $77,941.25$ & $44,124.7$ & $\mathbf{6 3 , 2 7 6 . 0 7}$ \\
\hline $\begin{array}{c}\text { Slip coefficient } \\
\left(\mathrm{k}_{\mathrm{s}}\right)\end{array}$ & 0.138 & 0.185 & 0.192 & 0.109 & $\mathbf{0 . 1 5 6}$ \\
\hline
\end{tabular}




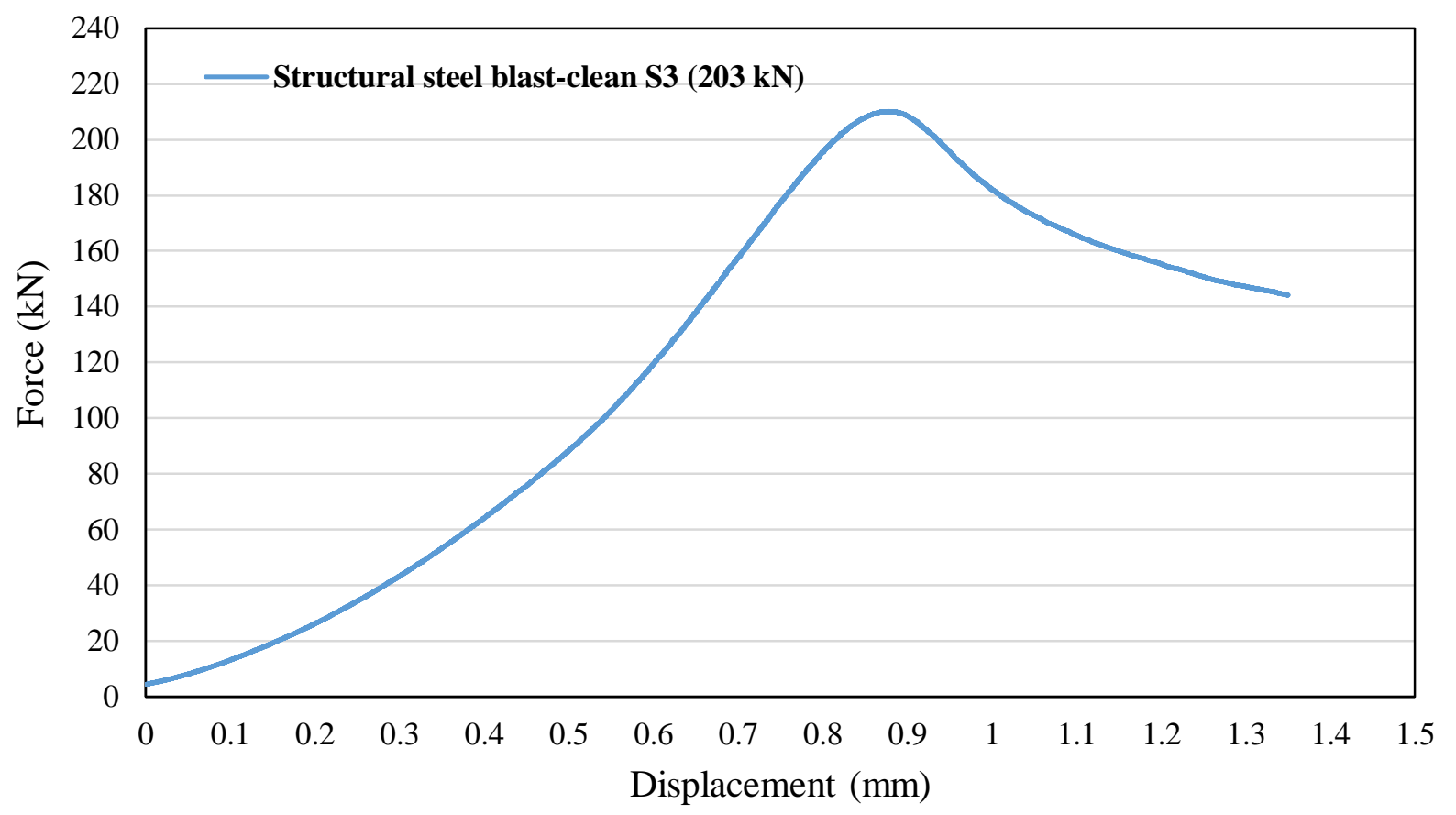

Figure 7-9: Force-displacement relationship for 350W structural steel with blast-clean surface condition for test specimen 3 with $\mathbf{A 3 2 5}$ bolt

Table 7-14: Results of values of slip load and slip coefficient for the three specimen tested along with mean values

\begin{tabular}{|l|c|c|c|c|}
\cline { 2 - 5 } \multicolumn{1}{c|}{} & $\begin{array}{c}\text { Specimen 1 } \\
\text { result }\end{array}$ & $\begin{array}{c}\text { Specimen 2 } \\
\text { result }\end{array}$ & $\begin{array}{c}\text { Specimen 3 } \\
\text { result }\end{array}$ & Mean \\
\hline Slip load (N) & $95,019.0$ & $62,668.0$ & $88,546.0$ & $\mathbf{8 2 , 0 7 7 . 6 7}$ \\
\hline Slip coefficient (ks) & 0.234 & 0.154 & 0.218 & $\mathbf{0 . 2 0 2}$ \\
\hline
\end{tabular}




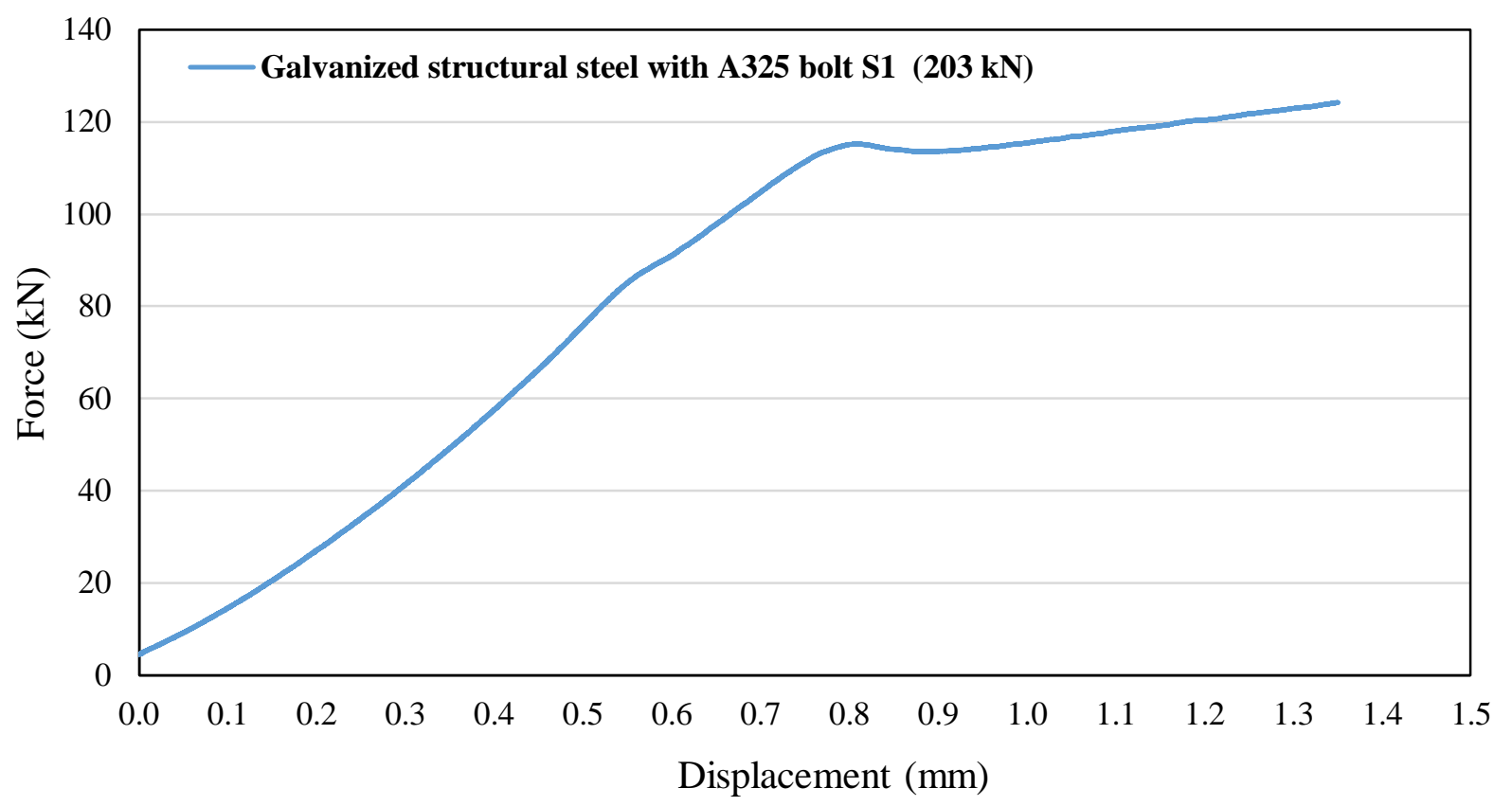

Figure 7-10: Force-displacement relationship for 350W structural steel with hot hip galvanized surface condition for test specimen 1 with $\mathrm{A325}$ bolt

Table 7-15: Results of values of slip load and slip coefficient for the three specimen tested along with mean values

\begin{tabular}{|c|c|c|c|c|}
\cline { 2 - 5 } \multicolumn{1}{c|}{} & $\begin{array}{c}\text { Specimen 1 } \\
\text { result }\end{array}$ & $\begin{array}{c}\text { Specimen 2 } \\
\text { result }\end{array}$ & $\begin{array}{c}\text { Specimen 3 } \\
\text { result }\end{array}$ & Mean \\
\hline Slip load $(\mathrm{N})$ & $75,655.05$ & $79,561.28$ & $73,883.3$ & $\mathbf{7 6 , 3 6 6 . 5 4}$ \\
\hline $\begin{array}{c}\text { Slip coefficient } \\
\left(\mathrm{k}_{\mathrm{s}}\right)\end{array}$ & 0.186 & 0.196 & 0.182 & $\mathbf{0 . 1 8 8}$ \\
\hline
\end{tabular}




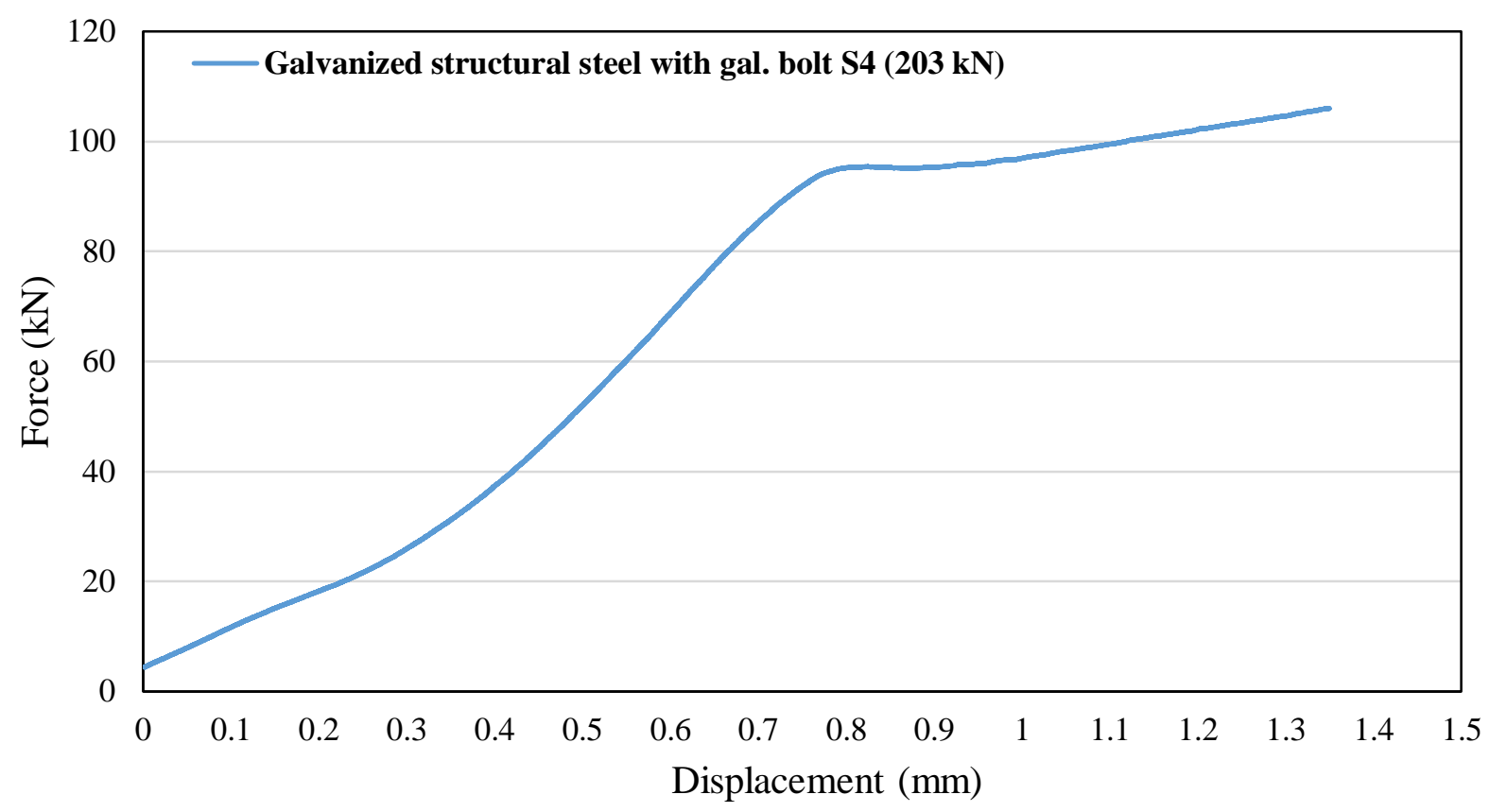

Figure 7-11: Force-displacement relationship for 350W structural steel with hot dip galvanized surface condition for test specimen 3 with galvanized bolt

Table 7-16: Results of values of slip load and slip coefficient for the three specimen tested along with mean values

\begin{tabular}{|c|c|c|c|c|c|}
\cline { 2 - 6 } \multicolumn{1}{c|}{} & $\begin{array}{c}\text { Specimen 1 } \\
\text { result }\end{array}$ & $\begin{array}{c}\text { Specimen 2 } \\
\text { result }\end{array}$ & $\begin{array}{c}\text { Specimen 3 } \\
\text { result }\end{array}$ & $\begin{array}{c}\text { Specimen 4 } \\
\text { result }\end{array}$ & Mean \\
\hline Slip load (N) & $74,379.88$ & $73,197.63$ & $73,593.58$ & $51,937.9$ & $\mathbf{6 8 , 2 7 7 . 2 5}$ \\
\hline $\begin{array}{c}\text { Slip coefficient } \\
\left(\mathrm{k}_{\mathrm{s}}\right)\end{array}$ & 0.198 & 0.195 & 0.196 & 0.138 & $\mathbf{0 . 1 8 2}$ \\
\hline
\end{tabular}




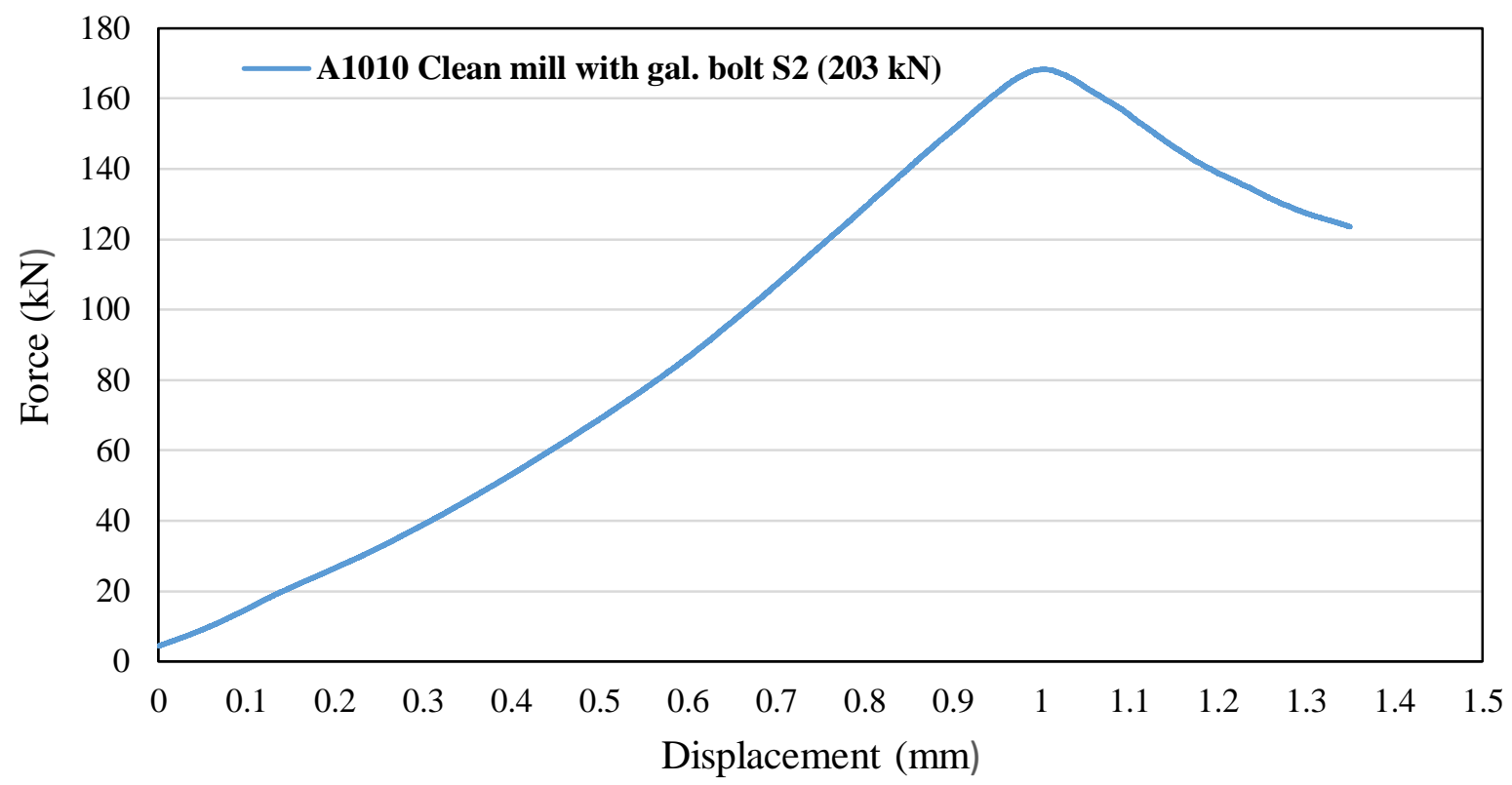

Figure 7-12: Force-displacement relationship for A1010 stainless steel with clean mill scale surface condition for test specimen 2 with galvanized bolt

Table 7-17: Results of values of slip load slip coefficient for the three specimen tested along with mean values

\begin{tabular}{|c|c|c|c|c|c|}
\cline { 2 - 6 } \multicolumn{1}{c|}{} & $\begin{array}{c}\text { Specimen 1 } \\
\text { result }\end{array}$ & $\begin{array}{c}\text { Specimen 2 } \\
\text { result }\end{array}$ & $\begin{array}{c}\text { Specimen 3 } \\
\text { result }\end{array}$ & $\begin{array}{c}\text { Specimen 4 } \\
\text { result }\end{array}$ & Mean \\
\hline Slip load $(\mathrm{N})$ & $59,056.9$ & $68,976.9$ & $55,109.6$ & $58,902.7$ & $\mathbf{6 0 , 5 1 1 . 5 2}$ \\
\hline $\begin{array}{c}\text { Slip coefficient } \\
\left(\mathrm{k}_{\mathrm{s}}\right)\end{array}$ & 0.157 & 0.184 & 0.147 & 0.157 & $\mathbf{0 . 1 6 1}$ \\
\hline
\end{tabular}




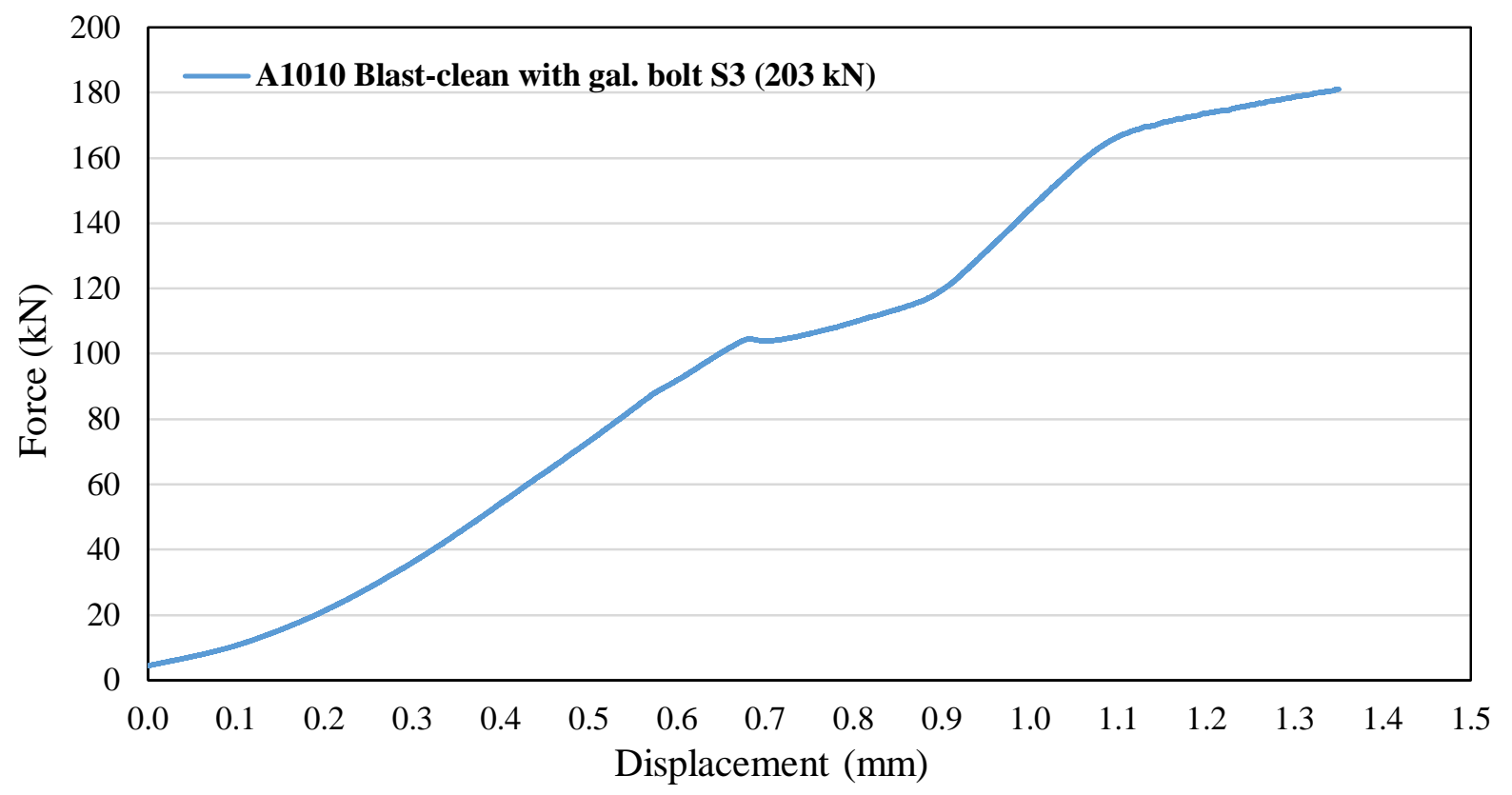

Figure 7-13: Force-displacement relationship for A1010 stainless steel with blast-clean surface condition for test specimen 3 with galvanized bolt

Table 7-18: Results of values of slip load and slip coefficient for the three specimen tested along with mean values

\begin{tabular}{|c|c|c|c|c|c|}
\cline { 2 - 6 } \multicolumn{1}{c|}{} & $\begin{array}{c}\text { Specimen 1 } \\
\text { result }\end{array}$ & $\begin{array}{c}\text { Specimen 2 } \\
\text { result }\end{array}$ & $\begin{array}{c}\text { Specimen 3 } \\
\text { result }\end{array}$ & $\begin{array}{c}\text { Specimen 4 } \\
\text { result }\end{array}$ & Mean \\
\hline Slip load $(\mathrm{N})$ & $72,471.47$ & $84,977.83$ & $73,027.07$ & $79,638.47$ & $\mathbf{7 7 , 5 2 8 . 7 1}$ \\
\hline $\begin{array}{c}\text { Slip coefficient } \\
\left(\mathrm{k}_{\mathrm{s}}\right)\end{array}$ & 0.193 & 0.226 & 0.195 & 0.212 & $\mathbf{0 . 2 0 7}$ \\
\hline
\end{tabular}




\subsection{Observations of slip test result and comparison with similar research}

Results showed that slip coefficients obtained in this research were always lower than those in the Canadian codes and Standards (CISC, 2014; CSA, 2014) as well as in other literature. Upon careful examination of this comparison, the following observations were drawn:

1- Testing for the determination of slip coefficient in this research was done using actual conditions practiced within the steel industry. The bolt was first pre-tensioned to the target value, then the bolt-plate assembly was left $72 \mathrm{hrs}$ before conducting the slip-resistance test. Then, the test was conducted with the actual clamping force in the bolt during the test that included effect of bolt relaxation. However, the ASTM test method and the research conducted to reach the slip coefficient values specified in the CHBDC mandated maintaining the clamping force through testing with a hydraulic jack and a load cell. This condition of maintaining clamping force during the test with an accuracy of $\pm 1 \%$ as stated in the test method may not represent the actual condition in bolted connections. As, such further research may be conducted to determine the actual clamping force during the slip resistance test when (i) a hydraulic jack is used to maintain the clamping force within $\pm 1 \%$ accuracy and (ii) the bolt pretension simulates the actual condition in the joint by applying the clamping force before the test with no further adjustment during the test. In addition, previous research that led to code values for slip-resistance appears not to consider whether bolt relaxation will affect the intended pretension force and thus the associated slip-resistance coefficient.

2- The achieved level of surface roughness in this research was less than that specified by MTO ( 2 mils). However, due to the fact that there is no set surface roughness standard mentioned in the CHBDC or in any other literature, hence surface roughness level is left to the discretion of the researcher. This difference in surface roughness value would have a direct impact on the slip coefficient. As such, it is recommended that CSA-S6-14 and CSA-S16-14 specify the required surface roughness required to achieve the specified slip resistance factor specified in the code.

3- The method of blast-cleaning the surface was not mentioned in the code and thus research may be conducted by using different blasting process, which would give different surface roughness value. These methods are (i) sand-blasting with a specified sand particle size to reach the target surface roughness without smoothing the surface, (ii) shot-blasting with steel balls with specified diameters and (iii) grit blasting with irregular-shape aluminum oxide particles. 


\section{Chapter 8: EXPERIMENTAL RESULTS AND DISCUSSION FOR BOLT RELAXATION AT ROOM TEMPERATURE}

This chapter presents the results of bolt relaxation testing and the impact it may have on the initial clamping force at the time of slip-resistance testing. The results are presented in a Table 8-1 and Table 8-2 below, where a number of parameters are examined, namely: (i) the change in length over time; (ii) the percentage loss over time; (iii) the mean losses and (iv) the standard deviation of those losses.

Yang et al. (2000) conducted bolt relaxation and the impact on (i) bolt tension force and (ii) shear capacity. They monitored relaxation for a period of 42 days. The parameter that was evaluated based on their research was the change in force. However, for this research, bolt relaxation was monitored for a period of 72 hours. Fisher et al. (1974) indicated that $90 \%$ of the loss in clamping force due to relaxation occurred within the first week after assembling. They, however, did not indicate at what particular time within this first week that this $90 \%$ loss was achieved. Also, the parameter been monitored in this research was the change in length of the bolt from the untensioned stage to the 72-hour period.

\subsection{Bolt Relaxation at $173 \mathrm{kN}$ and $203 \mathrm{kN}$ Clamping Force}

A mean percentage loss of $6 \%$ was observed for the $350 \mathrm{~W}$ structural steel clean mill scale surface condition, after 36 hours and a mean percentage loss of $12 \%$ was observed after 72 hours, which had an initial clamping force of $173 \mathrm{kN}$. When a clamping force of $203 \mathrm{kN}$ was applied to a plate of the same surface condition, a mean percentage loss of $17 \%$ was observed after 36 hours and a mean percentage loss of $26 \%$ was observed after 72 hours. For the hot dip galvanized plates with galvanized high strength bolts and clamped with an initial force of $173 \mathrm{kN}$, a mean percentage loss of $6 \%$ was observed after 36 hours and a mean percentage loss of $24 \%$ observed after 72 hours. However, for hot-dip galvanized plates with regular A325 high-strength bolt and clamped with the same initial clamping force, a mean percentage loss of $22 \%$ and $37 \%$ was observed after 36 hours and 72 hours, respectively. On the other hand, smaller mean percentage loss was observed for both hot-dip galvanized plates with high strength galvanized bolt when an initial clamping force of 203 $\mathrm{kN}$ was applied to the plates. 
According to Fisher et al (1974), a minimum clamping force of $173 \mathrm{kN}$, applied using the normal bolt installation and tightening techniques, can produce a $13 \%$ higher initial bolt force. However, when analysing the mean percentage losses after 72 hours (at which the slip test was conducted in this research), one can observe a high loss in clamping force due to bolt relaxation. This may have a negative impact on the slip-critical joint developing the required clamping force and thus affecting the slip load value for the determination of slip coefficient. It was also observed that the amount of relaxation for all surface treatment at the two clamping forces increase significantly at 72 hours from the time of applying it to the bolt. This would justify the lower slip load and hence the lower slip resistance coefficient in this research compared to those specified in the code. 


\subsubsection{Bolt relaxation with initial clamping force of $173 \mathrm{kN}$}

Table 8-1: Bolt relaxation mean change in length and standard deviation after $72 \mathrm{hrs}$ for a clamping force of $173 \mathrm{kN}$

\begin{tabular}{|c|c|c|c|c|c|c|c|c|c|c|c|c|}
\hline $\begin{array}{c}\text { Samples } \\
\# \\
\end{array}$ & $\begin{array}{l}\text { Length } \\
\text { before pre } \\
\text { tension }\end{array}$ & $\begin{array}{c}\text { Length } \\
\text { immediately } \\
\text { after pre } \\
\text { tension }\end{array}$ & $\begin{array}{l}\text { Length } \\
\text { at } 36 \mathrm{hrs}\end{array}$ & $\begin{array}{c}\text { Length } \\
\text { after } 72 \text { hrs }\end{array}$ & $\begin{array}{c}\text { Change in } \\
\text { length } \\
\text { immediately } \\
\text { after } \\
\text { tensioning } \\
\end{array}$ & $\begin{array}{c}\text { Change in } \\
\text { length after } \\
36 \mathrm{hrs} \\
\end{array}$ & \begin{tabular}{|c|} 
Change in length \\
after $72 \mathrm{hrs}$
\end{tabular} & $\begin{array}{c}\text { Mean } \\
\text { Change in } \\
\text { length after } \\
72 \mathrm{hrs} \\
\end{array}$ & $\begin{array}{c}\% \text { Loss after } \\
36 \mathrm{hrs}\end{array}$ & \begin{tabular}{|c|} 
Mean \% \\
loss after \\
$36 \mathrm{hrs}$ \\
\end{tabular} & $\begin{array}{c}\% \text { Loss } \\
\text { after } 72 \mathrm{hrs}\end{array}$ & $\begin{array}{c}\text { Mean \% } \\
\text { loss after } \\
72 \text { hrs } \\
\end{array}$ \\
\hline 1 & 101.646 & 102.599 & 102.501 & 102.362 & 0.953 & 0.098 & 0.139 & \multirow{4}{*}{0.086} & 10.283 & \multirow{4}{*}{19.49} & \begin{tabular}{|l|}
14.586 \\
\end{tabular} & \multirow{4}{*}{24.53} \\
\hline 2 & 101.667 & 101.941 & 101.859 & 101.749 & 0.274 & 0.082 & 0.110 & & 29.927 & & 40.146 & \\
\hline 3 & 101.957 & 102.106 & 102.074 & 102.016 & 0.149 & 0.032 & 0.058 & & 21.477 & & 38.926 & \\
\hline 4 & 101.063 & 101.893 & 101.758 & 101.721 & 0.830 & 0.135 & 0.037 & & 16.265 & & 4.458 & \\
\hline 1 & 101.103 & 102.508 & 101.833 & 101.745 & 1.405 & 0.675 & 0.088 & \multirow{4}{*}{0.253} & 48.043 & \multirow{4}{*}{51.85} & 6.263 & \multirow{4}{*}{22.08} \\
\hline 2 & 101.673 & 102.358 & 101.823 & 101.698 & 0.685 & 0.535 & 0.125 & & 78.102 & & 18.248 & \\
\hline 3 & 101.020 & 102.504 & 102.407 & 101.815 & 1.484 & 0.097 & 0.592 & & 6.536 & & 39.892 & \\
\hline 4 & 101.717 & 102.591 & 101.938 & 101.729 & 0.874 & 0.653 & 0.209 & & 74.714 & & 23.913 & \\
\hline 1 & 101.256 & 101.797 & 101.793 & 101.675 & 0.541 & 0.004 & 0.118 & \multirow{4}{*}{0.248} & 0.739 & \multirow{4}{*}{18.41} & 21.811 & \multirow{4}{*}{30.85} \\
\hline 2 & 102.316 & 102.985 & 102.972 & 102.784 & 0.669 & 0.013 & 0.188 & & 1.943 & & 28.102 & \\
\hline 3 & 102.028 & 102.765 & 102.395 & 102.185 & 0.737 & 0.370 & 0.210 & & 50.204 & & 28.494 & \\
\hline 4 & 101.821 & 102.881 & 102.661 & 102.184 & 1.060 & 0.220 & 0.477 & & 20.755 & & 45.000 & \\
\hline 1 & 101.155 & 101.767 & 101.340 & 101.206 & 0.612 & 0.427 & 0.134 & \multirow{4}{*}{0.280} & 69.771 & \multirow{4}{*}{47.48} & 21.895 & \multirow{4}{*}{24.76} \\
\hline 2 & 101.168 & 101.753 & \begin{tabular}{|l|}
101.458 \\
\end{tabular} & 101.338 & 0.585 & 0.295 & 0.120 & & 50.427 & & 20.513 & \\
\hline 3 & 100.531 & 102.382 & \begin{tabular}{|l|}
102.199 \\
\end{tabular} & 101.720 & 1.851 & 0.183 & 0.479 & & 9.887 & & 25.878 & \\
\hline 4 & 101.281 & 102.536 & 101.785 & 101.399 & 1.255 & 0.751 & 0.386 & & 59.841 & & 30.757 & \\
\hline 1 & 101.924 & 102.566 & 102.400 & 102.250 & 0.642 & 0.166 & 0.150 & \multirow{4}{*}{0.052} & 25.857 & \multirow{4}{*}{17.61} & 23.364 & \multirow{4}{*}{7.89} \\
\hline 2 & 102.007 & 102.527 & \begin{tabular}{|l|}
102.383 \\
\end{tabular} & 102.355 & 0.520 & 0.144 & 0.028 & & 27.692 & & 5.385 & \\
\hline 3 & 101.535 & 102.598 & \begin{tabular}{|l|}
102.552 \\
\end{tabular} & 102.523 & 1.063 & 0.046 & 0.029 & & 4.327 & & 2.728 & \\
\hline 4 & 101.438 & 102.687 & 102.530 & 102.529 & 1.249 & 0.157 & 0.001 & & 12.570 & & 0.080 & \\
\hline 1 & 102.419 & 103.116 & 103.087 & 102.451 & 0.697 & 0.029 & 0.636 & \multirow{4}{*}{0.195} & 4.161 & \multirow{4}{*}{20.69} & 91.248 & \multirow{4}{*}{27.53} \\
\hline 2 & 101.381 & 102.482 & \begin{tabular}{|l|}
102.402 \\
\end{tabular} & 102.340 & 1.101 & 0.080 & 0.062 & & 7.266 & & 5.631 & \\
\hline 3 & 101.946 & 102.586 & \begin{tabular}{|l|}
102.524 \\
\end{tabular} & 102.443 & 0.640 & 0.062 & 0.081 & & 9.687 & & 12.656 & \\
\hline 4 & 102.394 & 102.566 & 102.460 & 102.459 & 0.172 & 0.106 & 0.001 & & 61.628 & & 0.581 & \\
\hline
\end{tabular}




\subsubsection{Bolt relaxation with initial clamping force of $203 \mathrm{kN}$}

Table 8-2: Bolt relaxation mean change in length and standard deviation after 72 hrs for a clamping force of $203 \mathrm{kN}$

\begin{tabular}{|c|c|c|c|c|c|c|c|c|c|c|c|c|}
\hline $\begin{array}{c}\text { Samples } \\
\# \\
\end{array}$ & $\begin{array}{c}\text { Length } \\
\text { before } \\
\text { pre } \\
\text { tension } \\
\text { (mm) } \\
\end{array}$ & \begin{tabular}{|c|} 
Length \\
immediately \\
after pre \\
tension \\
$(\mathrm{mm})$ \\
\end{tabular} & \begin{tabular}{|c|} 
\\
Length at \\
$36 \mathrm{hrs}$ \\
$(\mathrm{mm})$ \\
\end{tabular} & \begin{tabular}{|l} 
\\
Length after \\
72 hrs (mm)
\end{tabular} & \begin{tabular}{|c|} 
Change in \\
length \\
immediately \\
after \\
tensioning \\
$(\mathrm{mm})$ \\
\end{tabular} & \begin{tabular}{|c} 
Change in \\
length after \\
$36 \mathrm{hrs}$ \\
$(\mathrm{mm})$ \\
\end{tabular} & \begin{tabular}{|c} 
Change in \\
length after \\
$72 \mathrm{hrs}$ \\
$(\mathrm{mm})$
\end{tabular} & \begin{tabular}{|c|} 
Mean \\
Change in \\
length after \\
$72 \mathrm{hrs}$ \\
$(\mathrm{mm})$ \\
\end{tabular} & $\begin{array}{c}\% \text { Loss } \\
\text { after } 36 \mathrm{hrs} \\
\end{array}$ & $\begin{array}{c}\text { Mean } \\
\% \text { loss } \\
\text { after } 36 \\
\text { hrs } \\
\end{array}$ & $\begin{array}{c}\% \text { Loss } \\
\text { after } 72 \text { hrs } \\
\end{array}$ & $\begin{array}{c}\text { Mean \% } \\
\text { loss after } \\
72 \mathrm{hrs} \\
\end{array}$ \\
\hline 1 & 101.649 & 102.646 & 102.145 & \begin{tabular}{|l|}
102.120 \\
\end{tabular} & 0.997 & 0.501 & 0.025 & \multirow{4}{*}{0.292} & 50.251 & \multirow{4}{*}{26.34} & 2.508 & \multirow{4}{*}{167.59} \\
\hline 2 & 101.398 & 101.877 & 101.846 & 101.780 & 0.479 & 0.031 & 0.066 & & 6.472 & & 13.779 & \\
\hline 3 & 102.124 & 102.320 & 102.290 & 101.302 & 0.196 & 0.030 & 0.988 & & 15.306 & & 504.082 & \\
\hline 4 & 101.993 & 102.053 & 102.033 & 101.943 & 0.060 & 0.020 & 0.090 & & 33.333 & & 150.000 & \\
\hline 1 & 101.173 & 102.333 & 101.797 & 101.754 & 1.160 & 0.536 & 0.043 & \multirow{4}{*}{0.025} & 46.207 & \multirow{4}{*}{16.43} & 3.707 & \multirow{4}{*}{2.75} \\
\hline 2 & 101.499 & 101.876 & 101.815 & 101.806 & 0.377 & 0.061 & 0.009 & & 16.180 & & 2.387 & \\
\hline 3 & 101.697 & 102.483 & 102.478 & 102.472 & 0.786 & 0.005 & 0.006 & & 0.636 & & 0.763 & \\
\hline 4 & 101.185 & 102.220 & 102.192 & 102.149 & 1.035 & 0.028 & 0.043 & & 2.705 & & 4.155 & \\
\hline 1 & 102.083 & 102.343 & 102.274 & 102.235 & 0.260 & 0.069 & 0.039 & \multirow{4}{*}{0.064} & 26.538 & \multirow{4}{*}{27.06} & 15.000 & \multirow{4}{*}{11.71} \\
\hline 2 & 101.838 & 102.323 & 102.242 & 102.176 & 0.485 & 0.081 & 0.066 & & 16.701 & & 13.608 & \\
\hline 3 & 102.096 & 103.036 & 102.447 & 102.343 & 0.940 & 0.589 & 0.104 & & 62.660 & & 11.064 & \\
\hline 4 & 101.626 & 102.310 & 102.294 & 102.245 & 0.684 & 0.016 & 0.049 & & 2.339 & & 7.164 & \\
\hline 1 & 101.642 & 102.391 & 102.287 & 101.993 & 0.749 & 0.104 & 0.294 & \multirow{4}{*}{0.190} & 13.885 & \multirow{4}{*}{24.24} & 39.252 & \multirow{4}{*}{31.68} \\
\hline 2 & 101.813 & 102.004 & 101.940 & 101.881 & 0.191 & 0.064 & 0.059 & & 33.508 & & 30.890 & \\
\hline 3 & 101.663 & 102.352 & 102.018 & 101.957 & 0.689 & 0.334 & 0.061 & & 48.476 & & 8.853 & \\
\hline 4 & 101.757 & 102.480 & 102.472 & 102.127 & 0.723 & 0.008 & 0.345 & & 1.107 & & 47.718 & \\
\hline 1 & 101.463 & 102.638 & 102.588 & 101.469 & 1.175 & 0.050 & 1.119 & \multirow{4}{*}{0.355} & 4.255 & \multirow{4}{*}{9.71} & 95.234 & \multirow{4}{*}{41.35} \\
\hline 2 & 102.330 & 102.583 & 102.546 & 102.493 & 0.253 & 0.037 & 0.053 & & 14.625 & & 20.949 & \\
\hline 3 & 101.918 & 102.783 & 102.775 & 102.652 & 0.865 & 0.008 & 0.123 & & 0.925 & & 14.220 & \\
\hline 4 & 102.289 & 102.646 & 102.578 & 102.453 & 0.357 & 0.068 & 0.125 & & 19.048 & & 35.014 & \\
\hline 1 & 102.008 & 102.904 & 102.839 & 102.337 & 0.896 & 0.065 & 0.502 & \multirow{4}{*}{0.160} & 7.254 & \multirow{4}{*}{22.81} & 56.027 & \multirow{4}{*}{25.29} \\
\hline 2 & 102.229 & 102.613 & 102.512 & 102.456 & 0.384 & 0.101 & 0.056 & & 26.302 & & 14.583 & \\
\hline 3 & 102.333 & 102.718 & 102.623 & 102.585 & 0.385 & 0.095 & 0.038 & & 24.675 & & 9.870 & \\
\hline 4 & 102.320 & 102.523 & 102.456 & 102.414 & 0.203 & 0.067 & 0.042 & & 33.005 & & 20.690 & \\
\hline
\end{tabular}




\section{Chapter 9: EXPERIMENTAL RESULTS AND DISCUSSION ON THE TEMPERATURE EFFECTS ON SLIP COEFFICIENT}

This chapter presents the results of the effect of temperature on slip coefficients. In this part of research, the steel plates, bolts, washers and nuts were placed in the environmental chamber at the target temperature for $36 \mathrm{hrs}$. Then, they were taken out of the chamber to apply the pretension force, then they the bolt-plate assembly was placed back in the chamber within 5 minutes after the loose parts were taken out. The assembly was left in the chamber for other $36 \mathrm{hrs}$ and then each brought to the MTS machine to perform the slip test. For each temperature, 3 bolt-plate assemblies were considered for each plate surface condition.

\subsection{Slip Resistance at a Target Temperature of $-5^{\circ} \mathrm{C}$}

Figure 9-1 through Figure 9-5 show sample graphs of the applied compressive load-displacement history for each surface condition within the $-5^{\circ} \mathrm{C}$ target temperature (with the rest of result graph presented in Appendix E). Table 9-1 through Table 9-5 show the mean slip load and slip coefficient

of the various surface conditions at target temperature. With no set way in maintaining the assembly temperature throughout the slip test process, monitoring of the temperature change of each specimen was conducted. Figure 9-6 shows the change in temperature of the bolt-plate assembly, as measured by the thermocouples, during the slip test for one test specimen while Table 9-6 show the mean increase in temperature throughout the test for all the tested samples. Table F1 in Appendix F shows the actual temperature of the bolt-plate assembly at the time the slip coefficient was calculated (i.e. at $0.5 \mathrm{~mm}$ displacement). It can be observed that the actual temperature at the time of $0.5 \mathrm{~mm}$ displacement was greater that the target temperature of $-5^{\circ} \mathrm{C}$. Thus, the results here may be considered as preliminary with which the hypnosis of the change in the slip resistance coefficient changes with changes in temperature at the time of the slip test can be examined. However, further tests can be conducted while the bolt-plate assembly is fully isolated to maintain the temperature during the slip test. Results showed that by maintaining the assembly target temperature at $-5{ }^{\circ} \mathrm{C}$ and changing the surface condition, there was a difference of $30,000 \mathrm{~N}$ between the highest mean slip load (stainless steel clean mill scale surface condition) and the lowest mean slip load (hot dip galvanized 350W structural steel) as shown in Table 9-3. 
Similarly, the mean slip coefficient for the surface conditions at $-5{ }^{\circ} \mathrm{C}$ increased from 0.159 at ambient temperature to 0.239 at the target temperature.

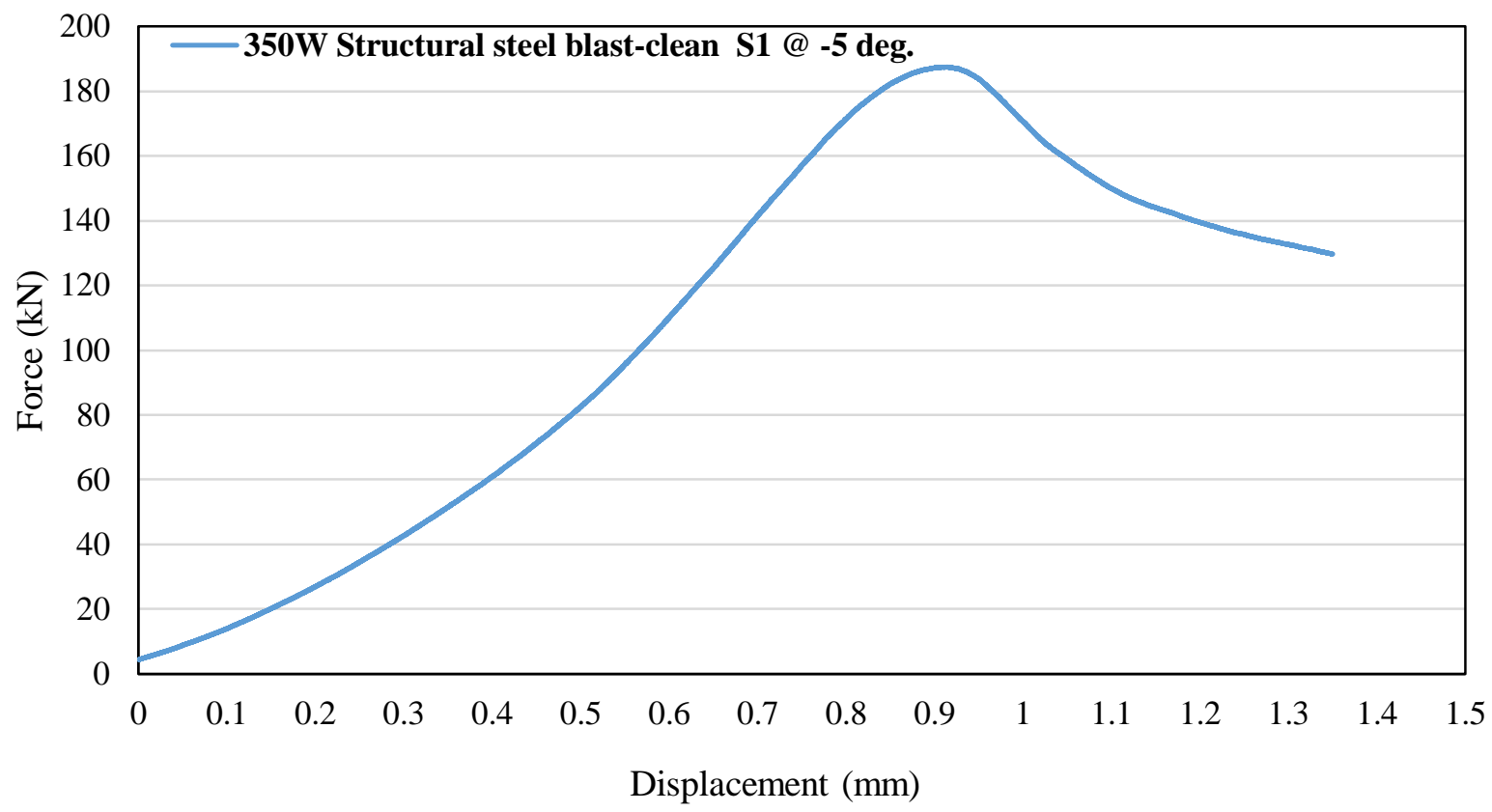

Figure 9-1: Force-displacement relationship for 350W structural steel with blasted clean surface condition with $\mathrm{A325}$ bolt for test specimen 1 at $-5^{\circ} \mathrm{C}$ temperature

Table 9-1: Results of values of slip load and slip coefficient for the three specimen tested along with mean values

\begin{tabular}{|c|c|c|c|c|}
\cline { 2 - 5 } \multicolumn{1}{c|}{} & $\begin{array}{c}\text { Specimen 1 } \\
\text { result }\end{array}$ & $\begin{array}{c}\text { Specimen 2 } \\
\text { result }\end{array}$ & $\begin{array}{c}\text { Specimen 3 } \\
\text { result }\end{array}$ & Mean \\
\hline Slip load $(\mathrm{N})$ & $82,408.5$ & $85,268.5$ & $84,330.2$ & $\mathbf{8 4 , 0 0 2 . 3 8}$ \\
\hline $\begin{array}{c}\text { Slip coefficient } \\
\left(\mathrm{k}_{\mathrm{s}}\right)\end{array}$ & 0.204 & 0.210 & 0.207 & $\mathbf{0 . 2 0 7}$ \\
\hline
\end{tabular}




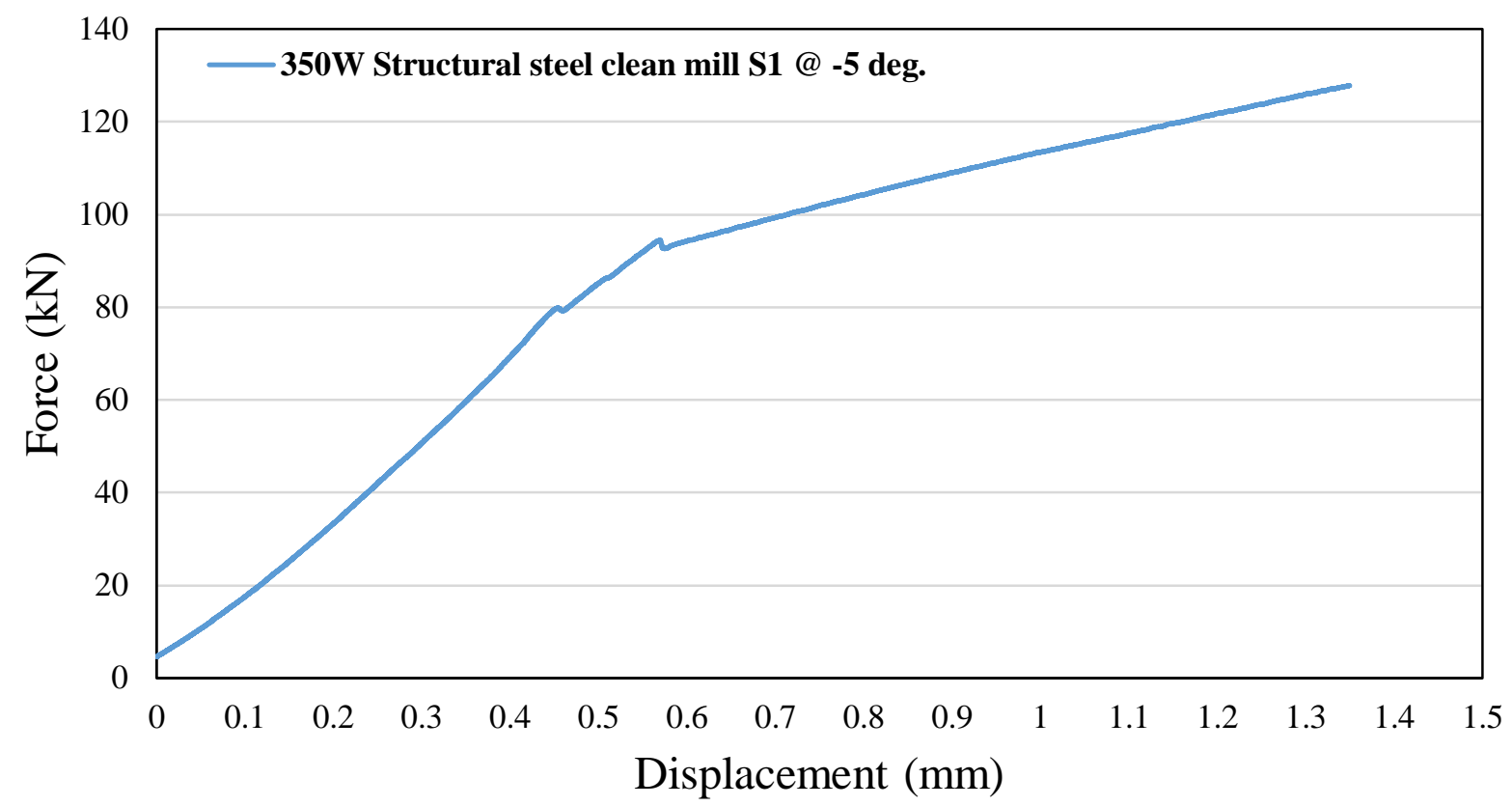

Figure 9-2: Force-displacement relationship for $350 \mathrm{~W}$ structural steel with clean mill scale surface condition with $\mathrm{A} 325$ bolt for test specimen 1 at $-5^{\circ} \mathrm{C}$ temperature

Table 9-2: Results of values of slip load and slip coefficient for the three specimen tested along with mean values

\begin{tabular}{|c|c|c|c|c|}
\cline { 2 - 5 } \multicolumn{1}{c|}{} & $\begin{array}{c}\text { Specimen } \\
\text { result 1 }\end{array}$ & $\begin{array}{c}\text { Specimen } \\
\text { result 2 }\end{array}$ & $\begin{array}{c}\text { Specimen } \\
\text { result 3 }\end{array}$ & Mean \\
\hline Slip load $(\mathrm{N})$ & $85,170.8$ & $79,535.5$ & $63,733.7$ & $\mathbf{7 6 , 1 4 6 . 6 6}$ \\
\hline $\begin{array}{c}\text { Slip coefficient } \\
\left(\mathrm{k}_{\mathrm{s}}\right)\end{array}$ & 0.210 & 0.196 & 0.157 & $\mathbf{0 . 1 8 7}$ \\
\hline
\end{tabular}




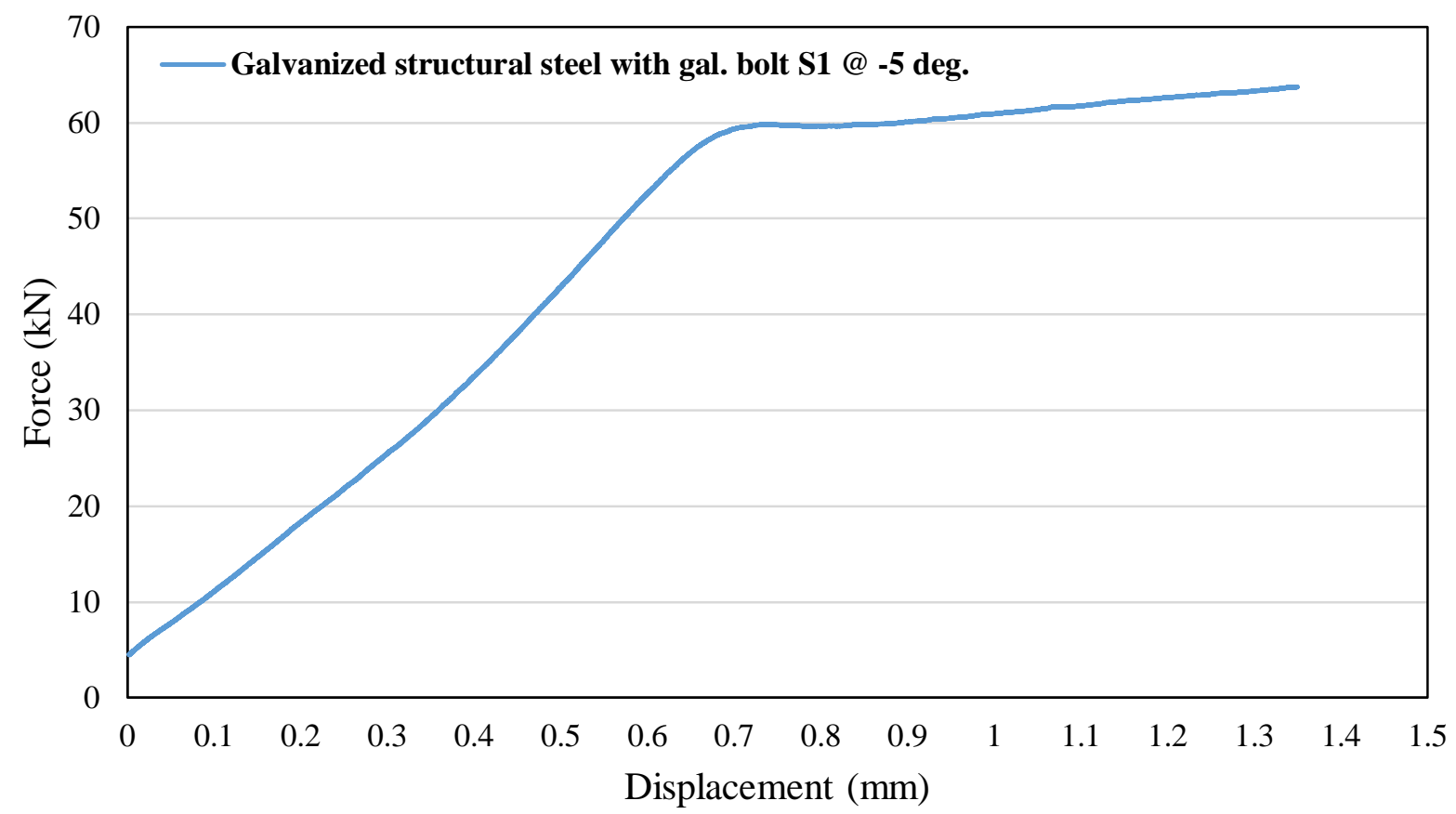

Figure 9-3: Force-displacement relationship for $350 \mathrm{~W}$ structural steel with hot dip galvanized surface condition with galvanized bolt for test specimen 1 at $-5^{\circ} \mathrm{C}$ temperature

Table 9-3: Results of values of slip load and slip coefficient for the three specimen tested along with mean values

\begin{tabular}{|c|c|c|c|c|}
\cline { 2 - 5 } \multicolumn{1}{c|}{} & $\begin{array}{c}\text { Specimen } \\
\text { result 1 }\end{array}$ & $\begin{array}{c}\text { Specimen } \\
\text { result 2 }\end{array}$ & $\begin{array}{c}\text { Specimen } \\
\text { result 3 }\end{array}$ & Mean \\
\hline Slip load (N) & $42,843.6$ & $76,815.3$ & $59,541.4$ & $\mathbf{5 9 , 7 3 3 . 4 4}$ \\
\hline $\begin{array}{c}\text { Slip coefficient } \\
\left(\mathrm{k}_{\mathrm{s}}\right)\end{array}$ & 0.114 & 0.204 & 0.159 & $\mathbf{0 . 1 5 9}$ \\
\hline
\end{tabular}




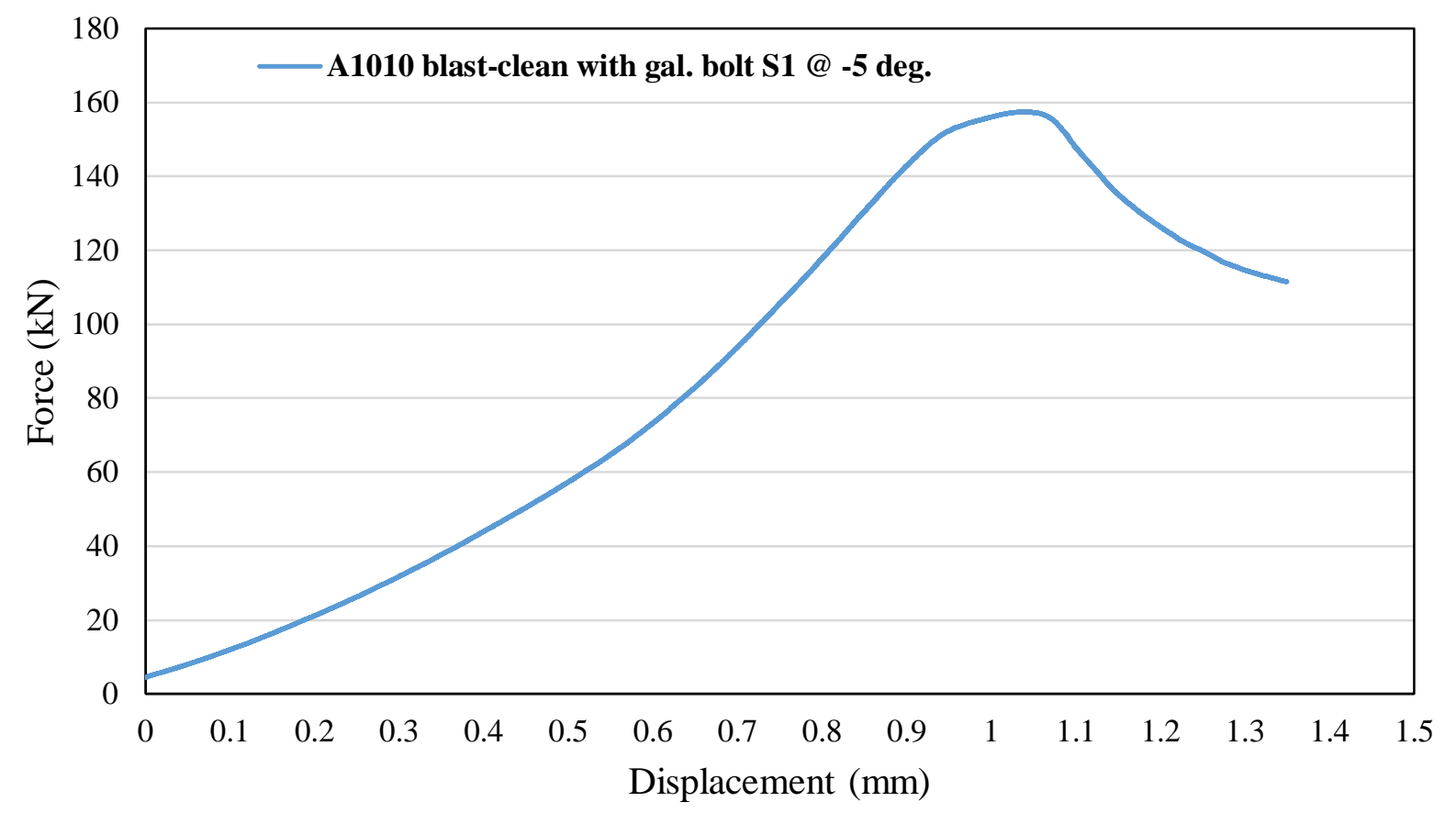

Figure 9-4: Force-displacement relationship for A1010 stainless steel with blast-clean surface condition with galvanized bolt for test specimen 1 at $-5^{\circ} \mathrm{C}$ temperature

Table 9-4: Results of values of slip load and slip coefficient for the three specimen tested along with mean value

\begin{tabular}{|c|c|c|c|c|}
\cline { 2 - 5 } \multicolumn{1}{c|}{} & $\begin{array}{c}\text { Specimen 1 } \\
\text { result }\end{array}$ & $\begin{array}{c}\text { Specimen 2 } \\
\text { result }\end{array}$ & $\begin{array}{c}\text { Specimen 3 } \\
\text { result }\end{array}$ & Mean \\
\hline Slip load $(\mathrm{N})$ & $95,034.6$ & $94,455.9$ & $79,424.7$ & $\mathbf{8 9 , 6 3 8 . 4 0}$ \\
\hline $\begin{array}{c}\text { Slip coefficient } \\
\left(\mathrm{k}_{\mathrm{s}}\right)\end{array}$ & 0.253 & 0.252 & 0.212 & $\mathbf{0 . 2 3 9}$ \\
\hline
\end{tabular}




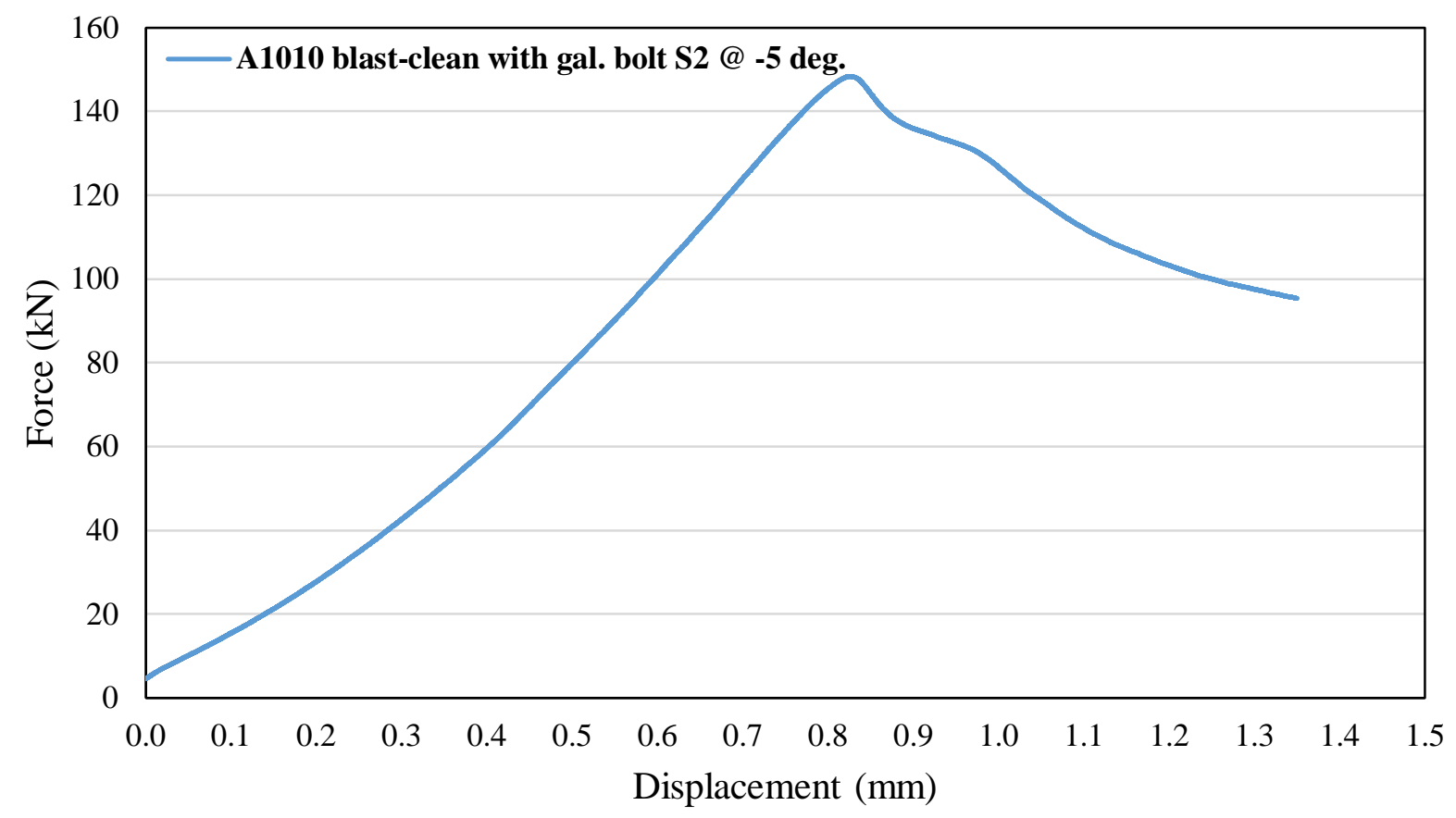

Figure 9-5: Force-displacement relationship for A1010 stainless steel with blast-clean surface condition with galvanized bolt for test specimen 2 at $-5^{\circ} \mathrm{C}$ temperature

Table 9-5: Results of values of slip load and slip coefficient for the three specimen tested along with mean value

\begin{tabular}{|c|c|c|c|c|}
\cline { 2 - 5 } \multicolumn{1}{c|}{} & $\begin{array}{c}\text { Specimen 1 } \\
\text { result }\end{array}$ & $\begin{array}{c}\text { Specimen 2 } \\
\text { result }\end{array}$ & $\begin{array}{c}\text { Specimen 3 } \\
\text { result }\end{array}$ & Mean \\
\hline Slip load (N) & $57,269.0$ & $79,809.9$ & $53,457.7$ & $\mathbf{6 3 , 5 1 2 . 1 6}$ \\
\hline $\begin{array}{c}\text { Slip coefficient } \\
\left(\mathrm{k}_{\mathrm{s}}\right)\end{array}$ & 0.153 & 0.213 & 0.142 & $\mathbf{0 . 1 6 9}$ \\
\hline
\end{tabular}


Table 9-6: Mean temperature progression throughout testing of specimen for various surface treatment at $-5^{\circ} \mathrm{C}$

\begin{tabular}{|c|c|c|c|c|c|c|c|c|c|c|c|c|}
\hline & & \multicolumn{11}{|c|}{ Time (mins) } \\
\hline $\begin{array}{c}\text { Test } \\
\text { material }\end{array}$ & $\begin{array}{l}\text { Surface type } \\
\text { (Class) }\end{array}$ & $\mathbf{0}$ & 2 & 4 & 6 & 8 & 10 & 12 & 14 & 16 & 18 & 20 \\
\hline & & \multicolumn{11}{|c|}{ Mean temperature between the specimen $\left({ }^{\circ} \mathrm{C}\right)$} \\
\hline $\begin{array}{c}\text { Structural } \\
\text { steel } \\
(350 \mathrm{~W})\end{array}$ & $\begin{array}{c}\text { A (clean mill } \\
\text { scale) }\end{array}$ & 5.5 & 2.3 & 6.1 & 8.9 & 11.1 & 13.1 & 14.6 & 15.7 & 16.7 & 17.5 & 18.2 \\
\hline $\begin{array}{c}\text { Structural } \\
\text { steel } \\
(350 \mathrm{~W})\end{array}$ & $\begin{array}{l}\text { B (Blast- } \\
\text { clean) }\end{array}$ & 5.5 & 1.3 & 4.9 & 7.7 & 10.0 & 11.9 & 13.6 & 15.0 & 16.0 & 16.7 & 17.3 \\
\hline $\begin{array}{c}\text { Structural } \\
\text { steel } \\
(350 \mathrm{~W})\end{array}$ & $\begin{array}{c}\text { C (Hot dip } \\
\text { galvanized } \\
\text { with gal. } \\
\text { bolt) }\end{array}$ & - & 0.7 & 3.6 & 6.8 & 9.3 & 11.0 & 12.5 & 14.0 & 14.9 & 15.7 & 16.5 \\
\hline $\begin{array}{l}\text { Stainless } \\
\text { steel }\end{array}$ & $\begin{array}{l}\text { A (clean mill } \\
\text { scale })\end{array}$ & - & 0.1 & 4.4 & 7.5 & 9.6 & 11.5 & 12.9 & 14.0 & 15.0 & 15.9 & 16.5 \\
\hline $\begin{array}{l}\text { Stainless } \\
\text { steel }\end{array}$ & $\begin{array}{l}\text { B (Blast- } \\
\text { clean) }\end{array}$ & $\begin{array}{c}- \\
5.7\end{array}$ & 0.4 & 4.3 & 6.9 & 8.7 & 10.3 & 11.9 & 13.1 & 14.2 & 14.9 & 15.5 \\
\hline
\end{tabular}




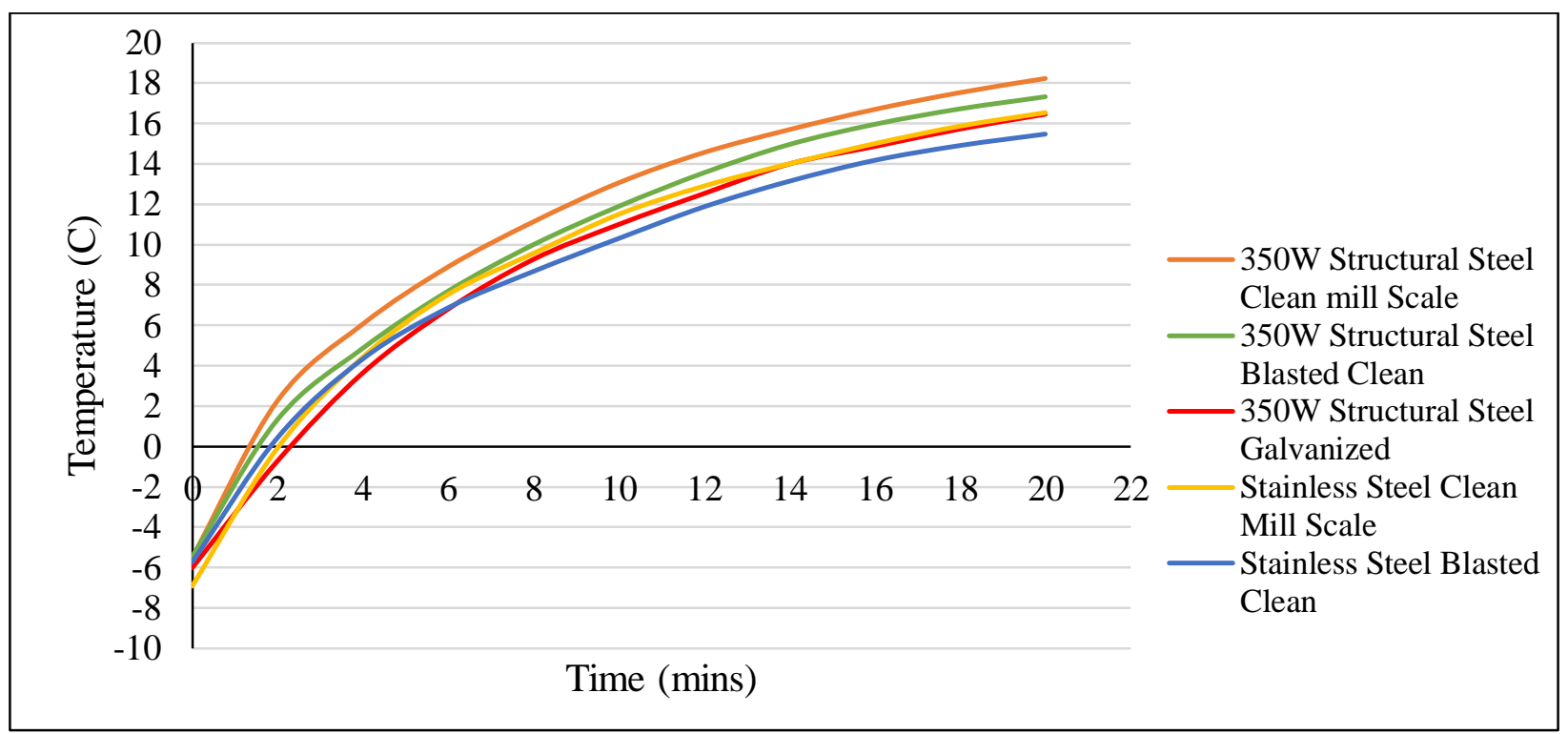

Figure 9-6: Mean Temperature vs time progression throughout testing for various surface condition at $-5^{\circ} \mathrm{C}$

\subsection{Slip Resistance at a Temperature of $-10^{\circ} \mathrm{C}$}

Figure 9-7 through Figure 9-11 show sample graphs of the applied compressive load-displacement relationship for the plate assemblies and their surface conditions at a test target temperature of -10 ${ }^{\circ} \mathrm{C}$, (with the rest of the results graphs shown in Appendix E). Table 9-7 through Table 9-11 present the mean slip coefficients of the various plate assemblies and their surface conditions. One may observe that surface condition appears to have insignificant effect on the slip coefficient at this temperature range. Monitoring of the change in temperature was done throughout the testing and is represented in Table 9-12 and Figure 9-12. 


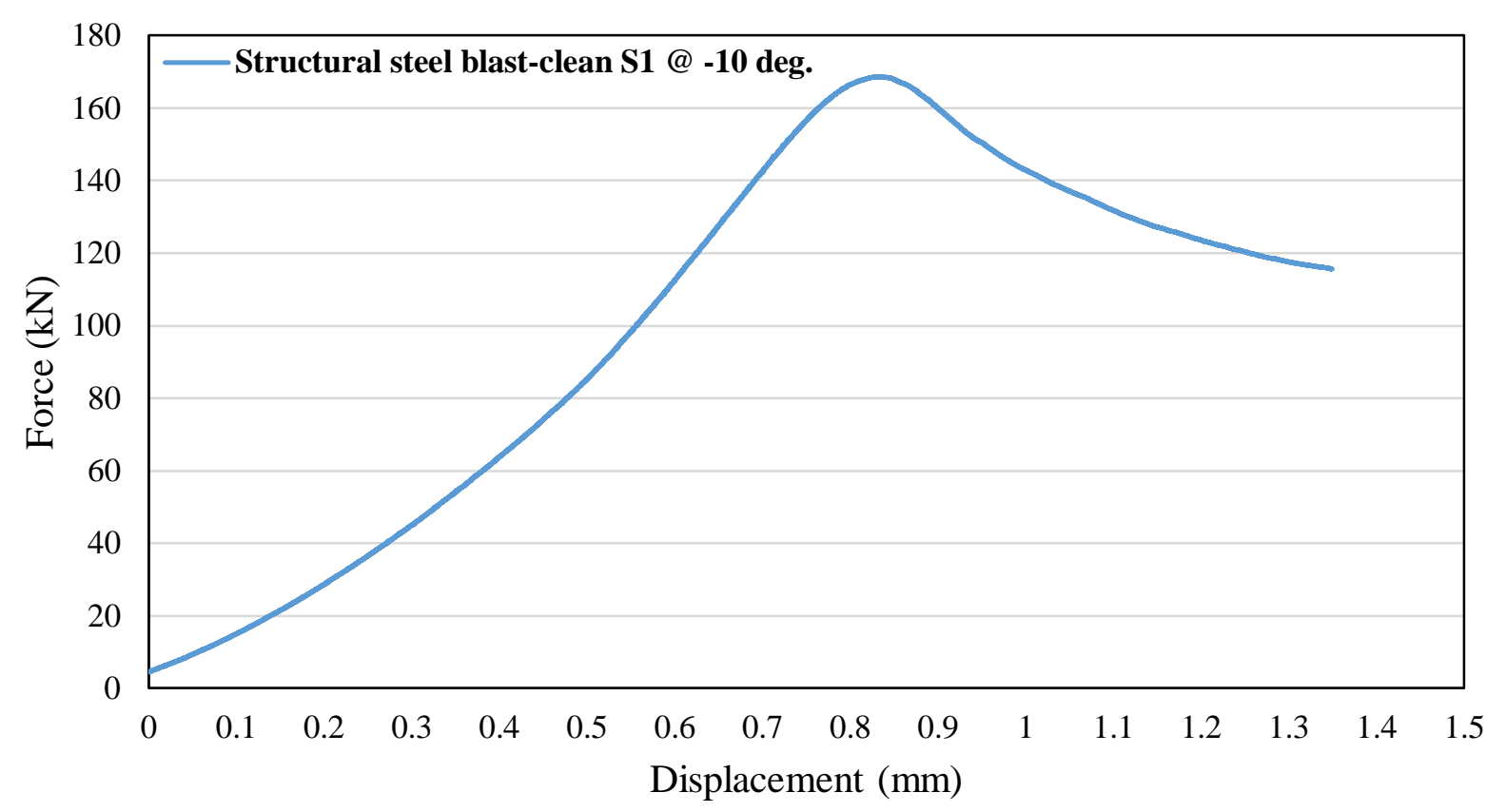

Figure 9-7: Force-displacement relationship for structural steel with blasted clean surface condition with $\mathbf{A 3 2 5}$ bolt for test specimen 1 at $-10^{\circ} \mathrm{C}$ temperature

Table 9-7: Results of values of slip load and slip coefficient for the three specimen tested along with mean values

\begin{tabular}{|c|c|c|c|c|}
\cline { 2 - 5 } \multicolumn{1}{c|}{} & $\begin{array}{c}\text { Specimen 1 } \\
\text { result }\end{array}$ & $\begin{array}{c}\text { Specimen 2 } \\
\text { result }\end{array}$ & $\begin{array}{c}\text { Specimen 3 } \\
\text { result }\end{array}$ & Mean \\
\hline Slip load $(\mathrm{N})$ & $85,148.6$ & $78,757.3$ & $87,103.9$ & $\mathbf{8 3 , 6 6 9 . 9 6}$ \\
\hline $\begin{array}{c}\text { Slip } \\
\text { coefficient }\left(\mathrm{k}_{\mathrm{s}}\right)\end{array}$ & 0.209 & 0.193 & 0.214 & $\mathbf{0 . 2 0 6}$ \\
\hline
\end{tabular}




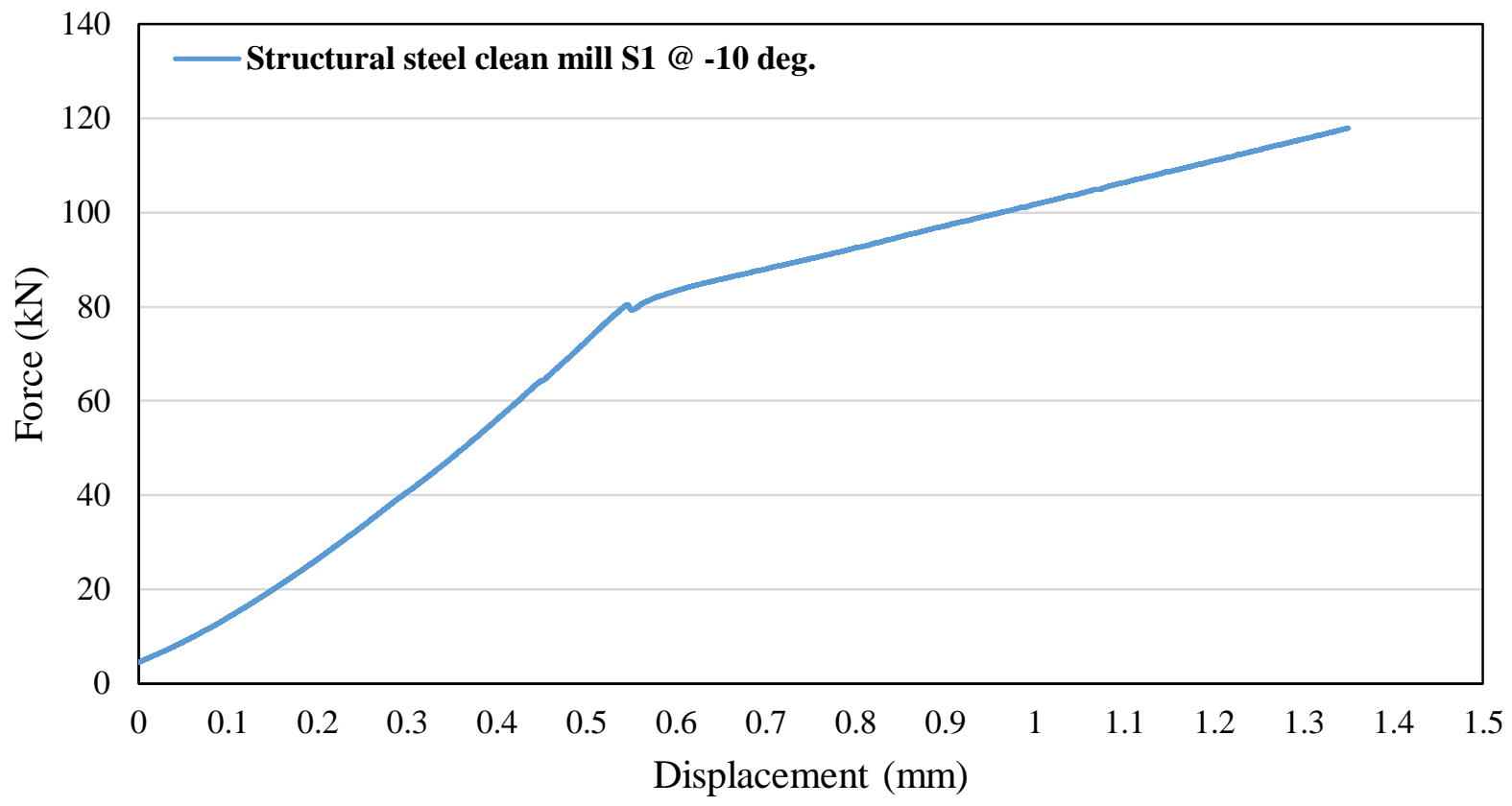

Figure 9-8: Force-displacement relationship for structural steel with clean mill scale surface condition with $\mathrm{A325}$ bolt for test specimen 1 at $-10^{\circ} \mathrm{C}$ temperature

Table 9-8: Results of values of slip load and slip coefficient for the three specimen tested along with mean values

\begin{tabular}{|c|c|c|c|c|}
\cline { 2 - 5 } \multicolumn{1}{c|}{} & $\begin{array}{c}\text { Specimen 1 } \\
\text { result }\end{array}$ & $\begin{array}{c}\text { Specimen 2 } \\
\text { result }\end{array}$ & $\begin{array}{c}\text { Specimen 3 } \\
\text { result }\end{array}$ & Mean \\
\hline Slip load $(\mathrm{N})$ & $72,761.0$ & $53,996.8$ & $78,137.1$ & $\mathbf{6 8 , 2 9 8 . 2 8}$ \\
\hline $\begin{array}{c}\text { Slip coefficient } \\
\left(\mathrm{k}_{\mathrm{s}}\right)\end{array}$ & 0.179 & 0.132 & 0.192 & $\mathbf{0 . 1 6 8}$ \\
\hline
\end{tabular}




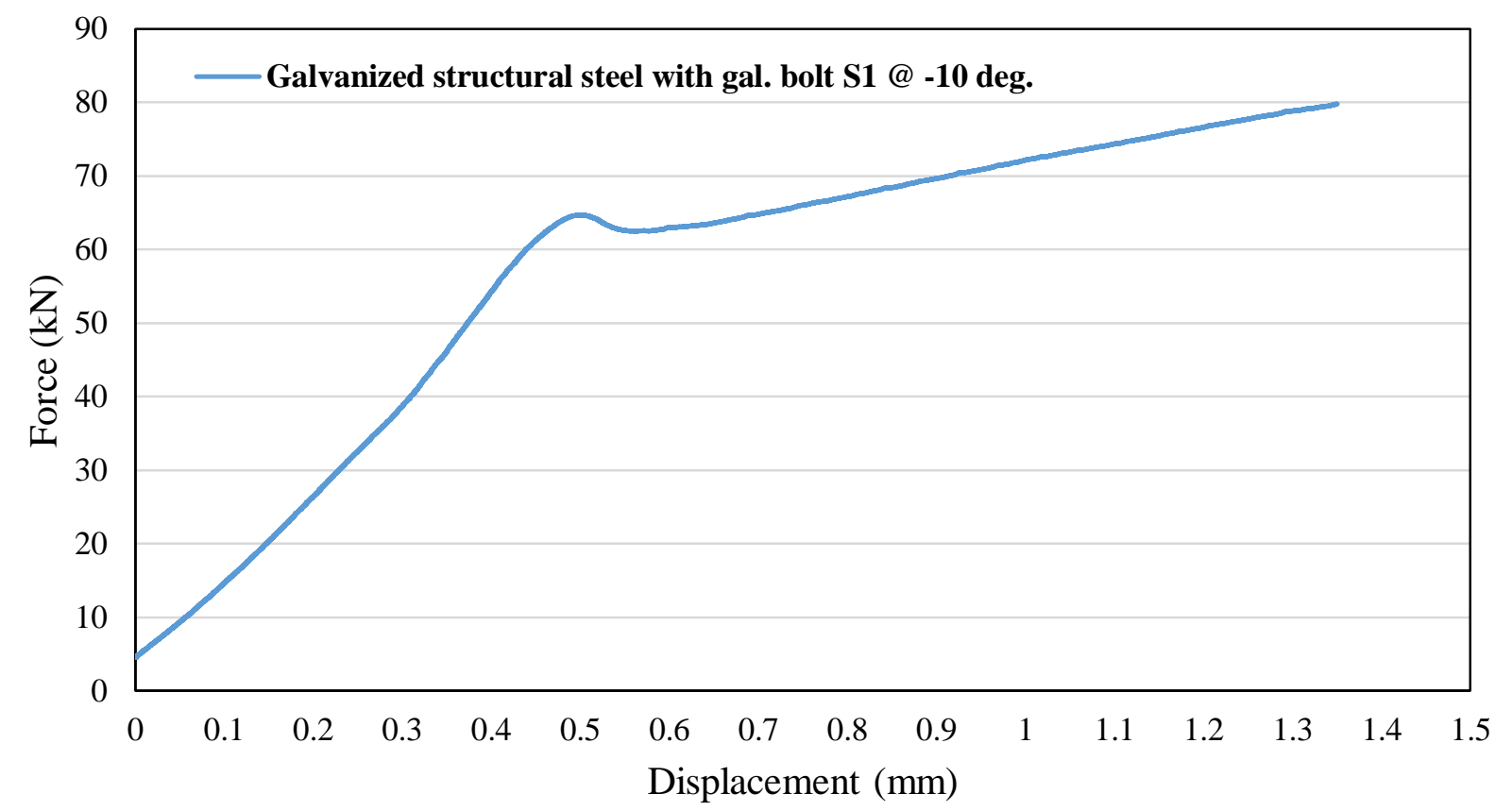

Figure 9-9: Force-displacement relationship for structural steel with hot dip galvanized surface condition with galvanized bolt for test specimen 1 at $-10^{\circ} \mathrm{C}$ temperature

Table 9-9: Results of values of slip load and slip coefficient for the three specimen tested along with mean values

\begin{tabular}{|c|c|c|c|c|}
\cline { 2 - 5 } \multicolumn{1}{c|}{} & $\begin{array}{c}\text { Specimen 1 } \\
\text { result }\end{array}$ & $\begin{array}{c}\text { Specimen 2 } \\
\text { result }\end{array}$ & $\begin{array}{c}\text { Specimen 3 } \\
\text { result }\end{array}$ & Mean \\
\hline Slip load $(\mathrm{N})$ & $64,675.3$ & $73,073.1$ & $71,597.2$ & $\mathbf{6 9 , 7 8 1 . 9}$ \\
\hline $\begin{array}{c}\text { Slip coefficient } \\
\left(\mathrm{k}_{\mathrm{s}}\right)\end{array}$ & 0.172 & 0.195 & 0.191 & $\mathbf{0 . 1 8 6}$ \\
\hline
\end{tabular}




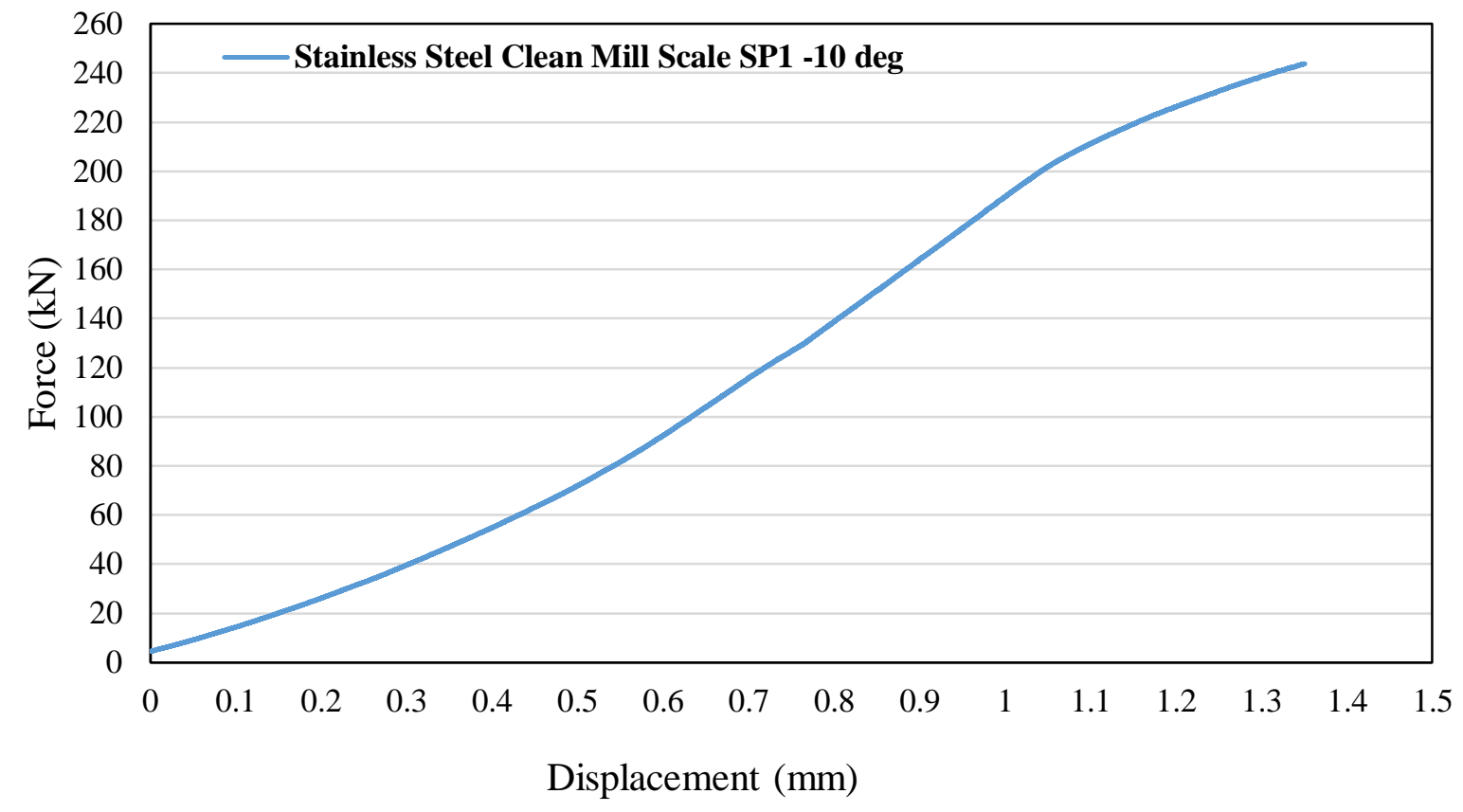

Figure 9-10: Force-displacement relationship for stainless steel with clean mill scale surface condition with galvanized bolt for test specimen 1 at $-10^{\circ} \mathrm{C}$ temperature

Table 9-10: Results of values of slip load and slip coefficient for the three specimen tested along with mean values

\begin{tabular}{|c|c|c|c|c|}
\cline { 2 - 5 } \multicolumn{1}{c|}{} & $\begin{array}{c}\text { Specimen 1 } \\
\text { result }\end{array}$ & $\begin{array}{c}\text { Specimen 2 } \\
\text { result }\end{array}$ & $\begin{array}{c}\text { Specimen 3 } \\
\text { result }\end{array}$ & Mean \\
\hline Slip load $(\mathrm{N})$ & $71,986.0$ & $79,714.9$ & $86,499.5$ & $\mathbf{7 9 , 4 0 0 . 1}$ \\
\hline $\begin{array}{c}\text { Slip coefficient } \\
\left(\mathrm{k}_{\mathrm{s}}\right)\end{array}$ & 0.192 & 0.212 & 0.230 & $\mathbf{0 . 2 1 2}$ \\
\hline
\end{tabular}




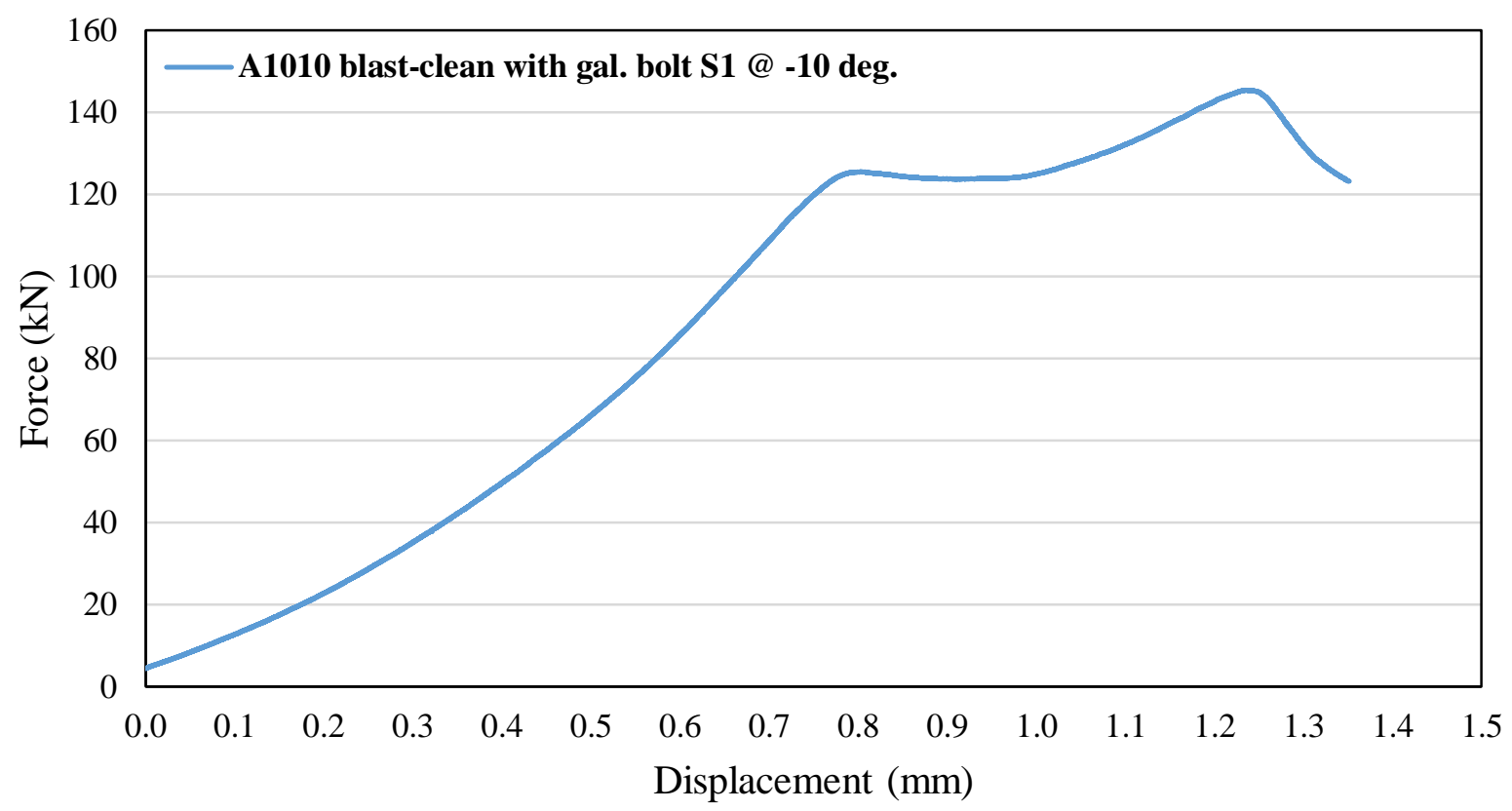

Figure 9-11: Force-displacement relationship for stainless steel with blasted clean surface condition with galvanized bolt for test specimen 1 at $-10^{\circ} \mathrm{C}$ temperature

Table 9-11: Results of values of slip load and slip coefficient for the three specimen tested along with mean values

\begin{tabular}{|c|c|c|c|c|}
\cline { 2 - 5 } \multicolumn{1}{c|}{} & $\begin{array}{c}\text { Specimen 1 } \\
\text { result }\end{array}$ & $\begin{array}{c}\text { Specimen 2 } \\
\text { result }\end{array}$ & $\begin{array}{c}\text { Specimen 3 } \\
\text { result }\end{array}$ & Mean \\
\hline Slip load (N) & $66,056.0$ & $48,627.8$ & $59,149.0$ & $\mathbf{5 7 , 9 4 4 . 2 9}$ \\
\hline $\begin{array}{c}\text { Slip coefficient } \\
\left(\mathrm{k}_{\mathrm{s}}\right)\end{array}$ & 0.176 & 0.130 & 0.158 & $\mathbf{0 . 1 5 4}$ \\
\hline
\end{tabular}


Table 9-12: Mean temperature progression throughout testing of specimen for various surface treatment at $-10^{\circ} \mathrm{C}$

\begin{tabular}{|c|c|c|c|c|c|c|c|c|c|c|c|c|}
\hline & & \multicolumn{11}{|c|}{ Time (mins) } \\
\hline $\begin{array}{c}\text { Test } \\
\text { material }\end{array}$ & $\begin{array}{l}\text { Surface type } \\
\text { (Class) }\end{array}$ & $\mathbf{0}$ & 2 & 4 & 6 & 8 & 10 & 12 & 14 & 16 & 18 & 20 \\
\hline & & \multicolumn{11}{|c|}{ Mean temperature between the specimen ( $\left.{ }^{\circ} \mathrm{C}\right)$} \\
\hline $\begin{array}{c}\text { Structural } \\
\text { steel } \\
(350 \mathrm{~W})\end{array}$ & $\begin{array}{c}\text { A (clean mill } \\
\text { scale) }\end{array}$ & -11.2 & -5.5 & 0.5 & 5.0 & 8.5 & 11.0 & 12.8 & 14.7 & 16.1 & 16.9 & 18.0 \\
\hline $\begin{array}{c}\text { Structural } \\
\text { steel } \\
(350 \mathrm{~W})\end{array}$ & $\begin{array}{l}\text { B (Blast- } \\
\text { clean) }\end{array}$ & -11.3 & -5.2 & 2.5 & 6.6 & 9.6 & 12.0 & 14.2 & 15.8 & 17.0 & 18.0 & 18.7 \\
\hline $\begin{array}{c}\text { Structural } \\
\text { steel } \\
(350 \mathrm{~W})\end{array}$ & $\begin{array}{c}\mathrm{C} \text { (Hot dip } \\
\text { galvanized } \\
\text { with gal. bolt) }\end{array}$ & -11.5 & -5.3 & 2.3 & 5.8 & 9.0 & 11.2 & 13.3 & 15.0 & 16.1 & 17.2 & 18.0 \\
\hline $\begin{array}{l}\text { Stainless } \\
\text { steel }\end{array}$ & $\begin{array}{c}\text { A Clean mill } \\
\text { scale })\end{array}$ & -11.3 & -5.2 & 2.8 & 6.8 & 8.9 & 11.1 & 12.8 & 14.4 & 15.5 & 16.5 & 17.3 \\
\hline $\begin{array}{l}\text { Stainless } \\
\text { steel }\end{array}$ & 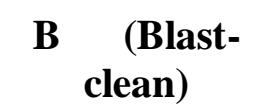 & -11.0 & -4.9 & -0.3 & 6.8 & 9.0 & 11.3 & 12.8 & 14.1 & 15.2 & 16.3 & 17.0 \\
\hline
\end{tabular}




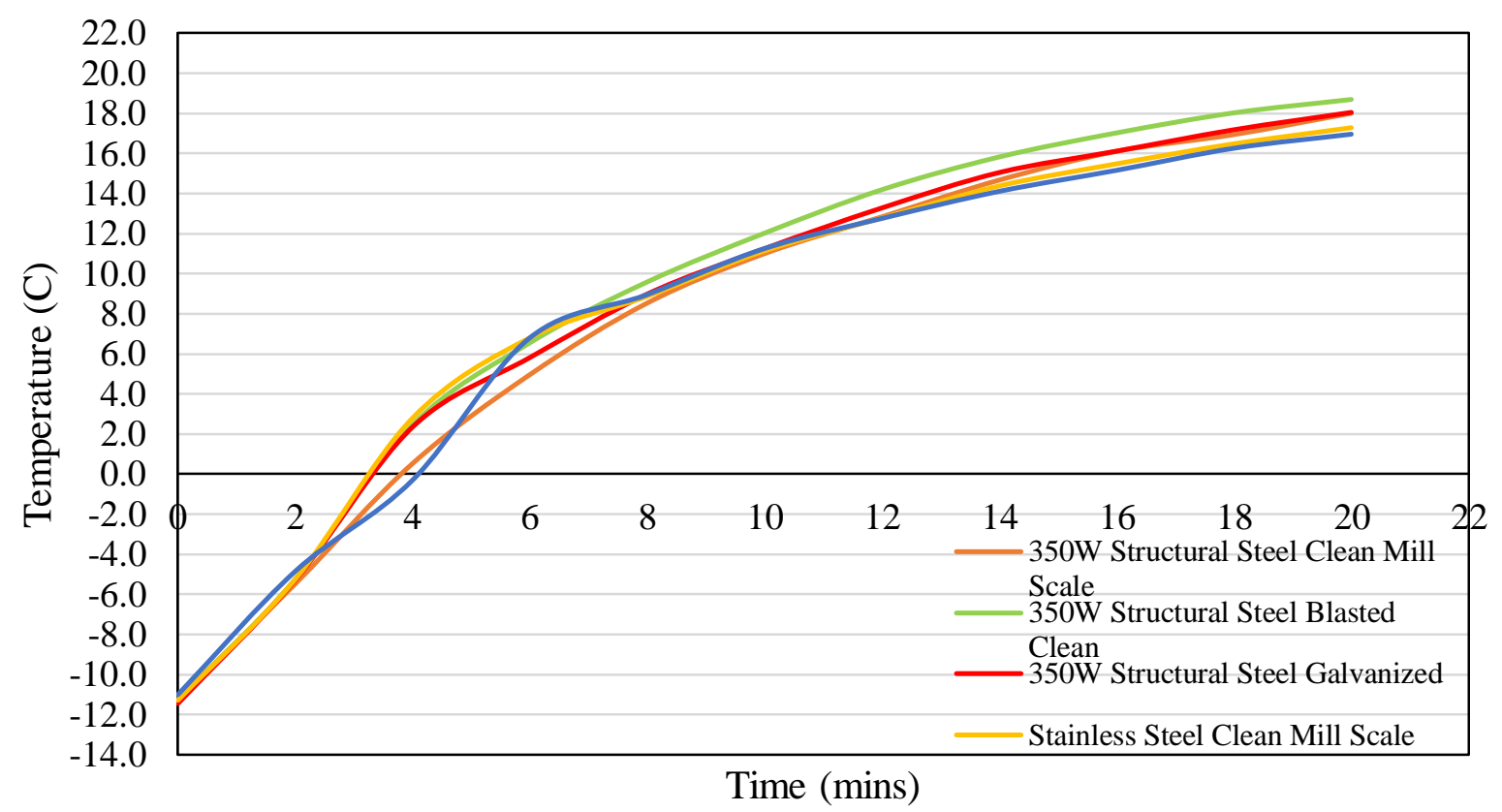

Figure 9-12: Mean temperature vs time progression throughout testing for various surface condition at $-10^{\circ} \mathrm{C}$

\subsection{Slip Resistance at a Target Temperature of $-20^{\circ} \mathrm{C}$}

Figure 9-13 through Figure 9-17 present a sample graph showing the applied compressive loaddisplacement relationship from the 3 bolt-plate assemblies for each surface condition (with the rest of the result graphs presented in Appendix E). Table 9-13 though Table 9-17 show the mean slip load and slip coefficient for these assemblies. Results showed no definitive correlation between surface condition and target temperature at the time of the test. Table 9-18 presents the mean temperature variation of the three specimens for each material surface condition, whereas Figure 9-18 shows the temperature progression monitoring throughout the testing at $-20^{\circ} \mathrm{C}$. 


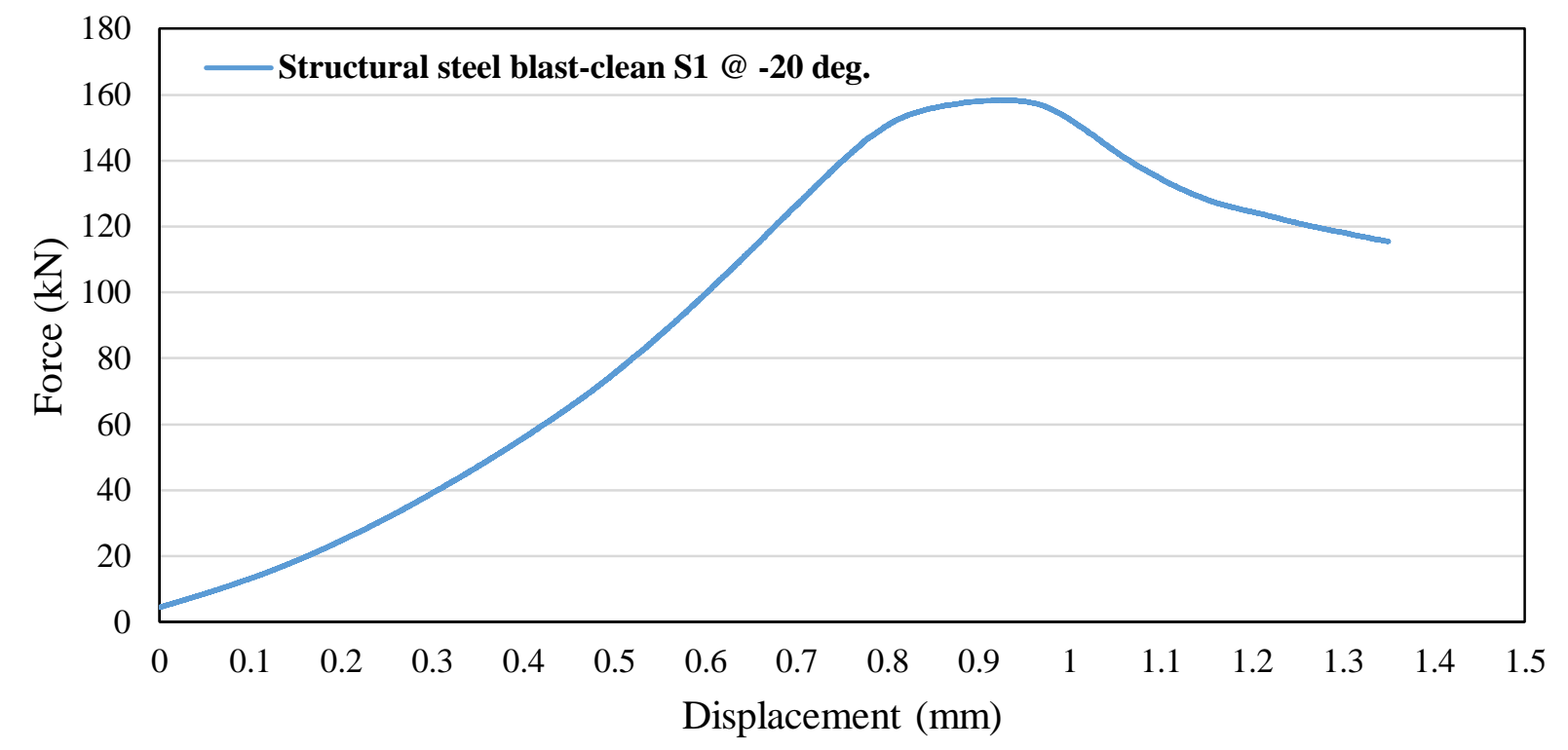

Figure 9-13: Force-displacement relationship for structural steel with blast-clean surface

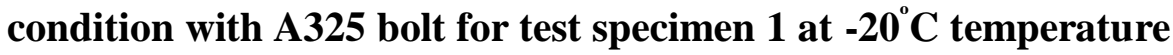

Table 9-13: Results of values of slip load and slip coefficient for the three specimen tested along with mean values

\begin{tabular}{|c|c|c|c|c|}
\cline { 2 - 5 } \multicolumn{1}{c|}{} & $\begin{array}{c}\text { Specimen 1 } \\
\text { result }\end{array}$ & $\begin{array}{c}\text { Specimen 2 } \\
\text { result }\end{array}$ & $\begin{array}{c}\text { Specimen 3 } \\
\text { result }\end{array}$ & Mean \\
\hline Slip load (N) & $75,378.0$ & $80,561.3$ & $81,101.2$ & $\mathbf{7 9 , 0 1 3 . 5}$ \\
\hline $\begin{array}{c}\text { Slip coefficient } \\
\left(\mathrm{k}_{\mathrm{s}}\right)\end{array}$ & 0.185 & 0.198 & 0.200 & $\mathbf{0 . 1 9 4}$ \\
\hline
\end{tabular}




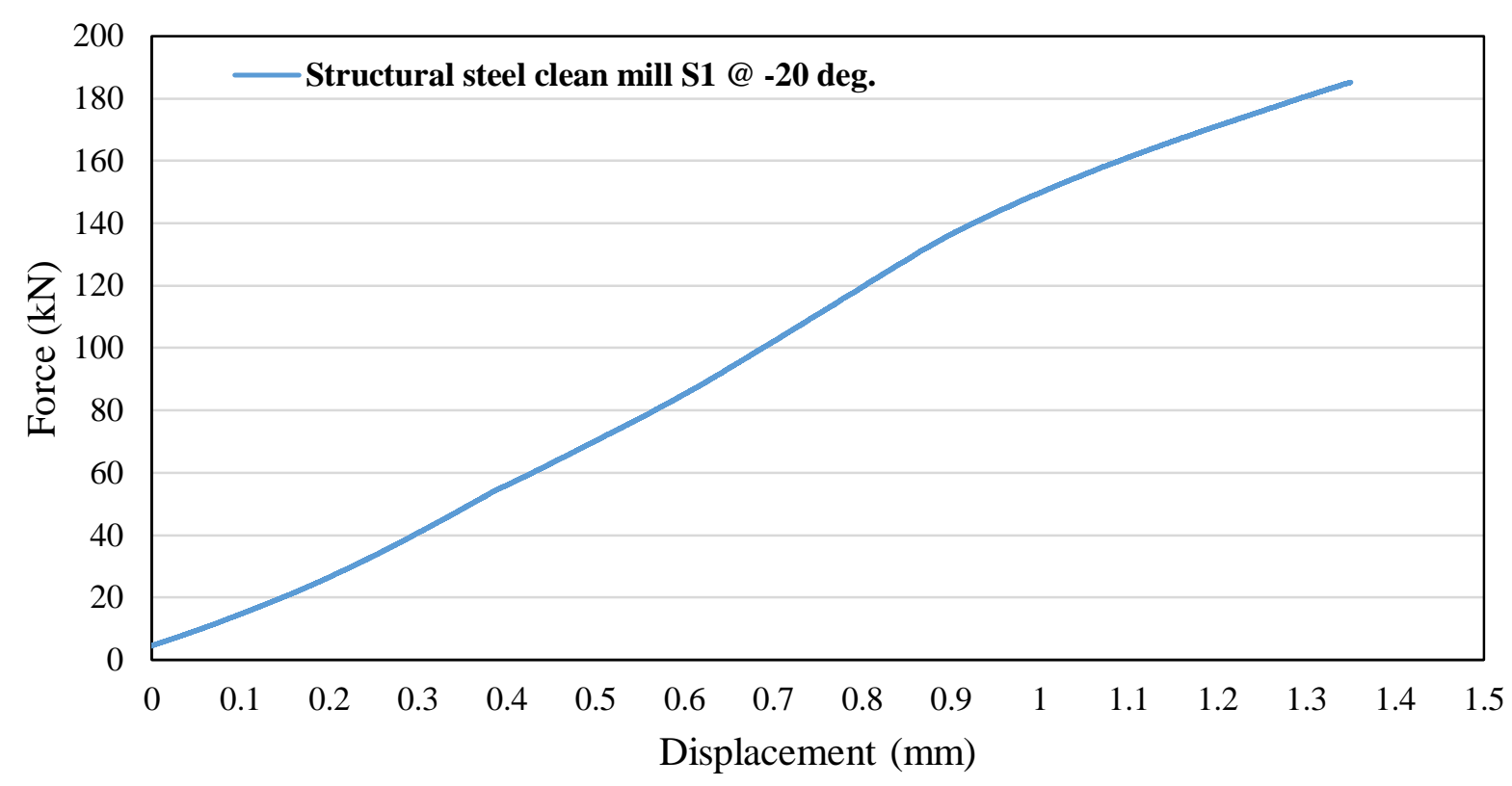

Figure 9-14: Force-displacement relationship for structural steel with clean mill scale surface condition with $\mathrm{A325}$ bolt for test specimen 1 at $-20^{\circ} \mathrm{C}$ temperature

Table 9-14: Results of values of slip load and slip coefficient for the three specimen tested along with mean values

\begin{tabular}{|c|c|c|c|}
\cline { 2 - 4 } \multicolumn{1}{c|}{} & $\begin{array}{c}\text { Specimen 1 } \\
\text { result }\end{array}$ & $\begin{array}{c}\text { Specimen 2 } \\
\text { result }\end{array}$ & Mean \\
\hline Slip load $(\mathrm{N})$ & $70,253.5$ & $62,586.1$ & $\mathbf{6 6 , 4 1 9 . 8}$ \\
\hline $\begin{array}{c}\text { Slip coefficient } \\
\left(\mathrm{k}_{\mathrm{s}}\right)\end{array}$ & 0.173 & 0.154 & $\mathbf{0 . 1 6 3}$ \\
\hline
\end{tabular}




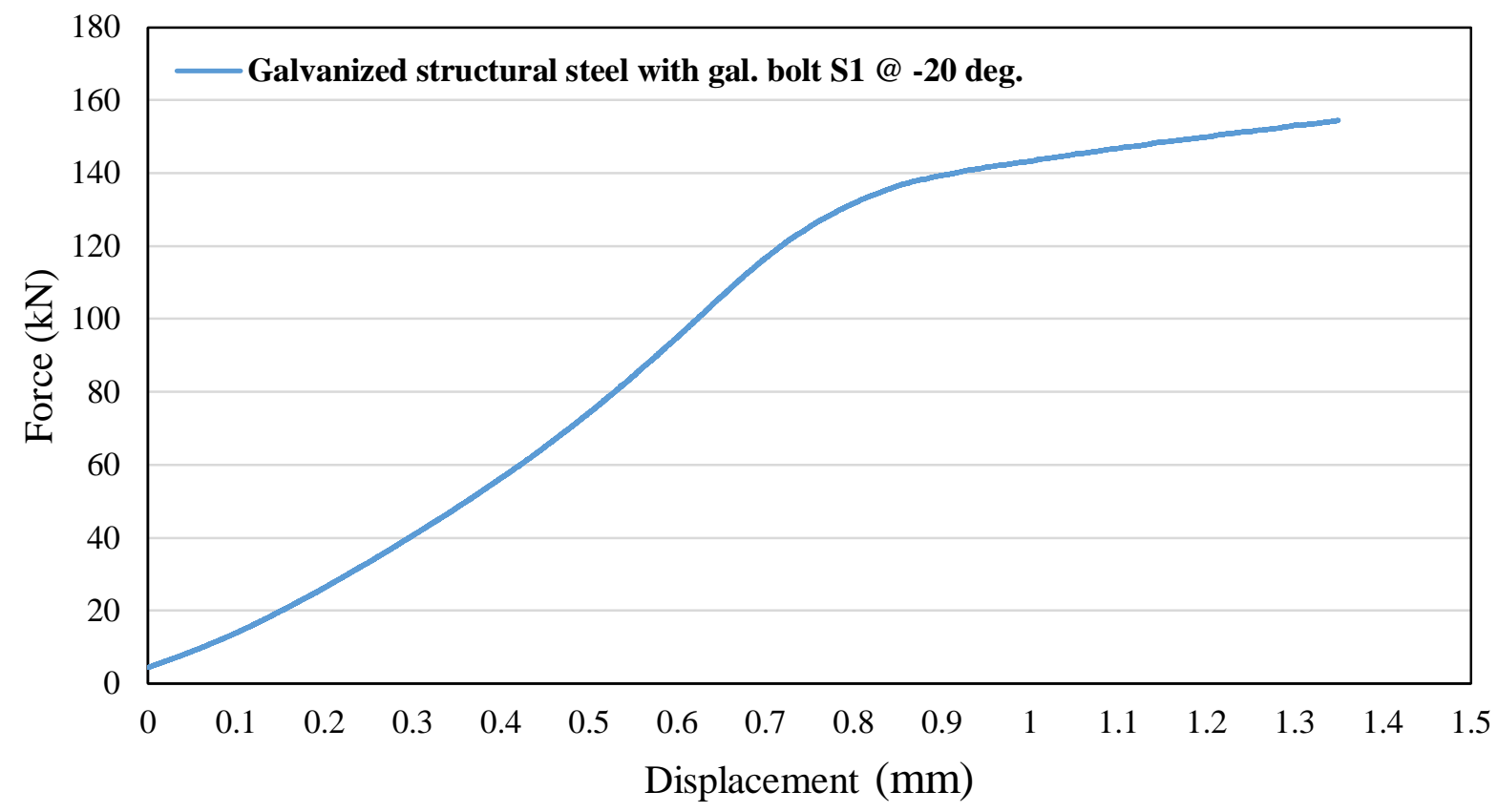

Figure 9-15: Force-displacement relationship for structural steel with hot dip galvanized surface condition with galvanized bolt for test specimen 1 at $-20^{\circ} \mathrm{C}$ temperature

Table 9-15: Results of values of slip load and slip coefficient for the three specimen tested along with mean values

\begin{tabular}{|c|c|c|c|c|}
\cline { 2 - 5 } \multicolumn{1}{c|}{} & $\begin{array}{c}\text { Specimen 1 } \\
\text { result }\end{array}$ & $\begin{array}{c}\text { Specimen 2 } \\
\text { result }\end{array}$ & $\begin{array}{c}\text { Specimen 3 } \\
\text { result }\end{array}$ & Mean \\
\hline Slip load $(\mathrm{N})$ & $74,237.0$ & $66,622.7$ & $58,311.0$ & $\mathbf{6 6 , 3 9 0 . 2}$ \\
\hline $\begin{array}{c}\text { Slip coefficient } \\
\left(\mathrm{k}_{\mathrm{s}}\right)\end{array}$ & 0.198 & 0.178 & 0.155 & $\mathbf{0 . 1 7 7}$ \\
\hline
\end{tabular}




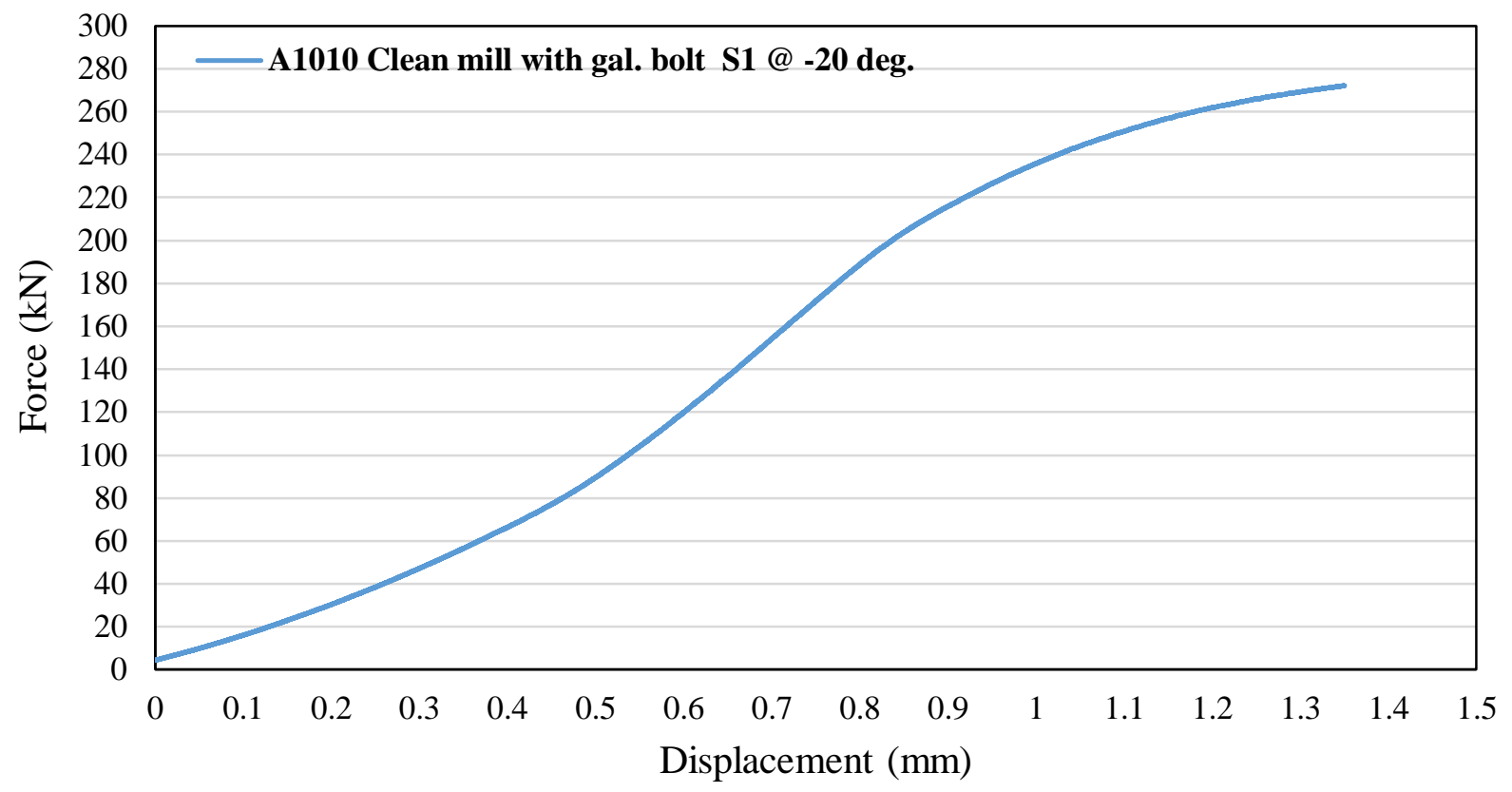

Figure 9-16: Force-displacement relationship for A1010 stainless steel with clean mill scale surface condition with galvanized bolt for test specimen 1 at $-20^{\circ} \mathrm{C}$ temperature

Table 9-16: Results of values of slip load and slip coefficient for the three specimen tested along with mean values

\begin{tabular}{|c|c|c|c|c|}
\cline { 2 - 5 } \multicolumn{1}{c|}{} & $\begin{array}{c}\text { Specimen 1 } \\
\text { result }\end{array}$ & $\begin{array}{c}\text { Specimen 2 } \\
\text { result }\end{array}$ & $\begin{array}{c}\text { Specimen 3 } \\
\text { result }\end{array}$ & Mean \\
\hline Slip load $(\mathrm{N})$ & $89,481.0$ & $94,478.2$ & $88,276.1$ & $\mathbf{9 0 , 7 4 5 . 1}$ \\
\hline $\begin{array}{c}\text { Slip coefficient } \\
\left(\mathrm{k}_{\mathrm{s}}\right)\end{array}$ & 0.238 & 0.252 & 0.235 & $\mathbf{0 . 2 4 2}$ \\
\hline
\end{tabular}




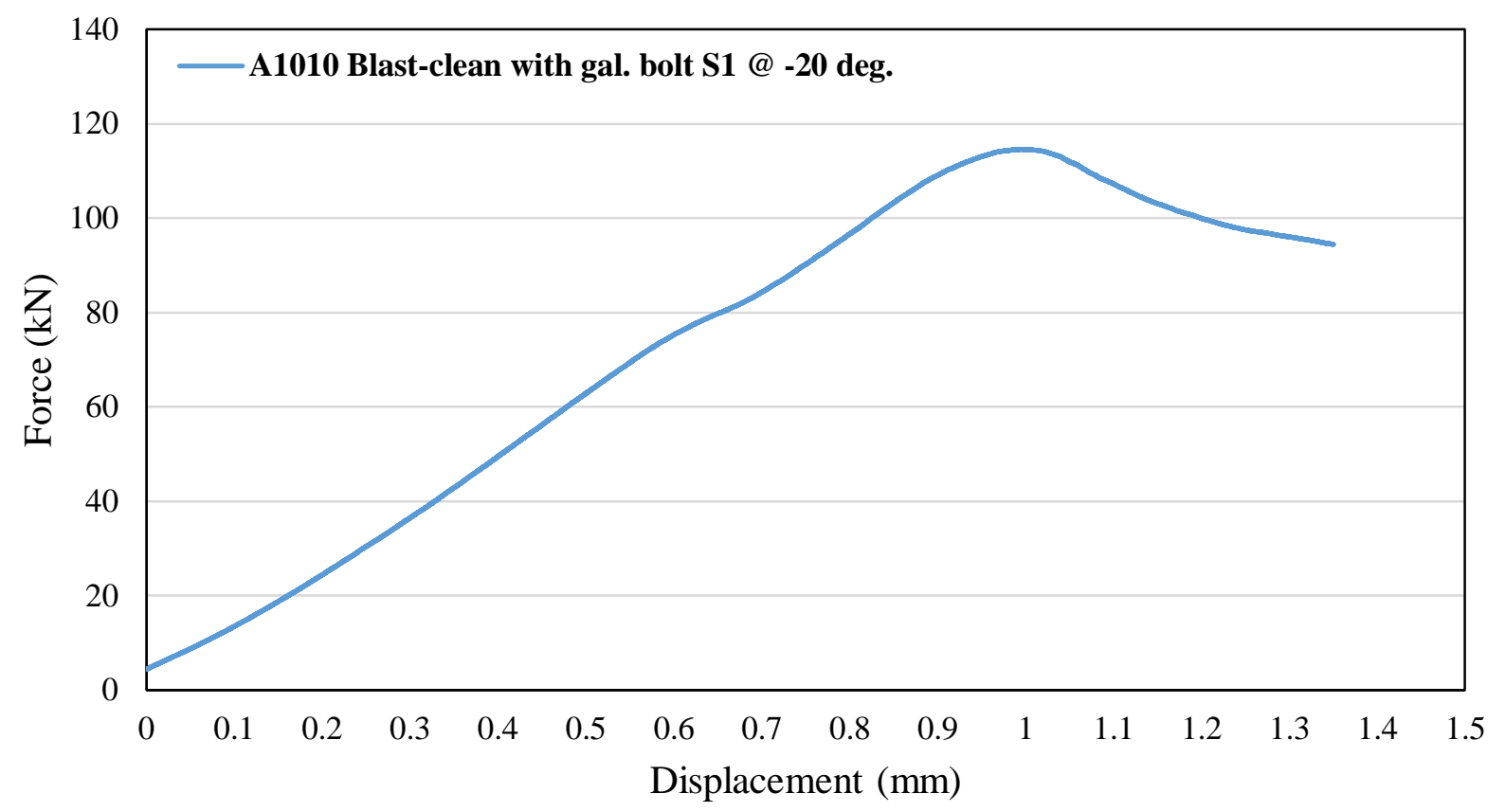

Figure 9-17: Force-displacement relationship for A1010 stainless steel with blasted clean surface condition with galvanized bolt for test specimen 1 at $-20^{\circ} \mathrm{C}$ temperature

Table 9-17: Results of values of slip load and slip coefficient for the three specimen tested along with mean values

\begin{tabular}{|c|c|c|c|c|}
\cline { 2 - 5 } \multicolumn{1}{c|}{} & $\begin{array}{c}\text { Specimen 1 } \\
\text { result }\end{array}$ & $\begin{array}{c}\text { Specimen 2 } \\
\text { result }\end{array}$ & $\begin{array}{c}\text { Specimen 3 } \\
\text { result }\end{array}$ & Mean \\
\hline Slip load $(\mathrm{N})$ & $62,800.9$ & $75,190.7$ & $82,112.1$ & $\mathbf{7 3 , 3 6 7 . 9}$ \\
\hline $\begin{array}{c}\text { Slip coefficient } \\
\left(\mathrm{k}_{\mathrm{s}}\right)\end{array}$ & 0.167 & 0.200 & 0.219 & $\mathbf{0 . 1 9 5}$ \\
\hline
\end{tabular}


Table 9-18: Mean temperature progression throughout testing of specimen for various surface treatment at $-20^{\circ} \mathrm{C}$

\begin{tabular}{|c|c|c|c|c|c|c|c|c|c|c|c|c|}
\hline \multirow[b]{2}{*}{$\begin{array}{c}\text { Test } \\
\text { material }\end{array}$} & \multirow[b]{2}{*}{$\begin{array}{c}\text { Surface } \\
\text { type (class) }\end{array}$} & \multicolumn{11}{|c|}{ Time (mins) } \\
\hline & & $\mathbf{0}$ & 2 & 4 & 6 & 8 & 10 & 12 & 14 & 16 & 18 & 20 \\
\hline & & \multicolumn{11}{|c|}{ Mean temperature between the specimen $\left({ }^{\circ} \mathrm{C}\right)$} \\
\hline $\begin{array}{c}\text { Structural } \\
\text { steel } \\
(350 \mathrm{~W})\end{array}$ & $\begin{array}{c}\text { A (clean } \\
\text { mill scale) }\end{array}$ & -22.0 & -10.2 & -3.1 & 2.9 & 4.7 & 7.8 & 11.6 & 13.5 & 14.9 & 16.0 & 17.3 \\
\hline $\begin{array}{c}\text { Structural } \\
\text { steel } \\
(350 \mathrm{~W})\end{array}$ & $\begin{array}{c}\text { B } \\
\text { (Blast- } \\
\text { clean) }\end{array}$ & -22.9 & -9.2 & -2.6 & 3.2 & 7.4 & 10.4 & 12.7 & 14.7 & 16.1 & 17.0 & 17.8 \\
\hline $\begin{array}{c}\text { Structural } \\
\text { steel } \\
(350 \mathrm{~W})\end{array}$ & $\begin{array}{c}\mathrm{C} \quad \text { (Hot } \\
\text { dip } \\
\text { galvanized } \\
\text { with gal. } \\
\text { bolt) }\end{array}$ & -22.6 & -13.6 & -6.3 & -0.4 & 4.7 & 8.0 & 10.6 & 12.9 & 14.5 & 15.7 & 16.7 \\
\hline $\begin{array}{l}\text { Stainless } \\
\text { steel }\end{array}$ & $\begin{array}{l}\text { A (Clean } \\
\text { mill scale) }\end{array}$ & -20.5 & -16.2 & -6.4 & 0.9 & 5.1 & 7.5 & 10.1 & 12.0 & 13.7 & 15.0 & 16.0 \\
\hline $\begin{array}{l}\text { Stainless } \\
\text { steel }\end{array}$ & $\begin{array}{c}\text { B } \\
\text { (Blast- } \\
\text { clean) }\end{array}$ & -20.8 & -11.1 & -1.8 & 4.2 & 6.2 & 8.6 & 10.6 & 12.6 & 14.2 & 15.3 & 16.1 \\
\hline
\end{tabular}




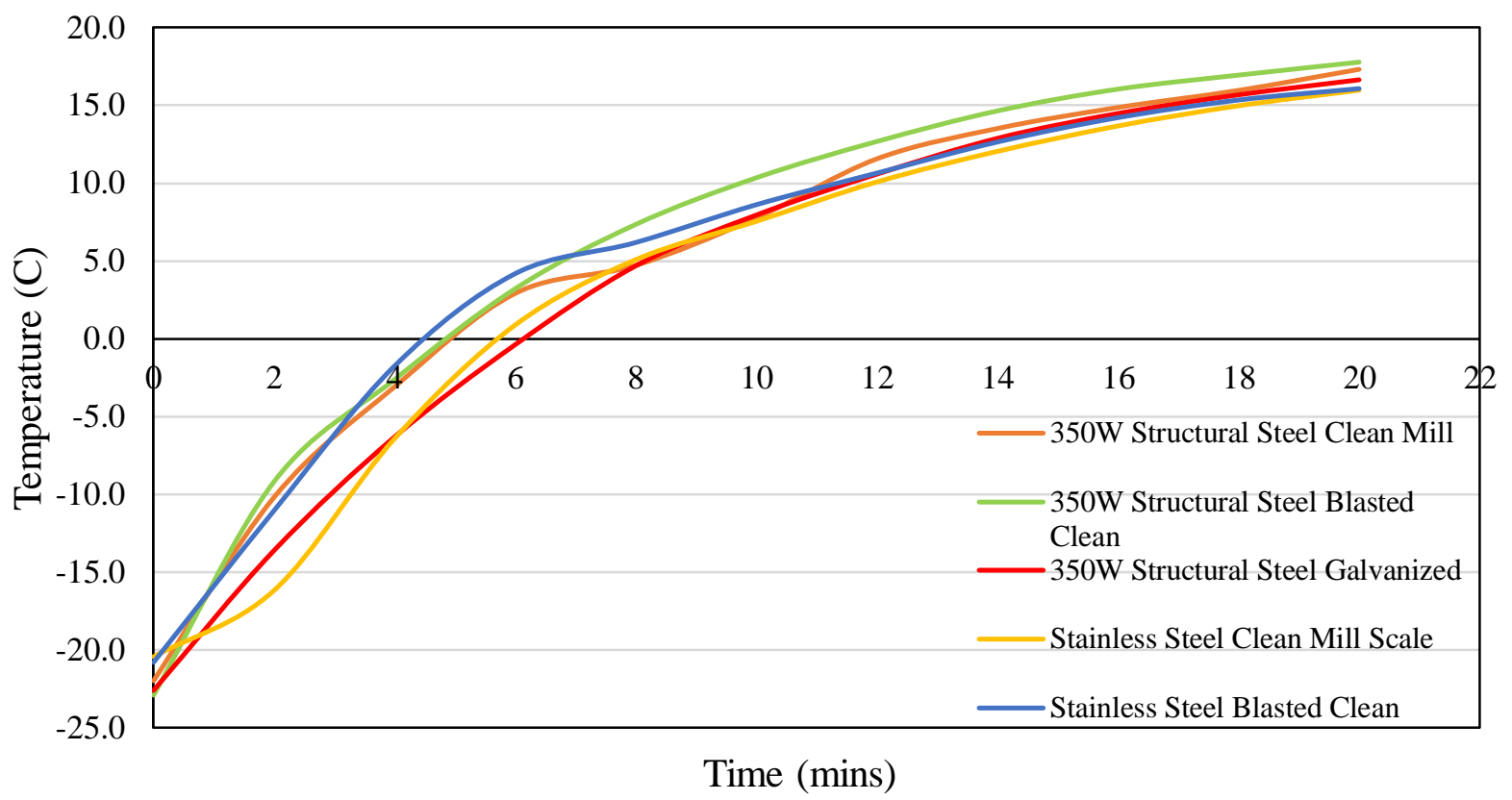

Figure 9-18: Mean temperature vs time progression throughout testing for various surface condition at $-20^{\circ} \mathrm{C}$ 


\subsection{Slip Resistance at a Target Temperature of $-30^{\circ} \mathrm{C}$}

Figure 9-19 through Figure 9-22 present sample graphs for the applied compressive loaddisplacement history for the tested bolt-plate assemblies (with the rest of the result graphs presented in Appendix E), with Table 9-19 through Table 9-22 presenting the mean slip load and mean slip coefficient for each test specimen at target temperature of $-30{ }^{\circ} \mathrm{C}$. Again, results showed insignificant change in slip coefficient at target temperature of $-30^{\circ} \mathrm{C}$. Table $9-23$ presents the mean temperature variation of each specimens tested at $-30^{\circ} \mathrm{C}$, whereas the temperature progression throughout testing is presented in Figure 9-23.

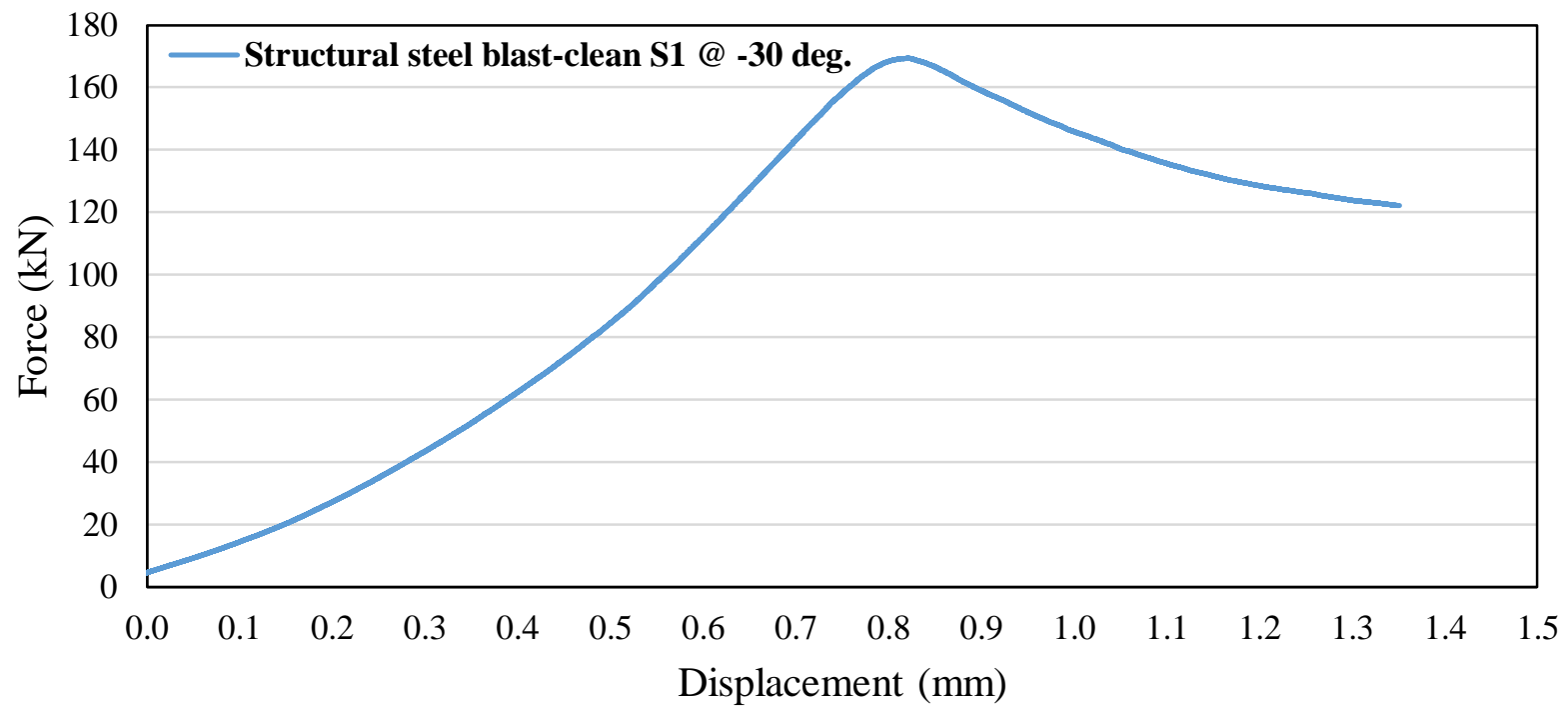

Figure 9-19: Force-displacement relationship for structural steel with blast-clean surface condition with $\mathrm{A325}$ bolt for test specimen 1 at $-30^{\circ} \mathrm{C}$ temperature

Table 9-19: Results of values of slip load and slip coefficient for the three specimen tested along with mean values

\begin{tabular}{|c|c|c|c|c|}
\cline { 2 - 5 } \multicolumn{1}{c|}{} & $\begin{array}{c}\text { Specimen 1 } \\
\text { result }\end{array}$ & $\begin{array}{c}\text { Specimen 2 } \\
\text { result }\end{array}$ & $\begin{array}{c}\text { Specimen 3 } \\
\text { result }\end{array}$ & Mean \\
\hline Slip load (N) & $84,451.5$ & $90,452.1$ & $77,560.8$ & $\mathbf{8 4 , 1 5 4 . 8}$ \\
\hline $\begin{array}{c}\text { Slip coefficient } \\
\left(\mathrm{k}_{\mathrm{s}}\right)\end{array}$ & 0.208 & 0.223 & 0.191 & $\mathbf{0 . 2 0 6}$ \\
\hline
\end{tabular}




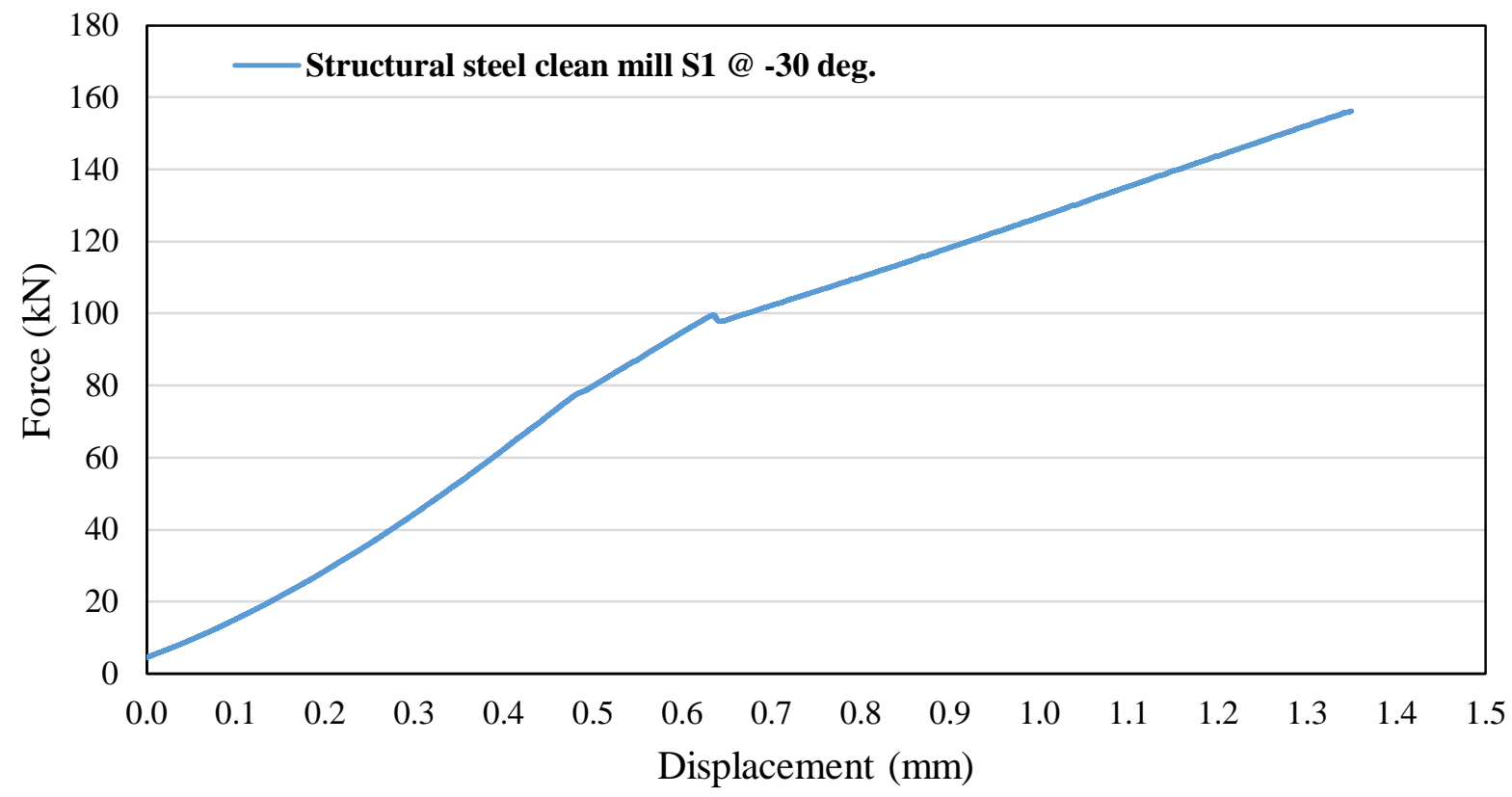

Figure 9-20: Force-displacement relationship for structural steel with clean mill scale surface condition with $\mathrm{A325}$ bolt for test specimen 1 at $-30^{\circ} \mathrm{C}$ temperature

Table 9-20: Results of values of slip load and slip coefficient for the three specimen tested along with mean values

\begin{tabular}{|c|c|c|c|c|}
\cline { 2 - 5 } \multicolumn{1}{c|}{} & $\begin{array}{c}\text { Specimen 1 } \\
\text { result }\end{array}$ & $\begin{array}{c}\text { Specimen 2 } \\
\text { result }\end{array}$ & $\begin{array}{c}\text { Specimen 3 } \\
\text { result }\end{array}$ & Mean \\
\hline Slip load (N) & $79,723.0$ & $80,757.4$ & $64,430.5$ & $\mathbf{7 4 , 9 7 0 . 3}$ \\
\hline $\begin{array}{c}\text { Slip coefficient } \\
\left(\mathrm{k}_{\mathrm{s}}\right)\end{array}$ & 0.196 & 0.199 & 0.159 & $\mathbf{0 . 1 8 4}$ \\
\hline
\end{tabular}




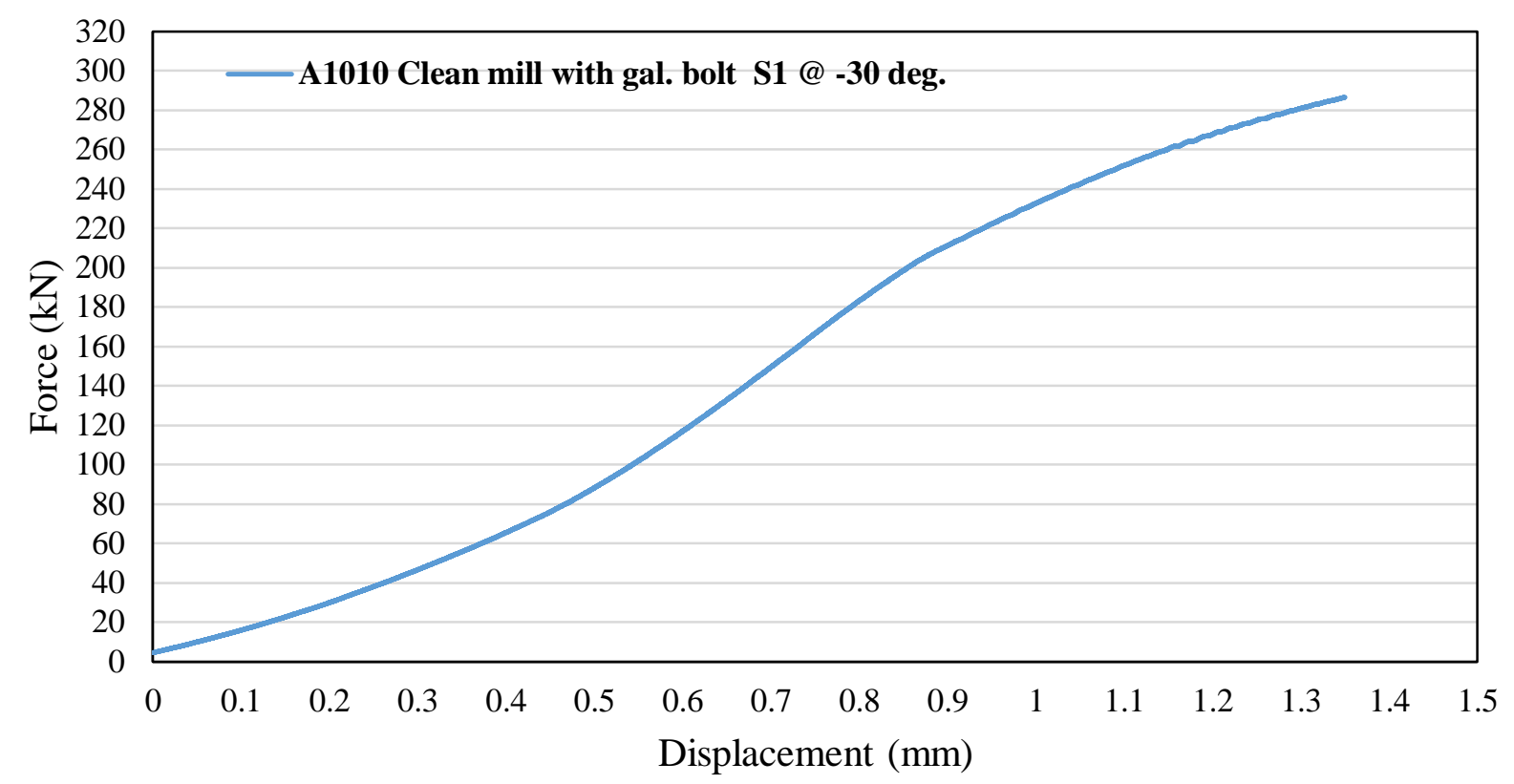

Figure 9-21: Force-displacement relationship for structural steel with clean mill scale surface condition with galvanized bolt for test specimen 1 at $-30^{\circ} \mathrm{C}$ temperature

Table 9-21: Results of values of slip load and slip coefficient for the three specimen tested along with mean values

\begin{tabular}{|c|c|c|c|c|}
\cline { 2 - 5 } \multicolumn{1}{c|}{} & $\begin{array}{c}\text { Specimen 1 } \\
\text { result }\end{array}$ & $\begin{array}{c}\text { Specimen 2 } \\
\text { result }\end{array}$ & $\begin{array}{c}\text { Specimen 3 } \\
\text { result }\end{array}$ & Mean \\
\hline Slip load $(\mathrm{N})$ & $88,145.7$ & $77,830.5$ & $84,538.0$ & $\mathbf{8 3 , 5 0 4 . 7}$ \\
\hline $\begin{array}{c}\text { Slip } \\
\text { coefficient }\left(\mathrm{k}_{\mathrm{s}}\right)\end{array}$ & 0.235 & 0.207 & 0.225 & $\mathbf{0 . 2 2 2}$ \\
\hline
\end{tabular}




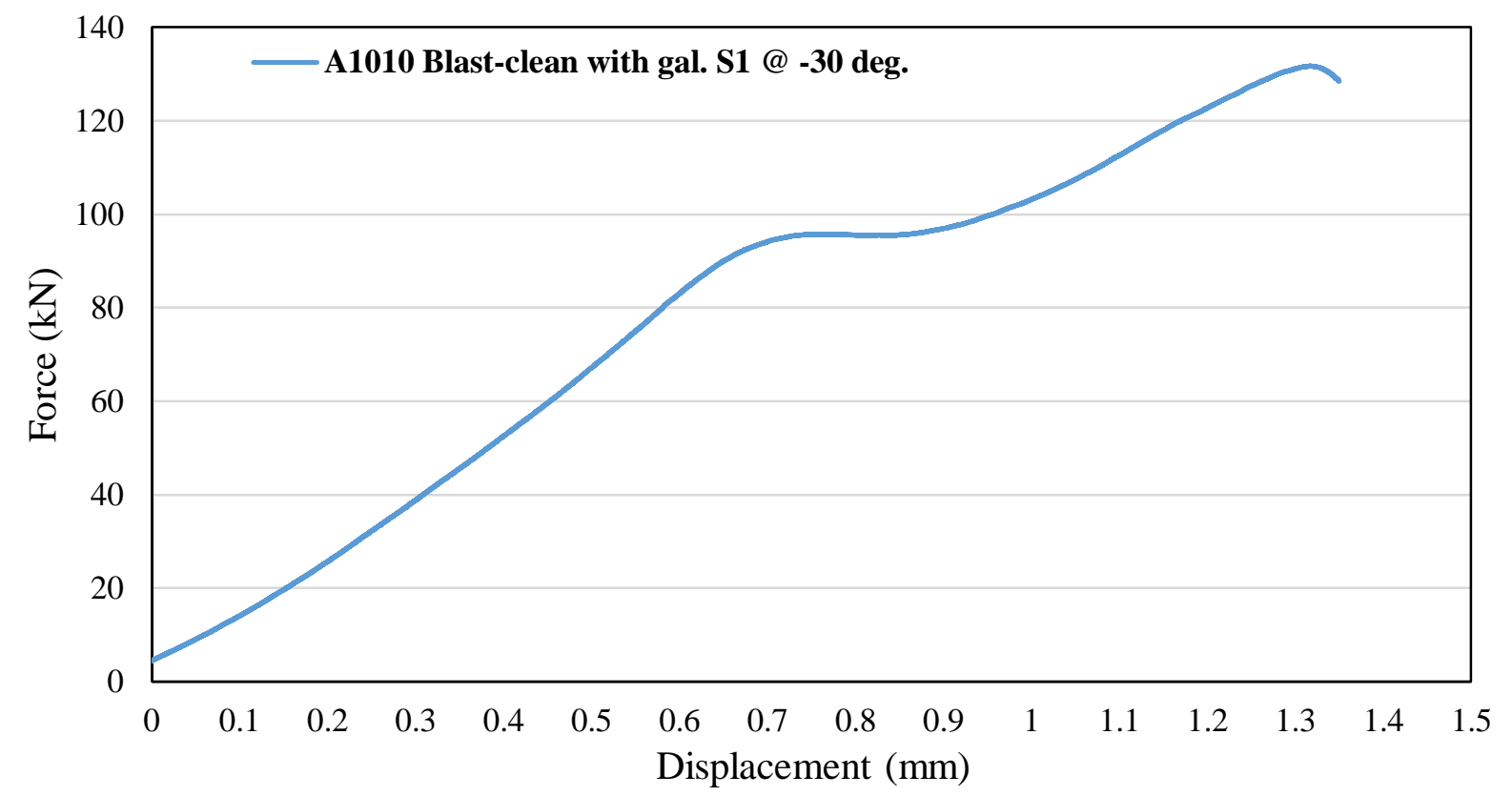

Figure 9-22: Force-displacement relationship for stainless steel with blast-clean surface condition with galvanized bolt for test specimen 1 at $-30^{\circ} \mathrm{C}$ temperature

Table 9-22: Results of values of slip load and slip coefficient for the three specimen tested along with mean values

\begin{tabular}{|c|c|c|c|c|}
\cline { 2 - 5 } \multicolumn{1}{c|}{} & Specimen 1 result & $\begin{array}{c}\text { Specimen 2 } \\
\text { result }\end{array}$ & $\begin{array}{c}\text { Specimen 3 } \\
\text { result }\end{array}$ & Mean \\
\hline Slip load $(\mathrm{N})$ & $67,109.5$ & $63,709.4$ & $60,161.9$ & $\mathbf{6 3 , 6 6 0 . 3}$ \\
\hline $\begin{array}{c}\text { Slip coefficient } \\
\left(\mathrm{k}_{\mathrm{s}}\right)\end{array}$ & 0.179 & 0.170 & 0.160 & $\mathbf{0 . 1 7 0}$ \\
\hline
\end{tabular}


Table 9-23: Mean temperature progression throughout testing of specimen for various surface treatment at $-30^{\circ} \mathrm{C}$

\begin{tabular}{|c|c|c|c|c|c|c|c|c|c|c|c|c|}
\cline { 3 - 11 } \multicolumn{1}{c|}{$\begin{array}{c}\text { Test } \\
\text { material }\end{array}$} & $\begin{array}{c}\text { Surface } \\
\text { type } \\
\text { (class) }\end{array}$ & $\mathbf{0}$ & $\mathbf{2}$ & $\mathbf{4}$ & $\mathbf{6}$ & $\mathbf{8}$ & $\mathbf{1 0}$ & $\mathbf{1 2}$ & $\mathbf{1 4}$ & $\mathbf{1 6}$ & $\mathbf{1 8}$ & $\mathbf{2 0}$ \\
\hline \multicolumn{1}{|c|}{$\begin{array}{c}\text { Structural } \\
\text { steel } \\
(350 \mathrm{~W})\end{array}$} & $\begin{array}{c}\mathbf{A} \text { (Clean } \\
\text { mill } \\
\text { scale) }\end{array}$ & -31.6 & -18.8 & -12.9 & -4.4 & 1.0 & 4.7 & 8.2 & 10.9 & 12.6 & 14.4 & 15.8 \\
\hline $\begin{array}{c}\text { Structural } \\
\text { steel (350W) }\end{array}$ & $\begin{array}{c}\text { B } \\
\text { (Blast- } \\
\text { clean) }\end{array}$ & -33.6 & -24.2 & -14.1 & -5.5 & 0.1 & 4.2 & 7.6 & 10.3 & 12.3 & 13.7 & 15.0 \\
\hline $\begin{array}{c}\text { Stainless } \\
\text { steel }\end{array}$ & $\begin{array}{c}\text { A clean } \\
\text { mill } \\
\text { scale) }\end{array}$ & -30.9 & -16.0 & -7.9 & -3.0 & 1.2 & 4.2 & 7.1 & 9.3 & 11.2 & 12.7 & 14.1 \\
\hline $\begin{array}{c}\text { Stainless } \\
\text { steel }\end{array}$ & $\begin{array}{c}\text { B } \\
\text { (Blast- } \\
\text { clean) }\end{array}$ & -30.5 & -15.0 & -8.0 & -3.6 & 1.8 & 3.6 & 6.2 & 8.4 & 10.1 & 11.7 & 12.9 \\
\hline
\end{tabular}




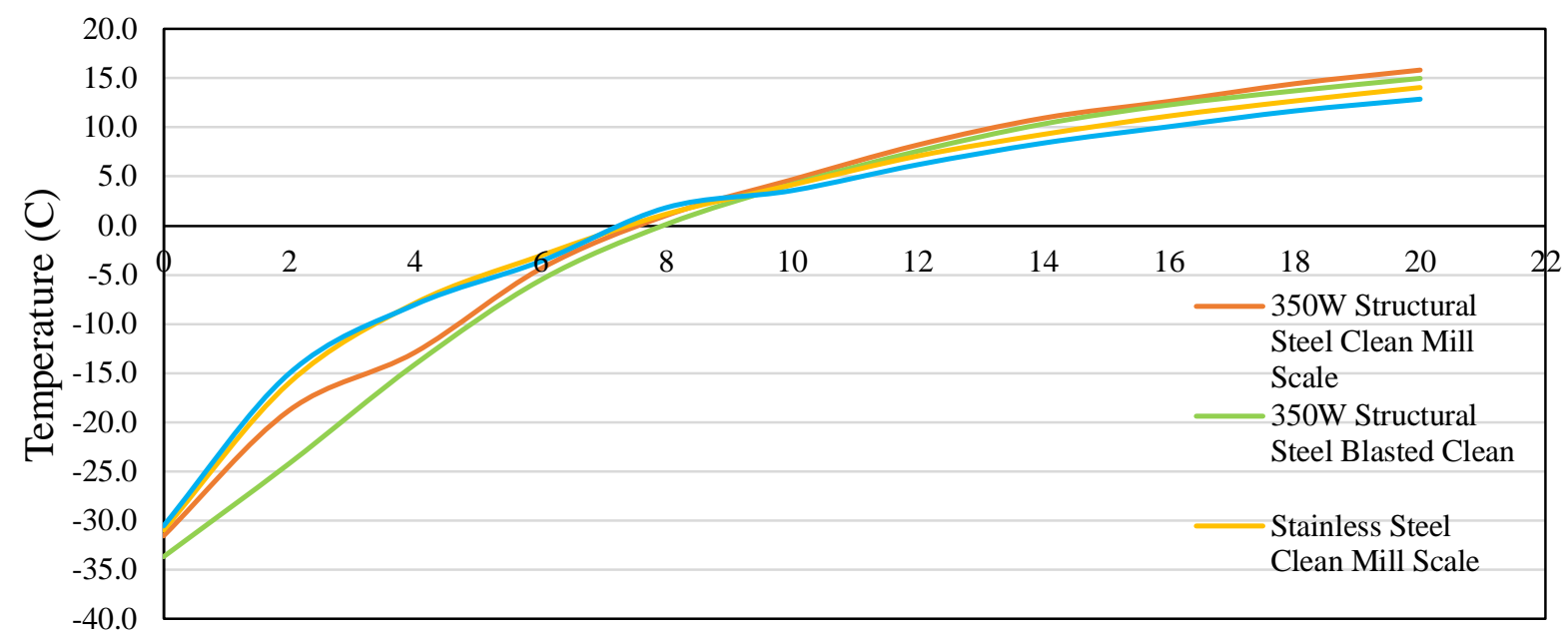

Time (mins)

Figure 9-23: Mean temperature vs time progression throughout testing for various surface condition at $-20^{\circ} \mathrm{C}$

\subsection{Analysis of Temperature Effect on Slip Coefficient for Different Surface Condition}

\subsubsection{W Structural steel material}

With the aim of testing in this phase of research been the analysis of temperature effect on slip coefficient performance, it was important to ascertain whether the degree of impact by temperature on the slip coefficient changes with different material and with different surface condition within the same material group. Based on testing results shown in Figure 9-24, for the clean mills scale surface condition of $350 \mathrm{~W}$ structural steel, there is a decrease in the slip coefficient as the target temperature decreases from $-5^{\circ} \mathrm{C}$ to $-20^{\circ} \mathrm{C}$. This decrease was in the order of approximately $12.8 \%$. However, with a further decrease in temperature from $-20^{\circ} \mathrm{C}$ to $-30^{\circ} \mathrm{C}$, there was an increase in the slip coefficient performance of approximately $12.8 \%$. Figure $9-25$ for the $350 \mathrm{~W}$ structural steel with blast-cleaned surface condition shows a more consistent performance of the slip coefficient when varying the target temperature, with slip coefficient remaining virtually the same throughout. This indicates that for the 350W structural steel with blast-cleaned surface condition, the effect of adverse temperature has no pronounce impact on the slip coefficient performance of the bolted joint connection. 


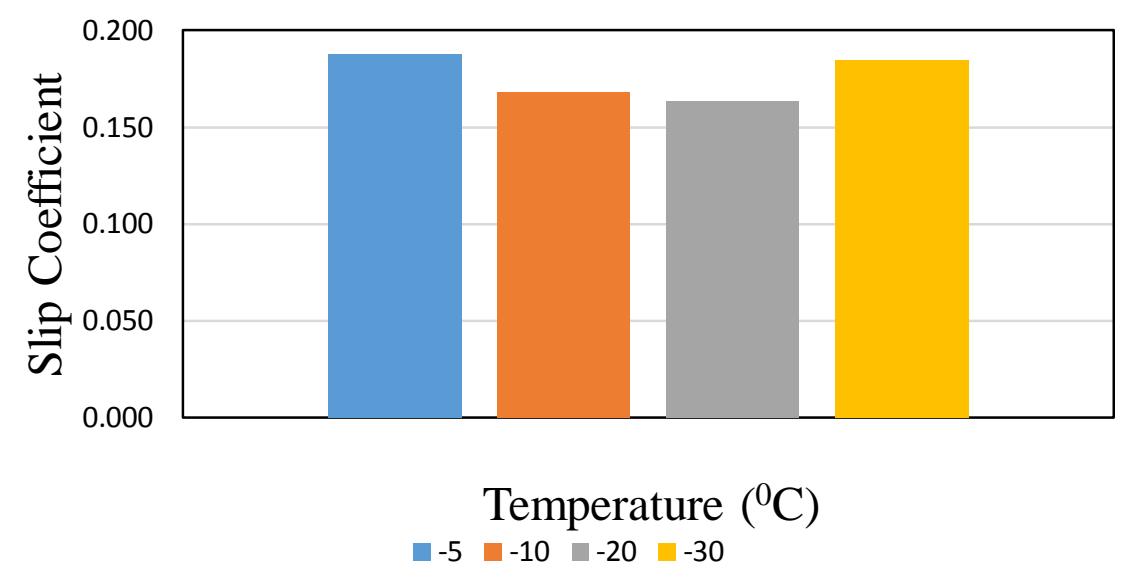

Figure 9-24: Effect of varying temperature on 350W Structural steel with clean mill scale surface condition

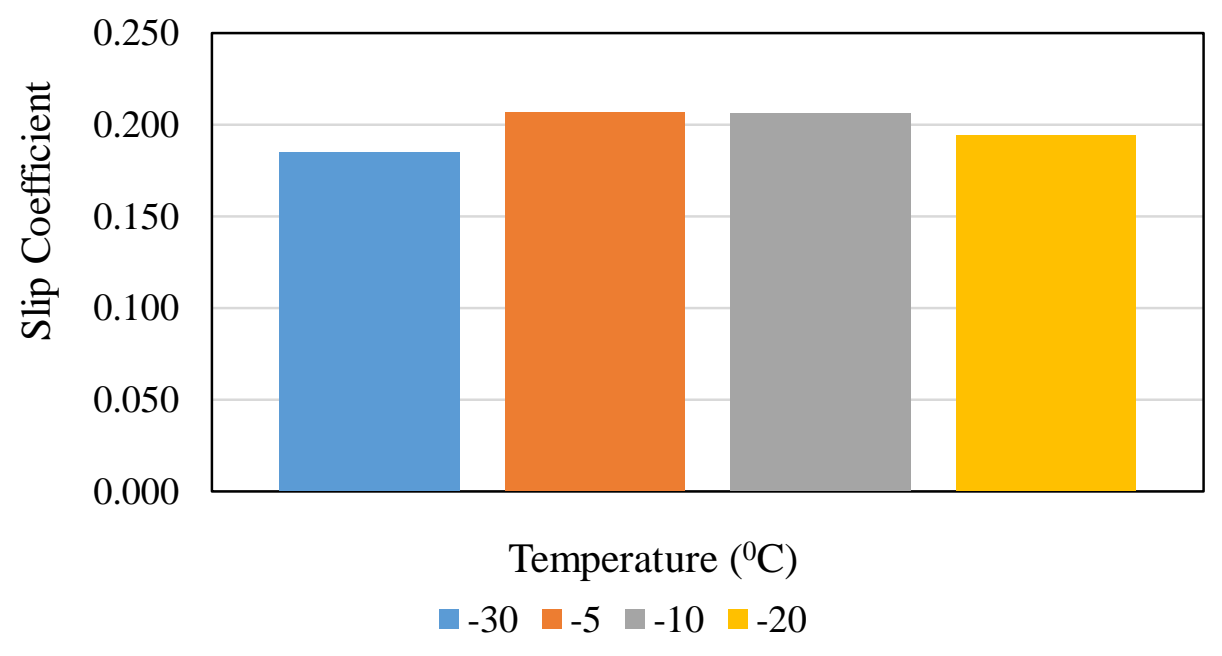

Figure 9-25: Effect of varying temperature on 350W structural steel with blasted clean surface condition.

\subsubsection{ASTM A1010 Stainless steel material}

Figure 9-26 depicts the slip coefficient performance of ASTM A1010 stainless steel with clean mill scale surface condition at varying target temperatures. It shows no definitive statistical pattern to say whether or not target temperature has a significant impact on the slip coefficient of this material with this surface condition. However, it is important to note that by comparing the slip 
coefficient performance for the A1010 stainless steel with clean mill scale surface condition at adverse temperatures was slightly higher than that at room temperature. For the ASTM A1010 stainless steel with blast-cleaned surface condition, results followed a similar trend as the A1010 stainless steel with clean mill scale surface condition, showing insignificant effect of target temperature during the test on the value of slip coefficient, see Figure 9-27.

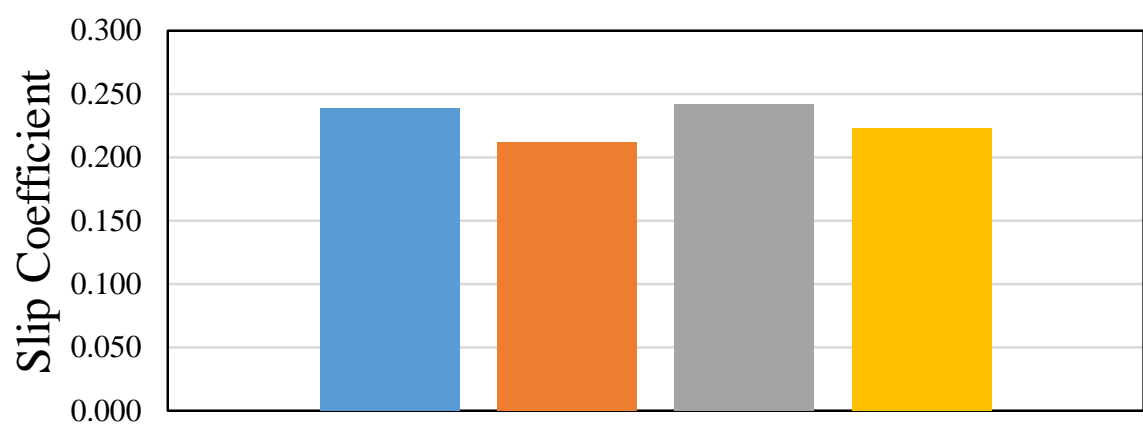

Temperature $\left({ }^{\circ} \mathrm{C}\right)$

$\because-5 \backsim-10 \backsim-20 \backsim-30$

Figure 9-26: Effect of varying temperature on ASTM A1010 stainless steel with clean mill scale surface condition.

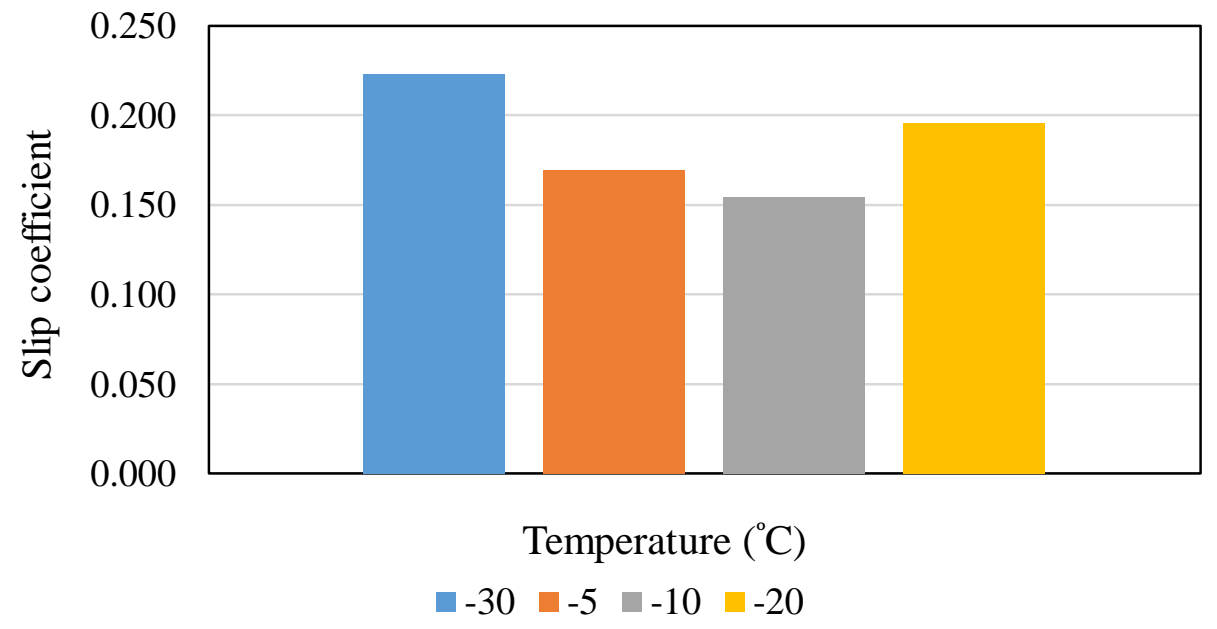

Figure 9-27: Effect of varying temperature on ASTM stainless steel with blasted clean surface condition 


\section{Chapter 10: CONCLUSIONS AND RECOMMENDATIONS FOR FUTURE WORK}

\subsection{Conclusions}

The primary aim of this experimental research was to provide information on the slip coefficient performance of ASTM A1010 stainless steel material and to ascertain if its behaviour is comparable to that of $350 \mathrm{~W}$ Structural Steel. In accomplishing this task, it was important to examine other parameters associated with slip resistance testing, such as (i) bolt relaxation and (ii) the effect of temperature variation and re-usability of high strength bolts. In the 2014 edition of the Canadian Highway Bridge Design Code, the slip coefficient for clean mill scale and hot dip galvanized surface condition for the $350 \mathrm{~W}$ structural steel is specified as 0.35 , whereas for blastedclean surface condition is specified as 0.5 . Based on test results, the following conclusions were drawn.

a) The mean coefficient of slip resistance of ASTM A1010 stainless steel was greater than that of $350 \mathrm{~W}$ structural steel for the clean mill scale surface conditions. Whereas, the mean coefficient of slip for the blast-cleaned surface condition for ASTM A1010 stainless steel did not outperformed the 350W structural steel. Though the slip coefficient values for both type of steel at various surface conditions were lower than those found in the CSA-S16-14 and CSA-S6-14, upon comparison with other research literature, such as Yura et al. (1981), the results obtained in this research were acceptable.

b) Testing for the determination of slip coefficient in this research was done using actual conditions practiced within the steel industry. The bolt was first pretensioned to the target value, then the bolt-plate assembly was left $72 \mathrm{hrs}$ before conducting the slip-resistance test. Then, the test was conducted with the actual clamping force in the bolt during the test that included effect of bolt relaxation. However, the ASTM test method and the research conducted to reach the slip coefficient values specified in the CHBDC mandated maintaining the clamping force through testing with a hydraulic jack and a load cell. This condition of maintaining clamping force during the test with an accuracy of $\pm 1 \%$ as stated in the test method may not represent the actual condition in bolted connections. As, such further research may be conducted to determine the actual clamping force during the slip resistance test when (i) a hydraulic jack is used to maintain the clamping force within $\pm 1 \%$ accuracy and (ii) the bolt pretension simulates the actual condition in the joint by applying 
the clamping force before the test with no further adjustment during the test. In addition, previous research that led to code values for slip-resistance appears not to consider whether bolt relaxation will affect the intended pretension force and thus the associated slipresistance coefficient.

c) The achieved level of surface roughness in this research was less than that specified by MTO (2 mils). However, due to the fact that there is no set surface roughness standard mentioned in the CHBDC or in any other literature, hence surface roughness level is left to the discretion of users (i.e. researchers and steel fabricators). This difference in the limiting value for surface roughness would have a direct impact on the slip coefficient value. As such, it is recommended that CSA-S6-14 and CSA-S16-14 specify the surface roughness required to achieve the specified slip resistance factor specified in the code.

d) The method of blast-cleaning the surface, considered in this research, was not mentioned in the code and thus research may be conducted by using different blasting process, which would give different surface roughness values. These methods are (i) sand-blasting with a specified sand particle size to reach the target surface roughness without smoothing the surface, (ii) shot-blasting with steel balls with specified diameters and (iii) grit blasting with irregular-shape aluminium oxide particles.

e) Within each surface condition, varying the temperature does not appear to have an impact on the slip coefficient performance. However, further research is research to support this finding by increasing number of tested samples and maintaining the plate-bolt assembly during slip test.

f) Results on the bolt re-usability on A325 and Galvanized A325 high strength bolts showed that the bolt can be reused up to 5 times without lubrication. On the other hand, the maximum clamping force applied to B8 Class 1 stainless steel bolts did not reach $70 \%$ of the capacity of the bolt. As such, it is recommended to use such bolt type in bearing-type connection with snug-tight condition till further research is conducted to examine its applicability to slip-resistance connection.

g) A standardized method of clamping force verification and application needs to be developed in order to eliminate ambiguity within future slip coefficient testing procedure. 


\subsection{Recommendations for Future Studies}

This research is by no means a final conclusion on design of ASTM A1010 stainless steel slipresistance joint. Based on the experiments performed within this research, there exist a number of other research opportunities which can be explored within this field of study. The following are recommendations for future research:

1) Examining the impact of different bolt tensioning methods on the behaviour of slip-critical joint.

2) Enlarging the present testing pool to ascertain better statistical analysis of the data to obtain a more precise trend.

3) Increasing the temperature intervals when conducting the effect of temperature variation on slip coefficient testing while maintaining such temperature during the test to obtain a better statistical data.

4) The effect of bolt relaxation on slip critical joints can be further investigated considering relaxation over longer period of time.

5) Determination of the slip resistance coefficient when (i) a hydraulic jack is used to maintain the clamping force within $\pm 1 \%$ accuracy and (ii) the bolt pretension simulates the actual condition in the joint by applying the clamping force before the test with no further adjustment during the test.

6) Examining the impact of the different method of obtaining blast-cleaned surface condition and determining the most appropriate method needed to obtain code results. These methods are (i) sand-blasting with a specified sand particle size to reach the target surface roughness without smoothing the surface, (ii) shot-blasting with steel balls with specified diameters and (iii) grit blasting with irregular-shape aluminium oxide particles.

7) Additional tests to be conducted on B8 Class 1 stainless steel bolt to (i) examine its capacity based on pull-out tension test as well as torque test and (ii) its applicability to use in slipcritical connections. 


\section{Appendix A: Bolt Re-usability Testing (unlubricated and lubricated threading)}

Table A - 1: Unlubricated bolt re usability testing results

\begin{tabular}{|c|c|c|c|c|c|c|c|c|}
\hline $\begin{array}{l}\text { Test bolt } \\
\text { sample } \\
\end{array}$ & $\begin{array}{l}\text { Bolt set } \\
\text { number }\end{array}$ & Turn angle ${ }^{\circ}(\theta)$ & & & sults for & t cycle of 10 & ling & \\
\hline \multirow{13}{*}{$\begin{array}{l}\text { A325 High } \\
\text { tensile bolt }\end{array}$} & \multirow{13}{*}{1} & & $\begin{array}{c}\text { Load (P } \text { reading) } \\
\text { (lbf) }\end{array}$ & $\begin{array}{c}\text { Load } \\
\text { (Preading) } \\
\text { (N) }\end{array}$ & $\begin{array}{c}\text { Initial } \\
\text { length } \\
\text { (mm) }\end{array}$ & $\begin{array}{c}\text { Gauge } \\
\text { elongation } \\
(\mathbf{m m})\end{array}$ & $\begin{array}{c}\text { Cummulative } \\
\text { elongation }\end{array}$ & $\begin{array}{c}\text { Difference } \\
\text { between cum. } \\
\text { \& gau. } \\
\text { elongation } \\
\end{array}$ \\
\hline & & & O & $\mathrm{O}$ & 101.377 & $\mathrm{O}$ & 101.377 & $\mathrm{O}$ \\
\hline & & $\mathrm{O}$ & 2000 & 8896.44 & & 0.030 & 101.407 & 0.030 \\
\hline & & 20 & 10000 & 44482.2 & & 0.077 & 101.484 & 0.107 \\
\hline & & 40 & 18000 & 80067.96 & & 0.123 & 101.607 & 0.230 \\
\hline & & 60 & 26000 & 115653.72 & & 0.162 & 101.769 & 0.392 \\
\hline & & 80 & 35000 & 155687.7 & & 0.203 & 101.972 & 0.595 \\
\hline & & 100 & 42000 & 186825.24 & & 0.237 & 102.209 & 0.832 \\
\hline & & 120 & 50000 & 222411 & & 0.268 & 102.477 & 1.100 \\
\hline & & 80 & 32000 & 142343.04 & & 0.185 & 102.292 & 0.915 \\
\hline & & 40 & 14000 & 62275.08 & & 0.108 & 102.184 & 0.807 \\
\hline & & $\mathrm{O}$ & 2000 & 8896.44 & & 0.040 & 102.144 & 0.767 \\
\hline & & $\begin{array}{c}\begin{array}{c}\text { after release of } \\
\text { load }\end{array} \\
\end{array}$ & $\mathrm{O}$ & $\mathrm{O}$ & & 0.022 & 102.122 & 0.745 \\
\hline \multirow{12}{*}{$\begin{array}{c}\text { A325 High } \\
\text { tensile } \\
\text { galvanized bolt }\end{array}$} & \multirow{12}{*}{1} & & $\mathrm{O}$ & $\mathbf{O}$ & 101.638 & O & 101.638 & $\mathrm{O}$ \\
\hline & & $\mathrm{O}$ & 2000 & 8896.44 & & 0.018 & 101.656 & 0.018 \\
\hline & & 20 & 8000 & 35585.76 & & 0.034 & 101.690 & 0.052 \\
\hline & & 40 & 14000 & 62275.08 & & 0.059 & 101.749 & 0.111 \\
\hline & & 60 & 20000 & 88964.4 & & 0.086 & 101.835 & 0.197 \\
\hline & & 80 & 29000 & 128998.38 & & 0.121 & 101.956 & 0.318 \\
\hline & & 100 & 37000 & 164584.14 & & 0.159 & 102.115 & 0.477 \\
\hline & & 120 & 43000 & 191273.46 & & 0.186 & 102.301 & 0.663 \\
\hline & & 80 & 32000 & 142343.04 & & 0.139 & 102.162 & 0.524 \\
\hline & & 40 & 16000 & 71171.52 & & 0.079 & 102.083 & 0.445 \\
\hline & & O & 2000 & 8896.44 & & 0.024 & 102.059 & 0.421 \\
\hline & & $\begin{array}{c}\text { after release of } \\
\text { load }\end{array}$ & $\mathrm{O}$ & O & & 0.015 & 102.044 & 0.406 \\
\hline \multirow{12}{*}{$\begin{array}{c}\text { Stainless steel } \\
\text { bolt }\end{array}$} & \multirow{12}{*}{1} & & O & $\mathrm{O}$ & 116.059 & $\mathrm{O}$ & 116.059 & $\mathrm{O}$ \\
\hline & & $\mathrm{O}$ & 2000 & 8896.44 & & 0.013 & 116.072 & 0.013 \\
\hline & & 20 & 8000 & 35585.76 & & 0.029 & 116.101 & 0.042 \\
\hline & & 40 & 11000 & 48930.42 & & 0.076 & 116.177 & 0.118 \\
\hline & & 60 & 12000 & 53378.64 & & 0.111 & 116.288 & 0.229 \\
\hline & & 80 & 13000 & 57826.86 & & 0.152 & 116.44 & 0.381 \\
\hline & & 100 & 13000 & 57826.86 & & 0.176 & 116.616 & 0.557 \\
\hline & & 120 & 13000 & 57826.86 & & 0.208 & 116.824 & 0.765 \\
\hline & & 80 & 10000 & 44482.2 & & 0.201 & 116.623 & 0.564 \\
\hline & & 40 & 2000 & 8896.44 & & 0.159 & 116.464 & 0.405 \\
\hline & & $\mathrm{O}$ & 2000 & 8896.44 & & 0.149 & 116.315 & 0.256 \\
\hline & & $\begin{array}{c}\text { after release of } \\
\text { load }\end{array}$ & o & O & & 0.089 & 116.226 & 0.167 \\
\hline
\end{tabular}


Table A - 1 con't: Unlubricated bolt re-usability testing results

\begin{tabular}{|c|c|c|c|c|c|c|c|}
\hline $\begin{array}{c}\text { Test bolt } \\
\text { sample } \\
\end{array}$ & $\begin{array}{l}\text { Bolt set } \\
\text { number }\end{array}$ & $\begin{array}{c}\text { Turn angle } \\
0(\theta)\end{array}$ & \multicolumn{5}{|c|}{ Results for second cycle of loading } \\
\hline \multirow{13}{*}{$\begin{array}{l}\text { A325 High } \\
\text { tensile bolt }\end{array}$} & \multirow{13}{*}{1} & & $\begin{array}{c}\text { Load (Preading) } \\
\text { (lbf) }\end{array}$ & $\begin{array}{c}\text { Coad } \\
\text { (Preading) } \\
\text { (N) }\end{array}$ & $\begin{array}{c}\text { Gauge } \\
\text { elongation } \\
(\mathrm{mm})\end{array}$ & $\begin{array}{c}\text { Cummulative } \\
\text { elongation }\end{array}$ & $\begin{array}{c}\text { Difference } \\
\text { between } \\
\text { cum. \& gau. } \\
\text { elongation }\end{array}$ \\
\hline & & & $\mathbf{O}$ & $\mathrm{O}$ & & 102.122 & 0.745 \\
\hline & & $\mathbf{O}$ & 2000 & 8896.44 & 0.049 & 102.171 & 0.794 \\
\hline & & 20 & 9000 & 40033.98 & 0.087 & 102.258 & 0.881 \\
\hline & & 40 & 18000 & 80067.96 & 0.127 & 102.385 & 1.008 \\
\hline & & 60 & 26000 & 115653.72 & 0.166 & 102.551 & 1.174 \\
\hline & & 80 & 35000 & 155687.7 & 0.204 & 102.755 & 1.378 \\
\hline & & 100 & 42000 & 186825.24 & 0.238 & 102.993 & 1.616 \\
\hline & & 120 & 50000 & 222411 & 0.270 & 103.263 & 1.886 \\
\hline & & 80 & 32000 & 142343.04 & 0.189 & 103.074 & 1.697 \\
\hline & & 40 & 14000 & 62275.08 & 0.112 & 102.962 & 1.585 \\
\hline & & $\mathrm{O}$ & 2000 & 8896.44 & 0.045 & 102.917 & 1.540 \\
\hline & & $\begin{array}{c}\text { after release of } \\
\text { load }\end{array}$ & $\mathbf{O}$ & o & 0.025 & 102.892 & 1.515 \\
\hline \multirow{12}{*}{$\begin{array}{c}\text { A325 High } \\
\text { tensile } \\
\text { galvanized bolt }\end{array}$} & \multirow{12}{*}{1} & & $\mathrm{O}$ & $\mathrm{O}$ & & 102.044 & 0.406 \\
\hline & & $\mathbf{O}$ & 2000 & 8896.44 & 0.016 & 102.060 & 0.422 \\
\hline & & 20 & 7000 & 31137.54 & 0.024 & 102.084 & 0.446 \\
\hline & & 40 & 16000 & 71171.52 & 0.053 & 102.137 & 0.499 \\
\hline & & 60 & 24000 & 106757.28 & 0.084 & 102.221 & 0.583 \\
\hline & & 80 & 34000 & 151239.48 & 0.125 & 102.346 & 0.708 \\
\hline & & 100 & 41000 & 182377.02 & 0.155 & 102.501 & 0.863 \\
\hline & & 120 & & & & & \\
\hline & & 80 & & & & & \\
\hline & & 40 & & & & & \\
\hline & & $\mathrm{O}$ & & & & & \\
\hline & & $\begin{array}{c}\text { after release of } \\
\text { load }\end{array}$ & & & & & \\
\hline \multirow{12}{*}{ Stainless steel } & \multirow{12}{*}{1} & & $\mathbf{O}$ & $\mathbf{O}$ & & 116.226 & 0.167 \\
\hline & & $\mathbf{O}$ & 2000 & 8896.44 & 0.012 & 116.238 & 0.179 \\
\hline & & 20 & 10000 & 44482.2 & 0.031 & 116.269 & 0.21 \\
\hline & & 40 & 12000 & 53378.64 & 0.066 & 116.335 & 0.276 \\
\hline & & 60 & 12000 & 53378.64 & 0.093 & 116.428 & 0.369 \\
\hline & & 80 & 12000 & 53378.64 & 0.133 & 116.561 & 0.502 \\
\hline & & 100 & 12000 & 53378.64 & 0.158 & 116.719 & 0.66 \\
\hline & & 120 & 12000 & 53378.64 & 0.196 & 116.915 & 0.856 \\
\hline & & 80 & 10000 & 44482.2 & 0.191 & 116.724 & 0.665 \\
\hline & & 40 & 2000 & 8896.44 & 0.136 & 116.588 & 0.529 \\
\hline & & $\mathrm{O}$ & 2000 & 8896.44 & 0.135 & 116.453 & 0.394 \\
\hline & & $\begin{array}{c}\text { after release of } \\
\text { load }\end{array}$ & O & O & 0.079 & 116.374 & 0.315 \\
\hline
\end{tabular}


Table A - 1 con't.: Unlubricated bolt re-usability testing results

\begin{tabular}{|c|c|c|c|c|c|c|c|}
\hline $\begin{array}{l}\text { Test bolt } \\
\text { sample }\end{array}$ & $\begin{array}{l}\text { Bolt set } \\
\text { number }\end{array}$ & $\begin{array}{c}\text { Turn angle } \\
\quad{ }^{\circ}(\theta)\end{array}$ & \multicolumn{5}{|c|}{ Results for third cycle of loading } \\
\hline \multirow{13}{*}{$\begin{array}{l}\text { A325 High } \\
\text { tensile bolt }\end{array}$} & \multirow{13}{*}{1} & & $\begin{array}{c}\text { Load (Preading) } \\
\text { (lbf) }\end{array}$ & $\begin{array}{c}\text { Load } \\
\text { (Preading) } \\
\text { (N) }\end{array}$ & $\begin{array}{c}\text { Gauge } \\
\text { elongation } \\
(\mathrm{mm})\end{array}$ & $\begin{array}{c}\text { Cummulative } \\
\text { elongation }\end{array}$ & $\begin{array}{c}\text { Difference } \\
\text { between } \\
\text { cum. \& gau. } \\
\text { elongation }\end{array}$ \\
\hline & & & $\mathbf{O}$ & $\mathrm{O}$ & & 102.892 & 1.515 \\
\hline & & $\mathbf{O}$ & 2000 & 8896.44 & 0.052 & 102.944 & 1.567 \\
\hline & & 20 & 10000 & 44482.2 & 0.092 & 103.036 & 1.659 \\
\hline & & 40 & 18000 & 80067.96 & 0.132 & 103.168 & 1.7910 \\
\hline & & 60 & 28000 & 124550.16 & 0.170 & 103.338 & 1.961 \\
\hline & & 80 & 36000 & 160135.92 & 0.208 & 103.546 & 2.169 \\
\hline & & 100 & 44000 & 195721.68 & 0.245 & 103.791 & 2.414 \\
\hline & & 120 & 52000 & 231307.44 & 0.279 & 104.070 & 2.693 \\
\hline & & 80 & 32000 & 142343.04 & 0.191 & 103.879 & 2.502 \\
\hline & & 40 & 15000 & 66723.3 & 0.119 & 103.760 & 2.383 \\
\hline & & $\mathbf{O}$ & 2000 & 8896.44 & 0.056 & 103.704 & 2.327 \\
\hline & & $\begin{array}{c}\text { after release } \\
\text { of load }\end{array}$ & $\mathbf{O}$ & $\mathbf{O}$ & 0.031 & 103.673 & 2.296 \\
\hline \multirow{11}{*}{$\begin{array}{c}\text { A325 High } \\
\text { tensile } \\
\text { galvanized } \\
\text { bolt }\end{array}$} & \multirow{11}{*}{1} & $\mathbf{O}$ & \multirow{11}{*}{\multicolumn{5}{|c|}{ test did not continue beyond second cycle as a result of galling of the bolt }} \\
\hline & & 20 & & & & & \\
\hline & & 40 & & & & & \\
\hline & & 60 & & & & & \\
\hline & & 80 & & & & & \\
\hline & & 100 & & & & & \\
\hline & & 120 & & & & & \\
\hline & & 80 & & & & & \\
\hline & & 40 & & & & & \\
\hline & & $\mathbf{O}$ & & & & & \\
\hline & & $\begin{array}{c}\text { after release } \\
\text { of load }\end{array}$ & & & & & \\
\hline \multirow{12}{*}{ Stainless steel } & \multirow{12}{*}{1} & & $\mathrm{O}$ & $\mathrm{O}$ & & 116.374 & 0.315 \\
\hline & & $\mathbf{O}$ & 2000 & 8896.44 & 0.019 & 116.393 & 0.334 \\
\hline & & 20 & 8000 & 35585.76 & 0.031 & 116.424 & 0.365 \\
\hline & & 40 & 13000 & 57826.86 & 0.065 & 116.489 & 0.43 \\
\hline & & 60 & 14000 & 62275.08 & 0.102 & 116.591 & 0.532 \\
\hline & & 80 & 14000 & 62275.08 & 0.130 & 116.721 & 0.662 \\
\hline & & 100 & 14000 & 62275.08 & 0.153 & 116.874 & 0.815 \\
\hline & & 120 & 14000 & 62275.08 & 0.185 & 117.059 & 1.000 \\
\hline & & 80 & $10 O O O$ & 44482.2 & O.168 & 116.891 & 0.832 \\
\hline & & 40 & 2000 & 8896.44 & 0.127 & 116.764 & 0.705 \\
\hline & & $\mathbf{O}$ & 2000 & 8896.44 & 0.118 & 116.646 & 0.587 \\
\hline & & $\begin{array}{c}\text { after release } \\
\text { of load }\end{array}$ & O & $\mathbf{O}$ & 0.064 & 116.582 & 0.523 \\
\hline
\end{tabular}

119 
Table A - 1 con't: Unlubricated bolt re-usability testing results

\begin{tabular}{|c|c|c|c|c|c|c|c|}
\hline $\begin{array}{l}\text { Test bolt } \\
\text { sample }\end{array}$ & $\begin{array}{l}\text { Bolt set } \\
\text { number }\end{array}$ & $\begin{array}{c}\text { Turn angle } \\
\left.\quad{ }^{(\theta)}\right)\end{array}$ & \multicolumn{5}{|c|}{ Results for fourth cycle of loading } \\
\hline \multirow{13}{*}{$\begin{array}{l}\text { A325 High } \\
\text { tensile bolt }\end{array}$} & \multirow{13}{*}{ 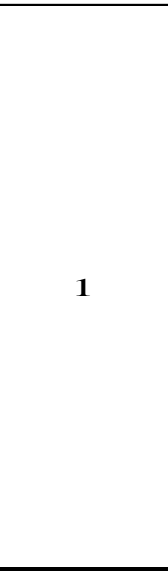 } & & \begin{tabular}{|c} 
Load (Preading) \\
(lbf) \\
\end{tabular} & $\begin{array}{c}\text { Load } \\
\begin{array}{c}\text { (Preading } \\
(\mathbf{N})\end{array} \\
\end{array}$ & $\begin{array}{c}\text { Gauge } \\
\text { elongation } \\
(\mathrm{mm})\end{array}$ & \begin{tabular}{|c|} 
Cummulative \\
elongation
\end{tabular} & $\begin{array}{c}\text { Difference } \\
\text { between } \\
\text { cum. \& gau. } \\
\text { elongation } \\
\end{array}$ \\
\hline & & & $\mathbf{O}$ & $\mathbf{O}$ & & 103.673 & 2.296 \\
\hline & & $\mathbf{O}$ & 2000 & 8896.44 & 0.057 & 103.730 & 2.353 \\
\hline & & 20 & 10000 & 44482.2 & 0.097 & 103.827 & 2.45 \\
\hline & & 40 & 20000 & 88964.4 & 0.139 & 103.966 & 2.589 \\
\hline & & 60 & 29000 & 128998.38 & 0.177 & 104.143 & 2.766 \\
\hline & & 80 & 38000 & 169032.36 & 0.218 & 104.361 & 2.984 \\
\hline & & 100 & 45000 & 200169.9 & 0.253 & 104.614 & 3.237 \\
\hline & & 120 & 50000 & 222411 & 0.270 & 104.884 & 3.507 \\
\hline & & 80 & 33000 & 146791.26 & 0.193 & 104.691 & 3.314 \\
\hline & & 40 & 15000 & 66723.3 & 0.121 & 104.570 & 3.193 \\
\hline & & $\mathbf{O}$ & 2000 & 8896.44 & 0.059 & 104.511 & 3.134 \\
\hline & & $\begin{array}{c}\text { after release } \\
\text { of load }\end{array}$ & O & $\mathbf{O}$ & 0.032 & 104.479 & 3.102 \\
\hline \multirow{11}{*}{$\begin{array}{l}\text { A325 High } \\
\text { tensile } \\
\text { galvanized } \\
\text { bolt }\end{array}$} & \multirow{11}{*}{1} & $\mathrm{O}$ & \multirow{11}{*}{\multicolumn{5}{|c|}{ test did not continue beyond second cycle as a result of galling of the bolt }} \\
\hline & & 20 & & & & & \\
\hline & & 40 & & & & & \\
\hline & & 60 & & & & & \\
\hline & & 80 & & & & & \\
\hline & & 100 & & & & & \\
\hline & & 120 & & & & & \\
\hline & & 80 & & & & & \\
\hline & & 40 & & & & & \\
\hline & & $\mathrm{O}$ & & & & & \\
\hline & & $\begin{array}{c}\text { after release } \\
\text { of load }\end{array}$ & & & & & \\
\hline \multirow{12}{*}{ Stainless steel } & \multirow{12}{*}{1} & & $\mathrm{O}$ & $\mathrm{O}$ & & 116.582 & 0.523 \\
\hline & & O & 2000 & 8896.44 & 0.010 & 116.592 & 0.533 \\
\hline & & 20 & 8000 & 35585.76 & 0.022 & 116.614 & 0.555 \\
\hline & & 40 & 12000 & 53378.64 & 0.055 & 116.669 & 0.61 \\
\hline & & 60 & 12000 & 53378.64 & 0.081 & 116.75 & 0.691 \\
\hline & & 80 & 12000 & 53378.64 & 0.117 & 116.867 & 0.808 \\
\hline & & 100 & 12000 & 53378.64 & 0.152 & 117.019 & 0.96 \\
\hline & & 120 & 12000 & 53378.64 & 0.169 & 117.188 & 1.129 \\
\hline & & 80 & 10000 & 44482.2 & 0.150 & 117.038 & 0.979 \\
\hline & & 40 & 2000 & 8896.44 & 0.110 & 116.928 & 0.869 \\
\hline & & $\mathrm{O}$ & 2000 & 8896.44 & 0.101 & 116.827 & 0.768 \\
\hline & & $\begin{array}{l}\text { after release } \\
\text { of load }\end{array}$ & $\mathbf{O}$ & $\mathbf{O}$ & 0.058 & 116.769 & 0.710 \\
\hline
\end{tabular}


Table A - 1 con't: Unlubricated bolt re-usability testing results

\begin{tabular}{|c|c|c|c|c|c|c|c|}
\hline $\begin{array}{l}\text { Test bolt } \\
\text { sample } \\
\end{array}$ & $\begin{array}{l}\text { Bolt set } \\
\text { number }\end{array}$ & $\begin{array}{c}\text { Turn angle } \\
{ }^{\circ}(\theta)\end{array}$ & \multicolumn{5}{|c|}{ Results for fifth cycle of loading } \\
\hline \multirow{13}{*}{$\begin{array}{l}\text { A325 High } \\
\text { tensile bolt }\end{array}$} & \multirow{13}{*}{1} & & $\begin{array}{c}\text { Load (Preading) } \\
\text { (lbf) } \\
\end{array}$ & $\begin{array}{c}\text { Load } \\
\left(\text { Preading }_{\text {rean }}\right) \\
\text { (N) }\end{array}$ & $\begin{array}{c}\text { Gauge } \\
\text { elongation } \\
(\mathbf{m m})\end{array}$ & $\begin{array}{c}\text { Cummulative } \\
\text { elongation }\end{array}$ & $\begin{array}{l}\text { Difference } \\
\text { between } \\
\text { cum. \& gau. } \\
\text { elongation }\end{array}$ \\
\hline & & & $\mathrm{O}$ & $\mathrm{O}$ & & 104.479 & 3.102 \\
\hline & & $\mathbf{O}$ & 2000 & 8896.44 & 0.057 & 104.536 & 3.159 \\
\hline & & 20 & 10000 & 44482.2 & 0.095 & 104.631 & 3.254 \\
\hline & & 40 & 18000 & 80067.96 & 0.137 & 104.768 & 3.391 \\
\hline & & 60 & 27000 & 120101.94 & 0.169 & 104.937 & 3.56 \\
\hline & & 80 & 36000 & 160135.92 & 0.208 & 105.145 & 3.768 \\
\hline & & 100 & 43000 & 191273.46 & 0.242 & 105.387 & 4.01 \\
\hline & & 120 & 46000 & 204618.12 & 0.258 & 105.645 & 4.268 \\
\hline & & 80 & & & & & \\
\hline & & 40 & & & & & \\
\hline & & $\mathrm{O}$ & & & & & \\
\hline & & $\begin{array}{c}\text { after release } \\
\text { of load }\end{array}$ & & & & & \\
\hline \multirow{11}{*}{$\begin{array}{c}\text { A325 High } \\
\text { tensile } \\
\text { galvanized } \\
\text { bolt }\end{array}$} & \multirow{11}{*}{1} & $\mathbf{O}$ & \multirow{11}{*}{\multicolumn{5}{|c|}{ test did not continue beyond second cycle as a result of galling of the bolt }} \\
\hline & & 20 & & & & & \\
\hline & & 40 & & & & & \\
\hline & & 60 & & & & & \\
\hline & & 80 & & & & & \\
\hline & & 100 & & & & & \\
\hline & & 120 & & & & & \\
\hline & & 80 & & & & & \\
\hline & & 40 & & & & & \\
\hline & & $\mathrm{O}$ & & & & & \\
\hline & & $\begin{array}{c}\text { after release } \\
\text { of load }\end{array}$ & & & & & \\
\hline \multirow{12}{*}{ Stainless steel } & \multirow{12}{*}{1} & & $\mathrm{O}$ & $\mathrm{O}$ & & 116.769 & 0.710 \\
\hline & & $\mathbf{O}$ & 2000 & 8896.44 & 0.018 & 116.787 & 0.728 \\
\hline & & 20 & 8000 & 35585.76 & 0.033 & 116.82 & 0.761 \\
\hline & & 40 & 12000 & 53378.64 & 0.071 & 116.891 & 0.832 \\
\hline & & 60 & \multirow{8}{*}{\multicolumn{5}{|c|}{ test did not continue beyond this point as a result of galling of the bolt }} \\
\hline & & 80 & & & & & \\
\hline & & 100 & & & & & \\
\hline & & 120 & & & & & \\
\hline & & 80 & & & & & \\
\hline & & 40 & & & & & \\
\hline & & $\mathrm{O}$ & & & & & \\
\hline & & $\begin{array}{c}\text { after release } \\
\text { of load }\end{array}$ & & & & & \\
\hline
\end{tabular}


Table A - 2: Lubricated bolt re-usability testing results

\begin{tabular}{|c|c|c|c|c|c|c|c|c|c|}
\hline \multirow[b]{2}{*}{$\begin{array}{l}\text { Bolt test } \\
\text { material }\end{array}$} & \multirow[b]{2}{*}{$\begin{array}{l}\text { Bolt set } \\
\text { number }\end{array}$} & \multirow{2}{*}{$\begin{array}{c}\text { Test } \\
\text { temperature } \\
\left({ }^{\circ} \mathrm{C}\right)\end{array}$} & \multirow{2}{*}{$\begin{array}{c}\text { Turn angle } \\
{ }^{0}(\theta)\end{array}$} & \multicolumn{6}{|c|}{ Results for first cycle of loading } \\
\hline & & & & $\begin{array}{c}\text { Load } \\
\left(\mathbf{P}_{\text {reading }}\right) \\
(\mathbf{l b f})\end{array}$ & $\begin{array}{c}\text { Load } \\
\left(\mathbf{P}_{\text {reading }}\right) \\
(\mathbf{N}) \\
\end{array}$ & $\begin{array}{l}\text { Initial } \\
\text { length } \\
\text { (mm) }\end{array}$ & $\begin{array}{c}\text { Gauge } \\
\text { elongation } \\
(\mathbf{m m}) \\
\end{array}$ & $\begin{array}{c}\text { Cummulative } \\
\text { elongation }\end{array}$ & $\begin{array}{c}\text { Difference } \\
\text { between } \\
\text { cum. \& gau. } \\
\text { elongation }\end{array}$ \\
\hline \multirow{12}{*}{$\begin{array}{l}\text { A325 High } \\
\text { tensile } \\
\text { galvanized } \\
\text { bolt }\end{array}$} & \multirow{12}{*}{1} & \multirow{12}{*}{20} & & 0 & 0 & 101.961 & 0 & 101.961 & 0 \\
\hline & & & 0 & 2000 & 8896.44 & & 0.023 & 101.984 & 0.023 \\
\hline & & & 20 & 8000 & 35585.76 & & 0.049 & 102.033 & 0.072 \\
\hline & & & 40 & 14000 & 62275.08 & & 0.080 & 102.113 & 0.152 \\
\hline & & & 60 & 22000 & 97860.84 & & 0.114 & 102.227 & 0.266 \\
\hline & & & 80 & 30000 & 133446.6 & & 0.150 & 102.377 & 0.416 \\
\hline & & & 100 & 38000 & 169032.4 & & 0.201 & 102.578 & 0.617 \\
\hline & & & 120 & 45000 & 200169.9 & & 0.228 & 102.806 & 0.845 \\
\hline & & & 80 & 26000 & 115653.7 & & 0.143 & 102.663 & 0.702 \\
\hline & & & 40 & 8000 & 35585.76 & & 0.070 & 102.593 & 0.632 \\
\hline & & & 0 & 2000 & 8896.44 & & 0.032 & 102.561 & 0.6 \\
\hline & & & $\begin{array}{c}\text { after release } \\
\text { of load } \\
\end{array}$ & 0 & 0 & & 0.026 & 102.535 & 0.574 \\
\hline \multirow{12}{*}{$\begin{array}{c}\text { Stainless steel } \\
\text { bolt }\end{array}$} & \multirow{12}{*}{1} & \multirow{12}{*}{20} & & 0 & 0 & 116.720 & 0 & 116.720 & 0 \\
\hline & & & 0 & 2000 & 8896.44 & & 0.018 & 116.738 & 0.018 \\
\hline & & & 20 & 8000 & 35585.76 & & 0.047 & 116.785 & 0.065 \\
\hline & & & 40 & 11000 & 48930.42 & & 0.084 & 116.869 & 0.149 \\
\hline & & & 60 & 12000 & 53378.64 & & 0.124 & 116.993 & 0.273 \\
\hline & & & 80 & 12000 & 53378.64 & & 0.162 & 117.155 & 0.435 \\
\hline & & & 100 & 12000 & 53378.64 & & 0.192 & 117.347 & 0.627 \\
\hline & & & 120 & 12000 & 53378.64 & & 0.222 & 117.569 & 0.849 \\
\hline & & & 80 & 2000 & 8896.44 & & 0.174 & 117.395 & 0.675 \\
\hline & & & 40 & 0 & 0 & & 0.157 & 117.238 & 0.518 \\
\hline & & & 0 & 0 & 0 & & 0.157 & 117.081 & 0.361 \\
\hline & & & $\begin{array}{c}\text { after release } \\
\text { of load }\end{array}$ & 0 & 0 & & 0.157 & 116.924 & 0.204 \\
\hline
\end{tabular}


Table A - 2 con't: Lubricated bolt re-usability testing results

\begin{tabular}{|c|c|c|c|c|c|c|c|c|c|}
\hline \multirow[b]{2}{*}{$\begin{array}{l}\text { Bolt test } \\
\text { material }\end{array}$} & \multirow[b]{2}{*}{$\begin{array}{l}\text { Bolt set } \\
\text { number }\end{array}$} & \multirow{2}{*}{$\begin{array}{c}\text { Test } \\
\text { temperature } \\
\left({ }^{\circ} \mathrm{C}\right)\end{array}$} & \multirow{2}{*}{$\begin{array}{l}\text { Turn angle } \\
{ }^{0}(\theta)\end{array}$} & \multicolumn{6}{|c|}{ Results for second cycle of loading } \\
\hline & & & & $\begin{array}{c}\text { Load } \\
\left(\mathbf{P}_{\text {reading }}\right) \\
(\mathbf{l b f}) \\
\end{array}$ & $\begin{array}{c}\text { Load } \\
\left(\mathbf{P}_{\text {reading }}\right) \\
(\mathbf{N}) \\
\end{array}$ & $\begin{array}{c}\text { Initial } \\
\text { length } \\
\text { (mm) }\end{array}$ & $\begin{array}{c}\begin{array}{c}\text { Gauge } \\
\text { elongation } \\
(\mathbf{m m})\end{array} \\
\end{array}$ & $\begin{array}{c}\text { Cummulative } \\
\text { elongation }\end{array}$ & $\begin{array}{c}\text { Difference } \\
\text { between cum. } \\
\& \text { gau. } \\
\text { elongation } \\
\end{array}$ \\
\hline \multirow{12}{*}{$\begin{array}{l}\text { A325 High } \\
\text { tensile } \\
\text { galvanized } \\
\text { bolt }\end{array}$} & \multirow{12}{*}{1} & \multirow{12}{*}{20} & & 0 & 0 & 102.535 & & 102.535 & 0.574 \\
\hline & & & 0 & 2000 & 8896.44 & & 0.038 & 102.573 & 0.612 \\
\hline & & & 20 & 7000 & 31137.54 & & 0.065 & 102.638 & 0.677 \\
\hline & & & 40 & 16000 & 71171.52 & & 0.102 & 102.740 & 0.779 \\
\hline & & & 60 & 24000 & 106757.3 & & 0.138 & 102.878 & 0.917 \\
\hline & & & 80 & 33000 & 146791.3 & & 0.180 & 103.058 & 1.097 \\
\hline & & & 100 & 40000 & 177928.8 & & 0.214 & 103.272 & 1.311 \\
\hline & & & 120 & 49000 & 217962.8 & & 0.260 & 103.532 & 1.571 \\
\hline & & & 80 & 32000 & 142343 & & 0.170 & 103.362 & 1.401 \\
\hline & & & 40 & 14000 & 62275.08 & & 0.099 & 103.263 & 1.302 \\
\hline & & & 0 & 2000 & 8896.44 & & 0.042 & 103.221 & 1.260 \\
\hline & & & $\begin{array}{c}\text { after release } \\
\text { of load }\end{array}$ & 0 & 0 & & 0.031 & 103.190 & 1.229 \\
\hline \multirow{12}{*}{$\begin{array}{c}\text { Stainless steel } \\
\text { bolt }\end{array}$} & \multirow{12}{*}{1} & \multirow{12}{*}{20} & & & 0 & 116.924 & & 116.924 & 0.204 \\
\hline & & & 0 & 2000 & 8896.44 & & 0.175 & 117.099 & 0.379 \\
\hline & & & 20 & 7000 & 31137.54 & & 0.196 & 117.295 & 0.575 \\
\hline & & & 40 & 13000 & 57826.86 & & 0.229 & 117.524 & 0.804 \\
\hline & & & 60 & 14000 & 62275.08 & & 0.272 & 117.796 & 1.076 \\
\hline & & & 80 & 14000 & 62275.08 & & 0.309 & 118.105 & 1.385 \\
\hline & & & 100 & 13000 & 57826.86 & & 0.338 & 118.443 & 1.723 \\
\hline & & & 120 & 13000 & 57826.86 & & 0.369 & 118.812 & 2.092 \\
\hline & & & 80 & 6000 & 26689.32 & & 0.328 & 118.484 & 1.764 \\
\hline & & & 40 & 0 & 0 & & 0.293 & 118.191 & 1.471 \\
\hline & & & 0 & 0 & 0 & & 0.293 & 117.898 & 1.178 \\
\hline & & & $\begin{array}{c}\text { after release } \\
\text { of load }\end{array}$ & 0 & 0 & & 0.293 & 117.605 & 0.885 \\
\hline
\end{tabular}


Table A - 2 con't: Lubricated bolt re-usability testing results

\begin{tabular}{|c|c|c|c|c|c|c|c|c|c|}
\hline \multirow[b]{2}{*}{$\begin{array}{l}\text { Bolt test } \\
\text { material }\end{array}$} & \multirow[b]{2}{*}{$\begin{array}{l}\text { Bolt set } \\
\text { number }\end{array}$} & \multirow{2}{*}{$\begin{array}{c}\text { Test } \\
\text { temperature } \\
\left({ }^{\circ} \mathrm{C}\right)\end{array}$} & \multirow[b]{2}{*}{ Turn angle ${ }^{0}(\theta)$} & \multicolumn{6}{|c|}{ Results for third cycle of loading } \\
\hline & & & & $\begin{array}{c}\text { Load } \\
\left(\mathbf{P}_{\text {reading }}\right) \\
(\text { lbf })\end{array}$ & $\begin{array}{c}\text { Load } \\
\left(\mathbf{P}_{\text {reading }}\right) \\
(\mathbf{N})\end{array}$ & $\begin{array}{l}\text { Initial } \\
\text { length } \\
\text { (mm) }\end{array}$ & $\begin{array}{c}\text { Gauge } \\
\text { elongation } \\
(\mathbf{m m})\end{array}$ & $\begin{array}{c}\text { Cummulative } \\
\text { elongation }\end{array}$ & $\begin{array}{c}\text { Difference } \\
\text { between cum. } \\
\text { \& gau. } \\
\text { elongation }\end{array}$ \\
\hline \multirow{12}{*}{$\begin{array}{c}\text { A325 High } \\
\text { tensile galvanized } \\
\text { bolt }\end{array}$} & \multirow{12}{*}{1} & \multirow{12}{*}{20} & & 0 & 0 & 103.190 & & 103.190 & 1.229 \\
\hline & & & 0 & 2000 & 8896.44 & & 0.047 & 103.237 & 1.276 \\
\hline & & & 20 & 9000 & 40033.98 & & 0.079 & 103.316 & 1.355 \\
\hline & & & 40 & 18000 & 80067.96 & & 0.114 & 103.430 & 1.469 \\
\hline & & & 60 & 27000 & 120101.94 & & 0.157 & 103.587 & 1.626 \\
\hline & & & 80 & 35000 & 155687.7 & & 0.196 & 103.783 & 1.822 \\
\hline & & & 100 & 42000 & 186825.24 & & 0.232 & 104.015 & 2.054 \\
\hline & & & 120 & 51000 & 226859.22 & & 0.277 & 104.292 & 2.331 \\
\hline & & & 80 & 34000 & 151239.48 & & 0.195 & 104.097 & 2.136 \\
\hline & & & 40 & 15000 & 66723.3 & & 0.114 & 103.983 & 2.022 \\
\hline & & & 0 & 2000 & 8896.44 & & 0.052 & 103.931 & 1.970 \\
\hline & & & $\begin{array}{c}\text { after release of } \\
\text { load }\end{array}$ & 0 & 0 & & 0.038 & 103.893 & 1.932 \\
\hline \multirow{12}{*}{$\begin{array}{l}\text { Stainless steel } \\
\text { bolt }\end{array}$} & \multirow{12}{*}{1} & \multirow{12}{*}{20} & & & 0 & & & 117.605 & 0.885 \\
\hline & & & 0 & 2000 & 8896.44 & & 0.308 & 117.913 & 1.193 \\
\hline & & & 20 & 5000 & 22241.1 & & 0.324 & 118.237 & 1.517 \\
\hline & & & 40 & 12000 & 53378.64 & & 0.359 & 118.596 & 1.876 \\
\hline & & & 60 & 14000 & 62275.08 & & 0.398 & 118.994 & 2.274 \\
\hline & & & 80 & 14000 & 62275.08 & & 0.435 & 119.429 & 2.709 \\
\hline & & & 100 & 14000 & 62275.08 & & 0.460 & 119.889 & 3.169 \\
\hline & & & 120 & 14000 & 62275.08 & & 0.494 & 120.383 & 3.663 \\
\hline & & & 80 & 6000 & 26689.32 & & 0.454 & 119.929 & 3.209 \\
\hline & & & 40 & 2000 & 8896.44 & & 0.418 & 119.511 & 2.791 \\
\hline & & & 0 & 0 & 0 & & 0.418 & 119.093 & 2.373 \\
\hline & & & $\begin{array}{c}\text { after release of } \\
\text { load }\end{array}$ & 0 & 0 & & 0.418 & 118.675 & 1.955 \\
\hline
\end{tabular}


Table A - 2 con't: Lubricated bolt re-usability testing results

\begin{tabular}{|c|c|c|c|c|c|c|c|c|c|}
\hline \multirow[b]{2}{*}{$\begin{array}{l}\text { Bolt test } \\
\text { material }\end{array}$} & \multirow[b]{2}{*}{$\begin{array}{l}\text { Bolt set } \\
\text { number }\end{array}$} & \multirow{2}{*}{$\begin{array}{c}\text { Test } \\
\text { temperature } \\
\left({ }^{\circ} \mathrm{C}\right)\end{array}$} & \multirow{2}{*}{$\begin{array}{c}\text { Turn angle } \\
\quad{ }^{0}(\theta)\end{array}$} & \multicolumn{6}{|c|}{ Results for fourth cycle of loading } \\
\hline & & & & 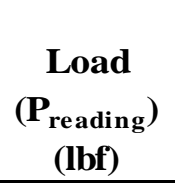 & $\begin{array}{c}\text { Load } \\
\left(\mathbf{P}_{\text {reading }}\right) \\
(\mathbf{N})\end{array}$ & $\begin{array}{c}\text { Initial } \\
\text { length }(\mathrm{mm})\end{array}$ & $\begin{array}{c}\text { Gauge } \\
\text { elongation } \\
(\mathbf{m m})\end{array}$ & $\begin{array}{c}\text { Cummulative } \\
\text { elongation }\end{array}$ & $\begin{array}{c}\text { Difference } \\
\text { between } \\
\text { cum. \& gau. } \\
\text { elongation }\end{array}$ \\
\hline \multirow{12}{*}{$\begin{array}{c}\text { A325 High } \\
\text { tensile } \\
\text { galvanized bolt }\end{array}$} & \multirow{12}{*}{1} & \multirow{12}{*}{20} & & 0 & 0 & 103.893 & & 103.893 & 1.932 \\
\hline & & & 0 & 2000 & 8896.44 & & 0.053 & 103.946 & 1.985 \\
\hline & & & 20 & 9000 & 40033.98 & & 0.086 & 104.032 & 2.071 \\
\hline & & & 40 & 17000 & 75619.74 & & 0.120 & 104.152 & 2.191 \\
\hline & & & 60 & 26000 & 115653.72 & & 0.159 & 104.311 & 2.350 \\
\hline & & & 80 & 35000 & 155687.7 & & 0.201 & 104.512 & 2.551 \\
\hline & & & 100 & 42000 & 186825.24 & & 0.234 & 104.746 & 2.785 \\
\hline & & & 120 & 51000 & 226859.22 & & 0.281 & 105.027 & 3.066 \\
\hline & & & 80 & 34000 & 151239.48 & & 0.198 & 104.829 & 2.868 \\
\hline & & & 40 & 16000 & 71171.52 & & 0.119 & 104.710 & 2.749 \\
\hline & & & \begin{tabular}{|l|}
0 \\
\end{tabular} & 2000 & 8896.44 & & 0.057 & 104.653 & 2.692 \\
\hline & & & $\begin{array}{c}\text { after release of } \\
\text { load }\end{array}$ & 0 & 0 & & 0.039 & 104.614 & 2.653 \\
\hline \multirow{12}{*}{$\begin{array}{c}\text { Stainless steel } \\
\text { bolt }\end{array}$} & \multirow{12}{*}{1} & \multirow{12}{*}{20} & & & 0 & & & 118.675 & 1.955 \\
\hline & & & 0 & 2000 & 8896.44 & & 0.435 & 119.110 & 2.390 \\
\hline & & & 20 & 7000 & 31137.54 & & 0.458 & 119.568 & 2.848 \\
\hline & & & 40 & 14000 & 62275.08 & & 0.493 & 120.061 & 3.341 \\
\hline & & & 60 & 14000 & 62275.08 & & 0.535 & 120.596 & 3.876 \\
\hline & & & 80 & 14000 & 62275.08 & & 0.535 & 121.131 & 4.411 \\
\hline & & & 100 & 14000 & 62275.08 & & 0.577 & 121.708 & 4.988 \\
\hline & & & 120 & 14000 & 62275.08 & & 0.610 & 122.318 & 5.598 \\
\hline & & & 80 & 6000 & 26689.32 & & 0.562 & 121.756 & 5.036 \\
\hline & & & 40 & 2000 & 8896.44 & & 0.530 & 121.226 & 4.506 \\
\hline & & & \begin{tabular}{|l|}
0 \\
\end{tabular} & 0 & 0 & & 0.530 & 120.696 & 3.976 \\
\hline & & & \begin{tabular}{|c|} 
after release of \\
load
\end{tabular} & 0 & 0 & & 0.530 & 120.166 & 3.446 \\
\hline
\end{tabular}


Table A - 2 con't: Lubricated bolt re-usability testing results

\begin{tabular}{|c|c|c|c|c|c|c|c|c|c|}
\hline \multirow[b]{2}{*}{$\begin{array}{l}\text { Bolt test } \\
\text { material }\end{array}$} & \multirow[b]{2}{*}{$\begin{array}{l}\text { Bolt set } \\
\text { number }\end{array}$} & \multirow{2}{*}{$\begin{array}{c}\text { Test } \\
\text { temperature } \\
\left({ }^{\circ} \mathrm{C}\right)\end{array}$} & \multirow[b]{2}{*}{$\begin{array}{c}\text { Turn angle } \\
{ }^{0}(\theta)\end{array}$} & \multicolumn{6}{|c|}{ Results for fifth cycle of loading } \\
\hline & & & & $\begin{array}{c}\text { Load } \\
\left(P_{\text {reading }}\right) \\
(\mathbf{l b f})\end{array}$ & $\begin{array}{c}\text { Load } \\
\left(\text { Preading }_{\text {reading }}\right) \\
(\mathbf{N})\end{array}$ & $\begin{array}{c}\text { Initial } \\
\text { length } \\
(\mathbf{m m})\end{array}$ & $\begin{array}{c}\text { Gauge } \\
\text { elongation } \\
(\mathbf{m m})\end{array}$ & $\begin{array}{c}\text { Cummulative } \\
\text { elongation }\end{array}$ & $\begin{array}{c}\text { Difference } \\
\text { between cum. } \\
\text { \& gau. } \\
\text { elongation }\end{array}$ \\
\hline \multirow{12}{*}{$\begin{array}{l}\text { A325 High } \\
\text { tensile } \\
\text { galvanized } \\
\text { bolt }\end{array}$} & \multirow{12}{*}{1} & \multirow{12}{*}{20} & & 0 & 0 & 104.614 & & 104.614 & 2.653 \\
\hline & & & 0 & 2000 & 8896.44 & & 0.058 & 104.672 & 2.711 \\
\hline & & & 20 & 10000 & 44482.2 & & 0.093 & 104.765 & 2.804 \\
\hline & & & 40 & 19000 & 84516.18 & & 0.133 & 104.898 & 2.937 \\
\hline & & & 60 & 28000 & 124550.2 & & 0.170 & 105.068 & 3.107 \\
\hline & & & 80 & 36000 & 160135.9 & & 0.212 & 105.280 & 3.319 \\
\hline & & & 100 & 44000 & 195721.7 & & 0.247 & 105.527 & 3.566 \\
\hline & & & 120 & 49000 & 217962.8 & & 0.296 & 105.823 & 3.862 \\
\hline & & & 80 & 31000 & 137894.8 & & 0.198 & 105.625 & 3.664 \\
\hline & & & 40 & 14000 & 62275.08 & & 0.116 & 105.509 & 3.548 \\
\hline & & & 0 & 2000 & 8896.44 & & 0.062 & 105.447 & 3.486 \\
\hline & & & $\begin{array}{c}\text { after release } \\
\text { of load }\end{array}$ & 0 & 0 & & 0.042 & 105.405 & 3.444 \\
\hline \multirow{12}{*}{$\begin{array}{c}\text { Stainless steel } \\
\text { bolt }\end{array}$} & \multirow{12}{*}{1} & \multirow{12}{*}{20} & & & 0 & & & 120.166 & 3.446 \\
\hline & & & 0 & 2000 & 8896.44 & & 0.550 & 120.716 & 3.996 \\
\hline & & & 20 & 9000 & 40033.98 & & 0.586 & 121.302 & 4.582 \\
\hline & & & 40 & 15000 & 66723.3 & & 0.627 & 121.929 & 5.209 \\
\hline & & & 60 & 15000 & 66723.3 & & 0.669 & 122.598 & 5.878 \\
\hline & & & 80 & 14000 & 62275.08 & & 0.706 & 123.304 & 6.584 \\
\hline & & & 100 & 14000 & 62275.08 & & 0.735 & 124.039 & 7.319 \\
\hline & & & 120 & 14000 & 62275.08 & & 0.772 & 124.811 & 8.091 \\
\hline & & & 80 & 6000 & 26689.32 & & 0.726 & 124.085 & 7.365 \\
\hline & & & 40 & 2000 & 8896.44 & & 0.684 & 123.401 & 6.681 \\
\hline & & & 0 & 0 & 0 & & 0.684 & 122.717 & 5.997 \\
\hline & & & $\begin{array}{c}\text { after release } \\
\text { of load }\end{array}$ & 0 & 0 & & 0.684 & 122.033 & 5.313 \\
\hline
\end{tabular}




\section{Appendix B: Temperature Effect on Bolt Pre-load testing}

Table B - 1: Effect of temperature variation on bolt pre-load

\begin{tabular}{|c|c|c|c|c|c|c|c|c|c|c|c|}
\hline \multirow{3}{*}{$\begin{array}{c}\text { Set } \\
\text { group } \\
\#\end{array}$} & \multirow{3}{*}{ Bolt type } & \multirow{3}{*}{$\begin{array}{l}\text { Sample } \\
\text { identity }\end{array}$} & \multirow{3}{*}{$\begin{array}{c}\text { Turn angle } \\
\text { (degrees) }\end{array}$} & \multicolumn{4}{|c|}{ Bolt Number 1} & \multicolumn{4}{|c|}{ Bolt Number 2} \\
\hline & & & & \multirow{2}{*}{$\begin{array}{l}\text { Pre-tension } \\
\text { (using } \\
\text { skidmore) } \\
\text { (lbf) }\end{array}$} & \multirow{2}{*}{$\begin{array}{l}\text { Start } \\
\text { temp } \\
\left({ }^{0} \mathrm{C}\right)\end{array}$} & \multicolumn{2}{|c|}{ Pretension (using x-ray) } & \multirow{2}{*}{$\begin{array}{l}\text { Pre-tension } \\
\text { (using } \\
\text { skidmore) } \\
\text { (lbf) }\end{array}$} & \multirow{2}{*}{$\begin{array}{l}\text { Start } \\
\text { temp } \\
\left({ }^{0} \mathrm{C}\right)\end{array}$} & \multicolumn{2}{|c|}{ Pretension (using $\mathrm{x}$-ray) } \\
\hline & & & & & & $\begin{array}{c}\text { Initial length } \\
\left(\Delta_{1}\right) \\
\end{array}$ & $\begin{array}{l}\text { Change in } \\
\text { length }\left(\Delta_{2}\right)\end{array}$ & & & $\begin{array}{c}\text { Initial length } \\
\left(\Delta_{1}\right)\end{array}$ & $\begin{array}{l}\text { Change in } \\
\text { length }\left(\Delta_{2}\right)\end{array}$ \\
\hline \multirow{5}{*}{1} & \multirow{5}{*}{$\begin{array}{l}\text { A325 High } \\
\text { Tensile bolt }\end{array}$} & 1-A-(20) & 170 & 46000 & 20 & 102.008 & 0.118 & 47000 & 20 & 101.178 & 0.229 \\
\hline & & $1-\mathrm{A}-(-5)$ & 170 & 42000 & -5.4 & 100.159 & 0.109 & 44000 & -5.5 & 100.96 & 0.201 \\
\hline & & $1-\mathrm{A}-(-10)$ & 170 & 50000 & -10.1 & 100.216 & 0.349 & 54000 & -10 & 100.738 & 0.337 \\
\hline & & $1-\mathrm{A}-(-20)$ & 170 & 47000 & -20.9 & 100.661 & 0.256 & 44000 & -21 & 101.713 & 0.061 \\
\hline & & $1-\mathrm{A}-(-30)$ & 170 & 44000 & -31.7 & 100.088 & 0.304 & 52000 & -32.3 & 100.166 & 0.305 \\
\hline \multirow{5}{*}{2} & \multirow{5}{*}{$\begin{array}{l}\text { A325 High } \\
\text { tensile } \\
\text { galvanized } \\
\text { bolt }\end{array}$} & $1-B-(20)$ & 170 & 41000 & 20 & 102.019 & 0.201 & 42000 & 20 & 101.827 & 0.206 \\
\hline & & $2-B-(-5)$ & 170 & 42000 & -5.3 & 102.73 & 0.262 & 39000 & -5.3 & 100.972 & 0.222 \\
\hline & & 2-B-(-10) & 170 & 54000 & -10 & 100.903 & 0.402 & 54000 & -10.3 & 100.967 & 0.319 \\
\hline & & $2-B-(-20)$ & 170 & 54000 & -20.1 & 100.942 & 0.396 & 50000 & 20.9 & 100.775 & 0.300 \\
\hline & & $2-B-(-30)$ & 170 & 52000 & -31.6 & 100.266 & 0.301 & 42000 & -31.5 & 101.202 & 0.202 \\
\hline
\end{tabular}

Table B - 1 con't.: Effect of temperature variation on bolt pre-load

\begin{tabular}{|c|c|c|c|c|c|c|c|c|c|c|c|}
\hline \multirow{3}{*}{$\begin{array}{l}\text { Set } \\
\text { group } \\
\#\end{array}$} & \multirow{3}{*}{ Bolt type } & \multirow{3}{*}{$\begin{array}{l}\text { Sample } \\
\text { identity }\end{array}$} & \multirow{3}{*}{$\begin{array}{l}\text { Turn angle } \\
\text { (degrees) }\end{array}$} & \multicolumn{4}{|c|}{ Bolt Number 3} & \multicolumn{4}{|c|}{ Bolt Number 4} \\
\hline & & & & \multirow{2}{*}{$\begin{array}{l}\text { Pre-tension } \\
\text { (using } \\
\text { skidmore) } \\
\text { (lbf) }\end{array}$} & \multirow{2}{*}{$\begin{array}{l}\text { Start } \\
\text { temp } \\
\left({ }^{0} \mathrm{C}\right)\end{array}$} & \multicolumn{2}{|c|}{ Pretension (using x-ray) } & \multirow{2}{*}{$\begin{array}{l}\text { Pre-tension } \\
\text { (using } \\
\text { skidmore) } \\
\text { (lbf) }\end{array}$} & \multirow{2}{*}{$\begin{array}{l}\text { Start } \\
\text { temp } \\
\left({ }^{0} \mathrm{C}\right)\end{array}$} & \multicolumn{2}{|c|}{ Pretension (using x-ray) } \\
\hline & & & & & & $\begin{array}{c}\text { Initial length } \\
\left(\Delta_{1}\right) \\
\end{array}$ & $\begin{array}{l}\text { Change in } \\
\text { length }\left(\Delta_{2}\right)\end{array}$ & & & $\begin{array}{c}\text { Initial length } \\
\left(\Delta_{1}\right)\end{array}$ & $\begin{array}{l}\text { Change in } \\
\text { length }\left(\Delta_{2}\right)\end{array}$ \\
\hline \multirow{5}{*}{1} & \multirow{5}{*}{$\begin{array}{l}\text { A325 High } \\
\text { Tensile bolt }\end{array}$} & $1-\mathrm{A}-(20)$ & 170 & 44000 & 20 & 101.113 & 0.193 & 50000 & 20 & 101.118 & 0.262 \\
\hline & & $1-A-(-5)$ & 170 & 48000 & -5.5 & 100.912 & 0.270 & 53000 & -5.4 & 100.562 & 0.335 \\
\hline & & $1-\mathrm{A}-(-10)$ & 170 & 48000 & -10 & 100.746 & 0.294 & 54000 & -10.1 & 100.766 & 0.347 \\
\hline & & $1-\mathrm{A}-(-20)$ & 170 & 48000 & -20.6 & 100.865 & 0.326 & 46000 & -20.5 & 100.629 & 0.270 \\
\hline & & $1-\mathrm{A}-(-30)$ & 170 & 49000 & -31.2 & 100.315 & 0.281 & 42000 & -32 & 100.597 & 0.215 \\
\hline \multirow{5}{*}{2} & \multirow{5}{*}{$\begin{array}{l}\text { A325 High } \\
\text { tensile } \\
\text { galvanized } \\
\text { bolt }\end{array}$} & $1-B-(20)$ & 170 & 38000 & 20 & 102.275 & 0.168 & 40000 & 20 & 101.846 & 0.180 \\
\hline & & $2-B-(-5)$ & 170 & 39000 & -5.4 & 100.870 & 0.239 & 41000 & -5.3 & 101.030 & 0.268 \\
\hline & & 2-B-(-10) & 170 & 52000 & -10.1 & 101.043 & 0.325 & 47000 & -10 & 100.311 & 0.277 \\
\hline & & $2-B-(-20)$ & 170 & 47000 & -21 & 101.546 & 0.267 & 54000 & -20.7 & 101.767 & 0.337 \\
\hline & & $2-B-(-30)$ & 170 & 53000 & -33.4 & 100.895 & 0.310 & 50000 & -33.7 & 101.195 & 0.490 \\
\hline
\end{tabular}


Table B -2 con't.: Effect of temperature variation on bolt pre-load

\begin{tabular}{|c|c|c|c|c|c|c|c|}
\hline & & & & & Bolt I & Jumber 5 & \\
\hline \multirow{2}{*}{$\begin{array}{l}\text { Set } \\
\text { group } \\
\quad \#\end{array}$} & \multirow{2}{*}{ Bolt type } & \multirow{2}{*}{$\begin{array}{l}\text { Sample } \\
\text { identity }\end{array}$} & \multirow{2}{*}{$\begin{array}{l}\text { Turn angle } \\
\text { (degrees) }\end{array}$} & \multirow{2}{*}{$\begin{array}{l}\text { Pre-tension } \\
\text { (using } \\
\text { skidmore) } \\
\text { (lbf) }\end{array}$} & \multirow{2}{*}{$\begin{array}{l}\text { Start } \\
\text { temp } \\
\left({ }^{\circ} \mathrm{C}\right)\end{array}$} & \multicolumn{2}{|c|}{ Pretension (using $x$-ray) } \\
\hline & & & & & & $\begin{array}{c}\text { Initial length } \\
\left(\Delta_{1}\right)\end{array}$ & $\begin{array}{l}\text { Change in } \\
\text { length }\left(\Delta_{2}\right)\end{array}$ \\
\hline \multirow{5}{*}{1} & \multirow{5}{*}{$\begin{array}{l}\text { A325 High } \\
\text { Tensile bolt }\end{array}$} & $1-\mathrm{A}-(20)$ & 170 & 46000 & 20 & 101.187 & 0.229 \\
\hline & & $1-A-(-5)$ & 170 & 51000 & -5.2 & 100.557 & 0.289 \\
\hline & & $1-A-(-10)$ & 170 & 48000 & -10.2 & 100.922 & 0.295 \\
\hline & & $1-A-(-20)$ & 170 & 52000 & -21.1 & 101.381 & 0.308 \\
\hline & & $1-A-(-30)$ & 170 & 45000 & -31 & 100.656 & 0.465 \\
\hline \multirow{5}{*}{2} & \multirow{5}{*}{$\begin{array}{c}\text { A325 High } \\
\text { tensile } \\
\text { galvanized } \\
\text { bolt }\end{array}$} & $1-\mathrm{B}-(20)$ & 170 & 42000 & 20 & 102.358 & 0.180 \\
\hline & & $2-B-(-5)$ & 170 & 46000 & -5.4 & 101.046 & 0.278 \\
\hline & & $2-B-(-10)$ & 170 & 54000 & -10.2 & 101.546 & 0.344 \\
\hline & & $2-B-(-20)$ & 170 & 54000 & -20.3 & 101.150 & 0.394 \\
\hline & & $2-B-(-30)$ & 170 & 52000 & -31.3 & 101.268 & 0.336 \\
\hline
\end{tabular}




\section{Appendix C: Slip Coefficient Testing at $173 \mathrm{kN}$ Clamping Force at Ambient Temperature}

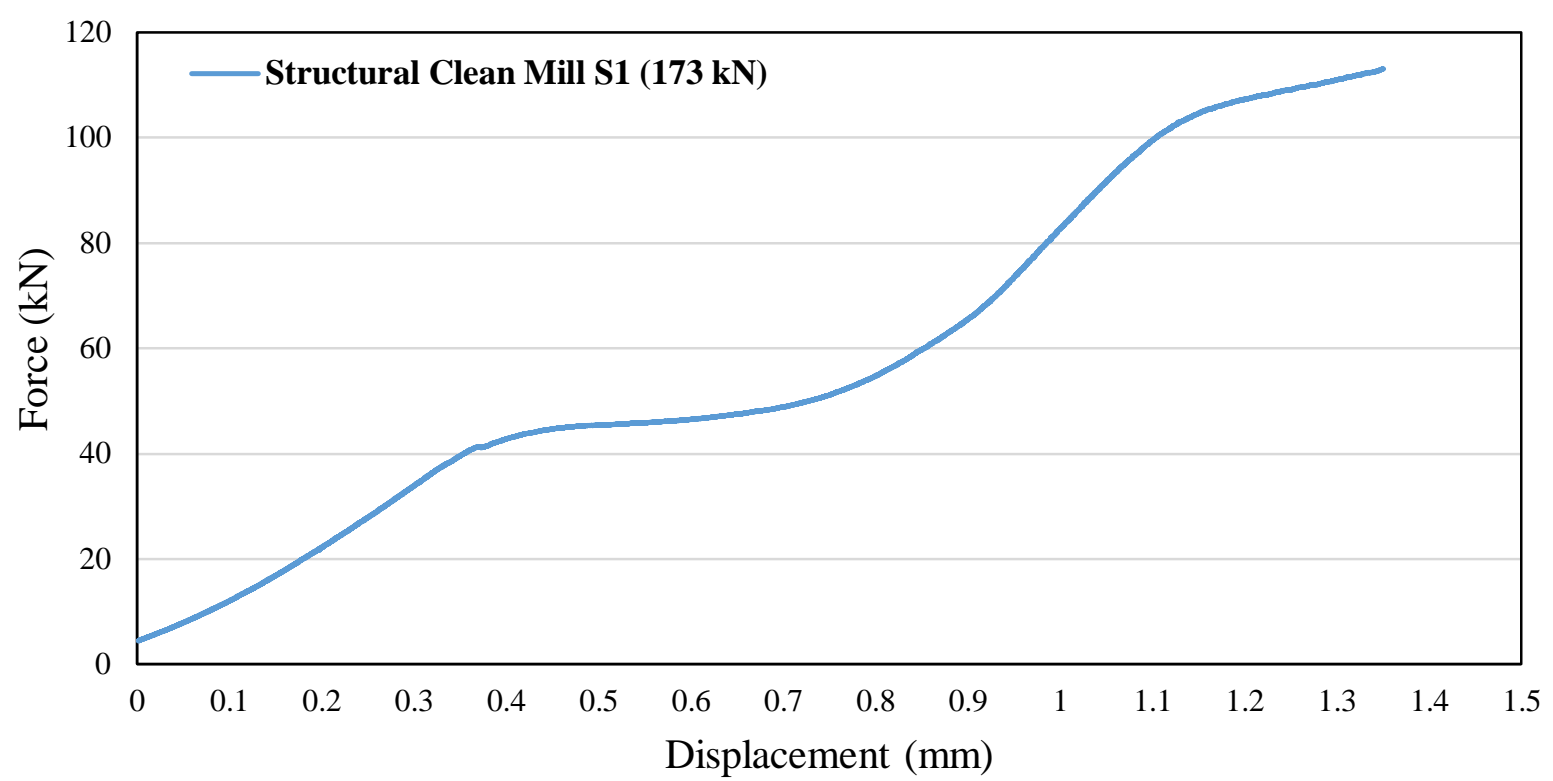

Figure C- 1: Force-displacement relationship for $350 \mathrm{~W}$ structural steel clean mill scale surface condition for test specimen 1 with A325 bolt

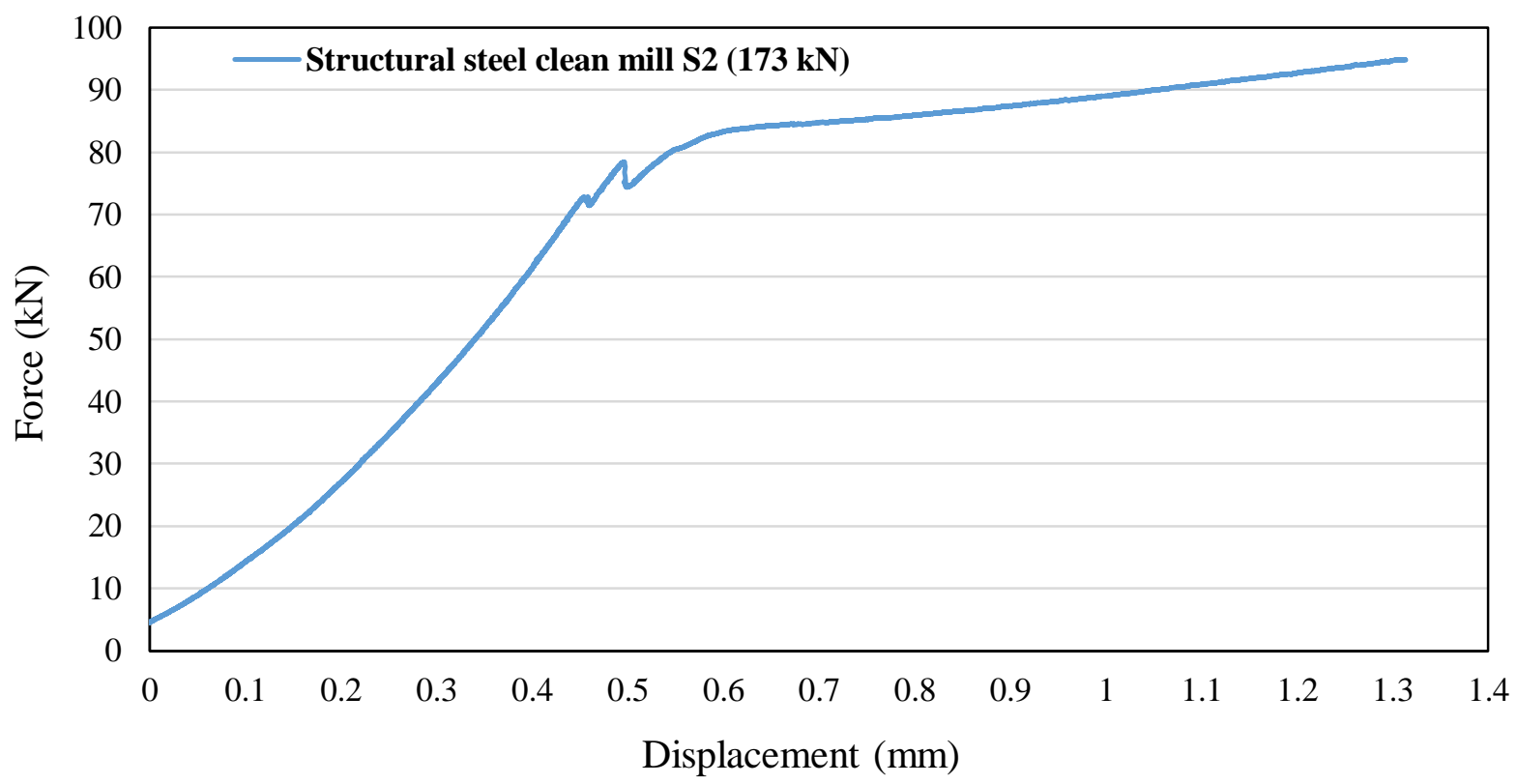

Figure C- 2: Force-displacement relationship for $350 \mathrm{~W}$ structural steel clean mill scale surface condition for test specimen 2 with $\mathbf{A 3 2 5}$ bolt 


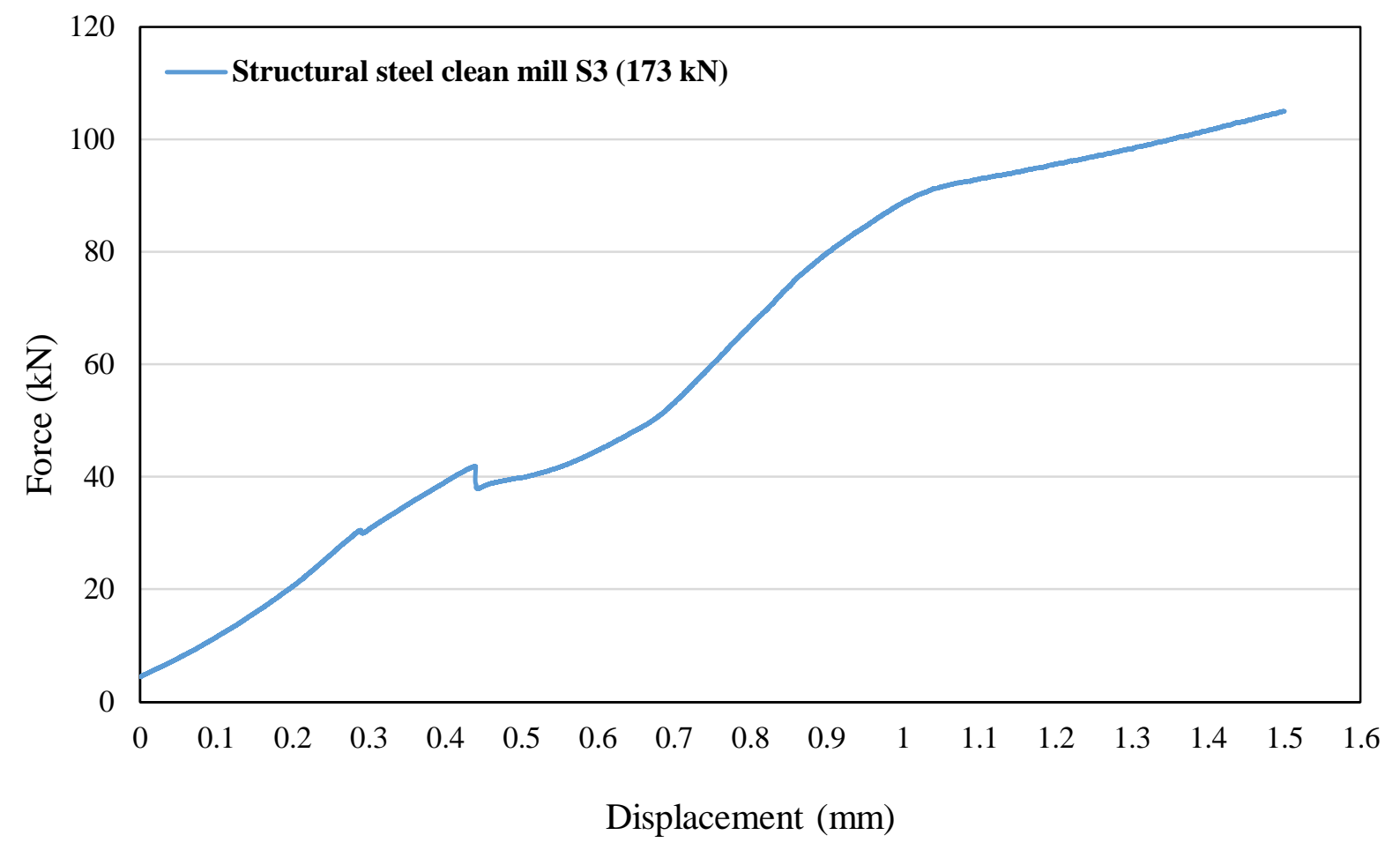

Figure C- 3: Force-displacement relationship for $350 \mathrm{~W}$ structural steel clean mill scale surface condition for test specimen 3 with A325 bolt

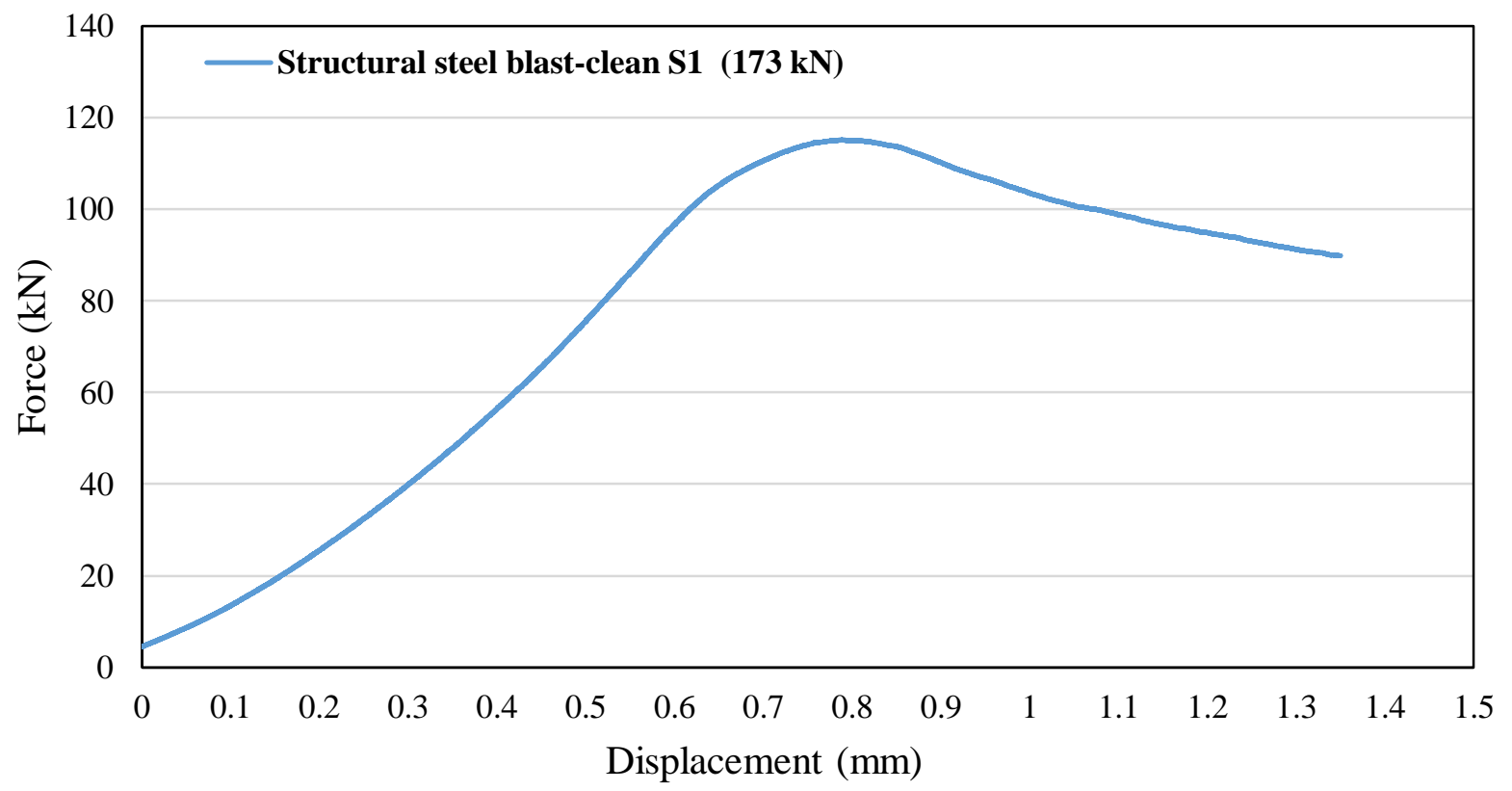

Figure C- 4: Force-displacement relationship for 350W structural steel blast-clean surface condition for test specimen 1 with A325 bolt 


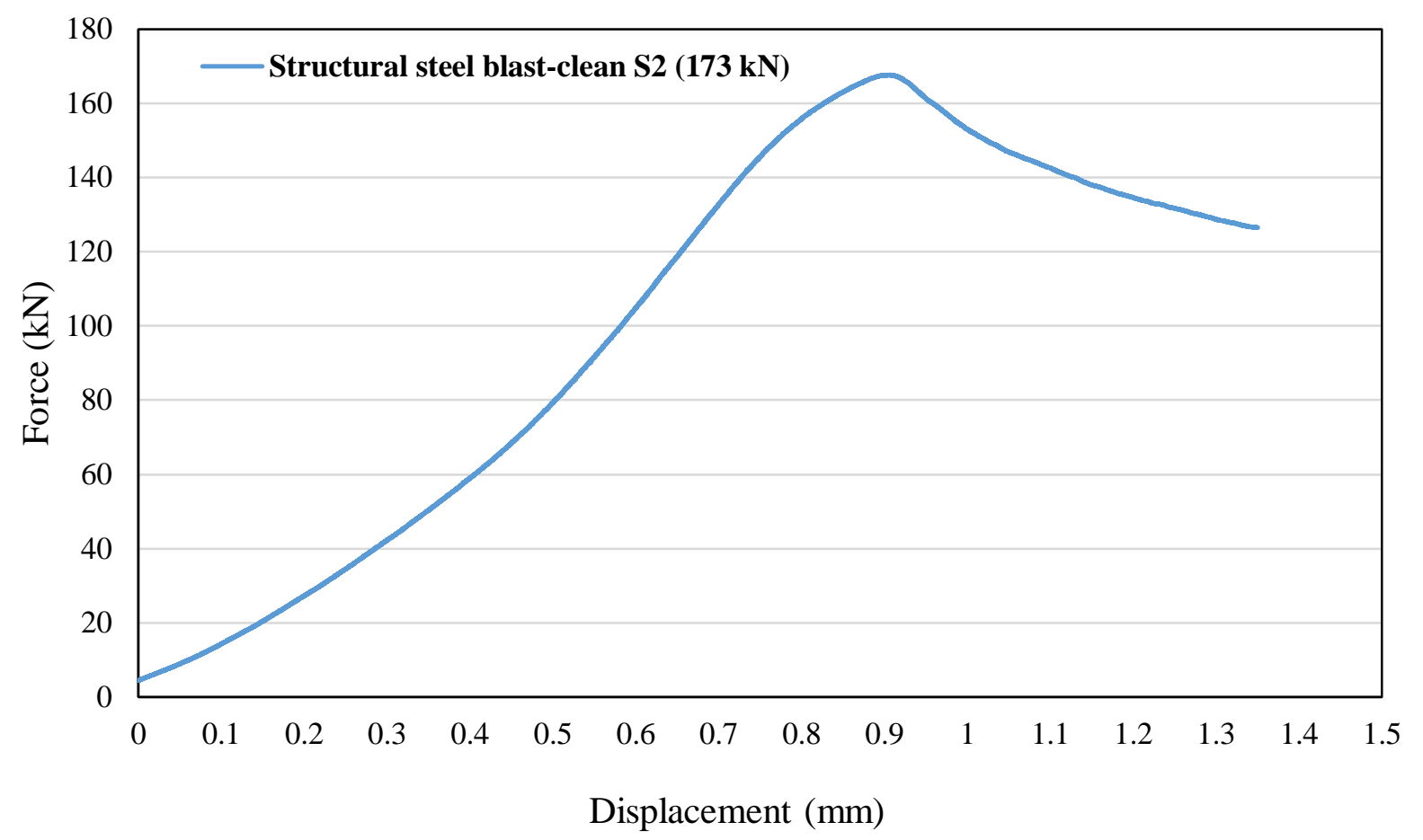

Figure C- 5: Force-displacement relationship for $350 \mathrm{~W}$ structural steel blast-clean surface condition for test specimen 2 with A325 bolt

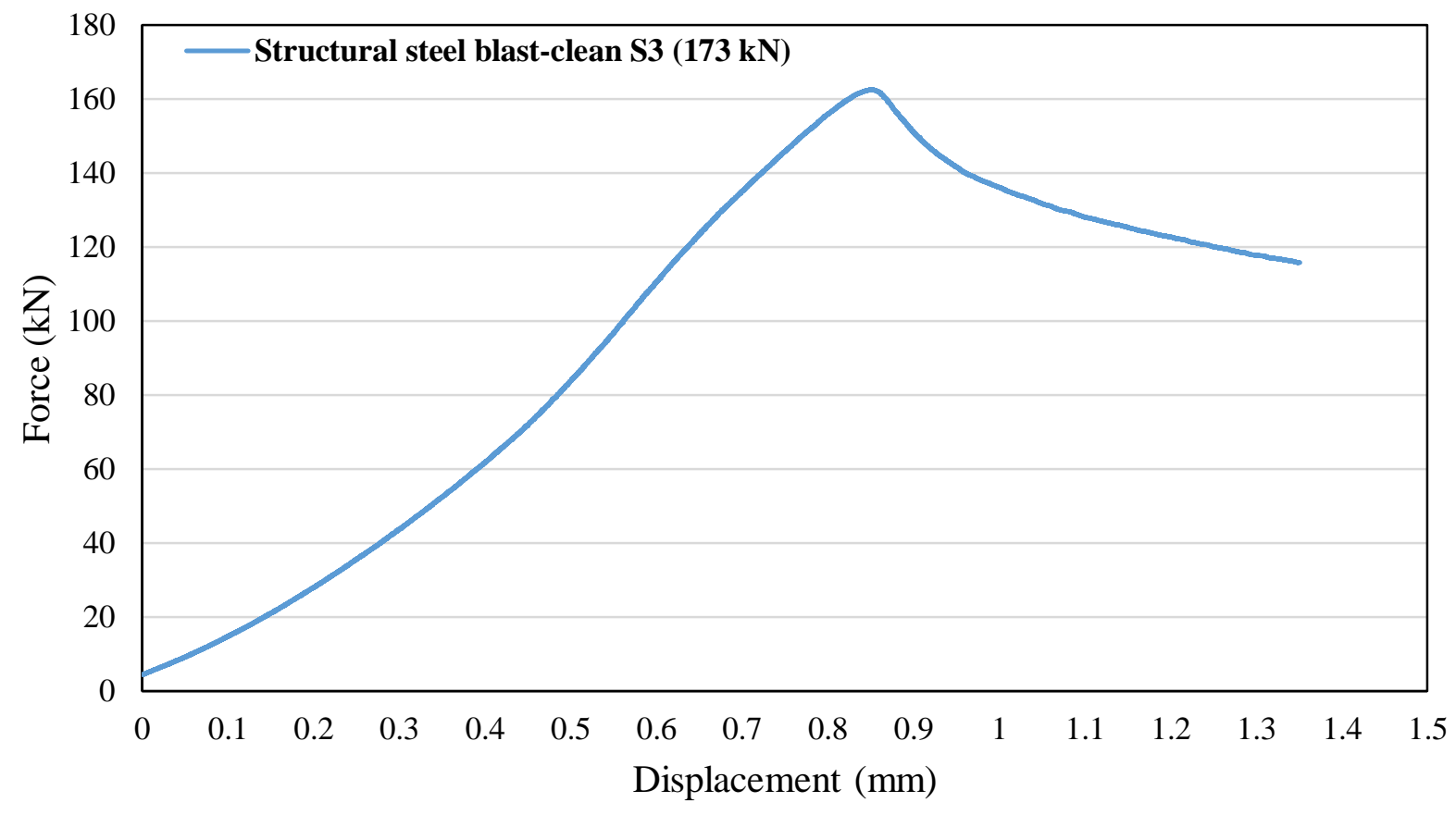

Figure C- 6: Force-displacement relationship for $350 \mathrm{~W}$ structural steel blast-clean surface condition for test specimen 3 with A325 bolt 


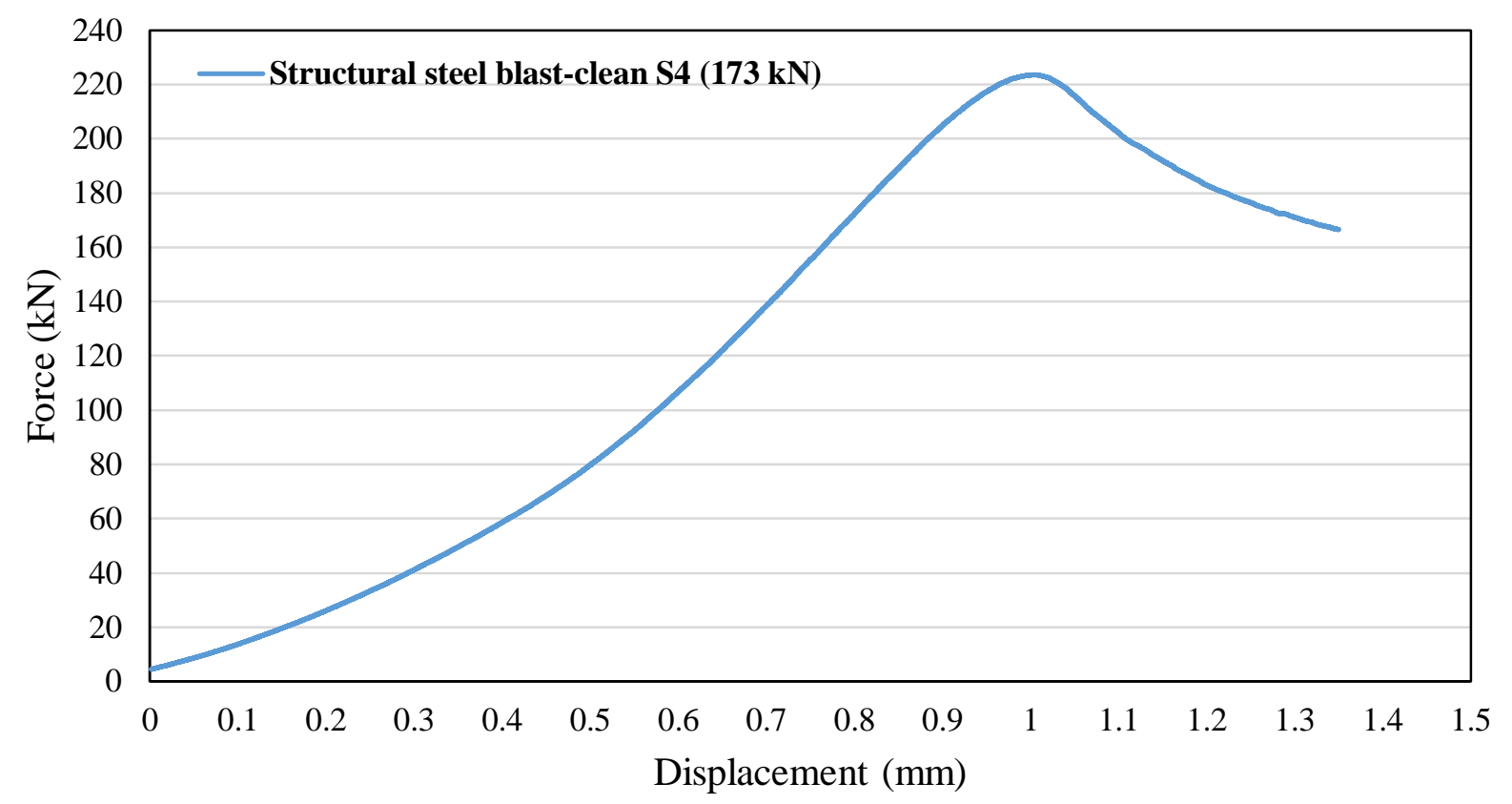

Figure C- 7: Force-displacement relationship for $350 \mathrm{~W}$ structural steel blast-clean surface condition for test specimen 3 with A325 bolt

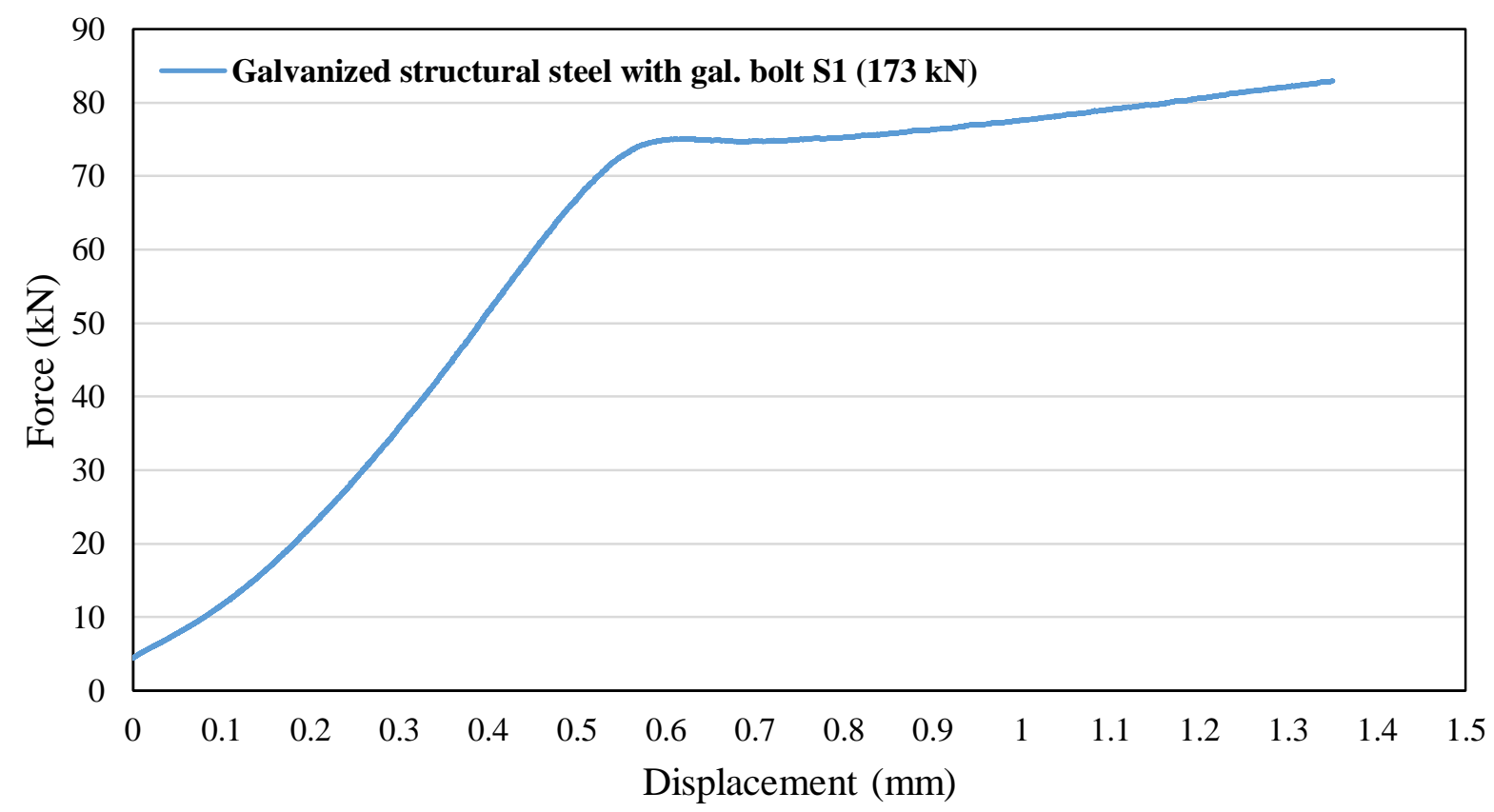

Figure C- 8: Force-displacement relationship for $350 \mathrm{~W}$ structural steel with hot dip galvanized surface condition for test specimen 1 with galvanized bolt 


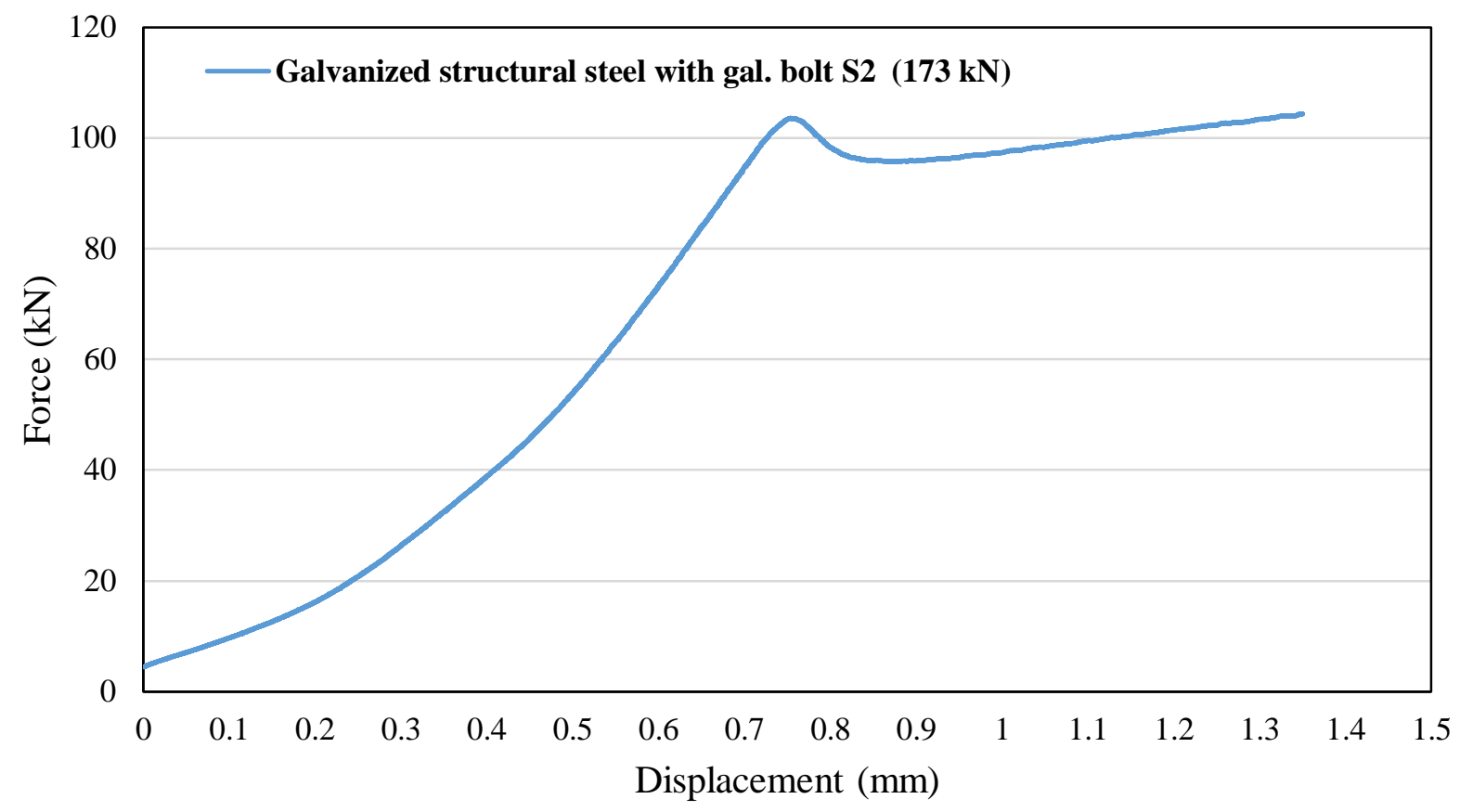

Figure C- 9: Force-displacement relationship for $350 \mathrm{~W}$ structural steel with hot dip galvanized surface condition for test specimen 2 with galvanized bolt

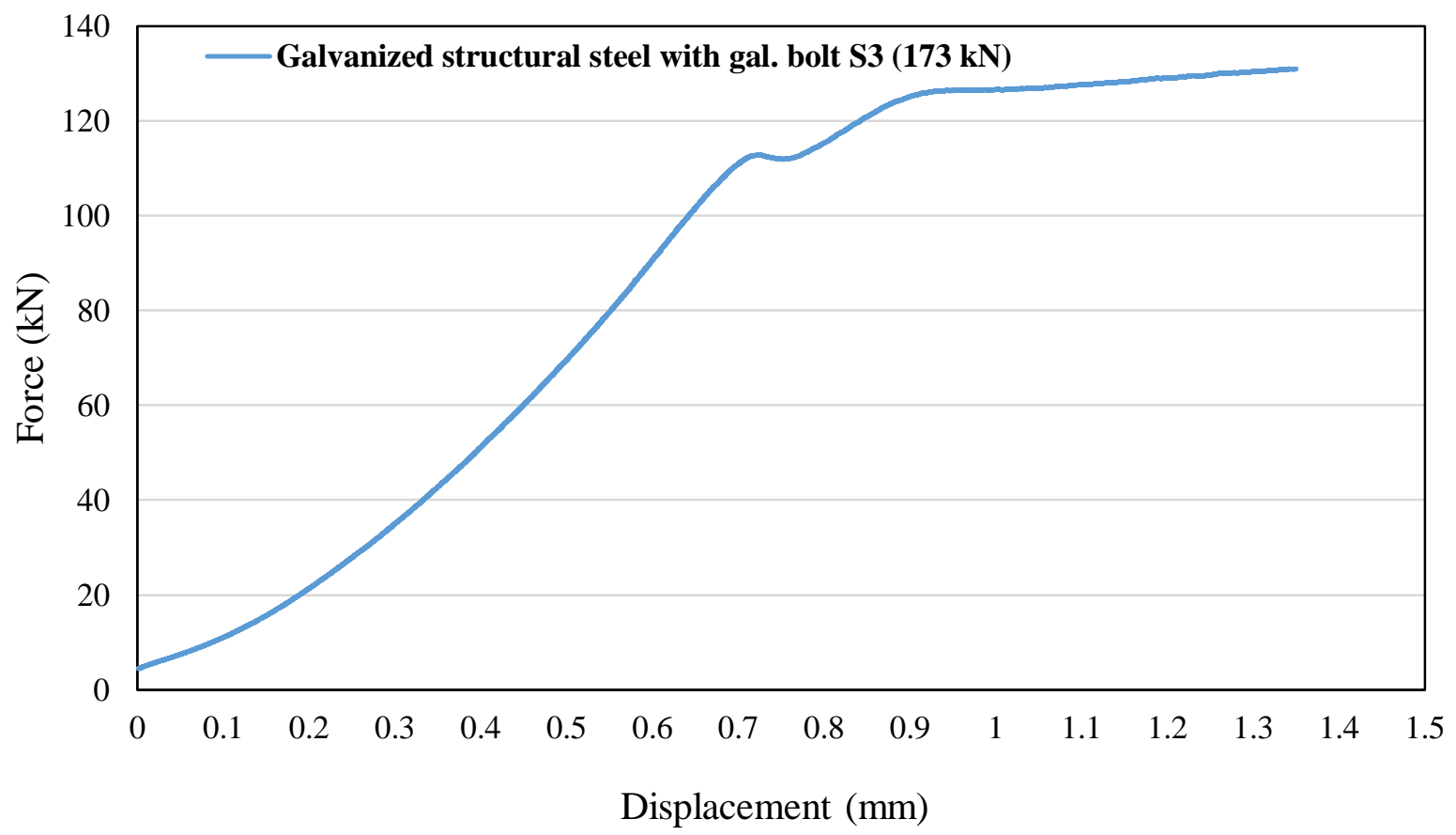

Figure C- 10: Force-displacement relationship for $350 \mathrm{~W}$ structural steel with hot dip galvanized surface condition for test specimen 3 with galvanized bolt 


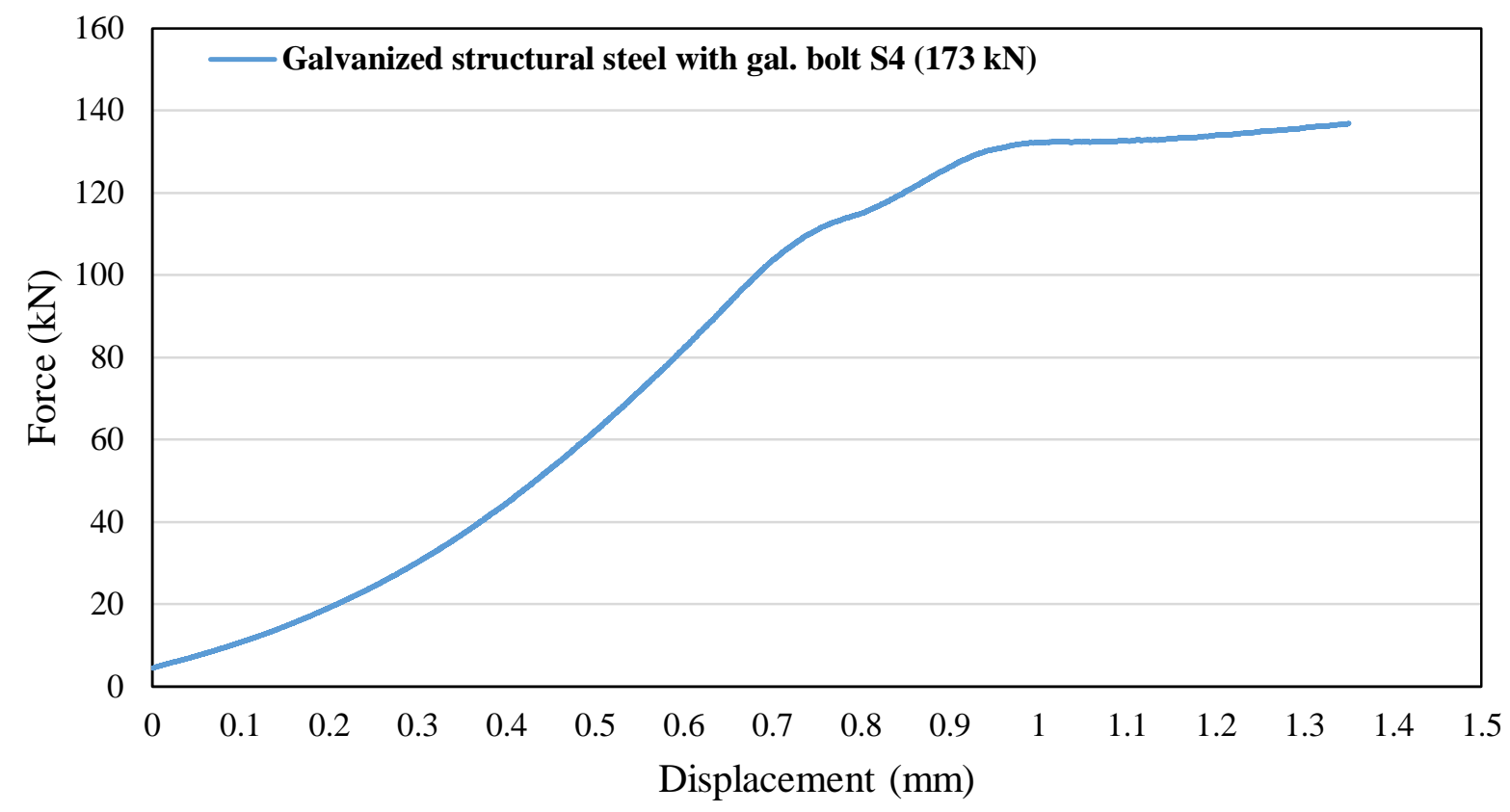

Figure C- 11: Force-displacement relationship for $350 \mathrm{~W}$ structural steel with hot dip galvanized surface condition for test specimen 4 with galvanized bolt

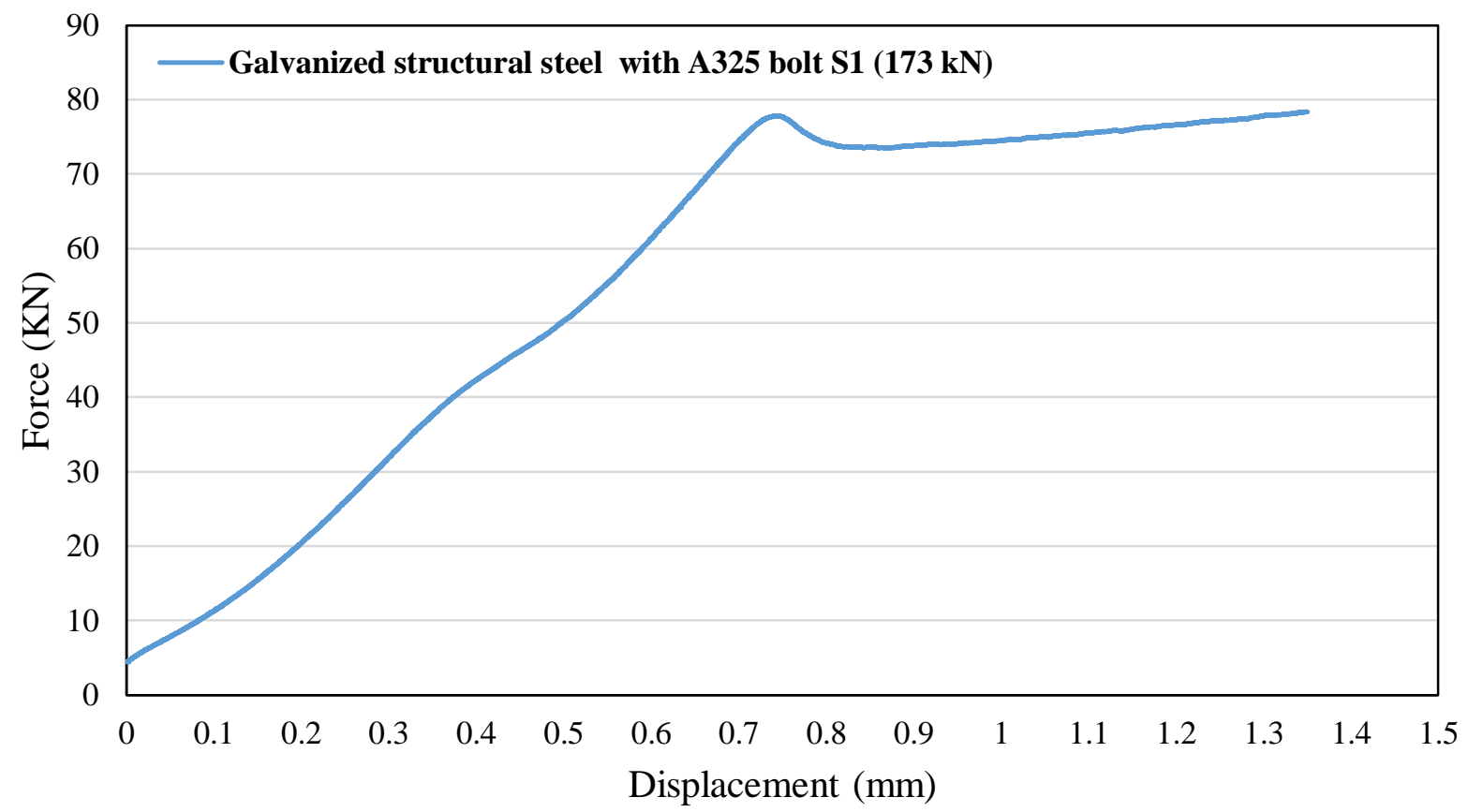

Figure C- 12: Force-displacement relationship for $350 \mathrm{~W}$ structural steel with hot dip galvanized surface condition for test specimen 1 with $\mathrm{A325}$ bolt 


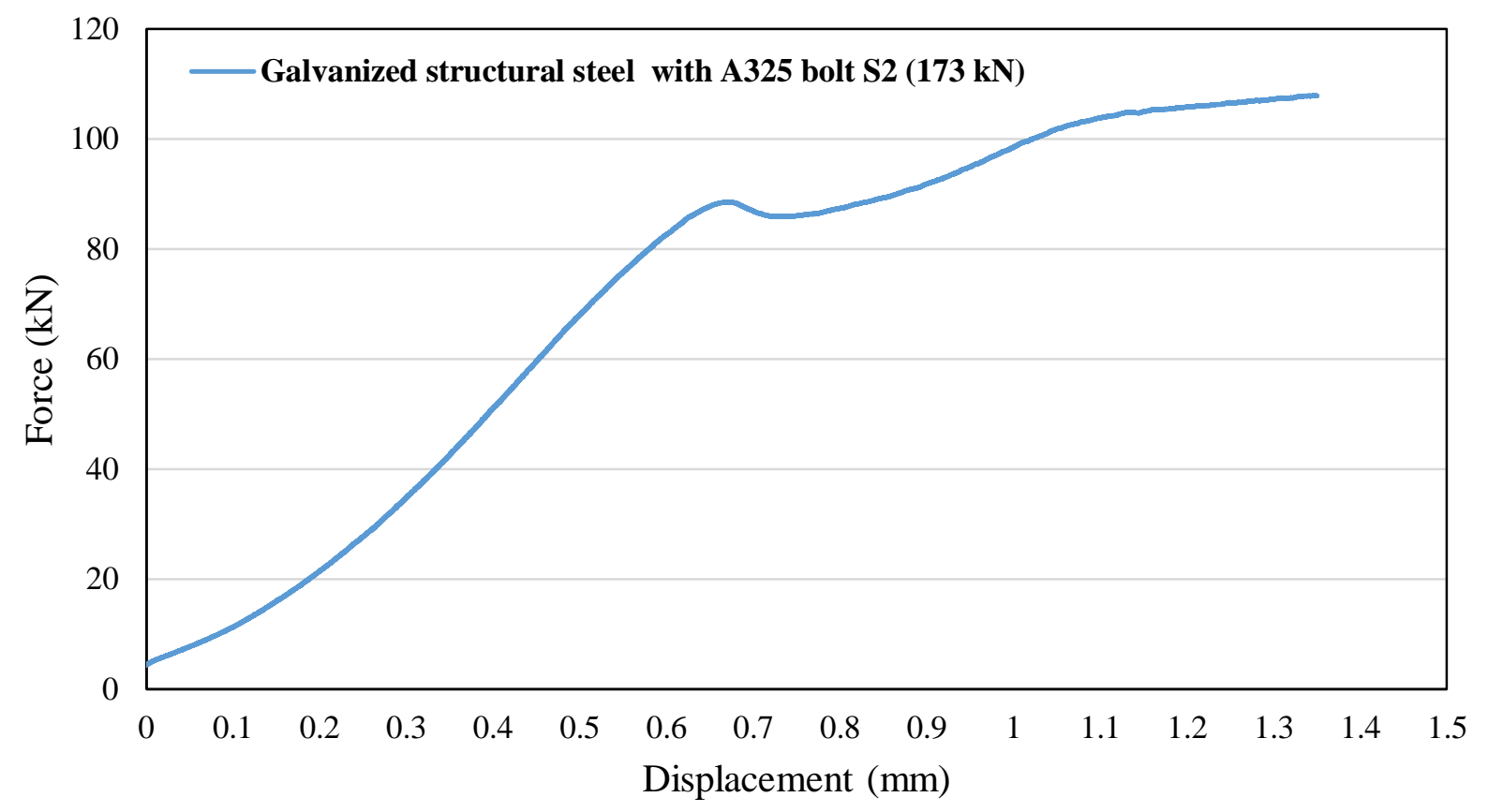

Figure C- 13: Force-displacement relationship for 350W structural steel with hot dip galvanized surface condition for test specimen 2 with A325 bolt

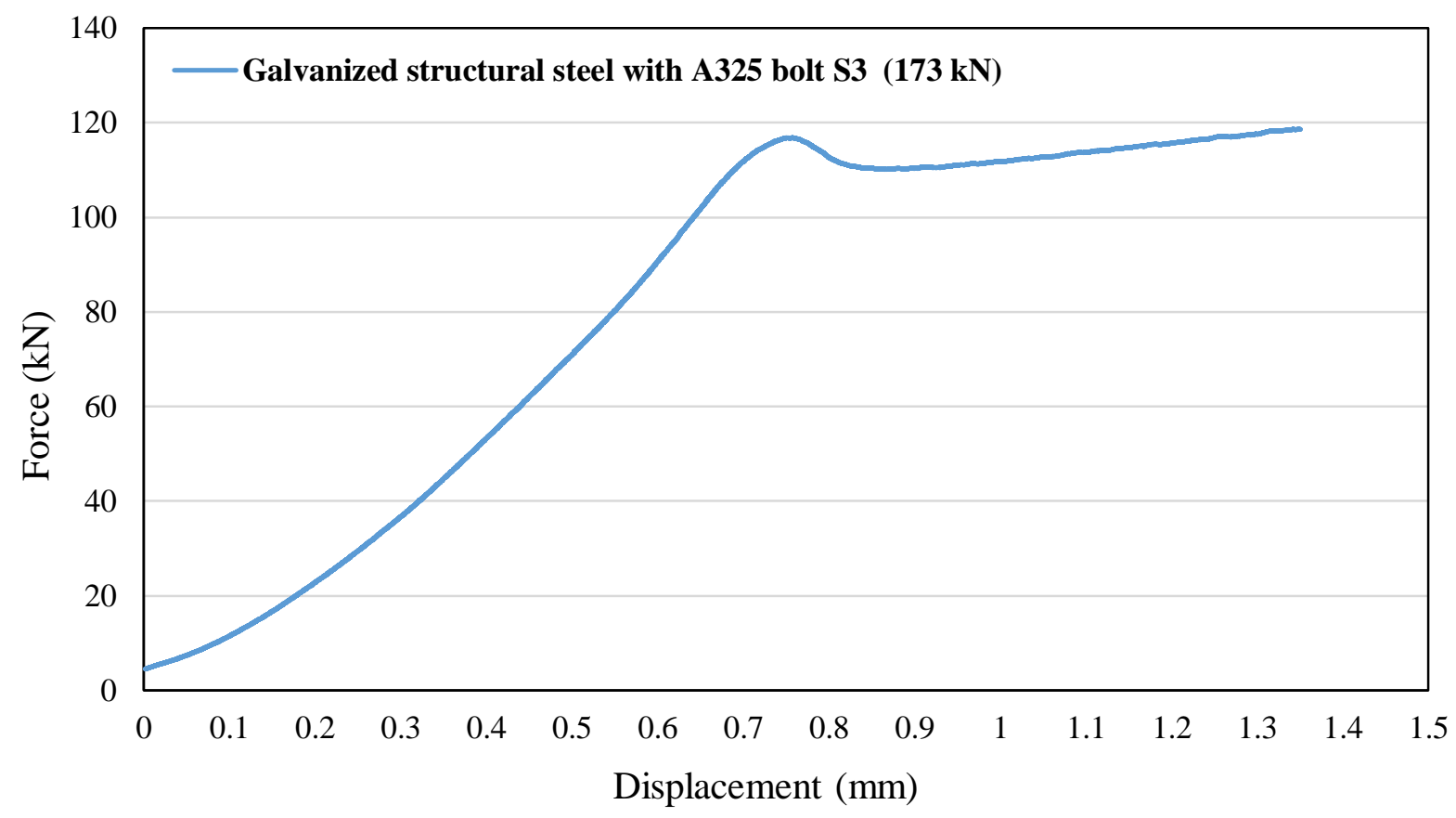

Figure C- 14: Force-displacement relationship for 350W structural steel with hot dip galvanized surface condition for test specimen 3 with A325 bolt 


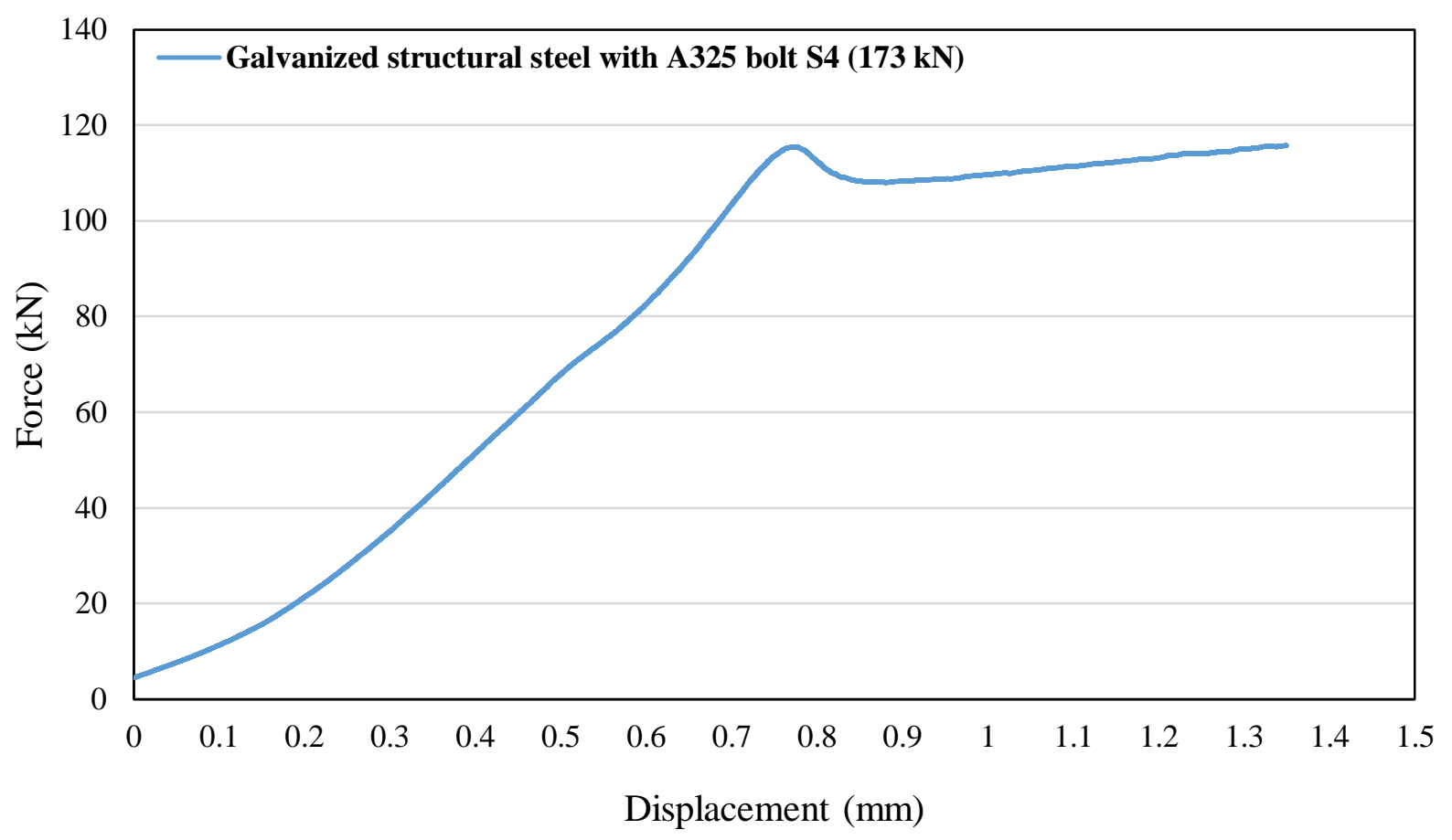

Figure C- 15: Force-displacement relationship for $350 \mathrm{~W}$ structural steel with hot dip galvanized surface condition for test specimen 4 with A325 bolt

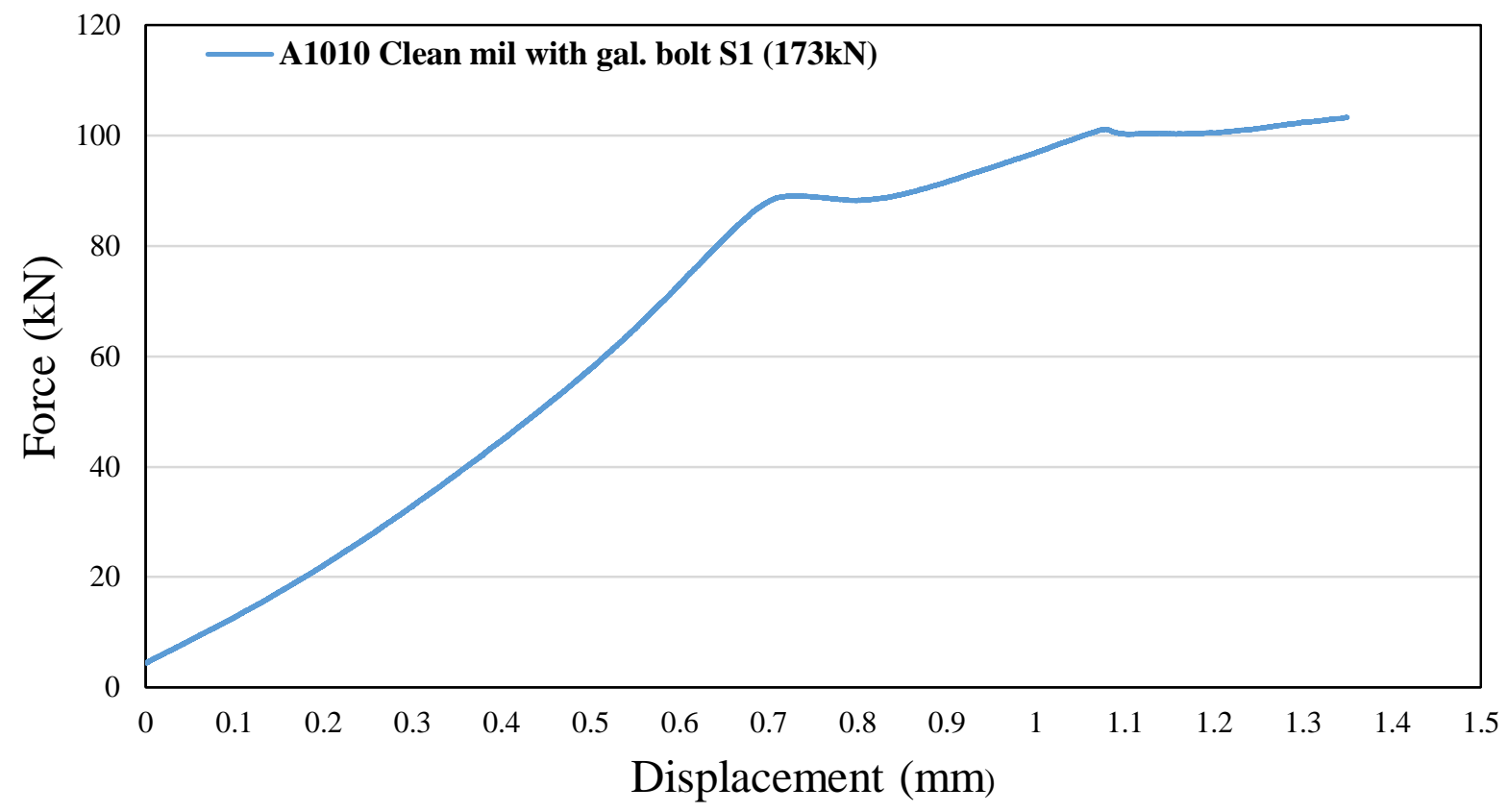

Figure C- 16: Force-displacement relationship for A1010 stainless steel with clean mill scale surface condition for test specimen 1 with galvanized bolt 


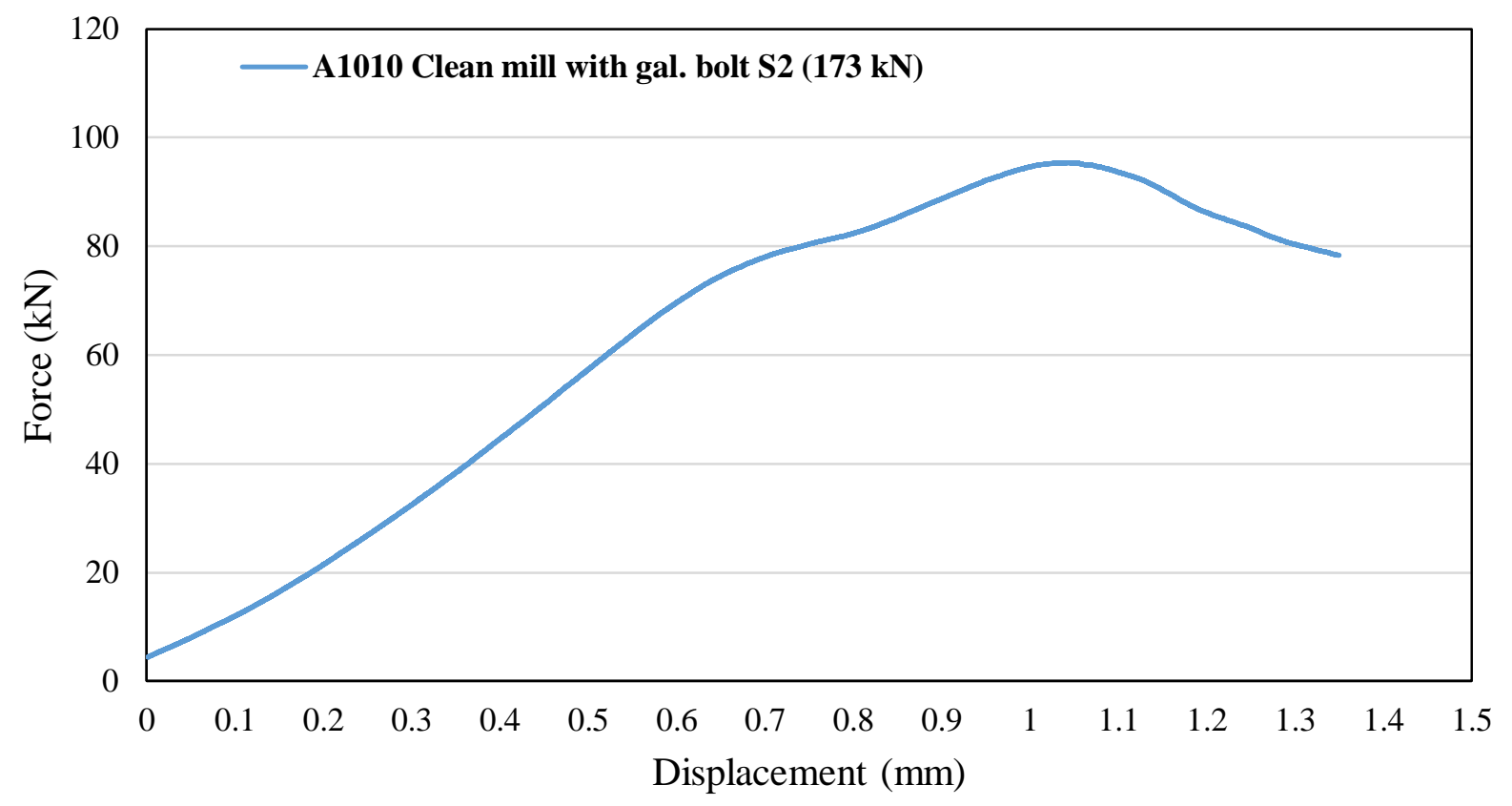

Figure C- 17: Force-displacement relationship for A1010 stainless steel with clean mill scale surface condition for test specimen 2 with galvanized bolt

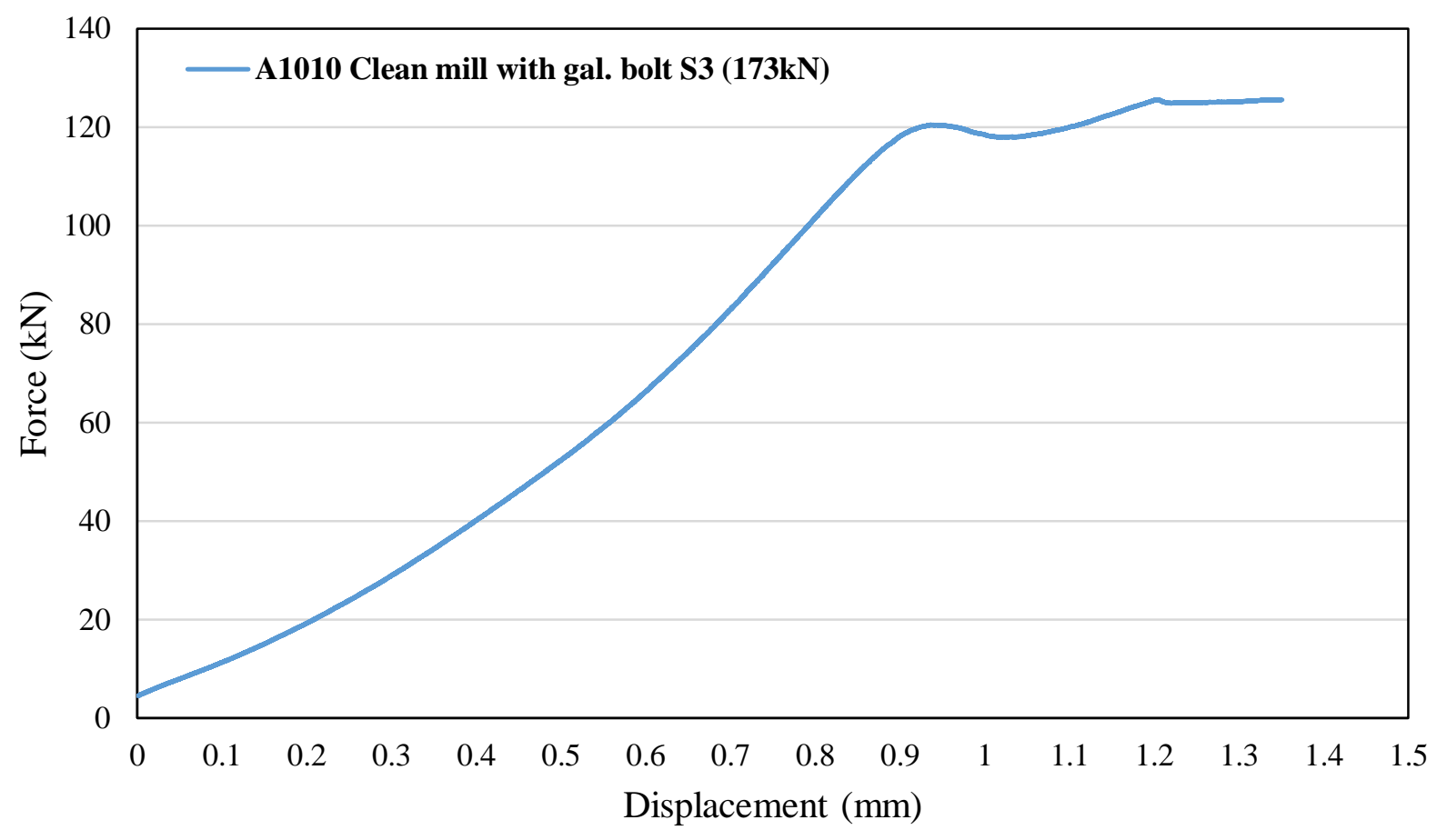

Figure C- 18: Force-displacement relationship for A1010 stainless steel with clean mill scale surface condition for test specimen 3 with galvanized bolt 


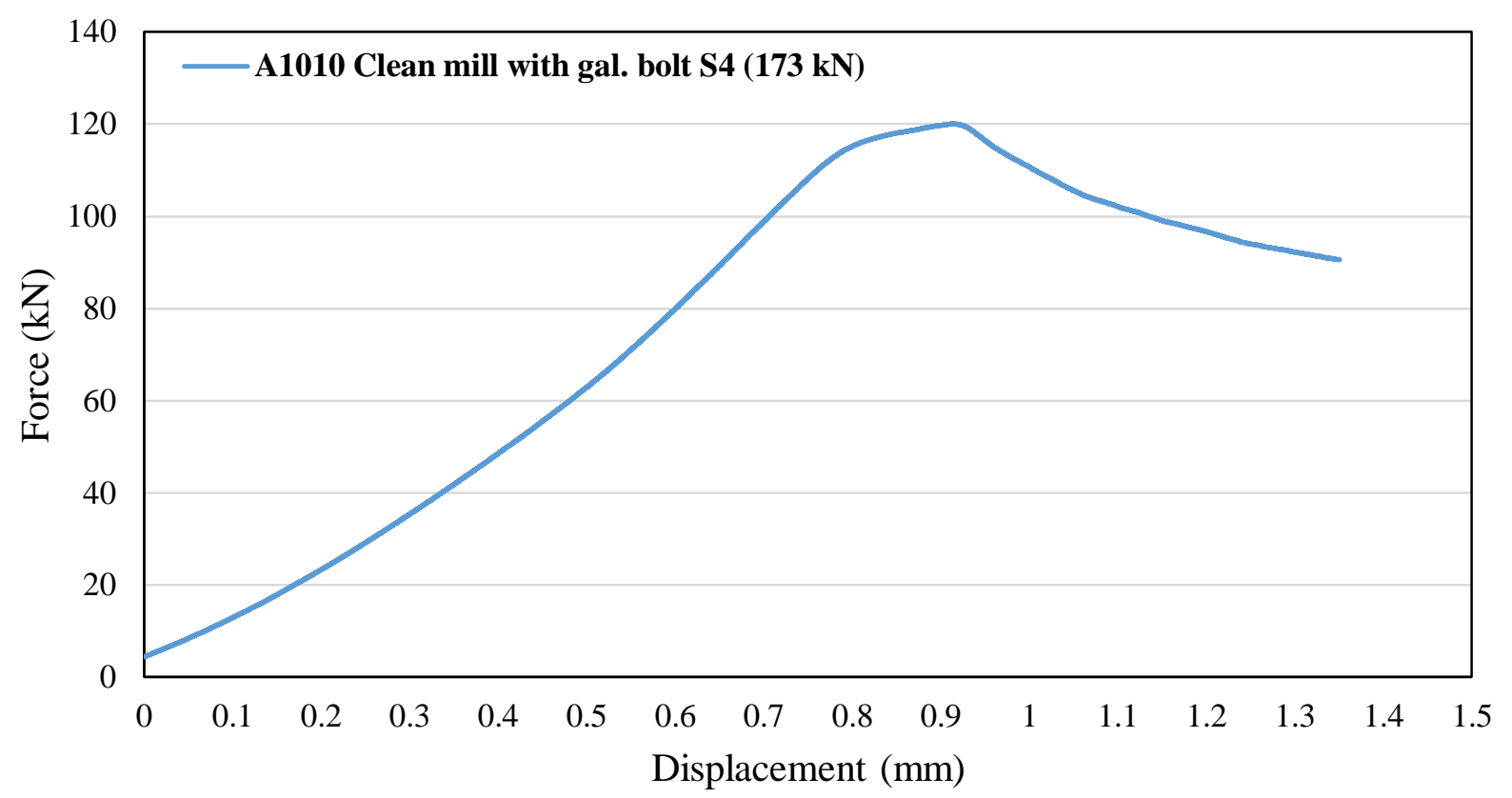

Figure C- 19: Force-displacement relationship for A1010 stainless steel with clean mill scale surface condition for test specimen 4 with galvanized bolt

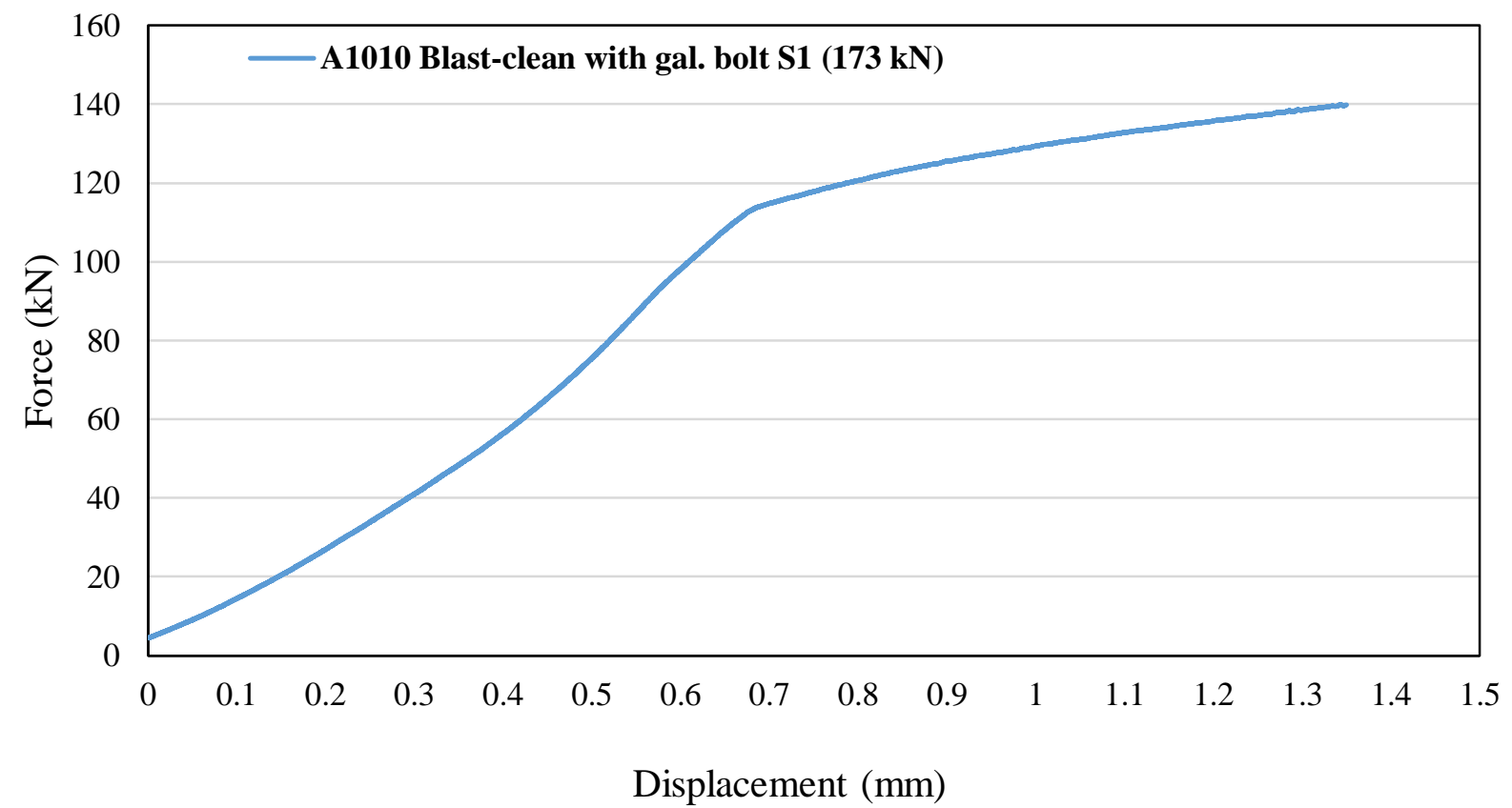

Figure C- 20: Force-displacement relationship for A1010 stainless steel with blast-clean surface condition for test specimen 1 with galvanized bolt 


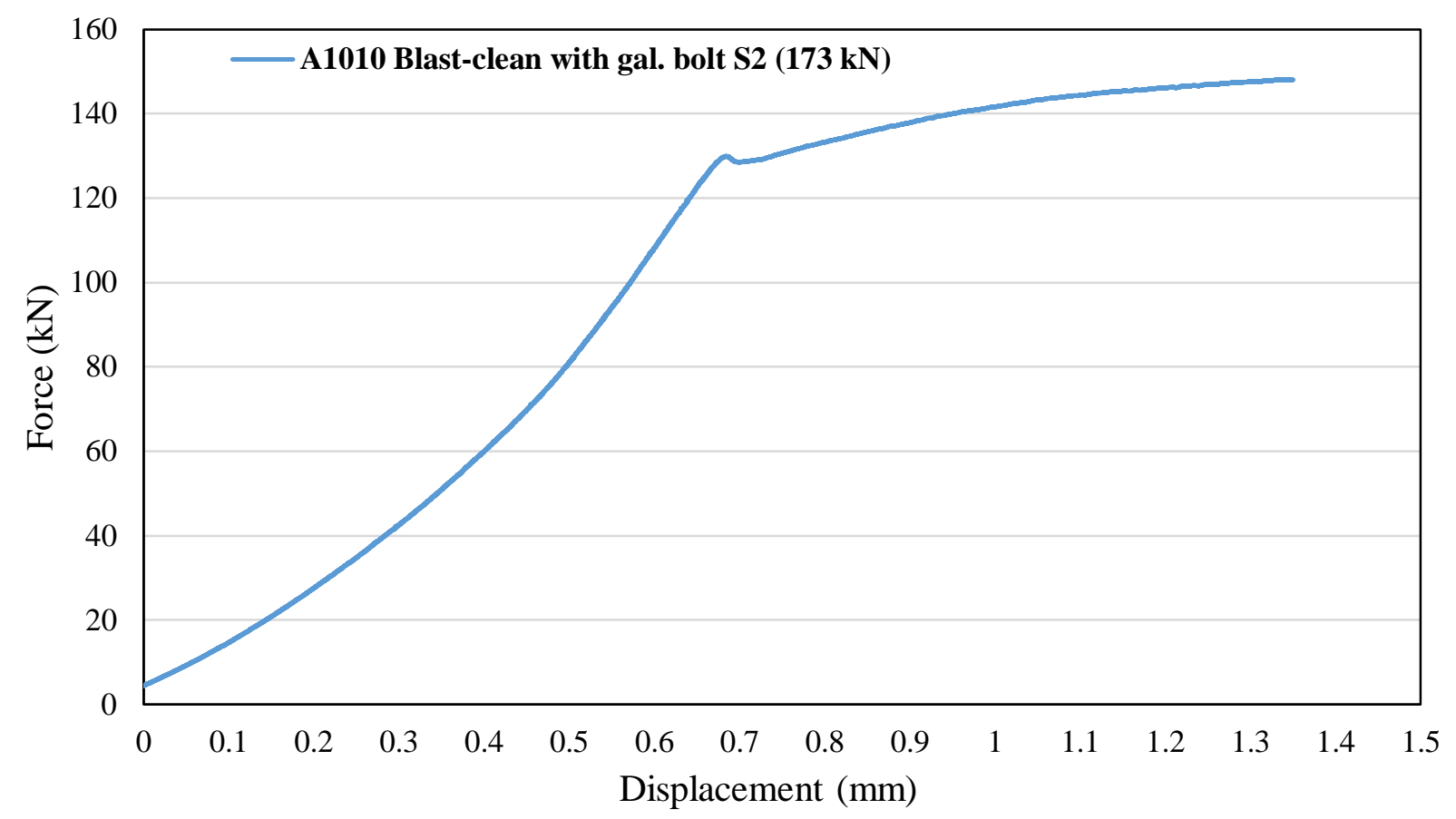

Figure C- 21: Force-displacement relationship for A1010 stainless steel with blast-clean surface condition for test specimen 2 with galvanized bolt

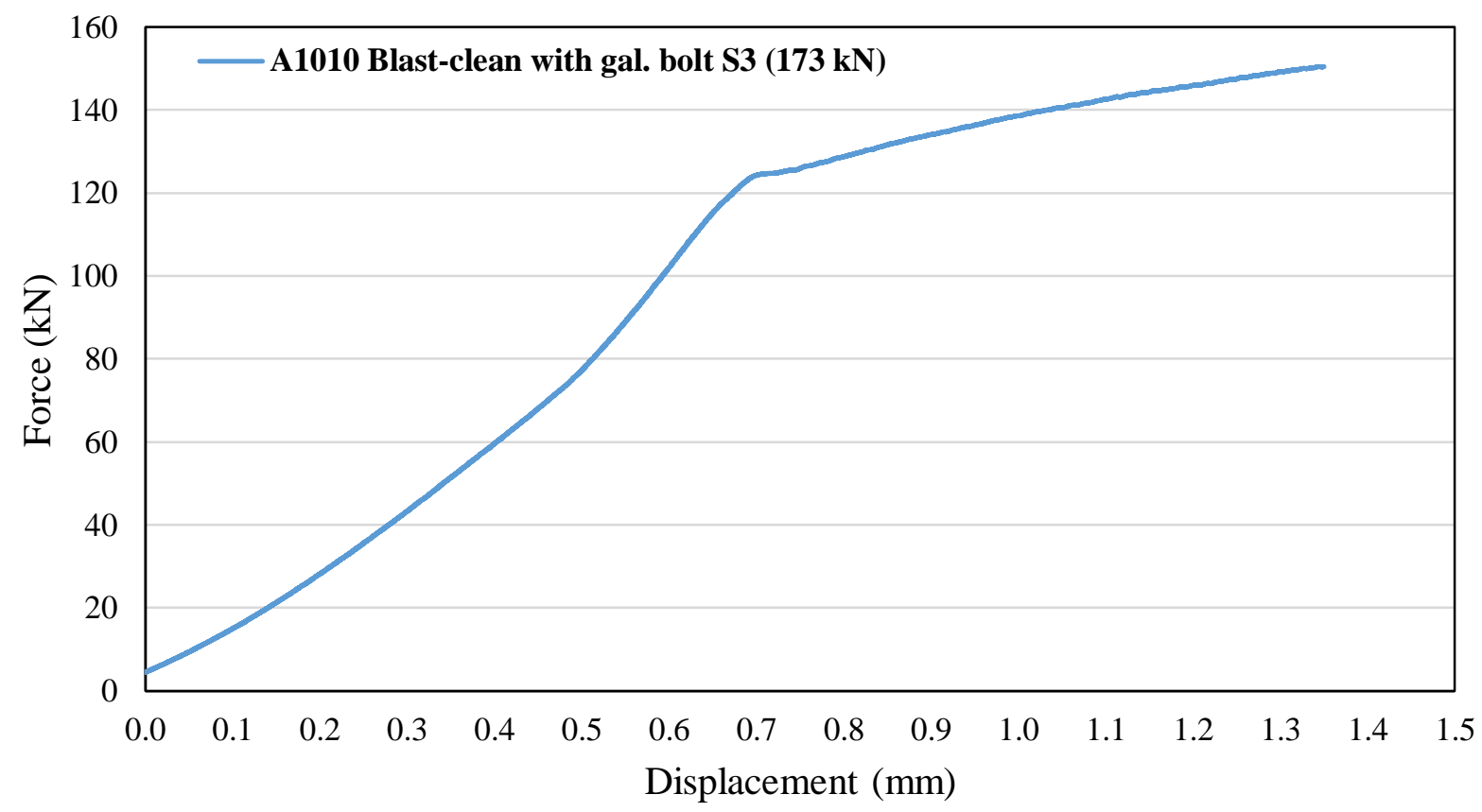

Figure C- 22: Force-displacement relationship for A1010 stainless steel with blast-clean surface condition for test specimen 3 with galvanized bolt 


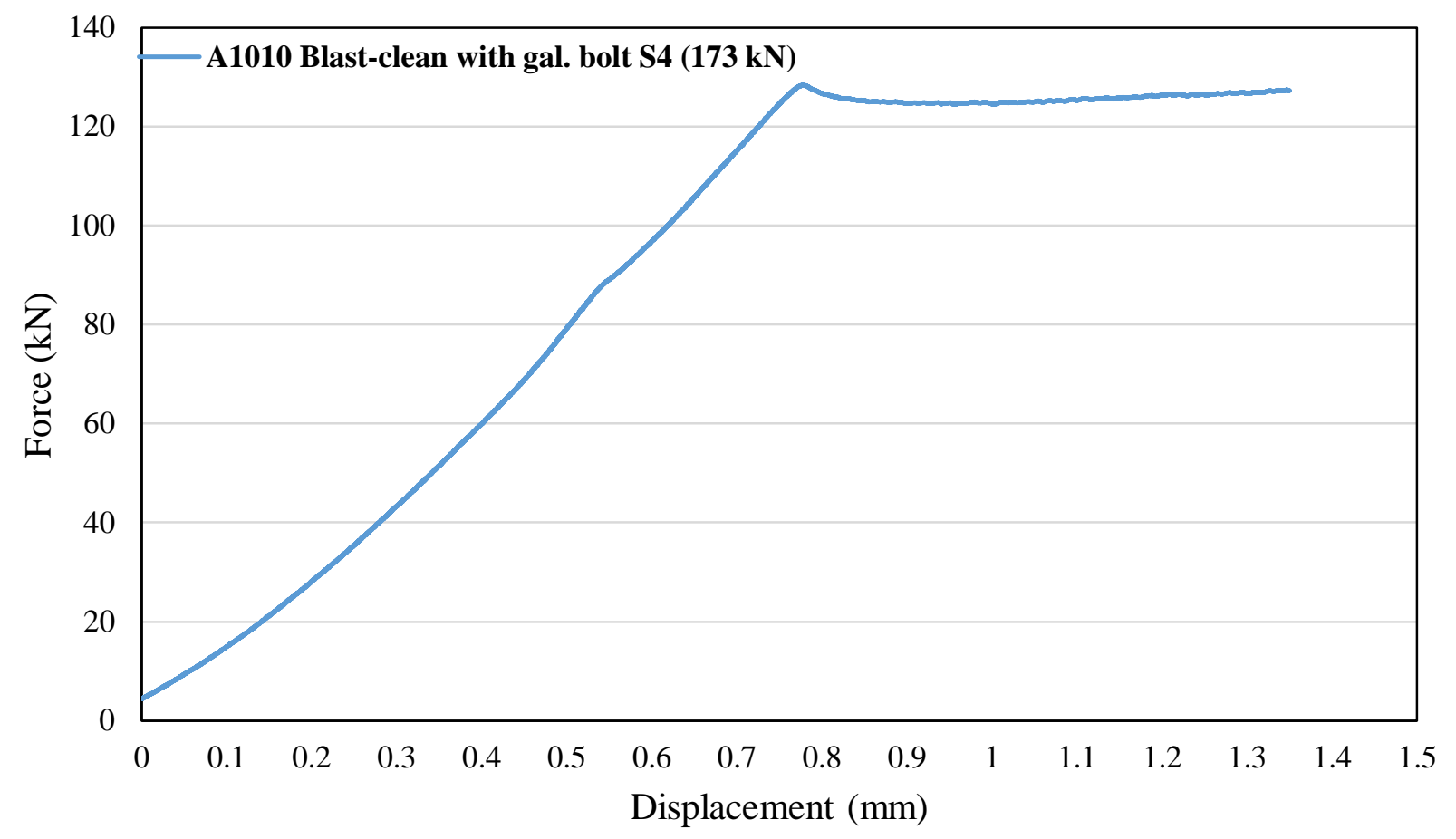

Figure C- 23: Force-displacement relationship for A1010 stainless steel with blast-clean surface condition for test specimen 4 with galvanized bolt 


\section{Appendix D: Slip Coefficient Testing at 203 kN Clamping Force at Ambient Temperature}

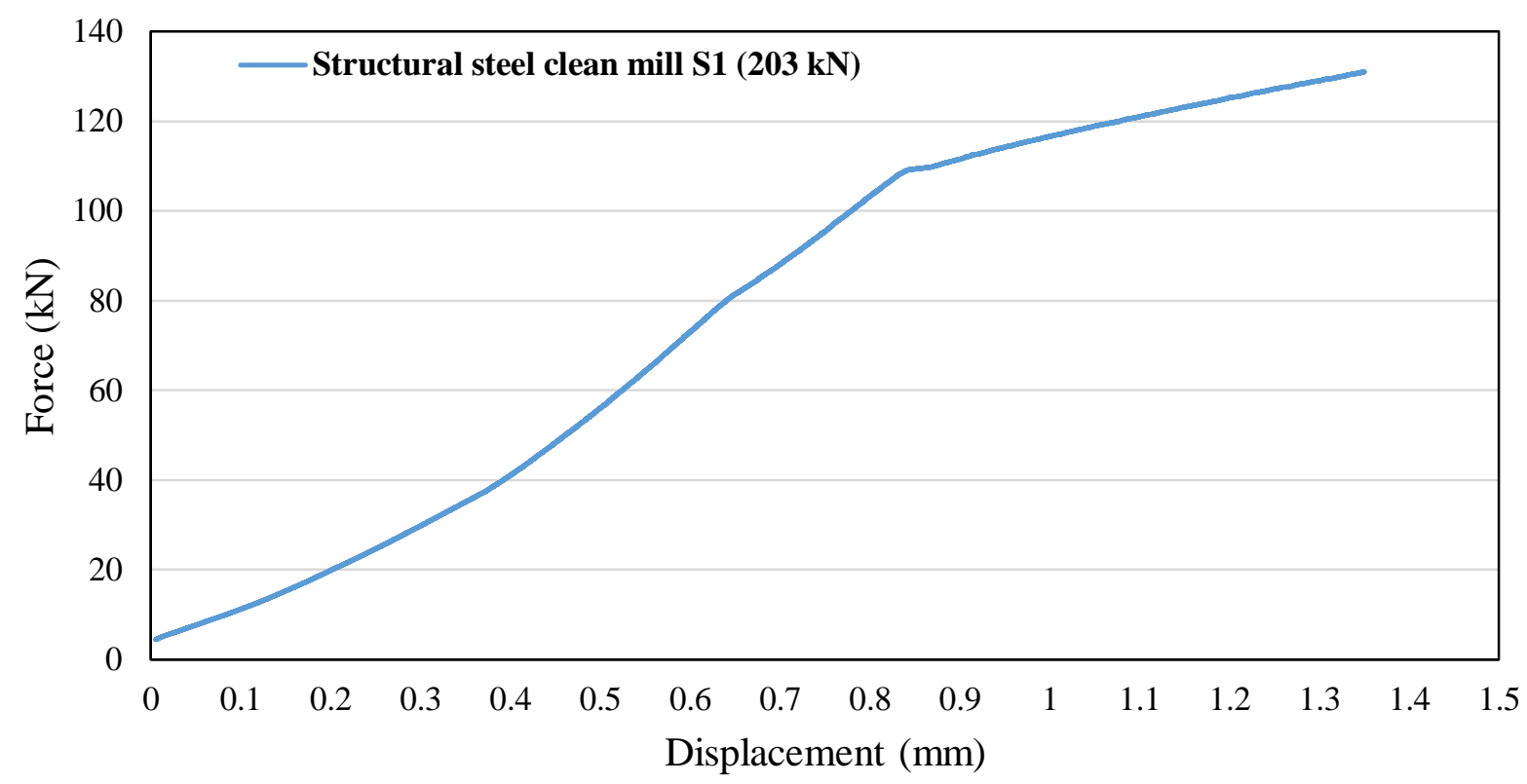

Figure D - 1: Force-displacement relationship for $350 \mathrm{~W}$ structural steel with clean mill scale surface condition for test specimen 1 with A325 bolt

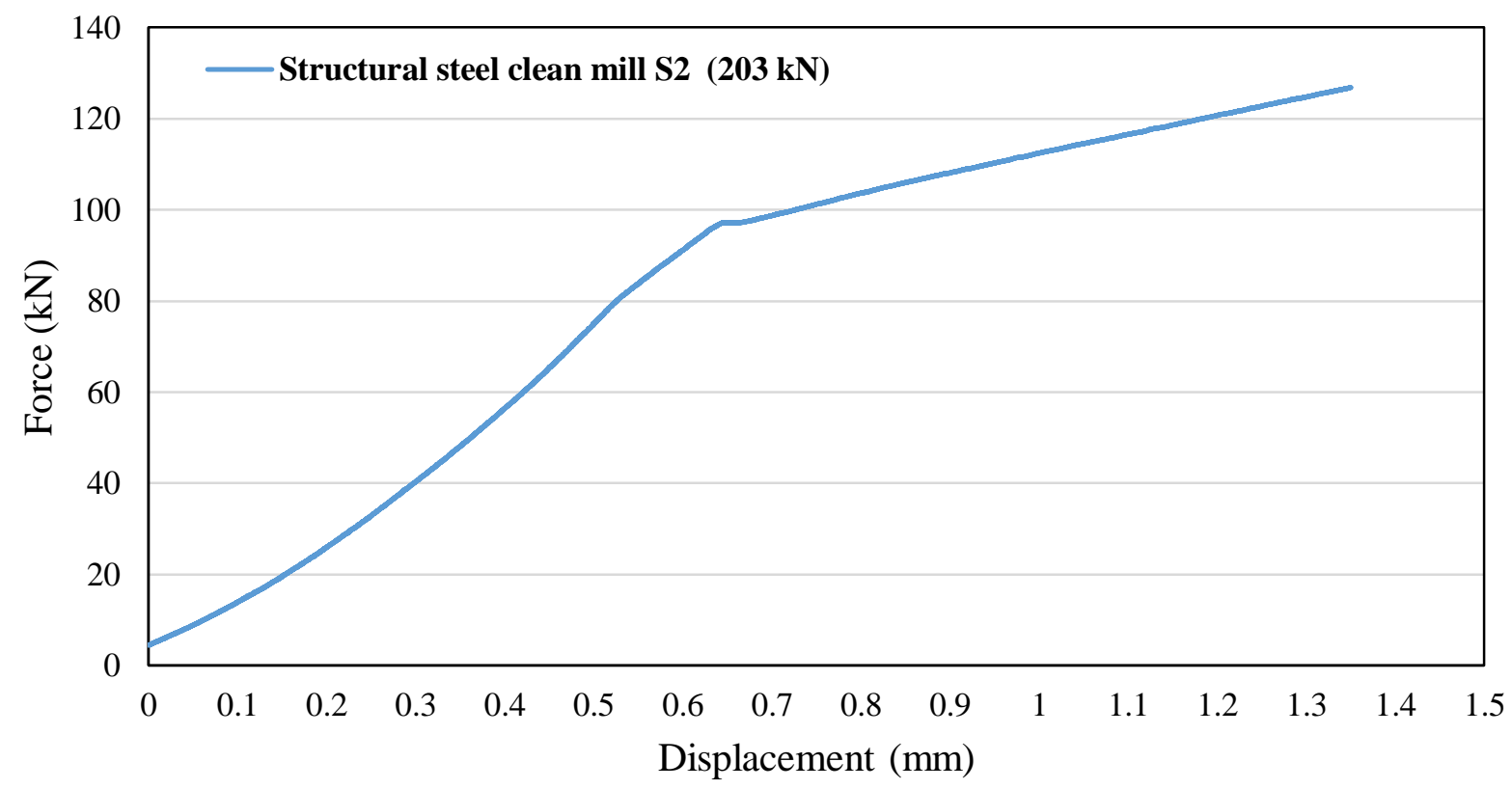

Figure D - 2: Force-displacement relationship for $350 \mathrm{~W}$ structural steel with clean mill scale surface condition for test specimen 2 with A325 bolt 


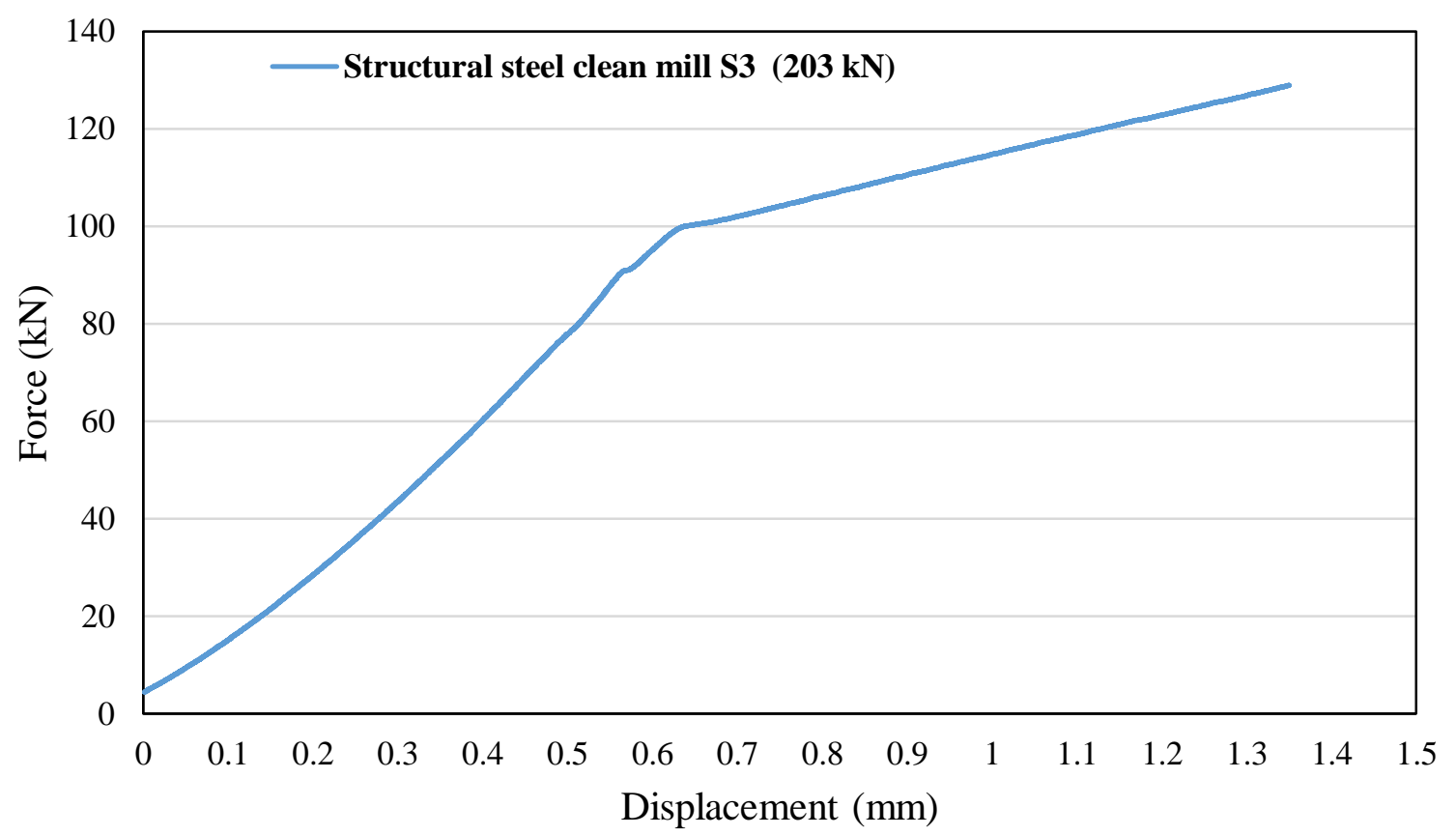

Figure D - 3: Force-displacement relationship for $350 \mathrm{~W}$ structural steel with clean mill scale surface condition for test specimen 3 with A325 bolt

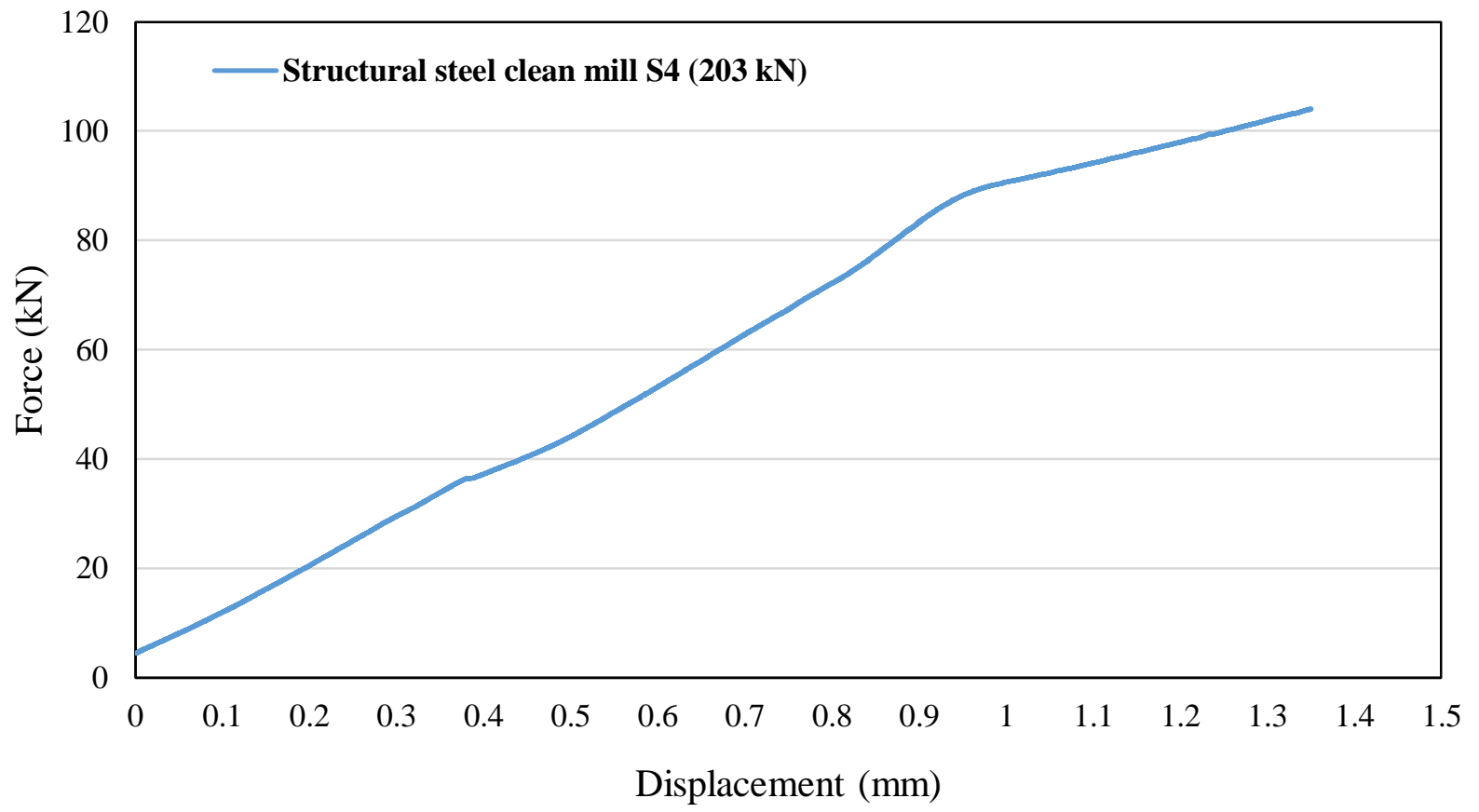

Figure D - 4: Force-displacement relationship for 350W structural steel with clean mill scale surface condition for test specimen 4 with A325 bolt 


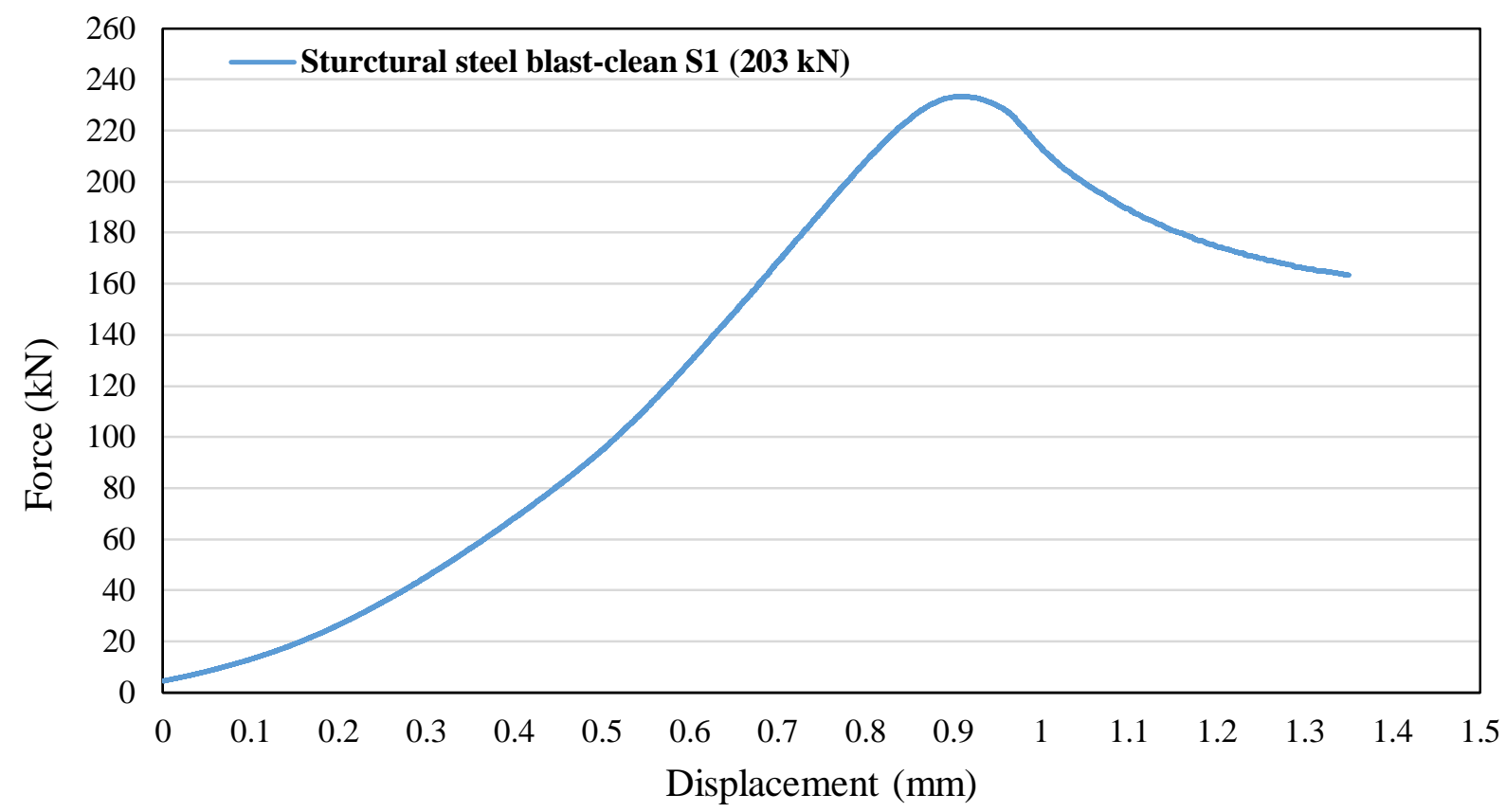

Figure D - 5: Force-displacement relationship for 350W structural steel with blast-clean surface condition for test specimen 1 with A325 bolt

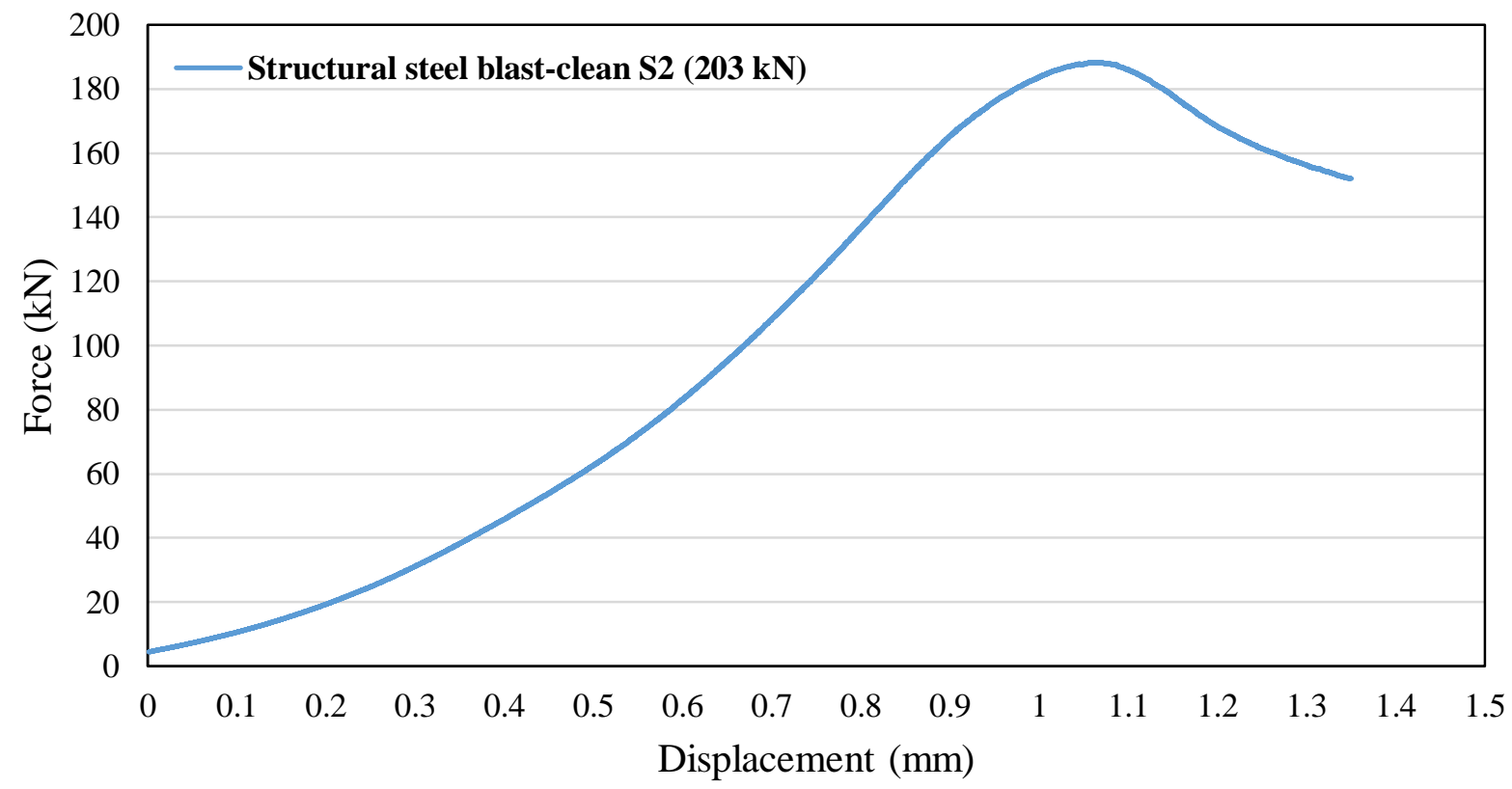

Figure D - 6: Force-displacement relationship for $350 \mathrm{~W}$ structural steel with blast-clean surface condition for test specimen 2 with $\mathrm{A} 325$ bolt 


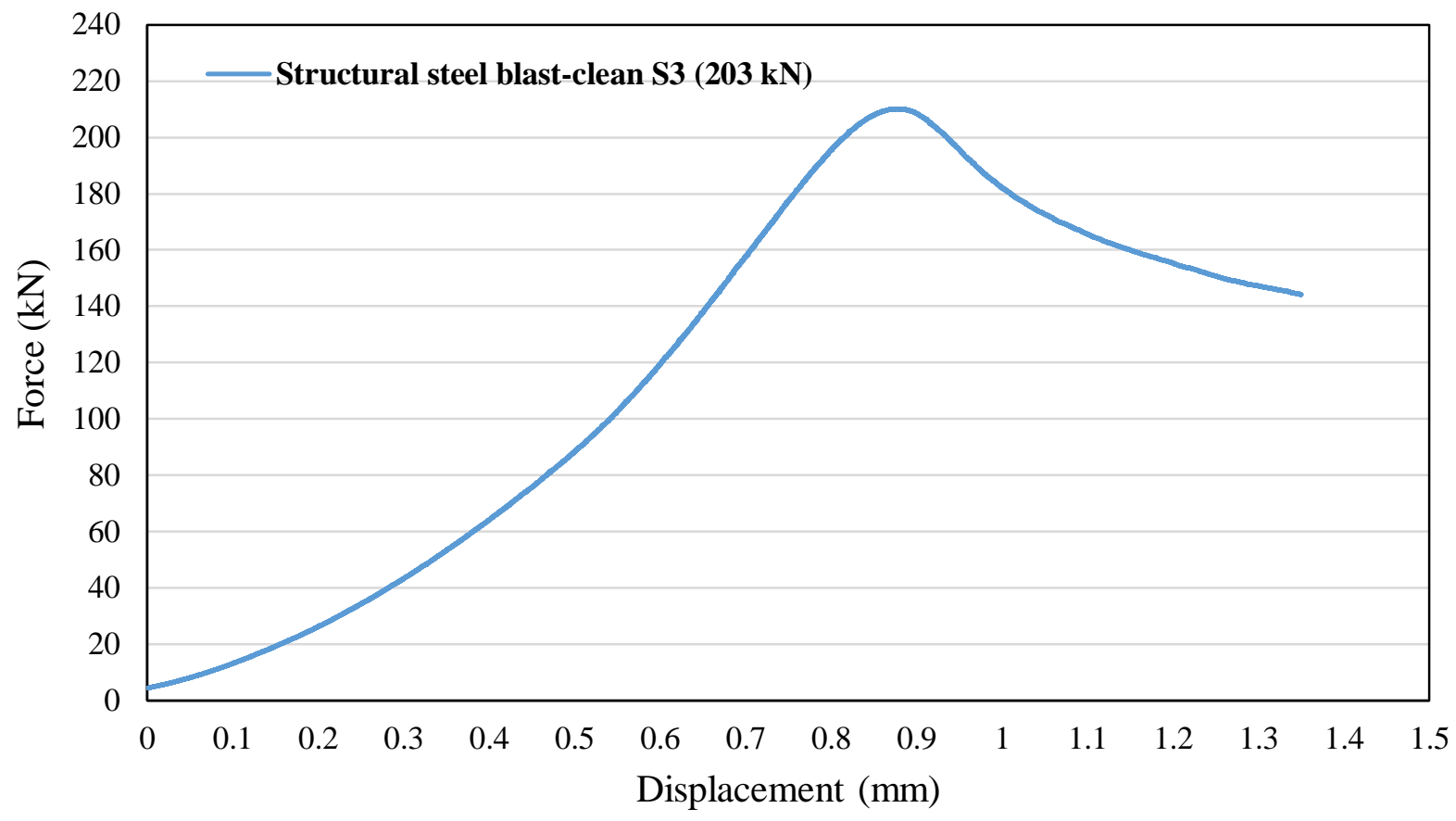

Figure D -7: Force-displacement relationship for $350 \mathrm{~W}$ structural steel with blast-clean surface condition for test specimen 3 with A325 bolt

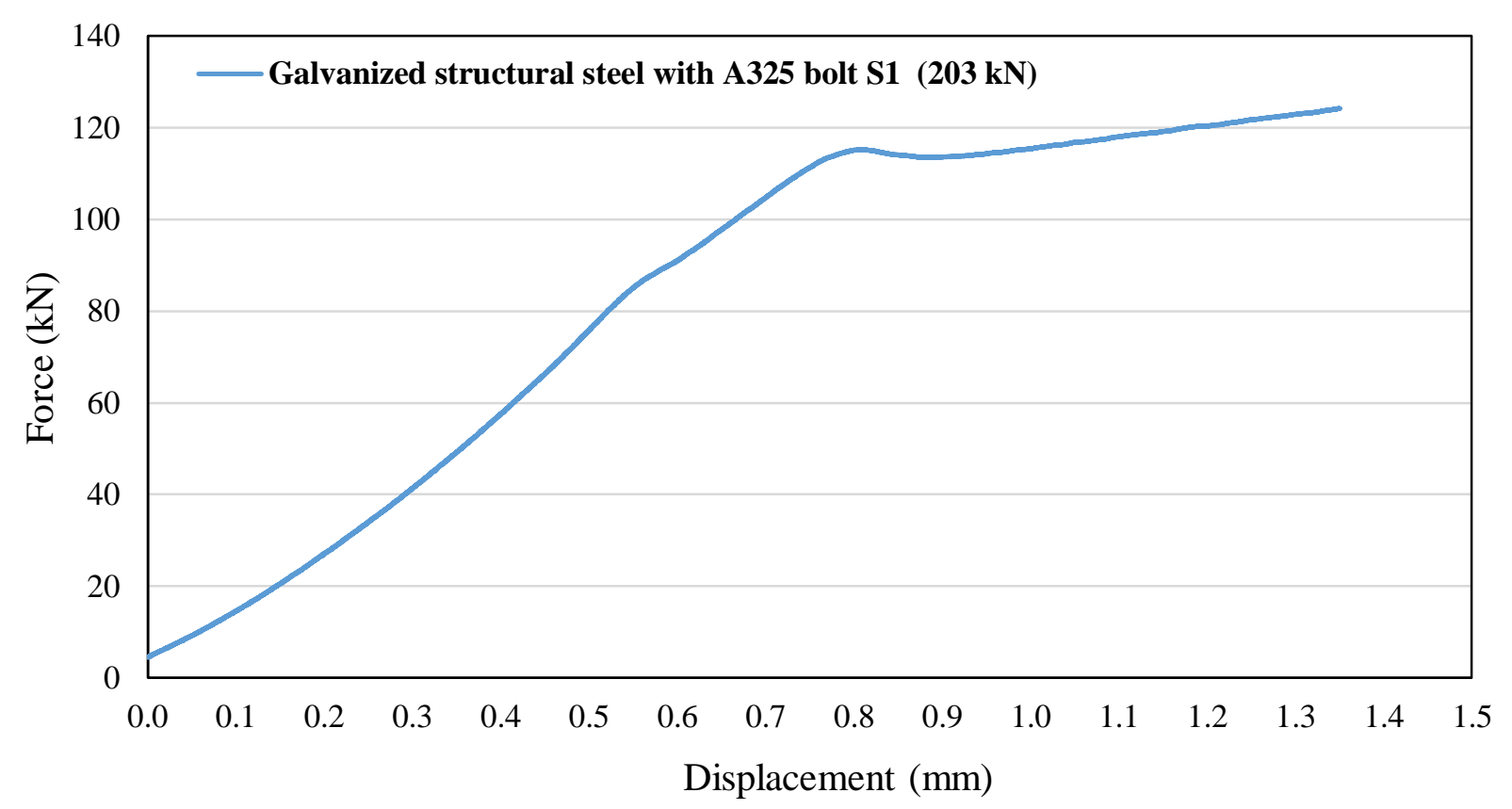

Figure D - 4: Force-displacement relationship for 350W structural steel with hot hip galvanized surface condition for test specimen 1 with A325 bolt 


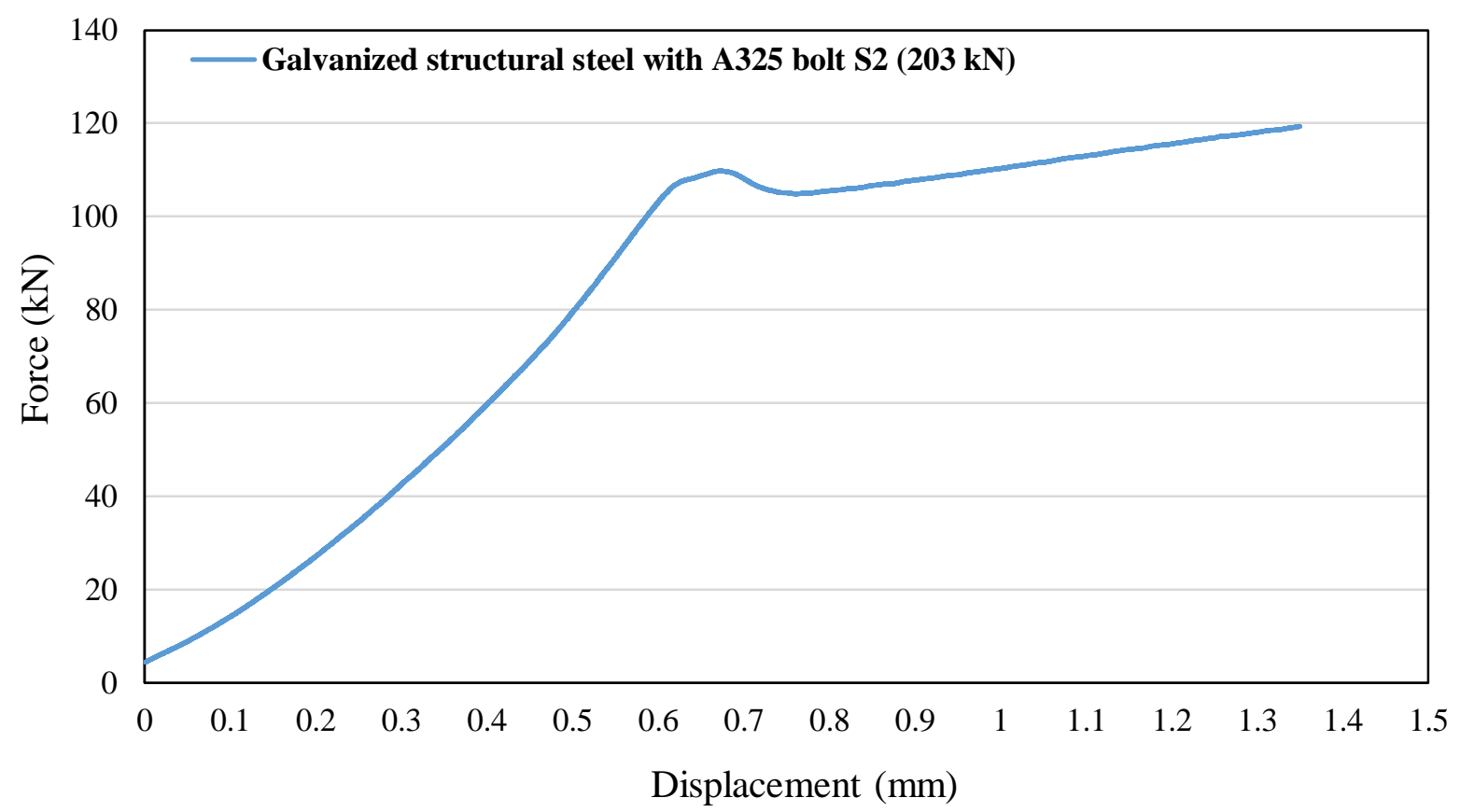

Figure D - 5: Force-displacement relationship for $350 \mathrm{~W}$ structural steel with hot hip galvanized surface condition for test specimen 2 with A325 bolt

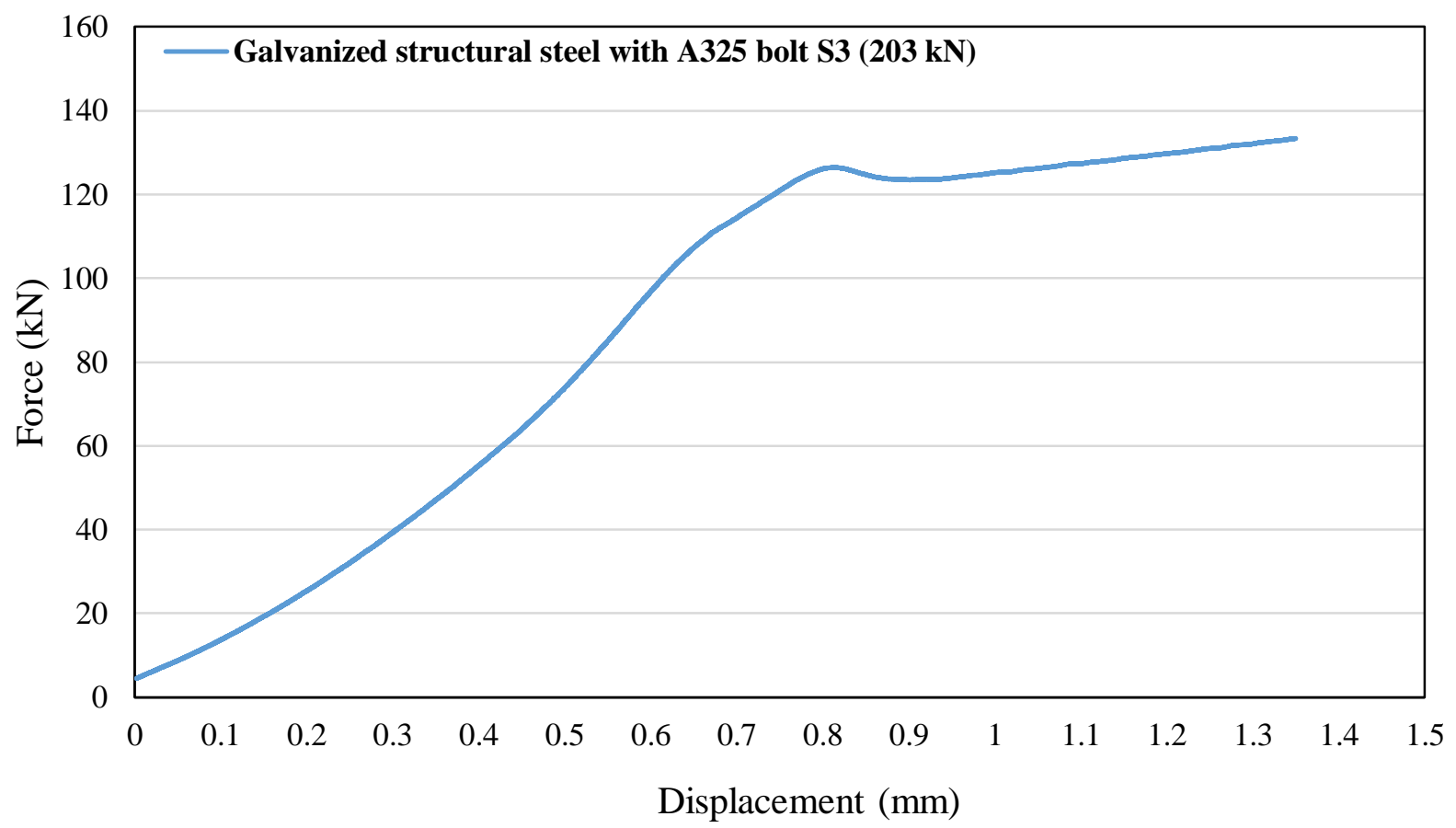

Figure D - 6: Force-displacement relationship for $350 \mathrm{~W}$ structural steel with hot dip galvanized surface condition for test specimen 3 with A325 bolt 


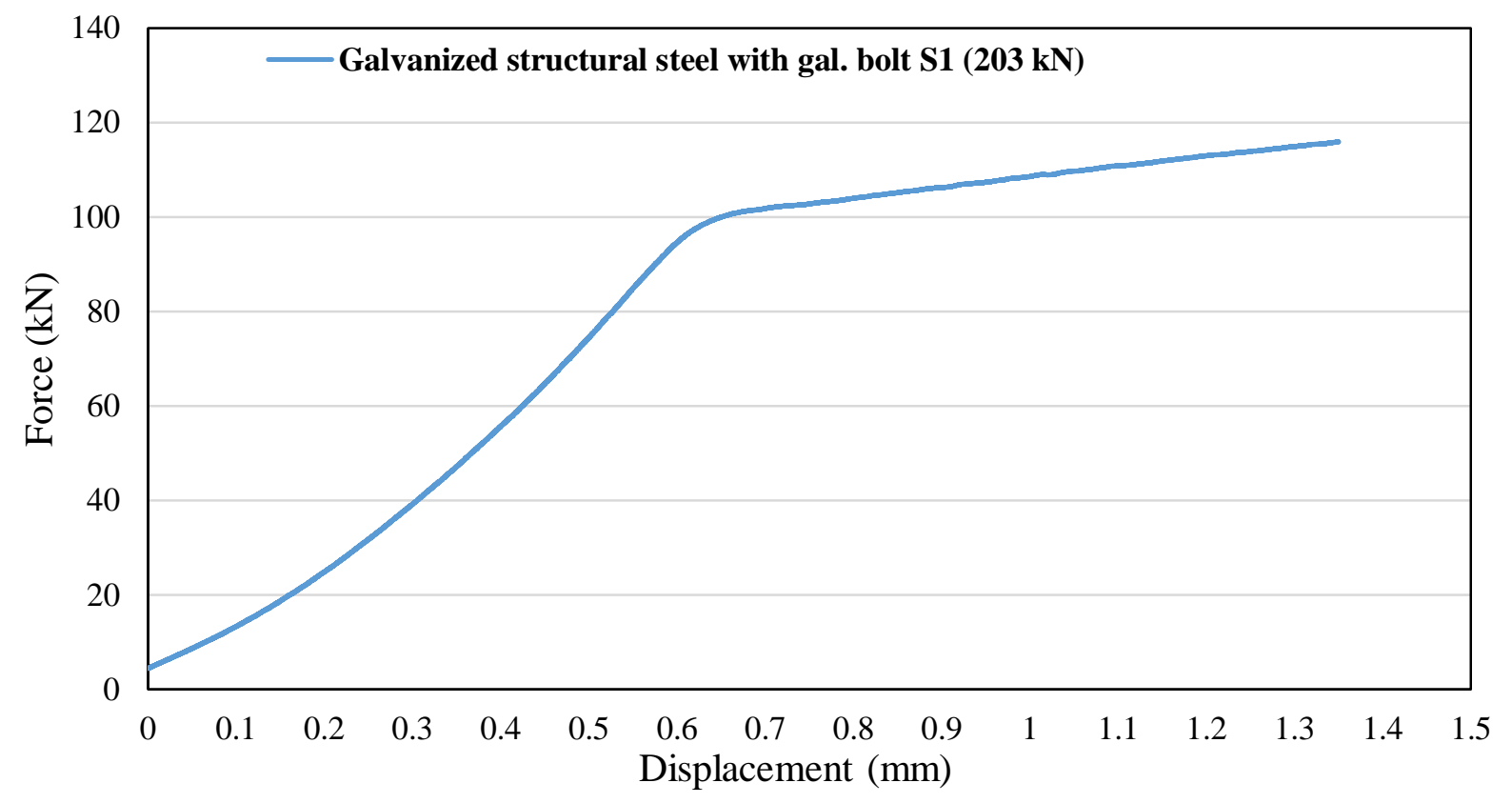

Figure D - 7: Force-displacement relationship for 350W structural steel with hot dip galvanized surface condition for test specimen 1 with galvanized bolt

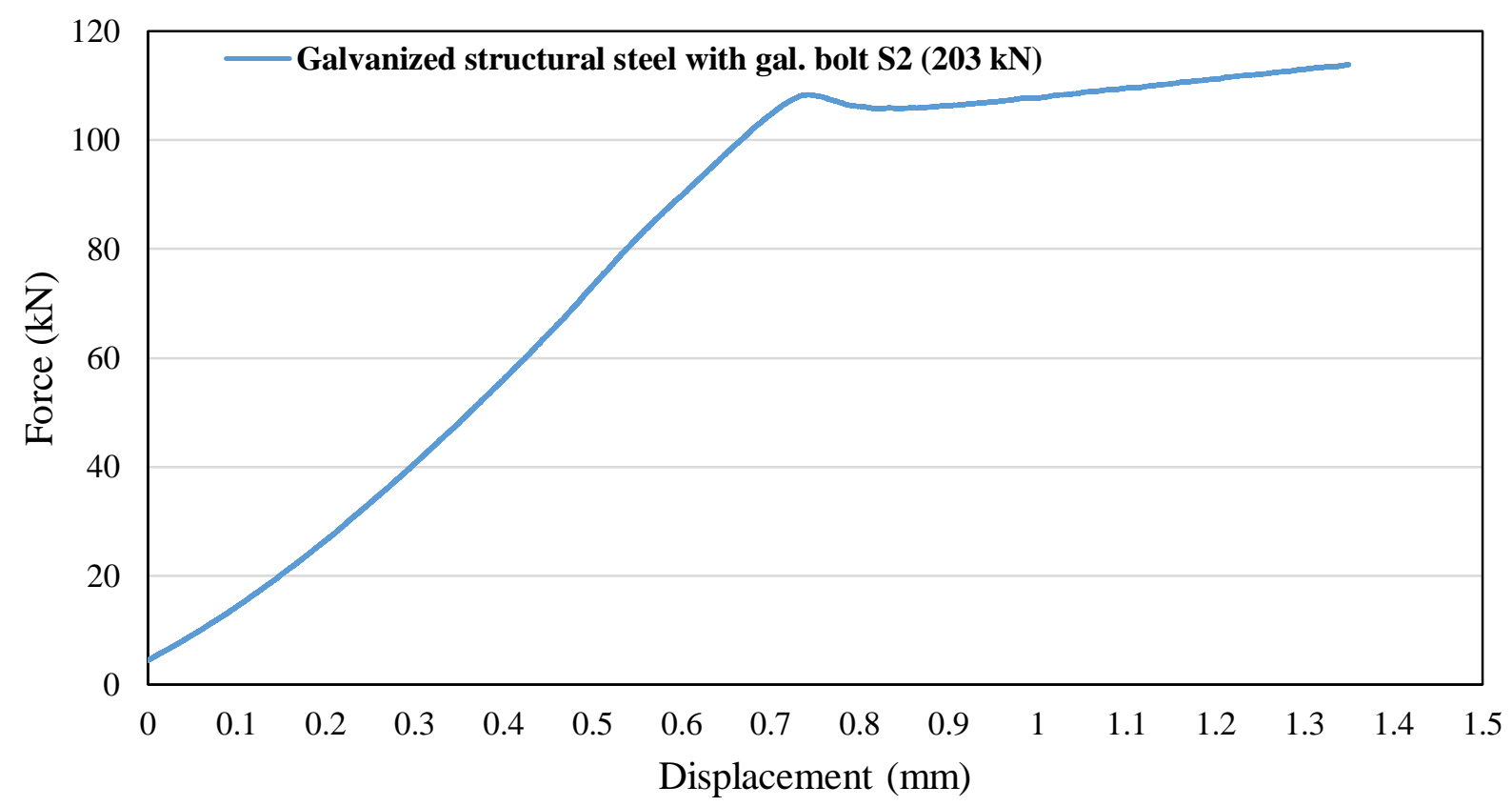

Figure D - 8: Force-displacement relationship for 350W structural steel with hot dip galvanized surface condition for test specimen 2 with galvanized bolt 


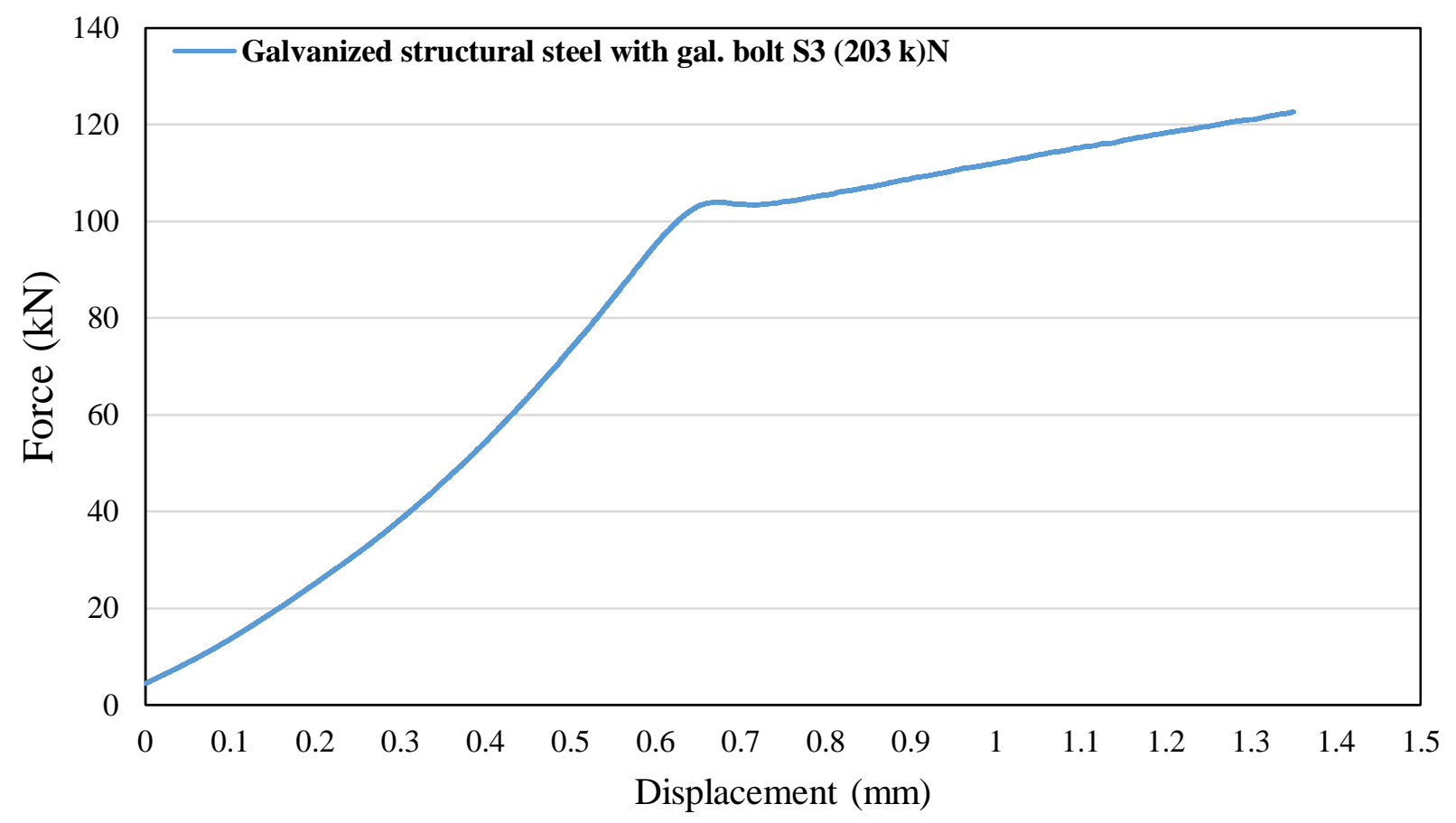

Figure D - 93: Force-displacement relationship for 350W structural steel with hot dip galvanized surface condition for test specimen 3 with galvanized bolt

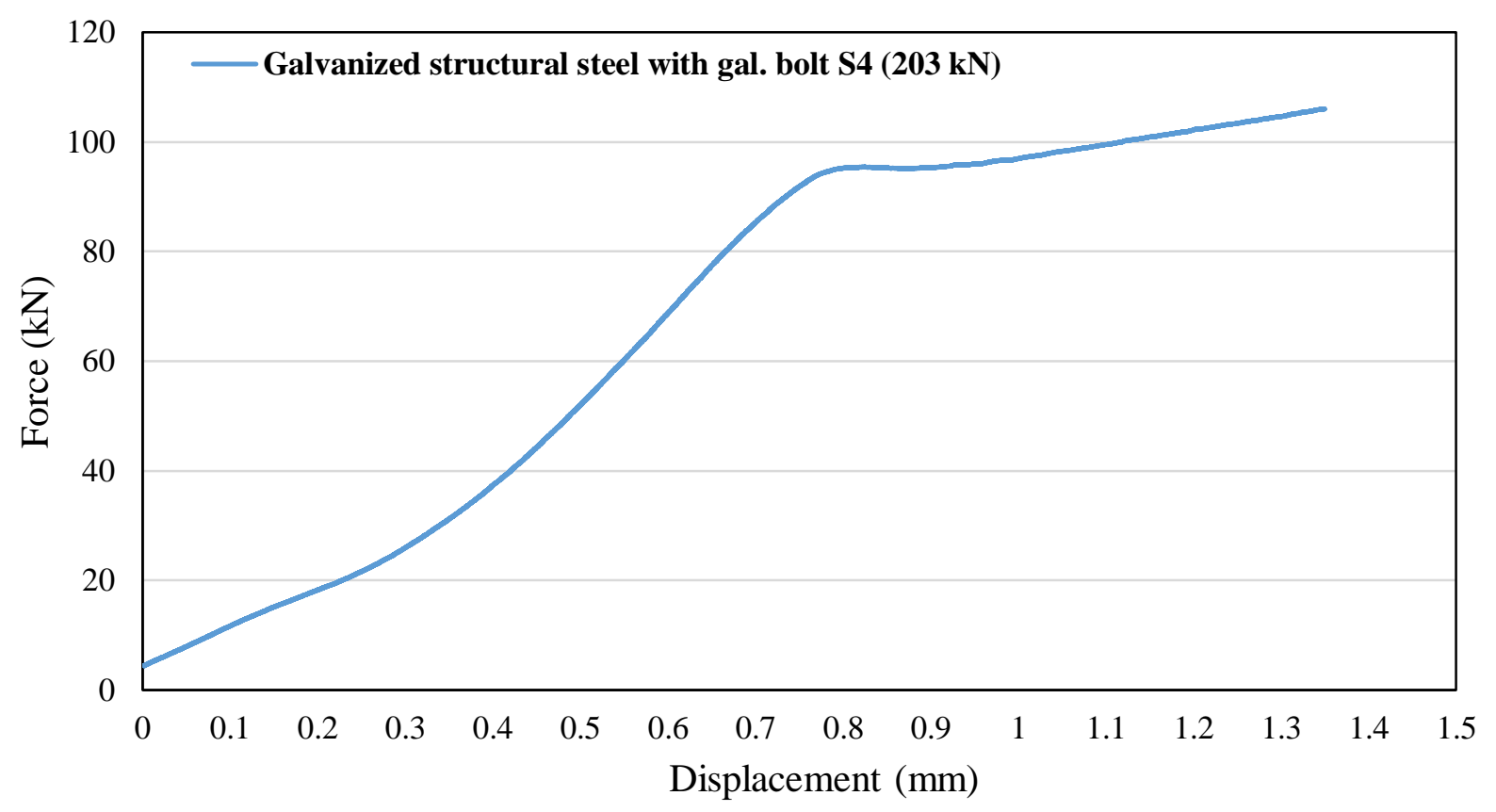

Figure D - 14: Force-displacement relationship for 350W structural steel with hot dip galvanized surface condition for test specimen 3 with galvanized bolt 


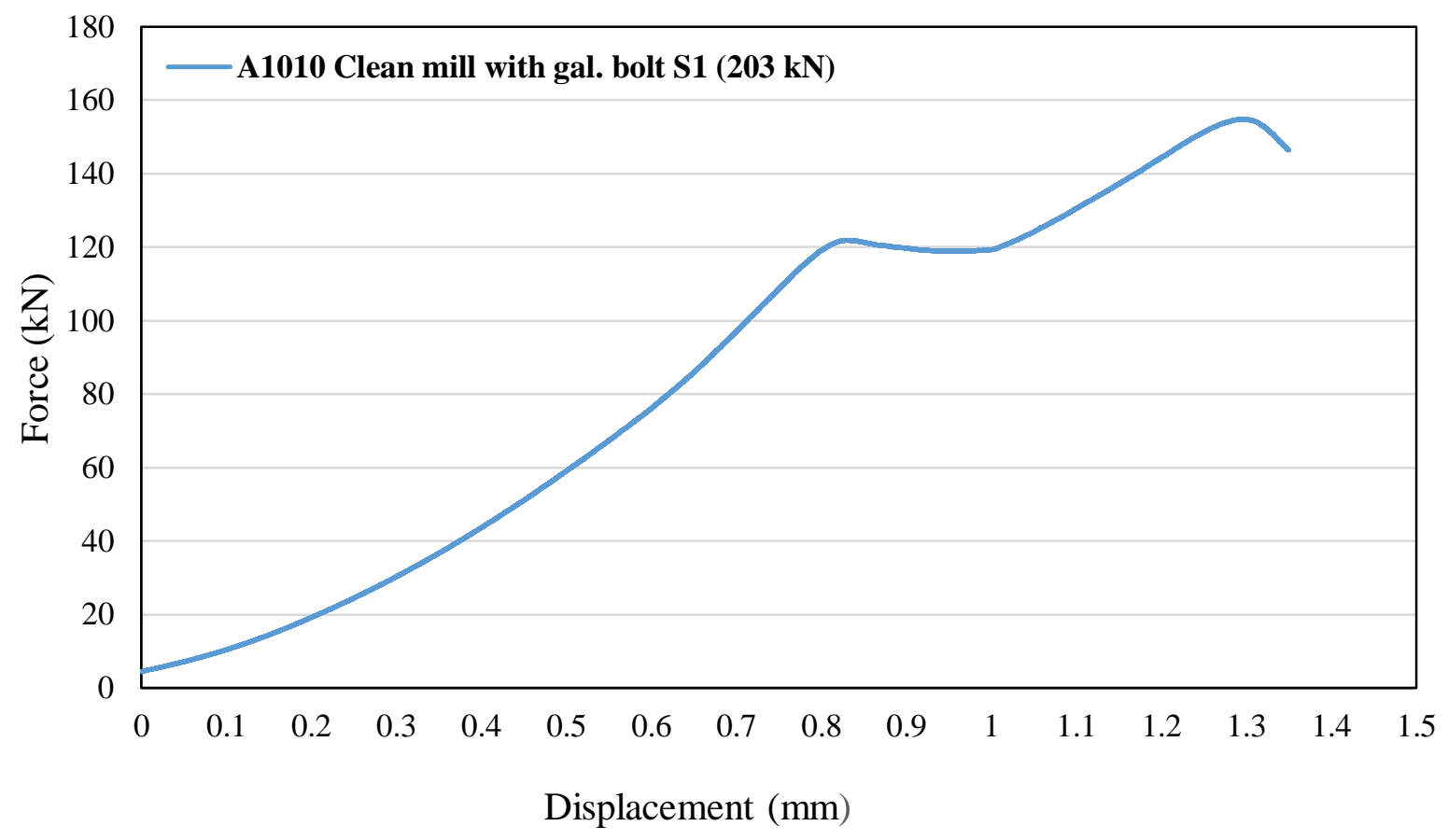

Figure D - 10: Force-displacement relationship for A1010 stainless steel with clean mill scale surface condition for test specimen 1 with galvanized bolt

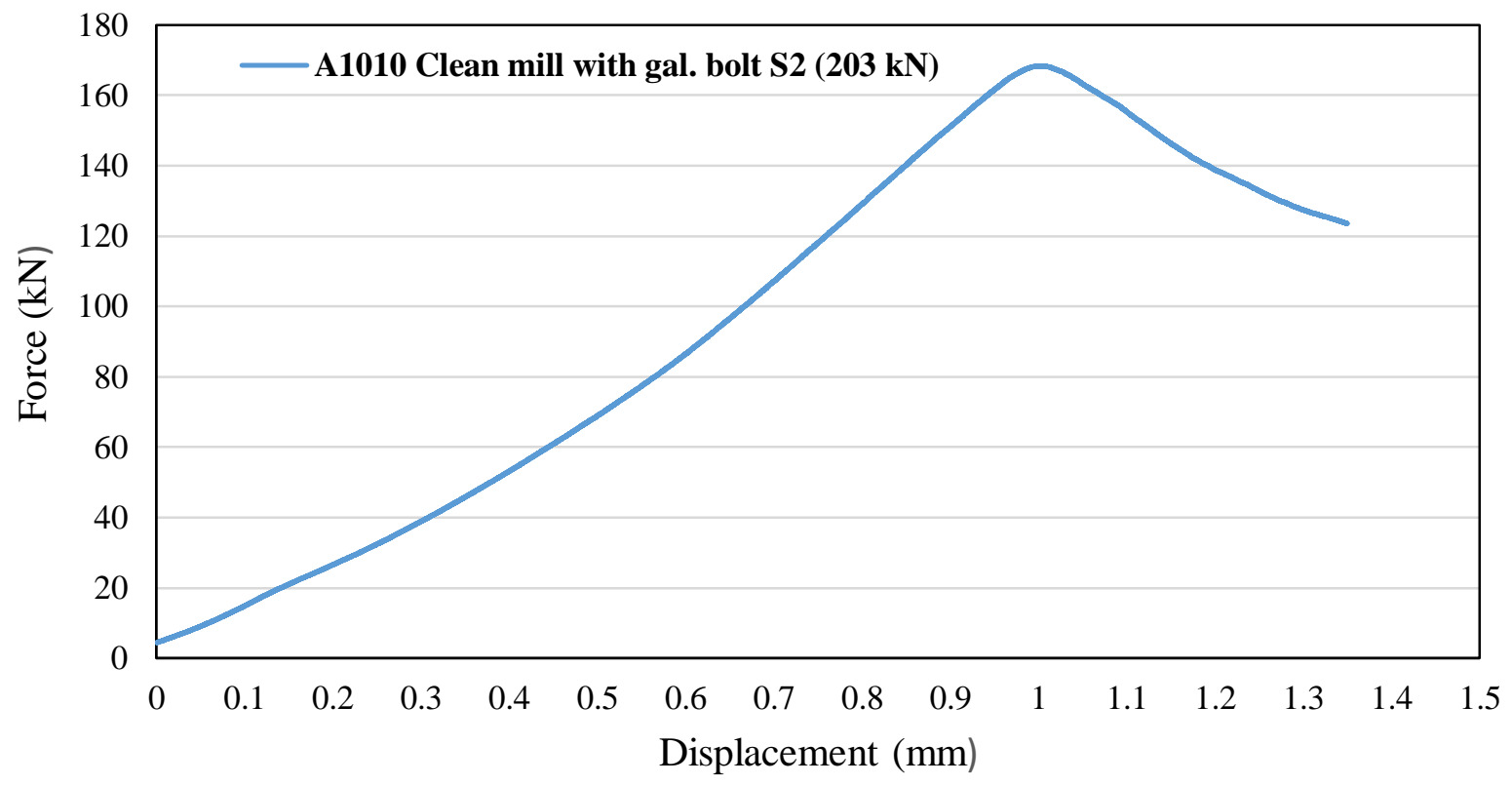

Figure D - 11: Force-displacement relationship for A1010 stainless steel with clean mill scale surface condition for test specimen 2 with galvanized bolt 


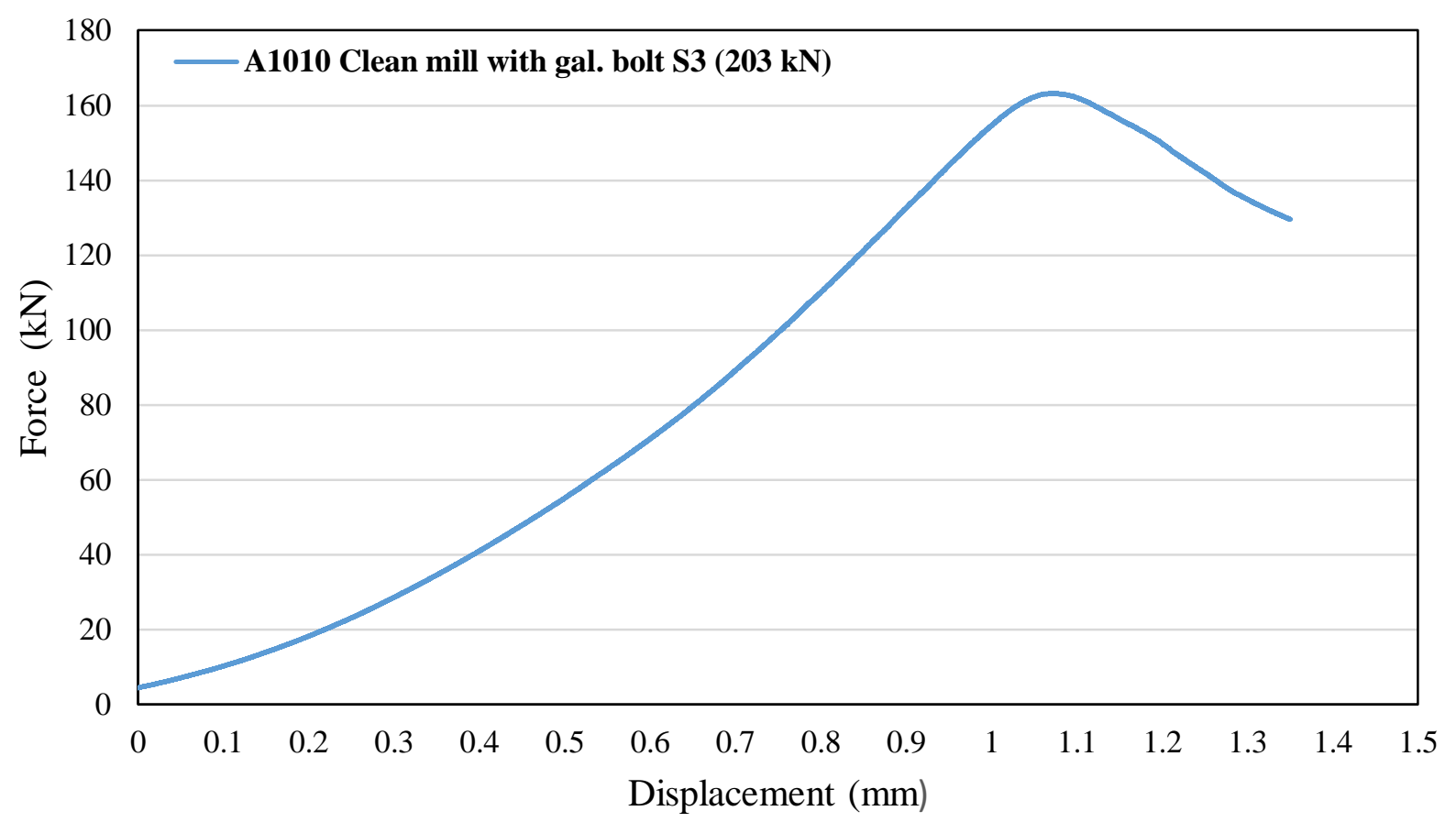

Figure D - 12: Force-displacement relationship for A1010 stainless steel with clean mill scale surface condition for test specimen 3 with galvanized bolt

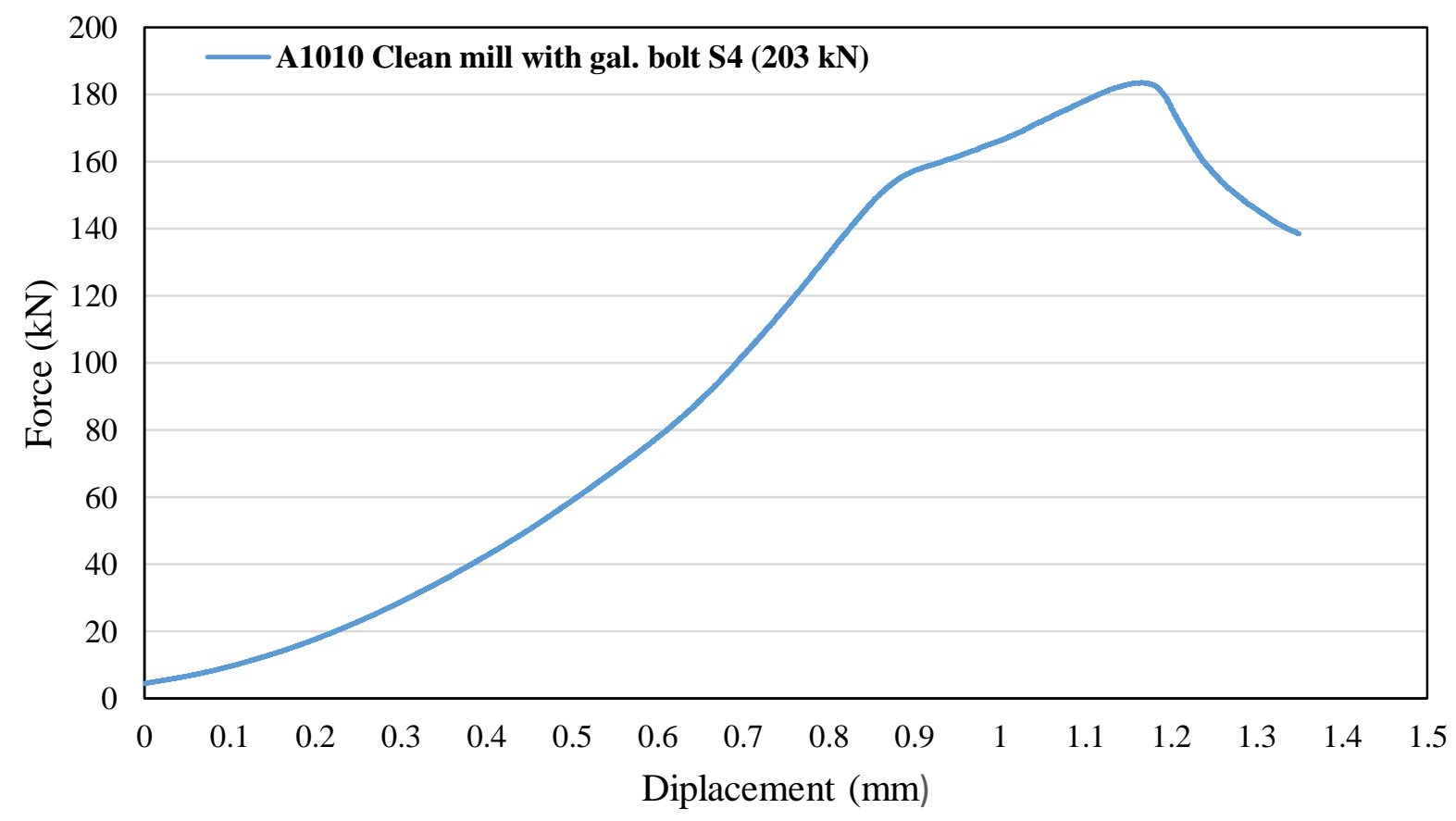

Figure D - 13: Force-displacement relationship for A1010 stainless steel with clean mill scale surface condition for test specimen 4 with galvanized bolt 


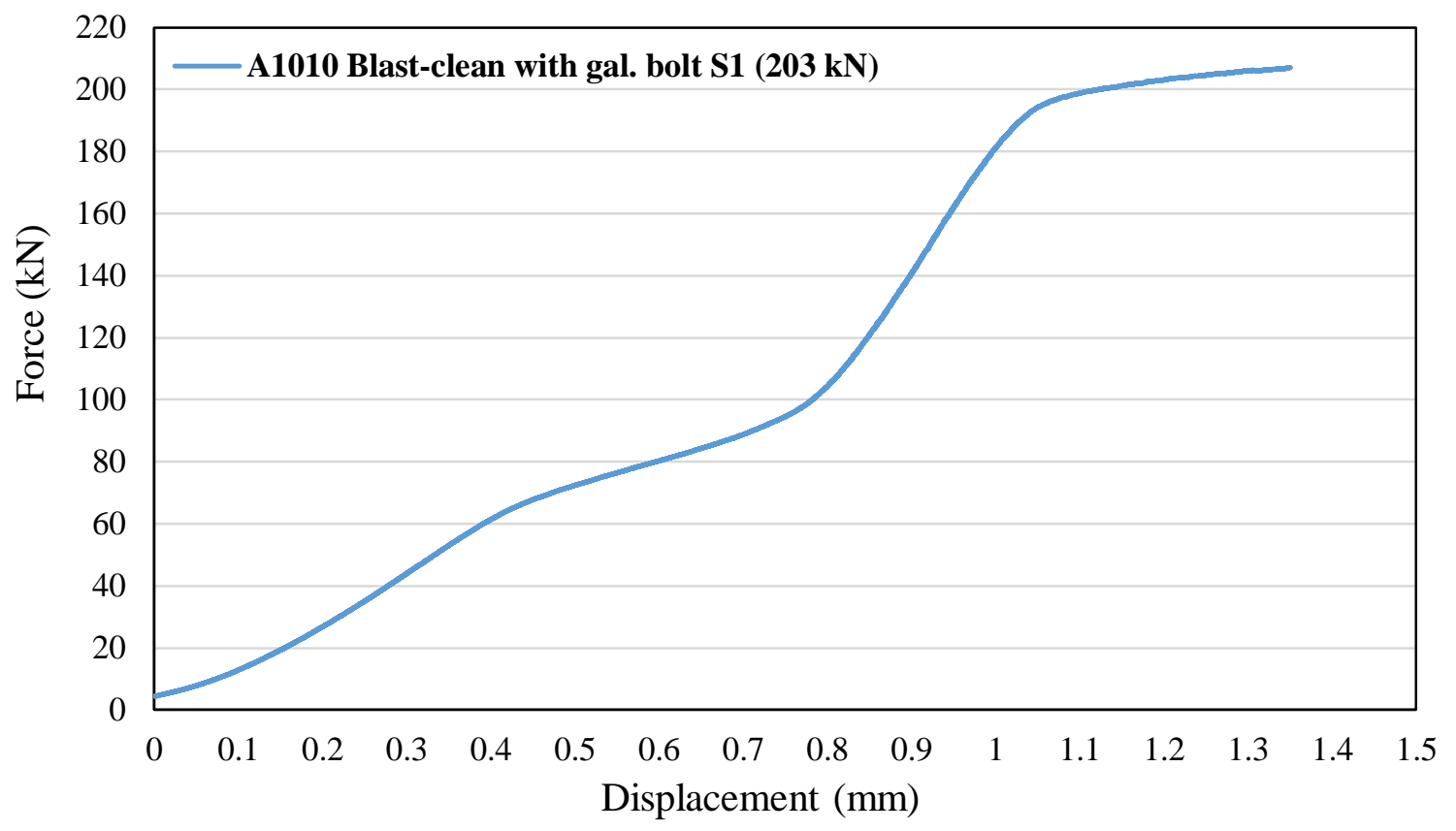

Figure D - 14: Force-displacement relationship for A1010 stainless steel with blast-clean surface condition for test specimen 1 with galvanized bolt

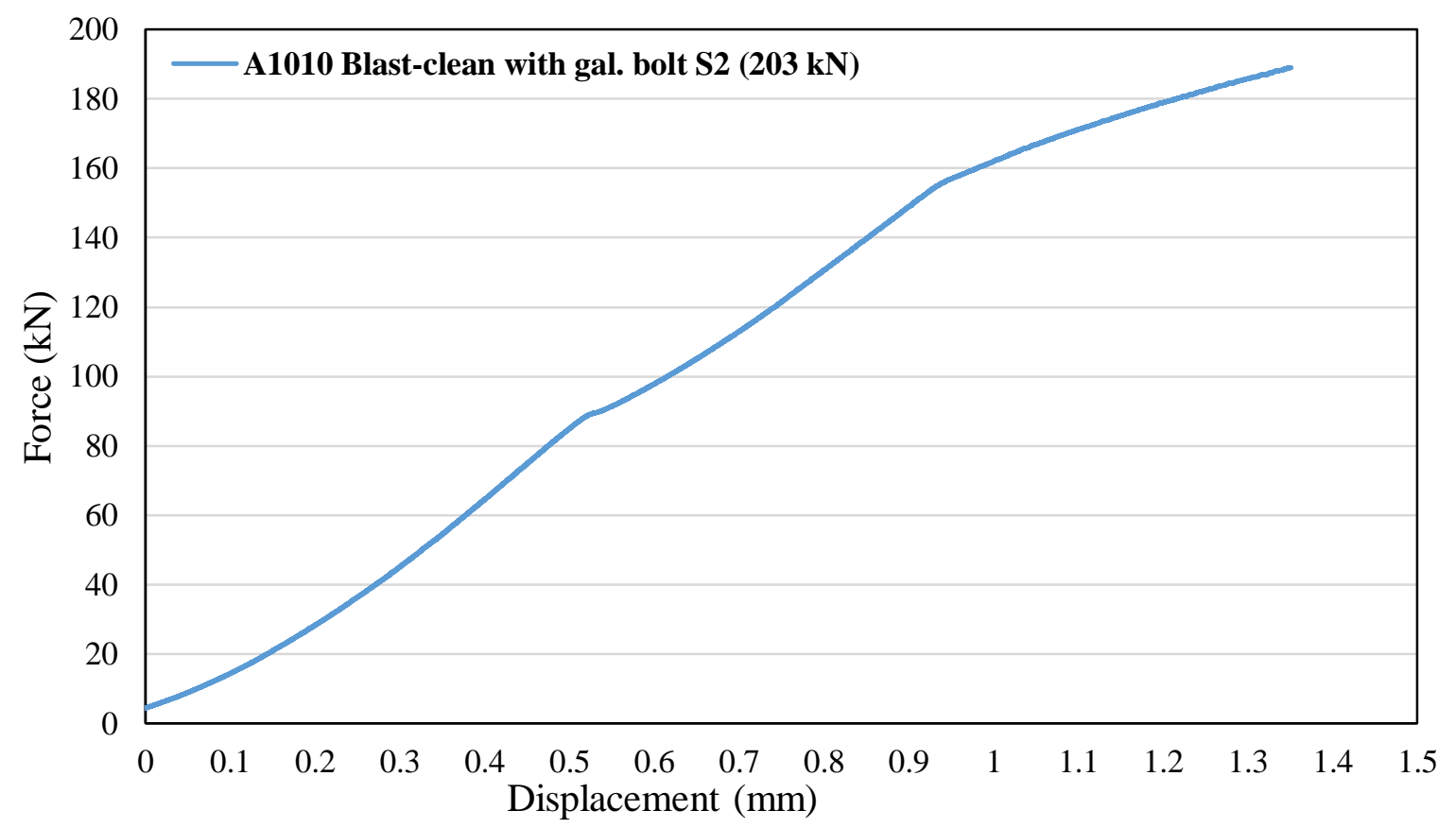

Figure D - 20: Force-displacement relationship for A1010 stainless steel with blast-clean scale surface condition for test specimen 2 with galvanized bolt 


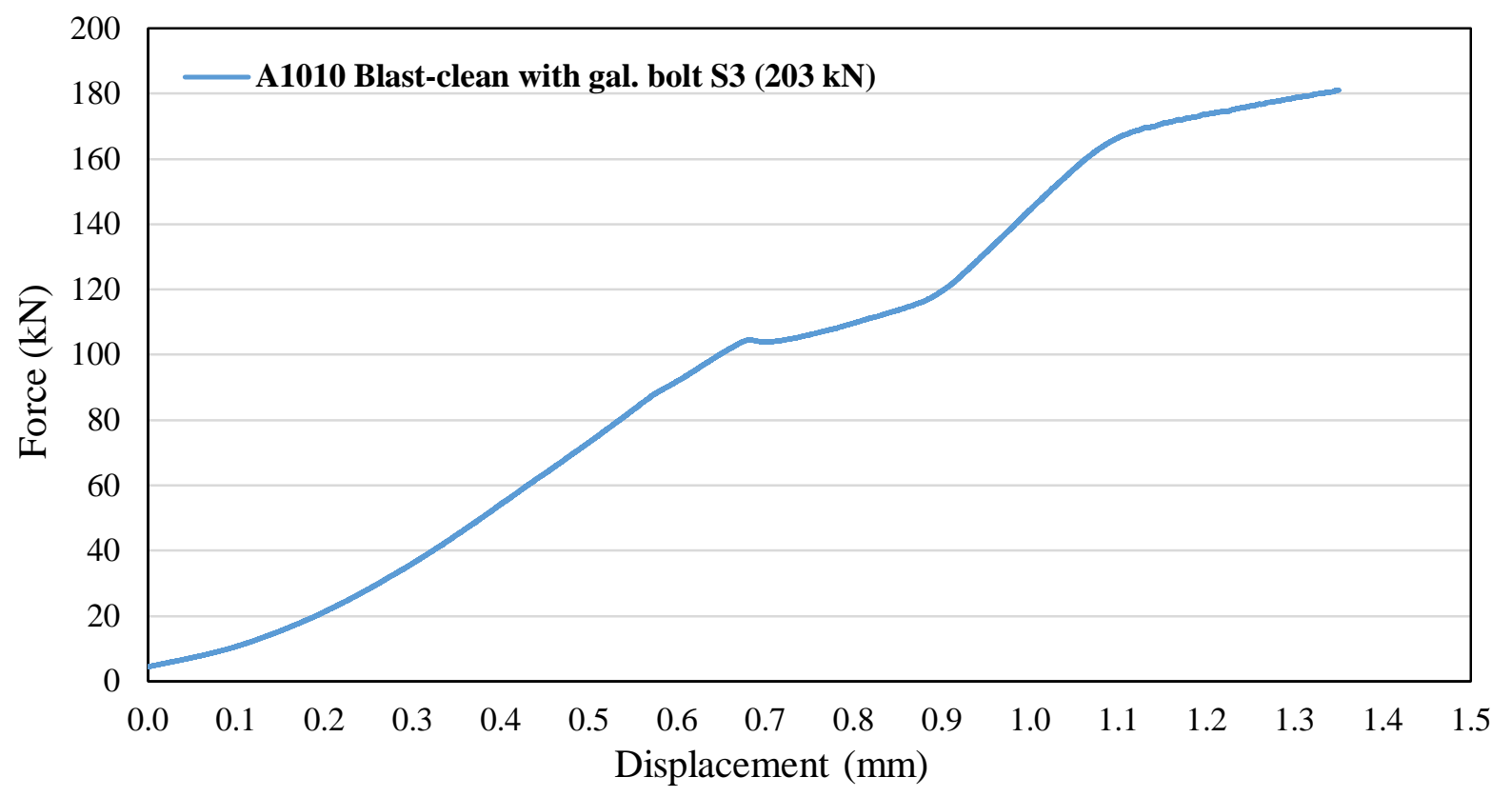

Figure D - 15: Force-displacement relationship for A1010 stainless steel with blast-clean surface condition for test specimen 3 with galvanized bolt

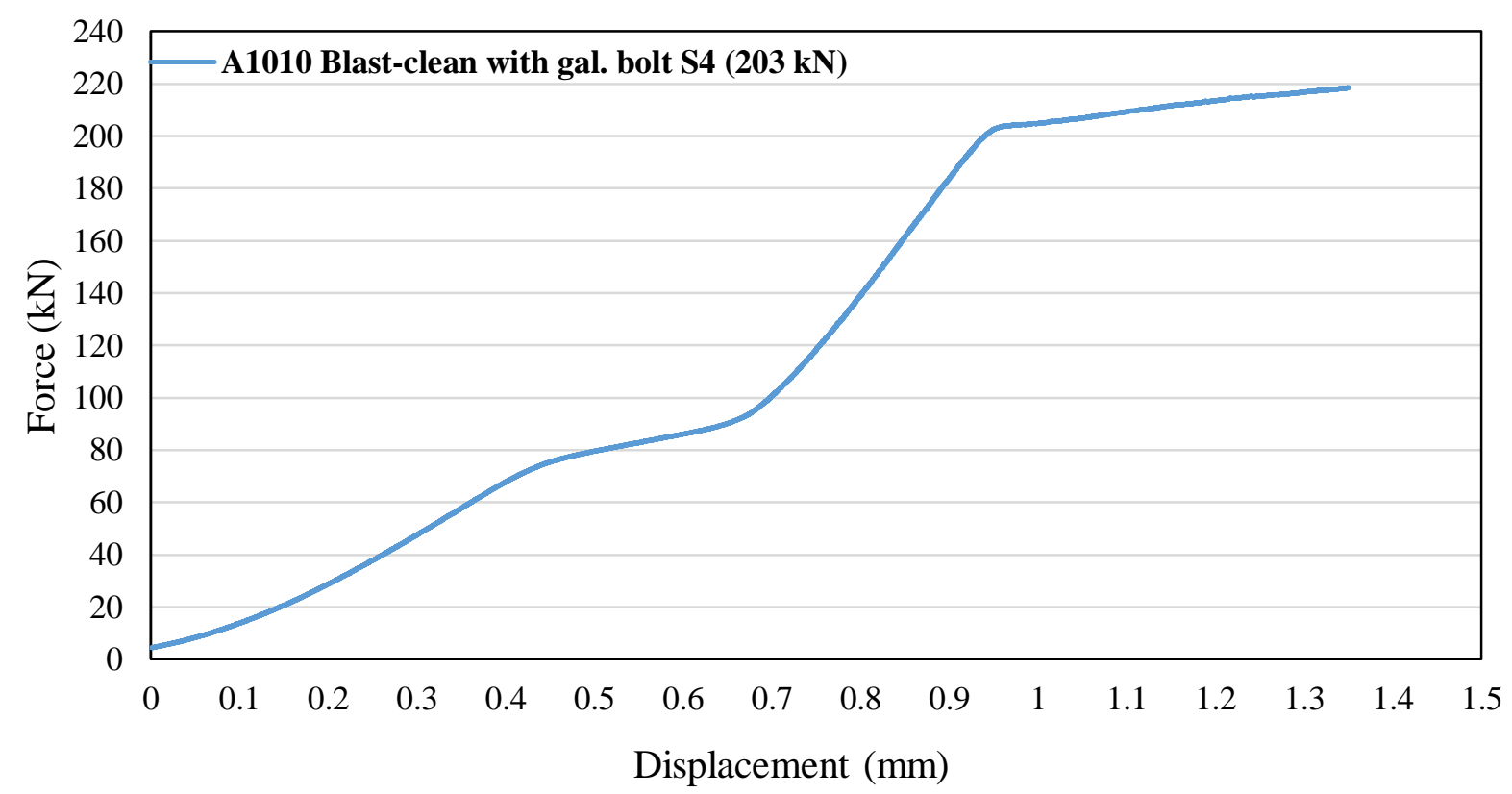

Figure D - 16: Force vs Displacement relationship for A1010 stainless steel with blasted clean surface condition for test specimen 4 with galvanized bolt 


\section{Appendix E: Slip Coefficient Testing at Varying Temperature}

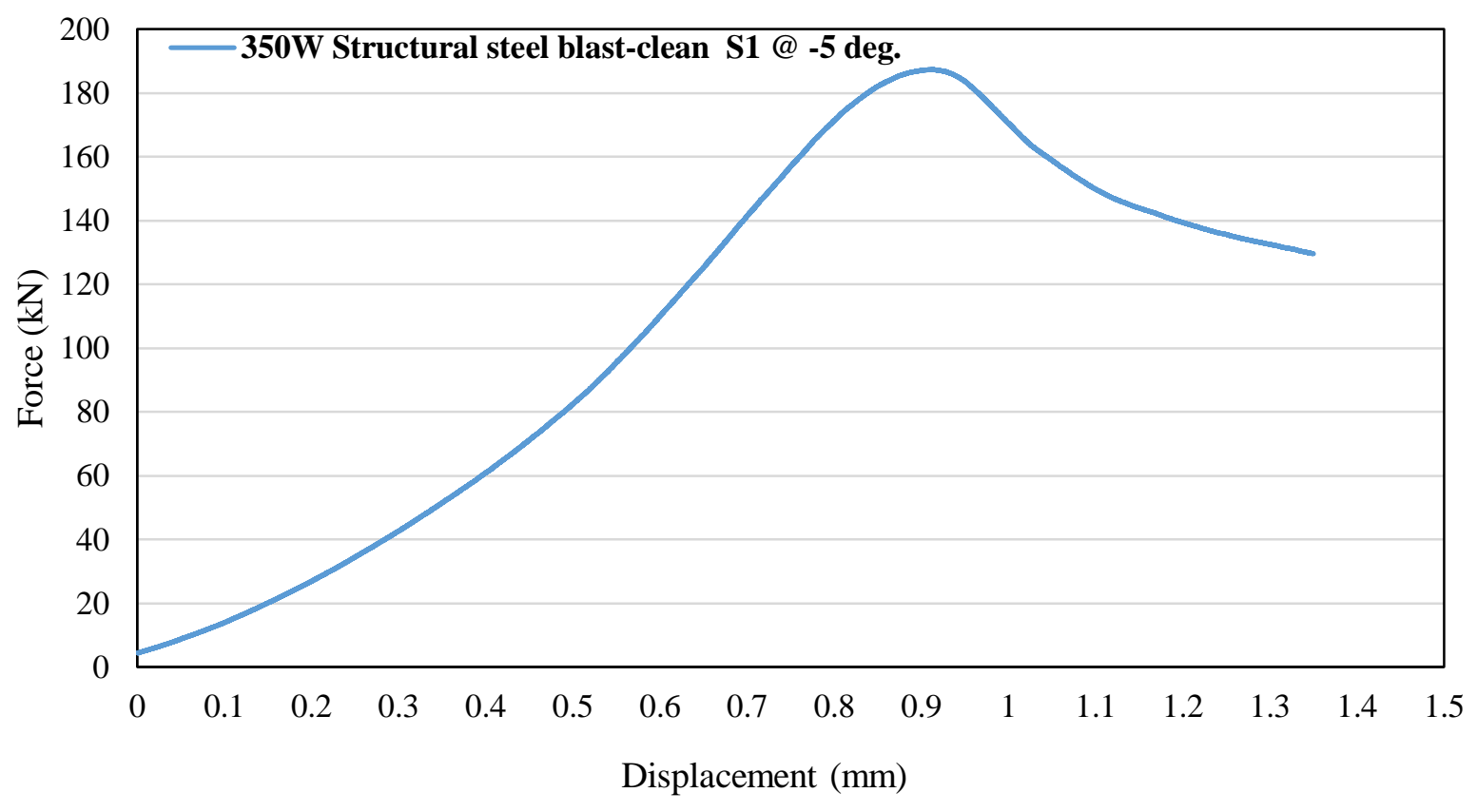

Figure E- 1: Force-displacement relationship for $350 \mathrm{~W}$ structural steel with blasted clean surface condition with $\mathrm{A325}$ bolt for test specimen 1 at $-5^{\circ} \mathrm{C}$ temperature

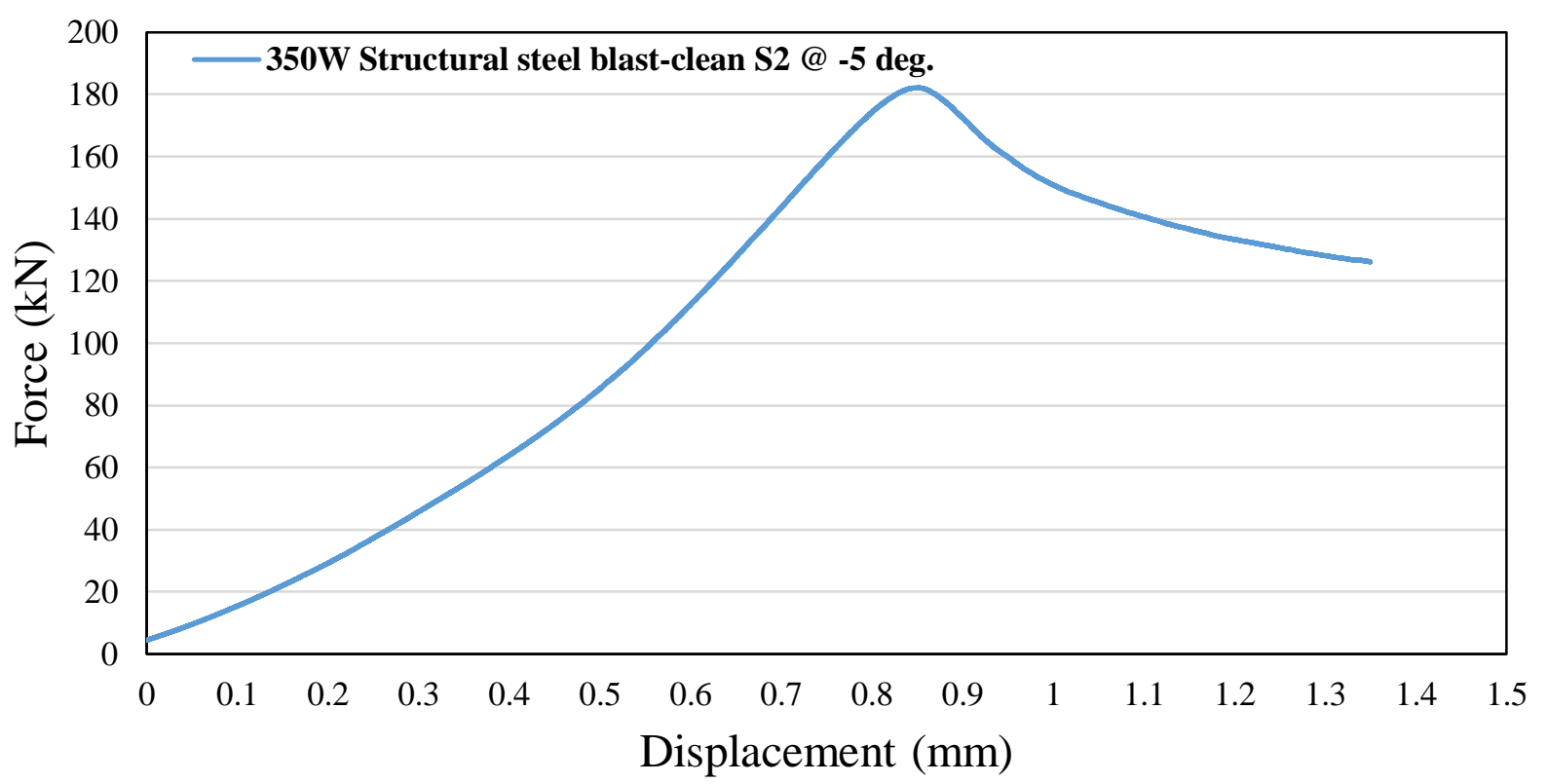

Figure E- 2: Force-displacement relationship for $350 \mathrm{~W}$ structural steel with blasted clean surface condition with $\mathrm{A325}$ bolt for test specimen 2 at $-5^{\circ} \mathrm{C}$ temperature 


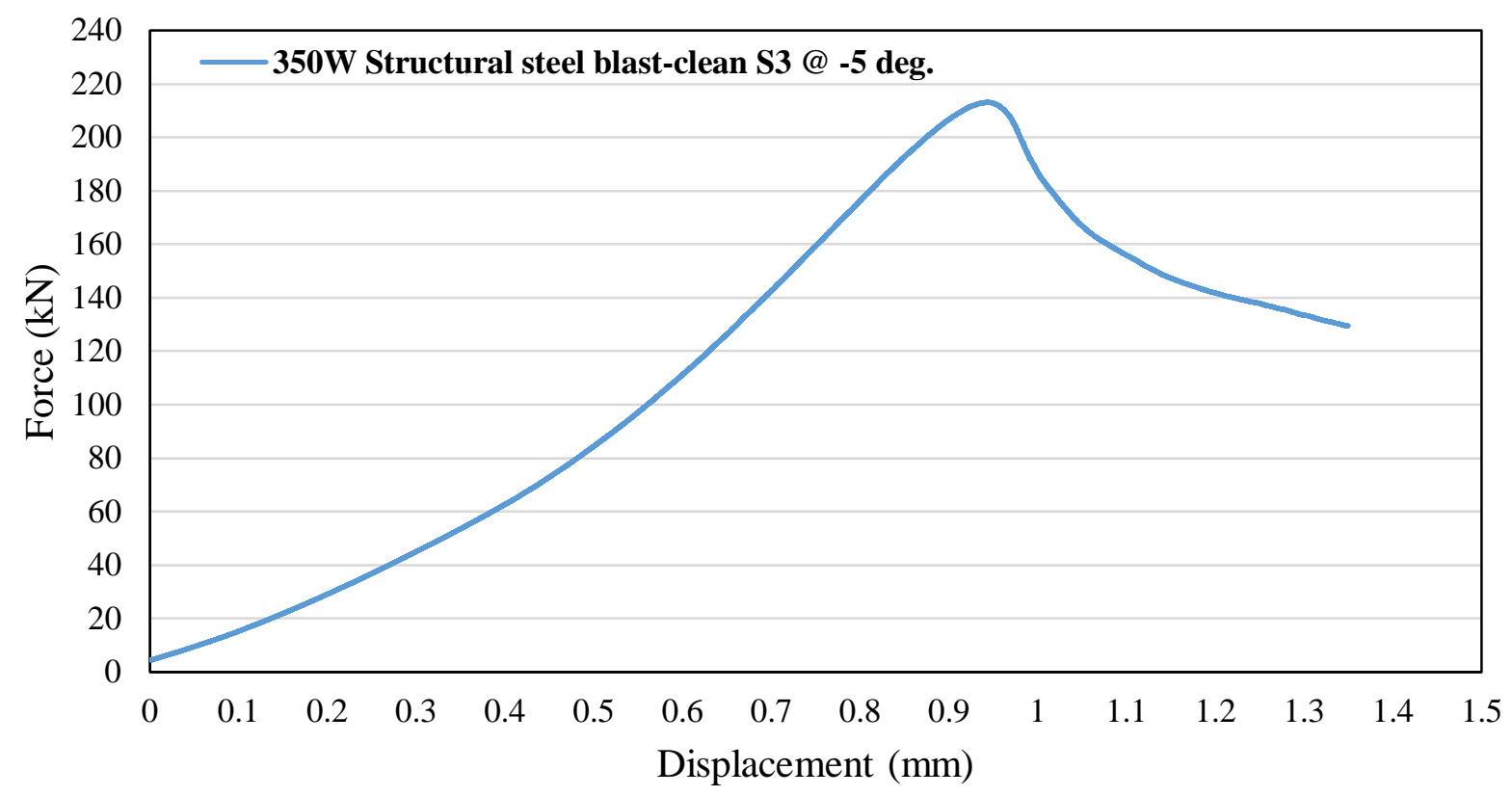

Figure E- 3: Force-displacement relationship for $350 \mathrm{~W}$ structural steel with blasted clean surface condition with $\mathrm{A325}$ bolt for test specimen 3 at $-5^{\circ} \mathrm{C}$ temperature

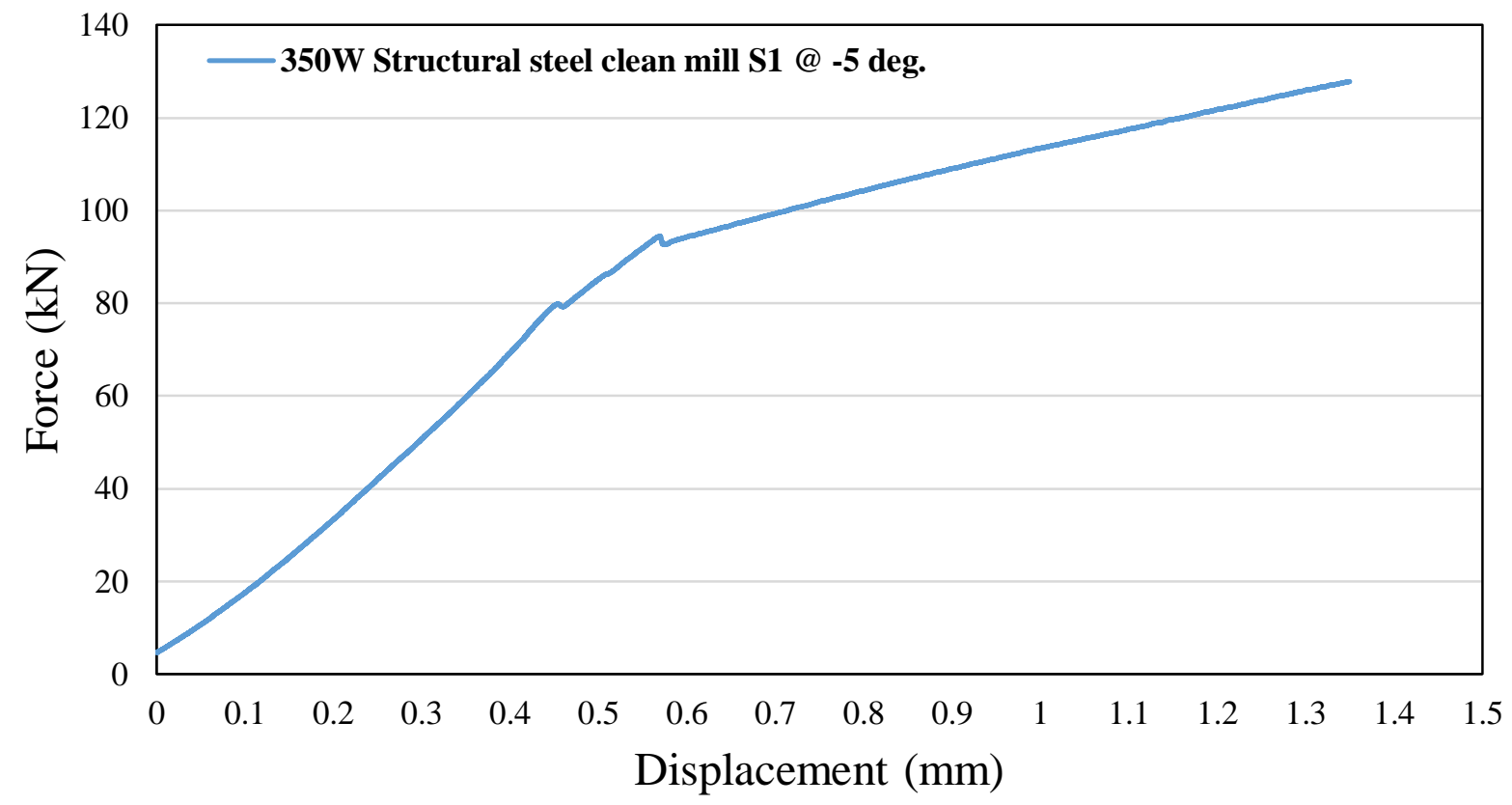

Figure E- 4: Force-displacement relationship for $350 \mathrm{~W}$ structural steel with clean mill scale surface condition with $\mathrm{A325}$ bolt for test specimen 1 at $-5^{\circ} \mathrm{C}$ temperature 


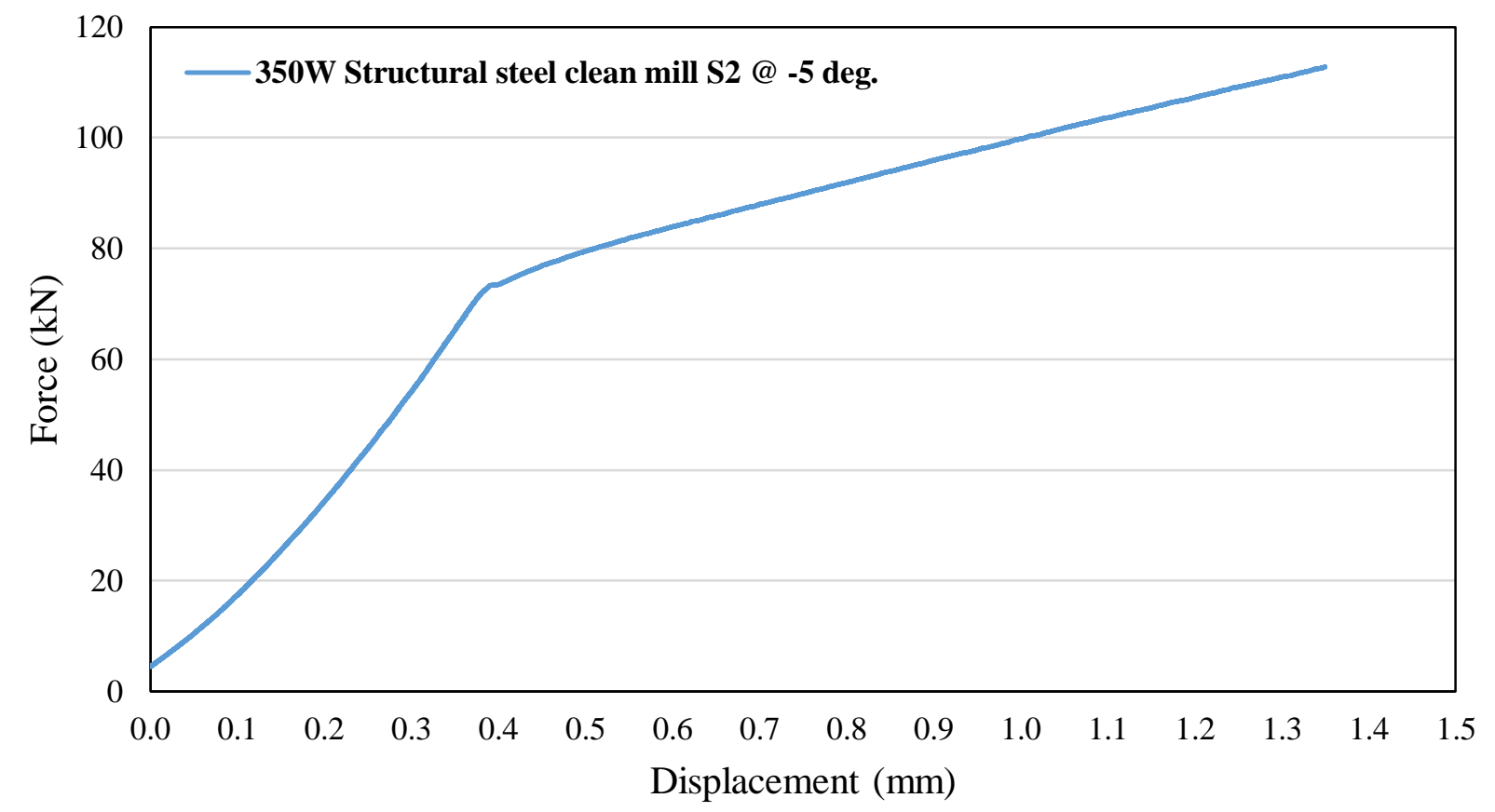

Figure E- 5: Force-displacement relationship for $350 \mathrm{~W}$ structural steel with clean mill scale surface condition with $\mathrm{A325}$ bolt for test specimen 2 at $-5^{\circ} \mathrm{C}$ temperature

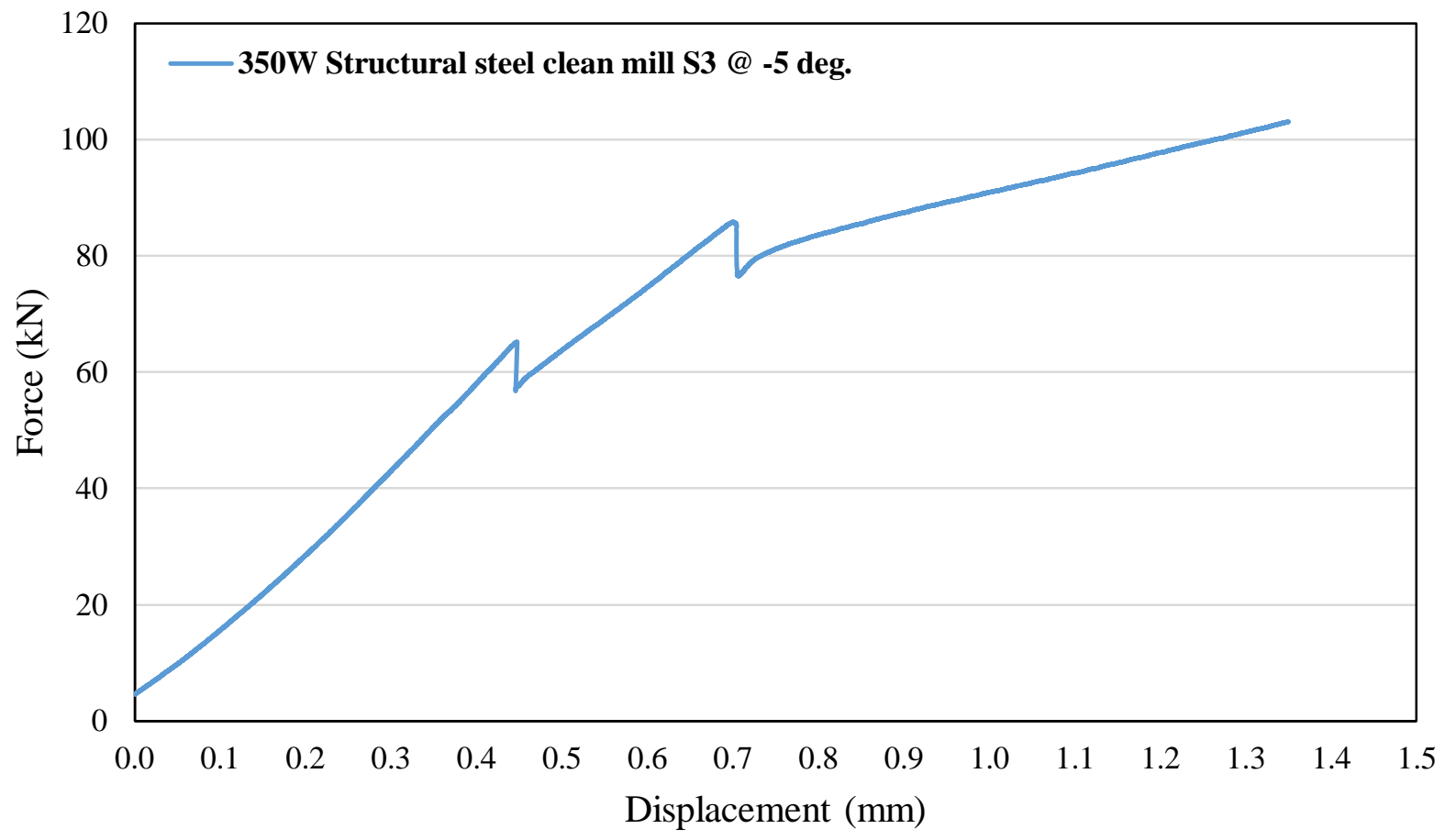

Figure E- 6: Force-displacement for $350 \mathrm{~W}$ structural steel with clean mill scale surface condition with $\mathrm{A325}$ bolt for test specimen 3 at $-5^{\circ} \mathrm{C}$ temperature 


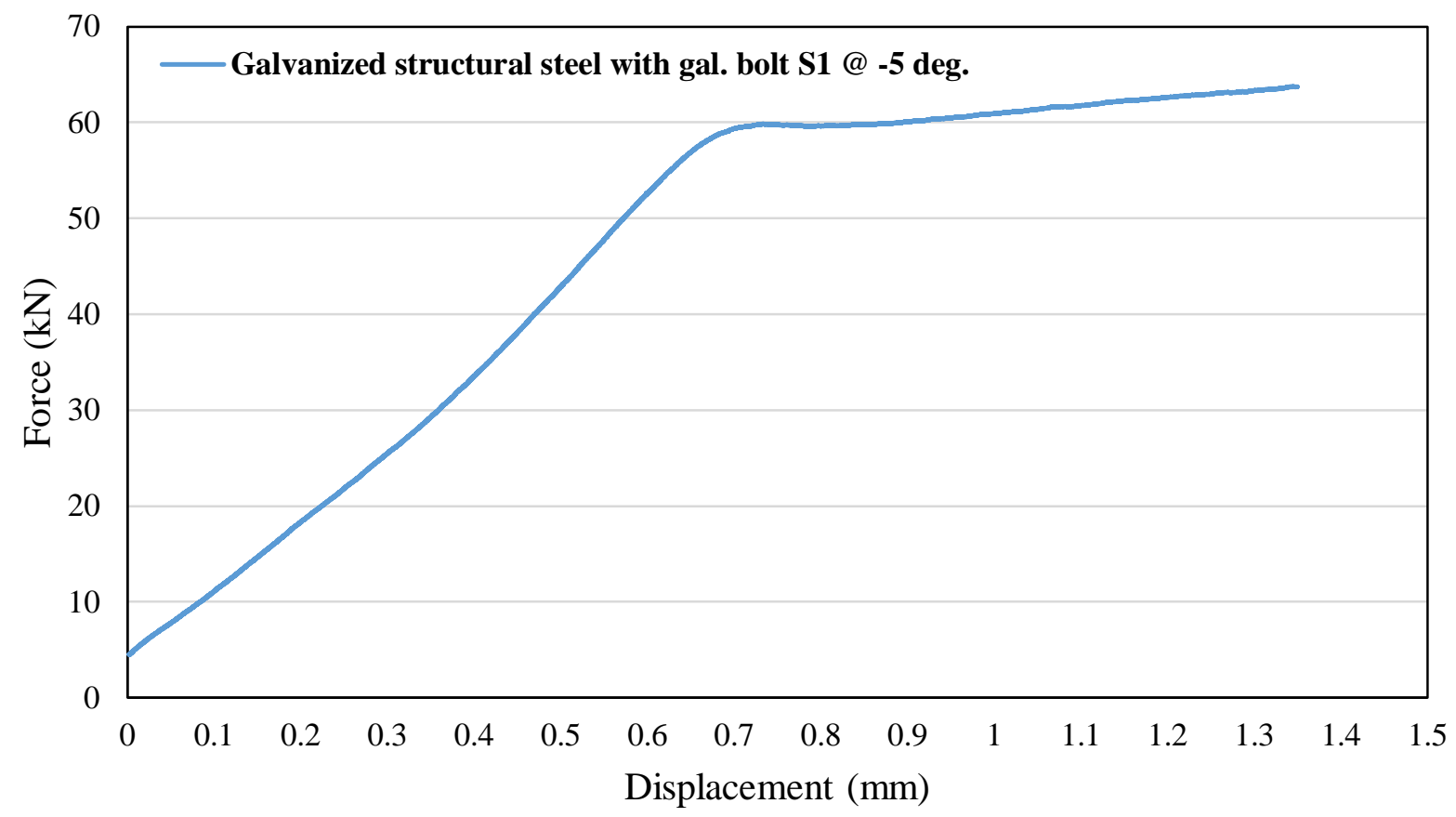

Figure E- 7: Force-displacement relationship for $350 \mathrm{~W}$ structural steel with hot dip galvanized surface condition with galvanized bolt for test specimen 1 at $-5^{\circ} \mathrm{C}$ temperature

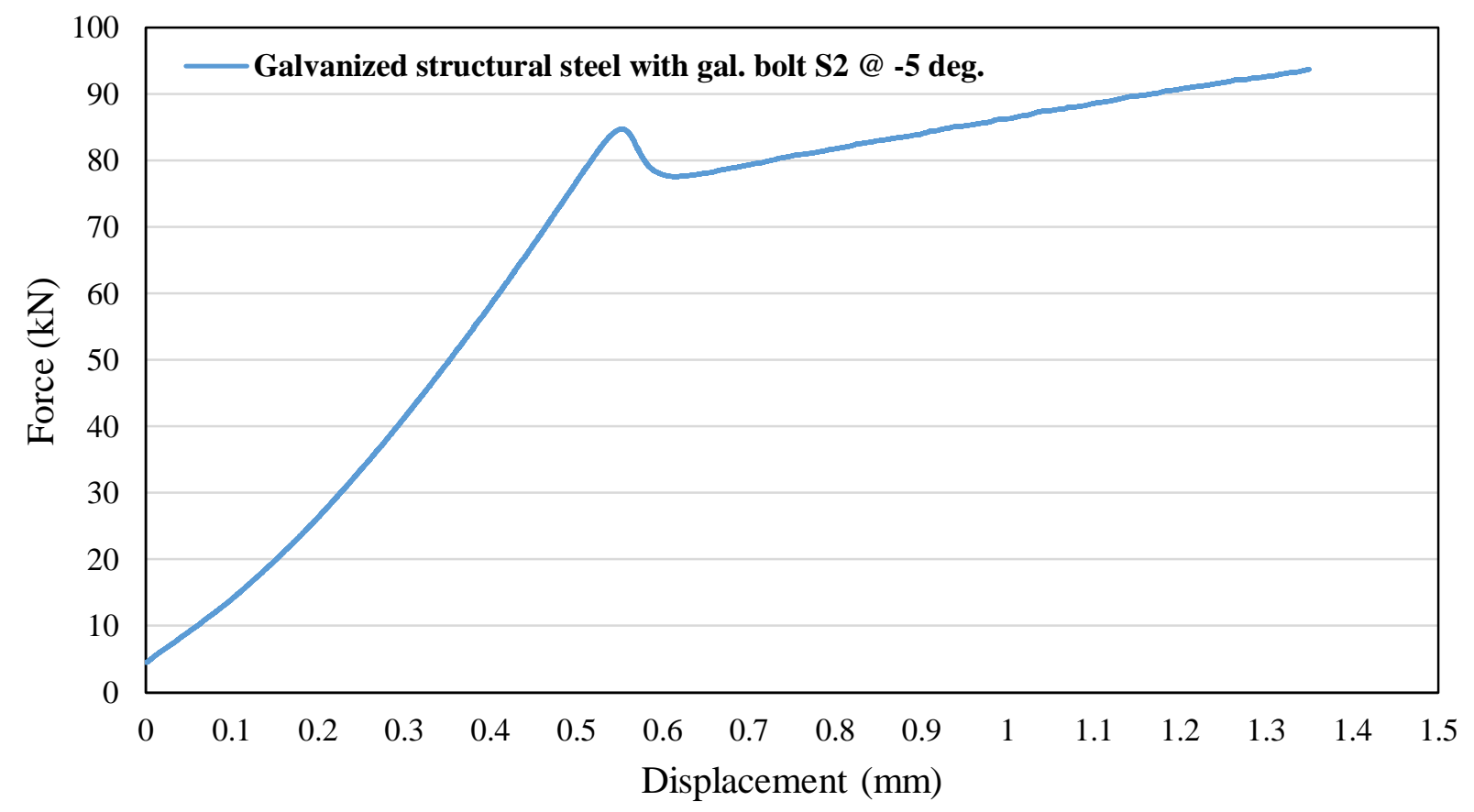

Figure E- 8: Force-displacement relationship for $350 \mathrm{~W}$ structural steel with hot dip galvanized surface condition with galvanized bolt for test specimen 2 at $-5^{\circ} \mathrm{C}$ temperature 


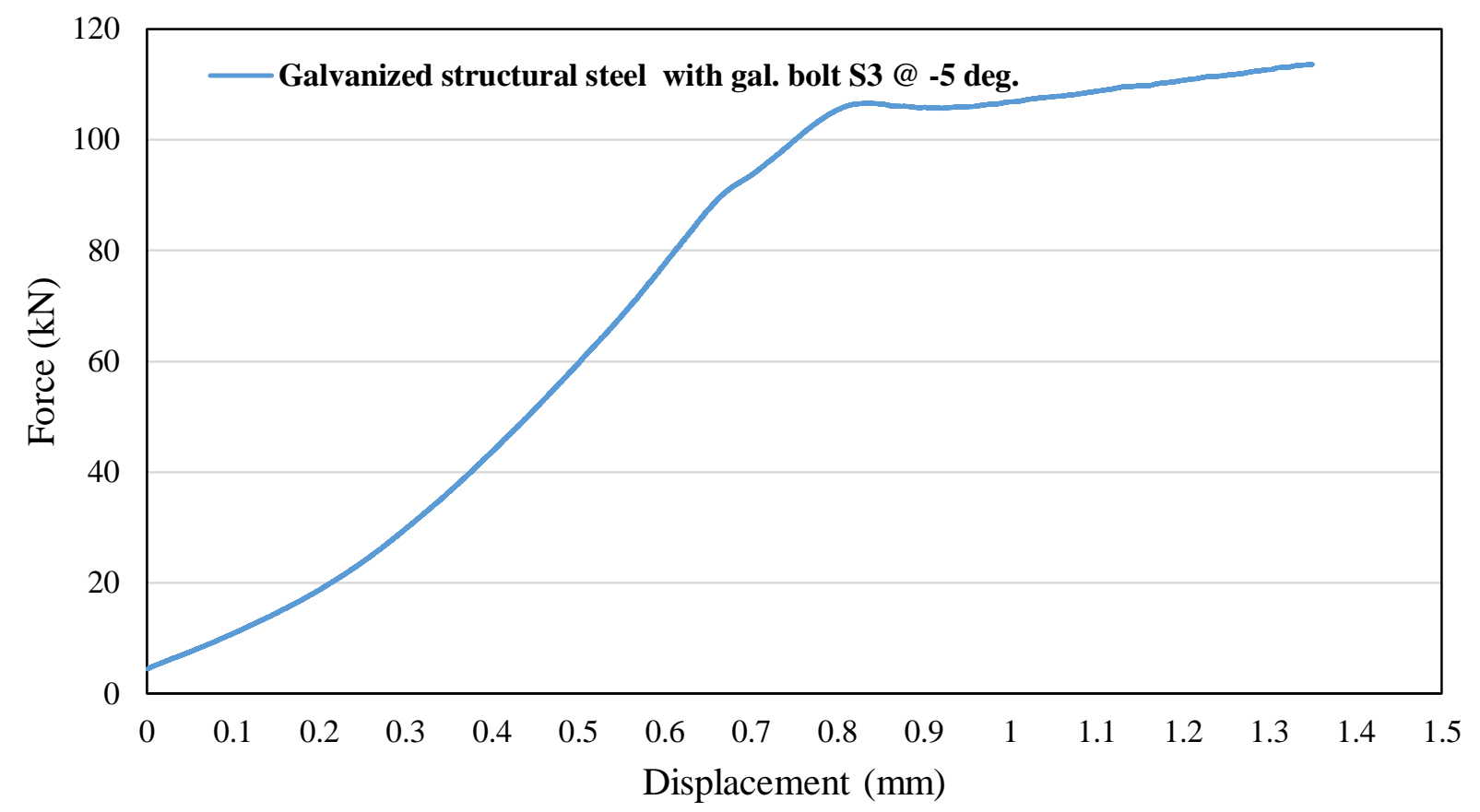

Figure E- 9: Force-displacement relationship for $350 \mathrm{~W}$ structural steel with hot dip galvanized surface condition with galvanized bolt for test specimen 3 at $-5^{\circ} \mathrm{C}$ temperature

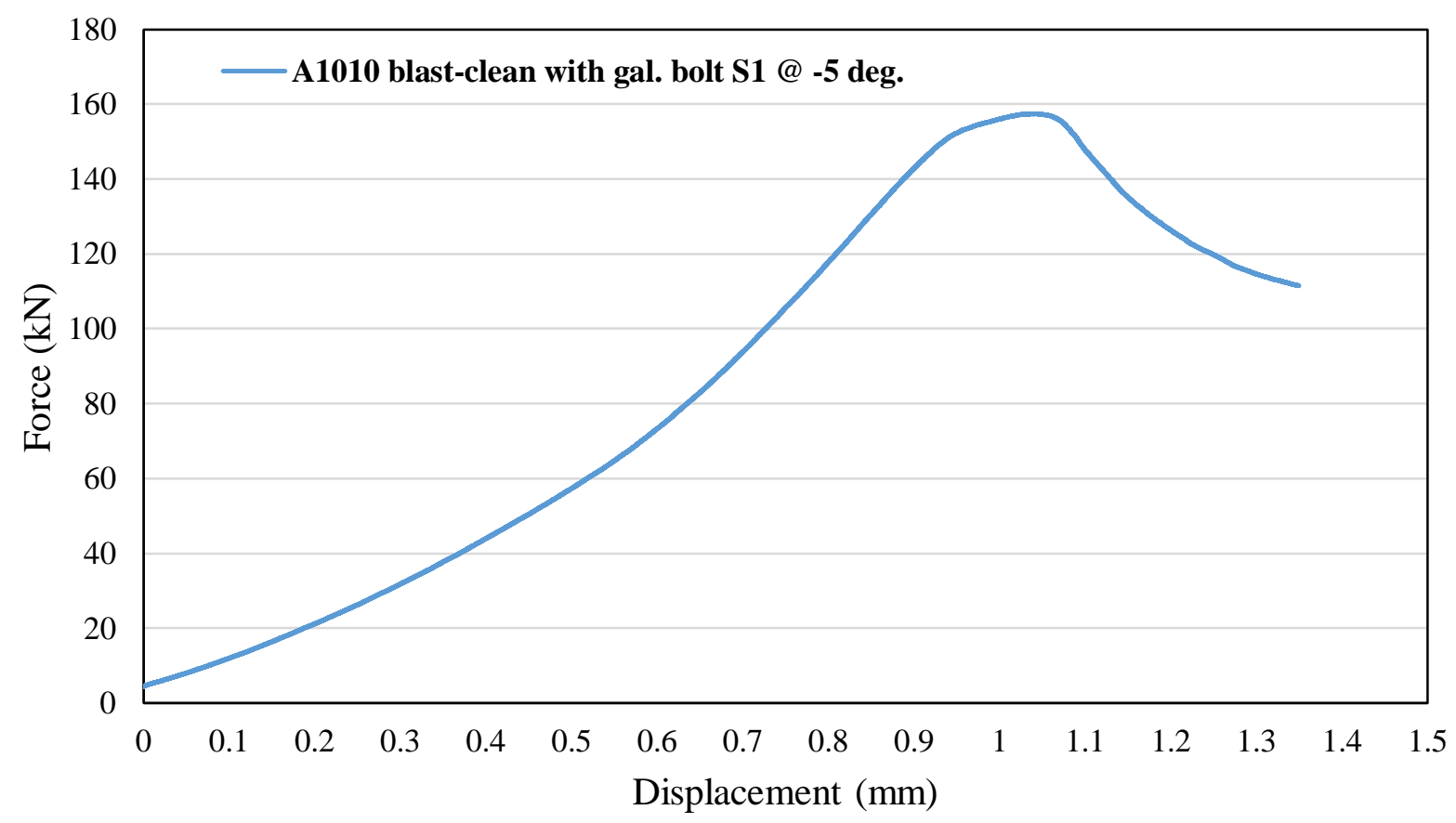

Figure E- 10: Force-displacement relationship for A1010 stainless steel with blast-clean surface condition with galvanized bolt for test specimen 1 at $-5^{\circ} \mathrm{C}$ temperature 


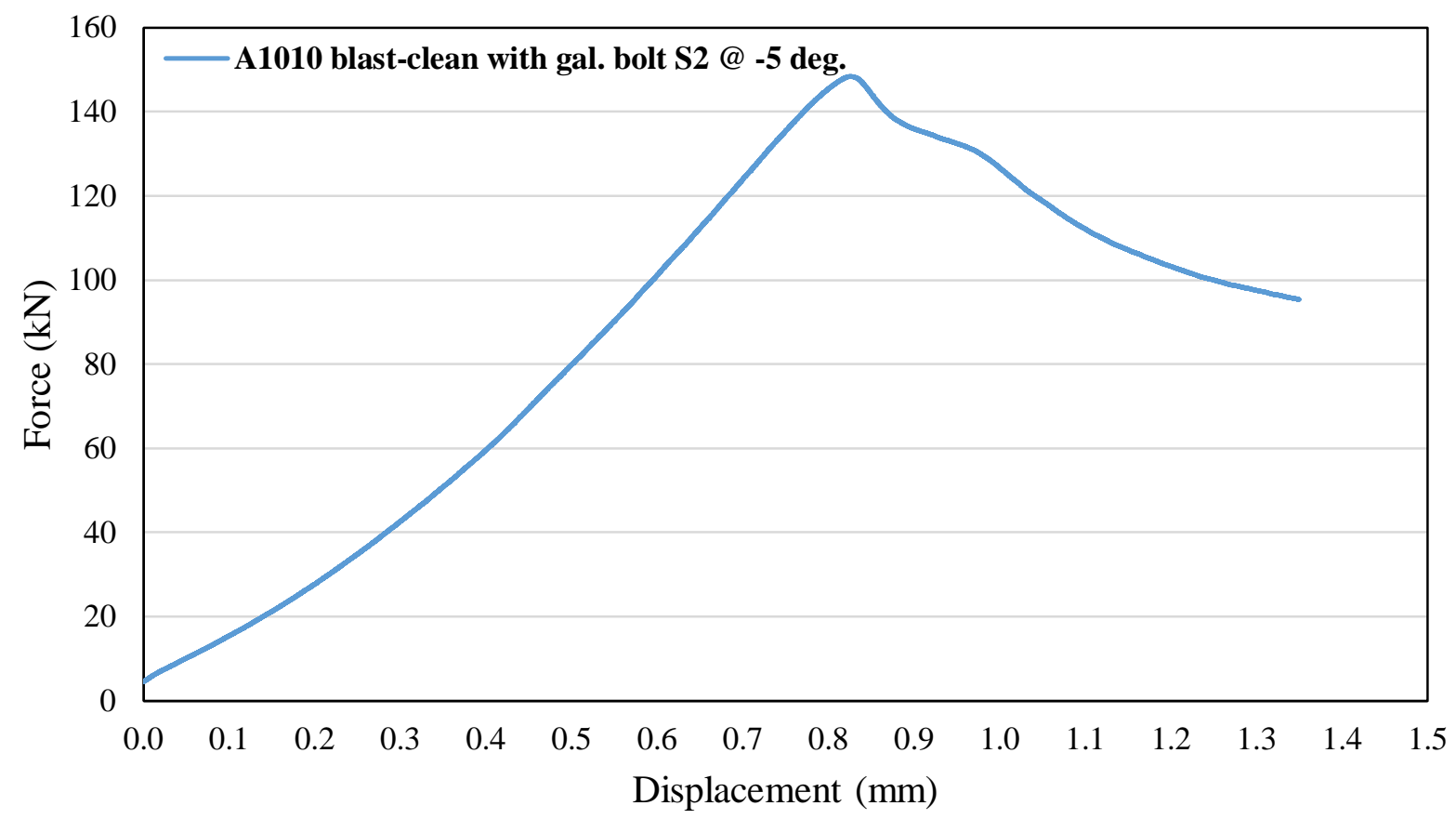

Figure E- 11: Force-displacement relationship for A1010 stainless steel with blast-clean surface condition with galvanized bolt for test specimen 2 at $-5^{\circ} \mathrm{C}$ temperature

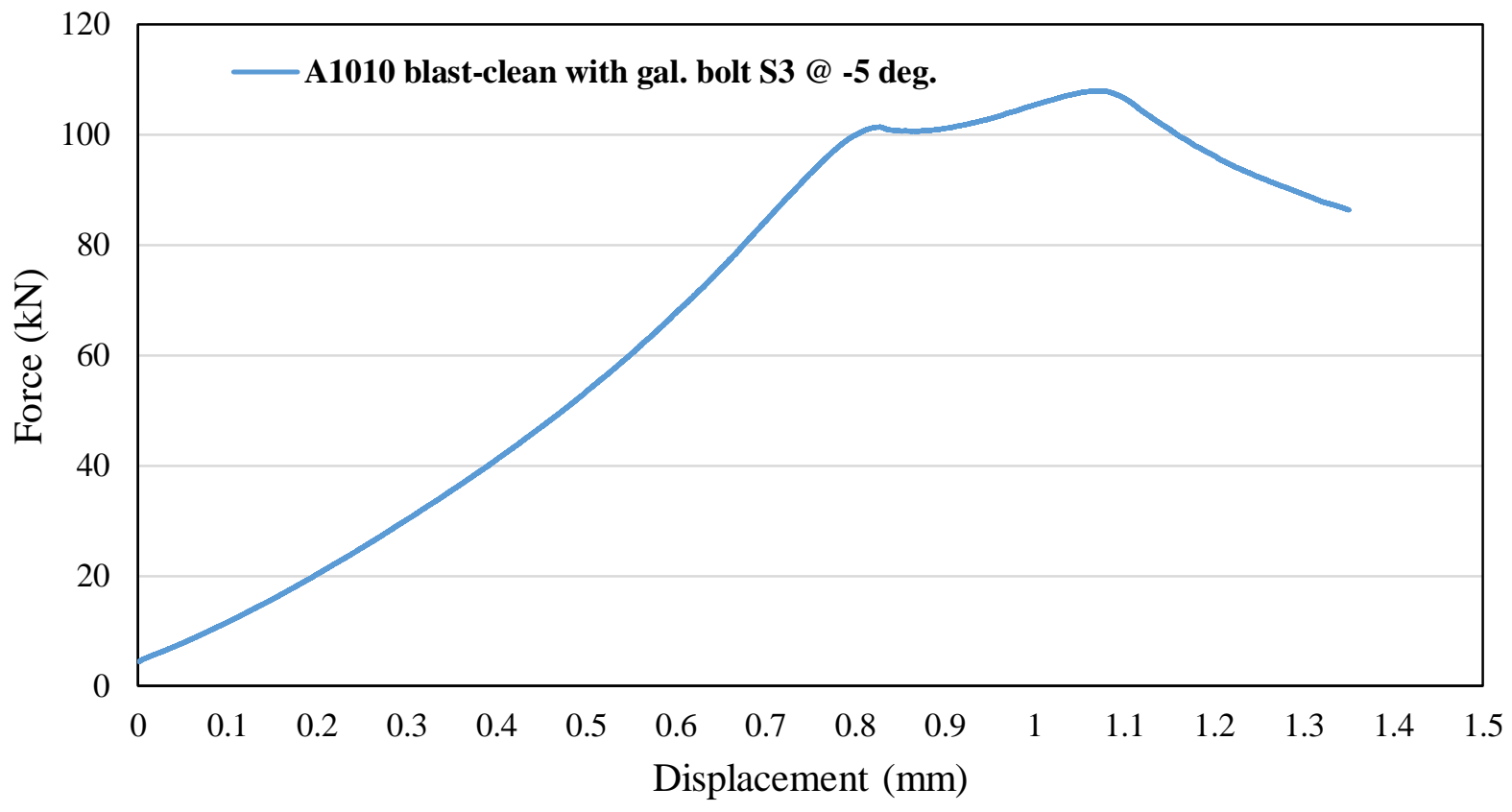

Figure E- 12: Force-displacement relationship for A1010 stainless steel with blast-clean surface condition with galvanized bolt for test specimen 3 at $-5^{\circ} \mathrm{C}$ temperature 


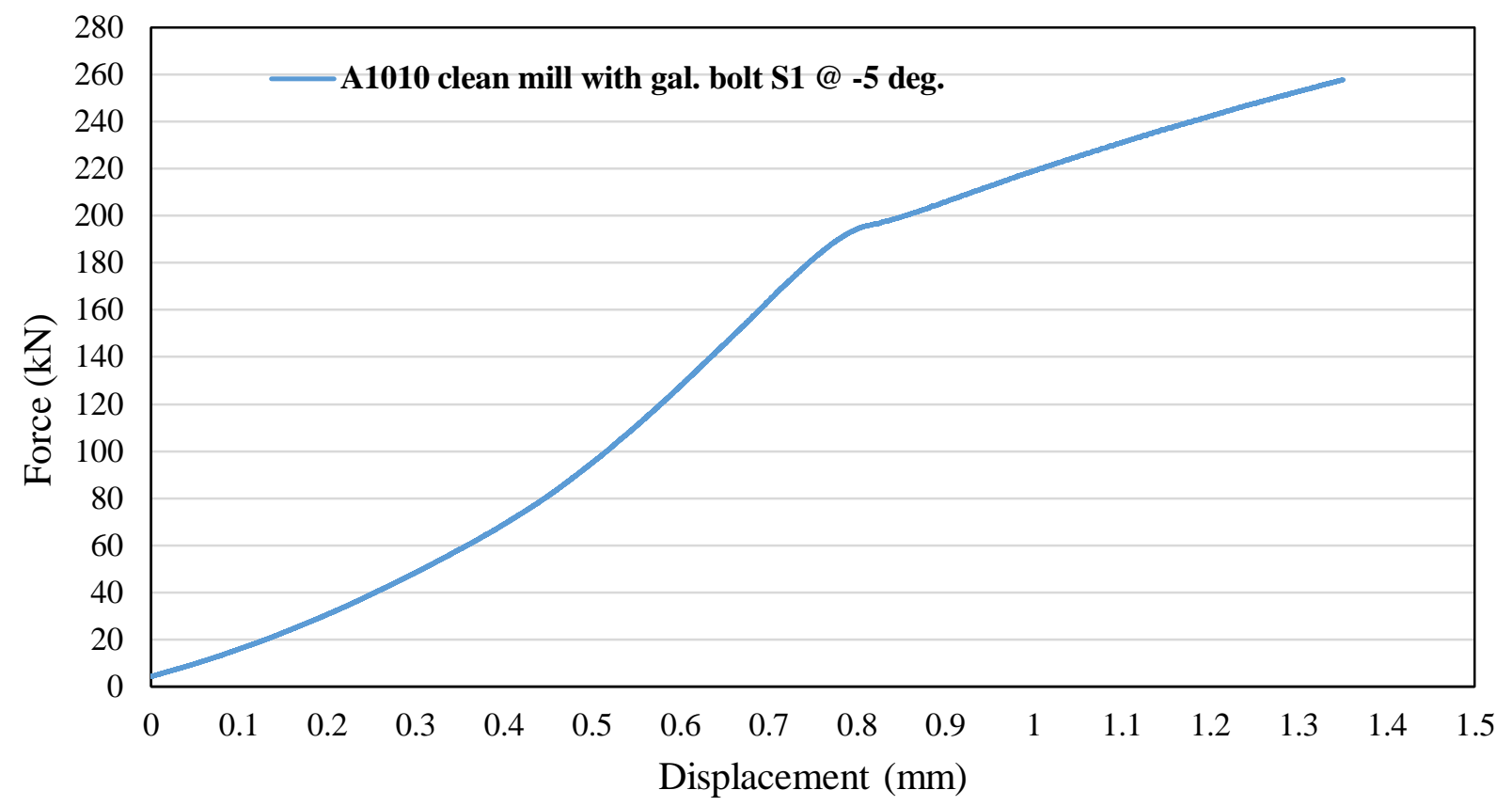

Figure E- 13: Force-displacement relationship for A1010 stainless steel with clean mill scale surface condition with galvanized bolt for test specimen 1 at $-5^{\circ} \mathrm{C}$ temperature

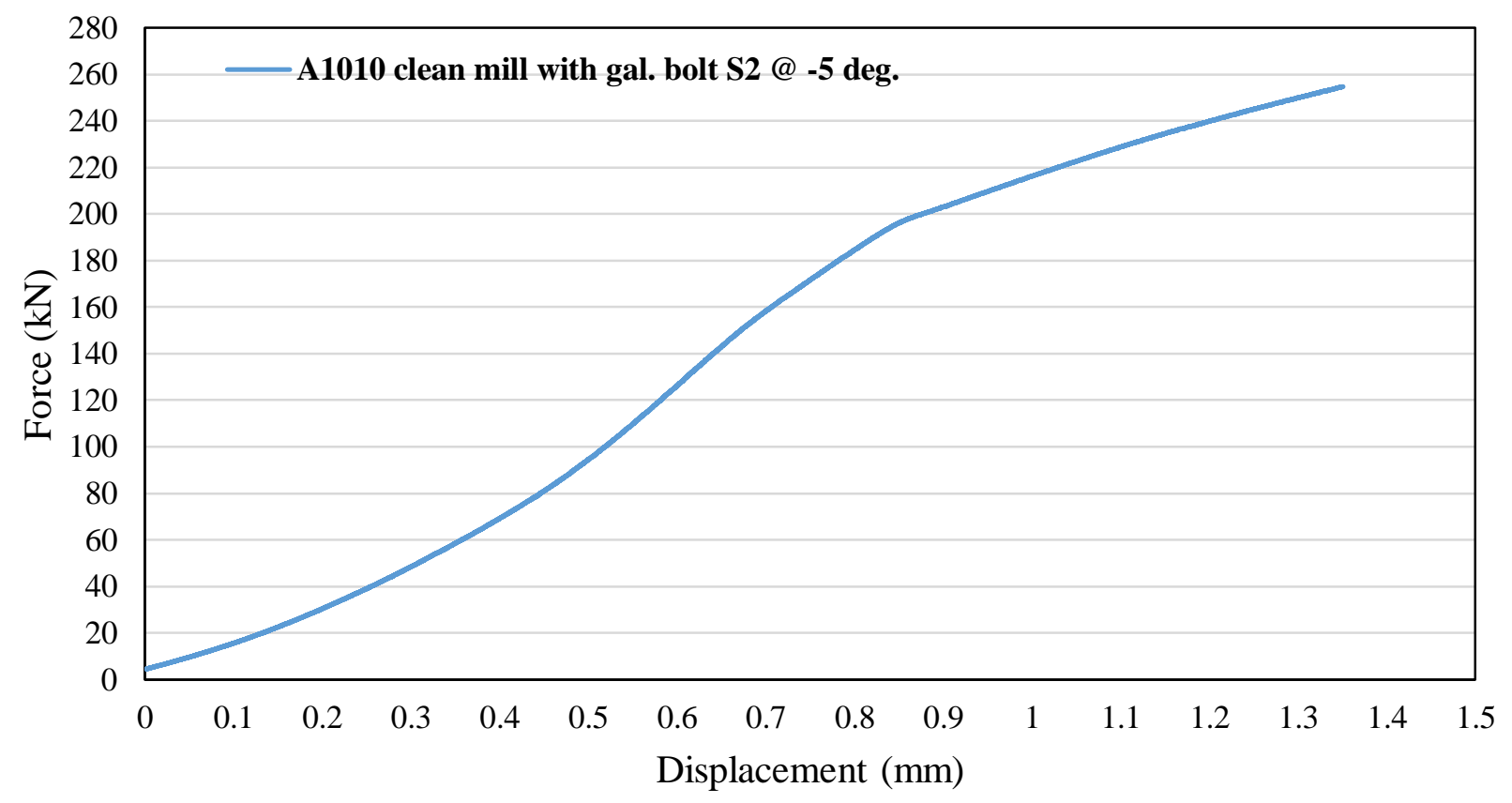

Figure E- 14: Force-displacement relationship for A1010 stainless steel with clean mill scale surface condition with galvanized bolt for test specimen 2 at $-5^{\circ} \mathrm{C}$ temperature 


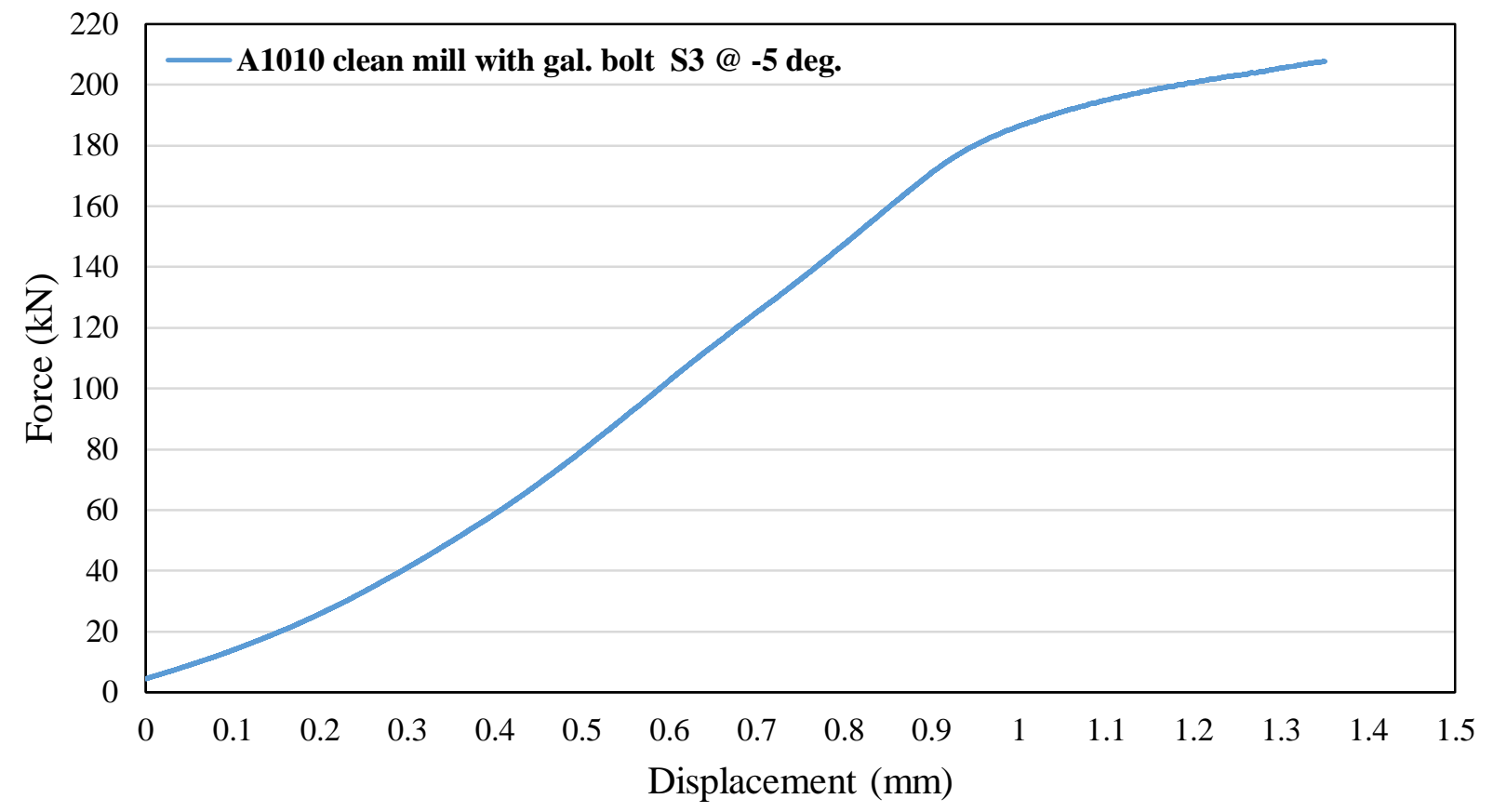

Figure E- 15: Force-displacement relationship for A1010 stainless steel with clean mill scale surface condition with galvanized bolt for test specimen 3 at $-5^{\circ} \mathrm{C}$ temperature 
Table E- 1: Recorded plate temperature during slip coefficient testing intended at $-5^{\circ} \mathrm{C}$ temperature monitoring results

\begin{tabular}{|c|c|c|c|c|c|c|c|c|c|c|c|c|c|c|c|}
\hline \multirow[b]{2}{*}{$\begin{array}{c}\text { Slip test plate } \\
\text { thickness = } \\
5 / 8 " \text { bolt dia.= } \\
7 / 8 "\end{array}$} & \multirow[b]{2}{*}{$\begin{array}{c}\text { Set } \\
\text { number }\end{array}$} & \multirow[b]{2}{*}{$\begin{array}{c}\text { Test } \\
\text { material }\end{array}$} & \multirow[b]{2}{*}{\begin{tabular}{|c} 
Surface type \\
(class)
\end{tabular}} & \multirow[b]{2}{*}{$\begin{array}{c}\text { Sample } \\
\# \\
\end{array}$} & \multirow[b]{2}{*}{$\begin{array}{c}\text { At start } \\
\text { of } \\
\text { testing } \\
\end{array}$} & \multicolumn{10}{|c|}{ Recorded temperature $\left({ }^{0} \mathrm{C}\right)$} \\
\hline & & & & & & 2 mins & 4 mins & 6 mins & 8 mins & 10 mins & 12 mins & 14 mins & 16 mins & 18 mins & 20 mins \\
\hline \multirow{15}{*}{$\begin{array}{l}\text { (using turn-of- } \\
\text { the-nut } \\
\text { method: effect } \\
\text { of temperature } \\
\text { on slip } \\
\text { resistance } \\
\text { determination) }\end{array}$} & \multirow{3}{*}{$1 *$} & \multirow{3}{*}{$\begin{array}{c}\text { Structural } \\
\text { Steel } \\
(350 \mathrm{~W})\end{array}$} & \multirow{3}{*}{$\begin{array}{c}\text { A }(\text { clean mill } \\
\text { scale })\end{array}$} & 1 & -4.9 & 5.0 & 8.1 & 10.7 & 12.8 & 14.6 & 16.1 & 17.0 & 18.0 & 18.7 & 19.3 \\
\hline & & & & 2 & -6.0 & 0.5 & 5.3 & 8.6 & 11.2 & 13.1 & 14.5 & 15.7 & 16.7 & 17.6 & 18.1 \\
\hline & & & & 3 & -5.6 & 1.3 & 4.8 & 7.4 & 9.4 & 11.5 & 13.1 & 14.4 & 15.4 & 16.3 & 17.3 \\
\hline & \multirow{3}{*}{$2 *$} & \multirow{3}{*}{$\begin{array}{c}\text { Structural } \\
\text { Steel } \\
(350 \mathrm{~W})\end{array}$} & \multirow{3}{*}{ B $\begin{array}{l}\text { (Blast - } \\
\text { cleaned) }\end{array}$} & 1 & -5.4 & 0.6 & 4.4 & 7.6 & 10.1 & 12.0 & 13.6 & 15.1 & 16.1 & 16.9 & 17.5 \\
\hline & & & & 2 & -5.2 & 3.1 & 6.5 & 8.4 & 10.5 & 12.3 & 13.9 & 15.2 & 16.0 & 16.7 & 17.3 \\
\hline & & & & 3 & -5.8 & 0.3 & 3.7 & 7.1 & 9.4 & 11.4 & 13.2 & 14.6 & 15.8 & 16.6 & 17.2 \\
\hline & \multirow{3}{*}{$3 * *$} & \multirow{3}{*}{$\mid \begin{array}{c}\text { Structural } \\
\text { Steel } \\
(350 \mathrm{~W})\end{array}$} & \multirow{3}{*}{$\begin{array}{c}\text { C (Hot dip } \\
\text { galvanized } \\
\text { with gal. } \\
\text { bolt) }\end{array}$} & 1 & -5.8 & 0.8 & 4.8 & 7.0 & 8.9 & 10.4 & 11.8 & 13.4 & 14.1 & 15.0 & 15.7 \\
\hline & & & & 2 & -6.1 & -3.0 & 2.4 & 6.5 & 9.5 & 11.2 & 12.8 & 14.2 & 15.1 & 16.0 & 16.8 \\
\hline & & & & 3 & -6.2 & 0.0 & 3.7 & 6.9 & 9.4 & 11.4 & 13.0 & 14.4 & 15.4 & 16.2 & 16.9 \\
\hline & \multirow{3}{*}{$4 * *$} & \multirow{3}{*}{$\begin{array}{c}\text { Stainless } \\
\text { Steel }\end{array}$} & \multirow{3}{*}{$\begin{array}{c}\text { A } \text { (clean mill } \\
\text { scale })\end{array}$} & 1 & -6.6 & -0.5 & 3.7 & 6.8 & 9.0 & 11.0 & 12.6 & 13.8 & 14.9 & 15.8 & 16.5 \\
\hline & & & & 2 & -7.1 & 0.9 & 5.0 & 7.5 & 9.8 & 11.9 & 13.1 & 14.2 & 15.2 & 16.0 & 16.7 \\
\hline & & & & 3 & -7.0 & -0.6 & 4.6 & 8.3 & 9.9 & 11.6 & 13.0 & 14.0 & 14.9 & 15.8 & 16.4 \\
\hline & \multirow{3}{*}{$5 * *$} & \multirow{3}{*}{$\begin{array}{c}\text { Stainless } \\
\text { Steel }\end{array}$} & \multirow{3}{*}{$\begin{array}{l}\text { B } \text { (Blast - } \\
\text { cleaned) }\end{array}$} & 1 & -6.4 & -0.5 & 3.2 & 6.1 & 8.2 & 10.0 & 11.8 & 13.2 & 14.4 & 15.2 & 15.8 \\
\hline & & & & 2 & -4.9 & 0.5 & 4.9 & 7.0 & 8.7 & 10.1 & 11.6 & 12.9 & 13.8 & 14.4 & 15.0 \\
\hline & & & & 3 & -5.9 & 1.3 & 4.9 & 7.5 & 9.1 & 10.8 & 12.2 & 13.3 & 14.3 & 15.1 & 15.6 \\
\hline
\end{tabular}

* with A325 bolt

** with galvanized bolt 


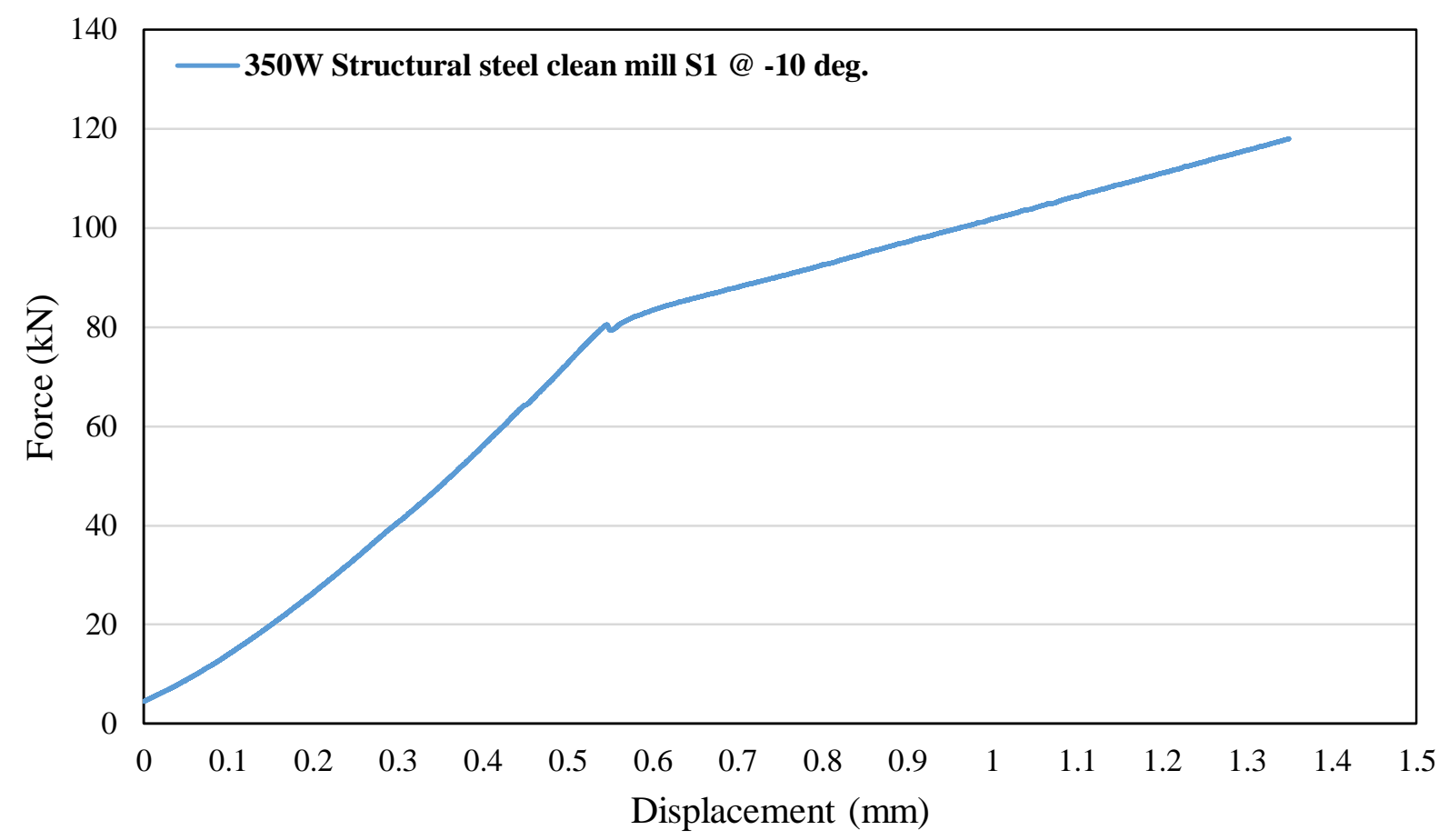

Figure E- 16: Force-displacement relationship for structural steel with clean mill scale surface condition with $\mathrm{A325}$ bolt for test specimen 1 at $-10^{\circ} \mathrm{C}$ temperature

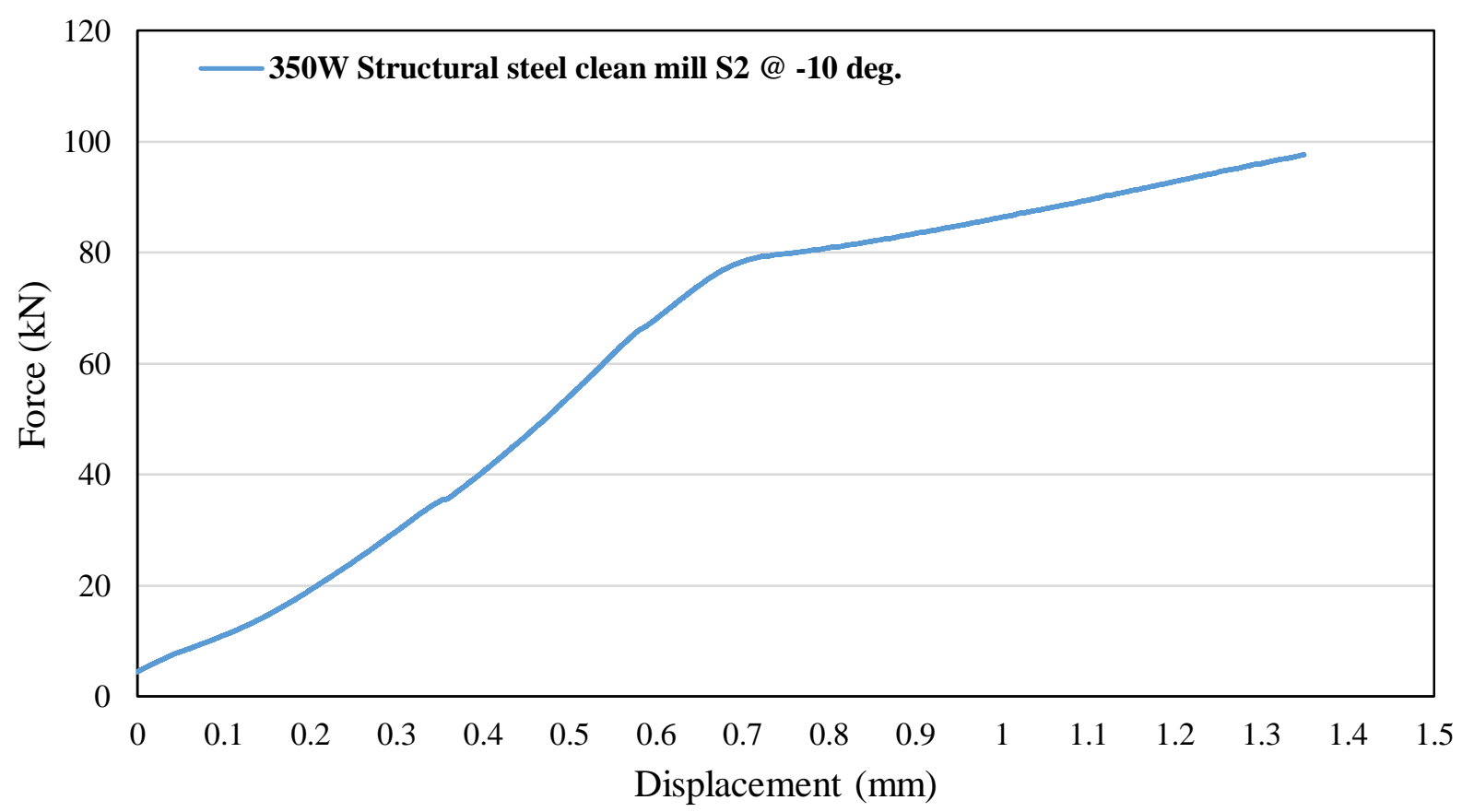

Figure E- 17: Force-displacement relationship for structural steel with clean mill scale surface condition with $\mathrm{A325}$ bolt for test specimen 2 at $-10^{\circ} \mathrm{C}$ temperature 


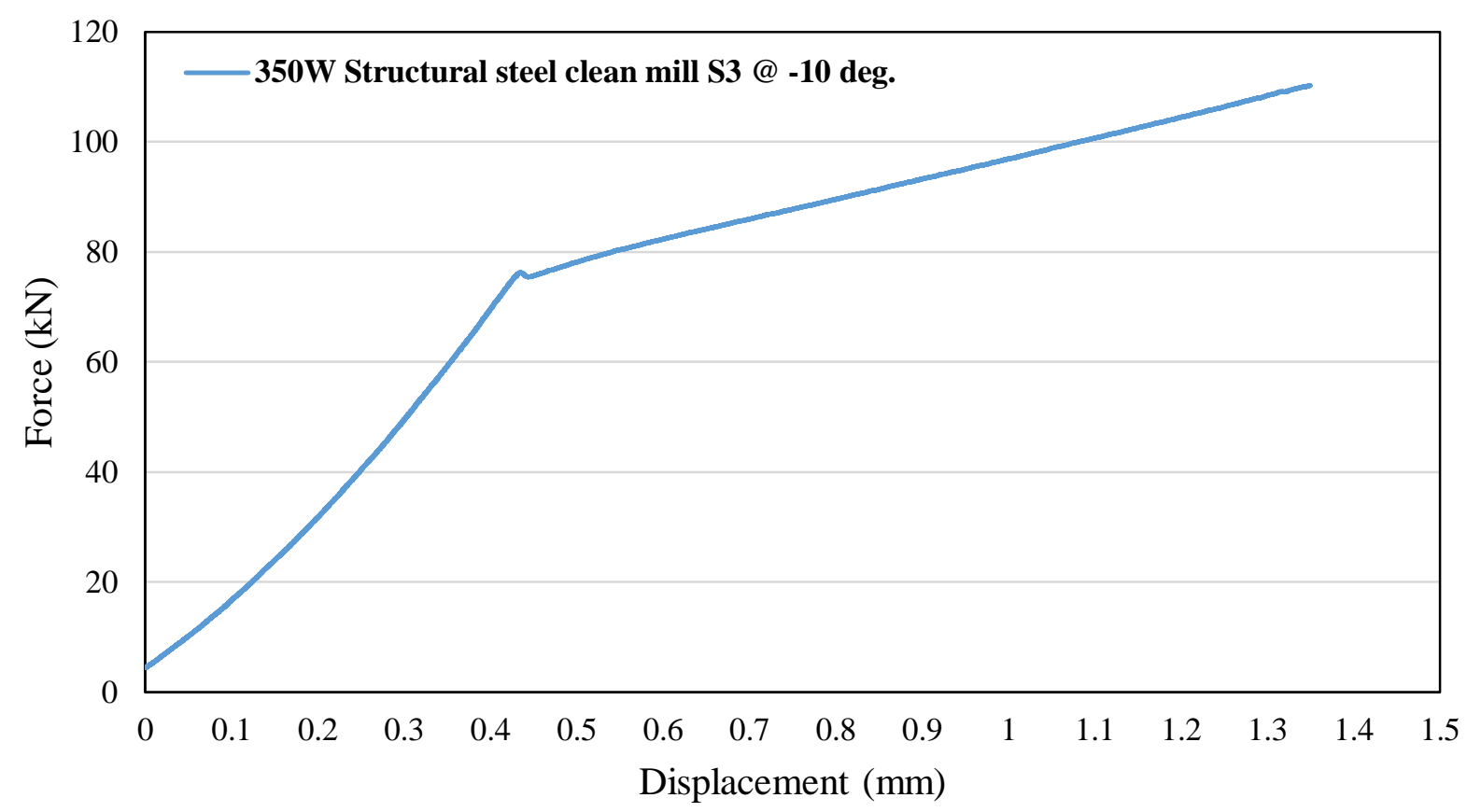

Figure E- 18: Force-displacement relationship for structural steel with clean mill scale surface condition with $\mathrm{A325}$ bolt for test specimen 3 at $-10^{\circ} \mathrm{C}$ temperature

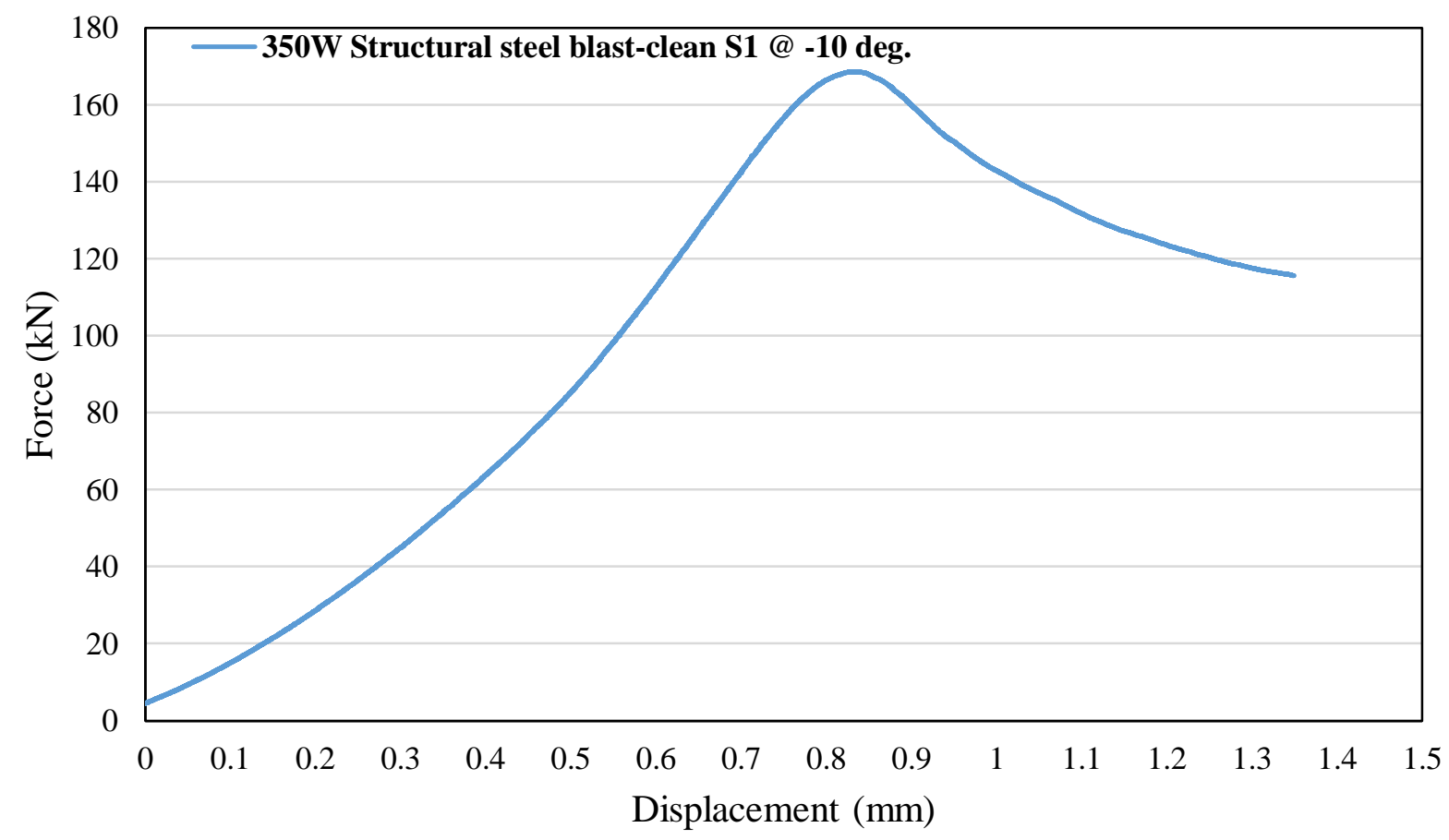

Figure E- 19: Force-displacement relationship for structural steel with blasted clean surface condition with $\mathrm{A325}$ bolt for test specimen 1 at $-10^{\circ} \mathrm{C}$ temperature 


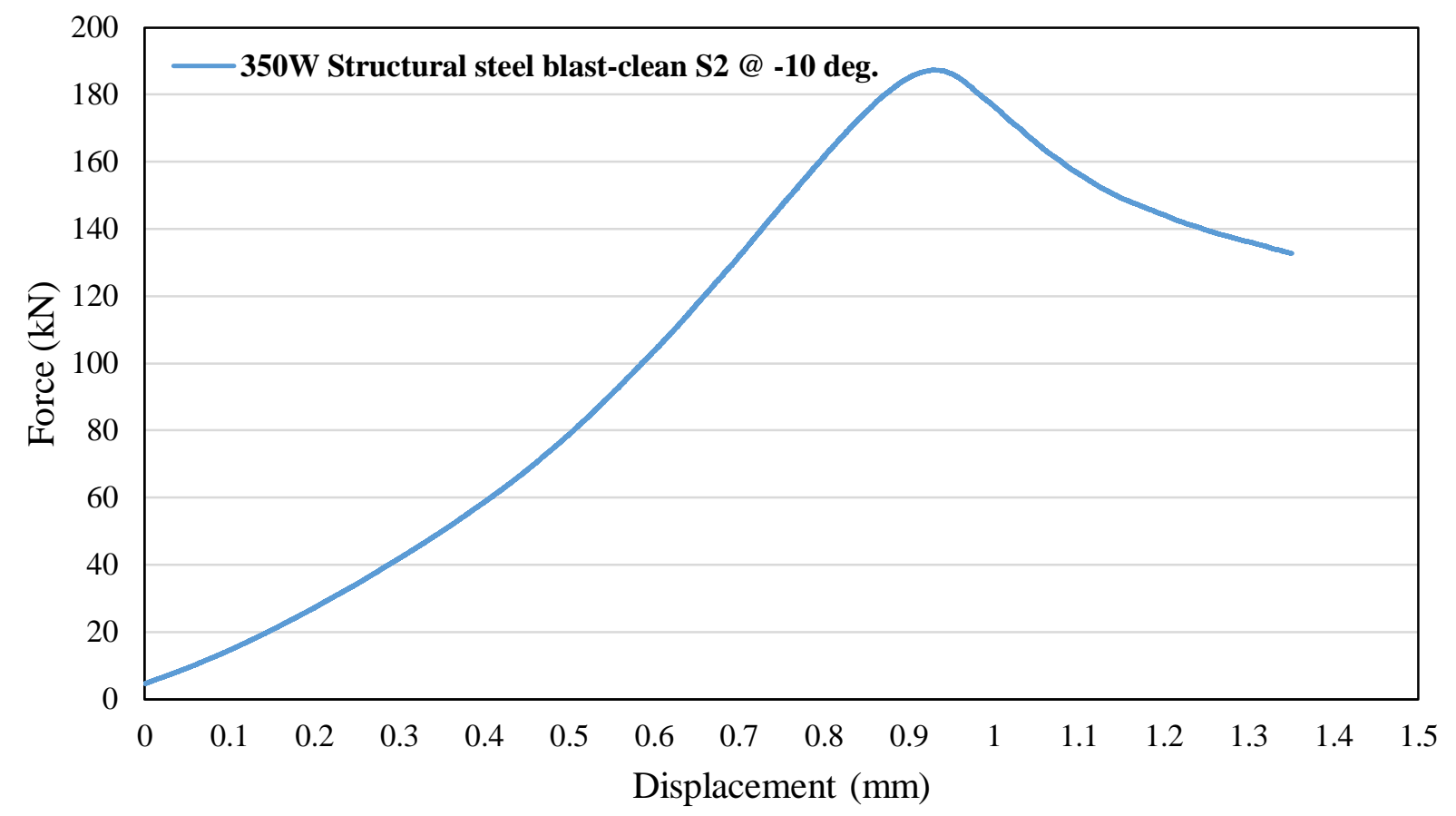

Figure E- 20: Force-displacement relationship for structural steel with blasted clean surface condition with $\mathrm{A} 325$ bolt for test specimen 2 at $-10^{\circ} \mathrm{C}$ temperature

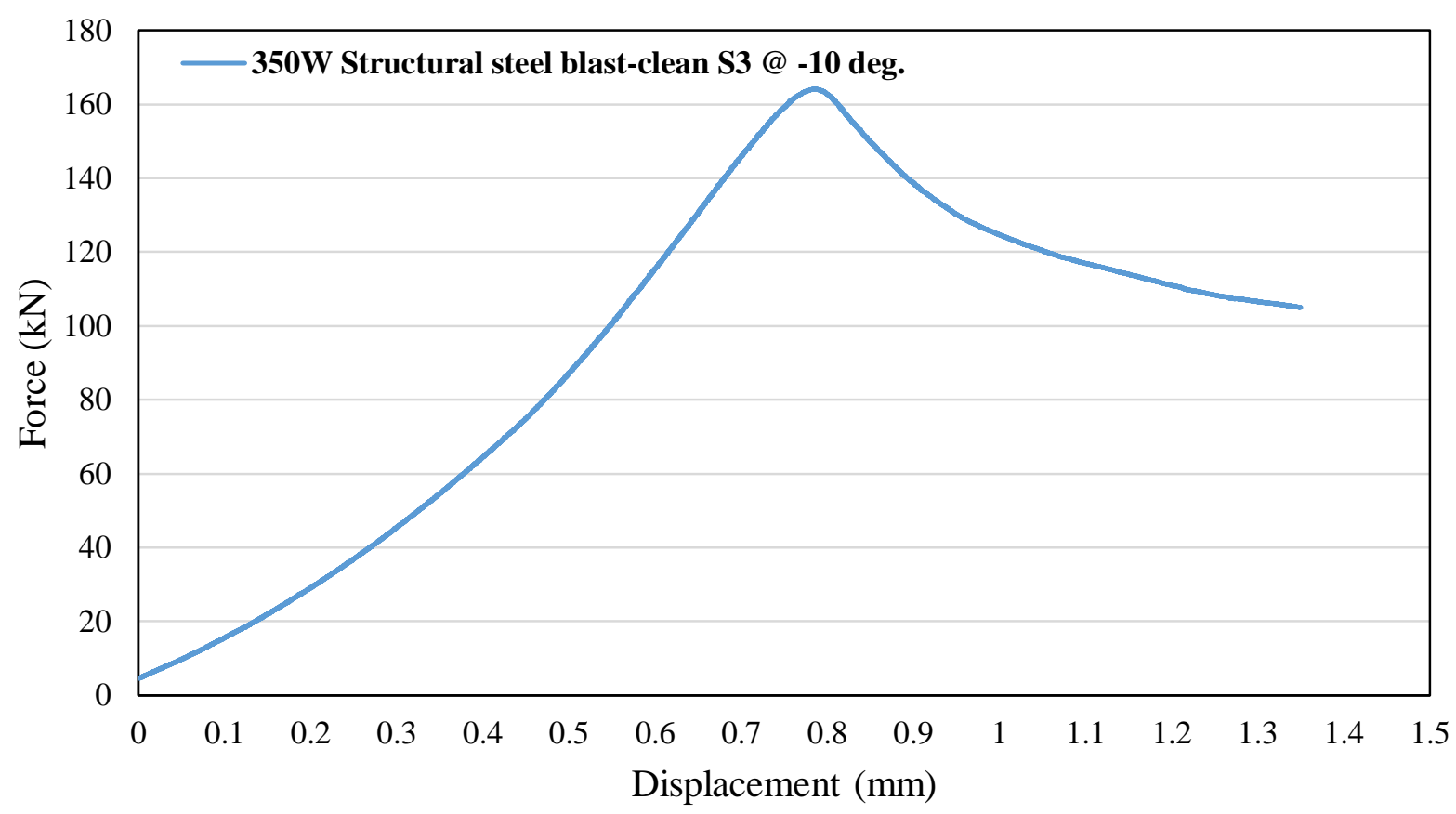

Figure E- 21: Force-displacement relationship for structural steel with blasted clean surface condition with $\mathrm{A325}$ bolt for test specimen 3 at $-10^{\circ} \mathrm{C}$ temperature 


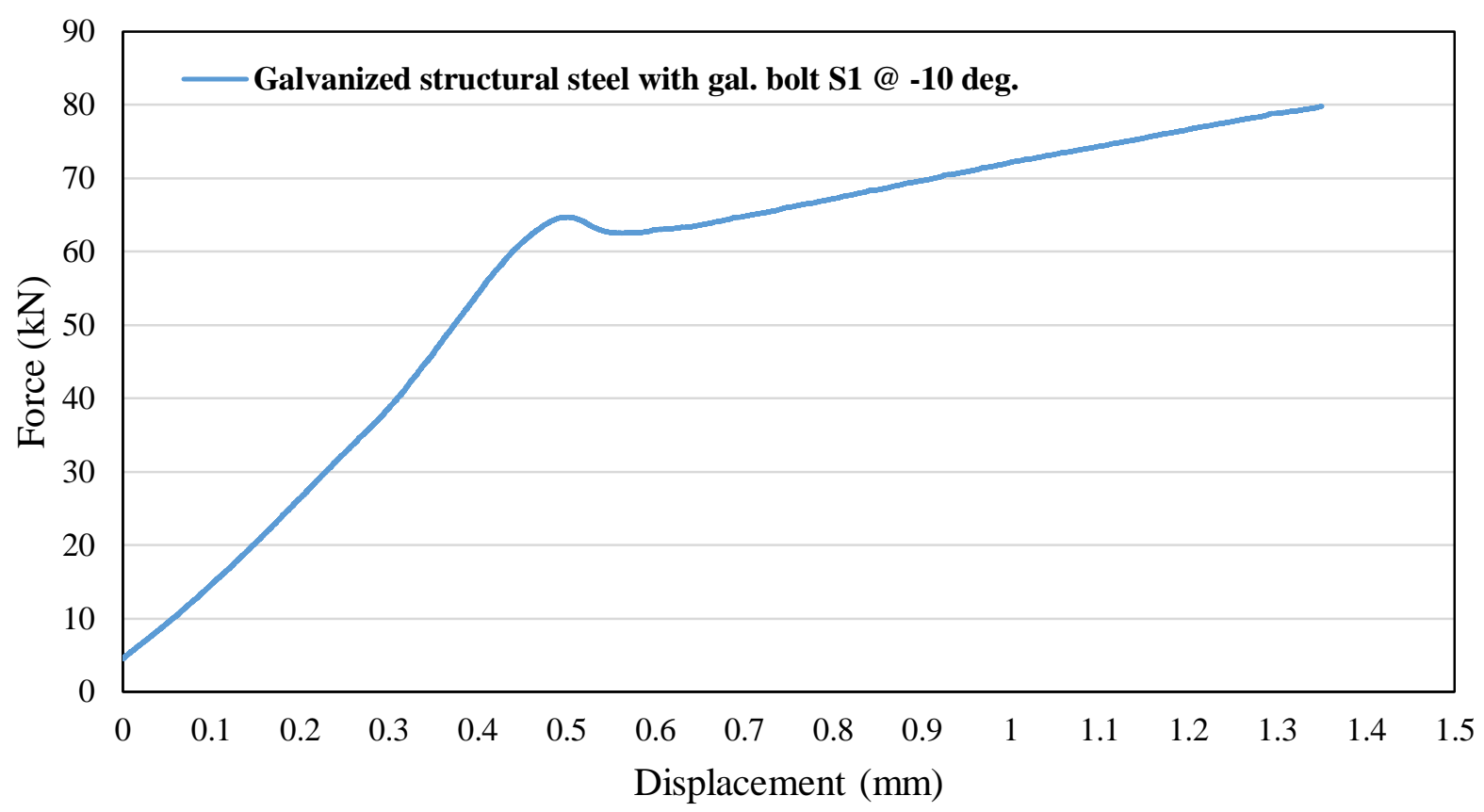

Figure E- 22: Force-displacement relationship for structural steel with hot dip galvanized surface condition with galvanized bolt for test specimen 1 at $-10^{\circ} \mathrm{C}$ temperature

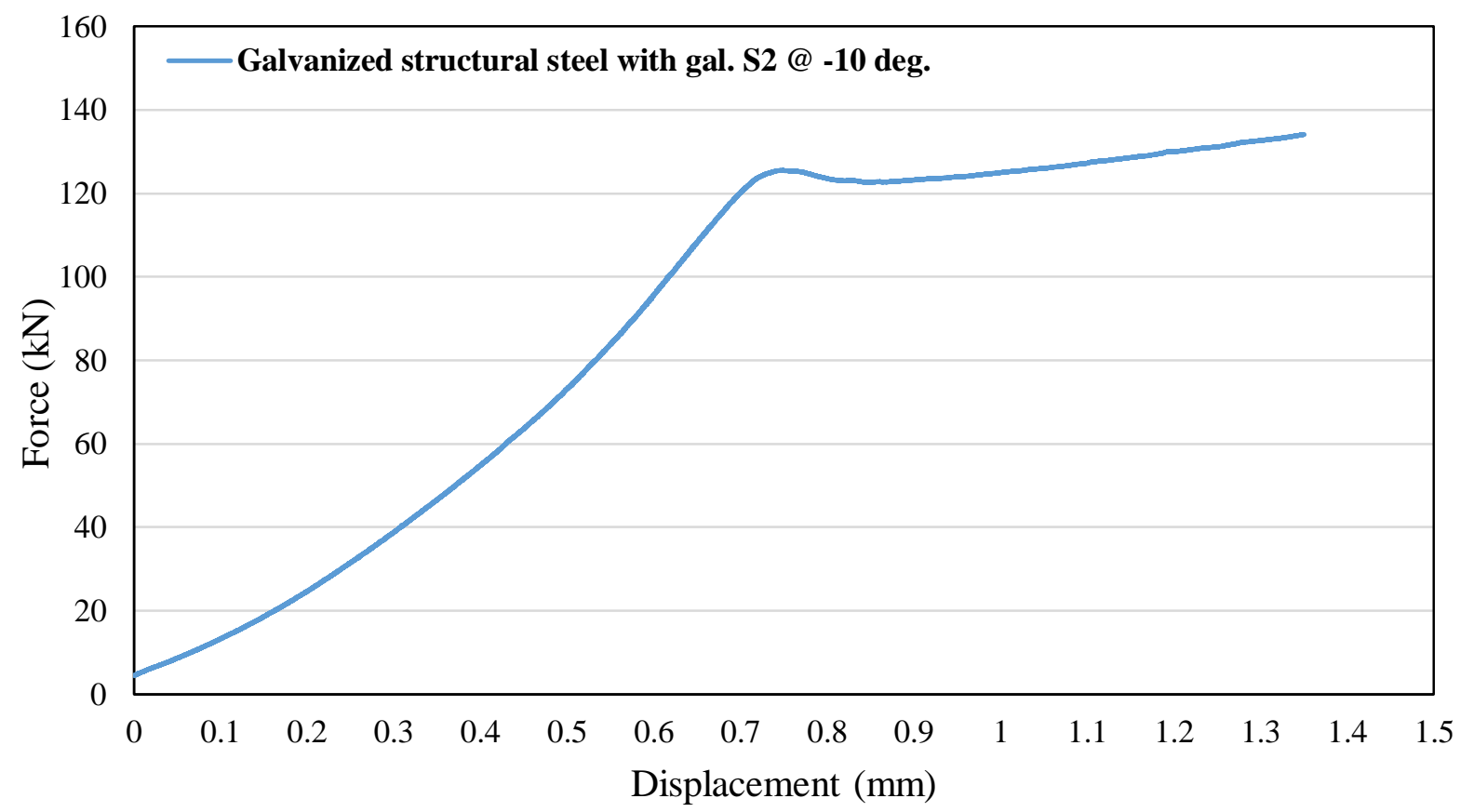

Figure E- 23: Force-displacement relationship for structural steel with hot dip galvanized surface condition with galvanized bolt for test specimen 2 at $-10^{\circ} \mathrm{C}$ temperature 


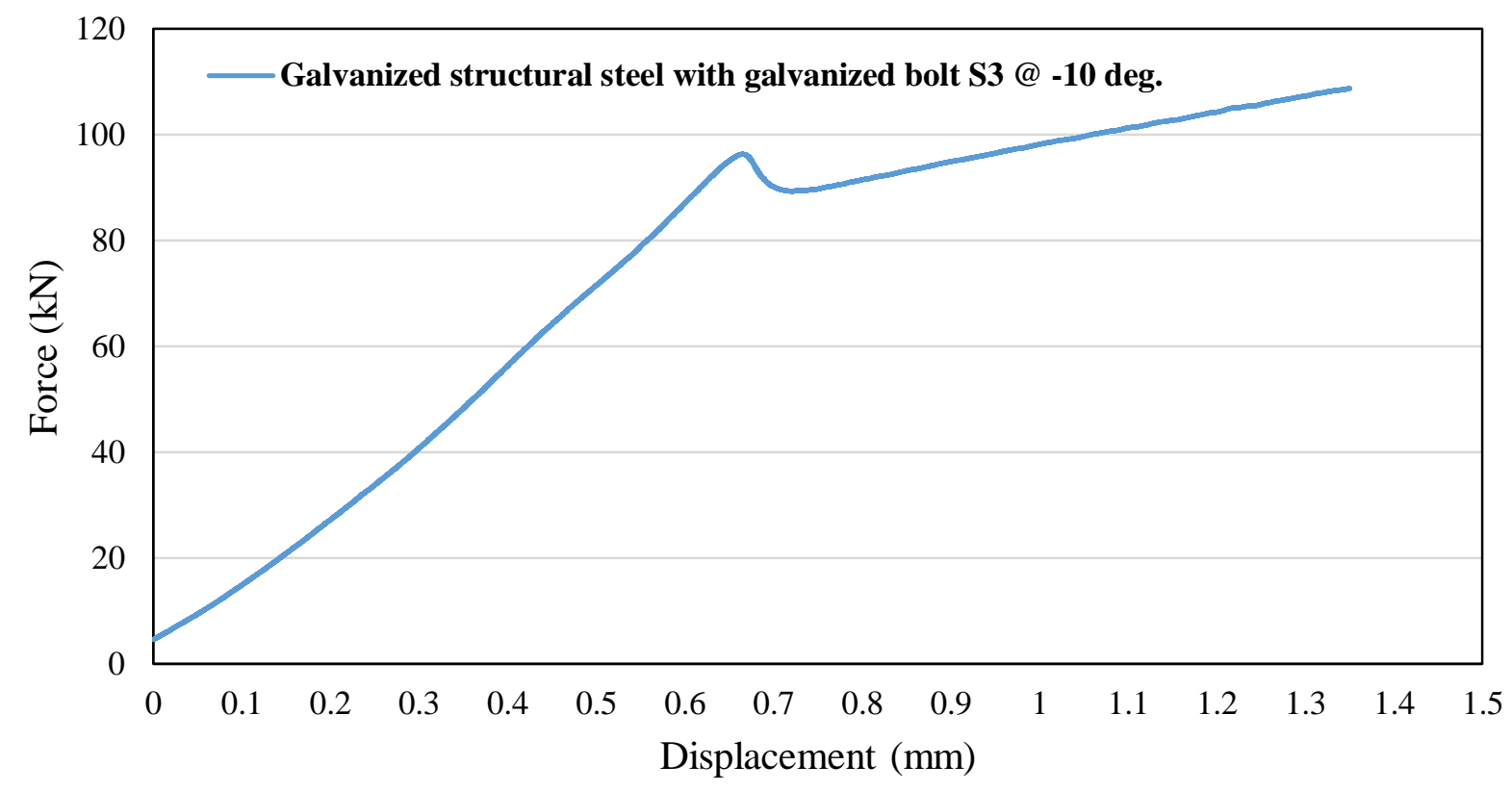

Figure E- 24: Force-displacement for structural steel with hot dip galvanized surface condition with galvanized bolt for test specimen 3 at $-10^{\circ} \mathrm{C}$ temperature

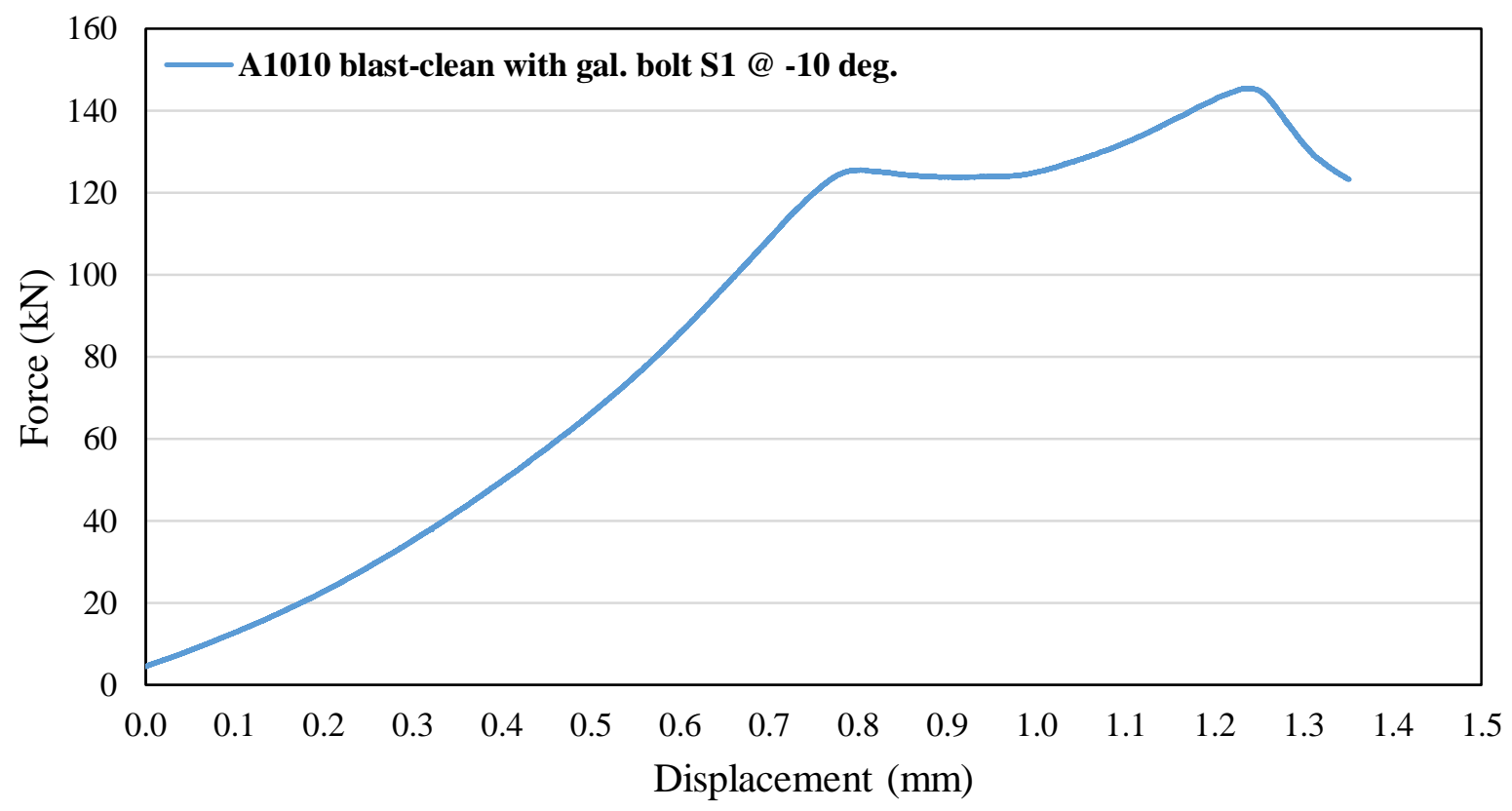

Figure E- 25: Force-displacement relationship for stainless steel with blasted clean surface condition with galvanized bolt for test specimen 1 at $-10^{\circ} \mathrm{C}$ temperature 


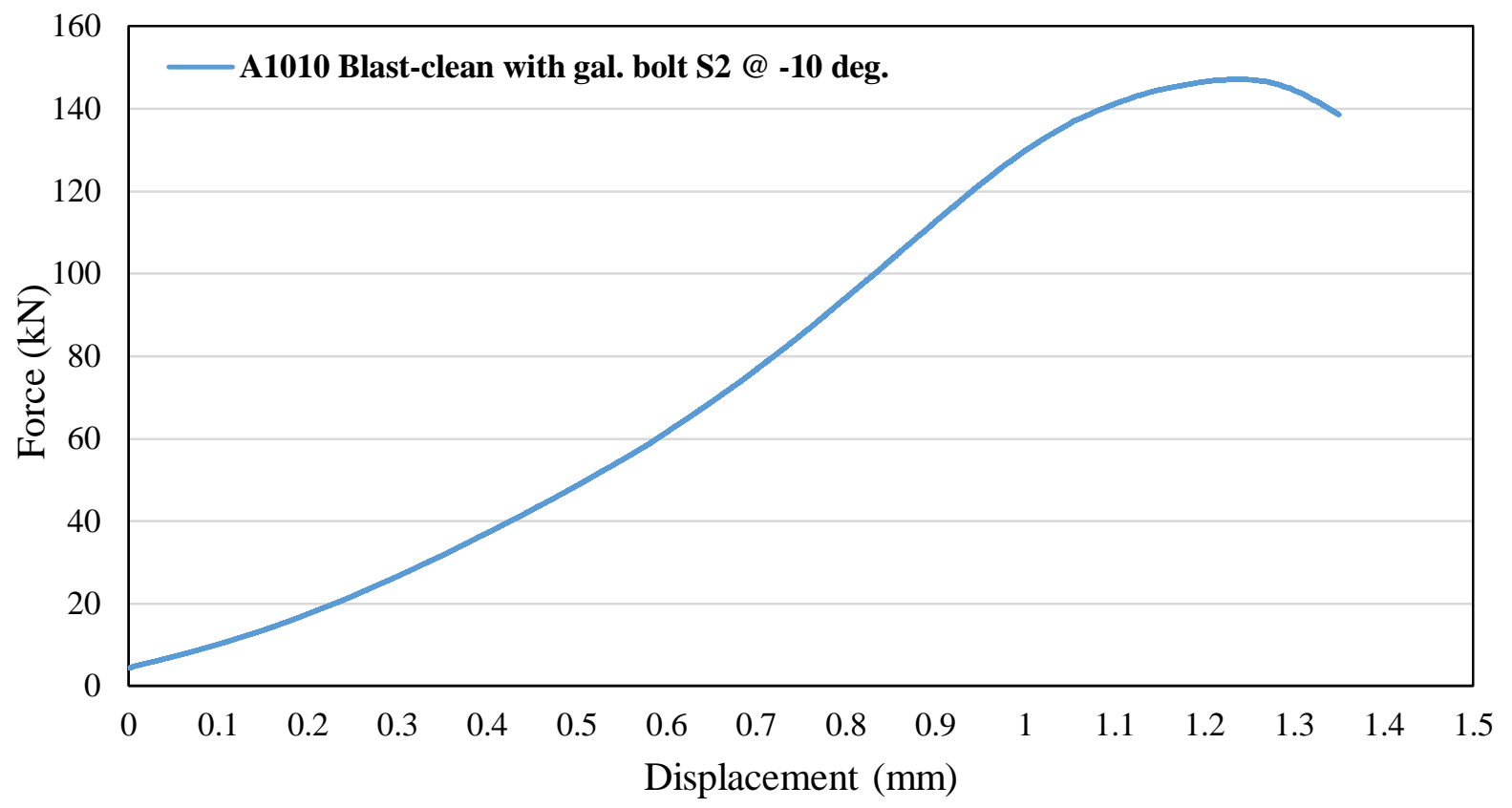

Figure E- 26: Force-displacement relationship for stainless steel with blasted clean surface condition with galvanized bolt for test specimen 2 at $-10^{\circ} \mathrm{C}$ temperature

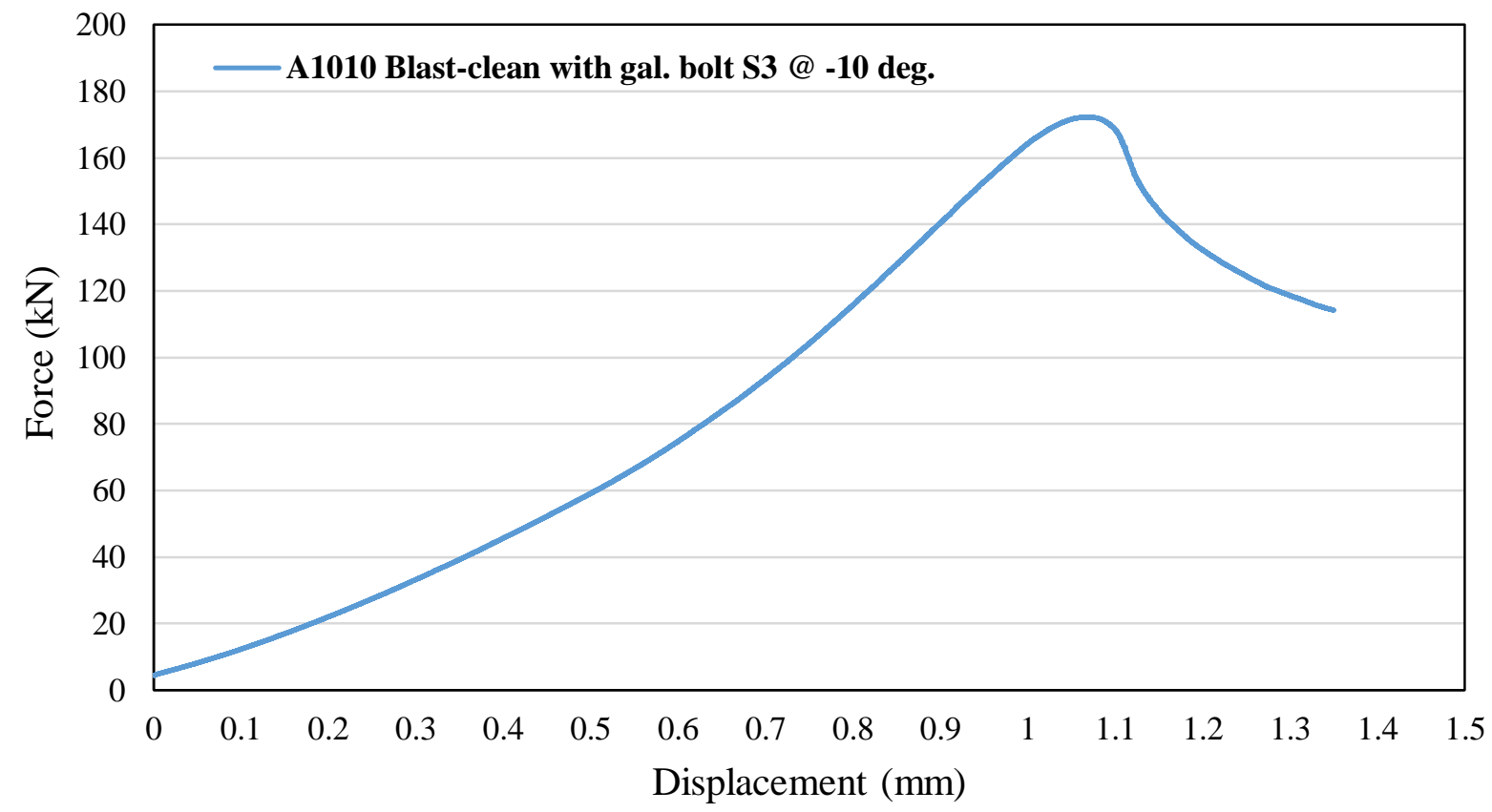

Figure E- 27: Force-displacement relationship for stainless steel with blasted clean surface condition with galvanized bolt for test specimen 3 at $-10^{\circ} \mathrm{C}$ temperature 


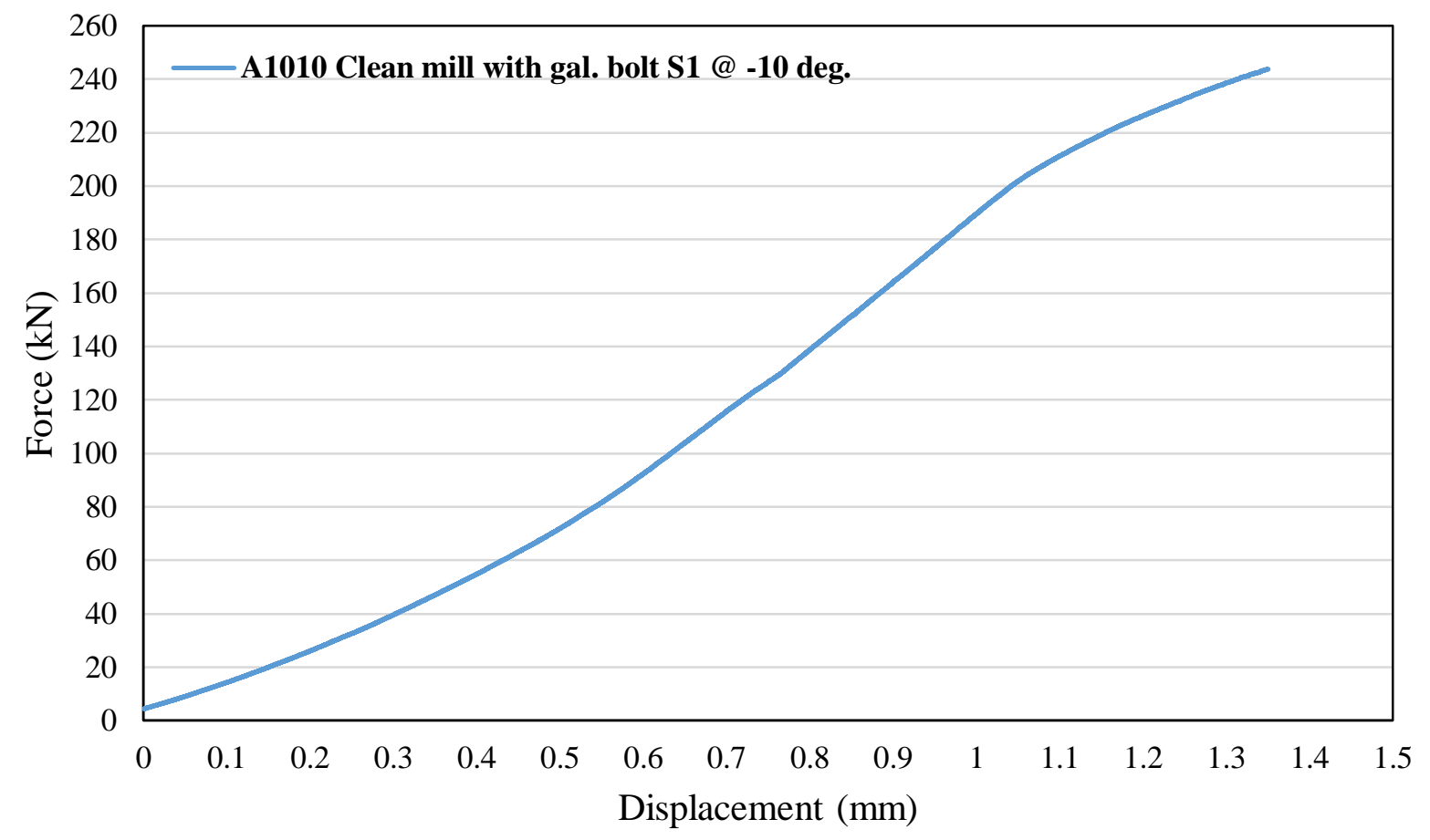

Figure E- 28: Force-displacement relationship for stainless steel with clean mill scale surface condition with galvanized bolt for test specimen 1 at $-10^{\circ} \mathrm{C}$ temperature

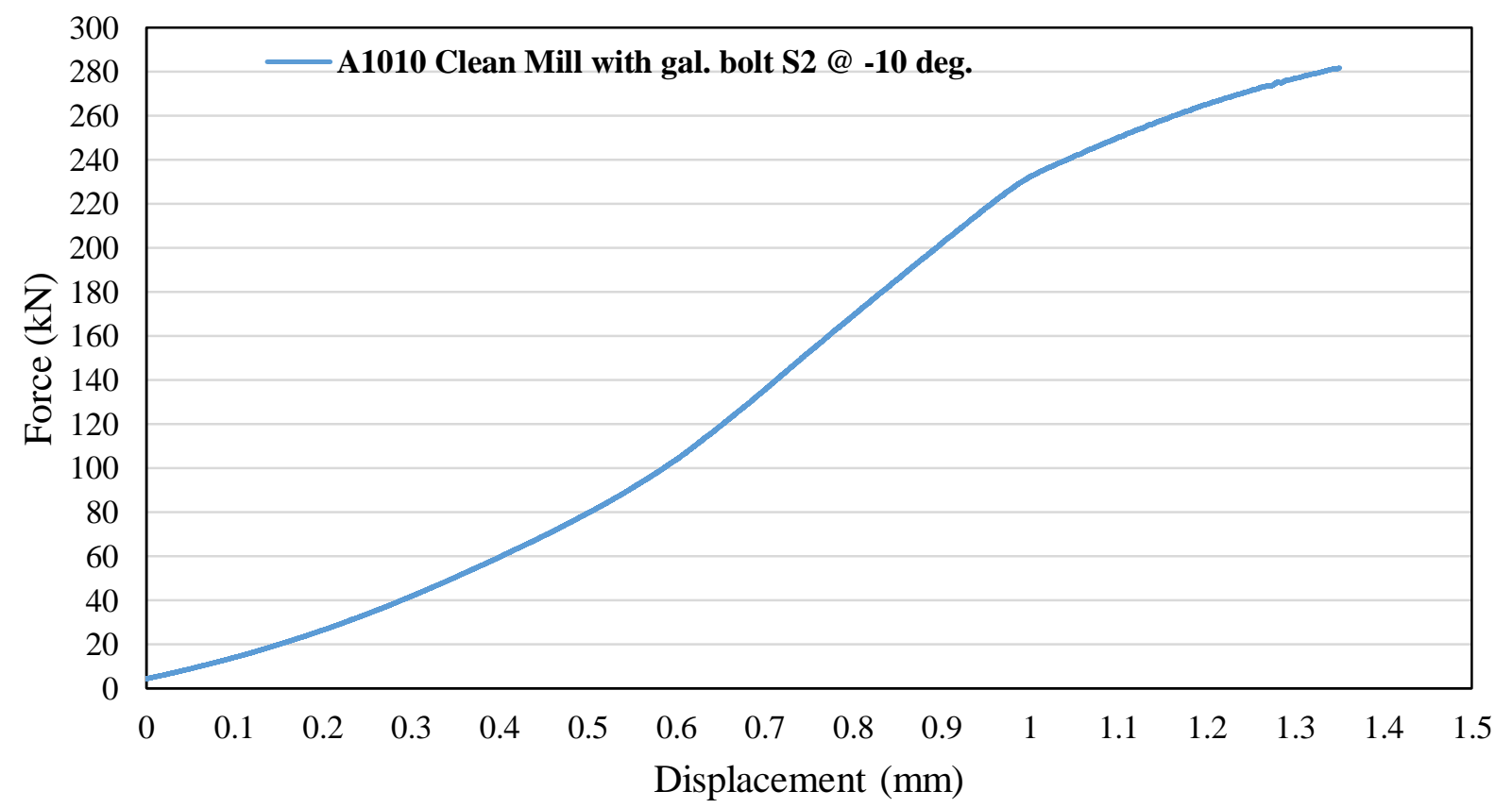

Figure E- 29: Force-displacement relationship for stainless steel with clean mill scale surface condition with galvanized bolt for test specimen 2 at $-10^{\circ} \mathrm{C}$ temperature 


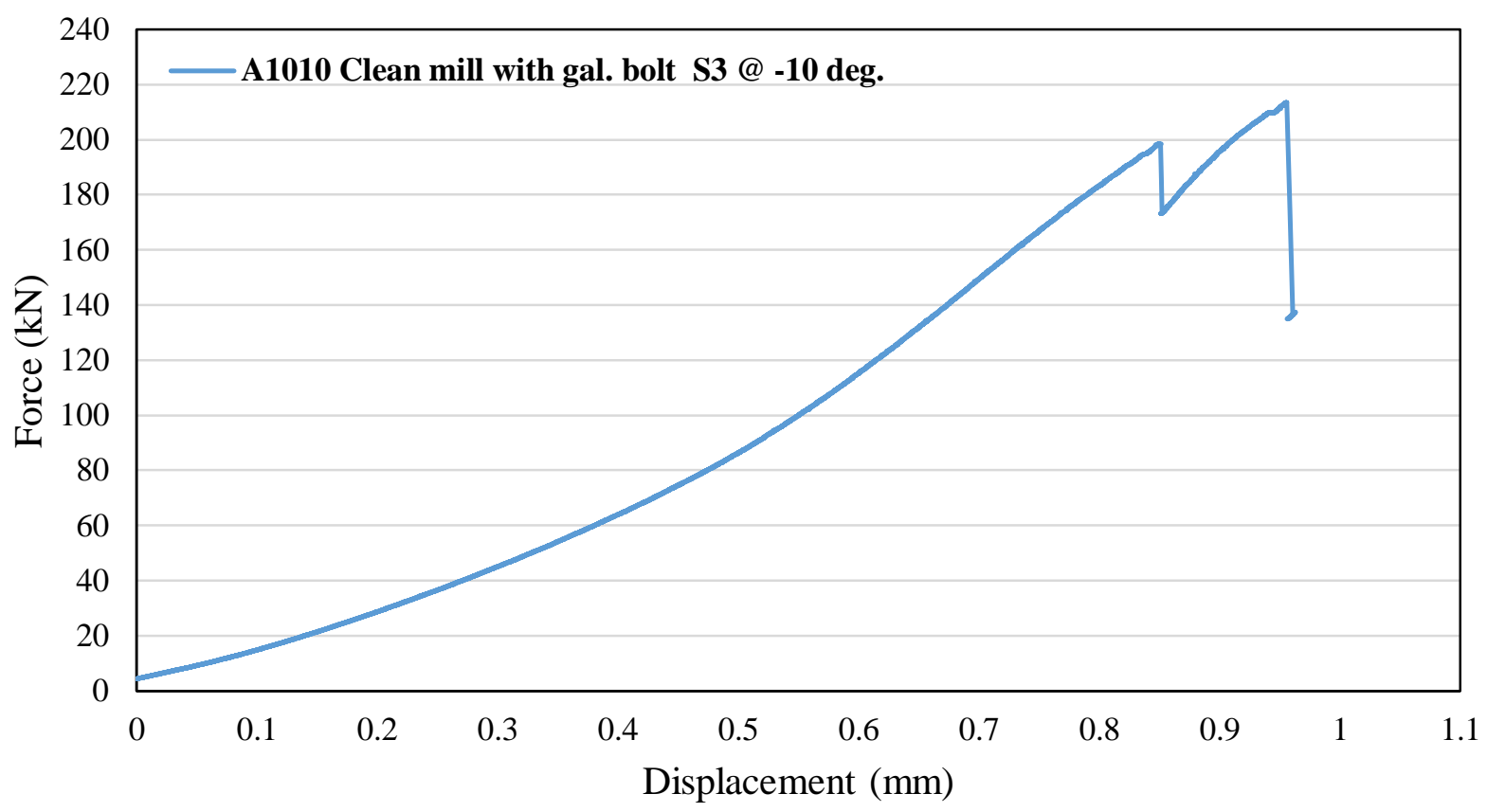

Figure E- 30: Force-displacement for stainless steel with clean mill scale surface condition with galvanized bolt for test specimen 3 at $-10^{\circ} \mathrm{C}$ temperature 
Table E- 2: Recorded plate temperature during slip coefficient testing intended at $-10^{\circ} \mathrm{C}$ temperature monitoring results

\begin{tabular}{|c|c|c|c|c|c|c|c|c|c|c|c|c|c|c|c|}
\hline \multirow[b]{2}{*}{$\begin{array}{c}\text { Slip test plate } \\
\text { thickness = } \\
\text { 5/8" bolt dia. = } \\
7 / 8^{\prime \prime}\end{array}$} & \multirow[b]{2}{*}{$\begin{array}{c}\text { Set } \\
\text { number }\end{array}$} & \multirow[b]{2}{*}{$\begin{array}{c}\text { Test } \\
\text { material }\end{array}$} & \multirow[b]{2}{*}{$\begin{array}{c}\text { Surface type } \\
\text { (class) }\end{array}$} & \multirow[b]{2}{*}{$\begin{array}{c}\text { Sample } \\
\# \\
\end{array}$} & \multirow[b]{2}{*}{$\begin{array}{c}\text { At start } \\
\text { of } \\
\text { testing }\end{array}$} & \multicolumn{10}{|c|}{ Recorded temperature $\left({ }^{0} \mathrm{C}\right)$} \\
\hline & & & & & & 2 mins & 4 mins & $6 \mathrm{mins}$ & 8 mins & 10 mins & 12 mins & 14 mins & 16 mins & $18 \mathrm{mins}$ & 20 mins \\
\hline \multirow{14}{*}{$\begin{array}{l}\text { (using turn-of- } \\
\text { the-nut } \\
\text { method: effect } \\
\text { of temperature } \\
\text { on slip } \\
\text { resistance } \\
\text { determination) }\end{array}$} & \multirow{3}{*}{$1 *$} & \multirow{3}{*}{$\begin{array}{c}\text { Structural } \\
\text { Steel } \\
(350 \mathrm{~W})\end{array}$} & \multirow{3}{*}{$\begin{array}{c}\text { A }(\text { clean mill } \\
\text { scale })\end{array}$} & 1 & -11.4 & -6.0 & -0.2 & 3.9 & 7.8 & 9.9 & 11.9 & 14.0 & 15.7 & 16.3 & 17.6 \\
\hline & & & & 2 & -11.3 & -5.4 & 0.0 & 4.7 & 8.2 & 11.0 & 12.8 & 14.7 & 16.1 & 17.1 & 18.1 \\
\hline & & & & 3 & -11.0 & -5.0 & 1.8 & 6.3 & 9.6 & 12.1 & 13.8 & 15.3 & 16.5 & 17.4 & 18.3 \\
\hline & \multirow{3}{*}{$2 *$} & \multirow{3}{*}{$\begin{array}{c}\text { Structural } \\
\text { Steel } \\
(350 \mathrm{~W})\end{array}$} & \multirow{3}{*}{ B $\begin{array}{l}\text { (Blast - } \\
\text { cleaned) }\end{array}$} & 1 & -11.2 & -5.0 & 2.9 & 6.6 & 10.0 & 12.5 & 14.5 & 16.1 & 17.4 & 18.4 & 19.1 \\
\hline & & & & 2 & -11.1 & -5.7 & 2.1 & 6.8 & 9.6 & 12.2 & 14.7 & 16.2 & 17.3 & 18.3 & 18.9 \\
\hline & & & & 3 & -11.5 & -5.0 & 2.4 & 6.3 & 9.2 & 11.4 & 13.4 & 15.2 & 16.4 & 17.4 & 18.1 \\
\hline & \multirow{3}{*}{$3 * *$} & \multirow{3}{*}{$\begin{array}{c}\text { Structural } \\
\text { Steel } \\
(350 \mathrm{~W})\end{array}$} & \multirow{3}{*}{$\begin{array}{l}\text { C (Hot dip } \\
\text { galvanized } \\
\text { with gal. } \\
\text { bolt) }\end{array}$} & 1 & -11.5 & -5.3 & 2.3 & 6.0 & 9.4 & 11.5 & 13.7 & 14.9 & 15.8 & 17.1 & 18.0 \\
\hline & & & & 2 & -11.3 & -5.1 & 2.5 & 5.9 & 9.1 & 11.4 & 13.1 & 15.4 & 16.7 & 17.6 & 18.4 \\
\hline & & & & 3 & -11.6 & -5.5 & 2.2 & 5.5 & 8.4 & 10.8 & 13.0 & 14.8 & 15.8 & 16.8 & 17.7 \\
\hline & \multirow{2}{*}{$4 * *$} & \multirow{2}{*}{$\begin{array}{c}\text { Stainless } \\
\text { Steel }\end{array}$} & \multirow{2}{*}{$\begin{array}{c}\text { A } \quad \text { (clean mill } \\
\text { scale })\end{array}$} & 1 & -11.4 & -5.6 & 2.7 & 6.7 & 8.8 & 11.1 & 12.7 & 13.9 & 15.1 & 16.1 & 17.1 \\
\hline & & & & 2 & -11.1 & -5.0 & 2.8 & 6.8 & 9.1 & 11.6 & 13.3 & 15.4 & 16.4 & 17.6 & 18.4 \\
\hline & \multirow{3}{*}{$5 * *$} & \multirow{3}{*}{$\begin{array}{c}\text { Stainless } \\
\text { Steel }\end{array}$} & \multirow{3}{*}{$\begin{array}{l}\text { B } \quad \text { (Blast - } \\
\text { cleaned) }\end{array}$} & 1 & -11.3 & -5.1 & 2.9 & 6.9 & 8.7 & 10.7 & 12.3 & 13.8 & 14.9 & 15.7 & 16.3 \\
\hline & & & & 2 & -11.0 & -4.9 & 3.0 & 6.6 & 8.9 & 11.2 & 12.5 & 13.8 & 14.9 & 15.8 & 16.5 \\
\hline & & & & 3 & -11.0 & -4.8 & -3.6 & 7.0 & 9.0 & 11.3 & 13.0 & 14.4 & 15.4 & 16.7 & 17.4 \\
\hline
\end{tabular}

*with A325 bolt

**with galvanized bolt 


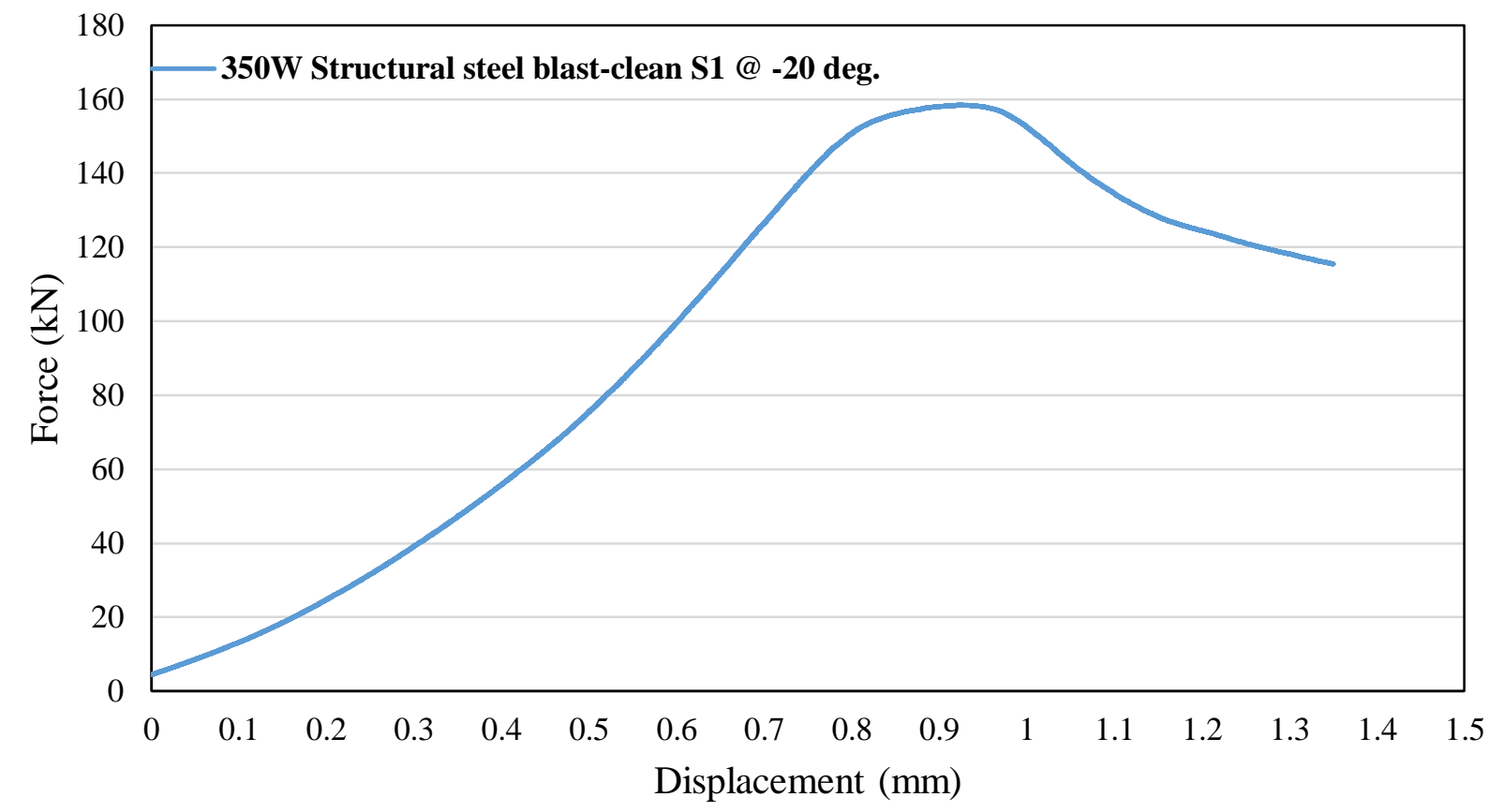

Figure E- 31: Force-displacement relationship for structural steel with blast-clean surface condition with $\mathrm{A325}$ bolt for test specimen 1 at $-20^{\circ} \mathrm{C}$ temperature

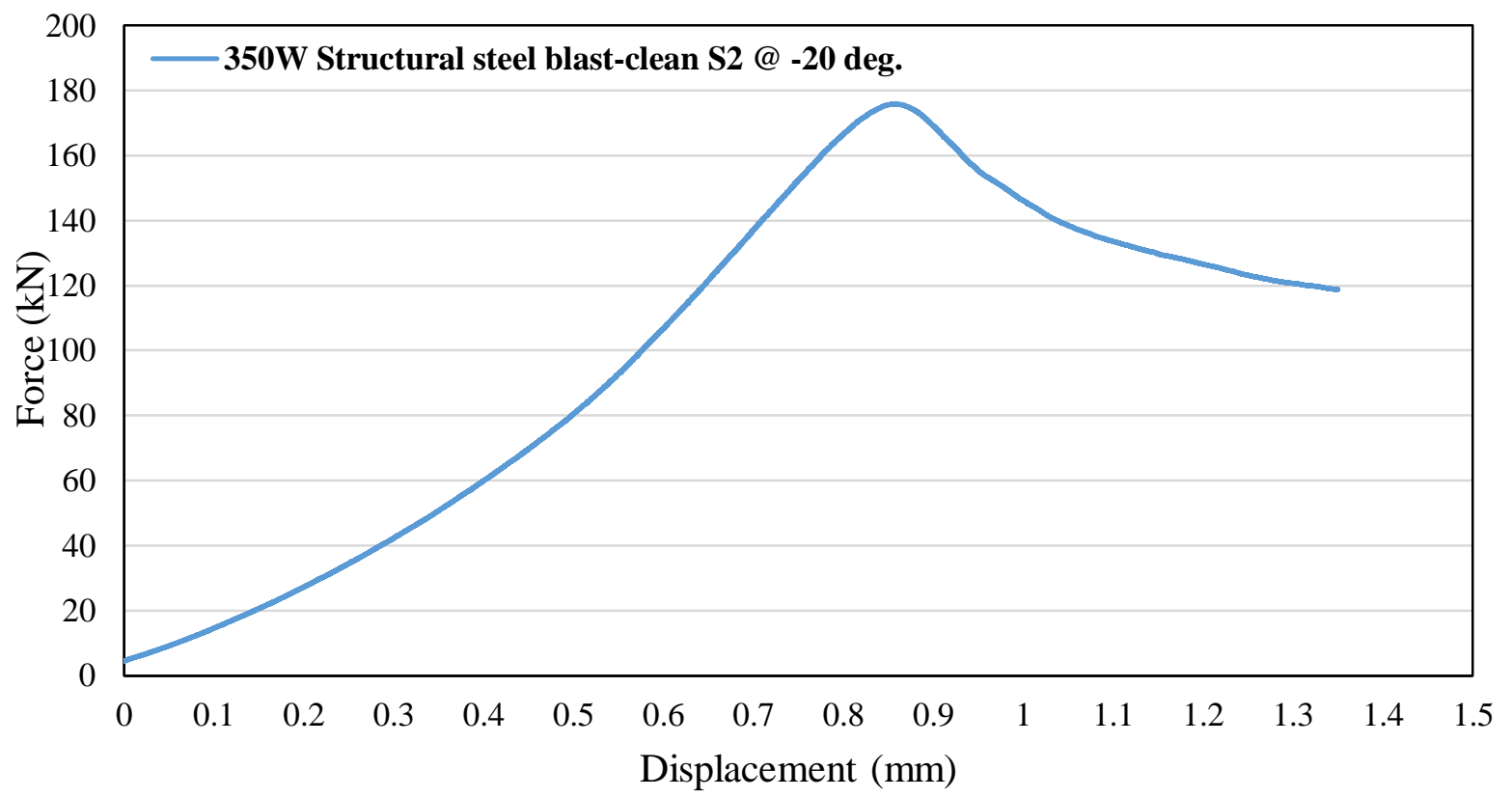

Figure E- 32: Force-displacement relationship for structural steel with blast-clean surface condition with $\mathrm{A325}$ bolt for test specimen 2 at $-20^{\circ} \mathrm{C}$ temperature 


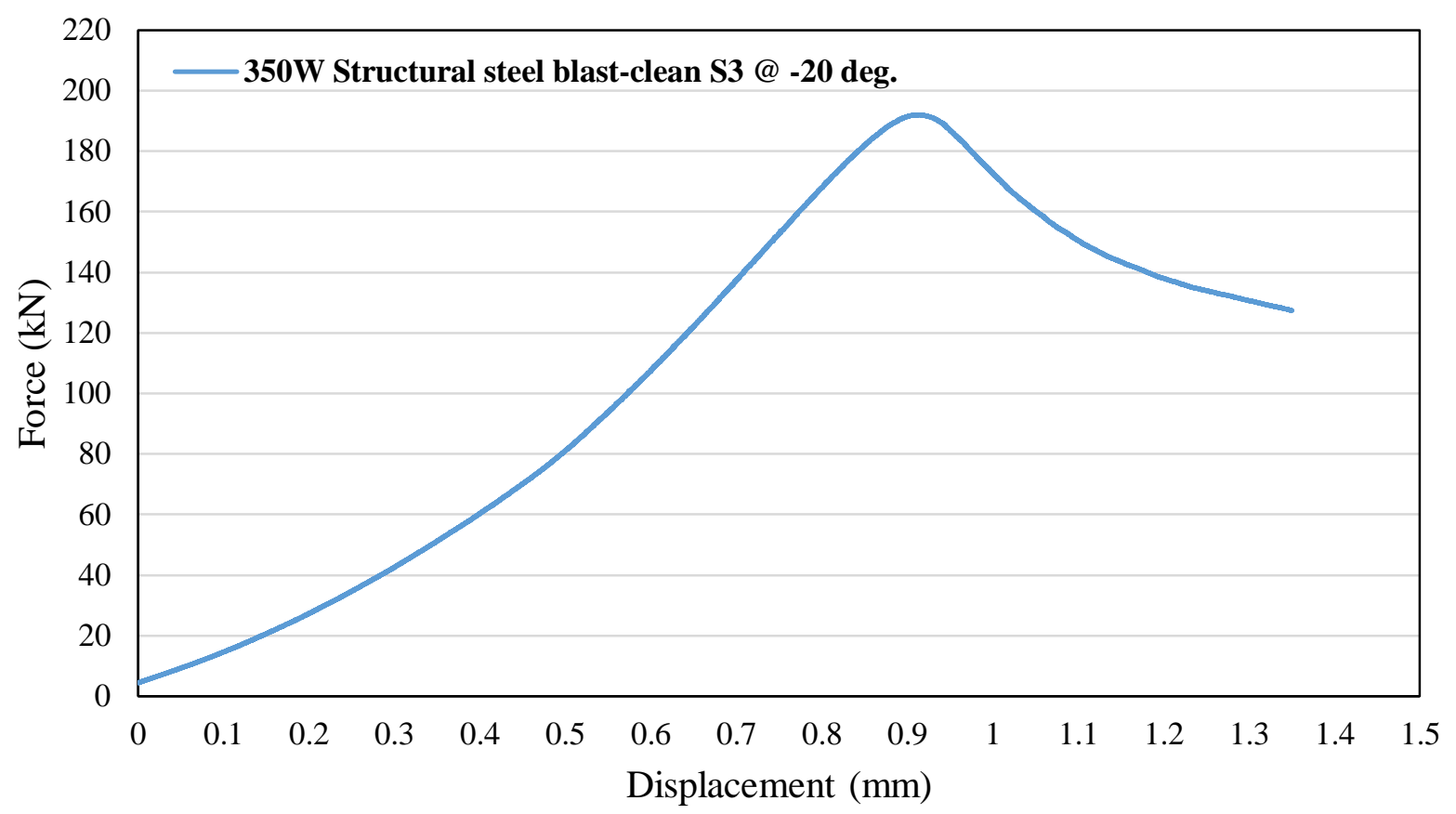

Figure E- 33: Force-displacement relationship for structural steel with blast-clean surface condition with $\mathrm{A325}$ bolt for test specimen 3 at $-\mathbf{2 0} 0^{\circ} \mathrm{C}$ temperature

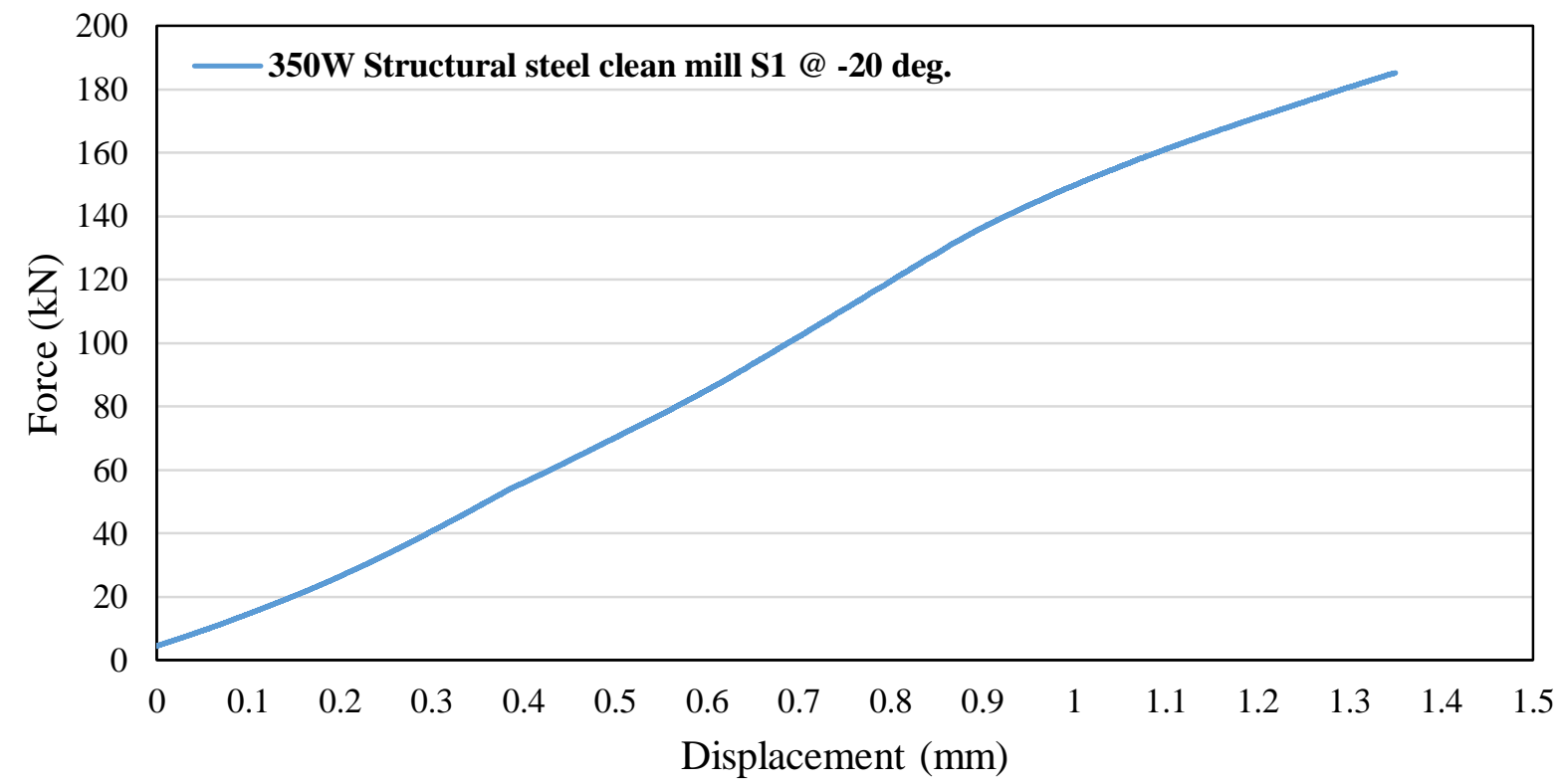

Figure E- 34: Force-displacement relationship for structural steel with clean mill scale surface condition with $\mathrm{A325}$ bolt for test specimen 1 at $-20^{\circ} \mathrm{C}$ temperature 


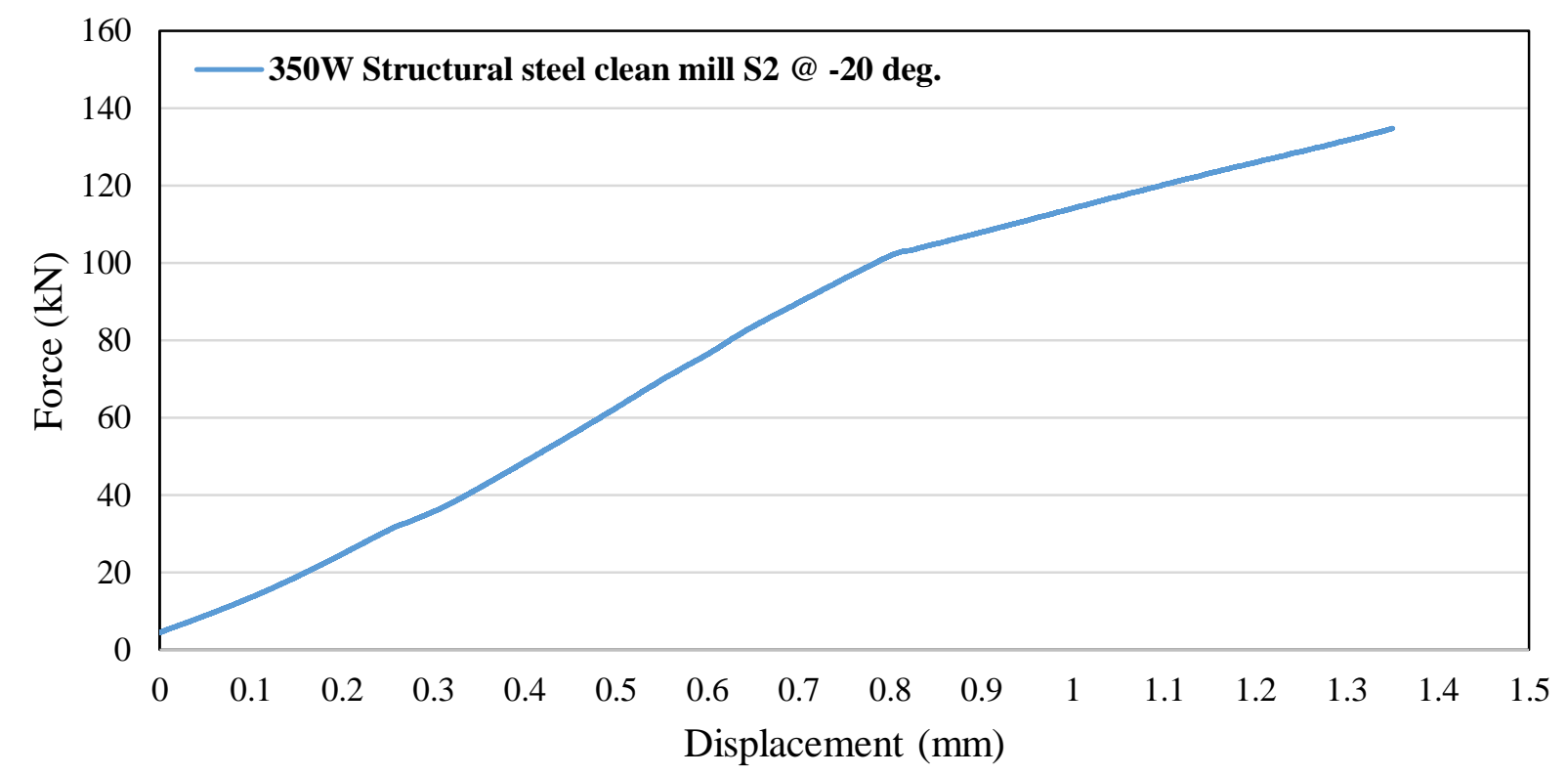

Figure E- 35: Force-displacement relationship for structural steel with clean mill scale surface condition with $\mathrm{A325}$ bolt for test specimen 2 at $-20^{\circ} \mathrm{C}$ temperature

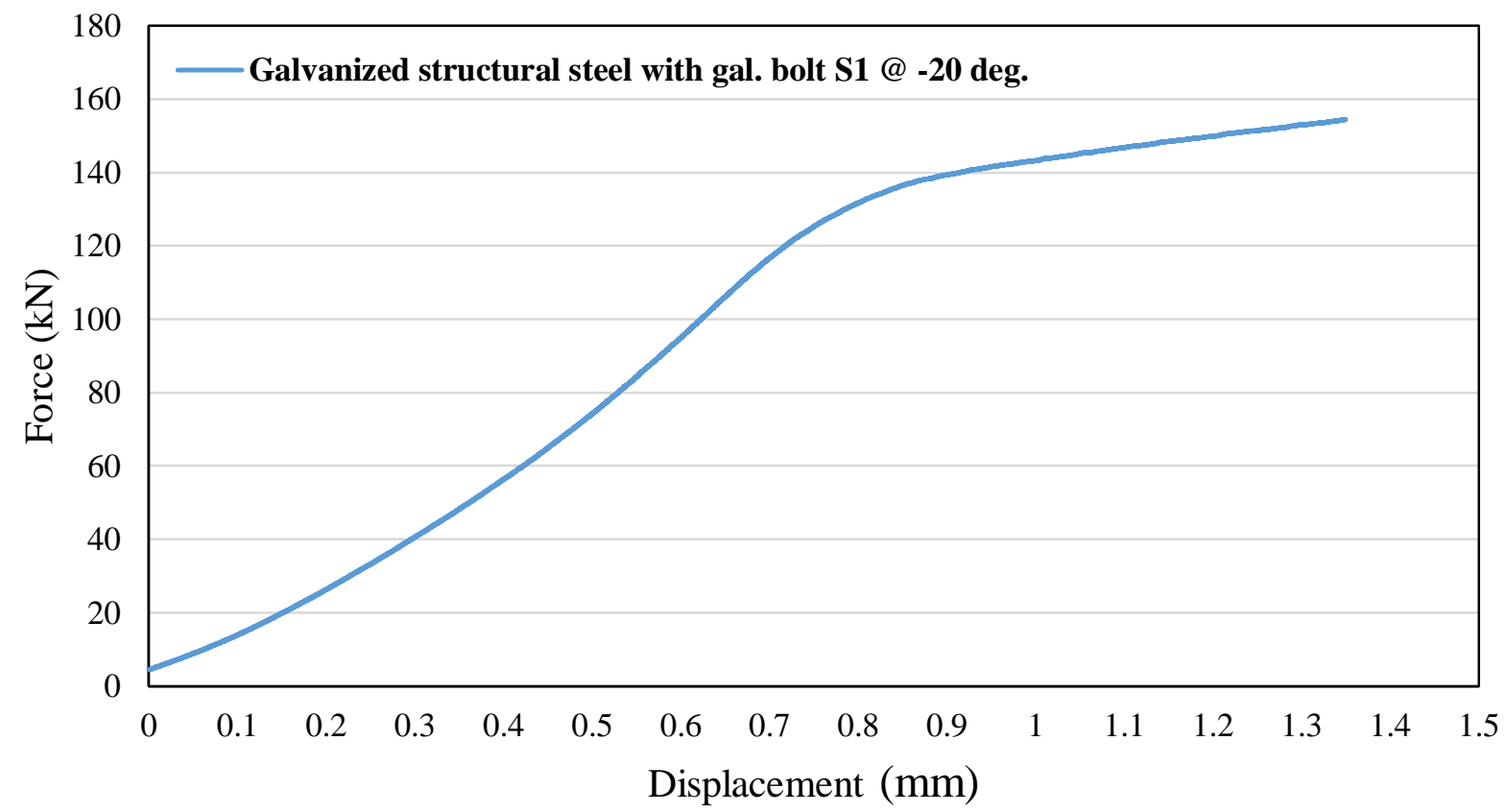

Figure E- 36: Force-displacement relationship for structural steel with hot dip galvanized surface condition with galvanized bolt for test specimen 1 at $-20^{\circ} \mathrm{C}$ temperature 


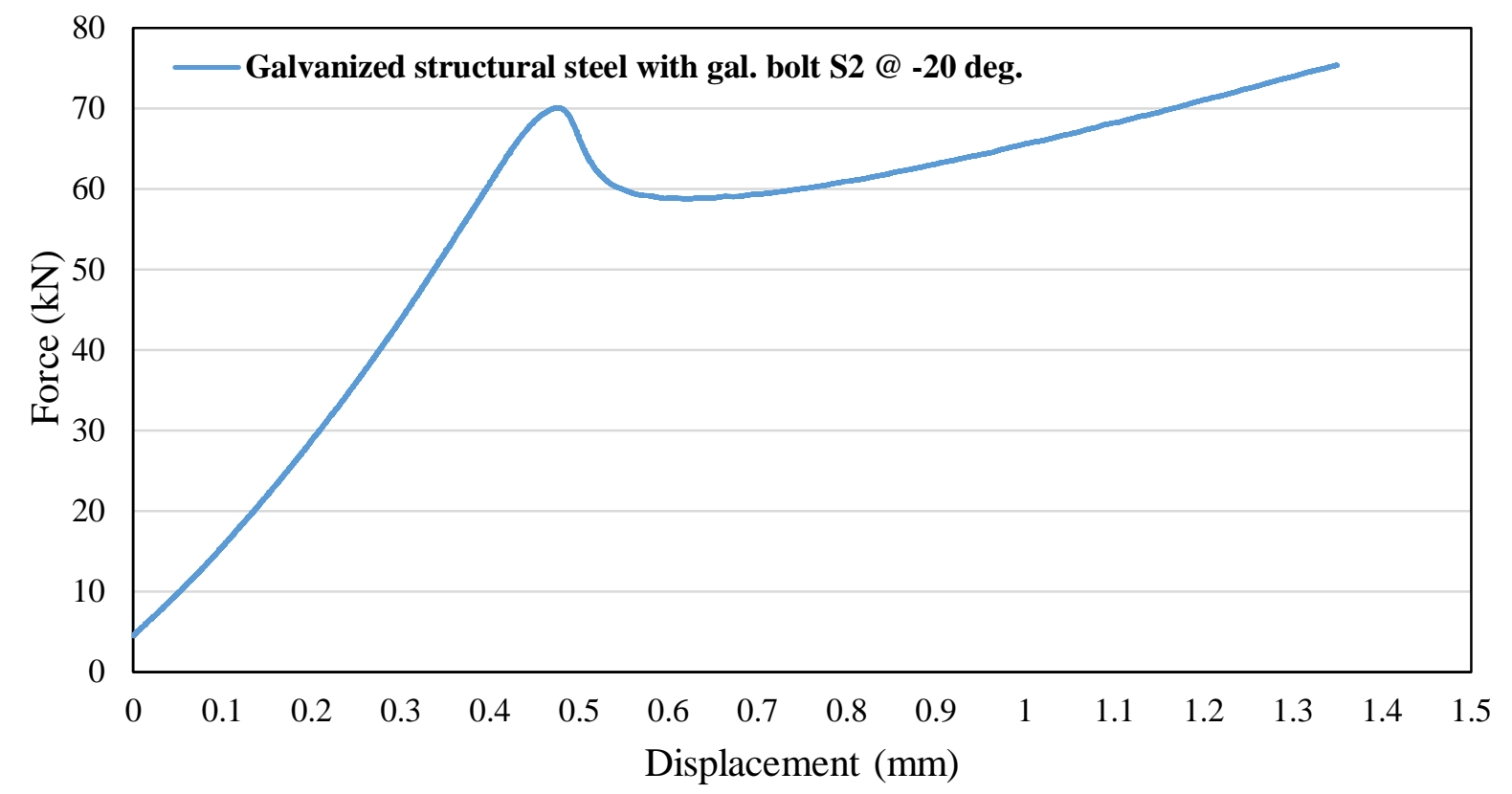

Figure E- 37: Force-displacement relationship for structural steel with hot dip galvanized surface condition with galvanized bolt for test specimen 2 at $-20^{\circ} \mathrm{C}$ temperature

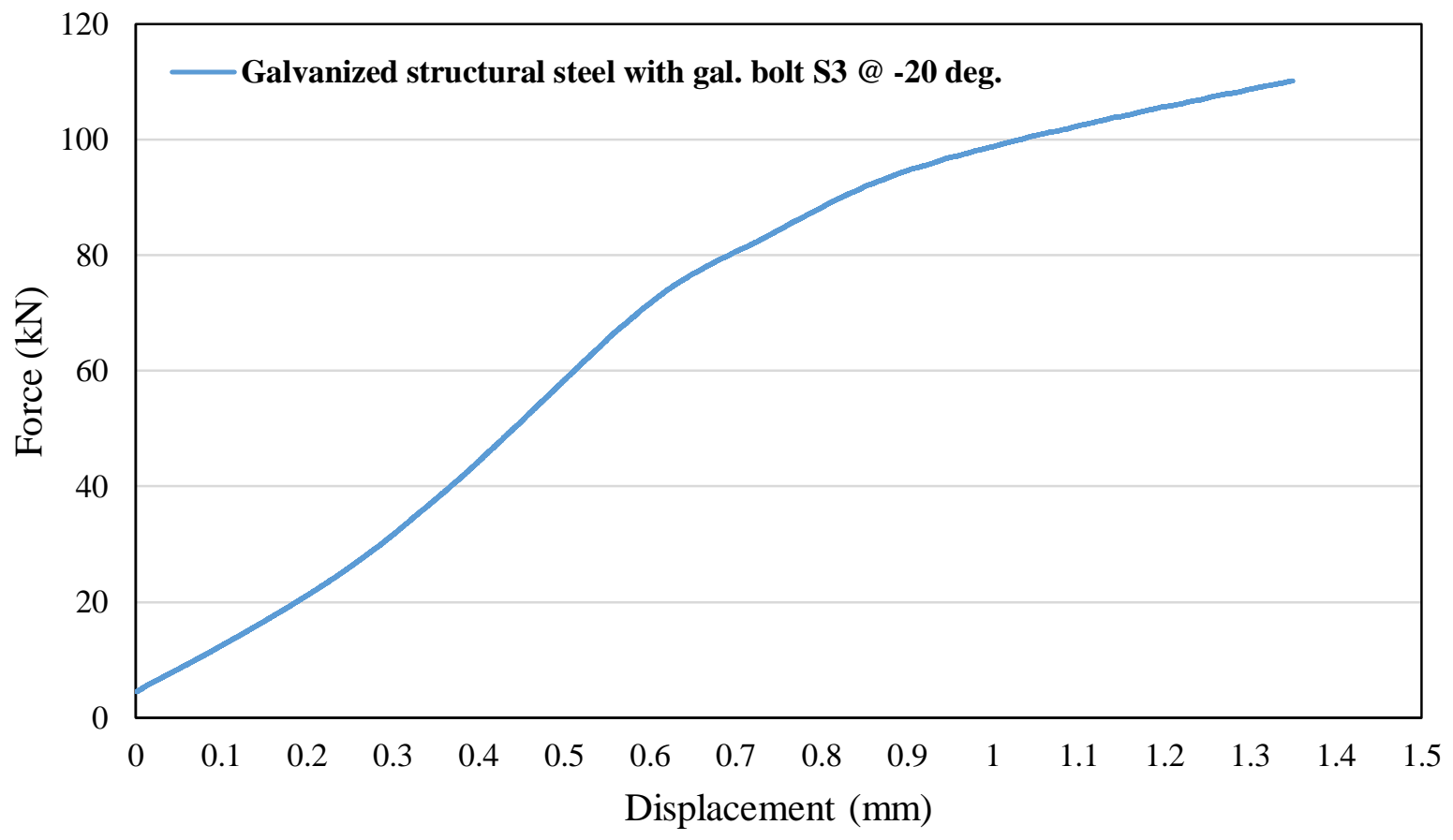

Figure E- 38: Force-displacement relationship for structural steel with hot dip galvanized surface condition with galvanized bolt for test specimen 3 at $-20^{\circ} \mathrm{C}$ temperature 


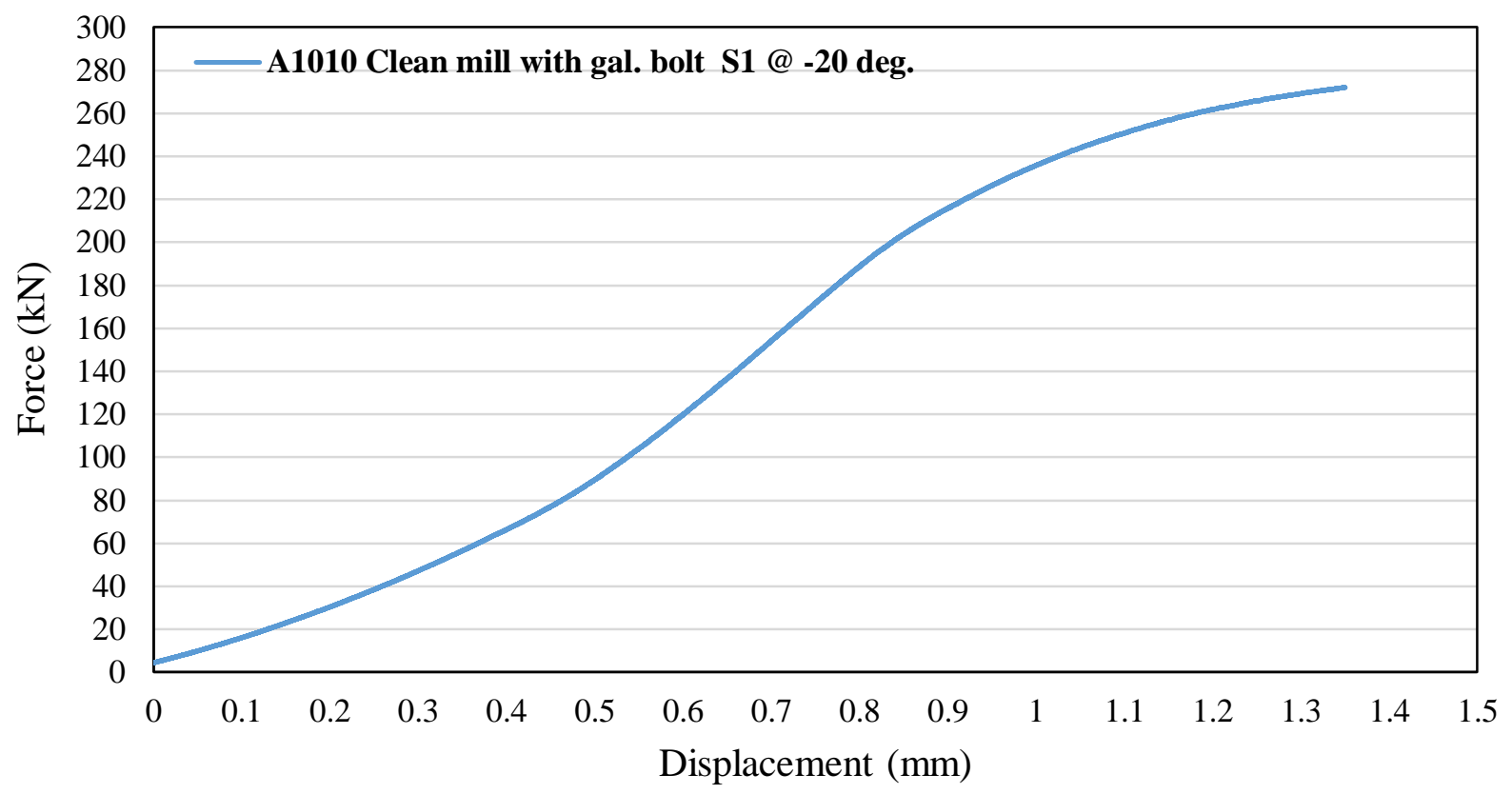

Figure E- 39: Force-displacement relationship for A1010 stainless steel with clean mill scale surface condition with galvanized bolt for test specimen 1 at $-20^{\circ} \mathrm{C}$ temperature

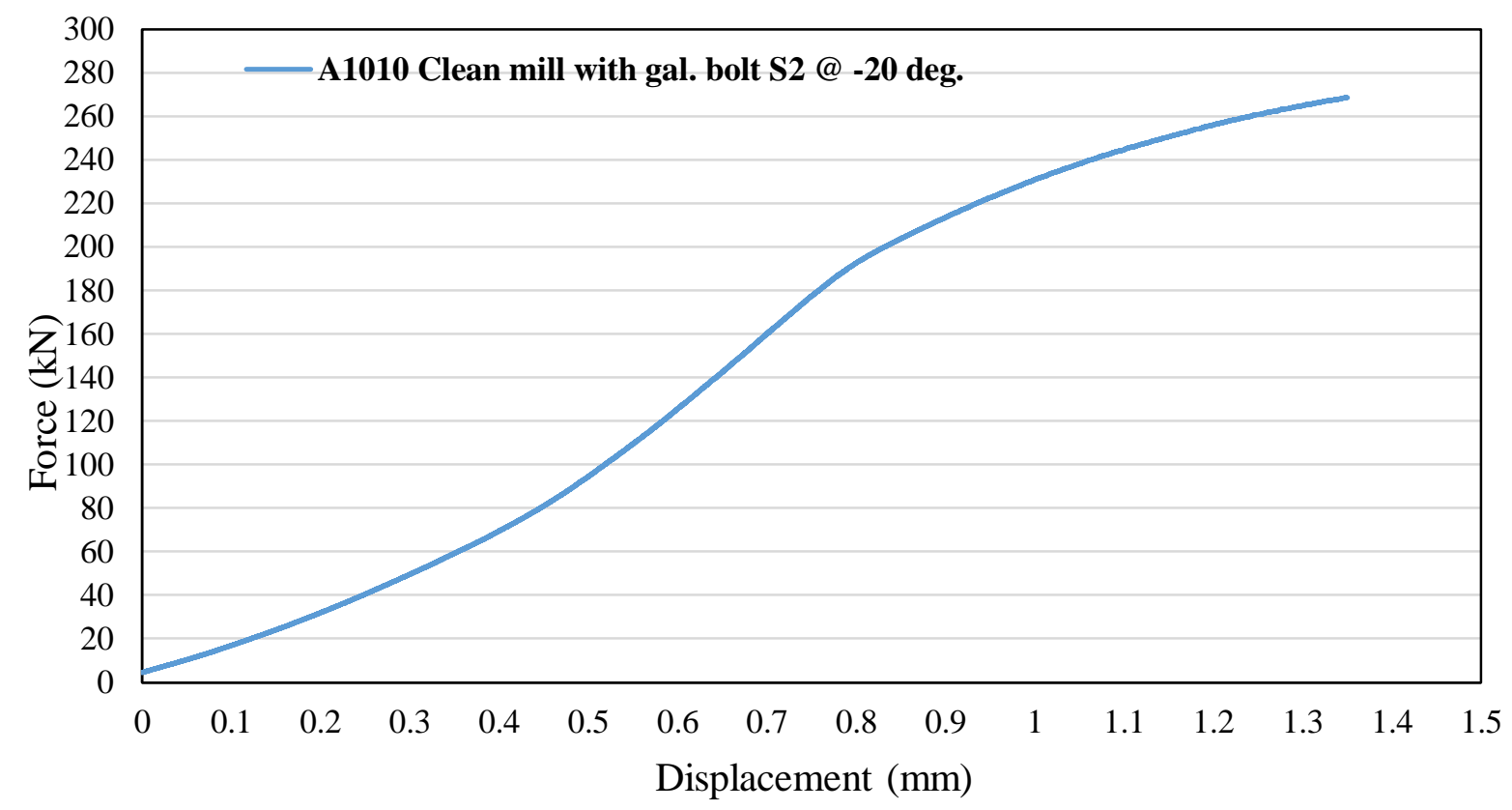

Figure E- 40: Force-displacement relationship for A1010 stainless steel with clean mill scale surface condition with galvanized bolt for test specimen 2 at $-20^{\circ} \mathrm{C}$ temperature 


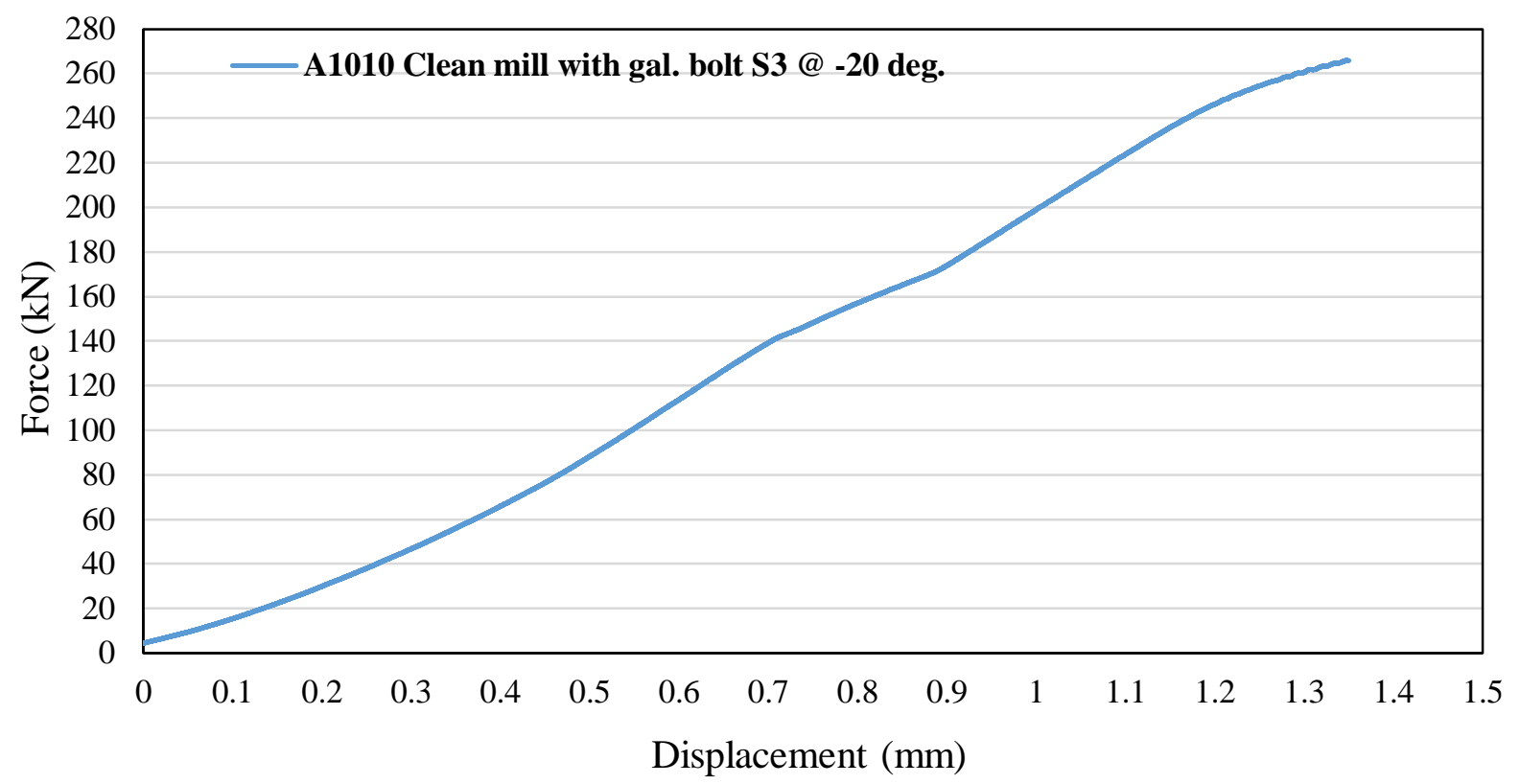

Figure E- 41: Force-displacement relationship for A1010 stainless steel with clean mill scale surface condition with galvanized bolt for test specimen 3 at $-20^{\circ} \mathrm{C}$ temperature

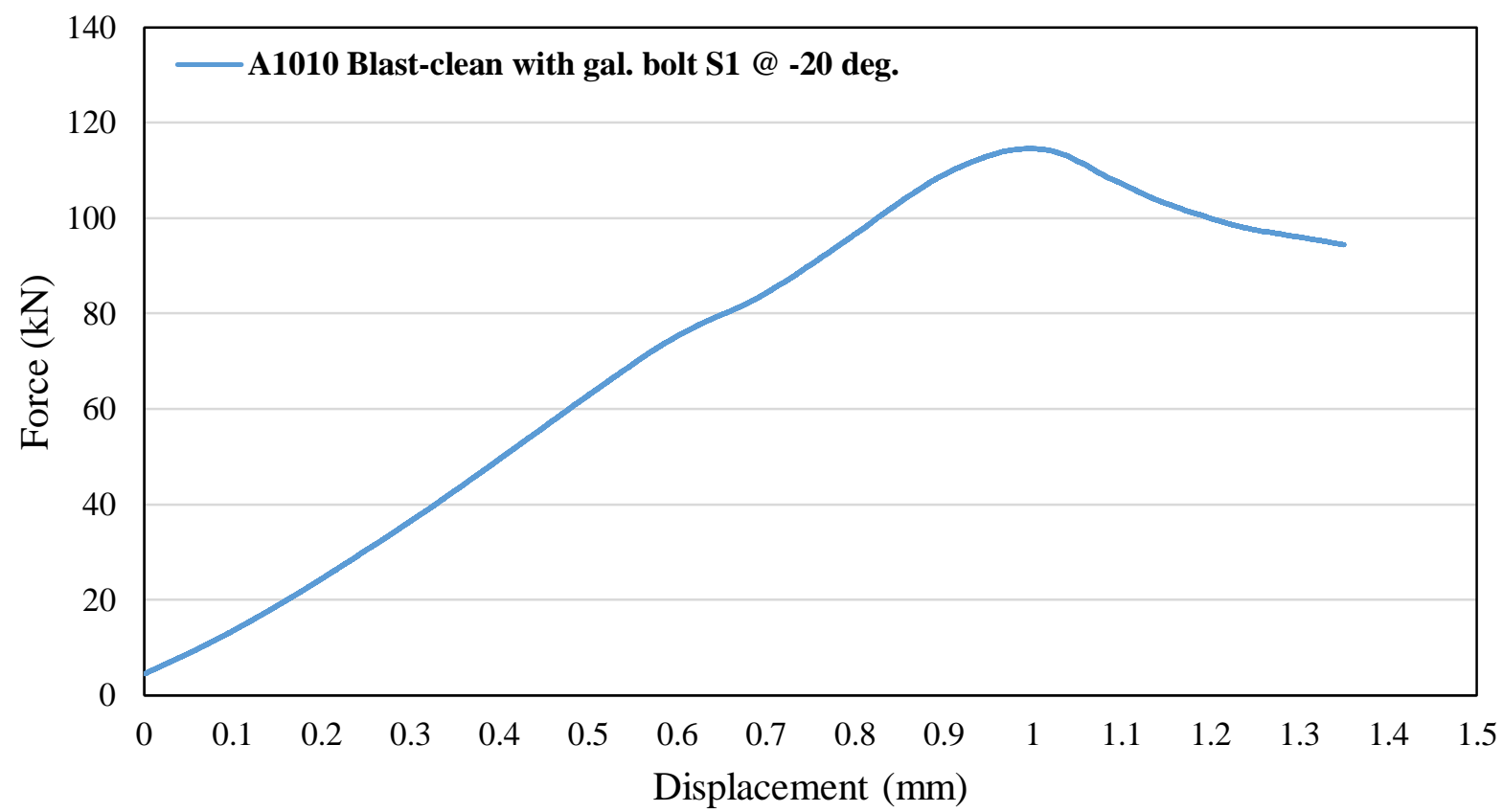

Figure E- 42: Force-displacement relationship for A1010 stainless steel with blasted clean surface condition with galvanized bolt for test specimen 1 at $-20^{\circ} \mathrm{C}$ temperature 


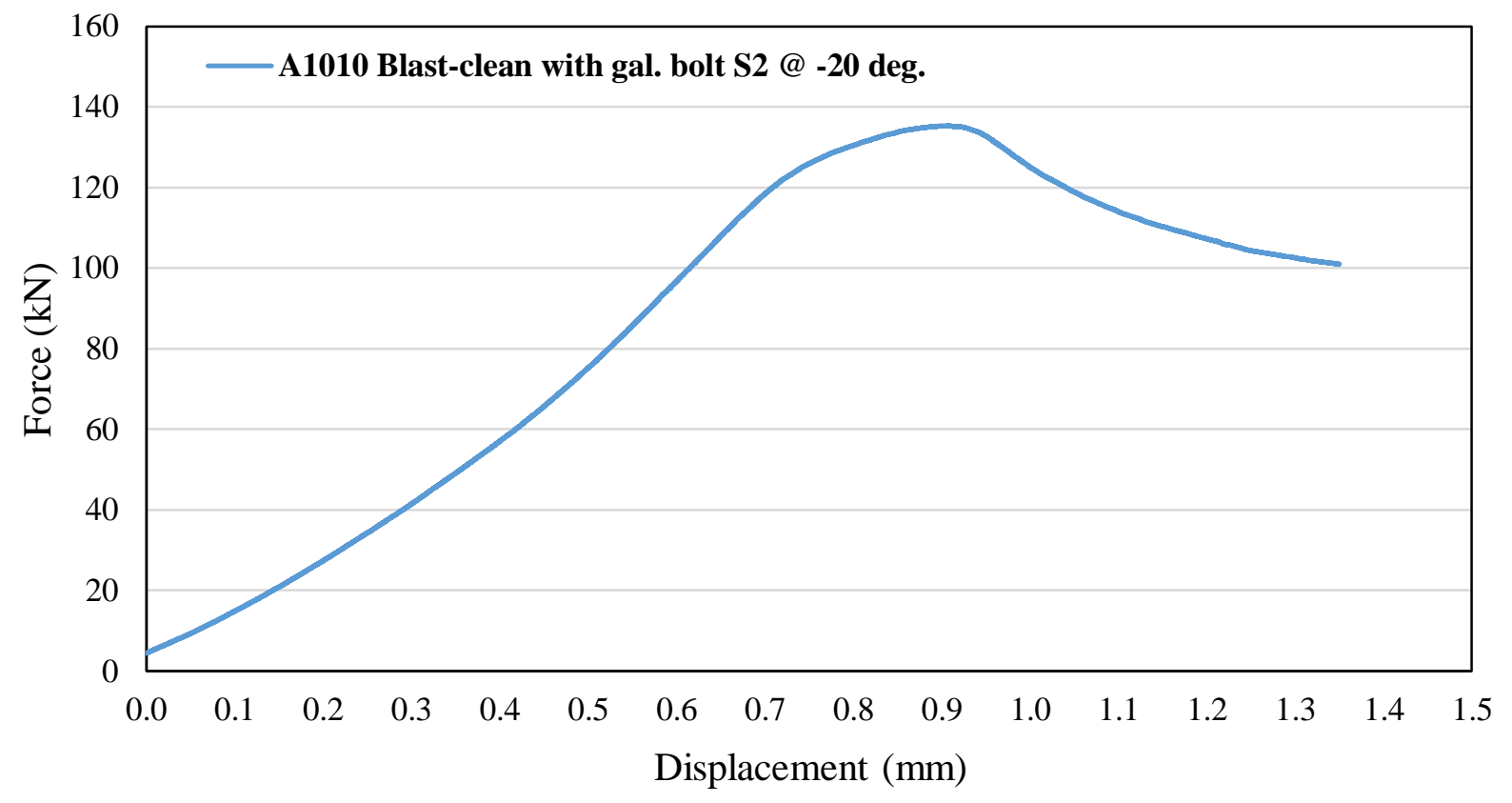

Figure E- 43: Force-displacement relationship for A1010 stainless steel with blasted clean surface condition with galvanized bolt for test specimen 2 at $-20^{\circ} \mathrm{C}$ temperature

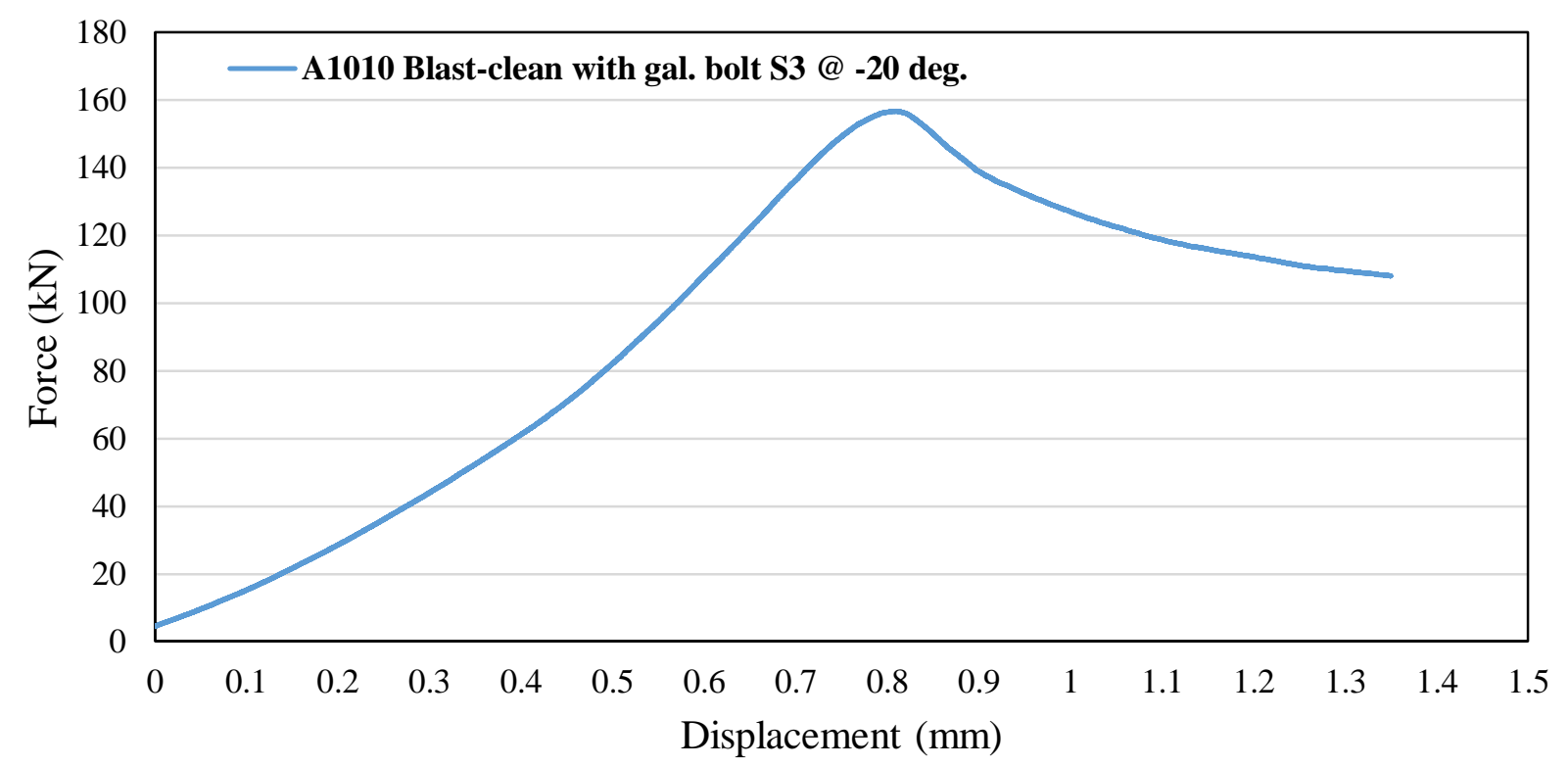

Figure E- 44: Force-displacement relationship for A1010 stainless steel with blasted clean surface condition with galvanized bolt for test specimen 3 at $-20^{\circ} \mathrm{C}$ temperature 
Table E- 3: Recorded plate temperature during slip coefficient testing intended at $-20^{\circ} \mathrm{C}$ temperature monitoring results

\begin{tabular}{|c|c|c|c|c|c|c|c|c|c|c|c|c|c|c|c|}
\hline \multirow[b]{2}{*}{$\begin{array}{c}\text { Slip test plate } \\
\text { thickness }= \\
5 / 8^{\prime \prime} \text { bolt dia. }= \\
7 / 8^{\prime \prime}\end{array}$} & \multirow[b]{2}{*}{$\begin{array}{c}\text { Set } \\
\text { number }\end{array}$} & \multirow[b]{2}{*}{$\begin{array}{c}\text { Test } \\
\text { material }\end{array}$} & \multirow[b]{2}{*}{$\begin{array}{c}\text { Surface type } \\
\text { (class) }\end{array}$} & \multirow[b]{2}{*}{$\begin{array}{c}\text { Sample } \\
\#\end{array}$} & \multirow[b]{2}{*}{$\begin{array}{c}\text { At start } \\
\text { of } \\
\text { testing }\end{array}$} & \multicolumn{10}{|c|}{ Recorded temperature $\left({ }^{0} \mathrm{C}\right)$} \\
\hline & & & & & & 2 mins & $4 \mathrm{mins}$ & $6 \mathrm{mins}$ & 8 mins & 10 mins & 12 mins & 14 mins & 16 mins & 18 mins & 20 mins \\
\hline \multirow{14}{*}{$\begin{array}{l}\text { (using turn-of- } \\
\text { the-nut } \\
\text { method: effect } \\
\text { of temperature } \\
\text { on slip } \\
\text { resistance } \\
\text { determination) }\end{array}$} & \multirow{2}{*}{$1 *$} & \multirow{2}{*}{$\begin{array}{c}\text { Structural } \\
\text { Steel } \\
(350 \mathrm{~W})\end{array}$} & \multirow{2}{*}{$\begin{array}{c}\text { A } \begin{array}{c}\text { (clean mill } \\
\text { scale })\end{array} \\
\end{array}$} & 1 & -21.9 & -10.4 & -3.0 & 3.0 & 4.8 & 7.7 & 12.1 & 14.4 & 15.2 & 15.9 & 17.4 \\
\hline & & & & 2 & -22.1 & -10.0 & -3.2 & 2.8 & 4.6 & 7.8 & 11.0 & 12.6 & 14.5 & 16.0 & 17.2 \\
\hline & \multirow{3}{*}{$2 *$} & \multirow{3}{*}{$\begin{array}{c}\text { Structural } \\
\text { Steel } \\
(350 \mathrm{~W})\end{array}$} & \multirow{3}{*}{$\begin{array}{l}\text { B (Blast - } \\
\text { cleaned) }\end{array}$} & 1 & -22.5 & -7.8 & -1.1 & 4.6 & 8.2 & 11.2 & 13.6 & 15.4 & 16.8 & 17.6 & 18.3 \\
\hline & & & & 2 & -23.2 & -7.6 & -2.2 & 3.5 & 7.7 & 10.8 & 12.7 & 14.6 & 16.0 & 17.0 & 17.8 \\
\hline & & & & 3 & -23.0 & -12.1 & -4.5 & 1.6 & 6.2 & 9.1 & 11.8 & 14.0 & 15.4 & 16.3 & 17.3 \\
\hline & \multirow{3}{*}{$3 * *$} & \multirow{3}{*}{$\begin{array}{c}\text { Structural } \\
\text { Steel } \\
(350 \mathrm{~W})\end{array}$} & \multirow{3}{*}{\begin{tabular}{|}
$\mathrm{C}$ (Hot-Dip \\
galvanized \\
with gal. \\
bolt $)$
\end{tabular}} & 1 & -22.6 & -12.3 & -4.4 & 1.6 & 6.1 & 9.1 & 11.6 & 13.7 & 15.1 & 16.2 & 17.1 \\
\hline & & & & 2 & -21.5 & -10.3 & -2.7 & 2.6 & 6.9 & 9.3 & 11.4 & 13.1 & 14.5 & 15.6 & 16.6 \\
\hline & & & & 3 & -23.7 & -18.2 & -11.8 & -5.3 & 1.1 & 5.5 & 8.8 & 11.9 & 13.9 & 15.3 & 16.3 \\
\hline & \multirow{3}{*}{$4 * *$} & \multirow{3}{*}{$\begin{array}{c}\text { Stainless } \\
\text { Steel }\end{array}$} & \multirow{3}{*}{$\begin{array}{c}\text { A } \begin{array}{c}\text { (clean mill } \\
\text { scale })\end{array} \\
\text { a }\end{array}$} & 1 & -20.1 & -17.6 & -7.1 & -0.9 & 4.1 & 6.8 & 9.5 & 11.6 & 13.2 & 14.7 & 15.7 \\
\hline & & & & 2 & -21.3 & -17.7 & -6.3 & 2.1 & 6.0 & 8.4 & 11.0 & 12.9 & 14.6 & 15.7 & 16.6 \\
\hline & & & & 3 & -20.0 & -13.3 & -5.9 & 1.4 & 5.1 & 7.4 & 9.7 & 11.6 & 13.2 & 14.5 & 15.6 \\
\hline & \multirow{3}{*}{5} & \multirow{3}{*}{$\begin{array}{c}\text { Stainless } \\
\text { Steel }\end{array}$} & \multirow{3}{*}{$\begin{array}{l}\text { B } \quad \text { (Blast - } \\
\text { cleaned) }\end{array}$} & 1 & -21.2 & -12.8 & -2.3 & 3.1 & 6.0 & 8.6 & 10.6 & 12.4 & 13.9 & 15.1 & 15.8 \\
\hline & & & & 2 & -20.6 & -10.1 & -1.7 & 4.8 & 6.4 & 8.8 & 10.9 & 12.9 & 14.4 & 15.6 & 16.5 \\
\hline & & & & 3 & -20.7 & -10.3 & -1.3 & 4.6 & 6.1 & 8.4 & 10.4 & 12.6 & 14.3 & 15.3 & 15.9 \\
\hline
\end{tabular}

*with A325 bolt

**with galvanized bolt 


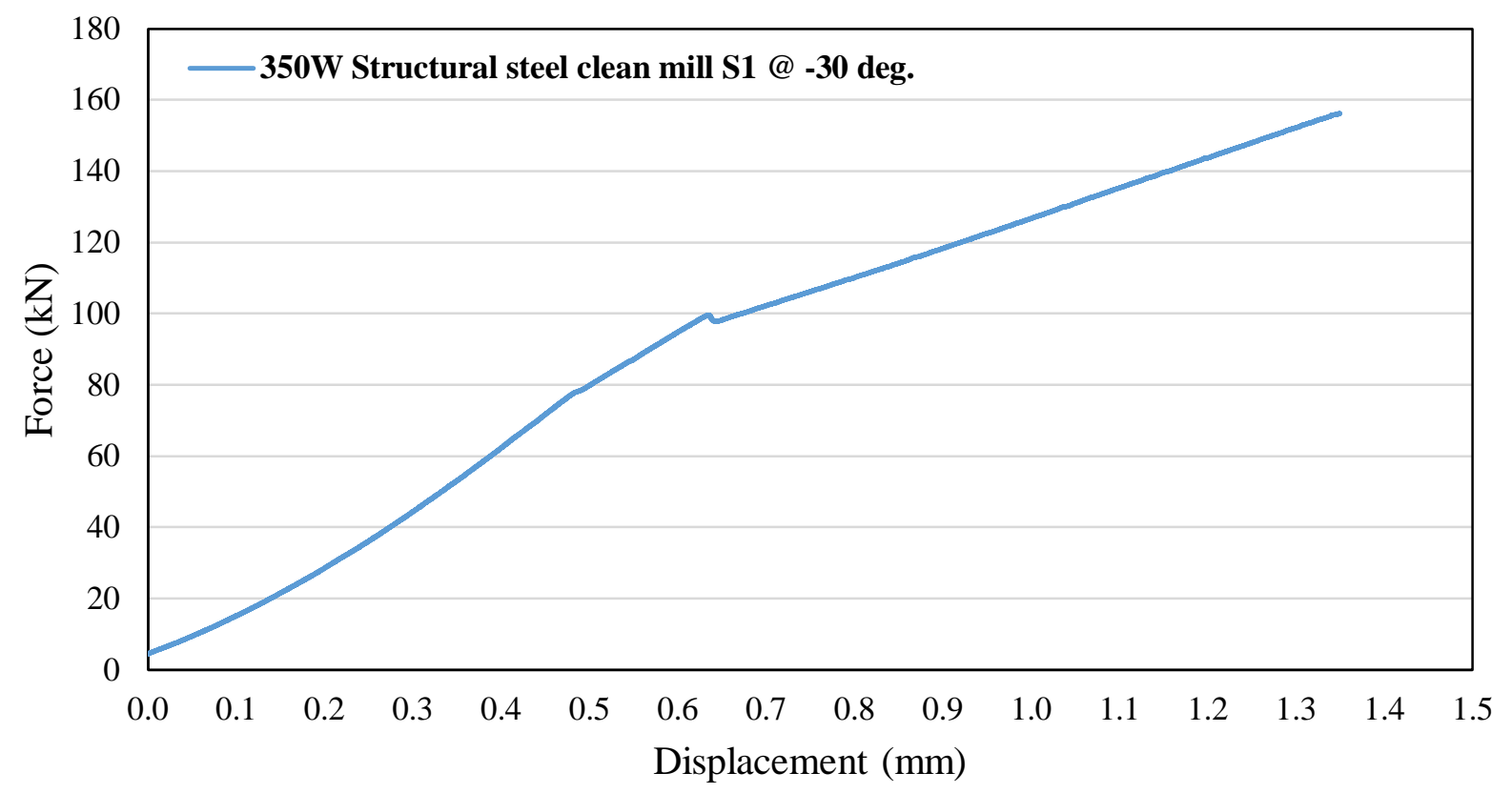

Figure E- 45: Force-displacement relationship for structural steel with clean mill scale surface condition with $\mathrm{A325}$ bolt for test specimen 1 at $-30^{\circ} \mathrm{C}$ temperature

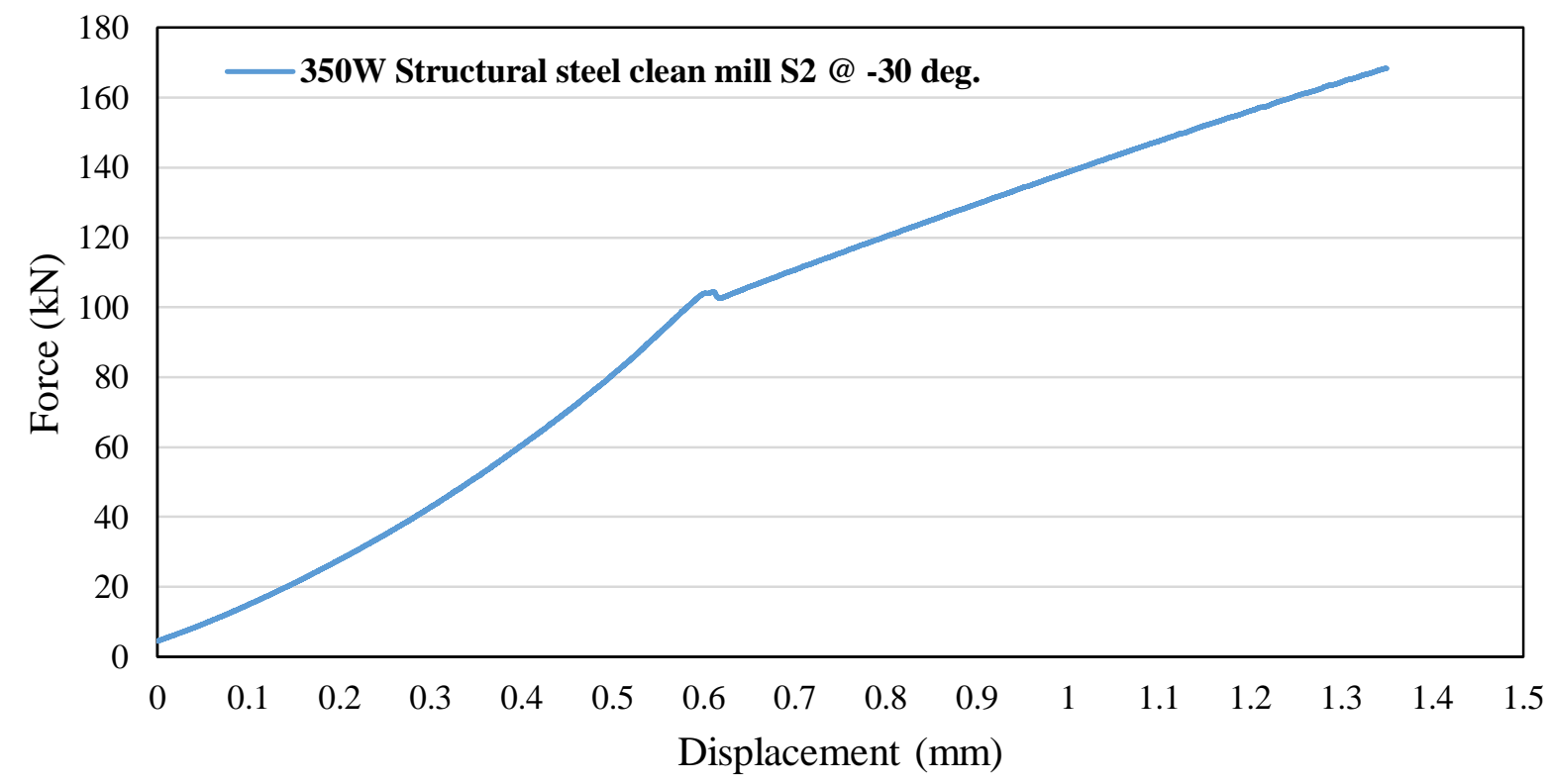

Figure E- 46: Force-displacement relationship for structural steel with clean mill scale surface condition with $\mathrm{A325}$ bolt for test specimen 2 at $-30^{\circ} \mathrm{C}$ temperature 


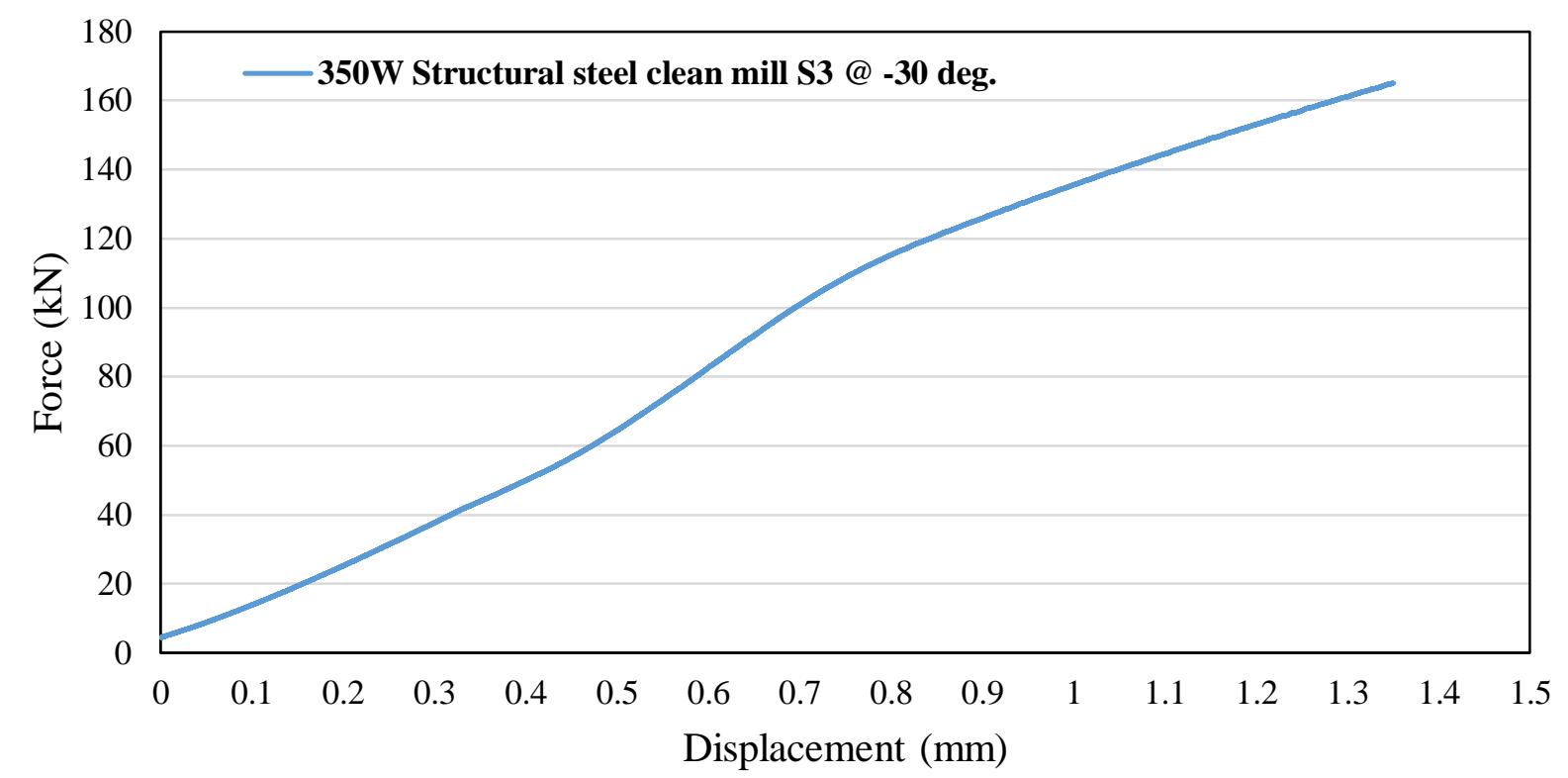

Figure E- 47: Force-displacement relationship for structural steel with clean mill scale surface condition with $\mathrm{A} 325$ bolt for test specimen 3 at $-30^{\circ} \mathrm{C}$ temperature

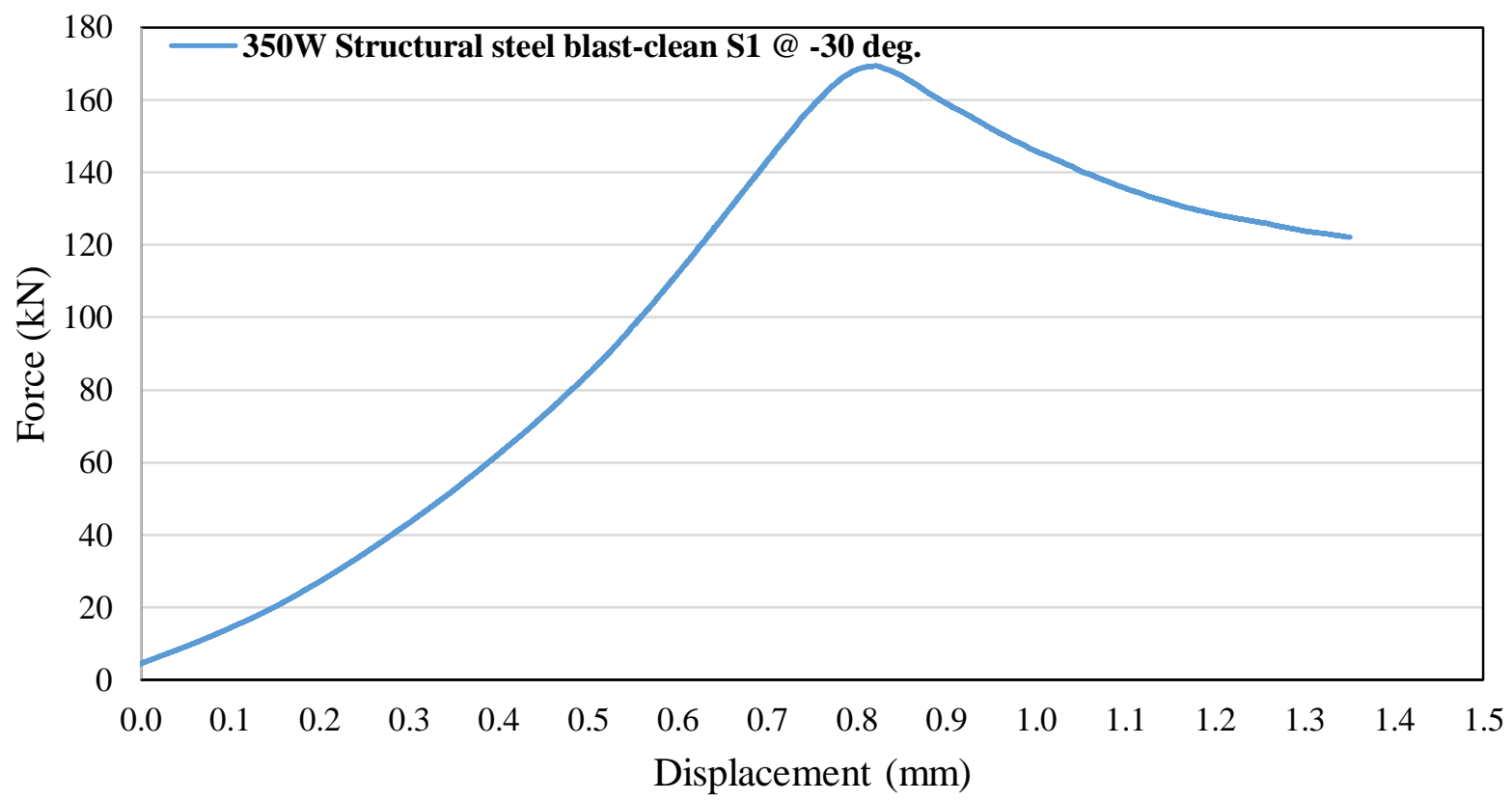

Figure E- 48: Force-displacement relationship for structural steel with blast-clean surface condition with $\mathrm{A325}$ bolt for test specimen 1 at $-30^{\circ} \mathrm{C}$ temperature 


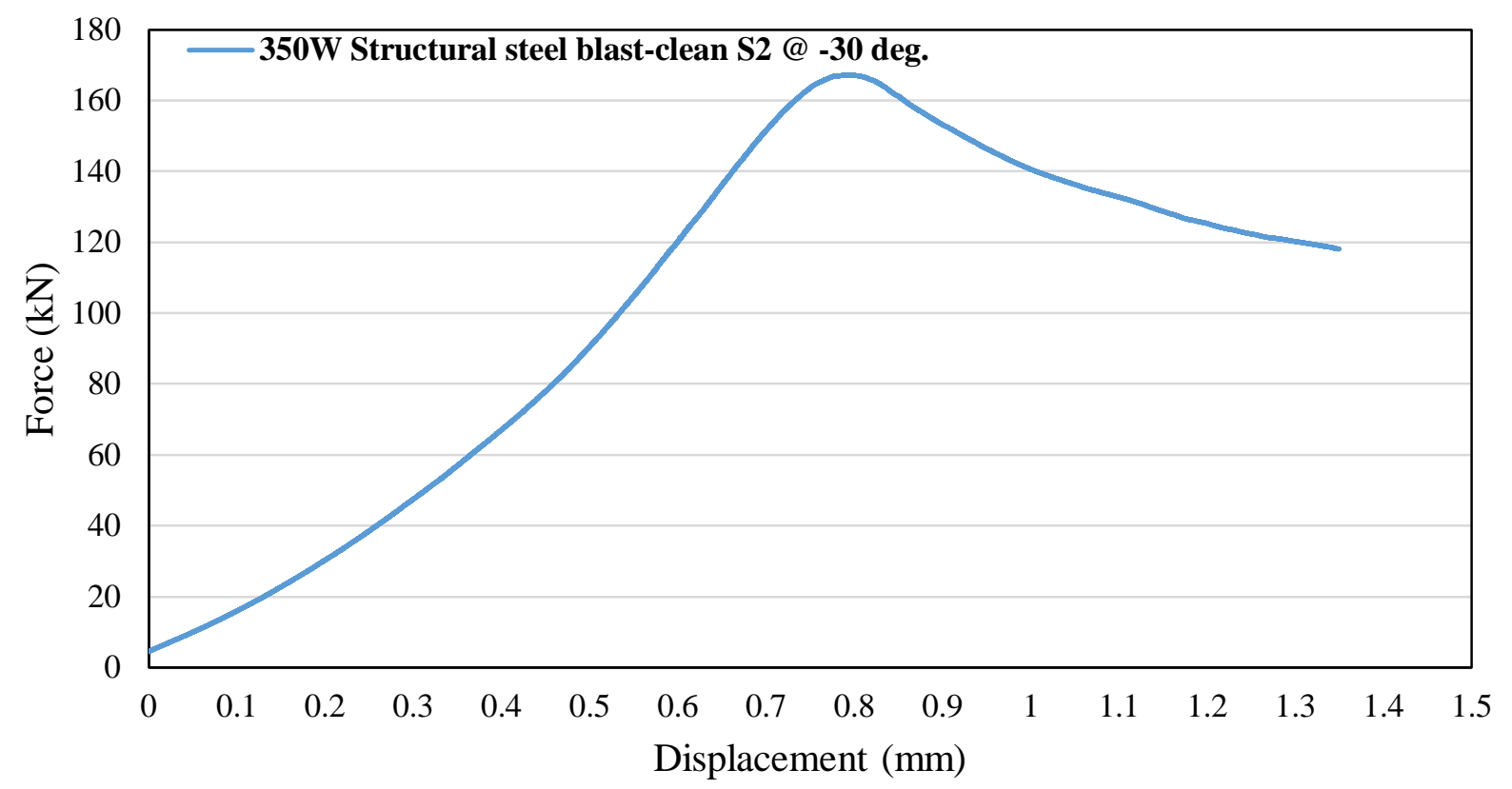

Figure E- 49: Force-displacement relationship for structural steel with blast-clean surface condition with $\mathrm{A325}$ bolt for test specimen 2 at $-30^{\circ} \mathrm{C}$ temperature

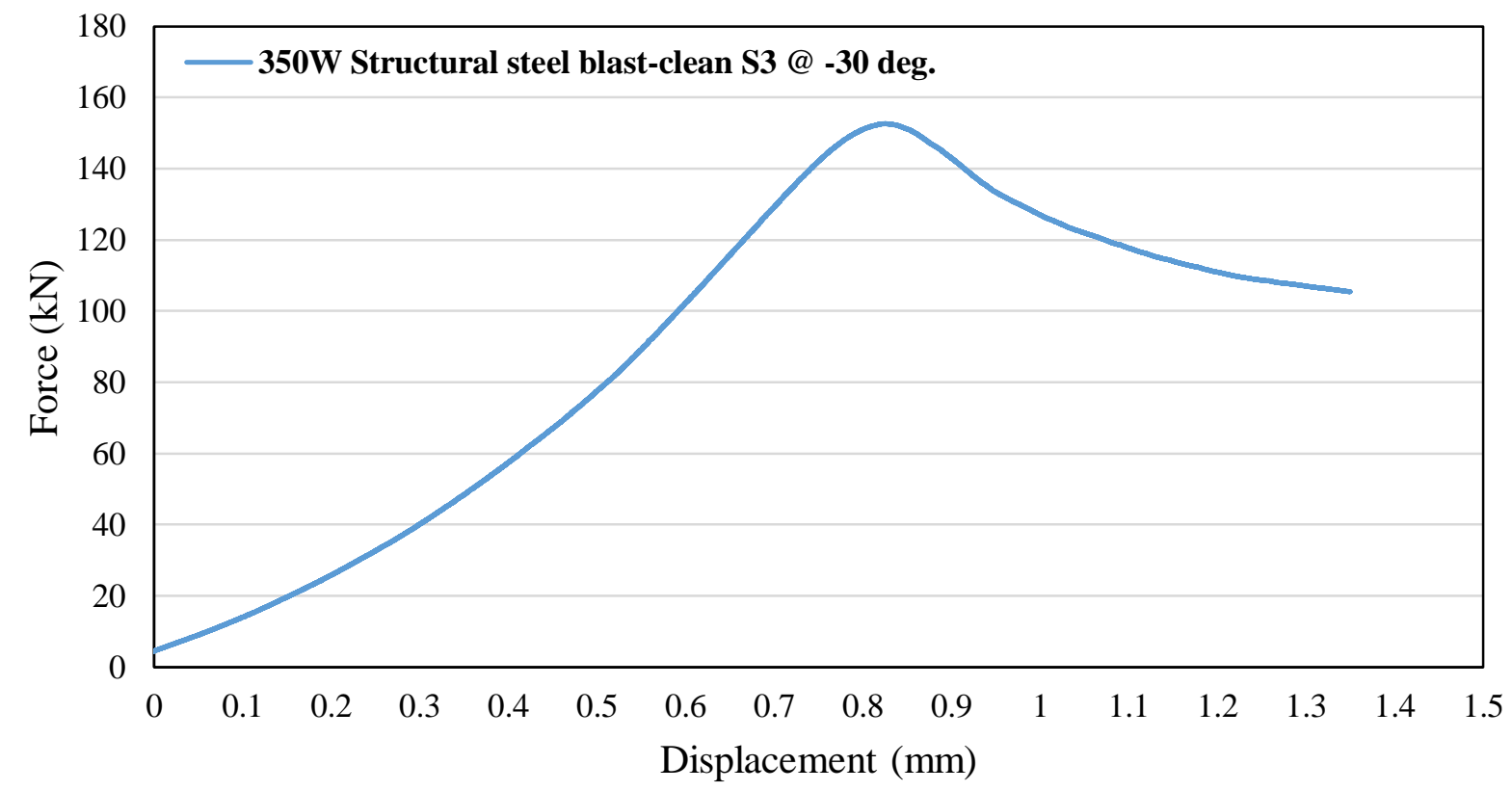

Figure E- 50: Force-displacement relationship for structural steel with blast-clean surface condition with $\mathrm{A} 325$ bolt for test specimen 3 at $-30^{\circ} \mathrm{C}$ temperature 


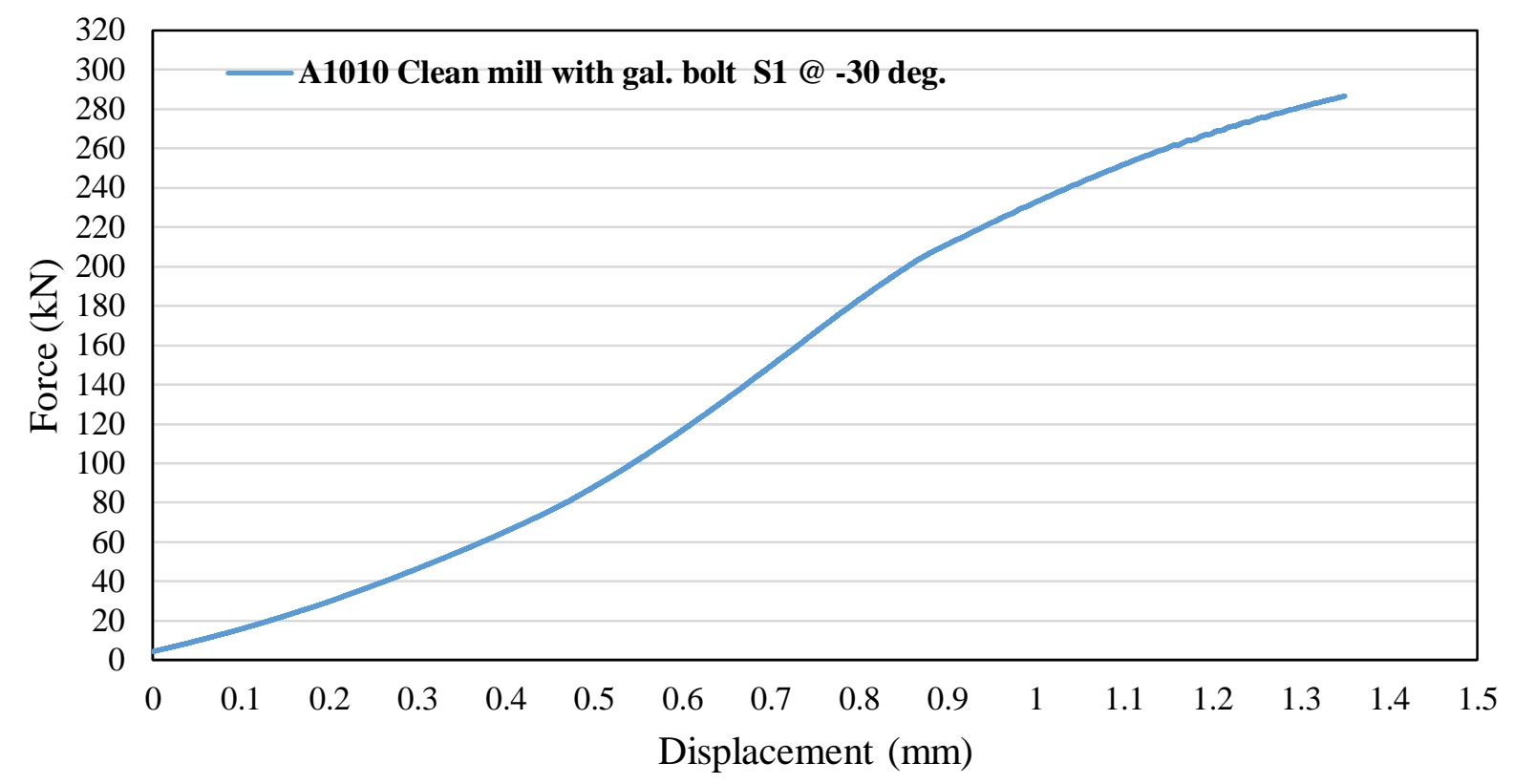

Figure E- 51: Force-displacement relationship for structural steel with clean mill scale surface condition with galvanized bolt for test specimen 1 at $-30^{\circ} \mathrm{C}$ temperature

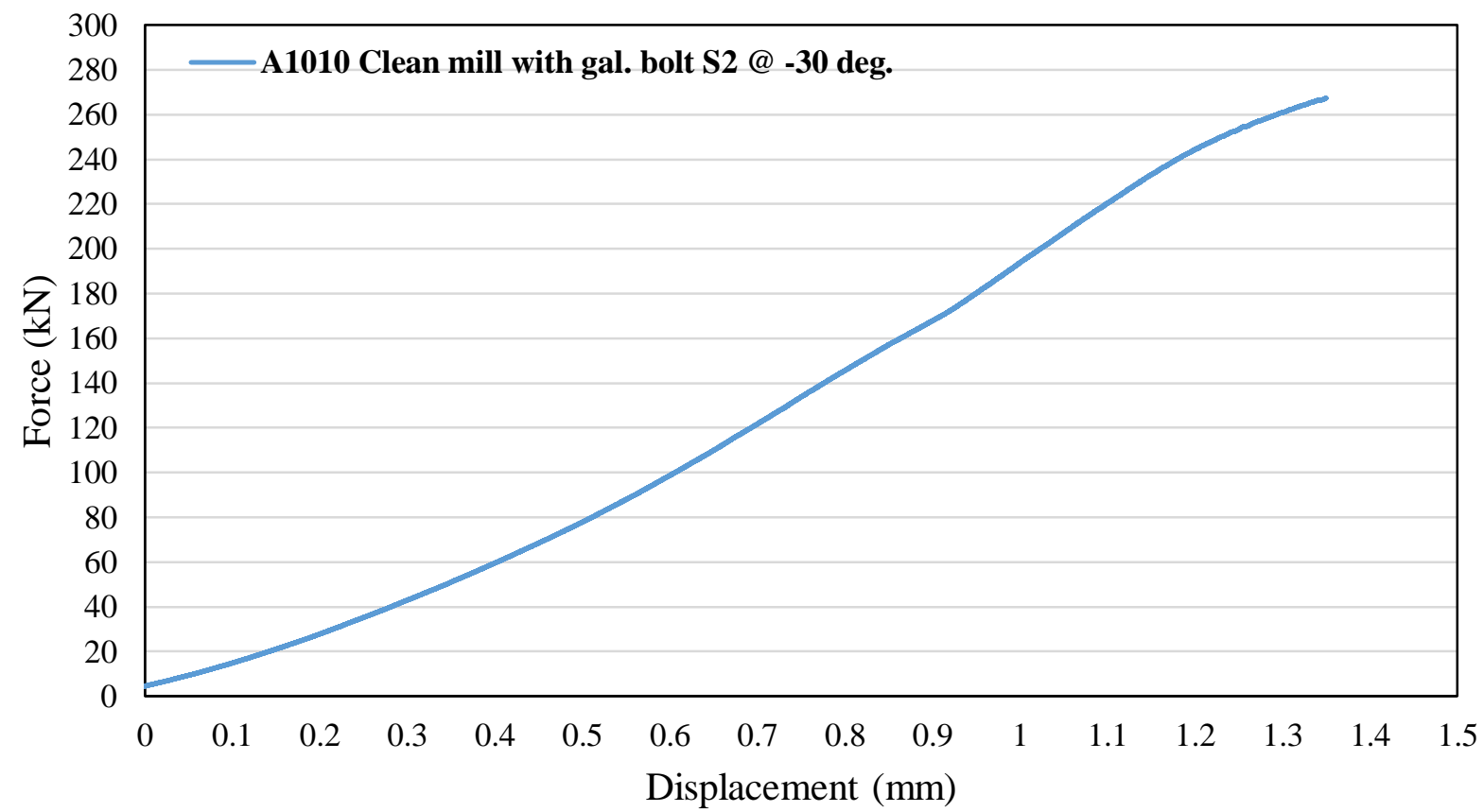

Figure E- 52: Force-displacement relationship for structural steel with clean mill scale surface condition with galvanized bolt for test specimen 2 at $-30^{\circ} \mathrm{C}$ temperature 


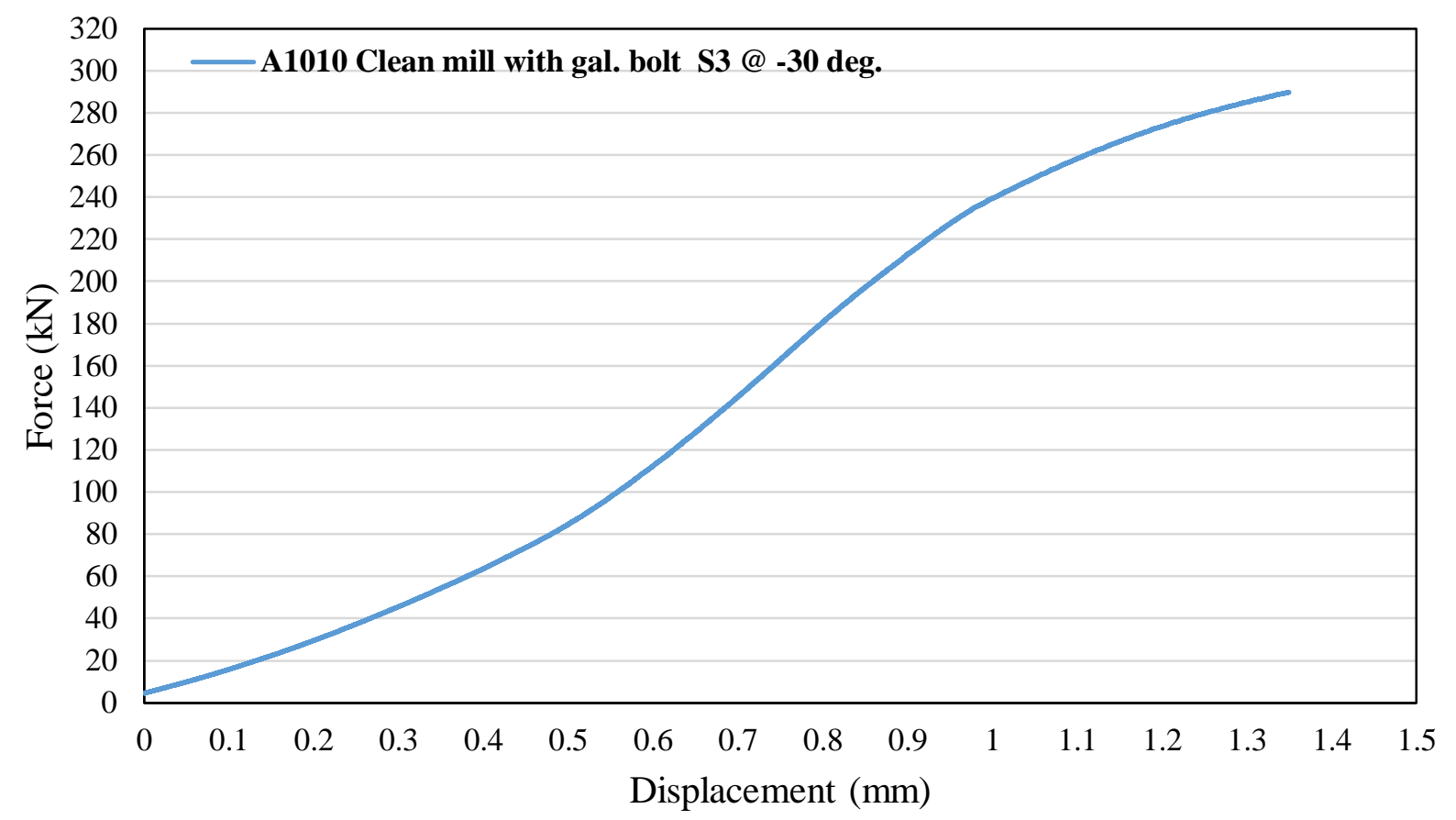

Figure E- 53: Force-displacement relationship for structural steel with clean mill scale surface condition with galvanized bolt for test specimen 3 at $-30^{\circ} \mathrm{C}$ temperature

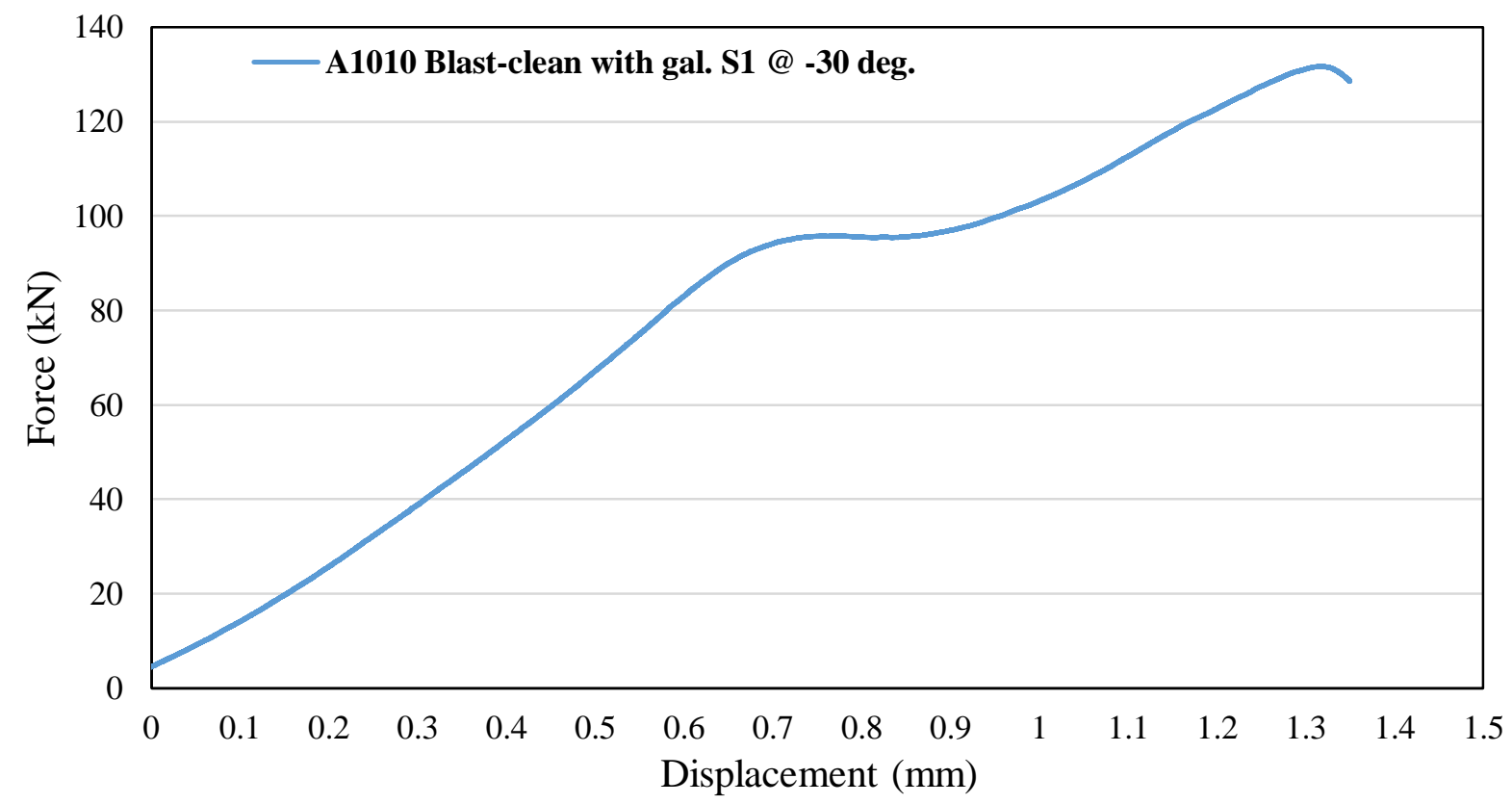

Figure E- 54: Force-displacement relationship for stainless steel with blast-clean surface condition with galvanized bolt for test specimen 1 at $-30^{\circ} \mathrm{C}$ temperature 


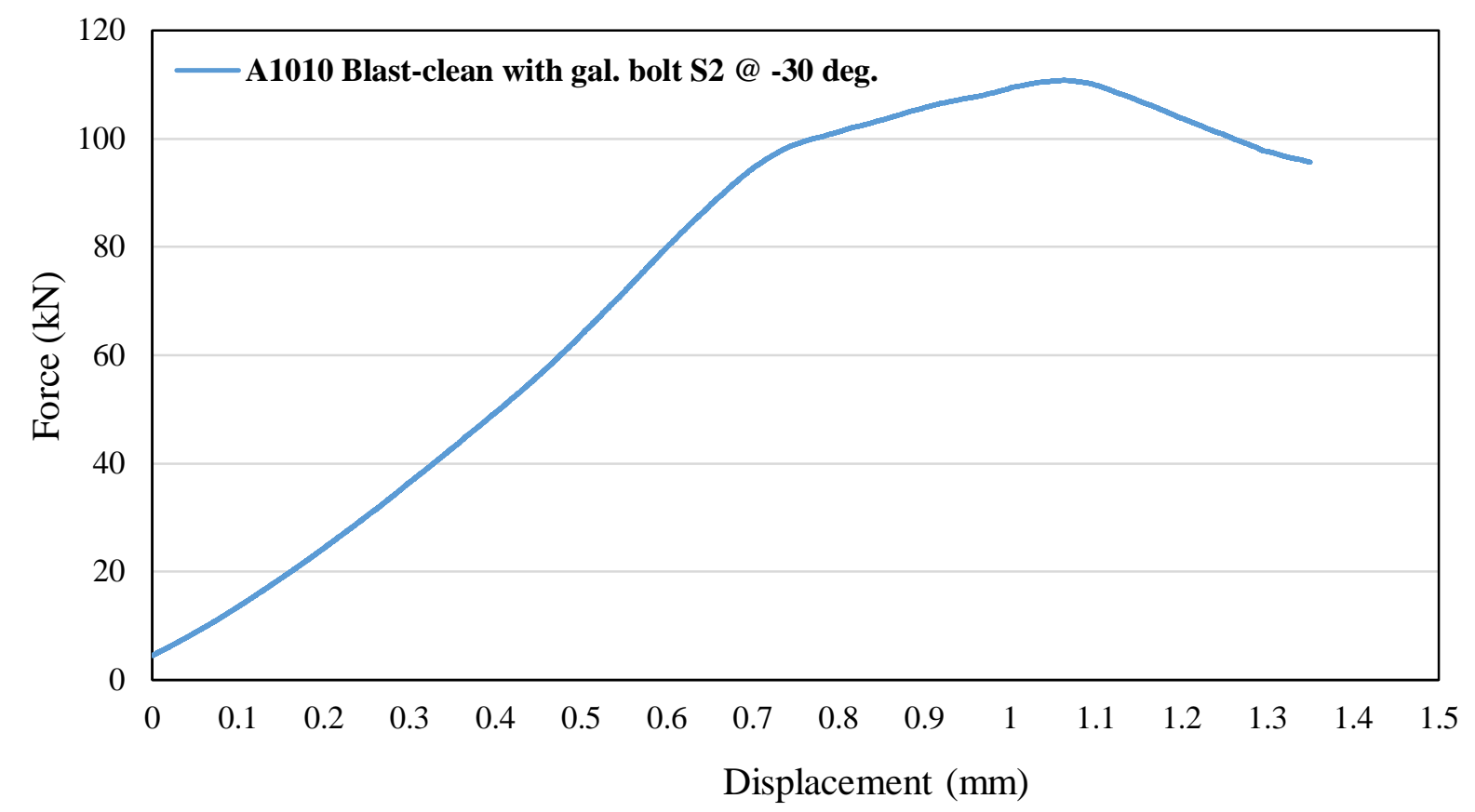

Figure E- 55: Force-displacement relationship for stainless steel with blast-clean surface condition with galvanized bolt for test specimen 2 at $-30^{\circ} \mathrm{C}$ temperature

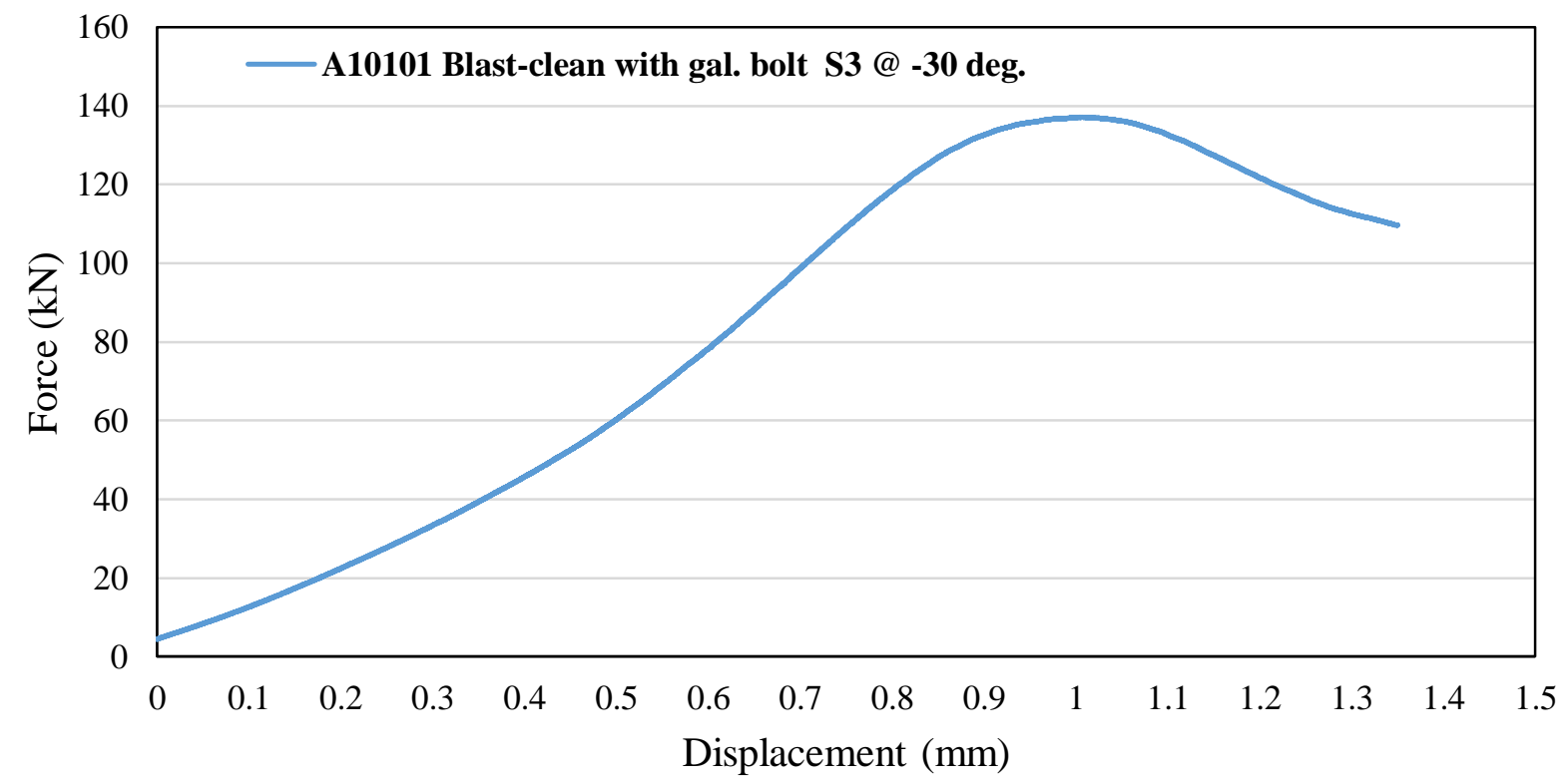

Figure E- 56: Force-displacement relationship for stainless steel with blast-clean surface condition with galvanized bolt for test specimen 3 at $-30^{\circ} \mathrm{C}$ temperature 
Table E- 4: Recorded plate temperature during slip coefficient testing intended at $-30^{\circ} \mathrm{C}$ temperature monitoring results

\begin{tabular}{|c|c|c|c|c|c|c|c|c|c|c|c|c|c|c|c|}
\hline \multirow[b]{2}{*}{$\begin{array}{c}\text { Slip test plate } \\
\text { thickness = } \\
5 / 8 " \text { bolt dia. = } \\
7 / 8^{\prime \prime}\end{array}$} & \multirow[b]{2}{*}{$\begin{array}{c}\text { Set } \\
\text { number }\end{array}$} & \multirow[b]{2}{*}{$\begin{array}{c}\text { Test } \\
\text { material }\end{array}$} & \multirow[b]{2}{*}{\begin{tabular}{|c} 
Surface type \\
(class)
\end{tabular}} & \multirow[b]{2}{*}{$\begin{array}{c}\text { Sample } \\
\# \\
\end{array}$} & \multirow[b]{2}{*}{$\begin{array}{c}\text { At start } \\
\text { of } \\
\text { testing } \\
\end{array}$} & \multicolumn{10}{|c|}{ Recorded temperature $\left({ }^{0} \mathrm{C}\right)$} \\
\hline & & & & & & 2 mins & 4 mins & 6 mins & 8 mins & 10 mins & 12 mins & 14 mins & 16 mins & 18 mins & 20 mins \\
\hline \multirow{13}{*}{$\begin{array}{l}\text { (using turn-of- } \\
\text { the-nut } \\
\text { method: effect } \\
\text { of temperature } \\
\text { on slip } \\
\text { resistance } \\
\text { determination) }\end{array}$} & \multirow{3}{*}{$1 *$} & \multirow{3}{*}{$\begin{array}{c}\text { Structural } \\
\text { Steel } \\
(350 \mathrm{~W})\end{array}$} & \multirow{3}{*}{$\begin{array}{c}\text { A } \begin{array}{c}\text { (clean mill } \\
\text { scale })\end{array} \\
\end{array}$} & 1 & -32.6 & -18.0 & -9.3 & -2.2 & 2.9 & 6.3 & 9.5 & 11.6 & 13.4 & 15.3 & 16.5 \\
\hline & & & & 2 & -30.5 & -20.1 & -12.0 & -3.3 & 2.5 & 6.1 & 9.4 & 11.8 & 13.7 & 15.3 & 16.6 \\
\hline & & & & 3 & -31.6 & -18.3 & -17.4 & -7.7 & -2.3 & 1.6 & 5.7 & 9.4 & 10.8 & 12.7 & 14.4 \\
\hline & \multirow{3}{*}{$2 *$} & \multirow{3}{*}{$\begin{array}{c}\text { Structural } \\
\text { Steel } \\
(350 \mathrm{~W})\end{array}$} & \multirow{3}{*}{$\begin{array}{l}\text { B } \quad \text { (Blast - } \\
\text { cleaned) }\end{array}$} & 1 & -32.5 & -25.8 & -15.6 & -5.3 & 0.6 & 4.9 & 8.3 & 11.1 & 13.0 & 14.4 & 15.6 \\
\hline & & & & 2 & -33.5 & -20.0 & -10.4 & -3.6 & 1.3 & 4.5 & 7.8 & 10.5 & 12.4 & 13.7 & 14.9 \\
\hline & & & & 3 & -34.9 & -26.7 & -16.3 & -7.7 & -1.5 & 3.2 & 6.6 & 9.4 & 11.4 & 13.0 & 14.4 \\
\hline & $3 * *$ & $\begin{array}{c}\text { Structural } \\
\text { Steel } \\
(350 \mathrm{~W})\end{array} \mid$ & $\begin{array}{c}\mathrm{C} \quad \text { (Hot dip } \\
\text { galvanized } \\
\text { with gal.bolt) }\end{array}$ & \multicolumn{12}{|c|}{ Not tested } \\
\hline & \multirow{3}{*}{$4 * *$} & \multirow{3}{*}{$\begin{array}{c}\text { Stainless } \\
\text { Steel }\end{array}$} & \multirow{3}{*}{$\begin{array}{c}\text { A }(\text { clean mill } \\
\text { scale })\end{array}$} & $\mathbf{1}$ & -31.5 & -15.7 & -7.8 & -2.9 & 1.5 & 4.4 & 7.6 & 9.9 & 11.7 & 13.2 & 14.6 \\
\hline & & & & 2 & -30.0 & -18.4 & -10.5 & -5.9 & -1.8 & 1.4 & 4.1 & 6.3 & 8.4 & 10.3 & 12.0 \\
\hline & & & & 3 & -31.3 & -13.8 & -5.3 & -0.3 & 3.9 & 6.7 & 9.6 & 11.7 & 13.4 & 14.6 & 15.6 \\
\hline & \multirow{3}{*}{$5 * *$} & \multirow{3}{*}{$\begin{array}{c}\text { Stainless } \\
\text { Steel }\end{array}$} & \multirow{3}{*}{$\begin{array}{l}\text { B } \quad \text { (Blast - } \\
\text { cleaned) }\end{array}$} & 1 & -30.8 & -12.1 & -6.3 & -2.4 & 6.0 & 4.0 & 6.4 & 8.8 & 10.7 & 12.3 & 13.6 \\
\hline & & & & 2 & -30.1 & -16.3 & -8.9 & -4.5 & -0.5 & 2.6 & 5.6 & 7.4 & 9.1 & 10.7 & 12.1 \\
\hline & & & & 3 & -30.7 & -16.7 & -8.9 & -4.0 & 0.0 & 4.1 & 6.6 & 9.0 & 10.4 & 12.0 & 12.9 \\
\hline
\end{tabular}

*with A325 bolt

**with galvanized bolt 


\section{Appendix F: Comparison of Slip Coefficient at Ambient Temperature and Low Temperature}

Table F-1: Slip coefficient for different steel plate surface conditions at ambient temperature and varying low temperature

\begin{tabular}{|c|c|c|c|c|c|}
\hline $\begin{array}{c}\text { Specimen and } \\
\text { surface condition }\end{array}$ & $\begin{array}{c}\text { Target temperature } \\
\left({ }^{0} \mathrm{C}\right)\end{array}$ & \begin{tabular}{|c|} 
Actual \\
temperature at \\
beginning of \\
test $\left({ }^{0} \mathrm{C}\right)$
\end{tabular} & $\begin{array}{c}\text { Temperature at } \\
\text { slip of } 0.5 \mathrm{~mm} \\
\left({ }^{0} \mathrm{C}\right)\end{array}$ & $\begin{array}{c}\text { Temperature } \\
\text { at end of test } \\
\text { (at } 1.35 \mathrm{~mm} \text { ) } \\
\left({ }^{0} \mathrm{C}\right)\end{array}$ & $\mathbf{k}_{\mathrm{s}}$ \\
\hline \multirow{5}{*}{$\begin{array}{l}350 \text { W Clean mill scale } \\
\text { plates with A325 bolt }\end{array}$} & Ambient temperature & 24 & 24 & 24 & 0.156 \\
\hline & -5 & -5.5 & 9.5 & 18.2 & 0.187 \\
\hline & -10 & -11.2 & 7 & 18 & 0.168 \\
\hline & -20 & -22 & 4 & 17.3 & 0.163 \\
\hline & -30 & -31.6 & -1 & 15.8 & 0.184 \\
\hline \multirow{5}{*}{$\begin{array}{l}\text { 350W Blast-clean } \\
\text { plates with A325 bolt }\end{array}$} & Ambient temperature & 24 & 24 & 24 & 0.202 \\
\hline & -5 & -5.5 & 8 & 17.3 & 0.207 \\
\hline & -10 & -11.3 & 7.5 & 18 & 0.206 \\
\hline & -20 & -22.9 & 5 & 17.8 & 0.194 \\
\hline & -30 & -33.6 & -2.5 & 15 & 0.206 \\
\hline \multirow{5}{*}{$\begin{array}{l}\text { 350W Hot dip } \\
\text { galvanized plates with } \\
\text { galvanized bolt }\end{array}$} & Ambient temperature & 24 & 24 & 24 & 0.188 \\
\hline & -5 & -6 & 7.5 & 16.5 & 0.159 \\
\hline & -10 & -11.5 & 6.8 & 18 & 0.186 \\
\hline & -20 & -22.6 & 2.5 & 16.7 & 0.177 \\
\hline & -30 & - & - & - & - \\
\hline \multirow{5}{*}{$\begin{array}{c}\text { A1010 Clean mill } \\
\text { plates with galvanized } \\
\text { bolts }\end{array}$} & Ambient temperature & 24 & 24 & 24 & 0.161 \\
\hline & -5 & -6.9 & 8 & 16.5 & 0.239 \\
\hline & -10 & -11.3 & 7.5 & 17.3 & 0.212 \\
\hline & -20 & -20.5 & 4 & 16 & 0.242 \\
\hline & -30 & -30.9 & -1 & 14.1 & 0.222 \\
\hline \multirow{5}{*}{$\begin{array}{l}\text { A1010 Blast-clean } \\
\text { plates with galvanized } \\
\text { bolt }\end{array}$} & Ambient temperature & 24 & 24 & 24 & 0.207 \\
\hline & -5 & -5.7 & 7.5 & -15.5 & 0.169 \\
\hline & -10 & -11 & 7 & 17 & 0.154 \\
\hline & -20 & -20.8 & 5 & 16.1 & 0.195 \\
\hline & -30 & -30.5 & -1 & 12.9 & 0.170 \\
\hline
\end{tabular}




\section{References}

AASHTO. 2012. AASHTO-LRFD Bridge Design Specifications. American Association of State Highway and Transportation Officials Washington, D.C.

AISC. 2005. Specification for Structural Steel Buildings. American institute of Steel Construction, Chicago, USA.

Annan, C.D., and Chiza, A. 2014. Slip Resistance of Metalized-Galvanized Faying Surface in Steel Bridge Construction. Journal of Constructional Steel Research, 95: 211-219.

ASTM. 2013. Standard Test Method for the Measurement of Surface Roughness of Abrasive Blast Cleaned Metal Surface using a Portable Stylus Instrument, ASTM D7127. American Society for Testing of Materials, West Conshohocken, PA.

ASTM. 2006. Standard Practice for Measuring the Change in Length of Fasteners using the Ultrasonic Pulse-Echo Technique. ASTM E1685, American Society for Testing of Materials, West Conshohocken, PA.

ASTM. 2010. Standard Specification for Structural Bolts, Steel, Heat-Treated, 120/105 ksi Minimum Tensile Strength, ASTM A325-10e1. American Society for Testing of Materials, West Conshohocken, PA.

ASTM. 2001. Standard Specification for Hardened Steel Washers, ASTM F436. American Society for Testing of Materials, West Conshohocken, PA.

ASTM. 2015. Standard Specification for Higher-Strength Martensitic Stainless Steel Plates, Sheet and Strip, A1010/A1010M. American Society for Testing of Materials, West Conshohocken, PA.

ASTM. 2015. Standard Test Method for Stress Relaxation for Materials and Structures. American Society for Testing of Materials, West Conshohocken, PA.

ASTM. 2015. Standard Specification for High Strength Structural Bolts, Steel Alloy Steel Treated, $120 \mathrm{ksi}$ and $150 \mathrm{ksi}$ minimum Tensile Strength, Inch and Metric dimensions, F3125/F3125M 15a. American Society for Testing of Materials, West Conshohocken, PA.

Borello, D. J., Denavit, M. D. and Hajjar, J. F. 2010. Bolted Steel Slip-Critical Connections with Fillers I Performance. Journal of Constructional Steel Research 67: 379 -388.

Abidelah, A., Bouchair, A.J. and Averseng, A. 2008. Analysis of the Behaviour of Stainless Steel Bolted Connections. Journal of Constructional Steel Research, 64: 1264-1274.

CSA. 2014. Canadian Highway Bridge Design Code, CAN/CSA-S6-14. Canadian Standards Association Toronto.

CISC. 2014. Handbook of Steel Construction, $11^{\text {th }}$ edition. Canadian Institute of Steel Construction Willowdale, Ontario.

Corbett, W.D., McGee, C. M. 2014. Understanding Slip Coefficient and Tension Creep Testing of Coatings Used in Slip-Critical Bolted Connections. Journal of Protective Coating and Lining, pp. 22-41.

Fletcher, F. B., Wilson, A. D., Strasky, J., Kilpatrick, J. N., Mlcock, L. T. and Wrysinski, J. S. 2000. Stainless Steel for Accelerated Bridge Construction. FHWA Accelerated Bridge Construction Conference, San Diego, Ca., p. 1-6.

Hechtman, R. A., Young, D. R., Chin, A. G., and Savikko, E. R. 1955. Slip of Joints under Static Loads Transactions, ASCE, 120: 1335-1352. 
Jhang, K. Y., Quan, H., Ha, J., and Kim, N. Y. 2006. Estimation of Clamping Force in HighTension Bolts through Ultrasonic Velocity Measurement. Ultrasonic Journal, 44: 1339-1342.

Kulak, G. L. and Fisher J. W. 1968. A514 Steel Joints Fastened by A490 Bolts. Journal of the Structural Division, ASCE, 94(ST10): 2303-2323.

Kulak, G. L. 2005. High Strength Bolting for Canadian Engineers, $1^{\text {st }}$ Edition. Quadrastone Graphic ltd.

Kulak, G. L., Fisher, J. W., and. Struik, J. H. A. 2001. Guide to Design Criteria for Bolted and Riveted Joints, $2^{\text {nd }}$ Edition. John Wiley and Son, New York.

Kulak, G. L., and Birkemoe, P. C. 1993. Field Studies of Bolt Pretension. Journal of Constructional Steel Research, 25(1 \& 2): 95-106.

Nah, H., and Kim, K. 2011. Establishment of Slip Coefficient for Slip Resistant Connection. Journal of Civil Engineering and Architecture, 5(2): 112-120.

Nah, H., Lee, H., Kim, K., Kim, J., and Kim, W. 2009. Method for Estimating the Clamping Force of High Strength Bolts Subjected to Temperature Variation. Journal of Steel Structures, 9: 123130.

Research Council on Structural Connections RCSC. 2000. Specification for Structural Joints Using ASTM A325 or A490 Bolts. American Institute of Steel Construction.

Reuther, D., Baker, I., Yetka A., Cleary, D. B., and Riddell, W. 2014. Relaxation of ASTM A325 Bolted Assemblies. Journal of Structural Engineering, (ASCE) 0733-9445.

Vasarhelyi, D. D., and Chiang, K. C. 1967. Coefficient of Friction in Joints of Various Steels. Journal of Structural Division, ASCE, 93(ST4): 227-243.

Yamada, H., and Li, C. 1972. Stress Relaxation and Mechanical Equation of State in Austenic Stainless Steels. Metallurgical Transactions, 4: 1973-2133.

Yang, J., and DeWolf, J. T. 1999. Mathematical Model for Relaxation in High Strength Bolted Connections. Journal of Structural Engineering, 10.1061/(ASCE) 0733-9445 (1999)125: 8(803), 803-809.

Yang, J., and DeWolf, J. T. 2000. Relaxation in High Strength Bolted Connections using Galvanized Steel. Journal of Bridge Engineering, 10.1061/(ASCE)1084-0702 (2000)5: 2(99), 99-106

Yura, J. A., Frank, K. H., and Cayes, L. 1981. Friction-Type Bolted Connections with A588 Weathering Steel. FHWA/RD-81/147 